Rogério Andrade Flauzino

\title{
IDENTIFICAÇÃO E LOCALIZAÇÃO DE FALTAS DE Alta IMPEdÂNCIA EM SISTEMAS dE DISTRIBUIÇÃO BASEADAS EM DECOMPOSIÇÃO POR COMPONENTES ORTOGONAIS E INFERÊNCIA FUZZY
}

Tese apresentada à Escola de Engenharia de São Carlos da Universidade de São Paulo, como parte dos requisitos para obtenção do Título de Doutor em Engenharia Elétrica.

Orientador: Prof. Dr. Ivan Nunes da Silva

São Carlos

2007 
Dedico este trabalho com carinho e estima à minha esposa Solange pelo constante incentivo e compreensão durante as pesquisas, estudos e elaboração deste trabalho. Dedico também aos meus pais Neuza e Djalma pelos esforços para me oferecer um bom estudo. 


\section{AGRADECIMENTOS}

Este trabalho teve a colaboração de diversas pessoas e instituições. Elencar todos os nomes e contribuições é uma tarefa árdua, havendo a possibilidade de deixar alguém sem o devido reconhecimento expresso nessas linhas. Desde já me desculpo por alguma omissão. Sendo dever de ofício e tradição atrevo-me a tentar:

Ao meu amigo e orientador Prof. Dr. Eng. Ivan Nunes da Silva pelos seus ensinamentos em sistemas inteligentes, pelas sugestões no decorrer do desenvolvimento deste trabalho, pelas inúmeras oportunidades e principalmente pelas lições de vida.

Ao professor e amigo Dr. José Alfredo Covolan Ulson pelas incontáveis sugestões e contribuições para este trabalho.

Aos amigos MSc. Eng. Cezar Sant'Ana, Eng. Fábio Randi, MSc. Eng. Alzira Sant'Ana, MSc. Letícia Takahashi, cujas contribuições estenderam a parte técnica e pelas ajudas e sugestões na elaboração desse trabalho. Não me esquecendo é claro dos agradecimentos a todos os professores, coordenação e direção do Instituto Tecnológico do Sudoeste Paulista - INTESP - que a alguns anos me acolheram de forma carinhosa e me permitiram a aquisição de grandes conhecimentos didáticos no ensino superior na Engenharia Elétrica.

Aos amigos, professores e chefia do Departamento de Engenharia de Produção da Faculdade de Engenharia da UNESP Campus de Bauru os quais deram apoio e suporte à realização desse trabalho, bem como se mostraram solidários durante sua execução.

Aos amigos e parceiros de trabalho João Luiz Lima e Silva e Edson de Oliveira pela motivação, apoio e compreensão.

À Secretária do Programa de Pós-Graduação em Engenharia Elétrica, Marisa, cuja dedicação e bom senso incentivou esse trabalho e nortearam os procedimentos burocráticos. 
Ao Programa de Pós-Graduação em Engenharia Elétrica da EESC, pela minha aceitação como pesquisador.

Meus agradecimentos também, e de forma geral, à USP que me acolheu como um de seus filhos. 
"A conduta é um espelho no qual todos exibem sua imagem" (Goethe) "Porque dele e por meio dele, e para ele, são todas as coisas. Glória, pois, a ele eternamente. Amém." 


\section{RESUMO}

Flauzino, R. A. (2007). Identificação e Localização de Faltas de Alta Impedância em Sistemas de Distribuição Baseadas em Decomposição por Componentes Ortogonais e Inferência Fuzzy. Tese (Doutorado) - Escola de Engenharia de São Carlos, Universidade de São Paulo, São Paulo, 2007.

Os atuais paradigmas dos sistemas elétricos de distribuição buscam melhorias contínuas sob inúmeros aspectos, com destaque para a segurança e a qualidade do fornecimento, as quais constituem metas a serem sempre alcançadas pelas concessionárias do setor. Refletindo-se sobre as ocorrências que degradam simultaneamente ambos os aspectos, constata-se que as faltas fase-terra de alta impedância possuem um destaque diferenciado, pois, em diversas situações, as magnitudes envolvidas com as mesmas são incapazes de sensibilizar os dispositivos relacionados com a proteção do sistema. Assim sendo, os objetivos principais desta tese consistiram em desenvolver ferramentas matemáticas e computacionais dedicadas à identificação, classificação e localização de faltas fase-terra de alta impedância, assim como a estimação de suas prováveis resistências. Mais especificamente, desenvolveu-se a técnica de decomposição em componentes ortogonais para formas de onda de tensão e de corrente, propondo ainda uma metodologia para ajuste estrutural e paramétrico de sistemas fuzzy com a finalidade de integrar as variáveis advindas de tal decomposição. Resultados de simulações baseadas na modelagem de um alimentador real de distribuição são apresentados para demonstrar a eficiência das técnicas desenvolvidas. 
X

Resumo 


\section{Abstract}

Flauzino, R. A. (2007). Identification and Location of High-Impedance Faults in Power Distribution Systems Based on Orthogonal Component Decomposition and Fuzzy Inference. Thesis (Doctorate Degree) - Escola de Engenharia de São Carlos, Universidade de São Paulo, São Paulo, 2007.

The current paradigms of power distribution systems highlight their continuous improvement on several aspects, which safety and supply quality constitute goals to be always reached by the distribution companies. Taking into account the occurrences that degrade both aspects simultaneously, it is verified that the phase-ground faults with high impedance have a differentiated prominence, therefore, in several situations, their magnitudes are unable to sensitize the devices involved with the protection of the system. Thus, the main objectives of this thesis have consisted of developing mathematical and computational tools dedicated to the identification, classification and location of phase-ground faults with high impedance, as well as to estimate their probable resistances. More specifically, it has been developed the decomposition technique in orthogonal components for voltage and current waveforms, as well as proposed a methodology for structural and parametric adjustment of systems fuzzy in order to integrate all variables from such decomposition. Simulation results based on modeling of real distribution feeder are presented to demonstrate the efficiency of the developed techniques. 


\section{LISTA DE FIGURAS}

Figura 2.1 Sistema elétrico no instante pré-falta ................................................. 16

Figura 2.2 Sistema elétrico no instante de ocorrência de uma falta......................... 17

Figura 2.3 Sistema elétrico equivalente no instante de ocorrência de uma

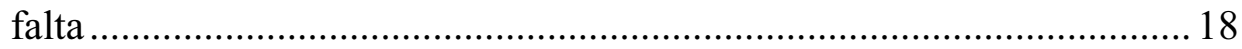

Figura 2.4 Rede de seqüência para uma falta fase-terra .........................................20

Figura 2.5 Modelo simplificado do alimentador de distribuição ...............................23

Figura 2.6 Modelo completo do alimentador de distribuição ...................................226

Figura 2.7 Formas de onda de corrente e tensão para uma falta fase terra com ocorrência de arco elétrico; (a) Tensões de fase; (b) Tensão de neutro; (c) Correntes de linha; (d) Corrente de neutro ....................... 27

Figura 2.8 Diagrama de blocos do método de diagnóstico de faltas baseado em características estatísticas das correntes de falta

Figura 2.9 Skewness para uma forma de onda de corrente faltosa e para uma forma de onda de corrente normal.

Figura 2.10 Curtose para uma forma de onda de corrente faltosa e para uma forma de onda de corrente normal.

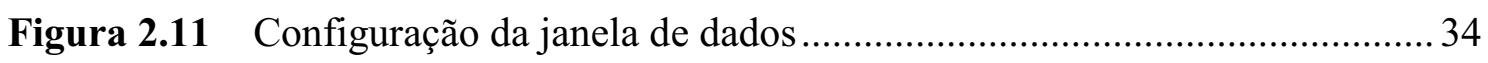

Figura 2.12 Estrutura do sistema de diagnóstico de falta proposto ..............................36

Figura 2.13 Exemplo de base de regras do sistema fuzzy ......................................... 37

Figura 2.14 Procedimentos para estimação de faltas para o sistema de

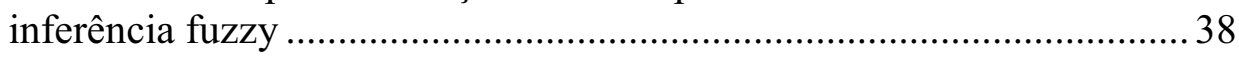

Figura 2.15 Fluxograma do algoritmo de localização de falta proposto..................... 39

Figura 2.16 Classificação de perturbações no domínio wavelet ................................. 41

Figura 2.17 Ilustração de um sinal composto por diversas perturbações e sua representação no domínio wavelet ....................................................... 42

Figura 2.18 Diagrama de blocos do esquema de detecção proposto .......................... 43

Figura 2.19 Diagrama de blocos representando o filtro adaptativo ........................... 44

Figura 2.20 Diagrama de blocos de modelo da falta de alta impedância ................... 46

Figura 2.21 Diagrama esquemático do sistema de localização de faltas por meio de redes neurais artificiais 48 
Figura 2.22 Distância de falta em função dos autovalores.

Figura 3.1 Representação esquemática do relacionamento espacial entre as funções $f(t), \dot{f}(t)$ e $\tilde{f}(t)$

Figura 3.2 Representação esquemática da projeção da função $g(t)$ sobre o espaço $\wp_{f}$

Figura 3.3 Representação esquemática da projeção da função $f(t)$ sobre o espaço $\wp_{g}$

Figura 3.4 Representação esquemática da projeção da função $g(t)$ sobre o espaço $\wp_{f}$ para o caso particular em que $f(t)$ é puramente senoidal

Figura 3.5 Representação esquemática da projeção da função $g(t)$ sobre o espaço $\wp_{f}$ para o caso particular em que $f(t)$ e $g(t)$ são puramente senoidais

Figura 3.6 Circuito elétrico empregado no desenvolvimento da interpretação da decomposição em componentes ortogonais em sistemas monofásicos

Figura 3.7 Circuito elétrico com a capacitância e indutância em paralelo à carga

Figura 3.8 Representação esquemática das funções $v_{A}(t), v_{B}(t)$ e $v_{C}(t)$ e da composição das funções $v_{A B}(t), v_{B C}(t)$ e $v_{C A}(t)$

Figura 3.9 Representação esquemática para obtenção da função ortogonal à $v_{A B}(t)$ .76

Figura 3.10 Representação esquemática para as projeções $v_{a}(t), v_{b}(t)$ e $v_{c}(t)$

Figura 3.11 Representação esquemática para as correntes de linha $i_{A}(t)$, $i_{B}(t)$ e $i_{C}(t)$

Figura 3.12 Representação esquemática da função planar das tensões de linha, das projeções das tensões de fase e das projeções das correntes de linha

Figura 3.13 Sistema de energia elétrica sob análise

Figura 3.14 Sistema de energia elétrica decomposto em suas componentes ortogonais; (a) Componentes contidas na função planar das tensões de linha; (b) Componentes ortogonais à função planar das tensões de linha

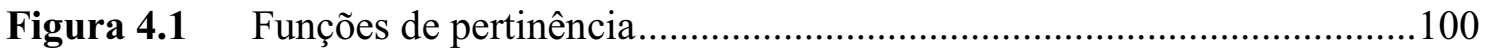

Figura 4.2 Representação da variável lingüística temperatura................................102 
Figura 4.3 Mecanismo de inferência fuzzy.......................................................... 104

Figura 4.4 Representação das entradas do sistema fuzzy multicamadas ................ 112

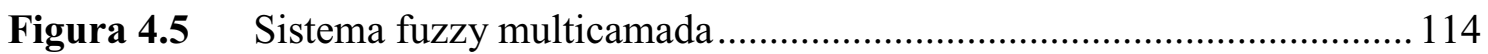

Figura 4.6 Algoritmo de extração de regras fuzzy ................................................. 116

Figura 4.7 Algoritmo de sintonia paramétrica ......................................................... 119

Figura 5.1 Diagrama esquemático para o modelo comum de sistemas identificadores/localizadores de faltas de alta impedância..

Figura 5.2 Diagrama esquemático para o modelo proposto de sistema identificador de faltas de alta impedância e identificador da fase participante na falta

Figura 5.3 Mapa dos trechos primários do alimentador piloto modelado computacionalmente

Figura 5.4 Modelagem do equivalente sistema de transmissão feito por meio do ATPDraw

Figura 5.5 Destaque para o alimentador principal no diagrama de blocos do modelo computacional do alimentador padrão.

Figura 5.6 Destaque para o Ramal 01, Ramal 02 e Ramal 03 ............................... 127

Figura 5.7 Destaque para o Ramal 04, Ramal 04, Ramal 06, Ramal 07 e Ramal 08

Figura 5.8 Destaque para o Ramal 09 em relação à disposição do alimentador principal

Figura 5.9 Destaque para o Ramal 10 e Ramal 12 em relação à disposição do alimentador principal.

Figura 5.10 Destaque para o Ramal 11 em relação à disposição do alimentador principal

Figura 5.11 Destaque para o Ramal 13 até o Ramal 19 em relação à disposição do alimentador principal

Figura 5.12 Destaque para o Ramal 20 até o Ramal 30 em relação à disposição do alimentador principal

Figura 5.13 Destaque para o Ramal 31 até o Ramal 39 em relação à disposição do alimentador principal

Figura 5.14 Destaque para o Ramal 35 em relação à disposição do alimentador principal

Figura 5.15 Destaque para o Ramal 40 até o Ramal 44 em relação à disposição do alimentador principal

Figura 5.16 Relacionamento entre o número de simulações e a distância de ocorrência da falta

Figura 5.17 Diagrama esquemático do processo de decomposição por componentes ortogonais 
Figura 5.18 Gráficos para as forma de onda obtidas por simulação computacional; (a) Formas de onda para as tensões de fase; (b) Formas de onda para as correntes de linha

Figura 5.19 Gráficos para os valores eficazes das componentes ortogonais;

(a) Valores eficazes para as funções $v_{a}^{p}(t), v_{b}^{p}(t)$ e $v_{c}^{p}(t)$; (b)

Valores eficazes para as funções $i_{a}^{p}(t), i_{b}^{p}(t)$ e $i_{c}^{p}(t)$

Figura 5.20 Gráficos para os valores eficazes das componentes ortogonais;

(a) Valor eficaz para a função $v_{n}^{p}(t)$; (b) Valor eficaz para a função $i_{n}^{p}(t)$ 148

Figura 5.21 Gráficos para os valores eficazes das componentes ortogonais;

(a) Valores eficazes para as funções $v_{a}^{q^{\prime \prime}}(t), v_{b}^{q^{\| \prime}}(t)$ e $v_{c}^{q^{\| \prime}}(t)$; (b)

Valores eficazes para as funções $i_{a}^{q^{\|}}(t), i_{b}^{q^{\prime \prime}}(t)$ e $i_{c}^{q^{\|}}(t)$

Figura 5.22 Gráficos para os valores eficazes das componentes ortogonais;

(a) Valor eficaz para a função $v_{n}^{q^{\prime \prime}}(t)$; (b) Valor eficaz para a função $i_{n}^{q 1}(t)$

Figura 5.23 Gráficos para os valores eficazes das componentes ortogonais;

(a) Valores eficazes para as funções $v_{a}^{q^{\perp}}(t), v_{b}^{q^{\perp}}(t)$ e $v_{c}^{q^{\perp}}(t)$;

(b) Valores eficazes para as funções $i_{a}^{q^{\perp}}(t), i_{b}^{q^{\perp}}(t)$ e $i_{c}^{q^{\perp}}(t)$ 150

Figura 5.24 Gráficos para os valores eficazes das componentes ortogonais;

(a) Valor eficaz para a função $v_{n}^{q^{\perp}}(t)$; (b) Valor eficaz para a

função $i_{n}^{q^{\perp}}(t)$

Figura 5.25 Gráficos para os valores eficazes das componentes ortogonais;

(a) Valores eficazes para as funções $v_{a}^{d}(t), v_{b}^{d}(t)$ e $v_{c}^{d}(t)$; (b)

Valores eficazes para as funções $i_{a}^{d}(t), i_{b}^{d}(t)$ e $i_{c}^{d}(t)$

Figura 5.26 Gráficos para os valores eficazes das componentes ortogonais;

(a) Valor eficaz para a função $v_{n}^{d}(t)$; (b) Valor eficaz para a função $i_{n}^{d}(t)$

Figura 5.27 Gráficos para os valores eficazes das componentes ortogonais;

(a) Valores eficazes para as funções $v_{\bar{a}}^{p}(t), v_{\bar{b}}^{p}(t)$ e $v_{\bar{c}}^{p}(t)$; (b)

Valores eficazes para as funções $i_{\bar{a}}^{p}(t), i_{\bar{b}}^{p}(t)$ e $i_{\bar{c}}^{p}(t)$

Figura 5.28 Gráficos para os valores eficazes das componentes ortogonais;

(a) Valor eficaz para a função $v_{h}^{p}(t)$; (b) Valor eficaz para a função $i_{h}^{p}(t)$ 153 
Figura 5.29 Gráficos para os valores eficazes das componentes ortogonais;

(a) Valores eficazes para as funções $v_{\bar{a}}^{q^{\prime \prime}}(t), v_{\frac{q^{\prime \prime}}{b}}(t)$ e $v_{\bar{c}}^{q^{\prime \prime}}(t)$; (b)

Valores eficazes para as funções $i_{\bar{a}}^{q^{\| \prime}}(t), i_{\bar{b}}^{q^{\prime \prime}}(t)$ e $i_{\bar{c}}^{q^{\prime \prime}}(t)$

Figura 5.30 Gráficos para os valores eficazes das componentes ortogonais;

(a) Valor eficaz para a função $v_{h}^{q^{\prime \prime}}(t)$; (b) Valor eficaz para a

função $i_{h}^{q^{\prime \prime}}(t)$

Figura 5.31 Gráficos para os valores eficazes das componentes ortogonais;

(a) Valores eficazes para as funções $v_{\bar{a}}^{q^{\perp}}(t), v_{\bar{b}}^{q^{\perp}}(t)$ e $v_{\bar{c}}^{q^{\perp}}(t)$;

(b) Valores eficazes para as funções $i_{\bar{a}}^{q^{\perp}}(t), i_{\bar{b}}^{q^{\perp}}(t)$ e $i_{\bar{c}}^{q^{\perp}}(t)$ 156

Figura 5.32 Gráficos para os valores eficazes das componentes ortogonais;

(a) Valor eficaz para a função $v_{h}^{q^{\prime \prime}}(t)$; (b) Valor eficaz para a função $i_{h}^{q \|}(t)$

Figura 5.33 Gráficos para os valores eficazes das componentes ortogonais;

(a) Valores eficazes para as funções $v_{\bar{a}}^{d}(t), v_{\bar{b}}^{d}(t)$ e $v_{\bar{c}}^{d}(t)$; (b)

Valores eficazes para as funções $i_{\bar{a}}^{d}(t), i_{\bar{b}}^{d}(t)$ e $i_{\bar{c}}^{d}(t)$

Figura 5.34 Gráficos para os valores eficazes das componentes ortogonais;

(a) Valor eficaz para a função $v_{h}^{d}(t)$; (b) Valor eficaz para a

função $i_{h}^{d}(t)$

Figura 5.35 Correlação e teste de hipótese para as projeções contidas na função planar das tensões de linha com relação à identificação de falta fase-terra

Figura 5.36 Correlação e teste de hipótese para as projeções ortogonais à função planar das tensões de linha com relação à identificação de falta fase-terra

Figura 5.37 Função densidade probabilidade empírica para as funções eleitas; (a) Função densidade probabilidade para $\left\|v_{n}^{p}(t)\right\|$; (b) Função densidade probabilidade para $\left\|i_{n}^{p}(t)\right\|$

Figura 5.38 Função densidade probabilidade empírica para as funções eleitas; (a) Função densidade probabilidade para $\left\|v_{a}^{p}(t)\right\|$; (b) Função densidade probabilidade para $\left\|v_{b}^{p}(t)\right\|$; (c) Função densidade probabilidade para $\left\|v_{c}^{p}(t)\right\|$

Figura 5.39 Comportamento do erro quadrático médio ao longo das iterações da primeira etapa de ajuste do sistema de inferência fuzzy para identificação de falta fase-terra

Figura 5.40 Base de regras fuzzy determinadas pela primeira etapa de ajuste 165 
Figura 5.41 Comportamento do erro quadrático médio ao longo das iterações da segunda etapa de ajuste do sistema de inferência fuzzy para identificação de faltas fase-terra

Figura 5.42 Ponderação para as regras fuzzy obtida ao término da segunda etapa de ajuste

Figura 5.43 Funções de pertinência para o universo de discurso da variável $\left\|v_{n}^{p}(t)\right\|$

Figura 5.44 Funções de pertinência para o universo de discurso da variável $\left\|i_{n}^{p}(t)\right\|$

Figura 5.45 Funções de pertinência para o universo de discurso da variável $\left\|v_{a}^{p}(t)\right\|$

Figura 5.46 Funções de pertinência para o universo de discurso da variável $\left\|v_{b}^{p}(t)\right\|$

Figura 5.47 Funções de pertinência para o universo de discurso da variável $\left\|v_{c}^{p}(t)\right\|$

Figura 5.48 Histograma do percentual de detecção para cada faixa temporal

Figura 5.49 Função densidade probabilidade para o tempo de detecção de faltas

Figura 5.50 Comportamento do tempo de detecção em função da resistência de falta para todo o conjunto de simulações ....

Figura 5.51 Comportamento do tempo de detecção em função da distância da falta em relação à subestação para todo o conjunto de simulações

Figura 5.52 Correlação e teste de hipótese para as projeções contidas na função planar das tensões de linha com relação à identificação da fase A

Figura 5.53 Correlação e teste de hipótese para as projeções ortogonais à função planar das tensões de linha com relação à identificação da fase A

Figura 5.54 Comportamento do erro quadrático médio ao longo das iterações da primeira etapa de ajuste do sistema de inferência fuzzy para identificação da fase $\mathrm{A}$

Figura 5.55 Base de regras fuzzy determinadas pela primeira etapa de ajuste para o sistema identificador para a Fase A

Figura 5.56 Comportamento do erro quadrático médio ao longo das iterações da segunda etapa de ajuste do sistema de inferência fuzzy para identificação da fase A. 
Figura 5.57 Funções de pertinência para as entradas do sistema fuzzy identificador da Fase A; (a) Funções de pertinência para a variável $\left\|v_{a}^{p}(t)\right\|$; (b) Funções de pertinência para a variável $\left\|v_{\bar{a}}^{p}(t)\right\|$; (c) Funções de pertinência para a variável $\left\|i_{\bar{a}}^{p}(t)\right\|$; (d) Funções de pertinência para a variável $\left\|i_{a}^{p}(t)\right\|$

Figura 5.58 Funções de pertinência para o universo de discurso da saída do sistema fuzzy identificador da Fase A

Figura 5.59 Correlação e teste de hipótese para as projeções contidas na função planar das tensões de linha com relação à identificação da Fase B

Figura 5.60 Correlação e teste de hipótese para as projeções contidas na função planar das tensões de linha com relação à identificação da Fase B

Figura 5.61 Comportamento do erro quadrático médio ao longo das iterações da primeira etapa de ajuste do sistema de inferência fuzzy para identificação da Fase B

Figura 5.62 Base de regras fuzzy determinadas pela primeira etapa de ajuste para o sistema identificador para a Fase B

Figura 5.63 Comportamento do erro quadrático médio ao longo das iterações da segunda etapa de ajuste do sistema de inferência fuzzy para identificação da fase B

Figura 5.64 Funções de pertinência para as entradas do sistema fuzzy identificador da Fase B; (a) Funções de pertinência para a variável $\left\|v_{b}^{p}(t)\right\|$; (b) Funções de pertinência para a variável $\left\|v_{\bar{b}}^{p}(t)\right\|$; (c) Funções de pertinência para a variável $\left\|i \frac{p}{b}(t)\right\|$; (d) Funções de pertinência para a variável $\left\|i_{b}^{p}(t)\right\|$

Figura 5.65 Funções de pertinência para o universo de discurso da saída do sistema fuzzy identificador da Fase B

Figura 5.66 Correlação e teste de hipótese para as projeções contidas na função planar das tensões de linha com relação à identificação da Fase C

Figura 5.67 Correlação e teste de hipótese para as projeções contidas na função planar das tensões de linha com relação à identificação da Fase C

Figura 5.68 Comportamento do erro quadrático médio ao longo das iterações da primeira etapa de ajuste do sistema de inferência fuzzy para identificação da Fase C

Figura 5.69 Base de regras fuzzy determinadas pela primeira etapa de ajuste para o sistema identificador para a Fase $\mathrm{C}$ 
Figura 5.70 Comportamento do erro quadrático médio ao longo das iterações da segunda etapa de ajuste do sistema de inferência fuzzy para identificação da Fase $\mathrm{C}$

Figura 5.71 Funções de pertinência para as entradas do sistema fuzzy identificador da Fase C; (a) Funções de pertinência para a variável $\left\|v_{c}^{p}(t)\right\|$; (b) Funções de pertinência para a variável $\left\|\nu_{\bar{c}}^{p}(t)\right\| ;$ (c) Funções de pertinência para a variável $\left\|i_{\bar{c}}^{p}(t)\right\| ;(\mathbf{d})$ Funções de pertinência para a variável $\left\|i_{c}^{p}(t)\right\|$

Figura 5.72 Funções de pertinência para o universo de discurso da saída do sistema fuzzy identificador da Fase C

Figura 6.1 Diagrama esquemático para o sistema localizador de faltas e de estimação da resistência de falta

Figura 6.2 Correlação e teste de hipótese para as componentes de tensão contidas na função planar das tensões de linha com a distância de ocorrência de falta na Fase A; (a) Correlação e teste de hipótese para os valores médios; (b) Correlação e teste de hipótese para os valores máximos; (c) Correlação e teste de hipótese para os valores mínimos

Figura 6.3 Correlação e teste de hipótese para as componentes de corrente contidas na função planar das tensões de linha com a distância de ocorrência de falta na Fase A; (a) Correlação e teste de hipótese para os valores médios; (b) Correlação e teste de hipótese para os valores máximos; (c) Correlação e teste de hipótese para os valores mínimos

Figura 6.4 Correlação e teste de hipótese para as componentes de tensão ortogonais à função planar das tensões de linha com a distância de ocorrência de falta na Fase A; (a) Correlação e teste de hipótese para os valores médios; (b) Correlação e teste de hipótese para os valores máximos; (c) Correlação e teste de hipótese para os valores mínimos

Figura 6.5 Correlação e teste de hipótese para as componentes de corrente ortogonais à função planar das tensões de linha com a distância de ocorrência de falta na Fase A; (a) Correlação e teste de hipótese para os valores médios; (b) Correlação e teste de hipótese para os valores máximos; (c) Correlação e teste de hipótese para os valores mínimos

Figura 6.6 Comportamento do erro quadrático médio do sistema fuzzy dedicado à estimação da distância de ocorrência da falta quando essa envolver a Fase A ao longo das iterações da primeira etapa de ajuste

Figura 6.7 Base de regras do sistema de inferência fuzzy dedicado à estimação da distância de ocorrência de faltas fase-terra quando essa envolver a Fase A 
Figura 6.8 Comportamento do erro quadrático médio do sistema fuzzy dedicado à estimação da distância de ocorrência da falta quando essa envolver a Fase A ao longo das iterações da segunda etapa de ajuste

Figura 6.9 Funções de pertinência ajustadas para as seis primeiras entradas;

(a) Entrada $\left\|v_{a}^{q^{\prime \prime}}(t)\right\|^{\min }$; (b) Entrada $\left\|i_{a}^{q^{\prime \prime}}(t)\right\|^{\min }$; (c) Entrada

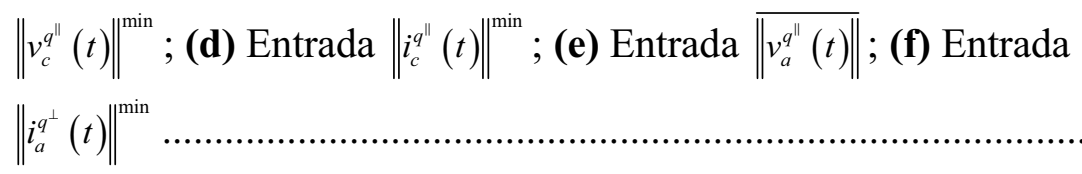

Figura 6.10 Funções de pertinência ajustadas para as seis primeiras entradas;

(a) Entrada $\left\|v_{\bar{a}}^{d}(t)\right\|^{\min }$; (b) Entrada $\left\|i_{a}^{d}(t)\right\|^{\min }$; (c) Entrada

$\left\|v_{h}^{q^{\prime}}(t)\right\|^{\min } ;$ (d) Entrada $\left\|i_{b}^{i^{\perp}}(t)\right\|^{\max } ;$ (e) Entrada $\left\|v_{\bar{a}}^{q^{\perp}}(t)\right\|^{\min } ;(\mathbf{f})$

Entrada $\overline{\left\|i_{b}^{q^{\perp}}(t)\right\|}$

Figura 6.11 Funções de pertinência associadas à distância de ocorrência de faltas fase-terra na Fase A

Figura 6.12 Ponderação das regras fuzzy do sistema de inferência fuzzy dedicado à estimação da distância de ocorrência de faltas faseterra na Fase A

Figura 6.13 Histograma do erro relativo de estimação da distância de ocorrência de faltas fase-terra na Fase A

Figura 6.14 Relacionamento entre o erro relativo e a distância de ocorrência da falta

Figura 6.15 Relacionamento entre o erro relativo e as demais variáveis independentes de simulação; (a) Relacionamento entre o erro relativo e o ângulo de falta; (b) Relacionamento entre o erro relativo e a resistência de falta; (c) Relacionamento entre o erro relativo e a duração da falta.

Figura 6.16 Histograma do erro relativo de estimação da distância de ocorrência de faltas fase-terra na Fase A para os dados do conjunto de teste

Figura 6.17 Distribuição normal para o conjunto de ajuste e para o conjunto de teste quando da localização de falta na Fase A

Figura 6.18 Correlação e teste de hipótese para as componentes de tensão contidas na função planar das tensões de linha com a distância de ocorrência de falta na Fase B; (a) Correlação e teste de hipótese para os valores médios; (b) Correlação e teste de hipótese para os valores máximos; (c) Correlação e teste de hipótese para os valores mínimos. 
Figura 6.19 Correlação e teste de hipótese para as componentes de corrente contidas na função planar das tensões de linha com a distância de ocorrência de falta na Fase B; (a) Correlação e teste de hipótese para os valores médios; (b) Correlação e teste de hipótese para os valores máximos; (c) Correlação e teste de hipótese para os valores mínimos

Figura 6.20 Correlação e teste de hipótese para as componentes de tensão ortogonais à função planar das tensões de linha com a distância de ocorrência de falta na Fase B; (a) Correlação e teste de hipótese para os valores médios; (b) Correlação e teste de hipótese para os valores máximos; (c) Correlação e teste de hipótese para os valores mínimos

Figura 6.21 Correlação e teste de hipótese para as componentes de corrente ortogonais à função planar das tensões de linha com a distância de ocorrência de falta na Fase B; (a) Correlação e teste de hipótese para os valores médios; (b) Correlação e teste de hipótese para os valores máximos; (c) Correlação e teste de hipótese para os valores mínimos

Figura 6.22 Comportamento do erro quadrático médio do sistema fuzzy dedicado à estimação da distância de ocorrência da falta quando essa envolver a Fase B ao longo das iterações da primeira etapa de ajuste

Figura 6.23 Base de regras do sistema de inferência fuzzy dedicado à estimação da distância de ocorrência de faltas fase-terra quando essa envolver a Fase B....

Figura 6.24 Comportamento do erro quadrático médio do sistema fuzzy dedicado à estimação da distância de ocorrência da falta quando essa envolver a Fase B ao longo das iterações da segunda etapa de ajuste

Figura 6.25 Funções de pertinência ajustadas para as seis primeiras entradas;

(a) Entrada $\left\|v_{b}^{q^{\prime \prime}}(t)\right\|^{\prime \text { min }}$; (b) Entrada $\left\|i_{b}^{q^{\prime \prime}}(t)\right\|^{\min } ;$ (c) Entrada

$\overline{\left\|v_{b}^{q^{\prime \prime}}(t)\right\|} ;$ (d) Entrada $\left\|i_{a}^{q^{\prime \prime}}(t)\right\|^{\min } ;$ (e) Entrada $\left\|v_{a}^{q^{\|}}(t)\right\|^{\min } ;(\mathbf{f})$

Entrada $\left\|v_{h}^{q^{\prime \prime}}(t)\right\|^{\min }$

Figura 6.26 Funções de pertinência ajustadas para as seis primeiras entradas;

(a) Entrada $\left\|v_{b}^{q^{\perp}}(t)\right\|^{\min } ;$ (b) Entrada $\left\|i_{\frac{q^{\prime \prime}}{b}}(t)\right\|^{\min } ;$ (c) Entrada

$\overline{\left\|i_{c}^{q^{\perp}}(t)\right\|}$; (d) Entrada $\overline{\left\|v_{\bar{a}}^{q^{\perp}}(t)\right\|} ;$; (e) Entrada $\overline{\left\|v_{\bar{a}}^{d}(t)\right\|} ;$ (f) Entrada

$\left\|v_{c}^{d}(t)\right\|^{\min }$

Figura 6.27 Funções de pertinência associadas à distância de ocorrência de faltas fase-terra na Fase B 
Figura 6.28 Ponderação das regras fuzzy do sistema de inferência fuzzy dedicado à estimação da distância de ocorrência de faltas faseterra na Fase B

Figura 6.29 Histograma do erro relativo de estimação da distância de ocorrência de faltas fase-terra na Fase B.

Figura 6.30 Relacionamento entre o erro relativo e a distância de ocorrência da falta

Figura 6.31 Relacionamento entre o erro relativo e as demais variáveis independentes de simulação; (a) Relacionamento entre o erro relativo e o ângulo de falta; (b) Relacionamento entre o erro relativo e a resistência de falta; (c) Relacionamento entre o erro relativo e a duração da falta

Figura 6.32 Histograma do erro relativo de estimação da distância de ocorrência de faltas fase-terra na Fase B para os dados do conjunto de teste.

Figura 6.33 Distribuição normal para o conjunto de ajuste e para o conjunto de teste quando da localização de falta na Fase B

Figura 6.34 Correlação e teste de hipótese para as componentes de tensão contidas na função planar das tensões de linha com a distância de ocorrência de falta na Fase C; (a) Correlação e teste de hipótese para os valores médios; (b) Correlação e teste de hipótese para os valores máximos; (c) Correlação e teste de hipótese para os valores mínimos

Figura 6.35 Correlação e teste de hipótese para as componentes de corrente contidas na função planar das tensões de linha com a distância de ocorrência de falta na Fase C; (a) Correlação e teste de hipótese para os valores médios; (b) Correlação e teste de hipótese para os valores máximos; (c) Correlação e teste de hipótese para os valores mínimos.

Figura 6.36 Correlação e teste de hipótese para as componentes de tensão ortogonais à função planar das tensões de linha com a distância de ocorrência de falta na Fase C; (a) Correlação e teste de hipótese para os valores médios; (b) Correlação e teste de hipótese para os valores máximos; (c) Correlação e teste de hipótese para os valores mínimos

Figura 6.37 Correlação e teste de hipótese para as componentes de corrente ortogonais à função planar das tensões de linha com a distância de ocorrência de falta na Fase C; (a) Correlação e teste de hipótese para os valores médios; (b) Correlação e teste de hipótese para os valores máximos; (c) Correlação e teste de hipótese para os valores mínimos.

Figura 6.38 Comportamento do erro quadrático médio do sistema fuzzy dedicado à estimação da distância de ocorrência da falta quando essa envolver a Fase $\mathrm{C}$ ao longo das iterações da primeira etapa de ajuste 
Figura 6.39 Base de regras do sistema de inferência fuzzy dedicado à estimação da distância de ocorrência de faltas fase-terra quando essa envolver a Fase $\mathrm{C}$.

Figura 6.40 Comportamento do erro quadrático médio do sistema fuzzy dedicado à estimação da distância de ocorrência da falta quando essa envolver a Fase $\mathrm{C}$ ao longo das iterações da segunda etapa de ajuste

Figura 6.41 Funções de pertinência ajustadas para as seis primeiras entradas;
(a) Entrada $\left\|v_{b}^{q^{\prime \prime}}(t)\right\|^{\min }$;
(b) Entrada $\overline{\left\|v_{c}^{q^{1}}(t)\right\|}$;
(c) Entrada $\left\|v_{c}^{q^{\| \prime}}(t)\right\|^{\min }$;
(d) Entrada $\left\|v_{b}^{q^{\perp}}(t)\right\|^{\min }$;
(e) Entrada $\left\|i_{b}^{q^{\|}}(t)\right\|^{\min }$;
; (f) Entrada $\left\|i_{c}^{q^{\prime \prime}}(t)\right\|^{\min }$

Figura 6.42 Funções de pertinência ajustadas para as seis primeiras entradas;
(a) Entrada $\left\|v_{c}^{d}(t)\right\|^{\min }$;
; (b) Entrada $\left\|i_{a}^{q^{\perp}}(t)\right\|^{\min } ;$ (c) Entrada
$\left\|i_{b}^{q^{\perp}}(t)\right\|^{\max } ;$ (d) Entrada $\left\|i_{a}^{d}(t)\right\|^{\min }$;
(e) Entrada $\left\|v_{h}^{q^{\prime \prime}}(t)\right\|^{\min } ;$ (f)
Entrada $\left\|i_{c}^{q^{\prime \prime}}(t)\right\|^{\min }$

Figura 6.43 Funções de pertinência associadas à distância de ocorrência de faltas fase-terra na Fase $\mathrm{C}$

Figura 6.44 Ponderação das regras fuzzy do sistema de inferência fuzzy dedicado à estimação da distância de ocorrência de faltas faseterra na Fase $\mathrm{C}$

Figura 6.45 Histograma do erro relativo de estimação da distância de ocorrência de faltas fase-terra na Fase $\mathrm{C}$

Figura 6.46 Relacionamento entre o erro relativo e a distância de ocorrência da falta.

Figura 6.47 Relacionamento entre o erro relativo e as demais variáveis independentes de simulação; (a) Relacionamento entre o erro relativo e o ângulo de falta; (b) Relacionamento entre o erro relativo e a resistência de falta; (c) Relacionamento entre o erro relativo e a duração da falta

Figura 6.48 Histograma do erro relativo de estimação da distância de ocorrência de faltas fase-terra ma Fase $\mathrm{C}$ para os dados do conjunto de teste

Figura 6.49 Distribuição normal para o conjunto de ajuste e para o conjunto de teste quando da localização de falta na Fase C

Figura 6.50 Correlação e teste de hipótese para as componentes de tensão contidas na função planar das tensões de linha com a resistência de falta na Fase A; (a) Correlação e teste de hipótese para os valores médios; (b) Correlação e teste de hipótese para os valores máximos; (c) Correlação e teste de hipótese para os valores mínimos 
Figura 6.51 Correlação e teste de hipótese para as componentes de corrente contidas na função planar das tensões de linha com a resistência de falta na Fase A; (a) Correlação e teste de hipótese para os valores médios; (b) Correlação e teste de hipótese para os valores máximos; (c) Correlação e teste de hipótese para os valores mínimos

Figura 6.52 Correlação e teste de hipótese para as componentes de tensão ortogonais à função planar das tensões de linha com a resistência de falta na Fase A; (a) Correlação e teste de hipótese para os valores médios; (b) Correlação e teste de hipótese para os valores máximos; (c) Correlação e teste de hipótese para os valores mínimos

Figura 6.53 Correlação e teste de hipótese para as componentes de corrente ortogonais à função planar das tensões de linha com a resistência de falta na Fase A; (a) Correlação e teste de hipótese para os valores médios; (b) Correlação e teste de hipótese para os valores máximos; (c) Correlação e teste de hipótese para os valores mínimos

Figura 6.54 Comportamento do erro quadrático médio do sistema fuzzy dedicado à estimação da resistência de falta quando essa envolver a Fase A ao longo das iterações da primeira etapa de ajuste

Figura 6.55 Base de regras do sistema de inferência fuzzy dedicado à estimação da resistência de falta fase-terra quando essa envolver a Fase A

Figura 6.56 Comportamento do erro quadrático médio do sistema fuzzy dedicado à estimação da resistência de falta quando essa envolver a Fase A ao longo das iterações da segunda etapa de ajuste.

Figura 6.57 Funções de pertinência ajustadas para as quatro primeiras entradas; (a) Entrada $\left\|v_{\bar{a}}^{q^{\prime \prime}}(t)\right\|^{\min }$; (b) Entrada $\left\|v_{\bar{c}}^{q^{\prime \prime}}(t)\right\|^{\min } ;$ (c) Entrada $\left\|i_{\frac{q^{\prime}}{c}}(t)\right\|^{\min } ;$ (d) Entrada $\left\|v_{\bar{b}}^{q^{\prime \prime}}(t)\right\|^{\min }$

Figura 6.58 Funções de pertinência ajustadas para as quatro primeiras entradas; (a) Entrada $\overline{\left\|i_{h}^{q^{\perp}}(t)\right\|}$; (b) Entrada $\overline{\left\|i_{h}^{d}(t)\right\|}$; (c) Entrada $\left\|v_{n}^{q^{\perp}}(t)\right\|^{\max } ;$ (d) Entrada $\left\|v_{n}^{d}(t)\right\|^{\max }$

Figura 6.59 Funções de pertinência associadas à resistência de falta na Fase A.

Figura 6.60 Ponderação das regras fuzzy do sistema de inferência fuzzy dedicado à estimação da resistência de falta na Fase $\mathrm{A}$

Figura 6.61 Histograma do erro relativo de estimação da resistência de falta na Fase A 
Figura 6.62 Função densidade probabilidade para o erro relativo de estimação da resistência de falta na Fase A

Figura 6.63 Relacionamento entre o erro relativo e a resistência de falta.

Figura 6.64 Histograma do erro relativo de estimação da resistência de falta na Fase A para os dados do conjunto de teste.

Figura 6.65 Distribuição normal para o conjunto de ajuste e para o conjunto de teste quando da estimação da resistência de falta na Fase A

Figura 6.66 Correlação e teste de hipótese para as componentes de tensão contidas na função planar das tensões de linha com a resistência de falta na Fase B; (a) Correlação e teste de hipótese para os valores médios; (b) Correlação e teste de hipótese para os valores máximos; (c) Correlação e teste de hipótese para os valores mínimos

Figura 6.67 Correlação e teste de hipótese para as componentes de corrente contidas na função planar das tensões de linha com a resistência de falta na Fase B; (a) Correlação e teste de hipótese para os valores médios; (b) Correlação e teste de hipótese para os valores máximos; (c) Correlação e teste de hipótese para os valores mínimos

Figura 6.68 Correlação e teste de hipótese para as componentes de tensão ortogonais à função planar das tensões de linha com a resistência de falta na Fase B; (a) Correlação e teste de hipótese para os valores médios; (b) Correlação e teste de hipótese para os valores máximos; (c) Correlação e teste de hipótese para os valores mínimos

Figura 6.69 Correlação e teste de hipótese para as componentes de corrente ortogonais à função planar das tensões de linha com a resistência de falta na Fase B; (a) Correlação e teste de hipótese para os valores médios; (b) Correlação e teste de hipótese para os valores máximos; (c) Correlação e teste de hipótese para os valores mínimos

Figura 6.70 Comportamento do erro quadrático médio do sistema fuzzy dedicado à estimação da resistência de falta quando essa envolver a Fase B ao longo das iterações da primeira etapa de ajuste

Figura 6.71 Base de regras do sistema de inferência fuzzy dedicado à estimação da resistência de falta fase-terra quando essa envolver a Fase B

Figura 6.72 Comportamento do erro quadrático médio do sistema fuzzy dedicado à estimação da resistência de falta quando essa envolver a Fase B ao longo das iterações da segunda etapa de ajuste 
Figura 6.73 Funções de pertinência ajustadas para as quatro primeiras entradas; (a) Entrada $\left\|v_{\bar{b}}^{q^{\prime \prime}}(t)\right\|^{\min }$; (b) Entrada $\left\|i_{\bar{a}}^{q^{\prime \prime}}(t)\right\|^{\min } ;$ (c) Entrada $\left\|v_{\bar{a}}^{q^{\| \prime}}(t)\right\|^{\min } ;$ (d) Entrada $\left\|v_{\bar{c}}^{q^{\prime \prime}}(t)\right\|^{\min }$

Figura 6.74 Funções de pertinência ajustadas para as quatro primeiras entradas; (a) Entrada $\left\|v_{c}^{q^{\|}}(t)\right\|^{\min }$; (b) Entrada $\overline{\left\|v_{\frac{q^{\perp}}{b}}(t)\right\|}$; (c) Entrada $\left\|i_{c}^{q^{\prime \prime}}(t)\right\|^{\min } ;$ (d) Entrada $\left\|v_{\bar{a}}^{d}(t)\right\|^{\min }$

Figura 6.75 Funções de pertinência associadas à resistência de falta na Fase $\mathrm{B}$

Figura 6.76 Ponderação das regras fuzzy do sistema de inferência fuzzy dedicado à estimação da resistência de falta na Fase B.

Figura 6.77 Histograma do erro relativo de estimação da resistência de falta na Fase B

Figura 6.78 Função densidade probabilidade para o erro relativo de estimação da resistência de falta na Fase B

Figura 6.79 Relacionamento entre o erro relativo e a resistência de falta.....

Figura 6.80 Histograma do erro relativo de estimação da resistência de falta na Fase B para os dados do conjunto de teste

Figura 6.81 Distribuição normal para o conjunto de ajuste e para o conjunto de teste quando da estimação da resistência de falta na Fase B

Figura 6.82 Correlação e teste de hipótese para as componentes de tensão contidas na função planar das tensões de linha com a resistência de falta na Fase C; (a) Correlação e teste de hipótese para os valores médios; (b) Correlação e teste de hipótese para os valores máximos; (c) Correlação e teste de hipótese para os valores mínimos

Figura 6.83 Correlação e teste de hipótese para as componentes de corrente contidas na função planar das tensões de linha com a resistência de falta na Fase C; (a) Correlação e teste de hipótese para os valores médios; (b) Correlação e teste de hipótese para os valores máximos; (c) Correlação e teste de hipótese para os valores mínimos

Figura 6.84 Correlação e teste de hipótese para as componentes de tensão ortogonais à função planar das tensões de linha com a resistência de falta na Fase C; (a) Correlação e teste de hipótese para os valores médios; (b) Correlação e teste de hipótese para os valores máximos; (c) Correlação e teste de hipótese para os valores mínimos. 
Figura 6.85 Correlação e teste de hipótese para as componentes de corrente ortogonais à função planar das tensões de linha com a resistência de falta na Fase C; (a) Correlação e teste de hipótese para os valores médios; (b) Correlação e teste de hipótese para os valores máximos; (c) Correlação e teste de hipótese para os valores mínimos

Figura 6.86 Comportamento do erro quadrático médio do sistema fuzzy dedicado à estimação da resistência de falta quando essa envolver a Fase $\mathrm{C}$ ao longo das iterações da primeira etapa de ajuste 290

Figura 6.87 Base de regras do sistema de inferência fuzzy dedicado à estimação da resistência de falta fase-terra quando essa envolver a Fase C

Figura 6.88 Comportamento do erro quadrático médio do sistema fuzzy dedicado à estimação da resistência de falta quando essa envolver a Fase $\mathrm{C}$ ao longo das iterações da segunda etapa de ajuste

Figura 6.89 Funções de pertinência ajustadas para as quatro primeiras entradas; (a) Entrada $\left\|v_{\frac{q^{\prime \prime}}{}}(t)\right\|^{\min }$; (b) Entrada $\left\|i \frac{q^{\prime \prime}}{b}(t)\right\|^{\min }$; (c) Entrada $\left\|v_{a}^{q^{\|}}(t)\right\|^{\text {min }} ;$ (d) Entrada $\left\|v_{\bar{b}}^{q^{\|}}(t)\right\|^{\text {min }}$

Figura 6.90 Funções de pertinência ajustadas para as quatro primeiras entradas; (a) Entrada $\left\|i_{\bar{c}}^{\|^{\prime \prime}}(t)\right\|^{\min }$; (b) Entrada $\left\|i_{a}^{q^{\prime \prime}}(t)\right\|^{\min } ;$ (c) Entrada $\left\|i_{a}^{q^{\prime \prime}}(t)\right\|^{\min } ;$ (d) Entrada $\left\|i_{h}^{q^{\perp}}(t)\right\|^{\max }$

Figura 6.91 Funções de pertinência associadas à resistência de falta na Fase C.

Figura 6.92 Ponderação das regras fuzzy do sistema de inferência fuzzy dedicado à estimação da resistência de falta na Fase $\mathrm{C}$

Figura 6.93 Histograma do erro relativo de estimação da resistência de falta na Fase C

Figura 6.94 Função densidade probabilidade para o erro relativo de estimação da resistência de falta na Fase $\mathrm{C}$

Figura 6.95 Relacionamento entre o erro relativo e a resistência de falta .298

Figura 6.96 Histograma do erro relativo de estimação da resistência de falta na Fase $\mathrm{C}$ para os dados do conjunto de teste.

Figura 6.97 Distribuição normal para o conjunto de ajuste e para o conjunto de teste quando da estimação da resistência de falta na Fase C. 300 


\section{LISTA DE TABELAS}

Tabela 5.1 Dados de ensaio do transformador da subestação ................................ 126

Tabela 5.2 Trechos constituintes do Ramal 01, Ramal 02 e Ramal 03 ................... 127

Tabela 5.3 Trechos constituintes do Ramal 04, Ramal 05, Ramal 6, Ramal 7

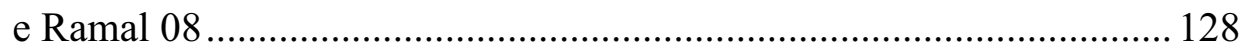

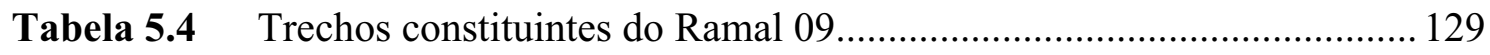

Tabela 5.5 Trechos constituintes do Ramal 10 e do Ramal 12 ............................... 130

Tabela 5.6 Trechos constituintes do Ramal 11.................................................... 131

Tabela 5.7 Trechos constituintes do Ramal 13 até o Ramal 19 .............................. 133

Tabela 5.8 Trechos constituintes do Ramal 20 até o Ramal 21 .............................. 135

Tabela 5.9 Trechos constituintes do Ramal 31 até o Ramal 39 ............................... 136

Tabela 5.10 Trechos constituintes do Ramal 40 até o Ramal 44 .............................. 137

Tabela 5.11 Distâncias dos barramentos relativas à subestação ................................ 138

Tabela 5.12 Faixa de variação da resistência de falta para cada grupo de

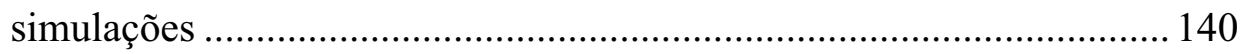

Tabela 5.13 Número de simulações de falta por fase .............................................. 140

Tabela 5.14 Correlação e teste de hipótese para as projeção contidas na função planar das tensões de linha ................................................... 159

Tabela 5.15 Correlação e teste de hipótese para as projeções ortogonais à função planar das tensões de linha ....................................................... 160

Tabela 5.16 Relação das variáveis eleitas como parâmetros no processo de identificação de falta fase-terra ......................................................... 161

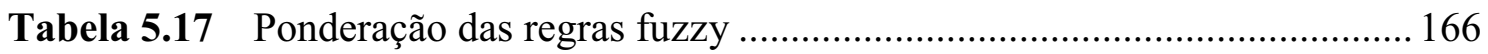

Tabela 5.18 Correlação entre as variáveis de simulação e o tempo de detecção de faltas.

Tabela 5.19 Correlação e teste de hipótese para as projeções contidas na função planar das tensões de linha 
Tabela 5.20 Correlação e teste de hipótese para as projeções ortogonais à função planar das tensões de linha........................................................175

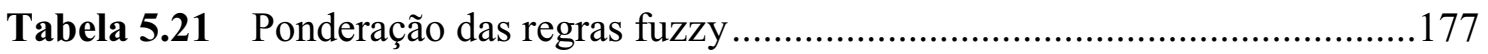

Tabela 5.22 Correlação e teste de hipótese para as projeções contidas na função planar das tensões de linha.

Tabela 5.23 Correlação e teste de hipótese para as projeções ortogonais à função planar das tensões de linha

Tabela 5.24 Ponderação das regras fuzzy ... 184

Tabela 5.25 Correlação e teste de hipótese para as projeção contidas na função planar das tensões de linha.

Tabela 5.26 Correlação e teste de hipótese para as projeções ortogonais à função planar das tensões de linha.

Tabela 5.27 Ponderação das regras fuzzy

Tabela 6.1 Correlação das componentes de tensão contidas na função planar das tensões de linha com relação à distância de ocorrência de falta na Fase A.

Tabela 6.2 Correlação das componentes de corrente contidas na função planar das tensões de linha com relação à distância de ocorrência de falta na Fase A

Tabela 6.3 Correlação das componentes de tensão ortogonais à função

planar das tensões de linha com relação à distância de ocorrência de falta na Fase A.

Tabela 6.4 Correlação das componentes de corrente ortogonais à função planar das tensões de linha com relação à distância de ocorrência de falta na Fase A.

Tabela 6.5 Variáveis mais correlatas à localização de faltas fase-terra na Fase A

Tabela 6.6 Correlação entre o erro relativo e as variáveis independentes das simulações computacionais

Tabela 6.7 Correlação das componentes de tensão contidas na função planar das tensões de linha com relação à distância de ocorrência de falta na Fase B

Tabela 6.8 Correlação das componentes de corrente contidas na função planar das tensões de linha com relação à distância de ocorrência de falta na Fase B

Tabela 6.9 Correlação das componentes de tensão ortogonais à função planar das tensões de linha com relação à distância de ocorrência de falta na Fase B . 
Tabela 6.10 Correlação das componentes de corrente ortogonais à função planar das tensões de linha com relação à distância de ocorrência de falta na Fase B

Tabela 6.11 Variáveis mais correlatas à localização de faltas fase-terra na Fase B

Tabela 6.12 Correlação entre o erro relativo e as variáveis independentes das simulações computacionais

Tabela 6.13 Correlação das componentes de tensão contidas na função planar das tensões de linha com relação à distância de ocorrência de falta na Fase C

Tabela 6.14 Correlação das componentes de corrente contidas na função planar das tensões de linha com relação à distância de ocorrência de falta na Fase C

Tabela 6.15 Correlação das componentes de tensão ortogonais à função planar das tensões de linha com relação à distância de ocorrência de falta na Fase C

Tabela 6.16 Correlação das componentes de corrente ortogonais à função planar das tensões de linha com relação à distância de ocorrência de falta na Fase C

Tabela 6.17 Variáveis mais correlatas à localização de faltas fase-terra na Fase C

Tabela 6.18 Correlação entre o erro relativo e as variáveis independentes das simulações computacionais

Tabela 6.19 Correlação das componentes de tensão contidas na função planar das tensões de linha com relação à resistência de falta na Fase A

Tabela 6.20 Correlação das componentes de corrente contidas na função planar das tensões de linha com relação à resistência de falta na Fase A

Tabela 6.21 Correlação das componentes de tensão ortogonais à função planar das tensões de linha com relação à resistência de falta na Fase A

Tabela 6.22 Correlação das componentes de corrente ortogonais à função planar das tensões de linha com relação à resistência de falta na Fase A

Tabela 6.23 Variáveis mais correlatas à estimação da resistência de falta na Fase A 256

Tabela 6.24 Correlação entre o erro relativo e as variáveis independentes das simulações computacionais 265 
Tabela 6.25 Correlação das componentes de tensão contidas na função planar das tensões de linha com relação à resistência de falta na Fase B

Tabela 6.26 Correlação das componentes de corrente contidas na função planar das tensões de linha com relação à resistência de falta na Fase B

Tabela 6.27 Correlação das componentes de tensão ortogonais à função planar das tensões de linha com relação à resistência de falta na Fase B

Tabela 6.28 Correlação das componentes de corrente ortogonais à função planar das tensões de linha com relação à resistência de falta na Fase B.

Tabela 6.29 Variáveis mais correlatas à estimação da resistência de falta na Fase B

Tabela 6.30 Correlação entre o erro relativo e as variáveis independentes das simulações computacionais

Tabela 6.31 Correlação das componentes de tensão contidas na função planar das tensões de linha com relação à resistência de falta na Fase C

Tabela 6.32 Correlação das componentes de corrente contidas na função planar das tensões de linha com relação à resistência de falta na Fase C

Tabela 6.33 Correlação das componentes de tensão ortogonais à função planar das tensões de linha com relação à resistência de falta na Fase C.

Tabela 6.34 Correlação das componentes de corrente ortogonais à função planar das tensões de linha com relação à resistência de falta na Fase C

Tabela 6.35 Variáveis mais correlatas à estimação da resistência de falta na Fase C.....

Tabela 6.36 Correlação entre o erro relativo e as variáveis independentes das simulações computacionais 


\section{LISTA DE SíMBOLOS}

$v_{A}(t) \quad$ Função descritiva da tensão de fase da Fase A.

$v_{B}(t) \quad$ Função descritiva da tensão de fase da Fase B.

$v_{C}(t)$ Função descritiva da tensão de fase da Fase C.

$i_{A}(t) \quad$ Função descritiva da corrente de linha da Fase A.

$i_{B}(t) \quad$ Função descritiva da corrente de linha da Fase B.

$i_{C}(t) \quad$ Função descritiva da corrente de linha da Fase C.

$v_{A B}(t) \quad$ Função descritiva da tensão de linha entre a Fase A e a Fase B.

$v_{B C}(t)$ Função descritiva da tensão de linha entre a Fase B e a Fase C.

$v_{A C}(t)$ Função descritiva da tensão de linha entre a Fase C e a Fase A.

$\|$.$\| \quad Norma quadrática do argumento, quando referida a grandezas elétricas, equivale$ ao valor eficaz da mesma.

$\langle.,$.$\rangle \quad Produto interno entre os argumentos.$

$v_{a}(t)$ Projeção da tensão de fase da Fase A sobre a função planar das tensões de linha.

$v_{b}(t)$ Projeção da tensão de fase da Fase B sobre a função planar das tensões de linha.

$v_{c}(t)$ Projeção da tensão de fase da Fase C sobre a função planar das tensões de linha.

$i_{a}(t)$ Projeção da corrente de linha da Fase A sobre a função planar das tensões de linha.

$i_{b}(t)$ Projeção da corrente de linha da Fase B sobre a função planar das tensões de linha.

$i_{c}(t)$ Projeção da corrente de linha da Fase C sobre a função planar das tensões de linha.

$v_{\bar{a}}(t)$ Componente da tensão de fase da Fase A ortogonal à função planar das tensões de linha. 
$v_{\bar{b}}(t)$ Componente da tensão de fase da Fase B ortogonal à função planar das tensões de linha.

$v_{\bar{c}}(t)$ Componente da tensão de fase da Fase $\mathrm{C}$ ortogonal à função planar das tensões de linha.

$i_{\bar{a}}(t)$ Componente da corrente de linha da Fase A ortogonal à função planar das tensões de linha.

$i_{\bar{b}}(t)$ Componente da corrente de linha da Fase B ortogonal à função planar das tensões de linha.

$i_{\bar{c}}(t)$ Componente da corrente de linha da Fase $\mathrm{C}$ ortogonal à função planar das tensões de linha.

$v_{a}^{p}(t) \quad$ Projeção da componente $v_{a}(t)$ sobre a função $i_{a}(t)$

$v_{b}^{p}(t) \quad$ Projeção da componente $v_{b}(t)$ sobre a função $i_{b}(t)$

$v_{c}^{p}(t)$ Projeção da componente $v_{c}(t)$ sobre a função $i_{c}(t)$

$i_{a}^{p}(t)$ Projeção da componente $i_{a}(t)$ sobre a função $v_{a}(t)$

$i_{b}^{p}(t)$ Projeção da componente $i_{b}(t)$ sobre a função $v_{b}(t)$

$i_{c}^{p}(t)$ Projeção da componente $i_{c}(t)$ sobre a função $v_{c}(t)$

$v_{a}^{q^{\prime \prime}}(t)$ Projeção da componente $v_{a}(t)$ sobre a função $\dot{i}_{a}(t)$

$v_{b}^{q^{\prime \prime}}(t) \quad$ Projeção da componente $v_{b}(t)$ sobre a função $\dot{i}_{b}(t)$

$v_{c}^{q^{\prime \prime}}(t)$ Projeção da componente $v_{c}(t)$ sobre a função $\dot{i}_{c}(t)$

$i_{a}^{q^{\prime \prime}}(t)$ Projeção da componente $i_{a}(t)$ sobre a função $\dot{v}_{a}(t)$

$i_{b}^{q^{\prime \prime}}(t)$ Projeção da componente $i_{b}(t)$ sobre a função $\dot{v}_{b}(t)$

$i_{c}^{q^{\prime \prime}}(t)$ Projeção da componente $i_{c}(t)$ sobre a função $\dot{v}_{c}(t)$

$v_{a}^{q^{\perp}}(t)$ Projeção da componente $v_{a}(t)$ sobre a função $\tilde{i}_{a}(t)-\left\langle\tilde{i}_{a}(t), \dot{i}_{a}(t)\right\rangle /\left\|\dot{i}_{a}(t)\right\|^{2} \dot{i}_{a}(t)$

$v_{b}^{q^{\perp}}(t) \quad$ Projeção da componente $v_{b}(t)$ sobre a função $\tilde{i}_{b}(t)-\left\langle\tilde{i}_{b}(t), \dot{i}_{b}(t)\right\rangle /\left\|\dot{i}_{b}(t)\right\|^{2} \dot{i}_{b}(t)$

$v_{c}^{q^{\perp}}(t) \quad$ Projeção da componente $v_{c}(t)$ sobre a função $\tilde{i}_{c}(t)-\left\langle\tilde{i}_{c}(t), \dot{i}_{c}(t)\right\rangle /\left\|\dot{i}_{c}(t)\right\|^{2} \dot{i}_{c}(t)$

$i_{a}^{q^{\perp}}(t) \quad$ Projeção da componente $i_{a}(t)$ sobre a função $\tilde{v}_{a}(t)-\left\langle\tilde{v}_{a}(t), \dot{v}_{a}(t)\right\rangle /\left\|\dot{v}_{a}(t)\right\|^{2} \dot{v}_{a}(t)$

$i_{b}^{q^{\perp}}(t)$ Projeção da componente $i_{b}(t)$ sobre a função $\tilde{v}_{b}(t)-\left\langle\tilde{v}_{b}(t), \dot{v}_{b}(t)\right\rangle /\left\|\dot{v}_{b}(t)\right\|^{2} \dot{v}_{b}(t)$

$i_{c}^{q^{\perp}}(t)$ Projeção da componente $i_{c}(t)$ sobre a função $\tilde{v}_{c}(t)-\left\langle\tilde{v}_{c}(t), \dot{v}_{c}(t)\right\rangle /\left\|\dot{v}_{c}(t)\right\|^{2} \dot{v}_{c}(t)$ 
$v_{a}^{d}(t)$ Componente de $v_{a}(t)$ não contida no espaço de $i_{a}(t)$

$v_{b}^{d}(t)$ Componente de $v_{b}(t)$ não contida no espaço de $i_{b}(t)$

$v_{c}^{d}(t)$ Componente de $v_{c}(t)$ não contida no espaço de $i_{c}(t)$

$i_{a}^{d}(t)$ Componente de $i_{a}(t)$ não contida no espaço de $v_{a}(t)$

$i_{b}^{d}(t)$ Componente de $i_{b}(t)$ não contida no espaço de $v_{b}(t)$

$i_{c}^{d}(t)$ Componente de $i_{c}(t)$ não contida no espaço de $v_{c}(t)$

$v_{\bar{a}}^{p}(t) \quad$ Projeção da componente $v_{\bar{a}}(t)$ sobre a função $i_{\bar{a}}(t)$

$v_{\bar{b}}^{p}(t)$ Projeção da componente $v_{\bar{b}}(t)$ sobre a função $i_{\bar{b}}(t)$

$v_{\bar{c}}^{p}(t) \quad$ Projeção da componente $v_{\bar{c}}(t)$ sobre a função $i_{\bar{c}}(t)$

$i_{\bar{a}}^{p}(t)$ Projeção da componente $i_{\bar{a}}(t)$ sobre a função $v_{\bar{a}}(t)$

$i_{\bar{b}}^{p}(t)$ Projeção da componente $i_{\bar{b}}(t)$ sobre a função $v_{\bar{b}}(t)$

$i_{\bar{c}}^{p}(t)$ Projeção da componente $i_{\bar{c}}(t)$ sobre a função $v_{\bar{c}}(t)$

$v_{\bar{a}}^{q^{\| \prime}}(t) \quad$ Projeção da componente $v_{\bar{a}}(t)$ sobre a função $\dot{i}_{\bar{a}}(t)$

$v_{\bar{b}}^{q^{\|}}(t) \quad$ Projeção da componente $v_{\bar{b}}(t)$ sobre a função $\dot{i}_{\bar{b}}(t)$

$v_{\bar{c}}^{q^{\| \prime}}(t) \quad$ Projeção da componente $v_{\bar{c}}(t)$ sobre a função $\dot{i}_{\bar{c}}(t)$

$i_{\bar{a}}^{q^{\|}}(t) \quad$ Projeção da componente $i_{\bar{a}}(t)$ sobre a função $\dot{v}_{\bar{a}}(t)$

$i_{\bar{b}}^{q^{\prime \prime}}(t) \quad$ Projeção da componente $i_{\bar{b}}(t)$ sobre a função $\dot{v}_{\bar{b}}(t)$

$i_{\bar{c}}^{q^{\| \prime}}(t) \quad$ Projeção da componente $i_{\bar{c}}(t)$ sobre a função $\dot{v}_{\bar{c}}(t)$

$v_{\bar{a}}^{q^{\perp}}(t) \quad$ Projeção da componente $v_{\bar{a}}(t)$ sobre a função $\tilde{i}_{\bar{a}}(t)-\left\langle\tilde{i}_{\bar{a}}(t), \dot{i}_{\bar{a}}(t)\right\rangle /\left\|i_{\bar{a}}(t)\right\|^{2} \dot{i}_{\bar{a}}(t)$

$v_{\bar{b}}^{q^{\perp}}(t) \quad$ Projeção da componente $v_{\bar{b}}(t)$ sobre a função $\tilde{i}_{\bar{b}}(t)-\left\langle\tilde{i}_{\bar{b}}(t), \dot{i}_{\bar{b}}(t)\right\rangle /\left\|\dot{i}_{\bar{b}}(t)\right\|^{2} \dot{i}_{\bar{b}}(t)$

$v_{\bar{c}}^{q^{\perp}}(t) \quad$ Projeção da componente $v_{\bar{c}}(t)$ sobre a função $\tilde{i}_{\bar{c}}(t)-\left\langle\tilde{i}_{\bar{c}}(t), \dot{i}_{\bar{c}}(t)\right\rangle /\left\|\dot{i}_{\bar{c}}(t)\right\|^{2} i_{\bar{c}}(t)$

$i_{\bar{a}}^{q^{\perp}}(t) \quad$ Projeção da componente $i_{\bar{a}}(t)$ sobre a função $\tilde{v}_{\bar{a}}(t)-\left\langle\tilde{v}_{\bar{a}}(t), \dot{\bar{v}}_{\bar{a}}(t)\right\rangle /\left\|\dot{v}_{\bar{a}}(t)\right\|^{2} \dot{\bar{v}}_{\bar{a}}(t)$

$i_{\bar{b}}^{q^{\perp}}(t) \quad$ Projeção da componente $i_{\bar{b}}(t)$ sobre a função $\tilde{v}_{\bar{b}}(t)-\left\langle\tilde{v}_{\bar{b}}(t), \dot{v}_{\bar{b}}(t)\right\rangle /\left\|\dot{v}_{\bar{b}}(t)\right\|^{2} \dot{v}_{\bar{b}}(t)$

$i_{\bar{c}}^{q^{\perp}}(t) \quad$ Projeção da componente $i_{\bar{c}}(t)$ sobre a função $\tilde{v}_{\bar{c}}(t)-\left\langle\tilde{v}_{\bar{c}}(t), \dot{v}_{\bar{c}}(t)\right\rangle /\left\|\dot{v}_{\bar{c}}(t)\right\|^{2} \dot{v}_{\bar{c}}(t)$

$v_{\bar{a}}^{d}(t) \quad$ Componente de $v_{\bar{a}}(t)$ não contida no espaço de $i_{\bar{a}}(t)$

$v_{\bar{b}}^{d}(t)$ Componente de $v_{\bar{b}}(t)$ não contida no espaço de $i_{\bar{b}}(t)$ 
$v_{\bar{c}}^{d}(t)$ Componente de $v_{\bar{c}}(t)$ não contida no espaço de $i_{\bar{c}}(t)$

$i_{\bar{a}}^{d}(t)$ Componente de $i_{\bar{a}}(t)$ não contida no espaço de $v_{\bar{a}}(t)$

$i_{\bar{b}}^{d}(t)$ Componente de $i_{\bar{b}}(t)$ não contida no espaço de $v_{\bar{b}}(t)$

$i_{\bar{c}}^{d}(t)$ Componente de $i_{\bar{c}}(t)$ não contida no espaço de $v_{\bar{c}}(t)$ 


\section{SUMÁRIO}

\section{CAPÍTULO 1. INTRODUÇÃO À TESE DE DOUTORADO}

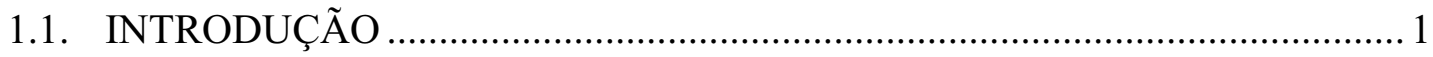

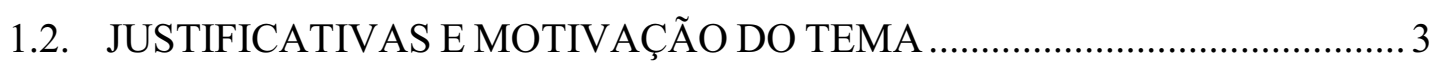

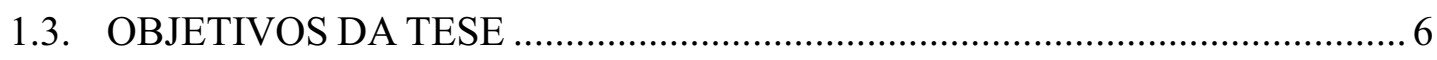

1.4. PRINCIPAIS CONTRIBUIÇÕES DA TESE …………………………........

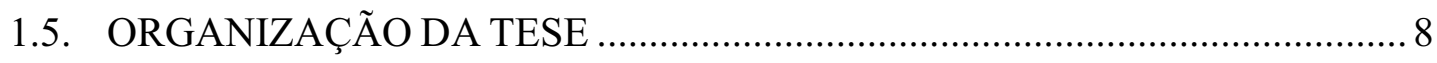

CAPÍTULO 2. TÉCNICAS DE IDENTIFICAÇÃO E LOCALIZAÇÃO DE FALTAS EM SISTEMAS DE DISTRIBUIÇÃO DE ENERGIA ELÉTRICA

2.1. INTRODUÇÃO 11

2.2. MÉTODO BASEADOS EM ANÁLISE DE CIRCUITOS ELÉTRICOS PARA LOCALIZAÇÃO DE FALTAS . 16

2.3. ABORDAGEM NEURAL UTILIZANDO CARACTERÍSTICAS ESTATÍSTICAS DAS CORRENTES DE FALTA . 26

2.4. ABORDAGEM NEURAL PARA DETECÇÃO DE FALTAS DE ALTA IMPEDÂNCIA EM ALIMENTADORES DE SISTEMA DE DISTRIBUIÇÃO 31

2.5. TÉCNICAS DE IDENTIFICAÇÃO DE FALTAS DE ALTA IMPEDÂNCIA USANDO REDES NEURAIS E TRANSFORMADA DE FOURIER 33

2.6. MODELAGEM FUZZY APLICADA NA IDENTIFICAÇÃO DE FALTAS DE ALTA IMPEDÂNCIA COM CARACTERÍSTICA PASSIVA. 34

2.7. MÉTODO PARA DIAGNÓSTICO DE FALTAS EM SUBESTAÇÕES DE DISTRIBUIÇÃO UTILIZANDO SISTEMAS FUZZY E REDES DE CAUSA E EFEITO. 36

2.8. TÉCNICAS DE LOCALIZAÇÃO DE FALTAS BASEADAS EM SINAIS DE ALTA FREQUÊNCIA E TRANSFORMADA WAVELET 
2.9. CLASSIFICAÇÃO E MEDIÇÃO DOS NÍVEIS DE PERTURBAÇÃ̃ EM SISTEMA DE POTÊNCIA ATRAVÉS DE WAVELETS

2.10. DETECÇÃO DE DISTÚRBIOS EM SISTEMAS DE

DISTRIBUIÇÃO ATRAVÉS DA UTILIZAÇÃO DE WAVELETS ...................42

2.11. MODELAGEM DE FALTAS DE ALTA IMPEDÂNCIA BASEADA NA TEORIA DE ARCOS ELÉTRICOS

2.12. LOCALIZAÇÃO DE FALTAS POR MEIO DE REDES NEURAIS E DA TRANSFORMADA DE CLARKE-CONCÓRDIA

2.13. ASPECTOS GERAIS RELACIONADOS ÀS ABORDAGENS DEDICADAS À IDENTIFICAÇ̃̃O E LOCALIZAÇÃO DE FALTAS EM SISTEMAS DE DISTRIBUIÇÃO DE ENERGIA ELÉTRICA

\section{CAPÍTULO 3. DECOMPOSIÇÃO EM COMPONENTES ORTOGONAIS}

3.1. INTRODUÇÃO.

3.2. ASPECTOS ANALÍTICOS E GEOMÉTRICOS DE FUNÇÕES TEMPORAIS

3.3. RELACIONAMENTO FUNCIONAL NO ESPAÇO DE FUNÇÕES

3.4. FORMULAÇÃO MATEMÁTICA PARA A DECOMPOSIÇÃO DAS TENSỐES DE UM SISTEMA DE ENERGIA ELÉTRICA TRIFÁSICO

3.5. FORMULAÇÃO MATEMÁTICA PARA A DECOMPOSIÇÃO DAS CORRENTES DE UM SISTEMA DE ENERGIA ELÉTRICA TRIFÁSICO

3.6. ANÁLISE DA COMPOSIÇÃO DA TENSÃO E DA CORRENTE DE DESBALANÇO EM SISTEMAS DE ENERGIA ELÉTRICA TRIFÁSICO

3.7. CONSIDERAÇÕES SOBRE O MÉTODO DE DECOMPOSIÇÃO EM COMPONENTES ORTOGONAIS

\section{CAPÍTULO 4. AJUSTE AUTOMÁTICO DE SISTEMAS DE INFERÊNCIA FUZZY}

4.1. INTRODUÇÃO... .97

4.2. FUNDAMENTOS SOBRE CONJUNTOS E LÓGICA FUZZY

4.2.1. DEFINIÇÃO DE OPERAÇÕES E OPERADORES DA LÓGICA FUZZY .

4.2.2. REGRAS DE INFERÊNCIA FUZZY

4.2.3. AGREGAÇÃO. 
4.3. TÉCNICAS PARA O AJUSTE ESTRUTURAL E

PARAMÉTRICO DE SISTEMAS DE INFERÊNCIA FUZZY 104

4.4. MODELO DO SISTEMA FUZZY MULTICAMADAS ................................ 110

4.4.1. CAMADA DE ENTRADA ........................................................ 111

4.4.2. CAMADA DE INFERÊNCIA …................................................ 113

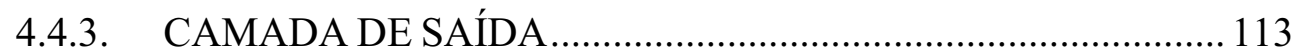

4.5. AJUSTE ESTRUTURAL DE SISTEMAS DE INFERÊNCIA FUZZY

4.6. AJUSTE PARAMÉTRICO DE SISTEMAS DE INFERÊNCIA FUZZY

4.7. CONSIDERAÇÕES SOBRE O SISTEMA FUZZY MULTICAMADAS

\section{CAPÍTULO 5. SISTEMA IDENTIFICADOR DE FALTA E SISTEMA DISCRIMINADOR DE FASE FALTOSA}

5.1. INTRODUÇÃO

5.2. MODELAGEM COMPUTACIONAL DO ALIMENTADOR PILOTO

5.3. SIMULAÇÕES COMPUTACIONAIS PARA FALTAS DE ALTA IMPEDÂNCIA

5.4. DETERMINAÇÃO DAS VARIÁVEIS PERTINENTES À IDENTIFICAÇÃO DE FALTAS DE ALTA IMPEDÂNCIA

5.5. AJUSTE DO SISTEMA DE INFERÊNCIA FUZZY PARA IDENTIFICAÇÃO DE FALTAS DE ALTA IMPEDÂNCIA

5.6. AJUSTE DO SISTEMA DE INFERÊNCIA FUZZY PARA IDENTIFICAÇÃO DA FASE PARTICIPANTE DA FALTA

5.6.1. SISTEMA IDENTIFICADOR DE FALTAS COM PARTICIPAÇÃO DA FASE A

5.6.2. SISTEMA IDENTIFICADOR DE FALTAS COM PARTICIPAÇÃO DA FASE B

5.6.3. SISTEMA IDENTIFICADOR DE FALTAS COM PARTICIPAÇÃO DA FASE C

5.7. CONSIDERAÇÕES SOBRE O SISTEMA IDENTIFICADOR DE FALTAS E DISCRIMINADOR DA FASE PARTICIPANTE.

\section{CAPÍTULO 6. SISTEMA PARA LOCALIZAÇÃO DE FALTAS E SISTEMA PARA ESTIMAÇÃO DA RESISTÊNCIA DE FALTA}

6.1. INTRODUÇÃO 
6.2. SISTEMA DE INFERÊNCIA FUZZY PARA LOCALIZAÇÃO DE FALTAS.

6.2.1. SISTEMA DE INFERÊNCIA FUZZY PARA LOCALIZAÇÃO DE FALTAS NA FASE A.

6.2.2. SISTEMA DE INFERÊNCIA FUZZY PARA LOCALIZAÇÃO DE FALTAS NA FASE B

6.2.3. SISTEMA DE INFERÊNCIA FUZZY PARA LOCALIZAÇÃO DE FALTAS NA FASE C .

6.3. SISTEMA DE INFERÊNCIA FUZZY PARA ESTIMAÇÃO DA RESISTÊNCIA DE FALTA

6.3.1. SISTEMA DE INFERÊNCIA FUZZY PARA ESTIMAÇÃO DA RESISTÊNCIA DE FALTA NA FASE A .251

6.3.2. SISTEMA DE INFERÊNCIA FUZZY PARA ESTIMAÇÃO DA RESISTÊNCIA DE FALTA NA FASE B

6.3.3. SISTEMA DE INFERÊNCIA FUZZY PARA ESTIMAÇÃO DA RESISTÊNCIA DE FALTA NA FASE C

6.4. CONSIDERAÇÕES SOBRE OS SISTEMAS DE LOCALIZAÇÃO DE FALTAS E DE ESTIMAÇÃO DA RESISTÊNCIA DE FALTA 300

\section{CAPÍTULO 7. CONCLUSÕES E TRABALHOS FUTUROS}

7.1. CONCLUSÕES 303

7.2. TRABALHOS FUTUROS 306 


\section{INTRODUÇÃO À TESE DE DOUTORADO}

\subsection{INTRODUÇÃO}

Nas últimas décadas, o setor de energia elétrica mundial experimentou inúmeras modificações. Essas modificações, em parte, foram decorrentes do advento de novas tecnologias e de sua incorporação aos sistemas elétricos de potência, de novas exigências do mercado consumidor, principalmente no que tange à qualidade do fornecimento de energia elétrica e do sensível aumento no emprego de formas alternativas de energia as quais colaboraram para o crescimento do que se denota por geração distribuída. Complementando, observa-se ainda a ampliação dos sistemas elétricos interconectados os quais, em função de sua complexidade, de sua área de abrangência e do número de consumidores, demandam estudos amplos e detalhados para elaboração de seu sistema de controle, de comunicação e de proteção a fim de alinhar sua operação aos novos paradigmas impostos aos sistemas elétricos de potência. Em Tomsovic et al. (2005) os autores descrevem o panorama atual dos sistemas elétricos de potência destacando as novas diretrizes para a implementação de sistemas de controle, de comunicação e de informação que sejam coerentes com as atuais e futuras necessidades dos sistemas de transmissão e distribuição de energia elétrica com destaque para o emprego de técnicas de computação distribuída.

O desenvolvimento de sistemas de proteção digitais e de redes de comunicação confiáveis e rápidas constituíram um grande avanço tecnológico os quais foram, de maneira acelerada, adotados nos sistemas elétricos de potência. Assim, por meio dos sistemas digitais 
de proteção e de controle é possível não apenas garantir a eliminação do setor sob falta, mas também fornecer um conjunto de dados que, quando de seu processamento, indicam informações relevantes sobre as condições operativas do sistema como um todo.

No entanto, muitos obstáculos ainda se fazem presentes e seu estudo recebe pertinência quando se tem como premissa a contínua evolução dos sistemas elétricos de potência e da garantia da qualidade da energia elétrica fornecida. Nesse contexto, a identificação e a localização de faltas recebem destaque, pois, diante da possibilidade de sua correta execução tem-se, a princípio, a eliminação do setor do sistema elétrico sob avaria e posteriormente, dado a localização da mesma, o restabelecimento do fornecimento de energia elétrica em tempo compatível com as exigências do conjunto de consumidores afetados pela interrupção.

Dessa forma, verifica-se por meio da bibliografia correlata ao tema um grande aporte de instituições de pesquisa internacionais e nacionais dedicado à elaboração de técnicas e metodologias para identificação de faltas em sistemas elétricos de potência. Ainda, tem-se verificado destaque especial aos segmentos de transmissão e de distribuição de energia elétrica. Em função da extensão geográfica desses sistemas, a necessidade de não apenas identificar, mas também localizar o ponto de falta desempenha papel primordial. Os referidos esforços podem ser divididos em dois grandes focos motivadores. O primeiro desses aborda a identificação e localização de faltas em sistemas de transmissão de energia elétrica e o segundo foco decai sobre os sistemas de distribuição de energia elétrica (OTHMAN et al., 2004). Com relação aos sistemas de transmissão de energia elétrica, observa-se que os estudos e desenvolvimentos realizados não se restringiram apenas à geração de conhecimento, mas também culminaram na disponibilização de equipamentos de proteção capazes de informar com precisão o setor da linha de transmissão sob avaria (YOUSSEF, 2004a; YOUSSEF, 2004b; YOUSSEF, 2004c).

Nos sistemas de distribuição de energia elétrica, por outro lado, em função de sua grande ramificação, do desbalanço elétrico e de particularidades que se fazem presentes apenas nesses sistemas, a localização de faltas não constitui em um problema fechado (DEPEW et al., 2006). Em complemento, tem-se que a identificação de faltas de alta impedância em tais sistemas, quando feita por meio de técnicas convencionais, não apresenta desempenho confiável o qual é destacado pela literatura correlata desde a década de 1980 até os dias atuais (L. XU \& MO-YUEN CHOW, 2006). 
Assim, é nesse contexto da identificação e localização de faltas de alta impedância em sistemas de distribuição de energia elétrica que essa tese se fundamenta. Tal fundamentação e proposição não apenas tem por objetivo ir de encontro às necessidades do atual segmento de distribuição de energia elétrica, mas também de aplicar técnicas e ferramentas contemporâneas ao setor de destaque. Portanto, esse capítulo introdutório à tese apresenta, após essa breve introdução, as principais justificativas e motivações da proposta na Seção 1.2. Na Seção 1.3 os objetivos são pontuados e na Seção 1.4, uma visão geral de como fora organizada a tese é apresentada.

\subsection{JUSTIFICATIVAS E MotivaÇÃo do TEMA}

Tendo como premissa a necessidade de fornecimento de energia elétrica com qualidade e de forma economicamente viável e segura, o sistema de distribuição de energia elétrica recebe uma atenção proporcional à sua grande importância no que tange à continuidade do fornecimento de energia elétrica e no seu rápido restabelecimento diante da ocorrência de faltas. Em função desses requisitos operativos, o estudo e desenvolvimento de técnicas capazes de identificar e localizar faltas em sistemas de distribuição é foco de inúmeras instituições de pesquisa mundiais deste a década de 1970. Naquele período, pesquisadores da Texas A\&M, sob aporte financeiro do Electric Power Research Institute EPRI, começaram suas investigações no contexto da identificação de faltas de alta impedância em sistemas de distribuição (RUSSELL et al., 1982). As pesquisas iniciadas nessa ocasião se estendem até os dias atuais sem, contudo, fazer desse tema um problema com solução fechada.

As faltas de alta impedância são faltas assimétricas, em geral entre fase e terra, que possuem uma corrente com amplitude incapaz de ser detectada por técnicas convencionais e, como conseqüências, de fazer atuar relés e fusíveis (L. XU \& MO-YUEN CHOW, 2006). Em outras palavras, pode-se afirmar que a identificação de faltas de alta impedância constitui em uma tarefa em que a simples análise da magnitude das tensões e das correntes do sistema não culmina em resultados satisfatórios. Outro aspecto característico das correntes de faltas de alta impedância é seu comportamento intermitente dado que, em muitos casos, essa corrente se faz circular por meio de arcos elétricos e esses, por possuírem uma variação temporal de impedância, decorrem na contínua alteração da magnitude da corrente de falta podendo inclusive resultar na aparente eliminação da falta. Dessa forma, mesmo que a corrente de falta seja capaz de sensibilizar a proteção do sistema, dado seu comportamento, 
ocorre que sua extinção natural pode se dar antes da atuação devida da proteção. No entanto, a extinção natural da falta não é sinônimo que o sistema esteja íntegro e isso se observa pela contínua repetição da falta, ou seja, tem-se sua evolução de falta intermitente para uma falta permanente, momento no qual, se sua amplitude permitir a identificação, a proteção atua, isolando o segmento sob avaria.

Essa característica de intermitência e de não atuação da proteção compromete dois requisitos primordiais que um sistema elétrico deve zelar, sendo o primeiro desses a qualidade do fornecimento de energia elétrica e, o segundo, a segurança quando de seu fornecimento, ambos com igual ponderação. Em situações de falta de alta impedância, tem-se que sua característica de assimetria compromete o balanço das tensões de fase e, degradando ainda mais a qualidade do fornecimento de energia, os transitórios de falta deturpam a forma de onda da tensão de fornecimento aos consumidores (YANQIU BI et al., 2004). Em adição, as faltas de alta impedância fase-terra, mesmo quando caracterizadas por pequenas correntes em magnitudes, criam na região de sua ocorrência tensões de passo e de contato que ferem a segurança de pessoas, animais e instalações (TENGDIN et al., 1996).

Por outro lado, supondo que a sensibilização da proteção ocorra e que o segmento sob falta seja isolado da fonte, tem-se como conseqüência imediata, a interrupção do fornecimento de energia elétrica aos consumidores alimentados pelo segmento que fora isolado. Nessas situações o foco de principal destaque é de localizar o ponto de ocorrência da falta a fim de que equipes de manutenção reparem o sistema, eliminando a condição que fez pelo terra fluir uma corrente de falta. Diante da reparação do sistema e da constatação que não existam mais condições indesejadas, o sistema pode ser reestabelecido e os consumidores, outrora desprovidos de energia elétrica, voltem a usufruí-lo. Assim, tão importante quanto a identificação da ocorrência de uma falta fase-terra, será a localização da mesma, pois, só assim a rápida restauração do fornecimento de energia elétrica será viável. No entanto, como a disponibilidade de técnicas e metodologias dedicadas à localização desse tipo de falta são, em grande parte, fundamentadas na inspeção visual do sistema e na experiência de seus responsáveis, tem-se que os tempos médios de reestabelecimento são alvos para uma contínua redução.

Não focado apenas nos comprometimentos à qualidade e à segurança prejudicadas diante da ocorrência de uma falta de alta impedância, a verificação da contribuição global desses tipos de falta para os sistemas de distribuição de energia elétrica se faz necessário a fim de justiçar o trabalho aqui proposto. Valores estatísticos relatados na literatura técnica 
internacional dão conta que cerca de $90 \%$ das faltas em um sistema de distribuição são faltas de alta impedância (ELMORE, 1994). Desse universo de faltas de alta impedância, aproximadamente $96 \%$ são faltas temporárias, ou seja, que se extingue naturalmente ou não se encontram mais presentes quando da reenergização do sistema, e apenas $4 \%$ das faltas de alta impedância são permanentes (KINDERMANN, 1992). Das causas mais freqüentes para as faltas de alta impedância permanentes se pode citar o rompimento e queda ao solo de cabos fase, o abalroamento de postes, o contato acidental permanente, e com destaque, danos permanentes em isoladores, danos na isolação de equipamentos e o deterioramento de páraraios. Por outro lado, as causas mais comuns para o desencadeamento de faltas de alta impedância temporárias são o arco elétrico em isoladores, a contaminação de isoladores por poeira e poluição, as correntes subseqüentes em pára-raios, a umidade, a salinidade e as condições atmosféricas. Observando-se as causas mais comuns associadas às faltas de alta impedância, constata-se a dificuldade em se determinar o local de sua ocorrência pela simples inspeção visual da rede de distribuição de energia elétrica que, como anteriormente comentado, constituem na prática mais comum quando da ocorrência desse tipo de falta.

Dessa maneira, tem-se que as faltas de alta impedância não apenas são responsáveis pela redução da qualidade e da segurança do sistema de distribuição, como também são responsáveis por grande parte das ocorrências indesejadas nesses sistemas.

Nesse contexto, inúmeras instituições de pesquisas internacionais e nacionais alinharam seus focos de estudo na identificação e localização de faltas de alta impedância em sistemas de distribuição de energia elétrica. Um expressivo número de técnicas e metodologias foram propostas desde então sem, contudo, se definir a melhor estratégia para sistemas de distribuição de energia elétrica radiais. Diante desses aspectos se pode pontuar os seguintes obstáculos:

* As características intrínsecas das faltas de alta-impedância tornam o processo de sua identificação complexo quando o mesmo é feito por meio de técnicas convencionais e, mesmo quando assim feitas, as atuações indevidas dos dispositivos de proteção fazem de seu emprego, em algumas situações, um impeditivo para sistemas de distribuição.

* Os fatores causadores desses tipos de faltas impedem a rápida e precisa localização dessas junto ao sistema de distribuição, alongando em dezenas de minutos ou até mesmo horas o restabelecimento do fornecimento de energia elétrica. 
* Em função da natureza radial de um sistema de distribuição e do reduzido número de pontos para medição de tensão e corrente, técnicas consagradas para sistemas de transmissão são impraticáveis (YANQIU BI et al., 2004).

Técnicas fundamentadas em análise por componentes simétricas são eficientes quando de cargas balanceadas, fato esse não garantido em sistemas de distribuição (JEN-HAO TENG, 2005). Além disso, o sistema de distribuição, em função do arranjo geométrico de sua rede primária também é eletricamente desequilibrado, coibindo em maior intensidade o emprego de tão difundida metodologia.

Tendo-se pontuado os principais obstáculos, verifica-se a grande necessidade do desenvolvimento de técnicas eficazes tanto para a identificação quanto para a localização de faltas de alta impedância em sistemas de distribuição radiais. Assim, diante dessa premissa, os objetivos principais e os específicos desse trabalho são apresentados na seção que se segue.

\subsection{OBJETIVOS DA TESE}

Esse trabalho, intitulado por "Identificação e Localização de Faltas de Alta Impedância em Sistemas de Distribuição Baseadas em Decomposição por Componentes Ortogonais e Inferência Fuzzy", consiste no desenvolvimento de técnicas e ferramentas computacionais dedicadas à identificação e localização automática de faltas de alta impedância em sistemas de distribuição. Esse trabalho está alinhado com as necessidades reportadas pelo setor de energia elétrica de forma que sua motivação vem da oportunidade de se dominar tecnologias que contribuam efetivamente para a minimização do tempo necessário para o restabelecimento do suprimento de energia elétrica.

Desta forma, os objetivos principais envolvidos com o desenvolvimento desta tese consistem em investigar, projetar e desenvolver tecnologias eficientes e ferramentas computacionais completas que auxiliem na identificação e localização automática de faltas. As tecnologias desenvolvidas tratarão de forma integrada tanto as técnicas convencionais como as técnicas de sistemas inteligentes, as quais serão incorporadas com outras ferramentas numéricas e computacionais que permitirão o tratamento do problema proposto.

Mais especificamente, o que se objetiva em primeira instância é o desenvolvimento de um sistema eficiente que identifica se a perturbação (distúrbio) observada nos alimentadores do sistema de distribuição deveu-se ou não a uma falta ocorrida no mesmo. Em segunda instância, dado como premissa de que uma falta ocorreu no sistema, deseja-se 
então estimar o trecho, o local, ou a distância (relativa à subestação) em que ocorreu o defeito no respectivo sistema. Dessa forma, os objetivos dessa tese podem ser pontuados da seguinte maneira:

Desenvolvimento de técnicas para extração de características e informações das formas de onda de tensão e corrente na subestação que permitam inferir sobre a ocorrência ou não de uma falta de alta impedância.

Elaboração de estratégias que, diante do indicativo de ocorrência de uma falta de alta impedância, determinem a fase participante da falta.

Formulação de estratégias que, dado o tipo de falta e a fase participante da mesma, seja capaz de estimar o local, no sistema de distribuição, de sua ocorrência.

Para que os objetivos pontuados nessa seção fossem atingidos se fez necessário a elaboração de desenvolvimentos dedicados aos propósitos citados. Dessa forma, tem-se na Seção 1.4 as contribuições retratadas nessa tese e, de forma que se apresente a estrutura adotada para delineamento do tema aqui abordado, reporta-se na Seção 1.5 , como a organização em capítulos fora feita.

\subsection{PRincipais CONTRIbuições da TESE}

Quando da revisão da literatura acadêmica e técnica acerca do tema abordado nesta tese de doutorado, verifica-se pontos comum às abordagens existentes. Um desses pontos é o uso de técnicas, em geral de processamento de sinais, dedicadas à extração de características das formas de onda de tensão e de corrente que auxiliem tanto na identificação da falta como na localização do ponto de sua ocorrência. Essa primeira etapa de extração de características é denotada pelo pré-processamento dos dados. Outro ponto comum é o emprego, nas abordagens mais recentes, de sistemas inteligentes que, a partir das características extraídas no pré-processamento, utilizam tais informações de maneira a identificar a ocorrência da falta ou sua provável localização.

Assim, permeando esse modelo habitual de sistema dedicado à identificação de faltas e à sua localização, ou seja, composto de um sistema dedicado ao pré-processamento e outro para o processamento em si, essa tese conduziu desenvolvimentos para aplicações em ambas as tarefas. Dessa forma, tais desenvolvimentos e a constituição de sua respectiva integração constituem as principais contribuições desta tese as quais, por sua vez, podem ser pontuadas da seguinte forma: 
Desenvolvimento da técnica de decomposição em componentes ortogonais.

* Elaboração do algoritmo para ajuste estrutural e paramétrico de sistemas de inferência fuzzy.

* Integração da técnica de decomposição em componentes ortogonais com os sistemas de inferência fuzzy a fim de realizar as seguintes tarefas:

- Identificação da ocorrência de uma falta fase-terra.

- Discriminação da fase participante da falta identificada.

- Localização do ponto de ocorrência da falta.

- Estimação da resistência de falta.

\subsection{ORgANiZAÇÃo da TESE DE DOUTORAdo}

Essa tese de doutorado está estruturada em sete capítulos de maneira que o tema abordado seja coerentemente explorado. Assim, após esse primeiro capítulo introdutório será desenvolvido o Capítulo 2, no qual será dado destaque às técnicas e metodologias reportadas na literatura correlata destinadas à identificação e localização de faltas em sistemas de energia elétrica com destaque especial para os sistemas de distribuição de energia elétrica. Ainda nesse capítulo, será dado destaque às técnicas contemporâneas para realização da identificação e localização de faltas e poder-se-á verificar dois principais aspectos. O primeiro deles é o da importância do pré-processamento dos sinais de tensão e de corrente oscilografados na subestação. O pré-processamento dos referidos sinais tem por meta a extração de características que permitam a diferenciação de uma condição operativa normal de uma outra faltosa, ou seja, fornecem subsídios para que, primeiramente, se faça a identificação da ocorrência de uma falta e, a posteriori, realizar-se-á sua localização. O segundo aspecto merecedor de destaque no levantamento bibliográfico apresentado no Capítulo 2 é o intenso uso de ferramentas advindas da inteligência computacional para que, a partir das informações providas pelo pré-processamento dos dados de tensão e de corrente, seja feita tanto a identificação como a localização de faltas em sistema de energia elétrica.

Dessa forma, procura-se contextualizar o tema abordado como sendo possível de ser subdividido na realização de duas tarefas: o pré-processamento dos sinais de tensão e de corrente e na identificação e localização de faltas. Assim, o Capítulo 3 e o Capítulo 4 buscam delinear as inovações propostas para realização de ambas as tarefas. 
No Capítulo 3 será apresentado, em um primeiro momento, como a partir de conceitos advindos da álgebra linear para o espaço de funções as formas de onda de tensão e de corrente podem ser decompostas em quatro componentes ortogonais entre si. Em um segundo momento, os princípios desenvolvidos para sistemas monofásicos serão estendidos para o caso trifásico. Por fim, partindo-se do conceito de componentes ortogonais, será então apresentado como essas se comportam frente à ocorrência de uma falta fase-terra num dado alimentador de um sistema de energia elétrica.

Prosseguindo com o desenvolvimento de técnicas que auxiliem na efetivação dos objetivos pontuados, no Capítulo 4 serão apresentados os fundamentos pertinentes aos sistemas de inferência fuzzy. Não apenas se restringindo ao delineamento de fundamentos solidificados pela literatura internacional, nesse capítulo será proposto um algoritmo dedicado ao ajuste paramétrico e estrutural de sistemas de inferência fuzzy. De forma ampla, apresentase uma metodologia que seja capaz de, a partir dos dados pré-processados, constituir um relacionamento entre as variáveis que conduza ao delineamento de conclusões sobre a ocorrência de faltas e de sua provável localização.

No Capítulo 5, antes de conduzir com a identificação de faltas, serão apresentados os detalhes da modelagem computacional do alimentador empregado na condução dos resultados pontuados nesse e no próximo capítulo. Prosseguindo, será apresentado como, por meio da decomposição em componentes ortogonais e de sistemas de inferência fuzzy, a identificação de faltas de alta impedância e a classificação da fase participante da falta podem ser feitas para sistemas de distribuição de energia elétrica. Para tanto, resultados advindos de simulações computacionais serão empregados.

Diante do indicativo da ocorrência de uma falta fase-terra de alta impedância, bem como da fase participante da referida falta, tarefas essas sintetizadas no Capítulo 5, no Capítulo 6 será delineada a apresentação dos resultados obtidos para a localização de faltas de alta impedância e para a estimação da resistência de falta. Assim, não apenas focando na determinação da distância relativa à subestação que a falta ocorrera, será conduzida a determinação da provável resistência de falta. A informação relativa à resistência de falta pode, de forma secundária, auxiliar na localização do ponto onde a falta fora estabelecida visto que uma falta de alta impedância pode se estabelecer de diferentes modos e, para cada um desses, uma faixa de resistência pode ser caracterizada. 
Por fim, no Capítulo 7 serão apresentadas as discussões decorrentes do trabalho desenvolvido, bem como se pontuará as conclusões gerais do mesmo. Além disso, proposições para trabalhos futuros serão também delineadas tendo como premissa as potencialidades das técnicas desenvolvidas. 


\section{TÉCNICAS DE IDENTIFICAÇÃO E LOCALIZAÇÃO DE FALTAS EM SISTEMAS DE DISTRIBUIÇÃO DE ENERGIA ELÉTRICA}

\subsection{INTRODUÇão}

Um dos requisitos para a operação econômica e confiável de um sistema de potência é a determinação exata em tempo hábil do ponto onde uma eventual falta ocorrera. A localização destas faltas nos sistema de distribuição de energia elétrica, em geral, é realizada pelo cruzamento das informações fornecidas pelos clientes com a experiência acumulada pelos profissionais da área técnica, os quais são responsáveis pelo despacho das equipes de manutenção aos lugares onde provavelmente a falta ocorreu. Se a estimação inicial estiver incorreta, então novos lugares candidatos deverão ser investigados pelas equipes responsáveis até que o local da falha seja identificado e os procedimentos de reparo possam ser efetuados.

Atualmente, a competição incremental ocasionada pela desregulamentação do setor de energia elétrica, aliada à necessidade crescente em fornecer melhores serviços aos clientes, tem contribuído para que as companhias de distribuição de energia elétrica investiguem novos métodos de localização de faltas que sejam mais rápidos e confiáveis que as abordagens convencionais (SENGER et al., 2005). Outro aspecto motivador que vem 
impulsionando o desenvolvimento de novas abordagens para identificação e localização de faltas é a possibilidade de otimização dos recursos técnico-financeiros das companhias, bem como a melhoria dos indicadores de eficiências energética do sistema de distribuição (ANIL PAHWA, 2001).

De uma maneira ampla, as faltas observadas junto aos sistemas de distribuição de energia elétrica podem ser classificadas em faltas de alta impedância e em faltas de baixa impedância.

As faltas de baixa impedância passíveis de ocorrência nos sistemas elétricos de distribuição são as faltas fase-fase e as faltas trifásicas. Estes tipos de faltas se caracterizam por provocarem a ocorrência de correntes com magnitudes suficientemente altas para sensibilizar de forma seletiva os dispositivos de proteção instalados ao longo do alimentador ou junto à subestação (HÄNNINEM et al., 2000). Além destes dois tipos, as faltas fase-terra de baixa impedância, num sistema de distribuição estrela aterrada, podem também ser identificadas pelos dispositivos de proteção do sistema de distribuição. Assim, as abordagens referenciadas na bibliografia correlata, relacionadas às faltas de baixa impedância, procuram, mediante a oscilografia do sistema e dos estados dos equipamentos seccionalizadores, estimar a distância relativa à subestação de ocorrência da falta para que as medidas corretivas cabíveis sejam providenciadas.

No entanto, dados estatísticos indicam uma maior probabilidade de ocorrência de faltas de alta impedância junto aos sistemas de distribuição de energia elétrica (RUSSELL, 1989a; RUSSELL, 1989b). As faltas de alta impedância se caracterizam por apresentarem magnitudes de corrente de falta menores do que a corrente de carga do alimentador (HÄNNINEM et al., 2000). Assim, os sistemas de proteção convencionais são ineficazes na identificação e na conseqüente atuação junto ao sistema de distribuição frente à ocorrência deste tipo de falta. Como uma decorrência direta destas limitações, tem-se que cabos rompidos sobre o solo, por exemplo, podem permanecer energizados por um longo período. Esta situação ilustrativa pode representar um sério risco, pois pode provocar acidentes envolvendo pessoas e animais, ou ainda, desencadear incêndios resultando em danos ao meio ambiente, bem como prejuízos de ordem econômica.

Desta maneira, as faltas de alta impedância podem ser definidas como um evento anormal sobre um alimentador de distribuição primário que não pode ser facilmente detectado por dispositivos de proteção convencionais. Essas faltas freqüentemente exibem arcos voltaicos quando nenhum retorno sólido para a corrente é disponível, resultando em correntes 
de falta com componentes de alta freqüência observáveis. Como decorrência direta destas faltas, este mesmo comportamento pode resultar de outros eventos, tais como o chaveamento de capacitores e mudanças de taps em transformadores. Todos esses aspectos, de forma conjunta, colaboram de maneira negativa para a qualidade da energia elétrica fornecida aos consumidores do sistema.

De forma ampla, pode-se destacar dois tipos de faltas de alta impedância, quais sejam elas as faltas ativas e as faltas passivas. Uma falta ativa é caracterizada pela presença de arco elétrico junto ao local de ocorrência da falta. A maioria das técnicas propostas na literatura para detecção de faltas ativas utiliza inferências que empregam os valores de módulo e de ângulo das freqüências harmônicas e não-harmônicas geradas pela corrente de arco-elétrico. Assim, diante do emprego dessas técnicas, uma detalhada decomposição das formas de onda de tensão e corrente para o domínio das freqüências se torna necessária.

Uma falta de alta impedância passiva é caracterizada pela ausência do arcoelétrico. Este tipo de falta pode representar um risco maior visto que o condutor não fornece qualquer indicação visual de uma condição de perigo. Além disso, as faltas passivas são mais difíceis de serem detectadas, pois as informações contidas no espectro harmônico da corrente da falta não são tão evidentes quanto aquelas contidas no espectro harmônico das correntes de falta ativas. Uma visão ampla sobre os principais aspectos relacionados às faltas de alta impedância passivas é apresentada em Jota \& Jota (1998).

Nas seções seguintes serão apresentadas em detalhes algumas das principais abordagens para identificação e localização de faltas em sistemas de distribuição de energia elétrica por meio de técnicas atuais. Dentre estas técnicas, destaque especial será conferido às redes neurais artificiais, aos sistemas de inferência fuzzy e às abordagens baseadas na transformada wavelet em função aos promissores resultados apresentados por essas abordagens relatados junto à bibliografia correlata. Além de destacar a grande diversidade de metodologias para identificação e localização de faltas de alta impedância, as seções constituintes desse capítulo objetivam pontuar os dois principais aspectos pertinentes ao desempenho dessas tarefas. O primeiro desses aspectos se refere ao pré-processamento dos dados oriundos da ocorrência da falta, ou seja, as maneiras pelas quais as formas de onda de tensão e de corrente são processadas de forma a aglutinar informações que sejam extremamente correlacionadas com a distância que a referida falta ocorrera. Assim, por meio desse pré-processamento, os sistemas responsáveis pela determinação da distância de 
ocorrência de falta poderão operar de forma mais coesa, resultando no segundo aspecto de destaque acima pontuado.

No entanto, as seções seguintes não se restringirão a apresentar as diferentes metodologias para pré-processamento e para, a partir dos dados processados, determinarem a distância que a falta ocorrera. Será conduzida também, por meio da Seção 2.2, como a partir da análise de circuitos elétricos, pode-se fazer uma estimativa da localização de uma eventual falta em um sistema de distribuição de energia elétrica.

Prosseguindo com a descrição de como esse capítulo fora organizado, tem-se na Seção 2.3 a apresentação de uma abordagem que se vale de coeficientes estatísticos para o pré-processamento dos dados e de redes neurais artificiais que determinam, em função desses coeficientes estatísticos, se um falta de alta-impedância está em curso.

Na Seção 2.4 uma segunda abordagem fundamentada em redes neurais artificiais para identificação de faltas de alta impedância é apresentada, onde o sistema responsável pelo pré-processamento das formas de onda não mais se baseia em coeficientes estatísticos, mas sim, em um misto de componentes simétricas e componentes harmônicas de regime permanente da corrente de falta, ou seja, dos coeficientes da série de Fourier. Quando do uso da série de Fourier para extração de características das formas de onda das tensões e das correntes, algumas limitações de análise podem decorrer. Dentre essas limitações, pode-se pontuar o fato de que essas formas de onda podem não se encontrar em regime permanente e de maneira perfeitamente periódica, ou seja, o emprego dos coeficientes da série de Fourier podem resultar na perda de informações as quais poderiam colaborar com a identificação da ocorrência de uma falta de alta impedância. Além disso, a maneira pela qual o espectro harmônico varia temporalmente não é claramente retratada por meio da decomposição harmônica.

Contornando as referidas limitações de pré-processamento da abordagem destacada na Seção 2.4, na Seção 2.5 se pontua o emprego da transformada de Fourier, em substituição à série, para realização, também por intermédio de redes neurais artificiais, da identificação de faltas de alta impedância em sistemas de distribuição de energia elétrica.

Dessa forma, nas Seções de 2.3 à 2.5 se apresenta como as redes neurais artificiais podem ser empregadas para identificação de faltas de alta impedância, sendo que em cada abordagem, diferentes metodologias de pré-processamento foram empregadas. Deve-se, contudo, observar que tanto o pré-processamento baseado em coeficientes estatísticos como 
aqueles fundamentados em componentes de freqüência são especialmente válidos quando da ocorrência de falta de alta impedância ativa, ou seja, aquelas onde o arco elétrico se faz presente.

Quando da ocorrência de falta de alta impedância passiva, o emprego das componentes em freqüência das tensões e das correntes se pode tornar uma técnica não tão promissora para a identificação das mesmas. Recorrendo aos sistemas de inferência fuzzy, na Seção 2.6, apresenta-se uma abordagem fundamentada nesses sistemas dedicada à identificação de faltas de alta impedância a qual busca comparar a resposta dinâmica do sistema frente ao impulso unitário.

Os sistemas de inferência fuzzy também são destaque na Seção 2.7, onde os referidos sistemas inteligentes são destinados no diagnóstico de faltas em subestações de distribuição de energia elétrica. A abordagem destacada nesta seção não apenas faz uso de sistemas de inferência fuzzy como também emprega redes neurais do tipo causa-efeito.

No âmbito da localização de faltas em sistemas de distribuição de energia elétrica, o pré-processamento das formas de onda de tensão e de corrente recebe tão ou mais importância que quando da sua identificação. Esse aspecto é evidenciado por meio da Seção 2.8 , onde se apresenta uma abordagem para localização de faltas de alta impedância baseada em redes neurais artificiais, tendo como núcleo do pré-processamento de formas de onda a Transformada Wavelet. A Transformada Wavelet realiza, tal como a Transformada de Fourier, a decomposição das formas de onda em componentes de freqüência processando como essas componentes variam temporalmente. Assim, por meio dessa ferramenta matemática, as formas de onda passam a ser representadas simultaneamente no domínio da freqüência e no domínio do tempo.

$\mathrm{Na}$ Seção 2.9, prosseguindo com a apresentação das potencialidades da Transformada Wavelet no estudo de sistemas faltosos, relata-se como essa transformada pode ser empregada na classificação e na medição dos níveis de perturbação em sistemas elétricos de potência. Seguindo a mesma linha da Seção 2.9, na Seção 2.10, apresenta-se uma segunda abordagem destinada à detecção de distúrbios específica para sistemas de distribuição de energia elétrica.

A forma como as faltas de alta impedância evoluem é tema da Seção 2.11, onde se destaca sua modelagem por meio da teoria de arcos elétricos. Na Seção 2.12, não se distanciando do objetivo de destacar os aspectos do pré-processamento e do processamento 
efetivo com a meta de localizar faltas de alta impedância, apresenta-se uma abordagem que se vale de redes neurais artificiais e da transformada de Clarke-Concórdia para o desempenho das tarefas mencionadas.

Por fim, tecendo-se os comentários gerais sobre as abordagens dedicadas à identificação e à localização de faltas em sistemas de distribuição de energia elétrica, delineiase a Seção 2.13.

\subsection{MÉtodo BaSEAdos EM ANÁlise de CirCuitos Elétricos Para localização de Faltas}

Os métodos para localização de faltas em sistemas de energia elétrica podem ser delineados de diferentes formas, sendo que aquelas que se baseiam em análises de circuitos elétricos constituem em uma dessas. Dessa forma, nessa seção será delineada a formulação proposta por Takagi et al. (1981) tanto para sistemas monofásicos como sua generalização para sistemas trifásicos.

Para tanto, será considerado o sistema elétrico apresentado por meio da Figura 2.1, onde a linha de transmissão possui uma impedância série $z$ e uma condutância shunt y.

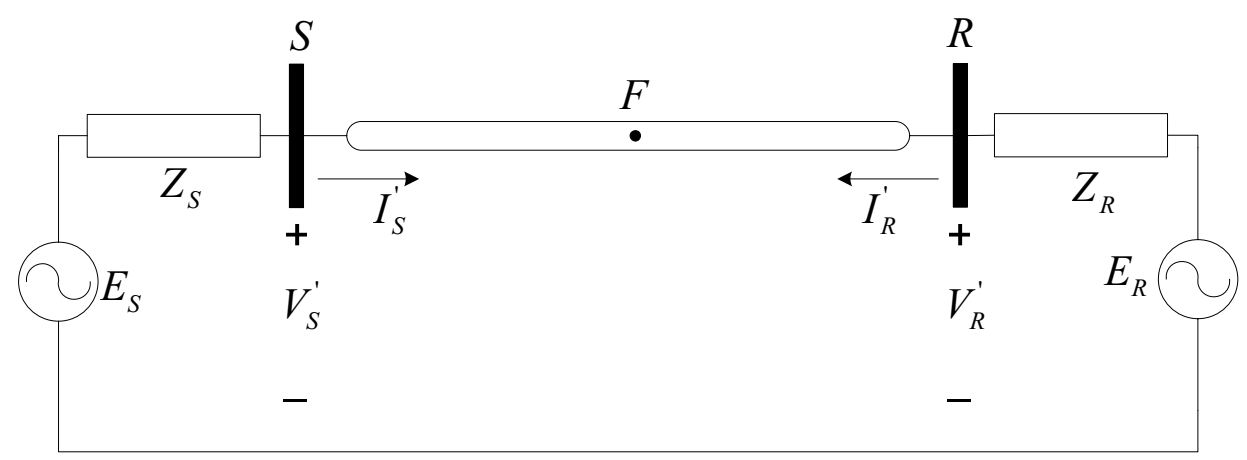

Figura 2.1 - Sistema elétrico no instante pré-falta.

No diagrama esquemático destacado por meio da Figura 2.1, tem-se que $V_{S}^{\prime}$ representa o fasor de tensão na barra $S$ antes da ocorrência da falta, bem como $V_{R}^{\prime}$ denota o fasor de tensão na barra $R$ nesse instante; a corrente medida na barra $S$ é representada pelo seu fasor $I_{S}^{\prime}$ enquanto que $I_{R}^{\prime}$ representa o fasor de corrente medido na barra $R$.

Com base no teorema da superposição de respostas para sistemas lineares, diante da ocorrência de uma falta tal como a ilustrada por meio da Figura 2.2, o circuito pode ser representado pela condição puramente faltosa, resultando, por sua vez, no circuito ilustrado por meio da Figura 2.3. 
No circuito ilustrado por meio da Figura 2.2, tem-se que $I_{F}$ representa o fasor da corrente de falta e $R_{F}$ a respectiva resistência para essa falta. É notável que em função dessa ocorrência os fasores de tensão e de corrente observados nas barras $R$ e $S$ também se alteraram sendo que, durante a condição de falta, nomear-se-á os fasores de tensão por $V_{R}$ e por $V_{S}$, enquanto que os fasores de corrente serão denotados por $I_{R}$ e $I_{S}$, respectivamente.

Assim, sendo $V_{F}$ o fasor de tensão no ponto de ocorrência da falta, a qual ocorrera a uma distância $x$ da barra $S$, e $I_{F}$ a corrente de falta que circula por meio da resistência de falta $R_{F}$, tem-se:

$$
V_{F}=R_{F} I_{F}=-R_{F}\left(I_{F S}^{\prime \prime}+I_{F R}^{\prime \prime}\right)
$$

onde $I_{F S}^{\prime \prime}$ é a parcela da corrente de falta que circula pela linha em direção à barra $S$, enquanto $I_{F R}^{\prime \prime}$ circula em direção à barra $R$.

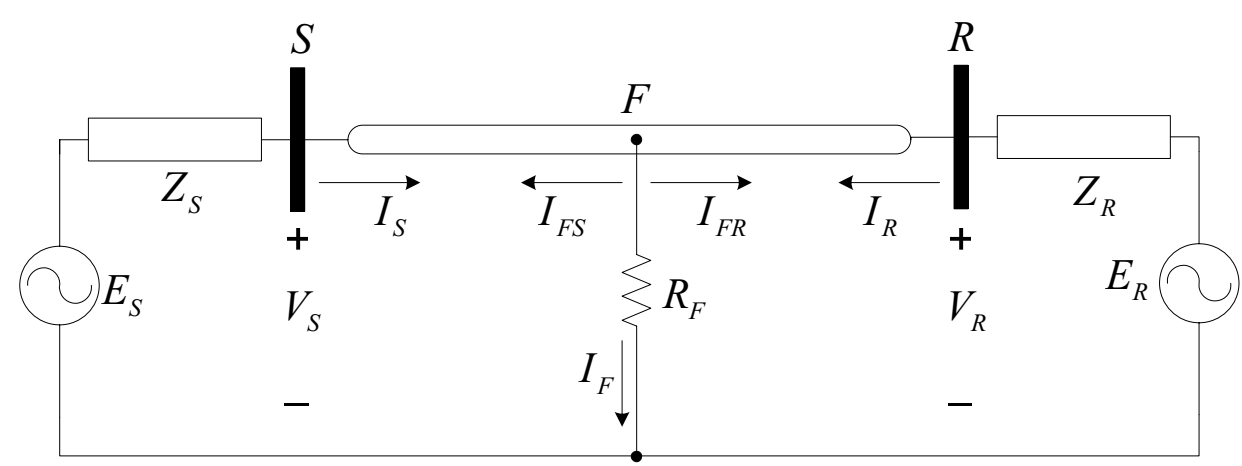

Figura 2.2 - Sistema elétrico no instante de ocorrência de uma falta.

Com base nesses dois fasores de corrente é possível definir a variável $K(x)$ a qual representa a razão entre os mesmos, ou seja:

$$
K(x)=\frac{I_{F R}^{\prime \prime}}{I_{F S}^{\prime \prime}}
$$

Dessa maneira, a expressão (2.1) pode ser escrita da seguinte forma:

$$
V_{F}=R_{F} I_{F}=-R_{F} I_{F S}^{\prime \prime}(1+K(x))
$$

Como os valores de $V_{F}$ e $I_{F S}^{\prime \prime}$ não são conhecidos, torna-se conveniente representar a linha de transmissão por meio de um quadripólo e assim, por meio da informação da barra $S$, determiná-los. Dessa forma, a seguinte representação é possível:

$$
V_{F}=A(x) V_{S}-B(x) I_{S}
$$




$$
I_{F S}^{\prime \prime}=C(x) V_{S}^{\prime \prime}-D(x) I_{S}^{\prime \prime}
$$

onde os parâmetros do quadripolo da linha no trecho $S-F$ podem ser obtidos por meio das seguintes equações:

$$
\begin{aligned}
& A(x)=D(x)=\cosh (\gamma x) \\
& B(x)=Z_{c} \operatorname{senh}(\gamma x) \\
& C(x)=\frac{1}{Z_{c}} \operatorname{senh}(\gamma x)
\end{aligned}
$$

onde $\lambda=\sqrt{z y}$ é denominada por constante de propagação da linha e $Z_{c}=\sqrt{z / y}$ é sua respectiva impedância característica. Os fasores observados quando da condição faltosa podem ser obtidos diretamente por meio de medidas realizadas na barra $S$ durante os instantes de pré-falta e de pós-falta.

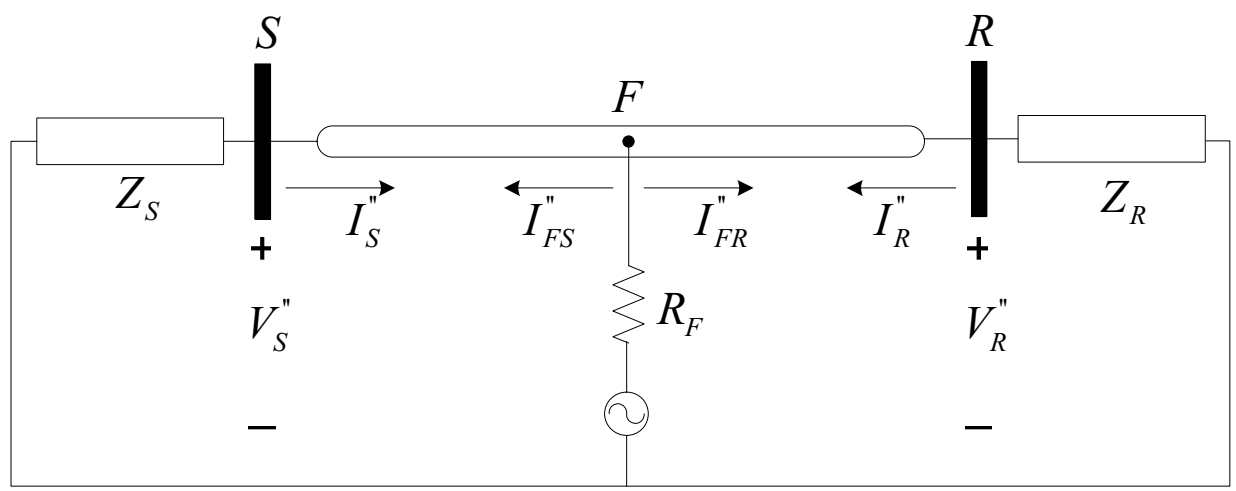

Figura 2.3 - Sistema elétrico equivalente no instante de ocorrência de uma falta.

Dessa maneira, as seguintes equivalências podem ser estabelecidas:

$$
\begin{aligned}
& V_{S}^{\prime \prime}=V_{S}-V_{S}^{\prime} \\
& I_{S}^{\prime \prime}=I_{S}-I_{S}^{\prime}
\end{aligned}
$$

Como conseqüência direta do exposto em (2.4) e (2.5), tem-se a possibilidade de desenvolver a expressão (2.3) da seguinte forma:

$$
\begin{aligned}
& V_{F}=-R_{F} I_{F S}^{\prime \prime}(1+K(x)) \\
& A(x) V_{S}-B(x) I_{S}=-R_{F}\left(C(x) V_{S}^{\prime \prime}-D(x) I_{S}^{\prime \prime}\right)(1+K(x)) \\
& R_{F}(1+K(x))=-\frac{A(x) V_{S}-B(x) I_{S}}{C(x) V_{S}^{\prime \prime}-D(x) I_{S}^{\prime \prime}}
\end{aligned}
$$


Observando-se a equação (2.11) é possível a identificação que a distância $x$ de ocorrência da falta, a resistência de falta $R_{F}$ e o valor de $K(x)$ constituem suas incógnitas. Assim, a fim de se determinar a distância $x$ torna-se necessário algumas aproximações que sejam hábeis na desconsideração de $R_{F}$ e o valor de $K(x)$. A primeira dessas aproximações impõe que $R_{F}$ seja puramente resistiva não possuindo, portanto, parcela imaginária. A segunda aproximação, pontuada por Takagi et al. (1981), estabelece que a relação $K(x)$ também é um valor real. Essa consideração é válida supondo-se uma linha de transmissão sem perdas, bem como tendo impedâncias equivalentes para as fontes como sendo puramente indutivas. Portanto, valendo-se de ambas considerações é possível inferir que $R_{F}(1+K(x))$ possui apenas componentes reais, ou seja:

$$
\operatorname{Im}\left(\frac{A(x) V_{S}-B(x) I_{S}}{C(x) V_{S}^{\prime \prime}-D(x) I_{S}^{\prime \prime}}\right)=0
$$

A expressão destacada em (2.12) possui um comportamento linear em função das funções $A(x), B(x), C(x)$ e $D(x)$, sendo imperativo para a obtenção de $x$ o emprego de técnicas para solução de equações não-lineares. No entanto, é possível constatar que a referida distância entre a barra $S$ e o ponto de ocorrência da falta é estimada apenas com medidas locais na referida barra. Além disso, a estimativa de $x$ não dependerá da resistência de falta $R_{F}$.

O método apresentado pode ser estendido para a localização de faltas em sistemas trifásicos, bem como ser particularizado para faltas fase-terra. Para que o desenvolvimento seja possível, torna-se conveniente a representação do sistema trifásico por meio de suas redes de seqüência, assim como se ilustra por meio da Figura 2.4.

Assim, empregando-se as equações de linha e se efetuando os desenvolvimentos e considerações necessárias, a Expressão (2.13) é alcançada, a qual mediante sua solução numérica, resulta na distância, em relação à barra $S$, da ocorrência da falta.

$$
\operatorname{Im}\left(\frac{V_{F}^{(0)}+V_{F}^{(1)}+V_{F}^{(2)}}{C(x)^{(1)} V_{S}^{(1)}-D(x)^{(1)} I_{S}^{\prime \prime(1)}}\right)=0
$$

onde:

$$
\left\{\begin{array}{l}
V_{F}^{(0)}=A(x)^{(0)} V_{S}^{(0)}-B(x)^{(0)} I_{S}^{(0)} \\
V_{F}^{(1)}=A(x)^{(1)} V_{S}^{(1)}-B(x)^{(1)} I_{S}^{(1)} \\
V_{F}^{(2)}=A(x)^{(2)} V_{S}^{(2)}-B(x)^{(2)} I_{S}^{(2)}
\end{array}\right.
$$


O método apresentado em Takagi et al. (1981) fora posteriormente particularizado para linhas com comprimento inferior a $100 \mathrm{~km}$. As considerações necessárias à referida particularização são relatados em Takagi et al. (1982) e, tal como feito em Takagi et al. (1981), o método se fundamenta sobre o conjunto de equações que segue.

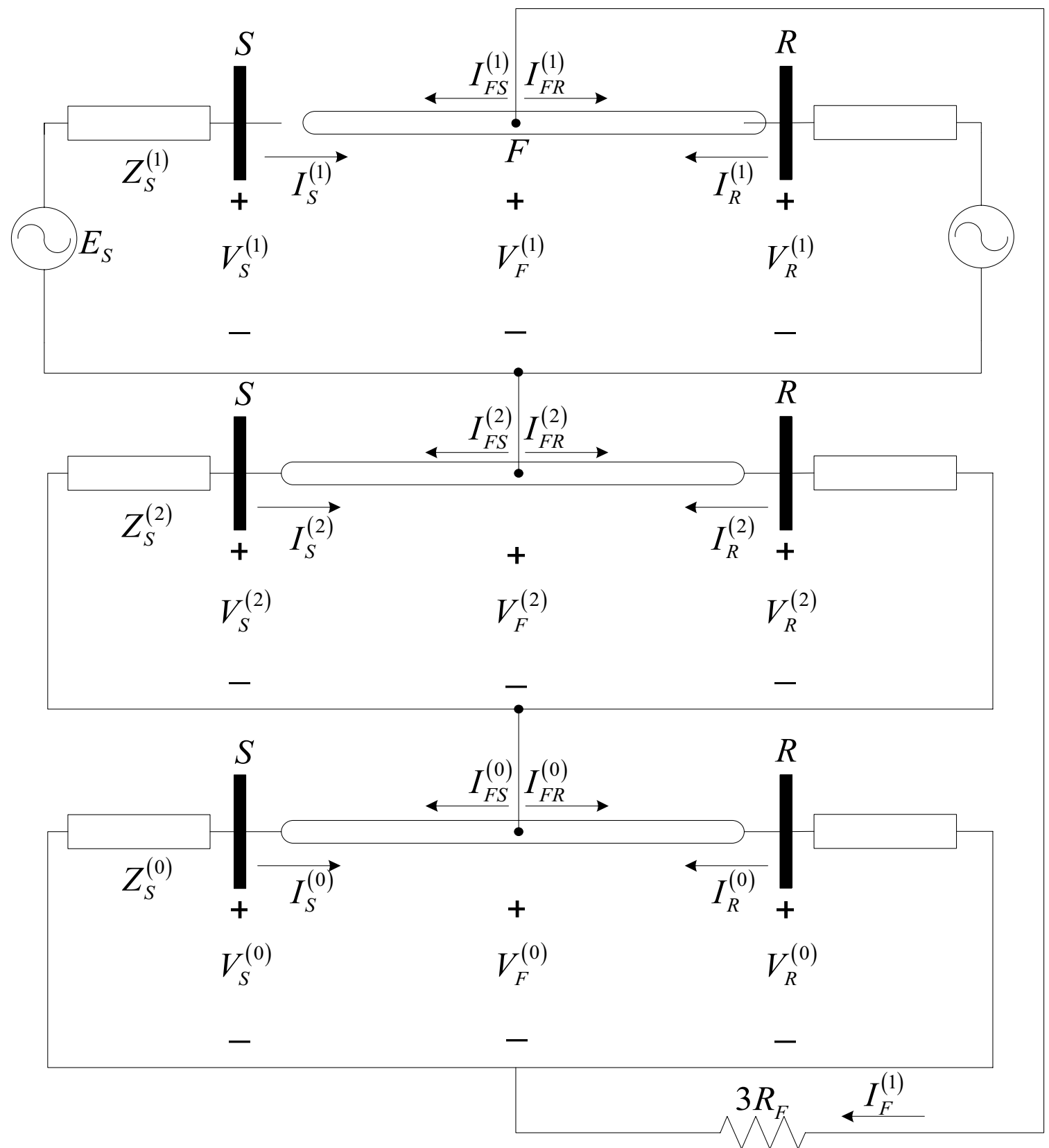

Figura 2.4 - Rede de seqüência para uma falta fase-terra.

$$
\begin{aligned}
& V_{F}=R_{F} I_{F}=-R_{F}\left(I_{F S}^{\prime \prime}+I_{F R}^{\prime \prime}\right) \\
& V_{F}=V_{S} \cosh (\gamma x)-I_{S} Z_{c} \operatorname{senh}(\gamma x) \\
& I_{F S}^{\prime \prime}=\frac{V_{S}^{\prime \prime}}{Z_{c}} \operatorname{senh}(\gamma x)-I_{S}^{\prime \prime} \cosh (\gamma x)
\end{aligned}
$$


Dessa forma, a corrente de falta $I_{F}$ fora expressa por meio do seguinte relacionamento:

$$
I_{F}=I_{F S}^{\prime \prime} \dot{\zeta}
$$

onde $\dot{\zeta}=\zeta e^{j \theta}$ e $\theta=\arg \left(I_{F} / I_{F S}^{\prime \prime}\right)$ representa a diferença angular entre as correntes de falta provenientes da barra $S$ e da barra $R$. Segundo Takagi et al. (1982), o valor de $\theta$ esperado é próximo a zero. Dessa forma, substituindo $\dot{\zeta}$ em (2.15), bem como (2.16), (2.17) e (2.18) na referida expressão e dividindo ambos os termos por $\cosh (\gamma x)$, tem-se:

$$
V_{S}-I_{S} Z_{c} \tanh (\gamma x)-R_{F}\left(\frac{V_{S}^{\prime \prime}}{Z_{c}} \tanh (\gamma x)-I_{S}^{\prime \prime}\right) \zeta e^{j \theta}=0
$$

Percebe-se que $\zeta$ e $R_{F}$ são números reais. Então, isolando-se o termo $\zeta R_{F}$ e tomando apenas a parte imaginária de ambos os lados da igualdade se pode eliminar estas duas incógnitas da formulação, chegando à seguinte expressão:

$$
\operatorname{Im}\left[\left(V_{S}-I_{S} Z_{c} \tanh (\gamma x)\right)\left(\frac{V_{S}^{\prime \prime}}{Z_{c}} \tanh (\gamma x)-I_{S}^{\prime \prime}\right)^{*} e^{j \theta}\right]=0
$$

Na equação acima, $\theta$ e $x$ são valores desconhecidos. Então, sabendo-se do valor de $\theta$, a distância da falta $x$ pode ser determinada. Conforme mencionado anteriormente, o ângulo $\theta$ representa a diferença angular entre as correntes de falta do terminal local e remoto. Segundo Takagi et al. (1982), o valor do ângulo $\theta$ é aproximadamente nulo. Então, substituindo $\theta$ por zero e usando as seguintes aproximações, que segundo Takagi et al. (1982) são válidas para linhas curtas,

$$
\begin{aligned}
& \tanh (\gamma x) \cong \gamma x \\
& \frac{V_{S}^{\prime \prime}}{Z_{c}} \tanh (\gamma x) \ll I_{S}^{\prime \prime}
\end{aligned}
$$

chega-se a expressão seguinte que pode ser utilizada para determinar a distância da falta:

$$
x=\frac{\operatorname{Im}\left(V_{S} I_{S}^{* *}\right)}{\operatorname{Im}\left(Z I_{S} I_{S}^{\prime *}\right)}
$$


onde $Z=\gamma Z_{c}$ é a impedância da linha por unidade de comprimento. Por meio das aproximações sugeridas em Takagi et al. (1982), a localização de faltas para sistemas trifásicos pode ser particularizada para as faltas fase-terra da seguinte maneira:

$$
x=\frac{\operatorname{Im}\left(I_{S}^{\prime *}\left(V_{S}^{(0)}+V_{S}^{(1)}+V_{S}^{(2)}\right)\right)}{\operatorname{Im}\left(I_{S}^{\prime \prime *}\left(Z^{(0)} I_{S}^{(0)}+Z^{(1)} I_{S}^{(1)}+Z^{(2)} I_{S}^{(2)}\right)\right)}
$$

Os métodos de localização de faltas apresentados nessa seção foram desenvolvidos especificamente para sistemas de transmissão de energia. As linhas de transmissão são geralmente consideradas homogêneas ao longo de sua extensão, ou seja, é constituída de um único condutor sem cargas ou derivações em pontos intermediários. Por outro lado, nos sistemas de distribuição de energia, um mesmo alimentador pode ser constituído de segmentos com diferentes condutores, resultando em trechos com valores de impedância por unidade de comprimento distintos. Além disso, diversas cargas e ramificações podem estar conectadas ao longo do alimentador. Estas características fazem com que os métodos descritos anteriormente não possam ser utilizados diretamente nestes sistemas. Para se obter uma estimativa precisa da distância da falta em sistemas de distribuição de energia elétrica se faz necessário considerar as diversas cargas conectadas ao longo do alimentador, bem como eventuais ramificações laterais, ou seja, a modelagem do alimentador deve contemplar o máximo de informações possíveis a fim de garantir resultados próximos aos observados em sistemas de distribuição reais.

Complementando a citação dos adventos nessa linha, no trabalho de Lee et al. (2004) foi apresentado um algoritmo iterativo para localização de faltas em sistemas de distribuição de energia que leva em conta as características de tais sistemas. O algoritmo executa o cálculo da distância de falta para cada seção do alimentador, sendo as tensões e correntes em cada nó do circuito estimadas via análise de circuitos. Assim, pode-se pensar no algoritmo proposto como a aplicação do Takagi simplificado para cada trecho da linha de distribuição. Além do referido trabalho, Girgis et al. (1993), Zhu et al. (1997) e Das et al. (2000) já haviam publicado anteriormente metodologias semelhantes, também baseadas nas estimativas dos valores de corrente e tensão em cada nó do alimentador. O algoritmo de Lee et al. (2004) será detalhado a seguir, uma vez que representa uma das abordagens, baseadas em análises de circuitos elétricos, mais recentes reportadas na literatura correlata. 
Para o desenvolvimento do método proposto por Lee et al. (2004) faz-se necessário, inicialmente, a consideração de uma falta fase-terra envolvendo a fase $a$ de um alimentador de distribuição de energia conforme a Figura 2.5.

Assim, a tensão na barra $S$, representativa da barra da subestação de distribuição, pode ser calculada da seguinte maneira:

$$
V_{S a}=x\left(Z_{L a} I_{S a}\right)+I_{F} R_{F}
$$

A equação (2.25) pode então ser desenvolvida da seguinte maneira:

$$
\begin{aligned}
& I_{F} R_{F}=V_{S a}-x Z_{L a} I_{S a} \\
& I_{F}^{*} I_{F} R_{F}=I_{F}^{*}\left(V_{S a}-x Z_{L a} I_{S a}\right)
\end{aligned}
$$

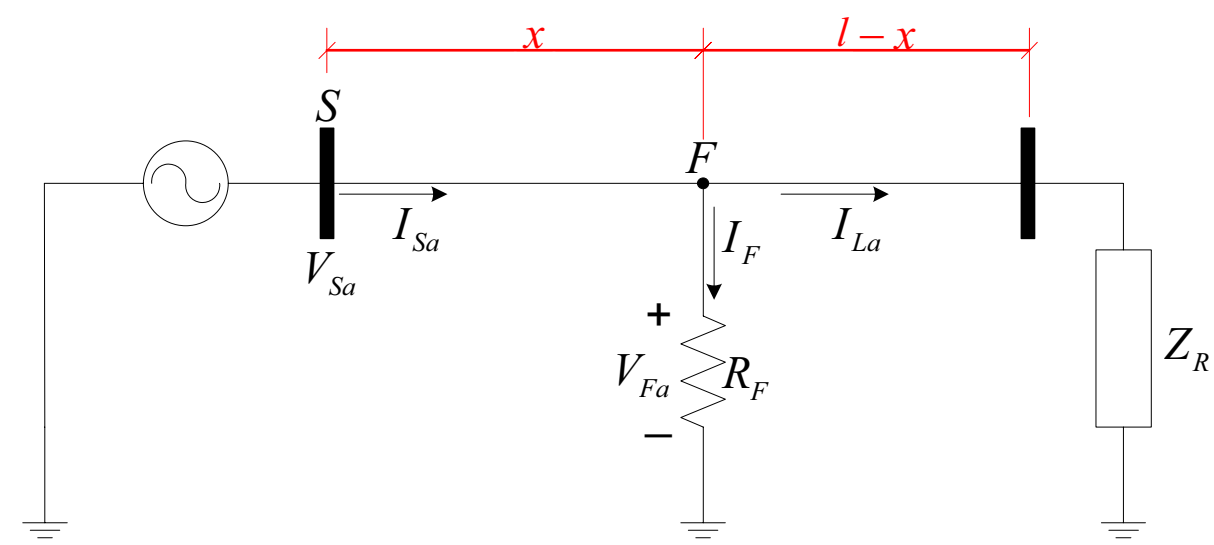

Figura 2.5 - Modelo simplificado do alimentador de distribuição.

Como $I_{F}^{*} I_{F} R_{F}$ resulta em um valor real, tem-se que a parcela imaginária de $I_{F}^{*}\left(V_{S a}-x Z_{L a} I_{S a}\right)$ será nula, tornando então possível a determinação da distância $x$, ou seja:

$$
x=\frac{\operatorname{Im}\left(V_{S a} I_{F}^{*}\right)}{\operatorname{Im}\left(Z_{L a} I_{S a} I_{F}^{*}\right)}
$$

onde:

$$
I_{F}=I_{S a}-I_{L a}
$$

Em função da existência de cargas intermediárias ao longo de um alimentador de distribuição e da elevada resistência da linha, as quedas de tensão provocadas pela falta podem se tornar significativas e com isso modificar a corrente consumida por cada carga do circuito, se estas forem modeladas como impedância ou potência constante. Assim, é equivocada a hipótese de que a corrente de carga durante a falta $\left(I_{L a}\right)$ pode ser assumida como 
sendo seu valor pré-falta $\left(I_{S a}\right)$. Pode-se observar que se esta aproximação for feita, a Equação (2.27) torna-se idêntica à Equação (2.23) determinada pelo método de Takagi para linha curtas.

Logo, $I_{L a}$, é também uma incógnita na formulação. Lee et al. (2004) propuseram em seu trabalho uma técnica iterativa para estimar seu valor. Esse processo iterativo compõe o algoritmo de localização de faltas em sistemas de distribuição de energia elétrica o qual é composto das seguintes etapas:

ETAPA 1: Assume-se $I_{L a}$ como sendo o valor da corrente de carga;

ETAPA 2: Calcula-se a corrente de falta $I_{F}$ utilizando (2.28);

ETAPA 3: Determina-se a primeira estimativa da localização da falta utilizando (2.27);

ETAPA 4: Calcula-se a tensão no ponto da falta utilizando (2.29);

$$
\left(\begin{array}{l}
V_{F a} \\
V_{F b} \\
V_{F c}
\end{array}\right)=\left(\begin{array}{l}
V_{S a} \\
V_{S b} \\
V_{S c}
\end{array}\right)-x\left(\begin{array}{c}
Z_{L a} I_{S a} \\
Z_{L b} I_{S b} \\
Z_{L c} I_{S a}
\end{array}\right)
$$

ETAPA 5: Utiliza-se a tensão de falta para obter um valor de $I_{L a}$ atualizado;

ETAPA 6: Volta-se à Etapa 2 com um novo valor de $I_{F}$ e o processo é repetido até que $x$ convirja.

Verifica-se, contudo, que conforme apresentado para a Etapa 4 do algoritmo proposto por Lee et al. (2004), faz-se necessário a estimação do valor da corrente de carga $I_{L a}$ durante a falta a partir do valor atualizado da tensão no ponto da falta. Se a carga é modelada como impedância constante e seu valor é conhecido, pode-se calcular $I_{L a}$ da seguinte forma:

$$
I_{L a}=Y_{L a} V_{F a}
$$

$\mathrm{Na}$ equação anterior, $Y_{L a}$ representa a matriz admitância da seção da linha após o ponto da falta e da carga, sendo que seu valor pode ser calculado da seguinte forma:

$$
Y_{L a}=\left((1-x) Z_{L a}+Z_{R}\right)^{-1}
$$

Se a impedância da carga não for conhecida, pode-se estimar $I_{L a}$ a partir da equação .

$$
I_{L a}=\frac{I_{L a}^{\prime}}{V_{F a}^{\prime}} V_{F a}
$$


onde $V_{F a}^{\prime}$ é a tensão pré-falta da fase $a$ no ponto da falta, dada por meio de (2.33); $I_{L a}^{\prime}$ é a corrente de carga pré-falta da fase $a$ tal como $V_{S a}^{\prime}$ é a tensão pré-falta da fase $a$ medida na barra $S$. Nota-se que na equação (2.32), $Y_{L a}$ foi substituído por uma estimativa do seu valor com base em valores pré-falta medidos na subestação.

$$
V_{F a}^{\prime}=V_{S a}^{\prime}-x Z_{L a} I_{L a}^{\prime}
$$

Se a distância de falta obtida $x$ é maior do que a extensão da seção considerada significa que a falta não ocorreu nesta, mas sim em alguma das seções seguintes. Então, um novo processo de localização da falta deve ser executado para a próxima seção, utilizando os valores de corrente e tensão no seu nó inicial. No entanto, como as medições de corrente e tensão são realizadas apenas na subestação, faz-se necessário uma maneira de estimar estes valores em cada nó do alimentador. Assim, considerando o modelo completo de um alimentador radial exposto na Figura 2.6, a tensão no nó $k+1$ pode ser obtida por meio da Equação (2.34).

$$
V_{k+1}=V_{k}-Z_{k} I_{k}
$$

onde $V_{k}$ é a tensão na barra $k, Z_{k}$ é a impedância da $k$-ésima seção de linha e $I_{k}$ é o valor da corrente na $k$-ésima seção. Considerando as cargas como impedância constante, a $k$-ésima corrente de carga pode ser calculada por meio de (2.35).

$$
I_{L k}=Y_{L k} V_{k}
$$

onde $I_{L k}$ é a corrente consumida pela carga conectada na barra $k$ e $Y_{L k}$ é a admitância desta carga. Finalmente, pode-se calcular a corrente da $k$-ésima seção do alimentador utilizando a equação (2.36).

$$
I_{k}=I_{k-1}-I_{L k}
$$

Assim, o algoritmo de localização de faltas em sistemas de distribuição de energia elétrica proposto executa um processo de localização de faltas para cada seção do alimentador, utilizando as estimativas de $V_{k}$ e de $I_{k}$ descritas. Uma vez que $x$ converge para um valor de distância no intervalo da seção em análise, o algoritmo é finalizado, bastando somar a distância $x$ com o valor das distâncias das seções de linha anteriores para que a localização da falta seja determinada. 


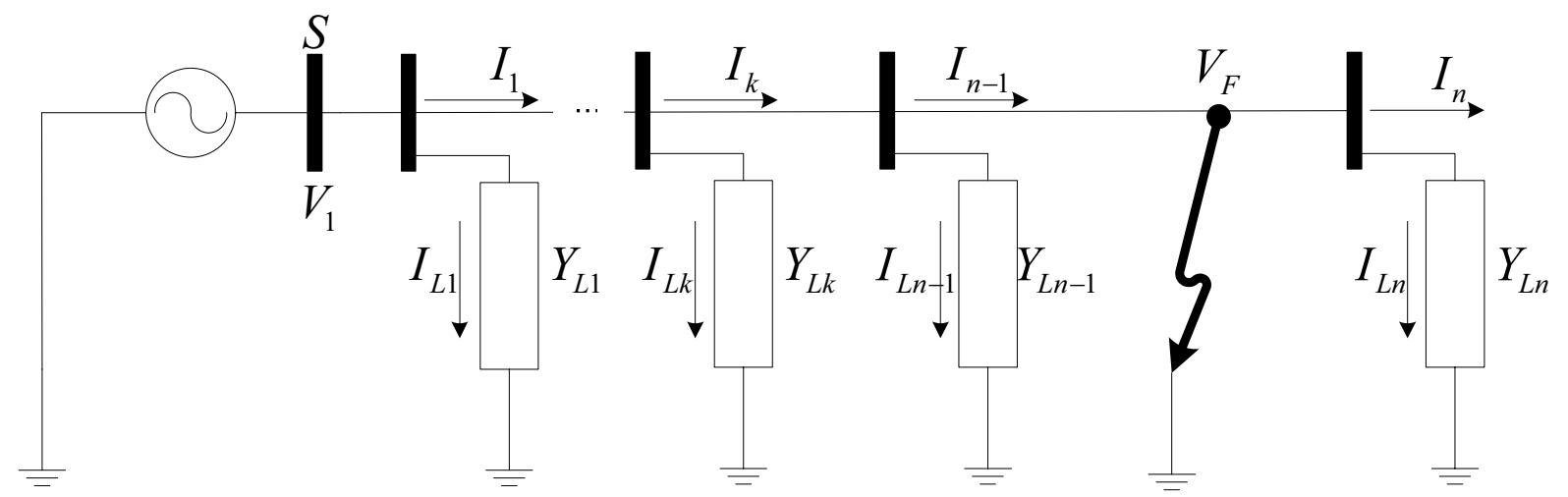

Figura 2.6 - Modelo completo do alimentador de distribuição.

Uma das características principais dos sistemas de distribuição de energia é a presença de ramificações laterais nos alimentadores. Nos métodos de localização de faltas descrito nessa seção, a presença de ramificações laterais pode fazer com que uma determinada falta seja localizada em diversos pontos diferentes do sistema. Ou seja, a mesma falta, aplicada em locais diferentes pode induzir valores de tensão e corrente iguais na subestação.

No trabalho de Lee et al. (2004) é também proposta uma metodologia para a identificação da lateral na qual ocorreu a falta. O método é baseado na observação dos padrões da corrente durante o tempo de isolamento da falta. Dadas as características dos diversos dispositivos de proteção presentes ao longo do alimentador (basicamente fusíveis e religadores) e suas localizações, é possível determinar, por meio da forma de onda da corrente na subestação, qual dispositivo atuou no isolamento da falta e com isso, determina-se a lateral. Além destas informações, o método utiliza a medida da quantidade de carga interrompida após a atuação da proteção, como indicativo da lateral envolvida na falta.

\subsection{Abordagem Neural Utilizando Características ESTATÍSTICAS DAS CORRENTES DE FALTA}

Um fato observável em faltas que exibem uma baixa corrente de falta é que as mesmas normalmente apresentam grandes magnitudes nos sinais de tensão de fase. Entretanto, há uma alteração destacável no formato de onda da corrente na fase faltante (BUTLER et al., 2000; BUTLER et al., 1993).

Para condições de faltas sem a presença de arco, a amplitude e/ou ângulo da corrente na fase faltante implica em alterações determinísticas, enquanto que nas condições de falta com presença de arco, distorções aleatórias em intervalos intermitentes podem ser 
observados na fase ou na amplitude da corrente da fase faltante. Na presença de um distúrbio devido à ocorrência de falta as formas de onda das correntes de fase e de neutro se apresentam distorcidas. Assim, a forma de onda de uma corrente faltosa pode ser representada pela corrente definida em (2.37) em adição ao distúrbio provocado pela falta, ou seja:

$$
i_{p}^{\prime}(t)=i_{p}(t)+n(t)
$$

onde $n(t)$ representa um processo randômico. No entanto, nas abordagens convencionalmente empregadas, tanto academicamente como tecnicamente, não contemplam os distúrbios gerados na forma de onda de tensão. A fim de garantir uma maior confiabilidade das estimações realizadas, a distorção na forma de onda de tensão será considerada ao longo da apresentação da metodologia proposta. A Figura 2.7 apresenta formas de onda de tensão e de corrente para um sistema elétrico sob falta fase-terra de alta impedância com presença de arco elétrico (Ziollkowski, 2007).

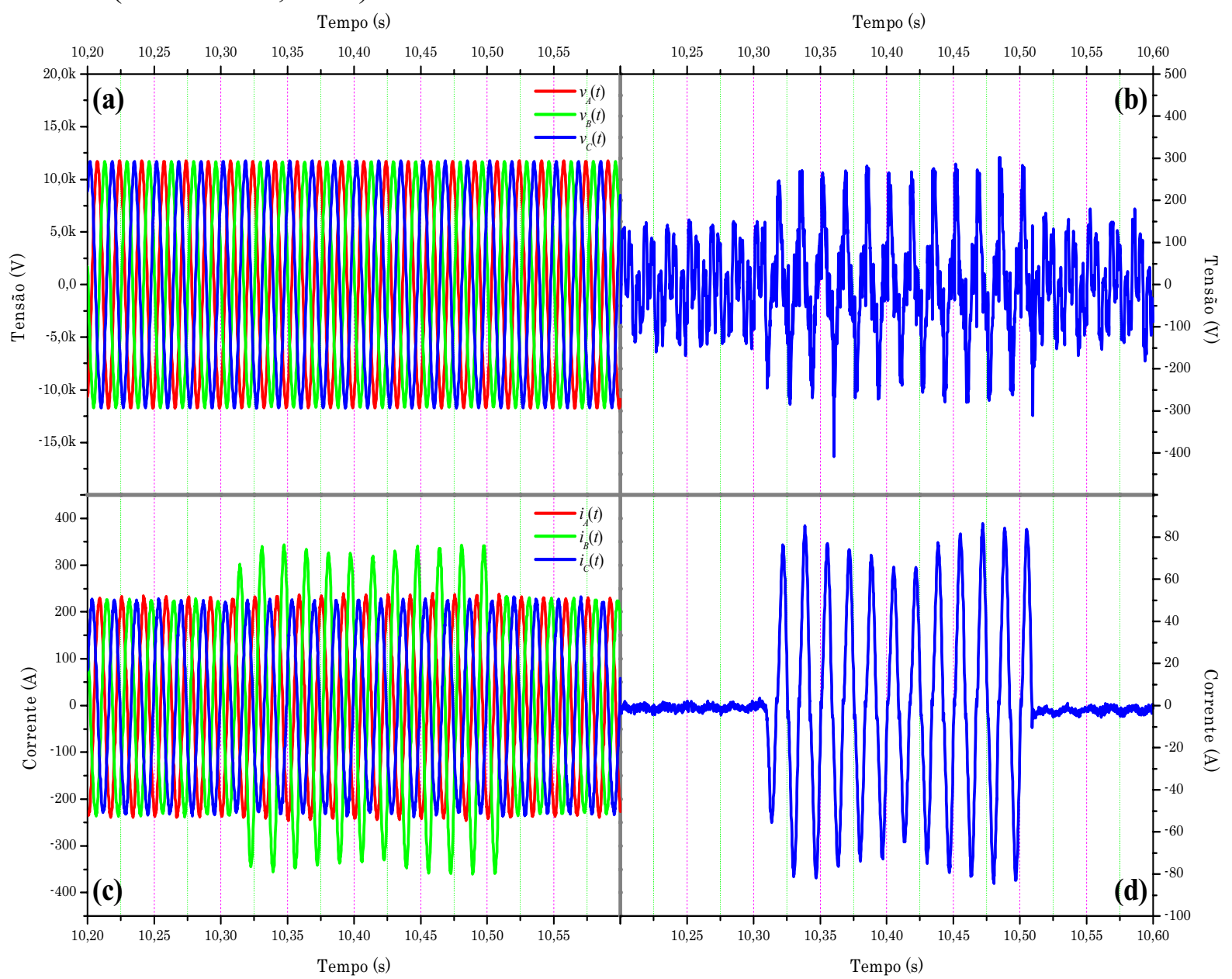

Figura 2.7 - Formas de onda de corrente e tensão para uma falta fase terra com ocorrência de arco elétrico; (a) Tensões de fase; (b) Tensão de neutro; (c) Correntes de linha; (d) Corrente de neutro. 
Pode-se observar por meio dos gráficos da Figura 2.7 a constante alteração de formato de onda a cada ciclo tanto para as formas de onda de tensão como para as formas de onda de corrente. A assimetria de formato das formas de onda no domínio do tempo torna complexa a tarefa de extração de características que permitem ajustar corretamente o sistema de identificação de faltas. No entanto, quando a análise espectral de freqüência é realizada sob os dados disponíveis, periodicidades ocultas ou pequenos picos de energia em determinadas freqüências podem ser observados. Assim, o levantamento destas peculiaridades do domínio da freqüência pode contribuir positivamente para a detecção de eventuais falhas junto ao sistema de distribuição de energia elétrica.

O método de diagnóstico de falta utilizado nesta abordagem consiste em aplicar as capacidades de reconhecimento de padrões oferecidos pelas redes neurais com o objetivo de detectar faltas de baixa e alta impedância, na presença de arco, em sistemas aterrados ou não aterrados que são normalmente não detectadas por dispositivos de proteção de sobrecorrente em virtude das baixas magnitudes das mesmas.

De forma geral, pode-se caracterizar esta abordagem por meio de duas etapas principais. A primeira etapa é responsável por realizar um pré-processamento de sinais e, a segunda etapa, é constituída por um sistema de diagnóstico baseado em clusterização supervisionado. As entradas do sistema de diagnóstico de faltas são as três correntes de fase medidas em cada alimentador. $\mathrm{O}$ alimentador da subestação monitora as tensões e correntes fornecidas pelos dispositivos de proteção do sistema. O pré-processador computa as características estatísticas vindas das correntes de fase passando as mesmas para o classificador neural de padrões. A Figura 2.8 ilustra o diagrama de blocos do método proposto por Butler et al. (2000) para diagnóstico de faltas.

As características pertinentes à forma de onda são fundamentais para se determinar o tipo de metodologia a ser empregada na análise em freqüência das formas de onda oscilografadas. Uma vez que os dados obtidos estão comprometidos por um ruído branco, o emprego da transformada de Fourier se torna inadequada (BUTLER, 1993). Desta maneira, o emprego de técnicas de processamento estatístico se configuram mais adequadas aos propósitos do problema de identificação de faltas em sistemas de distribuição de energia elétrica. 
Dentre as diversas metodologias disponíveis para se realizar a análise espectral estatística, destaca-se a abordagem apresentada por Ulrych \& Bishop (1975), aonde o conceito de análise espectral pela máxima entropia é formulada. Aplicando-se este conceito à análise espectral se verifica que tal procedimento pode ser representado como sendo um processo gaussiano estacionário, ou seja:

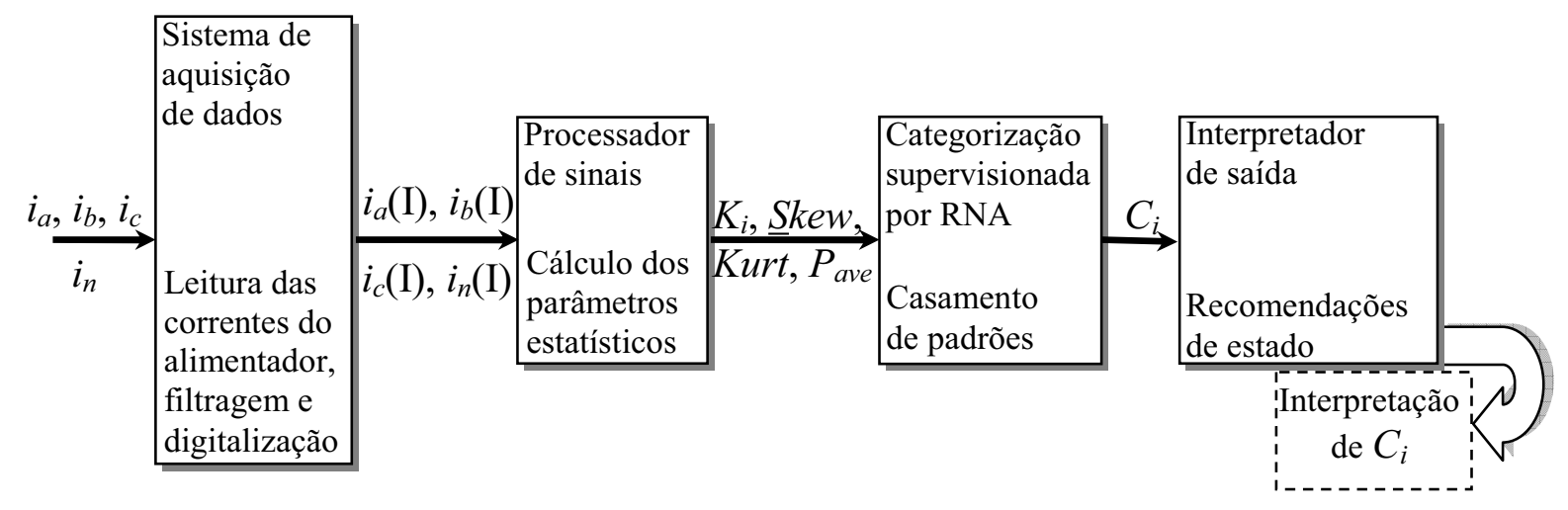

Figura 2.8 - Diagrama de blocos do método de diagnóstico de faltas baseado em características estatísticas das correntes de falta.

$$
H=\frac{1}{4 f_{n}} \int_{-f_{n}}^{f_{n}} \log (S(f)) d f
$$

onde $f_{n}$ é a freqüência de Nyquist. Reescrevendo a expressão (2.38) em termos da autocorrelação do sistema, tem-se:

$$
H=\frac{1}{4 f_{n}} \int_{-f_{n}}^{f_{n}} \log \left(\sum_{-\infty}^{+\infty} \phi(k) \exp (-j 2 \pi f k \Delta t)\right) d f
$$

Maximizando (2.39) com relação aos termos $\phi(k)$ desconhecidos e respeitando as restrições impostas por $S(f)$, aonde se deve observar a consistência das autocorrelações $\phi(0)$... $\phi(M-1)$, tem-se a função densidade espectral. Para um processo linear $x$, a função densidade espectral estimada pode ser representada da seguinte maneira:

$$
\hat{S}_{x}(t)=\frac{P_{m}}{2 B\left(1+\sum_{m=1}^{M} a_{m} e^{-j 2 \pi m f \Delta t v}\right)^{2}}
$$

onde $P_{m}$ é a potência normalizada do filtro de ordem $M$ e $B$ é a largura de banda do processo estocástico $x$. 
Um dos principais limitantes da aplicação da função densidade espectral, conforme apresentado em (2.40), reside na estimação da ordem do filtro de estimação de erro. No entanto, o critério de estimação do erro final desenvolvido por Akeike (1969), a qual incorpora o erro quadrático de estimação, mostra-se efetivo na determinação da ordem ótima para o filtro. O erro final de predição, denotado por EFP, pode ser calculado da seguinte maneira:

$$
\operatorname{EFP}(M)=\frac{N+M+1}{N-M-1} P_{m}
$$

Por meio do processamento espectral estatístico das formas de onda, as principais características extraídas pelo pré-processador de sinais e empregadas nesta metodologia são as seguintes:

* Matrizes de coeficientes de reflexão $\left(K_{i}\right)$.

Coeficientes de skewness (Skew).

Coeficientes de curtose (Kurt).

* Coeficientes de potência média $\left(P_{a v e}\right)$.

Cada um dos parâmetros estatísticos empregados nesta abordagem representa quantitativamente características inerentes às formas de onda de corrente e tensão. Os coeficientes de skewness fornecem informações estatísticas de terceira ordem e podem ser interpretados como sendo uma medida da assimetria em torno do valor médio das formas de onda das tensões e correntes faltosas, enquanto que os coeficientes de curtose indicam o quão próximo ou o quão distante a função densidade probabilidade está de uma distribuição gaussiana. Os coeficientes de reflexão são um indicativo da repetibilidade das formas de onda, enquanto que os coeficientes de potência média fornecem à abordagem um patamar referencial para a correta categorização dos eventos.

Para ilustrar como alguns destes parâmetros variam para uma forma de onda de corrente faltosa, são apresentados na Figura 2.9 e Figura 2.10 os valores de skewness e de curtose para uma corrente de falta e para uma corrente normal ao longo de 14 ciclos.

Os resultados fornecidos pela rede neural indicam se um determinado padrão de sinal se deve a uma falta ou não. Se o sinal é detectado como falta, a rede neural adicionalmente classifica o tipo de falta e identifica a fase faltante. 


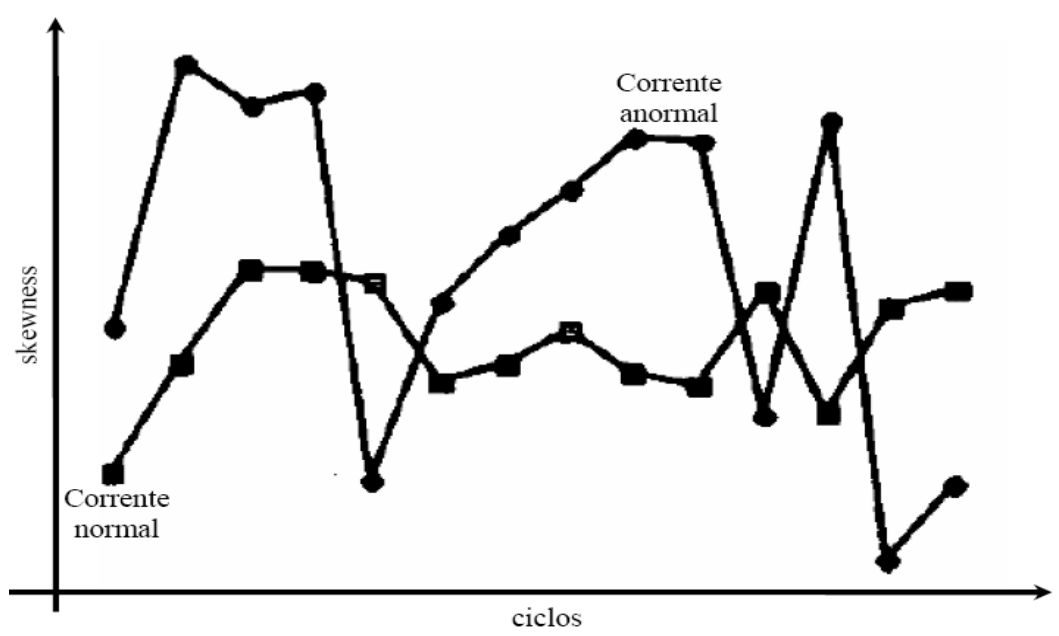

Figura 2.9 - Skewness para uma forma de onda de corrente faltosa e para uma forma de onda de corrente normal.

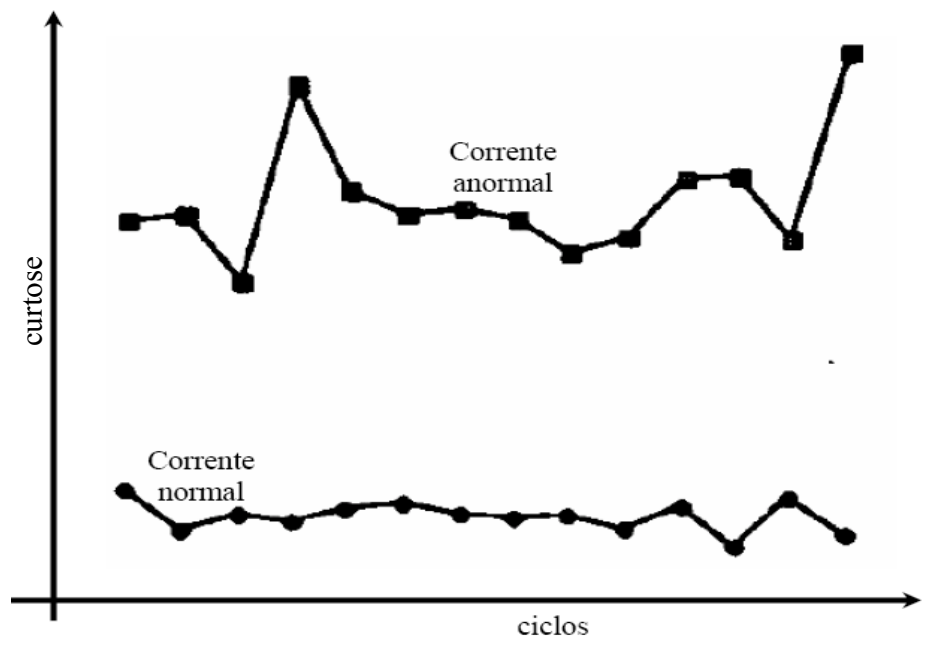

Figura 2.10 - Curtose para uma forma de onda de corrente faltosa e para uma forma de onda de corrente normal.

\subsection{Abordagem Neural Para detecÇÃo de Faltas de Alta IMPEDÂNCIA EM Alimentadores de Sistema de DiSTRIBUIÇÃo}

Nesta seção será descrita sucintamente uma das metodologias para identificação de faltas de alta impedância em sistemas de distribuição de energia elétrica por meio do emprego de redes neurais artificiais relatada em Ebron (1990).

De forma geral, a metodologia proposta é constituída de três etapas principais. A primeira etapa consiste em se coletar e processar um conjunto de sinais referentes às correntes de linha do alimentador. A segunda etapa é responsável por empregar este conjunto de medidas para treinar a abordagem neural de maneira que a mesma seja capaz de identificar 
situações de ocorrência de falta ou condições de operação normal do sistema. Finalmente, a terceira etapa é dedicada aos procedimentos envolvidos com a validação da abordagem neural com dados que não pertenceram ao conjunto de treinamento de maneira a comprovar a eficiência da abordagem frente a novas situações.

Tanto os dados de treinamento como os dados de validação da abordagem neural foram gerados utilizando para tal propósito o programa de simulações de transitórios eletromagnéticos EMTP. Diversas simulações foram executadas envolvendo diferentes situações de transitórios, tais como simulações de acionamento de motores e de energização de capacitores. Quatro tipos de casos foram gerados, sendo listados da seguinte maneira:

* Casos de chaveamento normal de cargas.

* Casos de carga normal com chaveamento de capacitores.

Casos de falta de alta impedância com chaveamento de cargas.

Casos de falta de alta impedância com chaveamento de carga e de capacitor.

As amostras de corrente empregadas no treinamento da rede foram inicialmente separadas dentro de conjuntos de um único ciclo cada. Para cada conjunto, 20 parâmetros foram computados para representar a condição do alimentador perante o ciclo de operação. Dentre estes parâmetros, pode-se listar os principais da seguinte maneira:

O valor de pico da corrente transitória nas três fases.

* O valor da corrente antes e imediatamente após a ocorrência do maior transitório.

* O número de transitórios caindo abaixo de $75 \%$ do valor máximo.

* A magnitude da corrente de seqüência positiva.

* O nível de desbalanço entre as fases.

As componentes harmônicas de primeira, terceira e quinta ordem da corrente de neutro.

Vários desses parâmetros, tais como a corrente de seqüência positiva, são somente empregados para propósitos de referência, pois desta maneira, permite-se que a rede neural possa fazer comparações entre os níveis de corrente transitória e outros parâmetros a fim de que a mesma possa extrair ponderações relativas às perturbações. 


\subsection{TÉCNICAS DE IdENTIFICAÇÃo de FALTAS de Alta IMPEDÂNCIA USANDO REDES NEURAIS E TRANSFORMADA DE FOURIER}

Conforme mencionado anteriormente, as faltas de alta impedância são geralmente difíceis ou impossíveis de serem detectadas com dispositivos de proteção de sobrecorrente (relés, elos fusíveis e religadores), pois a corrente de falta pode não possuir magnitude suficientemente alta para ativá-los, dificultando assim, a discriminação entre as correntes de carga e correntes de falta de alta impedância principalmente nos sistemas de distribuição multi-aterrados.

O método apresentado nessa seção, proposto por Ko et al. (1989) para detecção de faltas de alta impedância, consiste também em utilizar redes neurais do tipo perceptron para identificar a ocorrência ou não de faltas. A referida metodologia opera dividindo inicialmente um ciclo da forma de onda de corrente e tensão dentro de quatro janelas iguais, sendo duas localizadas em posições contendo os valores mais altos de tensão, e a outras duas estando localizadas junto aos valores mais baixos de tensão. Uma ilustração deste procedimento é apresentada na Figura 2.11.

Para detectar as componentes de alta impedância da corrente de falta, aplica-se a transformada rápida de Fourier (Fast Fourier Transform - FFT) nos sinais de corrente em cada uma das quatro janelas. Em seguida, as magnitudes das harmônicas fornecidas pela FFT são utilizadas como variáveis de entradas da rede neural do tipo perceptron. Baseado nas informações de entrada, a saída da rede fornece como resultado o valor +1 quando há ocorrência da falta de alta impedância, fornecendo o valor -1 quando o sistema opera em condições normais. No entanto, vale ressaltar as limitações que tal técnica pode acarretar como por exemplo a não contemplação de todo o espectro harmônico contido na análise de todas a forma de onda.

A rede perceptron utilizada neste método é composta de três camadas neurais, tendo 8 neurônios na primeira camada, 16 neurônios na segunda camada e 1 neurônio na camada de saída. As entradas da rede são as magnitudes das sete primeiras harmônicas do espectro de freqüência, as quais são fornecidas pela aplicação da FFT. O tempo de 
amostragem dos dados do sinal ficou em $260 \mu$ s (64 pontos por ciclo) ou 3840 amostras por segundo.

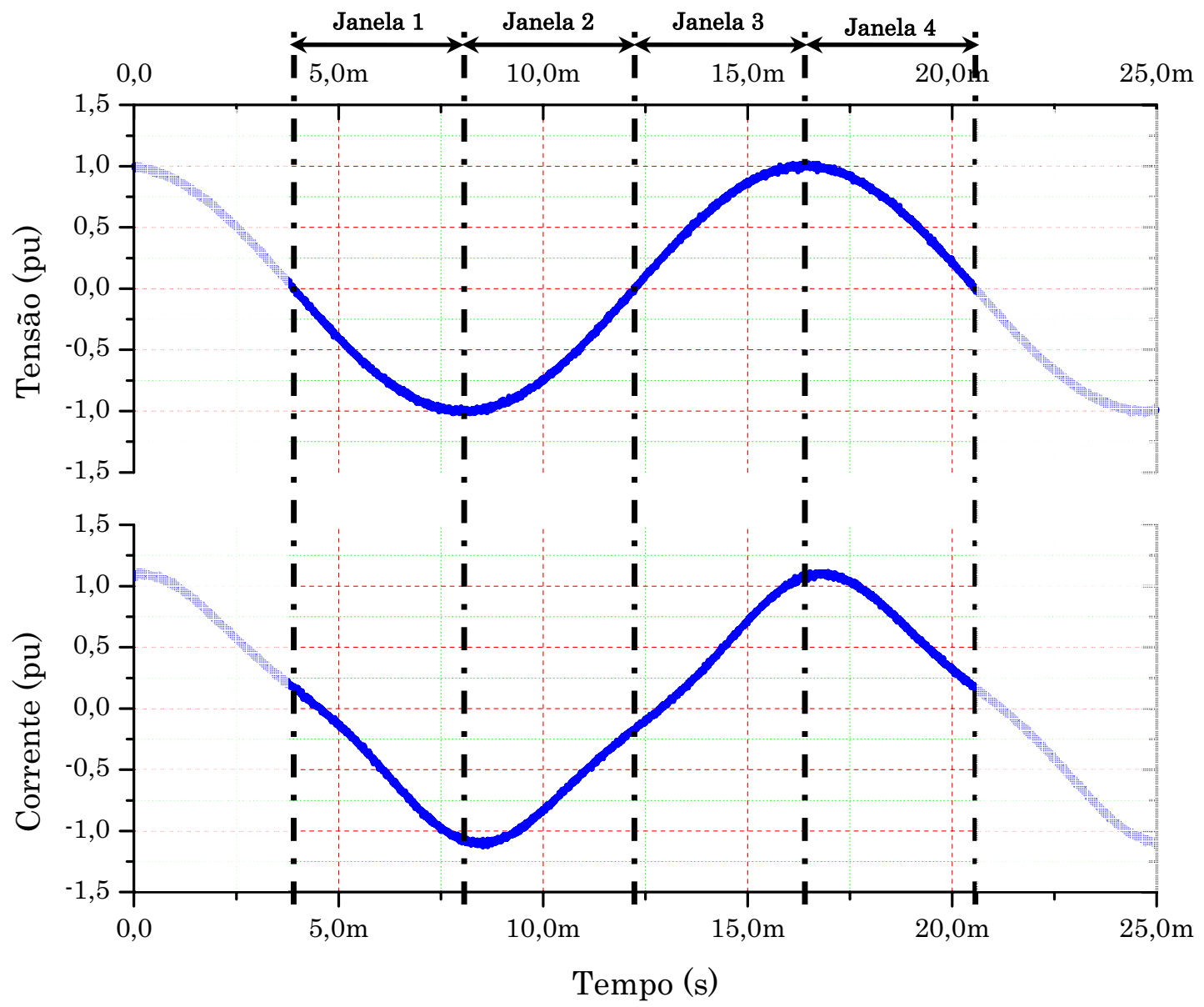

Figura 2.11 - Configuração da janela de dados.

\subsection{MODELAGEM FUZZY APLICADA NA IDENTIFICAÇÃO DE FALTAS de ALTA IMPEDÂNCIA COM CARACTERÍSTICA PASSIVA}

Poucas soluções são apresentadas na literatura correlata com o objetivo de identificar as faltas de alta impedância passiva. Verifica-se ainda, que a maioria das abordagens referenciadas são baseadas na análise do desbalanço de fases dos alimentadores do sistema de distribuição. No entanto, em virtude dos sistemas de distribuição apresentarem normalmente um alto nível de correntes desbalanceadas, verifica-se inúmeras limitação destas metodologias quanto da correta identificação de faltas. Um dos principais fatores que contribuem para o desbalanço natural dos sistemas de distribuição é a grande quantidade de 
cargas monofásicas (fase-terra e fase-fase) instaladas ao longo da extensão dos alimentadores do sistema.

Para contornar esses problemas, o método abordado nesta seção e reportado por Jota \& Jota (1998) consiste no emprego de um sistema fuzzy supervisório que periodicamente monitora as correntes e tensões dos alimentadores do sistema de distribuição. A partir dos valores de tensão e corrente observados, o sistema fuzzy, por meio de comparações e operadores específicos, realiza inferências que fornecem como resultado a indicação de uma ocorrência ou não de falta no sistema.

No entanto, para que o sistema fuzzy opere de maneira a fornecer níveis confiáveis de resposta é necessário que exista um volume adequado de conhecimento acerca do sistema de distribuição a fim de que as comparações e inferências ocorram dentro de universos de discurso com dados normalmente distribuídos. A base de dados responsável por armazenar este montante de informações pode ser construída por diferentes técnicas. Dentre as técnicas mais usuais, duas merecem destaque especial. Uma dessas técnicas consiste na simulação computacional dos possíveis eventos do alimentador. Por meio de exaustivas simulações, uma grande quantidade de informações pode ser computada e, como conseqüência direta, uma consistente base de dados é construída.

A segunda metodologia usualmente empregada é baseada na aplicação de formas de onda impulsivas no início dos alimentadores e na observância das respostas originadas por este procedimento. As ondas impulsivas, que são injetadas no alimentador, viajam ao longo da linha, trazendo informações sobre o status real do alimentador. Após a realização de cada medição, o sinal de resposta é pré-condicionado, convertido para o domínio da freqüência e então armazenado junto à base de regras correspondente. As componentes complexas dos sinais pré-processados são então calculadas por intermédio da transformada rápida de Fourier.

Na metodologia apresentada nesta seção a base de dados foi constituída por meio da aplicação de formas de onda impulsivas no início dos alimentadores. No entanto, a adoção desta metodologia deve respeitar importantes requisitos como, por exemplo, levar em consideração todas as possíveis configurações operacionais do alimentador. Para tanto, a equipe responsável pelo planejamento, operação e manutenção do sistema deve fornecer informações relevantes sobre as diversas configurações operacionais possíveis do alimentador. 
Com relação à operação do sistema, primeiramente, os sinais das respostas impulsivas são comparados com aqueles conhecidos e armazenados junto à base de regras. $\mathrm{Na}$ seqüência, o sistema busca por evidências de ocorrências de faltas de alta impedância, considerando para tanto o grau de discrepância entre os sinais medidos e as respostas armazenadas na referida base de dados. Como resposta, o sistema fuzzy é responsável por fornecer indicadores de supervisão dos estados do sistema de distribuição.

Análises de respostas típicas têm mostrado que a utilização de 20 freqüências características são suficiente para discriminar satisfatoriamente os sinais medidos. As respostas dos sinais impulsivos (5000 amostras) são decompostas em duas janelas $\mathrm{W}_{1}$ e $\mathrm{W}_{2}$. Para cada janela, componentes reais e imaginárias das 20 freqüências têm sido calculadas, perfazendo assim um total de 80 componentes que serão as entradas do sistema fuzzy.

\subsection{MÉtodo Para Diagnóstico de FALTAS EM SUBESTAÇÕES DE DISTRIBUIÇÃO UTILIZANDO SisTEMAS FUZZY E REDES DE CAUSA E EFEITO}

A estrutura do diagnóstico de falta apresentado nessa seção e descrito em detalhes em Chen et al.(2000) é compreendido por uma rede de causa e efeito, uma base de regras, uma base de dados fuzzy, um mecanismo de inferência e um processador de dados em tempo real. O diagrama esquemático do sistema proposto é mostrado na Figura 2.12.

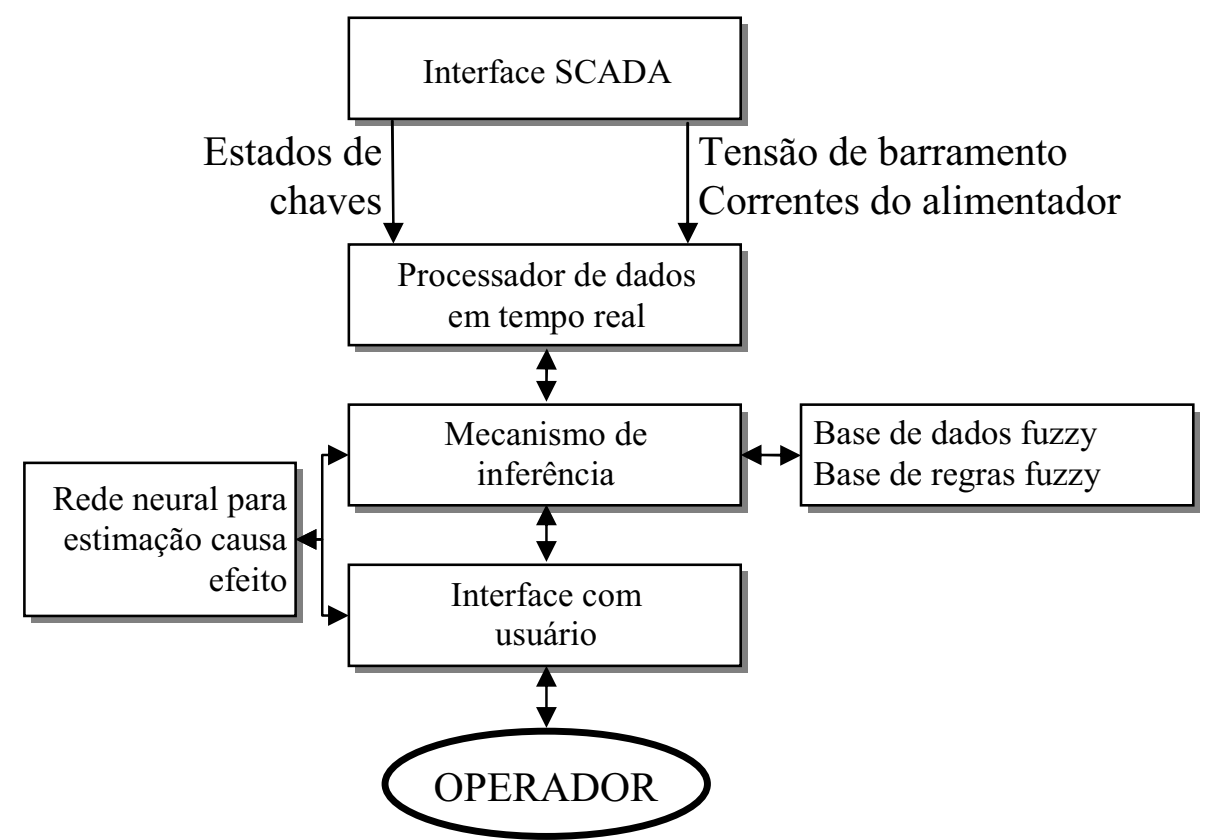

Figura 2.12 - Estrutura do sistema de diagnóstico de falta proposto. 
Nesta metodologia, a rede causa e efeito representa a casualidade entre faltas e ações de relés e disjuntores. Para os diversos tipos de faltas, considerando todas as seções possíveis, especifica-se os fluxogramas que representam as seqüências de causa e efeito.

A outra tarefa do método proposto é classificar os tipos de faltas, levando-se em consideração as correntes e tensões no alimentador, através da utilização de um sistema fuzzy. A base de regras fuzzy é formada por regras que são extraídas a partir de características de todos os tipos de faltas.

A definição dessas regras requer um conhecimento detalhado do comportamento dos sinais de corrente e tensão que são gerados durante uma situação de falta. As regras fuzzy desta abordagem são baseadas na premissa de que quando uma falta ocorre, as correntes normalmente aumentam em magnitude e as tensões diminuem. O formato das regras do sistema fuzzy possui o padrão apresentado na Figura 2.13.

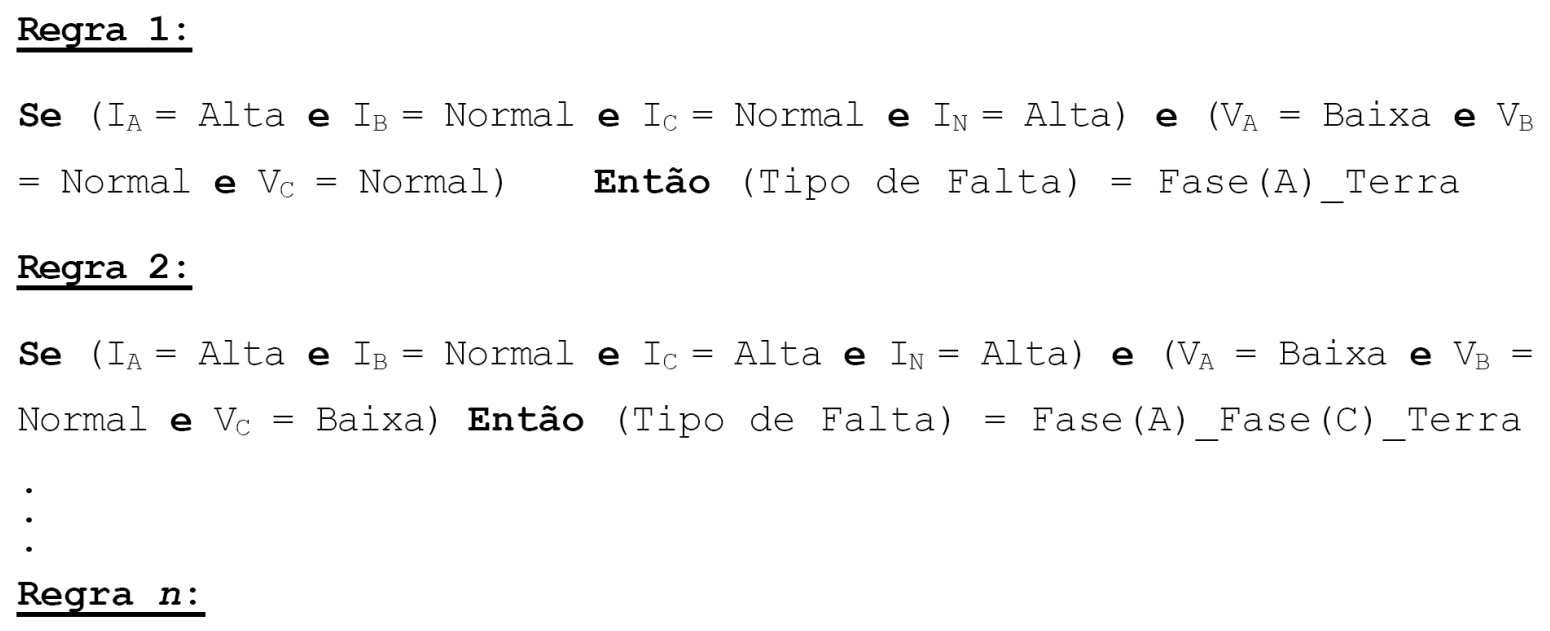

Regra n:

Figura 2.13 - Exemplo de base de regras do sistema fuzzy.

O processo de identificação da falta pelo sistema fuzzy consiste de quatro estágios que podem ser representados esquematicamente conforme apresentado na Figura 2.14.

De acordo com a descrição da Figura 2.14, o primeiro passo deste processo é a obtenção das correntes e tensões do alimentador. O segundo passo consiste em converter esses valores para os respectivos termos lingüísticos que são especificados através de funções de pertinência, em outras palavras, tem-se nessa etapa a conversão de valores crisp - valores não fuzzy - em valores fuzzy. Em seguida, esses termos lingüísticos serão empregados na avaliação das regras fuzzy. Finalmente, por meio da aplicação dos procedimentos de inferência, torna-se possível a obtenção dos resultados que permitam identificar o tipo de falta. 


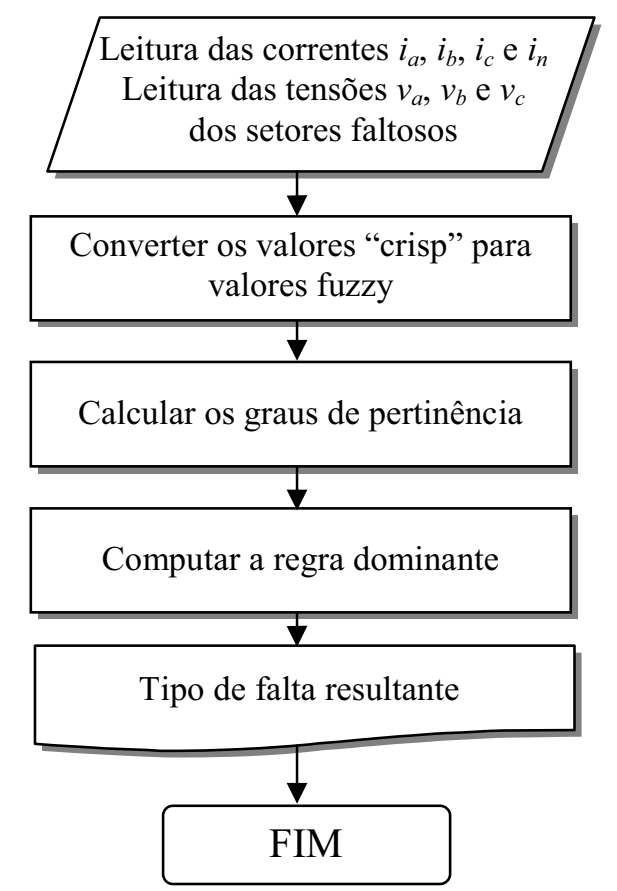

Figura 2.14 - Procedimentos para estimação de faltas para o sistema de inferência fuzzy.

\subsection{TÉCNICAS de LOCALIZAÇÃO de FALTAS BASEAdAS EM SINAIS DE ALTA FREQUÊNCIA E TRANSFORMADA WAVELET}

Neste método a técnica para localização de faltas em alimentadores de distribuição radial é formulada sob as informações fornecidas pelos equipamentos de medição instalados na subestação, levando-se também em consideração detalhes de configuração do alimentador.

O método proposto opera identificando o trecho da falta com base nas informações das ondas trafegantes fornecidas pelas componentes de alta freqüência, as quais estão intrínsecas nos transitórios dos sinais de faltas que são aquisitados pelos instrumentos de medição. Em seguida, é calculado, baseado nas potências dos sinais de freqüência, o local exato da falta ao longo do trecho identificado no passo anterior.

Para tanto, os sinais transitórios das correntes trifásicas são inicialmente decompostos em suas componentes modais. Em seguida, os sinais modais são decompostos em suas componentes wavelets, sendo obtidos então os correspondentes coeficientes wavelets. Esses coeficientes são usados para extrair padrões relevantes dos sinais, os quais são subseqüentemente utilizados para identificar o ramo ou trecho onde a falta está localizada. 
Finalmente, a distância da falta a partir da subestação principal é calculada utilizando informações baseadas nas potências dos sinais.

A fim de ilustrar esta metodologia, a Figura 2.15 apresenta o diagrama de blocos funcional da abordagem descrita nesta seção.

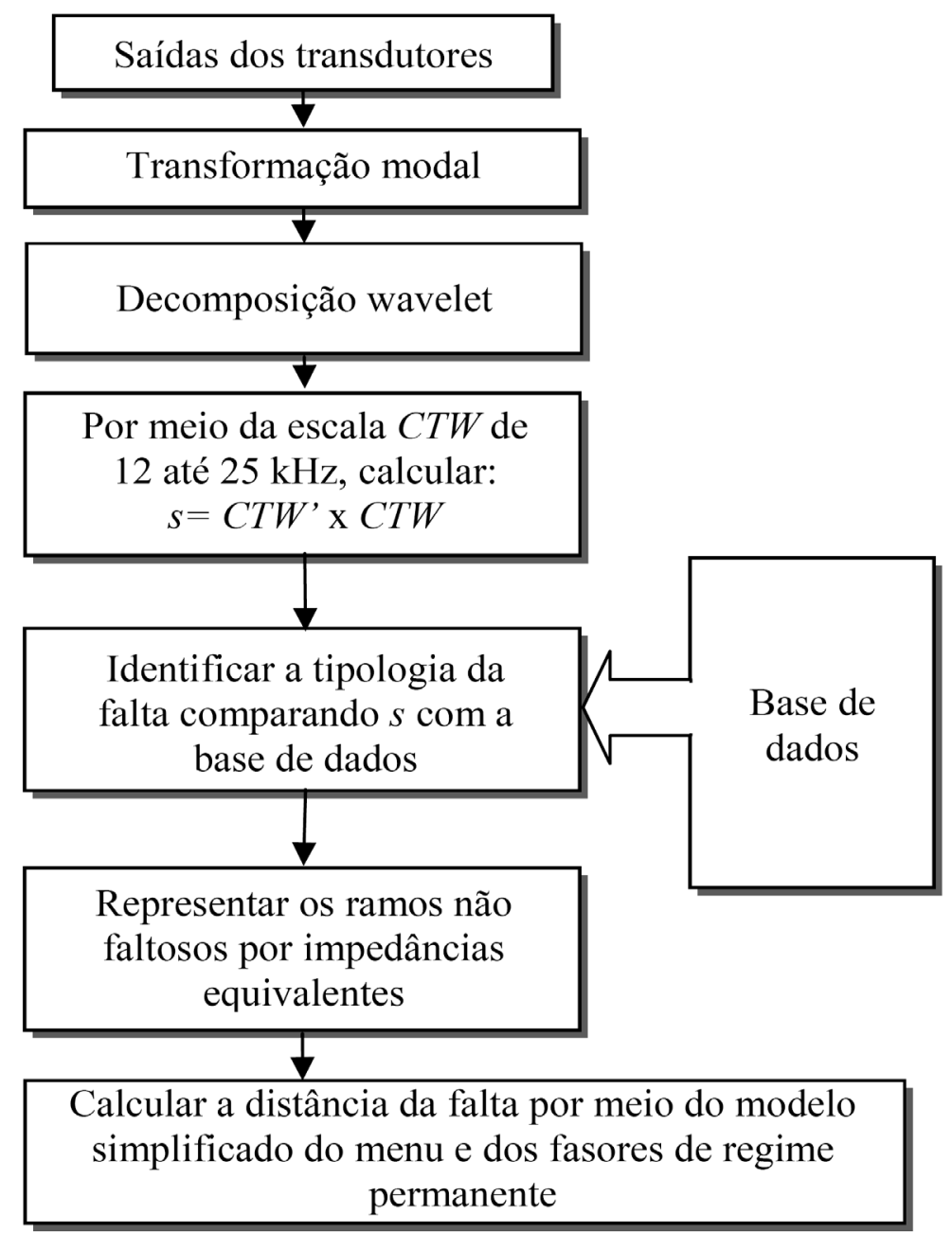

Figura 2.15 - Fluxograma do algoritmo de localização de falta proposto.

Em suma, o procedimento de localização de faltas pode ser posto da seguinte maneira:

As tensões e correntes de fase são transformadas para o domínio modal.

Os sinais modais são decompostos visando obter os Coeficientes da Transformada Wavelets (CTW).

O trecho e a distância à falta são estimados utilizando informações fornecidas pelos coeficientes da transformada wavelets. 
Um dos aspectos observados neste método está relacionado à ocorrência de faltas fase-terra. Se a falta é produzida quando a tensão da fase faltante é pequena, isto é, o ângulo de incidência é pequeno, os sinais transitórios produzidos pelas ondas trafegantes também serão pequenos. Entretanto, mesmo para os ângulos de incidência pequenos, os coeficientes da transformada wavelet identificam o trecho sob falta, pois se pode observar que este processo opera sob um mapeamento linear.

\subsection{ClassificaÇão E MEdição dOS NíVEIS de Perturbação em sistema de Potência Através de WAVELETS}

O método proposto nesta abordagem consiste em utilizar a técnica de wavelets para detectar, classificar e medir as perturbações que incidem nos sistemas de distribuição.

Um sinal $f_{s}(t)$ de comprimento finito com uma distorção aditiva $s_{d}(t)$ pode ser representado matematicamente por:

$$
f_{s}(t)=f_{p}(t)+s_{d}(t)
$$

onde $f_{p}(t)$ é o sinal puro que está compondo $f_{s}(t)$ e $s_{d}(t)$ representa o sinal de distúrbio inserido ao sinal original.

Aplicando análise multi-resolução é possível decompor o sinal $f_{s}(t)$ em diferentes níveis de resolução e apresentá-lo na forma de uma expansão por série utilizando uma combinação de funções escalas $\varphi_{k}(t)$ e funções wavelets $\psi_{k}(t)$. Formalmente, pode-se representar esta decomposição na sua forma canônica da seguinte maneira:

$$
f_{s}(t)=\sum_{k} c_{j}(k) \cdot \phi(t-k)+\sum_{k} \sum_{j=0}^{k-1} d_{j}(k) \cdot 2^{\frac{j}{2}} \cdot \psi\left(2^{j} t-k\right)
$$

onde $j$ representa o número total de níveis de resolução, $c_{j}(k)$ são os coeficientes da função escala e $d_{j}(k)$ são os coeficientes da função wavelets. Os coeficientes de escala $c_{j}(k)$ são obtidos a partir do sinal. Se a taxa de amostragem do sinal $f(t)$ estiver acima da taxa de amostragem determinada pelo Teorema de Niquist, então os mesmos são boas aproximações para os coeficientes de escala para determinada escala. Isto significa que nenhum coeficiente de escala será necessário. 
Assim, quaisquer alterações no sinal $f(t)$ pode ser detectadas e localizadas no tempo devido às mudanças nas magnitudes desses coeficientes. De acordo com o teorema de Parseval, a energia de $f(t)$ poderá ser particionada em diferentes caminhos dependendo do tipo de evento associado à distorção. Portanto, o mapeamento dos dados da distorção $s_{d}(t)$ dentro de um domínio wavelet é o primeiro passo para executar o processo de classificação dos sinais. Em seguida, a distribuição da energia de distorção $E_{d}$, em diferentes níveis de resolução, é computado para gerar um conjunto de características não variantes no que diz respeito à mudança de posição (translação) com baixa dimensionalidade.

A Figura 2.16 apresenta a diferença na distribuição de energia $\Delta E_{d}$ em diferentes níveis de resolução para 25 sinais distorcidos por diferentes perturbações. Pode-se observar por meio do gráfico da Figura 2.16 que as características de perturbações envolvendo harmônicas no sistema são melhores identificadas no nível 5, enquanto que afundamento e elevação de tensão são melhores reconhecidos no nível de resolução 7.

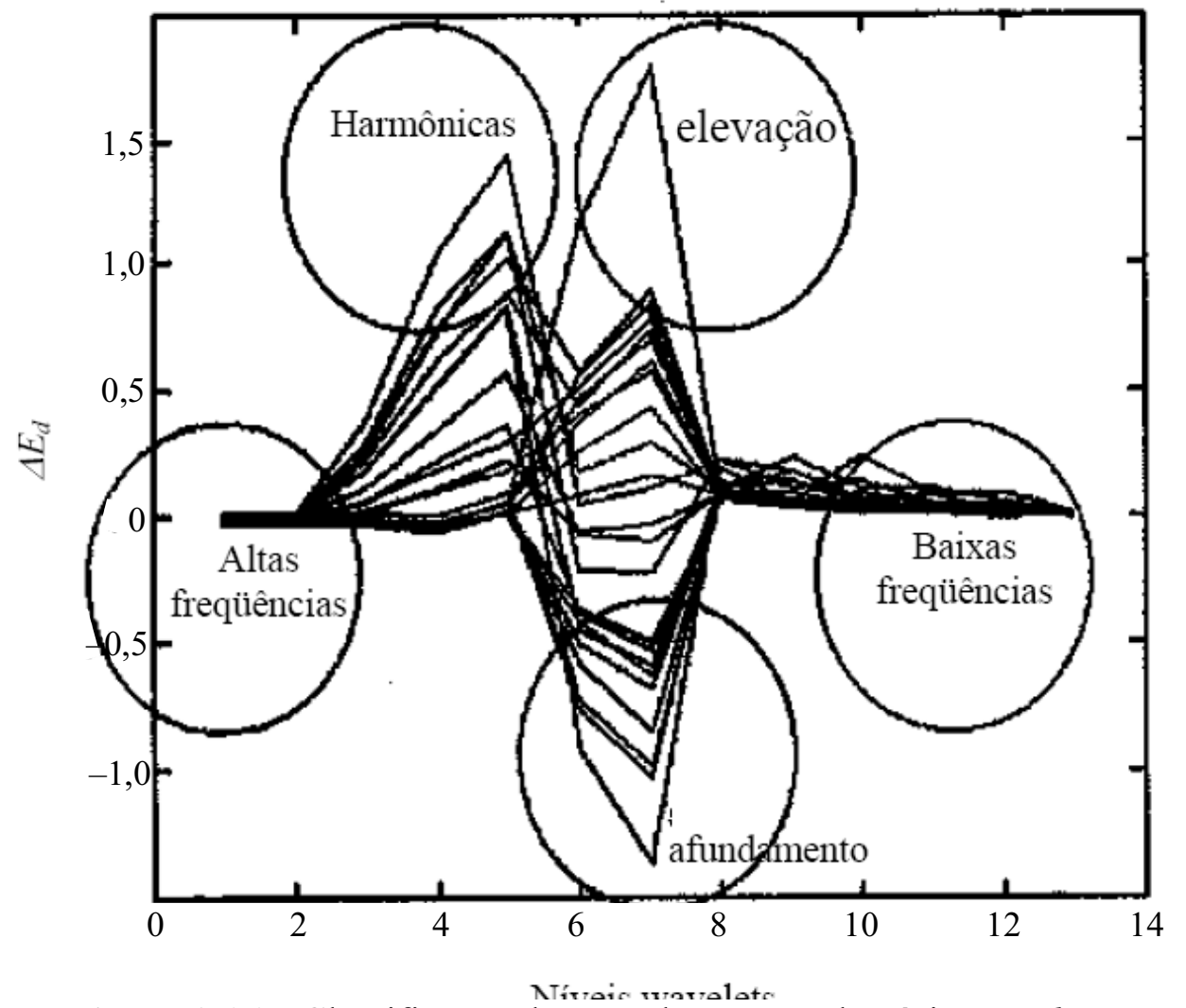

Figura 2.16 - Classificação de perturbações no domínio wavelet. 
A Figura 2.17 ilustra em detalhes um sinal $f(t)$ constituído de diversas perturbações, ilustrando a decomposição do sinal no primeiro nível $D_{l}$, bem como $\Delta E_{d}$ nos diferentes níveis de resolução.

Portanto, a partir da utilização desta técnica, diversas distorções nos sinais de medição podem ser detectados através da utilização dos coeficientes wavelets em diferentes níveis de resolução. A energia associada à distorção em distintos níveis de resolução é empregada como um vetor discriminante que pode classificar diferentes perturbações.
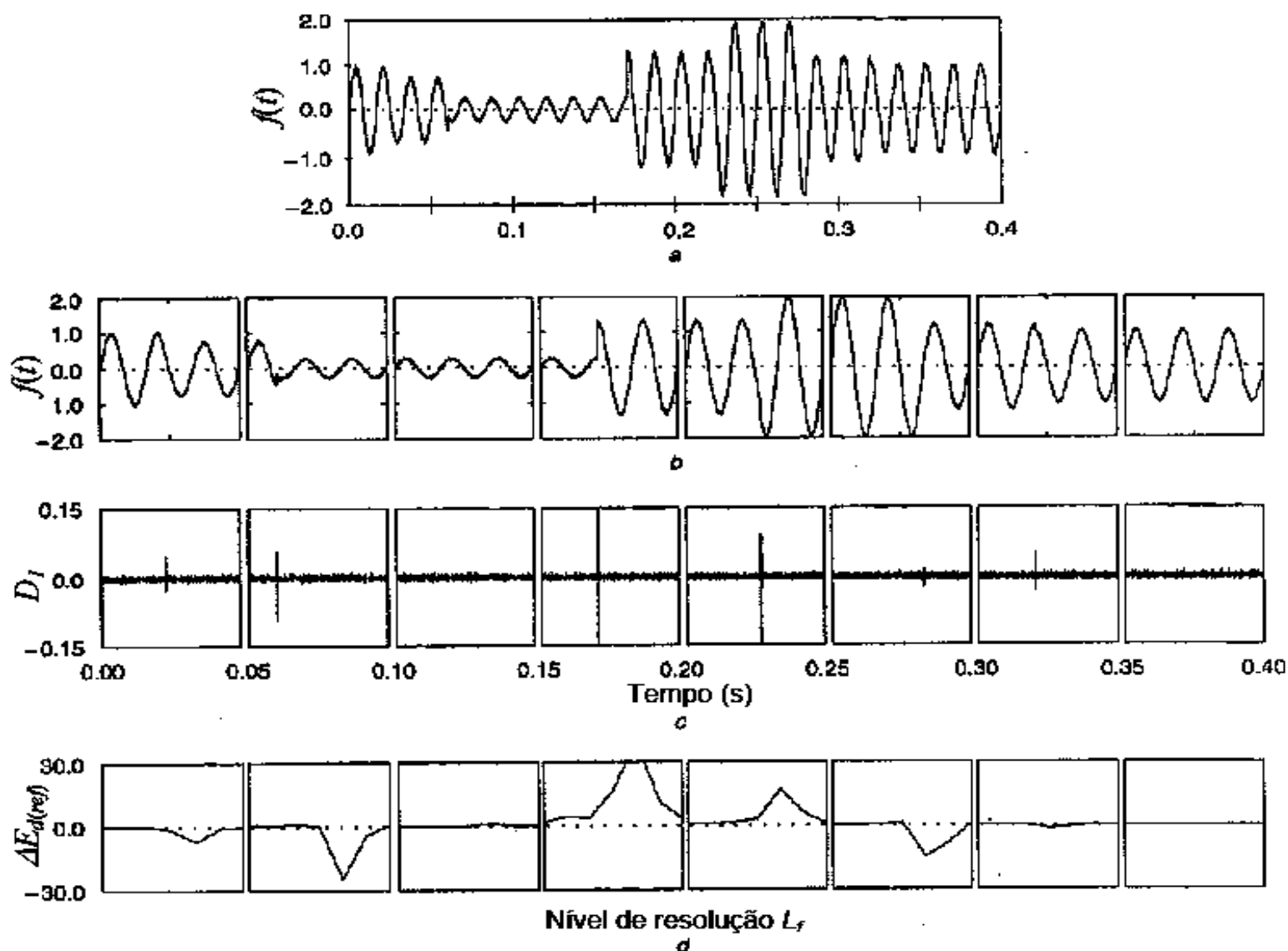

Figura 2.17 - Ilustração de um sinal composto por diversas perturbações e sua representação no domínio wavelet.

\subsection{DETECÇÃO DE DISTÚRBIOS EM SISTEMAS DE Distribuição ATRAVÉS da UTILIZAÇÃo de WAVELETS}

Existem eventos no sistema de distribuição que geram transitórios que são ocasionados pela energização das próprias cargas instaladas no sistema, como por exemplo, a energização de capacitores e o acionamento de máquinas de elevada potência. Nesses casos, mesmo que os distúrbios de tensão ultrapassem momentaneamente os limites normais que 
foram pré-estabelecidos para as cargas, nenhuma medida operacional é necessária, pois as oscilações são originadas pelas próprias particularidades do sistema.

Contrariamente, no caso de distúrbios de tensão provocados por eventos associados aos diversos tipos de faltas, há então a necessidade de realizar ações operacionais que levem à isolação da mesma. Portanto, a investigação de técnicas que permitam a classificação rápida desses eventos se torna de suma importância para o incremento da qualidade e confiabilidade do sistema.

O objetivo do método proposto nesta seção consiste na aplicação de transformadas wavelets para a detecção de distúrbios de tensão em sistemas de distribuição, assim como a identificação do tipo de evento transitório que resultou a respectiva perturbação.

O diagrama de blocos apresentando o esquema de detecção e classificação de distúrbios é ilustrado na Figura 2.18. Esta metodologia é composta por quatro blocos principais sendo eles a geração do sinal de erro, a análise do sinal de erro usando wavelets, a extração de características e o suporte à decisão.

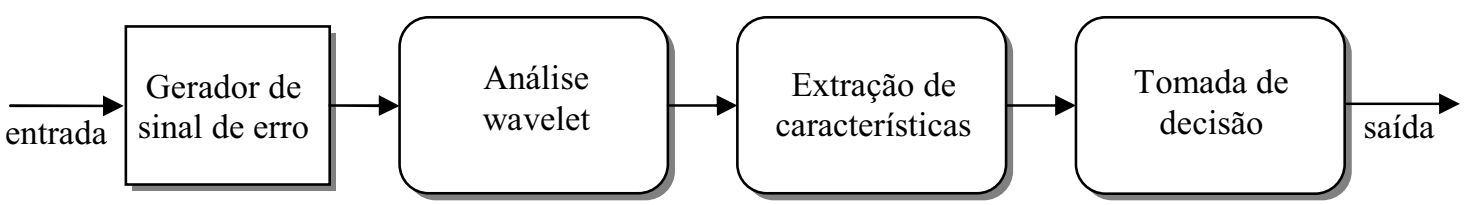

Figura 2.18 - Diagrama de blocos do esquema de detecção proposto.

O bloco dedicado à geração do sinal de erro extrai as distorções superpostas nas tensões medidas, gerando um sinal de erro por intermédio de um filtro adaptativo conforme apresentado na Figura 2.19. O filtro rastreia a amplitude $\left(\theta_{1}\right)$ e o ângulo $\left(\phi_{1}\right)$ da componente fundamental do sinal de entrada, sendo que o comportamento dinâmico do filtro é descrito por:

$$
\left\{\begin{array}{l}
\dot{\theta}_{1}=-2 \mu_{1} \cdot \sin \left(\phi_{1}\right) \cdot e(t) \\
\dot{\phi}_{1}=-2 \mu_{2} \cdot \theta_{1} \cdot \cos \left(\phi_{1}\right) \cdot e(t)+w_{0}
\end{array}\right.
$$

O sinal de erro $e(t)$ é obtido subtraindo a componente fundamental do sinal de entrada. Esta é a principal vantagem de usar este filtro no algoritmo.

O bloco responsável pela análise por wavelets transforma o sinal de erro em diferentes escalas no domínio da freqüência. A transformada wavelet fornece informações sobre o conteúdo das freqüências de um sinal da mesma forma com que faz a transformada de Fourier. Entretanto, diferentemente da transformada de Fourier, a transformada wavelet é 
capaz de focar componentes de alta freqüência em curtos intervalos de tempo, bem como componentes de baixa freqüência presentes em longos intervalos. Portanto, torna-se uma ferramenta adequada para análise de transitórios de alta freqüência na presença de componentes de baixa freqüência.

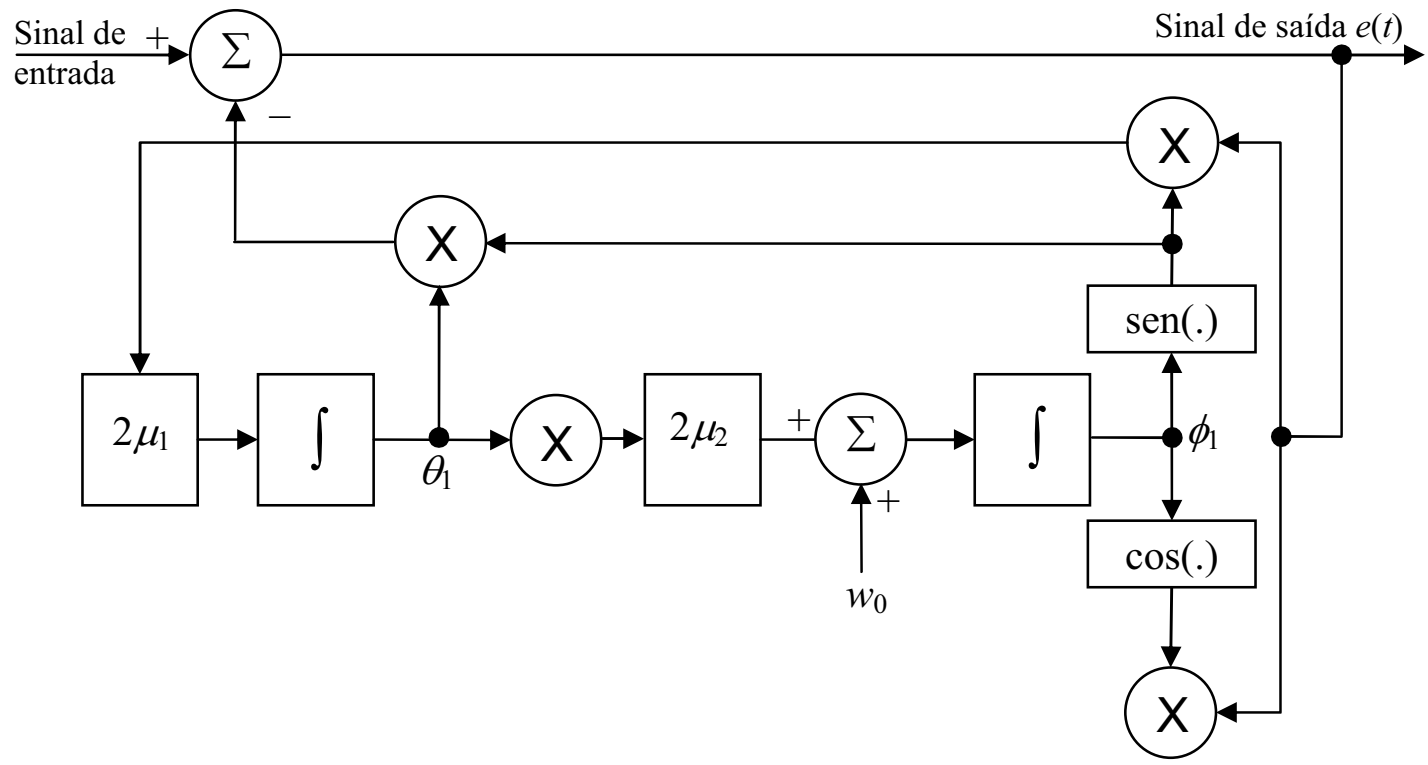

Figura 2.19 - Diagrama de blocos representando o filtro adaptativo.

O objetivo do bloco de extração de características é identificar assinaturas específicas dos diversos tipos de perturbações atuando no sistema. A transformada wavelet decompõe o sinal de erro dentro de diferentes escalas de freqüência. Cada escala representa o sinal de erro na banda correspondente. O conteúdo de energia dos sinais da escala relativo aos sinais de erro se altera dependendo do tipo de perturbação. Portanto, a amplitude relativa dos sinais da escala com relação ao sinal de erro é selecionada como características discriminantes.

Finalmente, a função do bloco de apoio à decisão é discriminar tipos de distúrbios tão precisamente quanto possível. Uma função probabilidade é definida para as características, e a decisão é realizada utilizando o critério de máxima verossimilhança. Este critério é baseado na maximização da função probabilidade das características.

\subsection{MODELAGEM de FALTAS DE ALTA IMPEDÂNCIA BASEADA NA TEORIA de ARCOS ElÉtricos}

A simulação de chaveamentos de bancos de capacitores em programas como EMTP e MatLab/SimPowerSystems são bem próximos da realidade e os resultados 
fornecidos tem um alto grau de precisão quando o sistema é modelado de forma adequada (KAWADY \& STENZEL, 2002; SYBILLE \& HOANG LE-HUY, 2000).

No entanto, a modelagem dos fenômenos que simulam o comportamento de faltas de alta impedância é complexa, pois, em função da presença do arco voltaico cuja natureza é bastante complexa e diversa, acarreta em um esforço extra durante a fase de confecção do sistema equivalente.

Desta maneira, a investigação de um modelo geral que represente de forma realista a falta de alta impedância é de suma importância para a pesquisa de métodos de detecção de falta de alta impedância, bem como para o projeto de equipamentos de proteção.

Alguns modelos de falta de alta impedância utilizam para propósitos de simulação a inclusão de uma resistência ou modelo de impedância não linear na rede no ponto de falta. O método proposto ao longo desta seção é baseado na teoria de arco voltaico, onde um modelo realista englobando impedância não linear, fonte de tensão variante no tempo, cujos chaveamentos são controlados por um TACS (Transient Analysis Control System) é empregado com a finalidade de encorpar às simulações um maior grau de fidelidade. A Figura 2.20 ilustra o diagrama esquemático do circuito elétrico dedicado à modelagem física do arco voltaico.

Conforme a Figura 2.20, as chaves 1 e 2 são chaves convencionais com controle temporal que isolam o alimentador da carga, conectando-o ao caminho da falta. A chave 3 é uma chave controlada por um TACS que simula a reignição e extinção do arco. Sua operação depende da comparação de tempo entre os parâmetros de simulação $T_{a}$ e $\Delta t$.

O parâmetro $T_{a}$ é o tempo para a reignição do arco a partir do momento que a tensão aplicada passa por zero e $\Delta t$ é o tempo de condução do arco em meio ciclo, sendo esses parâmetros dados por:

$$
\begin{aligned}
& T_{a}=\frac{1}{\omega} \operatorname{sen}^{-1} \frac{V_{r}}{V_{m}} \\
& \Delta t=\frac{\pi V_{r}+2 \sqrt{V_{m}^{2}+V_{r}^{2}}}{\omega\left(V_{a}+V_{r}\right)}
\end{aligned}
$$

onde $V_{r}$ é a tensão de reignição do arco, $V_{m}$ é o valor de pico da tensão aplicada e $V_{a}$ é a tensão de arco, sendo que a tensão aplicada é assumida como: 


$$
v=V_{m} \operatorname{sen}(w t)
$$

A resistência não linear $R$ controla a magnitude da corrente de falta e é conectada à parte de condução do arco que consiste de dois diodos $D_{1}$ e $D_{2}$, e duas fontes de tensão $S_{1}$ e $S_{2}$. Essas fontes possuem formato de onda tipo dente de serra com linearidade crescente e decrescente, as quais podem representar a característica dinâmica $v-i$ do arco melhor que fontes DC e ajustar a diferença de fase entre a tensão aplicada e a corrente de falta.

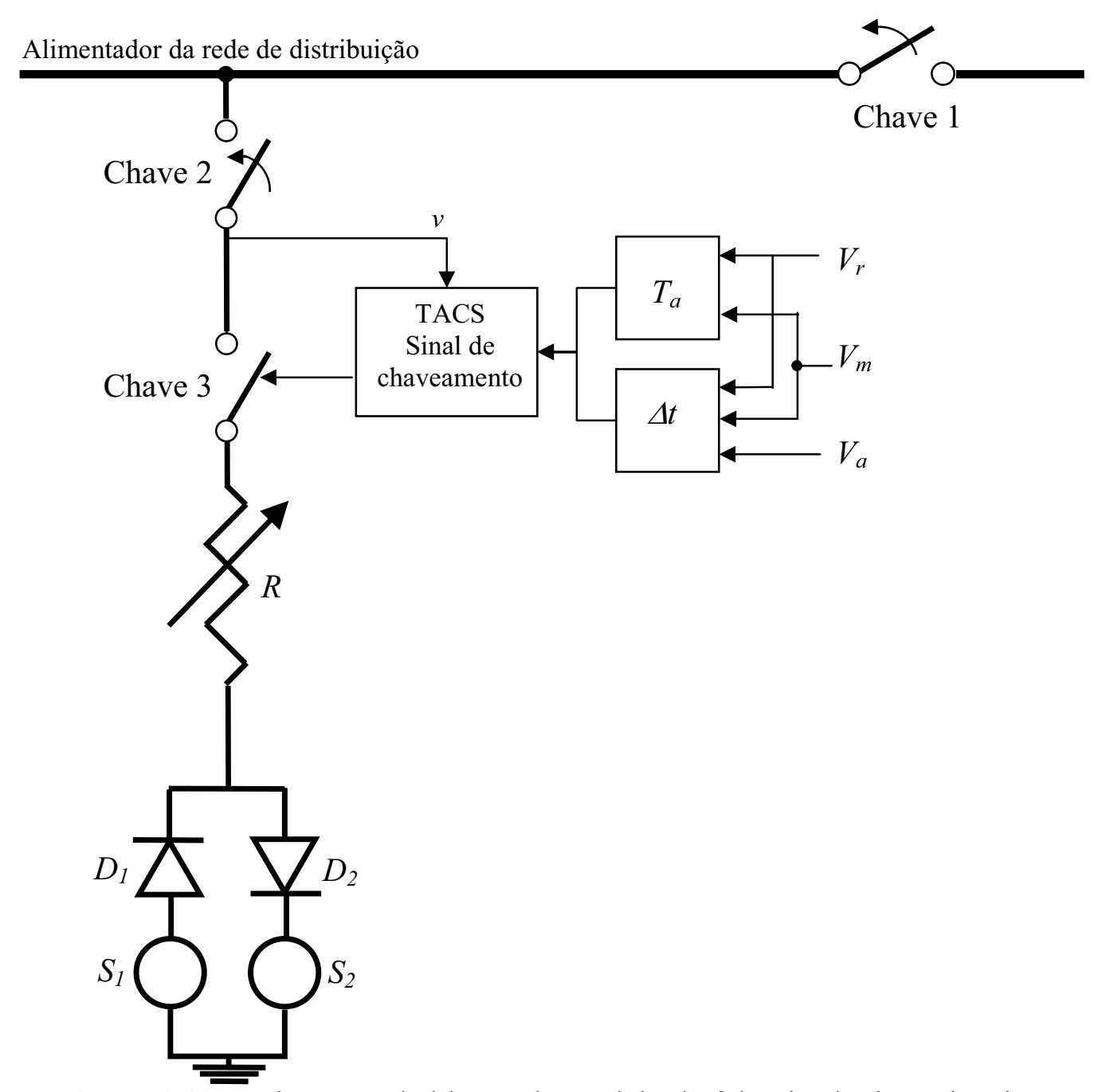

Figura 2.20 - Diagrama de blocos de modelo da falta de alta impedância.

\subsection{LOCALIZAÇÃo de FALTAS POR MEIO de REDES NEURAIS E DA TRANSFORMADA DE ClaRKE-CONCÓRDIA}

A localização de faltas em sistemas de distribuição de energia elétrica diretamente aterrados pode ser realizada de maneira semelhante à localização de faltas em sistemas de distribuição com alta impedância de aterramento. No entanto, devido às peculiaridades das 
formas de onda de tensão e corrente, novas técnicas de pré-processamento de sinais devem ser incorporadas.

Dentre as técnicas de pré-processamento usualmente empregadas nos diversos trabalhos verificados junto à bibliografia correlata, destaca-se o emprego da análise fasorial dos sinais em conjunto com redes neurais artificiais (MARTINS et al., 2002; MARTINS et al., 2005).

No entanto, devido à complexidade do processo de localização de faltas, observase a necessidade de se incorporar novas técnicas de processamento às técnicas convencionais. Nesta seção, será apresentada a metodologia de localização de faltas em sistemas de distribuição de energia elétrica diretamente aterrados empregando a transformada de ClarkeConcórdia em conjunto com abordagens que utilizam a teoria dos autovalores.

A principal vantagem observada quando da aplicação desta técnica reside no fato de que a mesma é imune à interferências harmônicas e de sinais ruidosos, uma vez que a localização das faltas é realizada com base na comparação de padrões por meio de uma rede neural artificial do tipo perceptron multicamada.

A Transformada de Clarke se constitui em uma metodologia para desacoplamento paramétrico para sistemas trifásicos. As duas componentes estacionárias de corrente são denotadas por $\alpha$ e $\beta$. A terceira variável originada desta transformação é conhecida por componente de seqüência zero. A fim de se desenvolver uma metodologia destinada à operação em tempo real de sinais, torna-se conveniente uma alteração da transformada original de Clarke. Dentre as possíveis alterações existentes, destaca-se a Transformada de Clarke-Concórdia descrita em detalhes por Faria (2000). O desenvolvimento teórico desta modificação é realizado, supondo-se que a componente $\alpha$ da transformada original está sobreposta à corrente da primeira fase do sistema trifásico. Desta maneira, verifica-se que a componente $\beta$ estará atrasada em relação à $\alpha$ de $\pi / 2$ rads. A matriz de transformação proposta pode então ser definida da seguinte maneira:

$$
\boldsymbol{T}_{c}=\sqrt{\frac{2}{3}}\left[\begin{array}{ccc}
1 & -\frac{1}{2} & -\frac{1}{2} \\
0 & \frac{\sqrt{3}}{2} & -\frac{\sqrt{3}}{2} \\
\frac{1}{\sqrt{2}} & \frac{1}{\sqrt{2}} & \frac{1}{\sqrt{2}}
\end{array}\right]
$$


Desta maneira, é possível caracterizar cada um dos estágios de falta por meio da análise das componentes de corrente $i_{\alpha}, i_{\beta}$ e $i_{0}$. Essas componentes de corrente podem ser obtidas por meio da seguinte expressão:

$$
\left[\begin{array}{l}
i_{\alpha} \\
i_{\beta} \\
i_{0}
\end{array}\right]=\boldsymbol{T}_{\boldsymbol{c}}\left[\begin{array}{l}
i_{1} \\
i_{2} \\
i_{3}
\end{array}\right]
$$

onde $i_{1}, i_{2}$ e $i_{3}$ são respectivamente as correntes de cada uma das fases do sistema de distribuição.

Com a finalidade de se extrair as principais características das componentes $i_{\alpha}, i_{\beta}$ e $i_{0}$ é conveniente a análise dos autovetores e autovalores da matriz de correlação de dados.

A arquitetura neural proposta nesta seção para localização de faltas possui como entradas os autovalores da matriz de correlação, bem como o tipo de falta identificado durante a fase de pré-processamento dos sinais. O diagrama esquemático da estrutura neural sugerida é apresentado na Figura 2.21.

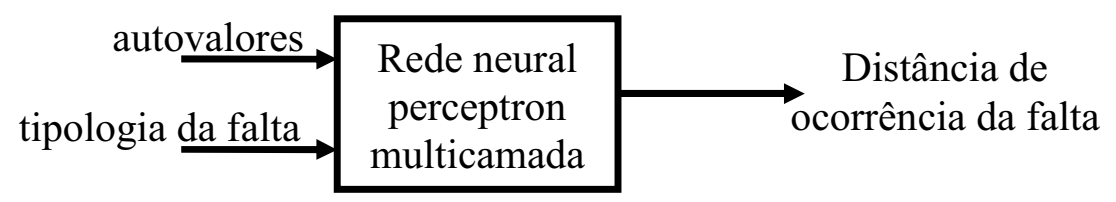

Figura 2.21 - Diagrama esquemático do sistema de localização de faltas por meio de redes neurais artificiais.

Para ilustrar a variação da distância de falta em função dos autovalores para diferentes tipos de falta, é apresentado na Figura 2.21 o gráfico da distância em função dos autovalores. 


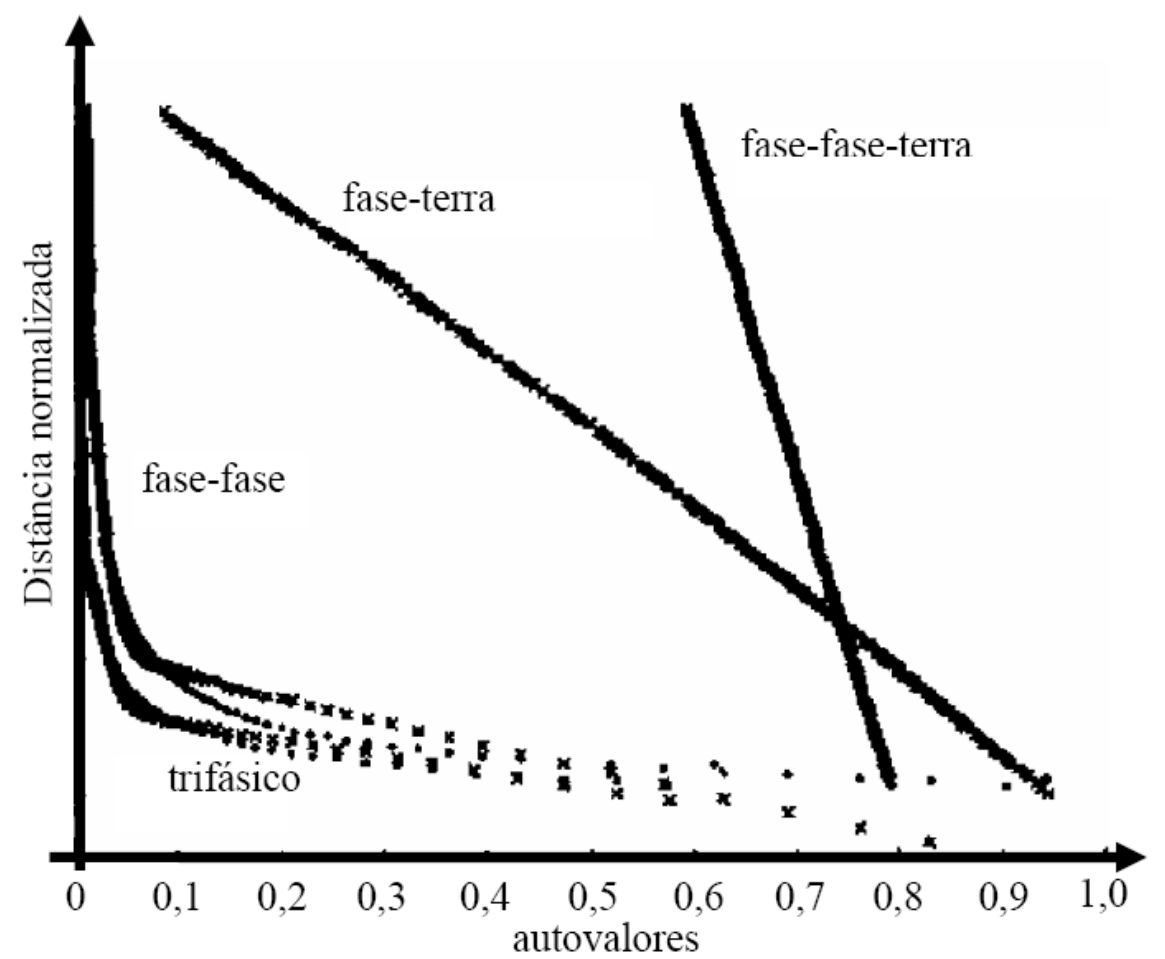

Figura 2.22 - Distância de falta em função dos autovalores.

\subsection{ASPECTOS GERAIS RELACIONADOS ÀS ABORDAGENS DEDICADAS À IDENTIFICAÇÃO E LOCALIZAÇÃO DE FALTAS EM SISTEMAS DE DisTRIBUIÇÃo DE ENERGIA ELÉTRICA}

Ao longo deste capítulo algumas das principais ferramentas para identificação e localização de faltas foram apresentadas. Verifica-se, contudo, a existência de limitações que, sob determinadas condições, podem comprometer a correta estimação desejada aos processos de identificação e localização de faltas.

No entanto, a observância de tais limitações e o levantamento das condições favoráveis para aplicação de cada uma das técnicas pode contribuir para o desenvolvimento de um sistema integrado onde as principais características de cada abordagem podem ser incorporadas. Desta maneira, ter-se-á um sistema capaz de identificar e localizar faltas sem que as limitações observadas nas abordagens atuais sejam pertinentes a este sistema.

O foco principal para utilização dessas abordagens consideradas recentes, principalmente aquelas baseadas em redes neurais artificiais e lógica fuzzy, estão em suas habilidades naturais de poder mapear os relacionamentos existentes entre as entradas e saídas de processos tipicamente não-lineares. Essas ferramentas são normalmente empregadas em 
processos onde o comportamento entre as variáveis de entrada e de saída não é bem estabelecido, tornando-se atrativas para o caso de identificação e localização de faltas.

Ainda, verifica-se que a maioria das abordagens investigadas nesse capítulo são altamente dependentes de técnicas de processamento de sinais. Assim sendo, há a necessidade de utilização intensa de ferramentas que lidam com os problemas envolvidos com o processamento e tratamento de sinais. Tendo esse aspecto como motivação, o Capítulo 3 apresenta a proposta de decomposição em componentes ortogonais para análise de sistemas de distribuição de energia elétrica sob condições faltosas. 


\section{APÍTULO 3}

\section{DECOMPOSIÇÃO EM COMPONENTES ORTOGONAIS}

\subsection{INTRODUÇÃO}

No Capítulo 2 se destacaram alguns dos trabalhos relacionados à identificação e localização de faltas, com atenção especial para aqueles de alta-impedância, em sistemas de distribuição de energia elétrica. Das abordagens reportadas na literatura correlata ao tema, procurou-se focar naquelas que fazem uso de ferramentas advindas da inteligência computacional, principalmente nas redes neurais artificiais e nos sistemas de inferência fuzzy, em função dos promissores resultados por essas técnicas fornecidas. Além dessas técnicas para processamento de informações para identificação e localização de faltas, uma ferramenta para pré-processamento também fora digna de destaque. Esse destaque fora conferido à transformada wavelet que, em função da particularidade da realização da decomposição multiníveis, mostra-se também como uma importante ferramenta não apenas no âmbito da identificação e localização de faltas em sistema elétricos de potência como também no estudo de parâmetros quantificadores para a qualidade da energia elétrica. No entanto, o capítulo precedente não se restringiu à apresentação de aplicações de técnicas contemporâneas na realização da identificação e localização de falta, fora também delineado como, por meio de análises de circuitos elétricos e de ferramentas estatísticas, as referidas tarefas podem ser também desempenhadas. 
Assim, de forma ampla, verifica-se, de forma independente à metodologia empregada, que uma das principais necessidades diante das formas de onda de corrente e de tensão é de se fazer seu pré-processamento. O pré-processamento das formas de onda de tensão e de corrente, oscilografados junto à subestação de distribuição de energia elétrica, tem por meta extrair características que sejam contundentes quando da identificação de faltas e que contenham dados de relevante qualidade para a localização da referida falta.

Dessa maneira, nesse capítulo será apresentado o conceito de decomposição em componentes ortogonais para as formas de onda de tensão e de corrente. A principal característica da ferramenta apresentada é de que a mesma é independente de sistemas de coordenadas, tais como são a transformada de Fourier e a transformada wavelet, ou seja, a decomposição em componentes ortogonais não se fundamenta na projeção de funções sobre outras pré-estabelecidas. Ao contrário disso, procura-se extrair das próprias formas de onda as funções base para a decomposição de maneira que o sistema de coordenadas está auto-contido nas funções que serão decompostas.

Esse aspecto difere a metodologia apresentada daquelas relatadas na literatura e, para fins de identificação e de localização de faltas em sistemas de distribuição de energia elétrica, poderão constituir, ao lado daquelas já consagradas, em uma nova perspectiva para o sucesso dos objetivos almejados. Portanto, os desenvolvimentos apresentados ao longo deste capítulo constituem em umas das principais contribuições originais desta tese.

Assim, esse capítulo será organizado de forma a apresentar na Seção 3.2, após essa sucinta introdução, alguns dos aspectos analíticos e espaciais de funções temporais periódicas que permitirão na, Seção 3.3, demonstrar como que, a partir das formas de onda de tensão e de corrente de um sistema monofásico, as referidas formas de onda poderão ser decompostas em suas componentes ortogonais. Na Seção 3.4 o conceito de componentes ortogonais será estendido aos sistemas de energia trifásicos com destaque especial para decomposição das tensões de fase nesse tipo de sistema, assim como na Seção 3.5 será conferida atenção à decomposição das correntes de linha em um sistema trifásico. Assim, na Seção 3.6, procurar-se-á agregar todos os desenvolvimentos delineados de maneira a possibilitar a extração de características que sejam pertinentes tanto quando da identificação como quando da estimação de sua localização. A técnica da decomposição em componentes ortogonais, além de ser empregada na identificação e na localização de faltas, será também empregada na determinação da fase participante da falta e na estimação da resistência de falta. 


\subsection{ASPECTOS ANALÍticos E GEOMÉtricos de FunÇõeS TEMPORAIS}

Seja $f(t)$ uma função real, temporal, contínua, finita e com periodicidade $T$ não-variante no tempo, de maneira que a seguinte condição não seja violada.

$$
f(k T+t)=f(t) ; k=1,2,3, \ldots
$$

Nesses termos, é possível definir as funções $\dot{f}(t)$ e $\tilde{f}(t)$ tal como se faz por meio das expressões (3.2) e (3.3), respectivamente.

$$
\begin{aligned}
& \dot{f}(t)=\frac{d f(t)}{d t} \\
& \frac{d \tilde{f}(t)}{d t}=f(t)
\end{aligned}
$$

As funções $f(t), \dot{f}(t)$ e $\tilde{f}(t)$ podem ser conceituadas como vetores pertencentes ao espaço de funções $\mathbb{R}^{\infty}$ e operadores como o da norma quadrática podem ser empregados. Assim, tem-se que a norma quadrática de $f(t)$, denotada por $\|f(t)\|$, pode ser calculada por meio da seguinte expressão:

$$
\|f(t)\|^{2}=\langle f(t), f(t)\rangle
$$

onde $\langle.,$.$\rangle representa o produto escalar entre os argumentos e pode ser definido, no espaço de$ funções, da seguinte forma:

$$
\langle f(t), g(t)\rangle=\frac{1}{T} \int_{t-T}^{t} f(\tau) g(\tau) d \tau
$$

A interpretação de funções temporais como sendo vetores de um espaço vetorial permite inferências sobre como essas funções se relacionam e se dispõem espacialmente uma em relação à outra. Dessa maneira, por meio desses operadores é possível a verificação de ortogonalidade entre as funções $f(t), \dot{f}(t)$ e $\tilde{f}(t)$. A determinação da ortogonalidade entre duas ou mais funções é de fundamental importância quando se objetiva a constituição de um conjunto de bases para a decomposição em componentes ortogonais. Assim, procura-se 
delinear na seqüência como, a partir das funções $f(t), \dot{f}(t)$ e $\tilde{f}(t)$, um conjunto de bases ortogonais para o espaço $\wp_{f} \subset \mathbb{R}^{\infty} \mid f(t) \in \wp_{f}$ pode ser constituído.

Para que duas funções sejam ortogonais no seu período é necessário que o produto escalar entre essas funções seja nulo. Logo, realizando-se o teste de ortogonalidade entre as funções $f(t)$ e $\dot{f}(t)$ o seguinte desenvolvimento é possível:

$$
\begin{aligned}
& \langle f(t), \dot{f}(t)\rangle=\frac{1}{T} \int_{t-T}^{t} f(\tau) \dot{f}(\tau) d \tau \\
& \langle f(t), \dot{f}(t)\rangle=\frac{1}{T} \int_{t-T}^{t} f(\tau) \frac{d f(\tau)}{d \tau} d \tau \\
& \langle f(t), \dot{f}(t)\rangle=\frac{1}{T} \int_{f(t-T)}^{f(t)} f(\tau) d f(\tau) \\
& \langle f(t), \dot{f}(t)\rangle=\left.\frac{1}{T} \frac{1}{2} f^{2}(\tau)\right|_{f(t-T)} ^{f(t)} \\
& \langle f(t), \dot{f}(t)\rangle=\frac{1}{T} \frac{1}{2}\left(f^{2}(t)-f^{2}(t-T)\right) \\
& \langle f(t), \dot{f}(t)\rangle=0
\end{aligned}
$$

Por meio do resultado expresso em (3.6) verifica-se que as funções $f(t)$ e $\dot{f}(t)$ são ortogonais entre si, pois, em função da garantia de periodicidade, tem-se que $f(t)=f(t-T)$. Desenvolvimento semelhante pode ser conduzido para verificar a ortogonalidade entre as funções $f(t)$ e $\tilde{f}(t)$, ou seja:

$$
\langle f(t), \tilde{f}(t)\rangle=\int_{t-T}^{t} f(\tau) \tilde{f}(\tau) d \tau
$$

Pelo método da integração por partes o desenvolvimento da expressão (3.7) pode ser conduzido de maneira a resultar em (3.8).

$$
\begin{aligned}
& \langle f(t), \tilde{f}(t)\rangle=\left.\frac{1}{T} \tilde{f}^{2}(\tau)\right|_{t-T} ^{t}-\underbrace{\frac{1}{T} \int_{t-T}^{t} f(\tau) \tilde{f}(\tau) d \tau}_{\langle f(t), \tilde{f}(t)\rangle} \\
& 2\langle f(t), \tilde{f}(t)\rangle=\frac{1}{T}\left(\tilde{f}^{2}(t)-\tilde{f}^{2}(t-T)\right)
\end{aligned}
$$




$$
\langle f(t), \tilde{f}(t)\rangle=0
$$

Logo, tal como as funções $f(t)$ e $\dot{f}(t)$ são ortogonais entre si, as funções $f(t)$ e $\tilde{f}(t)$ também o serão, restando então verificar a condição de ortogonalidade para as funções $\dot{f}(t)$ e $\tilde{f}(t)$, ou seja:

$$
\langle\dot{f}(t), \tilde{f}(t)\rangle=\frac{1}{T} \int_{t-T}^{t} \dot{f}(\tau) \tilde{f}(\tau) d \tau
$$

Fazendo novamente uso do método de integração por partes, a expressão (3.9) pode ser desenvolvida da seguinte forma:

$$
\begin{aligned}
& \langle\dot{f}(t), \tilde{f}(t)\rangle=\left.\frac{1}{T}[f(\tau) \tilde{f}(\tau)]\right|_{t-T} ^{t}-\underbrace{\frac{1}{T} \int_{t-T}^{t} f^{2}(\tau) d \tau}_{\|f(t)\|^{2}} \\
& \langle\dot{f}(t), \tilde{f}(t)\rangle=\frac{1}{T} \underbrace{(f(t) \tilde{f}(t)-f(t-T) \tilde{f}(t-T))}_{0}-\|f(t)\|^{2} \\
& \langle\dot{f}(t), \tilde{f}(t)\rangle=-\|f(t)\|^{2}
\end{aligned}
$$

O resultado destacado em (3.10) faz verificar que as funções $\dot{f}(t)$ e $\tilde{f}(t)$ não são ortogonais entre si. Diante disso, cabe verificar o ângulo formado entre as mesmas, denotado por $\theta$, o qual, pensado em termos de co-seno, por definição, é dado da seguinte forma:

$$
\cos (\theta)=\frac{\langle\dot{f}(t), \tilde{f}(t)\rangle}{\|\dot{f}(t)\|\|\tilde{f}(t)\|}=-\frac{\|f(t)\|^{2}}{\|\dot{f}(t)\|\|\tilde{f}(t)\|}
$$

Para fins de uma interpretação espacial é interessante verificar se as funções $\dot{f}(t)$ e $\tilde{f}(t)$ são colineares, ou seja, se o ângulo formado entre as mesmas é de $\pi$ radianos o que é equivalente a verificar se o co-seno desse ângulo vale -1 . Dessa forma, uma das condições necessárias para que as funções $\dot{f}(t)$ e $\tilde{f}(t)$ sejam colineares pode ser expressa como em (3.12).

$$
\|\dot{f}(t)\|\|\tilde{f}(t)\|=\|f(t)\|^{2}
$$


Para verificar se a condição de módulo expressa em (3.12) é válida para qualquer função $f(t)$, detentora das propriedades inicialmente formuladas ou então sob quais critérios a condição se torna válida, é pertinente representar a função $f(t)$ por meio de sua série de Fourier, ou seja:

$$
f(t)=\sum_{k \in \aleph_{f}} F_{k} \cos \left(k \omega t+\delta_{k}\right)
$$

onde $F_{k}$ representa o valor de pico da $k$-ésima harmônica necessária à composição da função $f(t)$ e $\delta_{k}$ a defasagem angular da referida harmônica, $\aleph_{f}$ denota o conjunto índice de todas as harmônicas componentes de $f(t)$ e $\omega=2 \pi / T$. Por meio de (3.13) e das definições apresentadas em (3.2) e (3.3), as funções $\dot{f}(t)$ e $\tilde{f}(t)$ passam a ser formuladas como na seqüência:

$$
\begin{aligned}
& \dot{f}(t)=-\omega \sum_{k \in \aleph_{f}} k F_{k} \operatorname{sen}\left(k \omega t+\delta_{k}\right) \\
& \tilde{f}(t)=\frac{1}{\omega} \sum_{k \in \aleph_{f}} \frac{F_{k}}{k} \operatorname{sen}\left(k \omega t+\delta_{k}\right)
\end{aligned}
$$

Na condição expressa em (3.12), o conhecimento da norma quadrática das funções envolvidas é imperativo. Dessa forma, valendo-se das equivalências feitas por meio da série de Fourier e apresentadas em (3.13), (3.14) e (3.15), o valor das normas quadráticas dessas funções, calculadas segundo (3.4), pode ser expresso como se faz a seguir:

$$
\begin{aligned}
& \|f(t)\|^{2}=\frac{1}{2} \sum_{k \in \aleph_{f}} F_{k}^{2} \\
& \|\dot{f}(t)\|^{2}=\frac{\omega^{2}}{2} \sum_{k \in \aleph_{f}} k^{2} F_{k}^{2} \\
& \|\tilde{f}(t)\|^{2}=\frac{1}{2 \omega^{2}} \sum_{k \in \aleph_{f}} \frac{F_{k}^{2}}{k^{2}}
\end{aligned}
$$

A fim de determinar $\|\dot{f}(t)\|\|\tilde{f}(t)\|$ as expressões (3.17) e (3.18) podem ser empregadas, o que resulta no seguinte desenvolvimento: 


$$
\begin{aligned}
& \|\dot{f}(t)\|^{2}\|\tilde{f}(t)\|^{2}=\left(\frac{\omega^{2}}{2} \sum_{k \in \aleph_{f}} k^{2} F_{k}^{2}\right)\left(\frac{1}{2 \omega^{2}} \sum_{k \in \aleph_{f}} \frac{F_{k}^{2}}{k^{2}}\right) \\
& \|\dot{f}(t)\|^{2}\|\tilde{f}(t)\|^{2}=\frac{1}{4} \sum_{k \in \aleph_{f}} \sum_{l \in \aleph_{f}} \frac{k^{2}}{l^{2}} F_{k}^{2} F_{l}^{2} \\
& \|\dot{f}(t)\|^{2}\|\tilde{f}(t)\|^{2}=\underbrace{\frac{1}{4}\left(\sum_{k \in \aleph_{f}} F_{k}^{2}\right)^{2}}_{\|f(t)\|^{4}}+\frac{1}{4} \sum_{\substack{k \in \aleph_{f} \\
\sum_{l \in \aleph_{f}} \sum_{l \neq k}}} F_{k}^{2} F_{l}^{2}\left(\frac{k^{2}}{l^{2}}-2\right) \\
& \|\dot{f}(t)\|^{2}\|\tilde{f}(t)\|^{2}=\|f(t)\|^{4}+\frac{1}{4} \sum_{k \in \aleph_{f}} \sum_{\substack{l \in \aleph_{f} \\
l \neq k}} F_{k}^{2} F_{l}^{2}\left(\frac{k^{2}}{l^{2}}-2\right)
\end{aligned}
$$

O resultado alcançado em (3.19) conduz à afirmação de que a condição expressa em (3.12) não é verificada quando da consideração de uma $f(t)$ genérica, ou seja, composta por harmônicas quaisquer. Assim, não existe a garantia de que as funções $\dot{f}(t)$ e $\tilde{f}(t)$ são colineares. Complementando, supondo que $f(t)$ seja puramente senoidal, verifica-se que a condição de colinearidade é válida apenas para esse caso em particular, pois, nessas condições, tem-se:

$$
\begin{aligned}
& \|\dot{f}(t)\|^{2}\|\tilde{f}(t)\|^{2}=\left(\frac{\omega}{2} F_{k}^{2}\right)\left(\frac{1}{2 \omega} F_{k}^{2}\right) \\
& \|\dot{f}(t)\|^{2}\|\tilde{f}(t)\|^{2}=\underbrace{\frac{1}{4} F_{k}^{4}}_{\|f(t)\|^{4}} \\
& \|\dot{f}(t)\|^{2}\|\tilde{f}(t)\|^{2}=\|f(t)\|^{4} \\
& \|\dot{f}(t)\|\|\tilde{f}(t)\|=\|f(t)\|^{2}
\end{aligned}
$$

Por fim, diante dos resultados dos desenvolvimentos delineados ao longo dessa seção é correto afirmar que dada uma função real, temporal, contínua, finita e com periodicidade $T$ não-variante no tempo, a mesma é mutuamente ortogonal às suas funções derivativas e integrativas as quais, por sua vez, serão colineares entre si apenas sob a consideração de que a função, premissa do desenvolvimento, seja puramente senoidal. 
O desenvolvimento apresentado nessa seção, além de demonstrar algumas propriedades que as funções reais e periódicas apresentam no espaço de funções, traz fundamentos para a constituição de um sistema de bases ortogonais para a decomposição de funções outras que não aquela empregada na conceituação delineada. Esse aspecto será fundamental quando do estudo do relacionamento entre as tensões e correntes, sejam essas observadas em sistemas monofásicos ou trifásicos.

Visto isso, a representação esquemática para o relacionamento espacial entre as funções $f(t), \dot{f}(t)$ e $\tilde{f}(t)$ é merecedora de apresentação, assim como feito por meio da Figura 3.1 .

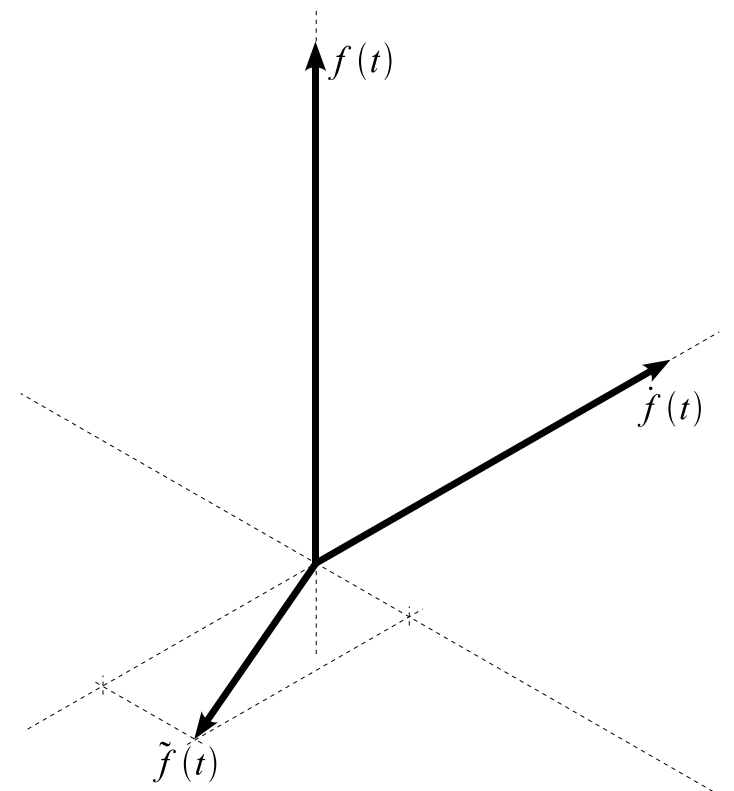

Figura 3.1 - Representação esquemática do relacionamento espacial entre as funções

$$
f(t), \dot{f}(t) \text { e } \tilde{f}(t) .
$$

A partir da Figura 3.1 se observa que $f(t)$ e $\dot{f}(t)$ são ortogonais entre si conforme (3.6) se fez provar, da mesma forma como (3.8) garante a ortogonalidade entre as funções $f(t)$ e $\tilde{f}(t)$. No entanto, as funções $\dot{f}(t)$ e $\tilde{f}(t)$ não são ortogonais entre si podendo ser colineares quando $f(t)$ for puramente senoidal. A fim de constituir um conjunto de bases ortogonais para a decomposição de funções outras no espaço de $f(t)$ se torna necessário a definição de bases todas ortogonais entre si. Como proposição para esse conjunto de bases tem-se: 


$$
\left\{\begin{array}{l}
f_{p}(t)=f(t) \\
f_{q}^{\|}(t)=\dot{f}(t) \\
f_{q}^{\perp}(t)=\tilde{f}(t)-\frac{\langle\tilde{f}(t), \dot{f}(t)\rangle}{\|\dot{f}(t)\|^{2}} \dot{f}(t)
\end{array}\right.
$$

Assim, verifica-se a possibilidade de, a partir de uma função $f(t)$ periódica, obter um conjunto de bases ortogonais passíveis de serem empregadas na projeção de outras funções no espaço de $f(t)$. Dessa forma, frente à possibilidade de se fazer projeções entre funções pertencentes a espaços distintos, desenvolve-se a Seção 3.3 onde se fará a análise do relacionamento entre funções.

\subsection{RELACIONAMENTO FUnCIONAL NO ESPAÇO DE FUNÇÕES}

Seja $f(t)$ e $g(t)$ funções reais, temporais, contínuas, finitas e com periodicidade $T$ não variante no tempo de maneira que $f(t) \in \wp_{f}$ e $g(t) \in \wp_{g}$ onde $\left\{\wp_{f}, \wp_{g}\right\} \subset \mathbb{R}^{\infty}$, ou seja, $f(t)$ e $g(t)$ são funções no espaço de funções podendo possuir aspectos em comum, porém não plenamente, o que caracterizaria o caso geral sob estudo nessa seção. A interpretação dessas colocações pode ser facilitada se as funções em questão forem pensadas em termos de sua representação por meio da série de Fourier, ou seja:

$$
\begin{aligned}
& f(t)=\sum_{k \in \aleph_{f}} F_{k} \cos \left(k \omega t+\delta_{k}\right) \\
& g(t)=\sum_{k \in \aleph_{g}} G_{k} \cos \left(k \omega t+\psi_{k}\right)
\end{aligned}
$$

onde $F_{k}$ e $G_{k}$ representam o valor de pico da $k$-ésima harmônica necessária à composição das funções $f(t)$ e $g(t)$, respectivamente, e $\delta_{k}$ e $\psi_{k}$ a defasagem angular da referida harmônica para as funções correspondentes; $\aleph_{f} \subset \mathbb{N}^{\infty}$ denota o conjunto índice de todas as harmônicas componentes de $f(t)$, enquanto $\aleph_{g} \subset \mathbb{N}^{\infty}$ representa o conjunto índice de todas as harmônicas componentes de $g(t)$ e, em ambas funções, $\omega=2 \pi / T$.

Os conjuntos $\aleph_{f}$ e $\aleph_{g}$ podem, então, auxiliar na interpretação dos espaços $\wp_{f}$ e $\wp_{g}$, respectivamente. Assim, define-se o espaço de funções $\wp_{f}$ como sendo aquele 
responsável por conter todas as funções reais, temporais, contínuas, finitas e com periodicidade $T$ não variante no tempo e que, quando de uma análise no domínio da freqüência, apresentem índices harmônicos não destoantes dos contidos no conjunto $\aleph_{f}$. Da mesma forma, define-se o espaço de funções $\wp_{g}$ como sendo aquele responsável por conter todas as funções reais, temporais, contínuas, finitas e com periodicidade $T$ não variante no tempo e que, quando de uma análise no domínio da freqüência, apresentem índices harmônicos não destoantes dos contidos no conjunto $\aleph_{g}$.

Por meio dos desenvolvimentos realizados na seção anterior é possível, a partir de uma conhecida função contida em um desses espaços, determinar as bases ortogonais necessárias à composição de todas as demais funções contidas nesse espaço. Assim, supondo que $f(t) \in \wp_{f}$ seja conhecida, tem-se que as bases ortogonais do espaço $\wp_{f}$ serão dadas por:

$$
\left\{\begin{array}{l}
f(t) \\
\dot{f}(t) \\
\tilde{f}(t)-\frac{\langle\tilde{f}(t), \dot{f}(t)\rangle}{\|\dot{f}(t)\|^{2}} \dot{f}(t)
\end{array}\right.
$$

Dessa forma, para $\alpha_{1}, \alpha_{2}$ e $\alpha_{3}$ escalares não simultaneamente nulos e $f_{\alpha}(t)$ definida conforme (3.25), tem-se que $f_{\alpha}(t) \in \wp_{f}$.

$$
f_{\alpha}(t)=\alpha_{1} f(t)+\alpha_{2} \dot{f}(t)+\alpha_{3}\left(\tilde{f}(t)-\frac{\langle\tilde{f}(t), \dot{f}(t)\rangle}{\|\dot{f}(t)\|^{2}} \dot{f}(t)\right)
$$

onde $f_{\alpha}(t)$ representa qualquer função contida no espaço de $f(t)$, ou seja, possível de ser representada por meio da combinação linear das bases ortogonais dessa função.

O conjunto de bases ortogonais especificado para o espaço $\wp_{f}$ permite ainda determinar a projeção que uma função $g(t)$, contida em espaço supostamente distinto a $\wp_{f}$, possui sobre o mesmo. Assim, seja $g(t) \in \wp_{g}$ e $g_{f}(t) \in \wp_{f}$ sua respectiva projeção sobre o espaço $\wp_{f}$ e assumindo que $\langle\dot{f}(t), \tilde{f}(t)\rangle=-\|f(t)\|^{2}$ conforme (3.10), tem-se então que $g_{f}(t)$ pode ser determinada da seguinte maneira: 


$$
\begin{aligned}
& g_{f}(t)=\frac{\langle g(t), f(t)\rangle}{\|f(t)\|^{2}} f(t)+\frac{\langle g(t), \dot{f}(t)\rangle}{\|\dot{f}(t)\|^{2}} \dot{f}(t)+\cdots \\
& \cdots+\frac{\left\langle g(t), \tilde{f}(t)+\frac{\|f(t)\|^{2}}{\|\dot{f}(t)\|^{2}} \dot{f}(t)\right\rangle}{\left\|\tilde{f}(t)+\frac{\|f(t)\|^{2}}{\|\dot{f}(t)\|^{2}} \dot{f}(t)\right\|^{2}}\left(\tilde{f}(t)+\frac{\|f(t)\|^{2}}{\|\dot{f}(t)\|^{2}} \dot{f}(t)\right) \\
& g_{f}(t)=\frac{\langle g(t), f(t)\rangle}{\|f(t)\|^{2}} f(t)+\frac{\langle g(t), \dot{f}(t)\rangle}{\|\dot{f}(t)\|^{2}} \dot{f}(t)+\cdots \\
& \cdots+\frac{\langle g(t), \tilde{f}(t)\rangle+\frac{\|f(t)\|^{2}}{\|\dot{f}(t)\|^{2}}\langle g(t), \dot{f}(t)\rangle}{\|\tilde{f}(t)\|^{2}+\frac{\|f(t)\|^{4}}{\|\dot{f}(t)\|^{4}}\|\dot{f}(t)\|^{2}-2 \frac{\|f(t)\|^{4}}{\|\dot{f}(t)\|^{2}}}\left(\tilde{f}(t)+\frac{\|f(t)\|^{2}}{\|\dot{f}(t)\|^{2}} \dot{f}(t)\right) \\
& g_{f}(t)=\frac{\langle g(t), f(t)\rangle}{\|f(t)\|^{2}} f(t)+\frac{\langle g(t), \dot{f}(t)\rangle}{\|\dot{f}(t)\|^{2}} \dot{f}(t)+\cdots \\
& \cdots+\frac{\|\dot{f}(t)\|^{2}\langle g(t), \tilde{f}(t)\rangle+\|f(t)\|^{2}\langle g(t), \dot{f}(t)\rangle}{\|\dot{f}(t)\|^{2}\|\tilde{f}(t)\|^{2}-\|f(t)\|^{4}}\left(\tilde{f}(t)+\frac{\|f(t)\|^{2}}{\|\dot{f}(t)\|^{2}} \dot{f}(t)\right) \\
& g_{f}(t)=\frac{\langle g(t), f(t)\rangle}{\|f(t)\|^{2}} f(t)+\frac{\|\dot{f}(t)\|^{2}\langle g(t), \tilde{f}(t)\rangle+\|f(t)\|^{2}\langle g(t), \dot{f}(t)\rangle}{\|\dot{f}(t)\|^{2}\|\tilde{f}(t)\|^{2}-\|f(t)\|^{4}} \tilde{f}(t)+\cdots \\
& \cdots+\left(\frac{\langle g(t), \dot{f}(t)\rangle}{\|\dot{f}(t)\|^{2}}+\frac{\|\dot{f}(t)\|^{2}\langle g(t), \tilde{f}(t)\rangle+\|f(t)\|^{2}\langle g(t), \dot{f}(t)\rangle}{\|\dot{f}(t)\|^{2}\|\tilde{f}(t)\|^{2}-\|f(t)\|^{4}} \frac{\|f(t)\|^{2}}{\|\dot{f}(t)\|^{2}}\right) \dot{f}(t) \\
& g_{f}(t)=\frac{\langle g(t), f(t)\rangle}{\|f(t)\|^{2}} f(t)+\cdots \\
& \cdots+\frac{\|\tilde{f}(t)\|^{2}\langle g(t), \dot{f}(t)\rangle+\|f(t)\|^{2}\langle g(t), \tilde{f}(t)\rangle}{\|\dot{f}(t)\|^{2}\|\tilde{f}(t)\|^{2}-\|f(t)\|^{4}} \dot{f}(t)+\cdots \\
& \cdots+\frac{\|\dot{f}(t)\|\left\|^{2}\langle g(t), \tilde{f}(t)\rangle+\right\| f(t) \|^{2}\langle g(t), \dot{f}(t)\rangle}{\|\dot{f}(t)\|^{2}\|\tilde{f}(t)\|^{2}-\|f(t)\|^{4}} \tilde{f}(t)
\end{aligned}
$$


O resultado alcançado em (3.26) permite a determinação da projeção de $g(t) \in \wp_{g}$ sobre o espaço $\wp_{f}$ e observações sobre o relacionamento entre os espaços $\wp_{f}$ e $\wp_{g}$ podem ser direcionadas, pois, se $\left\|g_{f}(t)\right\| \neq 0$ é possível afirmar que $\wp_{f} \cap \wp_{g} \neq 0$, ou seja, $\wp_{f}$ e $\wp_{g}$ não serão espaços disjuntos ou de forma equivalente, $\aleph_{f} \cap \aleph_{g} \neq \varnothing$. Dessa maneira, o fato de que $\aleph_{f} \cap \aleph_{g} \neq \varnothing$ leva à conclusão que existirão componentes harmônicas na função $f(t)$ que são comuns à função $g(t)$. Para fins de ilustração, pode-se representar esquematicamente a projeção de $g(t)$ sobre o espaço $\wp_{f}$ assim como feito por meio da Figura 3.2 .

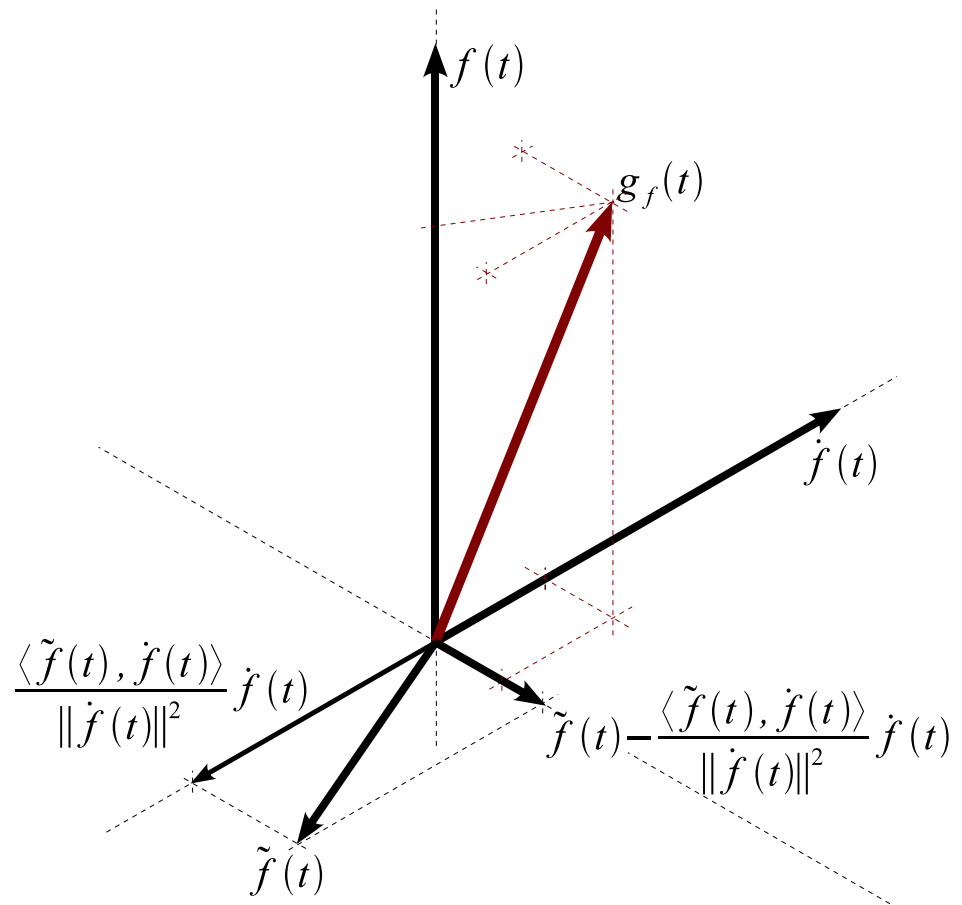

Figura 3.2 - Representação esquemática da projeção da função $g(t)$ sobre o espaço $\wp_{f}$.

Em complemento, pode-se determinar a parcela de $g(t)$ não contida no espaço $\wp_{f}$ a qual será denotada por $g_{\bar{f}}(t)$ e definida como em (3.27), ou seja:

$$
\begin{aligned}
& g(t)=g_{\bar{f}}(t)+g_{f}(t) \\
& g_{\bar{f}}(t)=g(t)-g_{f}(t)
\end{aligned}
$$

A função $g_{\bar{f}}(t)$ pertencerá ao espaço $\wp_{g} \backslash \wp_{f}$ o qual representa o espaço das funções de $\wp_{g}$ que não pertencem à $\wp_{f} \cap \wp_{g}$, ou de forma equivalente tem-se que os índices 
das componentes harmônicas constituintes de $g_{\bar{f}}(t)$ estarão contidos no conjunto $\aleph_{g} \backslash \aleph_{f}$. Mais ainda, $g_{\bar{f}}(t)$ será ortogonal à $g_{f}(t)$ o que permite escrever a norma quadrática de $g(t)$ da seguinte maneira:

$$
\|g(t)\|^{2}=\left\|g_{\bar{f}}(t)\right\|^{2}+\left\|g_{f}(t)\right\|^{2}
$$

O mesmo desenvolvimento alcançado em (3.26) pode ser conduzido para a projeção de $f(t)$ sobre o espaço $\wp_{g}$ o que resultaria nas seguintes expressões:

$$
\begin{aligned}
& f_{g}(t)=\frac{\langle f(t), g(t)\rangle}{\|g(t)\|^{2}} g(t)+\cdots \\
& \cdots+\frac{\|\tilde{g}(t)\|^{2}\langle f(t), \dot{g}(t)\rangle+\|g(t)\|^{2}\langle f(t), \tilde{g}(t)\rangle}{\|\dot{g}(t)\|^{2}\|\tilde{g}(t)\|^{2}-\|g(t)\|^{4}} \dot{g}(t)+\cdots \\
& \cdots+\frac{\|\dot{g}(t)\|^{2}\langle f(t), \tilde{g}(t)\rangle+\|g(t)\|^{2}\langle f(t), \dot{g}(t)\rangle}{\|\dot{g}(t)\|^{2}\|\tilde{g}(t)\|^{2}-\|g(t)\|^{4}} \tilde{g}(t) \\
& f_{\bar{g}}(t)=f(t)-f_{g}(t) \\
& \|f(t)\|^{2}=\left\|f_{\bar{g}}(t)\right\|^{2}+\left\|f_{g}(t)\right\|^{2}
\end{aligned}
$$

Assim como feito para a função $g_{f}(t)$, é possível para a função $f(t)$ representar esquematicamente sua projeção no espaço $\wp_{g}$ conforme feito por meio da Figura 3.3.

No entanto, apesar do resultado alcançado para a projeção de uma determinada função no espaço que contem uma segunda atender ao caso geral, ou seja, aquele em que ambas as funções são não-senoidais, a análise para o caso particular em que a função base é senoidal é digna de estudo. O aspecto motivador dessa análise baseia-se no resultado alcançado em (3.20). A referida igualdade conduz a uma aparente indeterminação matemática de (3.26) a qual será delineada a seguir.

Supondo que a função $f(t)$ seja puramente senoidal, tem-se que:

$$
\tilde{f}(t)-\frac{\langle\tilde{f}(t), \dot{f}(t)\rangle}{\|\dot{f}(t)\|^{2}} \dot{f}(t)=\tilde{f}(t)+\frac{\|f(t)\|^{2}}{\|\dot{f}(t)\|^{2}} \dot{f}(t)=0
$$




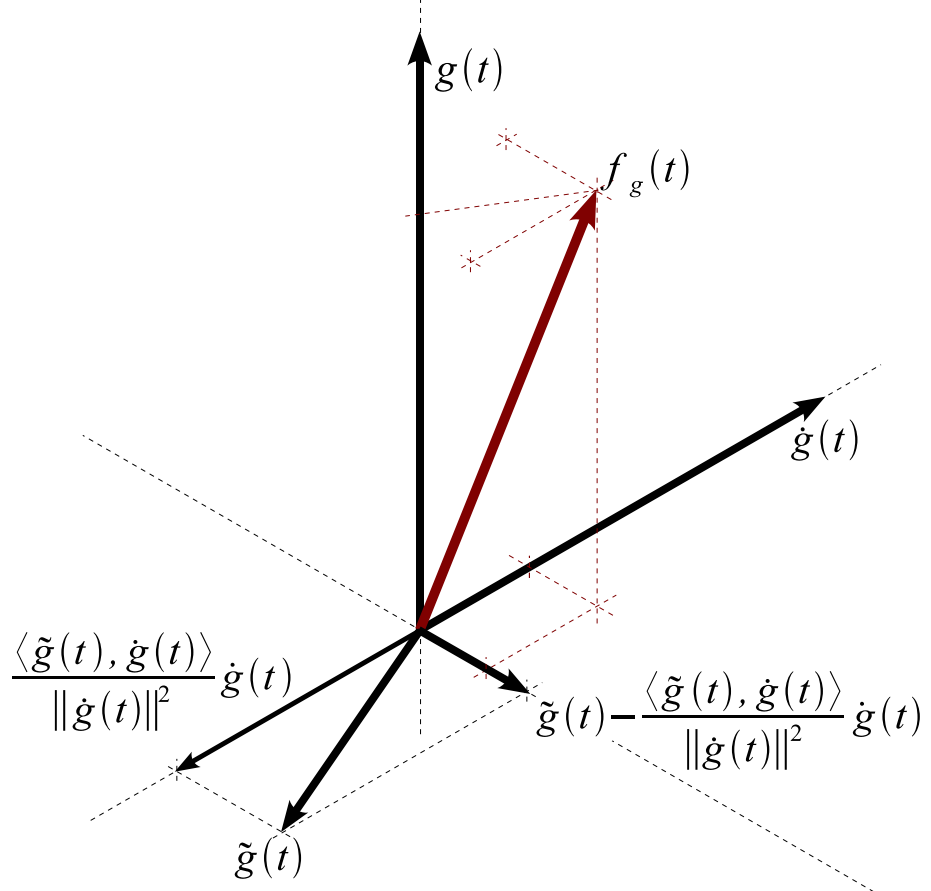

Figura 3.3 - Representação esquemática da projeção da função $f(t)$ sobre o espaço $\wp_{g}$.

Para demonstrar que (3.32) é verdade quando $f(t)$ for puramente senoidal, tornase necessário verificar se a norma quadrática de $\tilde{f}(t)+\|f(t)\|^{2} /\|\dot{f}(t)\|^{2} \dot{f}(t)$ é nula. Dessa forma, prosseguindo com a necessária demonstração, tem-se:

$$
\begin{aligned}
& \left\|\tilde{f}(t)+\frac{\|f(t)\|^{2}}{\|\dot{f}(t)\|^{2}} \dot{f}(t)\right\|^{2}=\left\langle\tilde{f}(t)+\frac{\|f(t)\|^{2}}{\|\dot{f}(t)\|^{2}} \dot{f}(t), \tilde{f}(t)+\frac{\|f(t)\|^{2}}{\|\dot{f}(t)\|^{2}} \dot{f}(t)\right\rangle \\
& \left\|\tilde{f}(t)+\frac{\|f(t)\|^{2}}{\|\dot{f}(t)\|^{2}} \dot{f}(t)\right\|^{2}=\langle\tilde{f}(t), \tilde{f}(t)\rangle+\frac{\|f(t)\|^{2}}{\|\dot{f}(t)\|^{2}}\langle\tilde{f}(t), \dot{f}(t)\rangle+\cdots \\
& \cdots+\frac{\|f(t)\|^{2}}{\|\dot{f}(t)\|^{2}}\langle\dot{f}(t), \tilde{f}(t)\rangle+\frac{\|f(t)\|^{4}}{\|\dot{f}(t)\|^{4}}\langle\dot{f}(t), \dot{f}(t)\rangle \\
& \left\|\tilde{f}(t)+\frac{\|f(t)\|^{2}}{\|\dot{f}(t)\|^{2}} \dot{f}(t)\right\|^{2}=\|\tilde{f}(t)\|^{2}+\frac{\|f(t)\|^{4}}{\|\dot{f}(t)\|^{4}}\|\dot{f}(t)\|^{2}+2 \frac{\|f(t)\|^{2}}{\|\dot{f}(t)\|^{2}} \underbrace{\left\langle f(t) \|^{2}\right.}_{-\tilde{f}(t), \dot{f}(t)\rangle} \\
& \left\|\tilde{f}(t)+\frac{\|f(t)\|^{2}}{\|\dot{f}(t)\|^{2}} \dot{f}(t)\right\|^{2}=\|\tilde{f}(t)\|^{2}+\frac{\|f(t)\|^{4}}{\|\dot{f}(t)\|^{2}}-2 \frac{\|f(t)\|^{4}}{\|\dot{f}(t)\|^{2}}
\end{aligned}
$$




$$
\begin{aligned}
& \left\|\tilde{f}(t)+\frac{\|f(t)\|^{2}}{\|\dot{f}(t)\|^{2}} \dot{f}(t)\right\|^{2}=\|\tilde{f}(t)\|^{2}-\frac{\|f(t)\|^{4}}{\|\dot{f}(t)\|^{2}} \\
& \left\|\tilde{f}(t)+\frac{\|f(t)\|^{2}}{\|\dot{f}(t)\|^{2}} \dot{f}(t)\right\|^{2}=\frac{\|\tilde{f}(t)\|^{2}\|\dot{f}(t)\|^{2}-\|f(t)\|^{4}}{\|\dot{f}(t)\|^{2}}
\end{aligned}
$$

Retomando o resultado alcançado em (3.20), particular para quando $f(t)$ é puramente senoidal, e o substituindo em (3.33), pode-se proceder com o seguinte desenvolvimento:

$$
\begin{aligned}
& \left\|\tilde{f}(t)+\frac{\|f(t)\|^{2}}{\|\dot{f}(t)\|^{2}} \dot{f}(t)\right\|^{2}=\frac{\overbrace{\|\tilde{f}(t)\|^{2}\|\dot{f}(t)\|^{2}}^{\|f(t)\|^{4}}-\|f(t)\|^{4}}{\|\dot{f}(t)\|^{2}} \\
& \left\|\tilde{f}(t)+\frac{\|f(t)\|^{2}}{\|\dot{f}(t)\|^{2}} \dot{f}(t)\right\|^{2}=\frac{\|f(t)\|^{4}-\|f(t)\|^{4}}{\|\dot{f}(t)\|^{2}} \\
& \left\|\tilde{f}(t)+\frac{\|f(t)\|^{2}}{\|\dot{f}(t)\|^{2}} \dot{f}(t)\right\|^{2}=0
\end{aligned}
$$

Dessa maneira, por meio de (3.34), a veracidade de (3.32) é comprovada, ou seja, a função $\tilde{f}(t)$ será colinear à $\dot{f}(t)$ o que impossibilita a formulação de uma base de funções ortogonais para o espaço $\wp_{f}$ como necessário para o equacionamento sob consideração. Assim, para demonstrar que o desenvolvimento realizado é válido mesmo quando diante dessa singularidade será considerado que:

$$
\tilde{f}(t)=\alpha \dot{f}(t) \text { onde } \alpha \rightarrow-\frac{\|f(t)\|^{2}}{\|\dot{f}(t)\|^{2}}
$$

Dessa forma, a expressão (3.26) pode ser desenvolvida da seguinte maneira: 


$$
\begin{aligned}
& g_{f}(t)=\lim _{\alpha \rightarrow-\frac{\|f(t)\|^{2}}{\|f(t)\|^{2}}}\left[\frac{\langle g(t), f(t)\rangle}{\|f(t)\|^{2}} f(t)+\cdots\right. \\
& \cdots+\frac{\|\alpha \dot{f}(t)\|^{2}\langle g(t), \dot{f}(t)\rangle+\|f(t)\|^{2}\langle g(t), \alpha \dot{f}(t)\rangle}{\|\dot{f}(t)\|^{2}\|\alpha \dot{f}(t)\|^{2}-\|f(t)\|^{4}} \dot{f}(t)+\cdots \\
& \left.\cdots+\frac{\|\dot{f}(t)\|^{2}\langle g(t), \alpha \dot{f}(t)\rangle+\|f(t)\|^{2}\langle g(t), \dot{f}(t)\rangle}{\|\dot{f}(t)\|^{2}\|\alpha \dot{f}(t)\|^{2}-\|f(t)\|^{4}} \alpha \dot{f}(t)\right] \\
& g_{f}(t)=\lim _{\alpha \rightarrow-\frac{\|f(t)\|^{2}}{\|f(t)\|^{2}}}\left[\frac{\langle g(t), f(t)\rangle}{\|f(t)\|^{2}} f(t)+\cdots\right. \\
& \cdots+\frac{\alpha^{2}\|\dot{f}(t)\|^{2}\langle g(t), \dot{f}(t)\rangle+\alpha\|f(t)\|^{2}\langle g(t), \dot{f}(t)\rangle}{\alpha^{2}\|\dot{f}(t)\|^{2}\|\dot{f}(t)\|^{2}-\|f(t)\|^{4}} \dot{f}(t)+\cdots \\
& \left.\cdots+\frac{\alpha^{2}\|\dot{f}(t)\|^{2}\langle g(t), \dot{f}(t)\rangle+\alpha\|f(t)\|^{2}\langle g(t), \dot{f}(t)\rangle}{\alpha^{2}\|\dot{f}(t)\|^{2}\|\dot{f}(t)\|^{2}-\|f(t)\|^{4}} \dot{f}(t)\right] \\
& g_{f}(t)=\frac{\langle g(t), f(t)\rangle}{\|f(t)\|^{2}} f(t)+\cdots \\
& \cdots+\lim _{\alpha \rightarrow-\frac{\|f(t)\|^{2}}{\|\dot{f}(t)\|^{2}}}\left(2 \frac{\alpha^{2}\|\dot{f}(t)\|^{2}\langle g(t), \dot{f}(t)\rangle+\alpha\|f(t)\|^{2}\langle g(t), \dot{f}(t)\rangle}{\alpha^{2}\|\dot{f}(t)\|^{4}-\|f(t)\|^{4}}\right) \dot{f}(t) \\
& g_{f}(t)=\frac{\langle g(t), f(t)\rangle}{\|f(t)\|^{2}} f(t)+\cdots \\
& \cdots+2 \frac{\lim _{\alpha \rightarrow-\frac{\|f(t) \mid\|^{2}}{\|\dot{f}(t)\|^{2}}} \frac{\partial}{\partial \alpha}\left(\alpha^{2}\|\dot{f}(t)\|^{2}\langle g(t), \dot{f}(t)\rangle+\alpha\|f(t)\|^{2}\langle g(t), \dot{f}(t)\rangle\right)}{\lim _{\alpha \rightarrow-\frac{\|f(t)\|^{2}}{\|\dot{f}(t)\|^{2}}} \frac{\partial}{\partial \alpha}\left(\alpha^{2}\|\dot{f}(t)\|^{4}-\|f(t)\|^{4}\right)} \dot{f}(t)
\end{aligned}
$$




$$
\begin{aligned}
g_{f}(t) & =\frac{\langle g(t), f(t)\rangle}{\|f(t)\|^{2}} f(t)+\cdots \\
& -2 \frac{\|f(t)\|^{2}}{\|\dot{f}(t)\|^{2}}\|\dot{f}(t)\|^{2}\langle g(t), \dot{f}(t)\rangle+\|f(t)\|^{2}\langle g(t), \dot{f}(t)\rangle \\
\cdots+2- & -2 \frac{\|f(t)\|^{2}}{\|\dot{f}(t)\|^{2}}\|\dot{f}(t)\|^{4}
\end{aligned}
$$

Em (3.36), tem-se a particularização da projeção de $g(t)$ no espaço $\wp_{f}$ quando $f(t)$ é uma função puramente senoidal. Em decorrência da igualdade considerada em (3.35) é possível ainda escrever $g_{f}(t)$ em termos de $\tilde{f}(t)$, ou seja:

$$
g_{f}(t)=\frac{\langle g(t), f(t)\rangle}{\|f(t)\|^{2}} f(t)-\frac{\langle g(t), \tilde{f}(t)\rangle}{\|\tilde{f}(t)\|^{2}} \tilde{f}(t)
$$

Para esse caso em particular é possível representar graficamente o relacionamento espacial entre as funções $f(t)$ e $g(t)$, assim como se apresenta por meio da Figura 3.4.

Particularizando-se mais ainda o desenvolvimento delineado, tem-se a possibilidade de que ambas as funções sejam puramente senoidais o que resultará, por sua vez, no fato de que $\wp_{f} \equiv \wp_{g}$ e de que $g_{f}(t)=g(t) ; g_{\bar{f}}(t)=0$, sendo a representação esquemática feita por meio da Figura 3.5.

Assim, uma vez que as funções $f(t)$ e $g(t)$ podem ser decompostas em suas respectivas componentes ortogonais, torna-se possível estudar como funções representativas de tensões e correntes se relacionam espacialmente. No entanto, o desenvolvimento conduzido fora feito supondo duas funções $f(t)$ e $g(t)$ genéricas de forma que se torna interessante delinear o significado dessa composição quando de seu emprego para a análise de sistemas de energia elétrica, mais especificamente para sistemas monofásicos. 


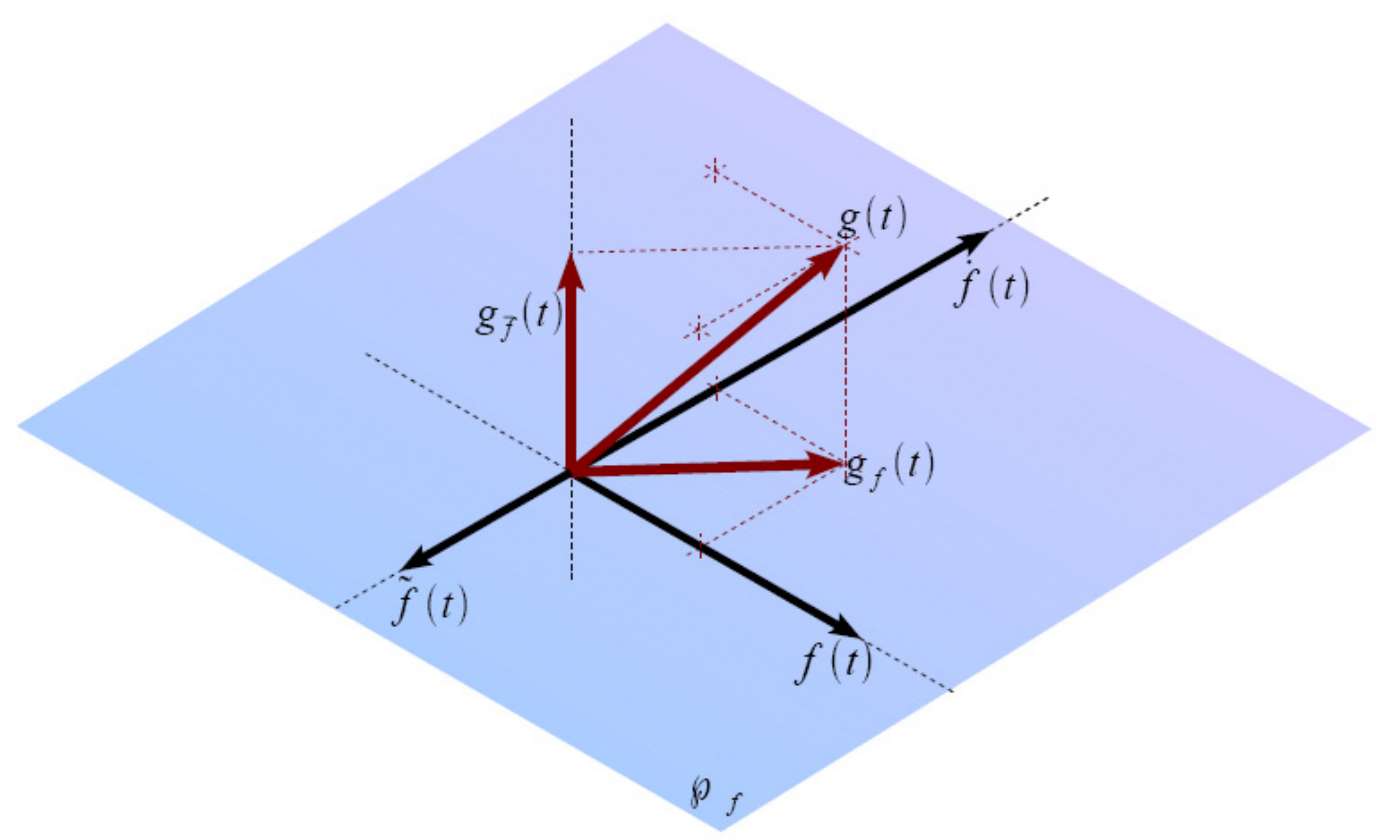

Figura 3.4 - Representação esquemática da projeção da função $g(t)$ sobre o espaço $\wp_{f}$ para o caso particular em que $f(t)$ é puramente senoidal.

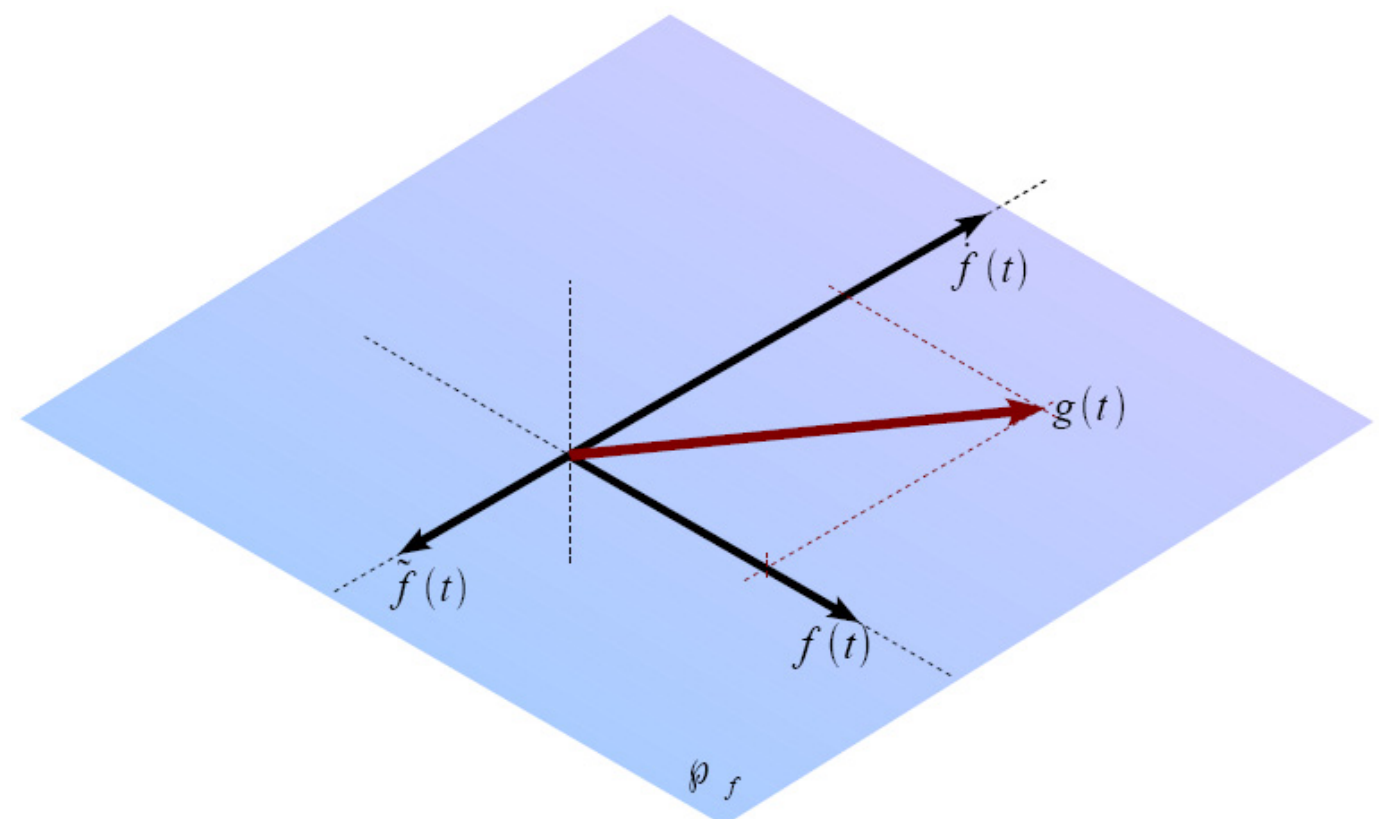

Figura 3.5 - Representação esquemática da projeção da função $g(t)$ sobre o espaço $\wp_{f}$ para o caso particular em que $f(t)$ e $g(t)$ são puramente senoidais.

O delineamento da interpretação da decomposição em componentes ortogonais proposta nessa seção é baseado no circuito elétrico esquematicamente representado por meio da Figura 3.6. Nesse circuito elétrico, a fonte de tensão fornece à carga uma tensão $v(t)$ a qual possui uma periodicidade $T$. A carga, por sua vez, quando alimentada pela referida tensão faz por si circular uma corrente $i(t)$. Considerando-se que a carga seja não-linear, então a fonte de alimentação fornece à carga uma potência aparente $S$ tal que: 


$$
S=\sqrt{P^{2}+Q^{2}+H^{2}}
$$

onde $P$ denota a potência ativa, $Q$ representa a potência reativa e a parcela $H$ denota a potência de distorção. Por meio do cálculo da norma quadrática das formas de onda de tensão e de corrente, referenciados por valores eficazes, a potência aparente $S$ pode ser inteiramente calculada no domínio do tempo a partir dos valores eficazes de tensão $(V)$ e de corrente $(I)$ conforme se delineia na seqüência e se destaca em (3.39). De maneira similar, a potência ativa $P$ também pode ser definida inteiramente no domínio do tempo conforme pontuado em (3.40) por meio do conceito de potência instantânea $p(t)$.

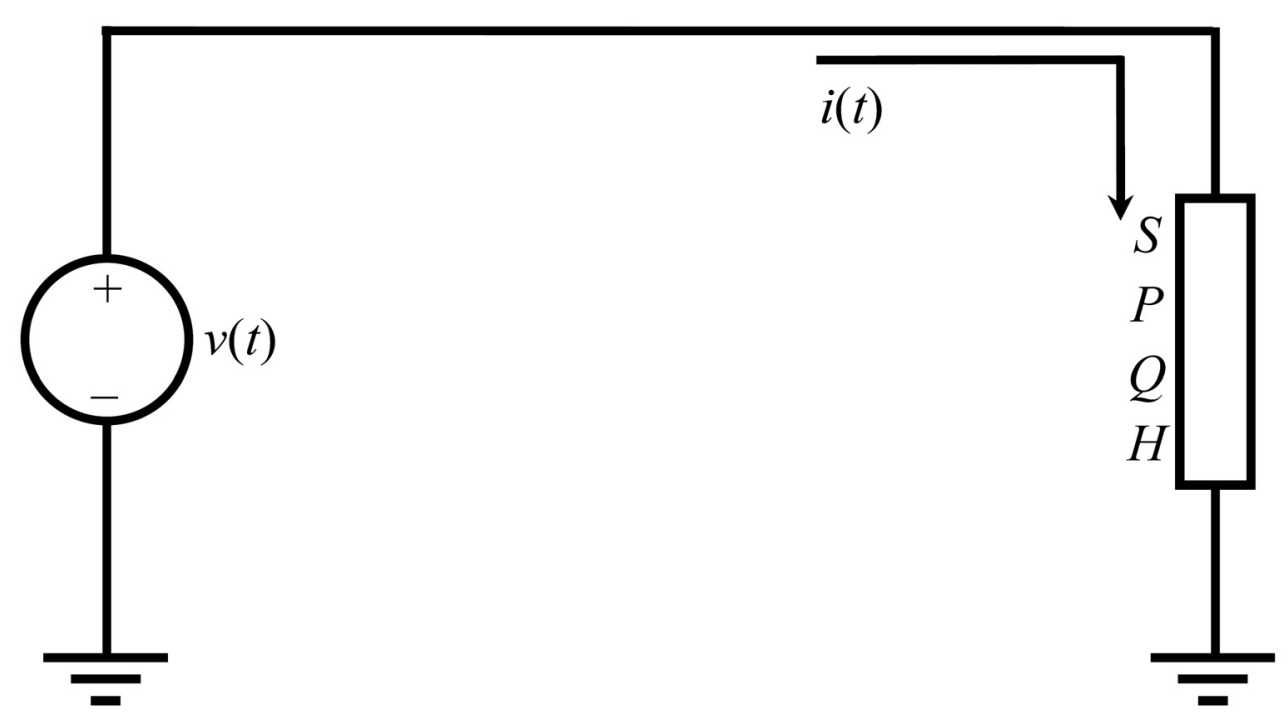

Figura 3.6 - Circuito elétrico empregado no desenvolvimento da interpretação da decomposição em componentes ortogonais em sistemas monofásicos.

$$
\begin{aligned}
& S=V I \\
& S=\sqrt{\frac{1}{T} \int_{t-T}^{t} v^{2}(\tau) d \tau} \sqrt{\frac{1}{T} \int_{t-T}^{t} i^{2}(\tau) d \tau} \\
& S=\frac{1}{T} \sqrt{\int_{t-T}^{t} v^{2}(\tau) d \tau \int_{t-T}^{t} i^{2}(\tau) d \tau} \\
& P=\frac{1}{T} \int_{t-T}^{t} p(\tau) d \tau \\
& P=\frac{1}{T} \int_{t-T}^{t} v(\tau) i(\tau) d \tau
\end{aligned}
$$

Assim, a interpretação para a decomposição em componentes ortogonais em sistemas de energia elétrica pressupõe que em paralelo à carga seja inserida uma capacitância ideal $C$ em conjunto com uma indutância $L$ também ideal, conforme ilustrado por meio da 
Figura 3.7. Dessa maneira, a corrente que a fonte de alimentação passa a fornecer ao conjunto carga-capacitância-indutância será $i_{F}(t)=i(t)+i_{C}(t)+i_{L}(t)$, onde $i_{C}(t)$ é a corrente que circula pelo capacitor e a corrente $i_{L}(t)$ é aquela que se faz circular pelo indutor, sendo que ambas podem ser expressas em função da tensão de alimentação $v(t)$ da seguinte maneira:

$$
\begin{aligned}
& i_{C}(t)=C \dot{v}(t) ; \operatorname{com} \dot{v}(t)=\frac{d v(t)}{d t} \\
& i_{L}(t)=\frac{1}{L} \tilde{v}(t) ; \operatorname{com} \tilde{v}(t)=\int_{-\infty}^{t} v(\tau) d \tau
\end{aligned}
$$

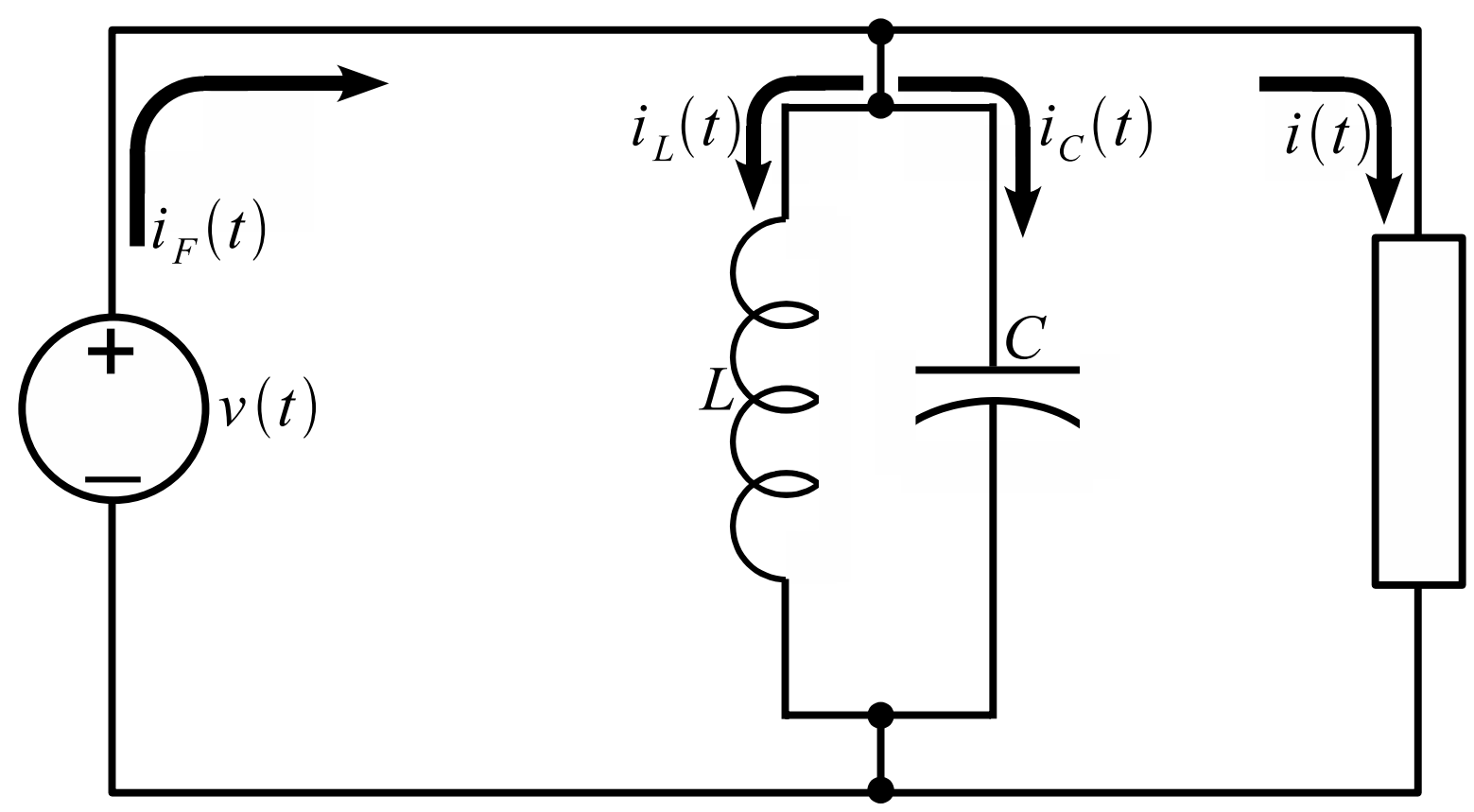

Figura 3.7 - Circuito elétrico com a capacitância e indutância em paralelo à carga.

A inclusão do conjunto capacitor-indutor no sistema elétrico faz com que a corrente provida pela fonte de alimentação se modifique tal como se apresenta em (3.43), e independente da característica da carga, é possível determinar mutuamente o valor da capacitância e da indutância que fazem ser mínima a potência aparente total. Além disso, vale ressaltar que em função das características lineares do conjunto capacitor-indutor, a potência de distorção permanece inalterada uma vez que a fonte de alimentação fora considerada como sendo possuidora de uma admitância infinita. Nesse ponto de potência aparente mínima, a potência reativa da carga estará em circulação pelo conjunto capacitor-indutor e a fonte de alimentação não mais será responsável pelo seu provimento.

$$
\left\|i_{F}(t)\right\|^{2}=\left\|i(t)+C \dot{v}(t)+\frac{1}{L} \tilde{v}(t)\right\|^{2}
$$


Assim, diante dessa constatação, o valor da capacitância e da indutância que minimizam a potência aparente total será aquela capaz de tornar nula a derivada primeira da potência aparente total em função da referida capacitância, ou de forma equivalente, façam nula a derivada primeira da corrente eficaz que proveniente da fonte de alimentação. Procedendo com o cálculo da capacitância e da indutância que minimizam a potência reativa total, torna-se necessário a apresentação da derivada parcial da corrente eficaz da fonte em relação à capacitância e à indutância, assim como será delineado na seqüência.

$$
\begin{aligned}
& \frac{\partial\left\|i_{F}(t)\right\|^{2}}{\partial C}=\frac{\partial}{\partial C}\left(\|i(t)\|^{2}+C^{2}\|\dot{v}(t)\|^{2}+\frac{1}{L^{2}}\|\tilde{v}(t)\|^{2}+\cdots\right. \\
& \left.\cdots+2 C\langle\dot{v}(t), \imath(t)\rangle+\frac{2}{L}\langle\tilde{v}(t), \imath(t)\rangle+2 \frac{C}{L}\langle\dot{v}(t), \tilde{v}(t)\rangle\right) \\
& \frac{\partial\left\|i_{F}(t)\right\|^{2}}{\partial C}=2 C\|\dot{v}(t)\|^{2}+2\langle\dot{v}(t), t(t)\rangle+\frac{2}{L}\langle\dot{v}(t), \tilde{v}(t)\rangle \\
& \frac{\partial\left\|i_{F}(t)\right\|^{2}}{\partial L}=\frac{\partial}{\partial L}\left(\|i(t)\|^{2}+C^{2}\|\dot{v}(t)\|^{2}+\frac{1}{L^{2}}\|\tilde{v}(t)\|^{2}+\cdots\right. \\
& \left.\cdots+2 C\langle\dot{v}(t), i(t)\rangle+\frac{2}{L}\langle\tilde{v}(t), i(t)\rangle+2 \frac{C}{L}\langle\dot{v}(t), \tilde{v}(t)\rangle\right) \\
& \frac{\partial\left\|i_{F}(t)\right\|^{2}}{\partial L}=-\frac{2}{L^{3}}\|\tilde{v}(t)\|^{2}-\frac{2}{L^{2}}\langle\tilde{v}(t), i(t)\rangle-2 \frac{C}{L^{2}}\langle\dot{v}(t), \tilde{v}(t)\rangle
\end{aligned}
$$

Dessa maneira, por meio das equações (3.44) e (3.45) é possível determinar o valor da capacitância $C$ e da indutância $L$ capazes de tornar mínima a corrente eficaz total do sistema elétrico em questão. Para tanto, deve-se determinar os valores de $C$ e $L$ que anulam as derivadas parciais expressas em (3.44) e (3.45). Assim, procedendo com a determinação almejada e focando, inicialmente em (3.44), tem-se:

$$
\begin{aligned}
& 2 \hat{C}\|\dot{v}(t)\|^{2}+2\langle\dot{v}(t), i(t)\rangle+\frac{2}{\hat{L}}\langle\dot{v}(t), \tilde{v}(t)\rangle=0 \\
& \hat{C}=-\frac{\langle\dot{v}(t), i(t)\rangle}{\|\dot{v}(t)\|^{2}}-\frac{1}{\hat{L}} \frac{\langle\dot{v}(t), \tilde{v}(t)\rangle}{\|\dot{v}(t)\|^{2}}
\end{aligned}
$$

Substituindo (3.46) em (3.45) e igualando a expressão resultante à zero, tem-se: 


$$
\begin{aligned}
& -\frac{2}{\hat{L}^{3}}\|\tilde{v}(t)\|^{2}-\frac{2}{\hat{L}^{2}}\langle\tilde{v}(t), i(t)\rangle-2 \frac{\hat{C}}{\hat{L}^{2}} \underbrace{\langle\dot{v}(t), \tilde{v}(t)\rangle}_{-\|v(t)\|^{2}}=0 \\
& -\frac{1}{\hat{L}}\|\tilde{v}(t)\|^{2}-\langle\tilde{v}(t), i(t)\rangle+C\|v(t)\|^{2}=0 \\
& -\frac{1}{\hat{L}}\|\tilde{v}(t)\|^{2}-\langle\tilde{v}(t), i(t)\rangle+\left(\frac{1}{\hat{L}} \frac{\|v(t)\|^{2}}{\|\dot{v}(t)\|^{2}}-\frac{\langle\dot{v}(t), i(t)\rangle}{\|\dot{v}(t)\|^{2}}\right)\|v(t)\|^{2}=0 \\
& \left.\frac{1}{\hat{L}} \frac{\|v(t)\|^{2}}{\|\dot{v}(t)\|^{2}}-\|\tilde{v}(t)\|^{2}\right)=\langle\tilde{v}(t), i(t)\rangle+\frac{\|v(t)\|^{2}}{\|\dot{v}(t)\|^{2}}\langle\dot{v}(t), i(t)\rangle \\
& \frac{1}{\hat{L}}=\frac{\|\dot{v}(t)\|^{2}\langle\tilde{v}(t), l(t)\rangle+\|v(t)\|^{2}\langle\dot{v}(t), l(t)\rangle}{\|v(t)\|^{4}-\|\dot{v}(t)\|\left\|^{2}\right\| \tilde{v}(t) \|^{2}}
\end{aligned}
$$

Em (3.47) tem-se o cálculo que permite determinar a indutância que posta em paralelo à carga reduz ao mínimo a potência aparente do conjunto carga-capacitânciaindutância. Valendo-se desse resultado e substituindo-o em (3.46) é possível encontrar o valor da capacitância desejada, ou seja:

$$
\begin{aligned}
& \hat{C}=-\frac{\langle\dot{v}(t), i(t)\rangle}{\|\dot{v}(t)\|^{2}}+\frac{\|\dot{v}(t)\|^{2}\langle\tilde{v}(t), i(t)\rangle+\|v(t)\|^{2}\langle\dot{v}(t), i(t)\rangle}{\|v(t)\|^{4}-\|\dot{v}(t)\|^{2}\|\tilde{v}(t)\|^{2}} \frac{\|v(t)\|^{2}}{\|\dot{v}(t)\|^{2}} \\
& \hat{C}=\frac{\|\tilde{v}(t)\|^{2}\langle\dot{v}(t), l(t)\rangle+\|v(t)\|^{2}\langle\tilde{v}(t), i(t)\rangle}{\|v(t)\|\left\|^{4}-\right\| \dot{v}(t)\left\|^{2}\right\| \tilde{v}(t) \|^{2}}
\end{aligned}
$$

Dessa forma, considerando-se os resultados destacados, é possível definir a projeção da corrente de carga no espaço da tensão da seguinte maneira:

$$
\begin{aligned}
& i_{v}(t)=\frac{\langle i(t), v(t)\rangle}{\|v(t)\|^{2}} v(t)+\frac{\|\tilde{v}(t)\|^{2}\langle i(t), \dot{v}(t)\rangle+\|v(t)\|^{2}\langle i(t), \tilde{v}(t)\rangle}{\|\dot{v}(t)\|^{2}\|\tilde{v}(t)\|^{2}-\|v(t)\|^{4}} \dot{v}(t)+\cdots \\
& \cdots+\frac{\|\dot{v}(t)\|^{2}\langle i(t), \tilde{v}(t)\rangle+\|v(t)\|^{2}\langle i(t), \dot{v}(t)\rangle}{\|\dot{v}(t)\|^{2}\|\tilde{v}(t)\|^{2}-\|v(t)\|^{4}} \tilde{v}(t)
\end{aligned}
$$

onde a parcela $\langle i(t), v(t)\rangle /\|v(t)\|^{2} v(t)$ representa a projeção da corrente $i(t)$ sobre a tensão $v(t)$ e pode ser representada como sendo a razão da potência ativa $P$ pelo quadrado do valor 
eficaz da tensão, ou ainda, como sendo o produto da condutância equivalente da carga pela tensão de alimentação, ou ainda:

$$
i_{v}(t)=G v(t)+\hat{C} \dot{v}(t)+\frac{1}{\hat{L}} \tilde{v}(t)
$$

\subsection{Formulação Matemática Para a decomposição das TENSÕes de UM Sistema de ENERGIA ElÉTrICA TRIFÁSICO}

Sejam $v_{A}(t), v_{B}(t)$ e $v_{C}(t)$ funções temporais contínuas com periodicidade $T$ constante as quais descrevem o comportamento das tensões de fase de um sistema trifásico qualquer. Considerando que essas tensões possuem como referência o ponto comum de conexão da fonte, por meio das funções $v_{A}(t), v_{B}(t)$ e $v_{C}(t)$ se pode definir as tensões de linha desse sistema de energia elétrica tal como se destaca pelas expressões seguintes:

$$
\begin{aligned}
& v_{A B}(t)=v_{A}(t)-v_{B}(t) \\
& v_{B C}(t)=v_{B}(t)-v_{C}(t) \\
& v_{C A}(t)=v_{C}(t)-v_{A}(t)
\end{aligned}
$$

Para que as tensões de fase sejam consideradas coplanares sob o ponto de vista da álgebra linear é necessário que existam reais $a, b$ e $c$, não todos simultaneamente nulos capazes de satisfazerem a igualdade destacada em (3.54).

$$
a v_{A}(\tau)+b v_{B}(\tau)+c v_{C}(\tau)=0 \text { para } t-T \leq \tau \leq t
$$

onde o intervalo temporal $t-T \leq \tau \leq t$ define o domínio de interesse para a análise. Conforme se pode verificar por meio de (3.54) não fica evidente que a mesma é verídica para todas as situações possíveis, ou seja, pode-se considerar que a referida expressão será verdadeira em casos específicos e não para o caso geral foco do desenvolvimento ao longo dessa seção.

Por outro, a pertinência em se verificar a extensão desse resultado para as tensões de fase conduzirá a uma importante constatação para os fins que esse estudo almeja alcançar. Assim, de forma análoga ao apresentado anteriormente, para que as funções $v_{A B}(t), v_{B C}(t) \mathrm{e}$ $v_{C A}(t)$ sejam coplanares é necessário que existam reais $x_{A B}, x_{B C} \mathrm{e} x_{C A}$, não todos simultaneamente nulos, capazes de fazerem verdade incondicional a expressão (3.55). 


$$
x_{A B} v_{A B}(\tau)+x_{B C} v_{B C}(\tau)+x_{C A} v_{C A}(\tau)=0 \text { para } t-T \leq \tau \leq t
$$

A demonstração de que (3.55) é verídica, independente da forma e magnitude das funções descritoras das tensões de fase, é conduzida, considerando-se as definições apresentadas em (3.51), (3.52) e (3.53) e da seguinte relação para os reais $x_{A B}, x_{B C}$ e $x_{C A}$ :

$$
x_{A B}=x_{B C}=x_{C A}=x \text { tal que } x \neq 0
$$

Procedendo com o desenvolvimento de (3.55) o resultado destacado em (3.57) é alcançado.

$$
\begin{aligned}
& x\left(v_{A}(\tau)-v_{B}(\tau)\right)+x\left(v_{B}(\tau)-v_{C}(\tau)\right)+x\left(v_{C}(\tau)-v_{A}(\tau)\right)=0 \\
& v_{A}(\tau)(x-x)+v_{B}(\tau)(x-x)+v_{C}(\tau)(x-x)=0 \\
& 0 v_{A}(\tau)+0 v_{B}(\tau)+0 v_{C}(\tau)=0 \\
& 0=0 \text { para } t-T \leq \tau \leq t
\end{aligned}
$$

Dessa maneira, por meio do resultado alcançado em (3.57), é possível constatar que as funções $v_{A B}(t), v_{B C}(t)$ e $v_{C A}(t)$ serão, sob o ponto de vista da álgebra linear, funções coplanares. Assim, tem-se que as funções $v_{A B}(t), v_{B C}(t)$ e $v_{C A}(t)$ formam duas a duas uma função planar. Como a apresentação geométrica do espaço funcional que contém a função planar definida por meio das funções $v_{A B}(t), v_{B C}(t)$ e $v_{C A}(t)$ não é viável, destaca-se, por meio da Figura 3.8, a representação esquemática da forma pela qual as referidas funções se dispõe nesse espaço.

Uma vez verificada a existência da função planar definida por meio das funções $v_{A B}(t), v_{B C}(t)$ e $v_{C A}(t)$, pode-se comprovar ainda que as funções $v_{A}(t), v_{B}(t)$ e $v_{C}(t)$ podem não estar contidas nesse plano, pois não existe garantia de que as mesmas são linearmente dependentes como destacado por meio de (3.54). Estando essas funções contidas ou não na função planar é possível obter as projeções de $v_{A}(t), v_{B}(t)$ e $v_{C}(t)$ sob essa função, empregando-se os mesmos conceitos delineados no contexto da álgebra linear.

No entanto, para garantir coesão de magnitude das projeções das funções descritoras das tensões de fase sob a função planar é necessário adotar uma das funções constituintes da função planar como um dos elementos base e outra base como sendo uma função ortogonal à primeira. 
No desenvolvimento que prossegue, será considerada a função $v_{A B}(t)$ como uma das bases e a função ortogonal a essa será obtida por meio das projeções ortogonais de $v_{B C}(t)$ sobre a função $v_{A B}(t)$, tal como, esquematicamente, se apresenta por meio da Figura 3.9.

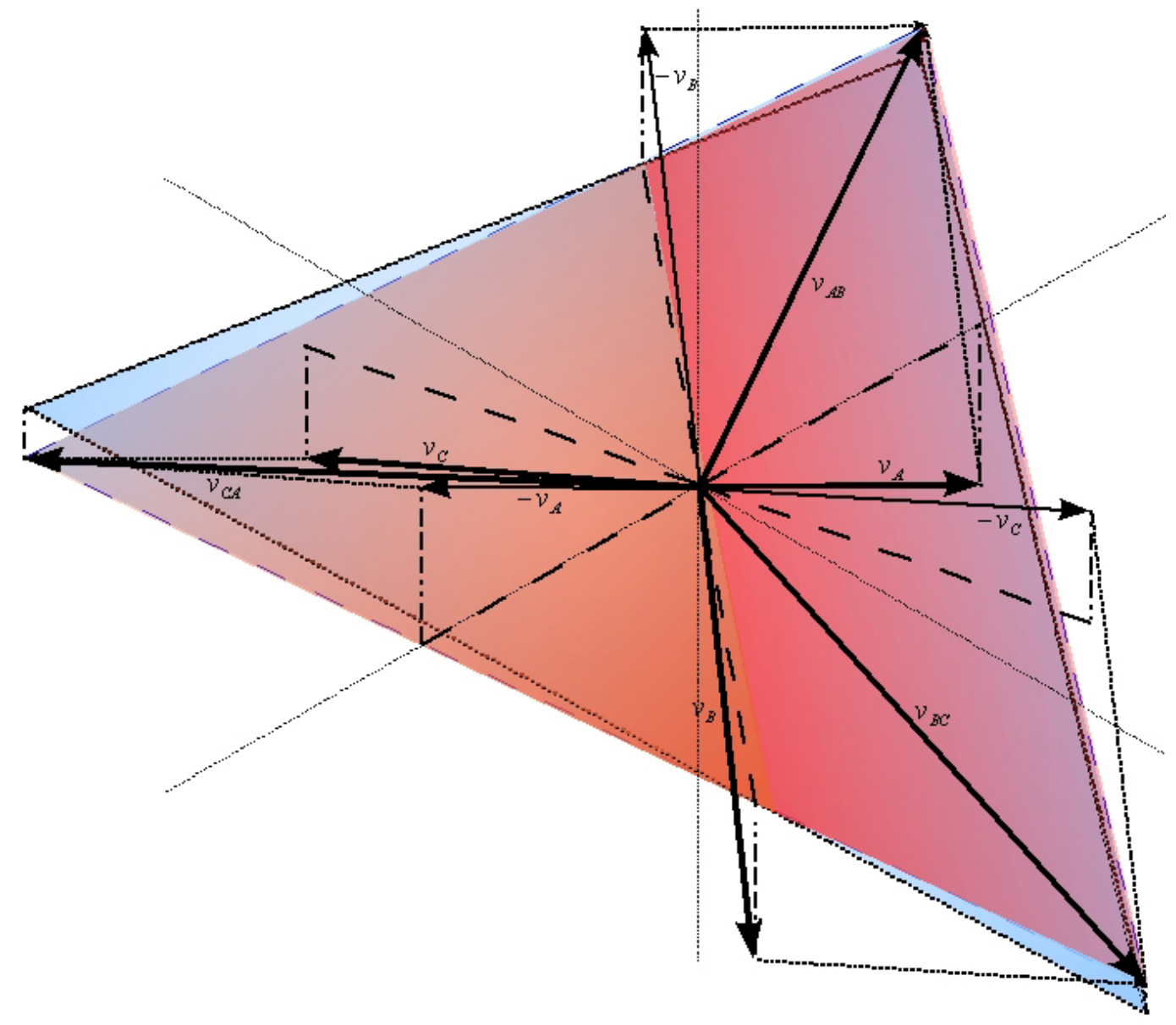

Figura 3.8 - Representação esquemática das funções $v_{A}(t), v_{B}(t)$ e $v_{C}(t)$ e da composição das funções $v_{A B}(t), v_{B C}(t)$ e $v_{C A}(t)$.

Conforme se observa por meio da Figura 3.9, a função ortogonal à $v_{A B}(t)$, denotada por $v_{\perp}(t)$, pode ser obtida por meio da seguinte expressão:

$$
v_{\perp}(t)=v_{B C}(t)-\operatorname{proj}_{v_{A B}(t)}\left(v_{B C}(t)\right)
$$

onde $\operatorname{proj}_{v_{A B}(t)}\left(v_{B C}(t)\right)$ denota a projeção de $v_{B C}(t)$ sobre $v_{A B}(t)$, de forma que a seguinte relação denota essa operação:

$$
\operatorname{proj}_{x(t)}(y(t))=\frac{\langle x(t), y(t)\rangle}{\|x(t)\|^{2}} x(t)
$$




$$
\begin{aligned}
& \langle x(t), y(t)\rangle=\int_{t-T}^{t} x(\tau) y(\tau) d \tau \\
& \|x(t)\|^{2}=\int_{t-T}^{t} x^{2}(\tau) d \tau
\end{aligned}
$$

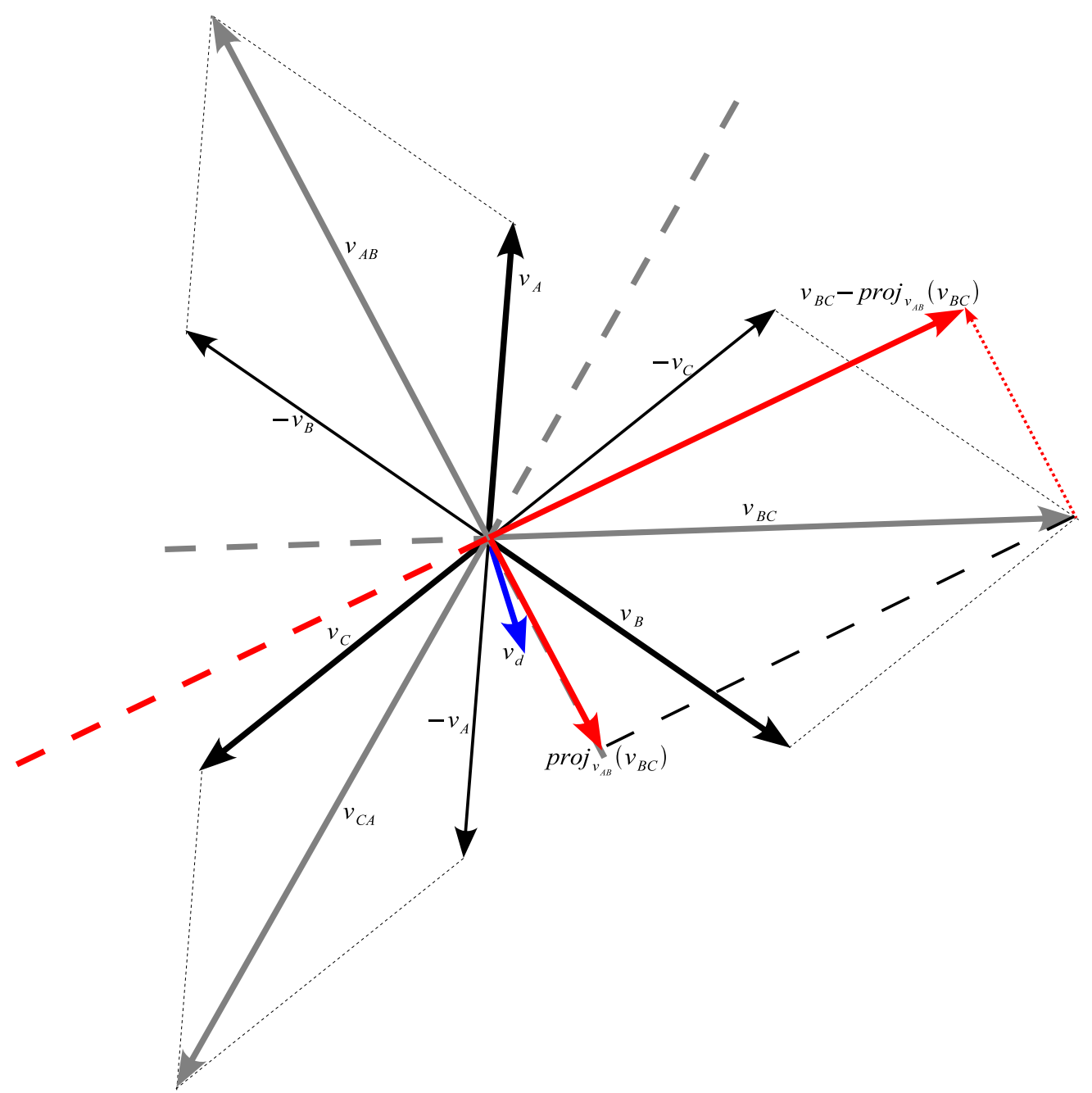

Figura 3.9 - Representação esquemática para obtenção da função ortogonal à $v_{A B}(t)$.

Por meio da definição apresentada em (3.59), a expressão (3.58) pode decorrer na seguinte equivalência:

$$
v_{\perp}(t)=v_{B C}(t)-\frac{\left\langle v_{A B}(t), v_{B C}(t)\right\rangle}{\left\|v_{A B}(t)\right\|^{2}} v_{A B}(t)
$$

Por meio da inspeção da função $v_{\perp}(t)$, destacada em (3.62), é possível verificar que a mesma está contida na função planar definida por meio do arranjo em duplas das funções descritoras das tensões de linha. Essa afirmação é comprovada visto que $v_{\perp}(t)$ é resultante da combinação linear das funções $v_{A B}(t)$ e $v_{B C}(t)$. 
Uma vez definida as bases, denotadas por $v_{\|}(t)=v_{A B}(t)$ e $v_{\perp}(t)$, da função planar responsável por conter as funções $v_{A B}(t), v_{B C}(t)$ e $v_{C A}(t)$, é possível deduzir as expressões das projeções de $v_{A}(t), v_{B}(t)$ e $v_{C}(t)$, denotadas respectivamente por $v_{a}(t)$, $v_{b}(t)$ e $v_{c}(t)$, sobre a referida função planar tal como representado esquematicamente por meio da Figura 3.10.

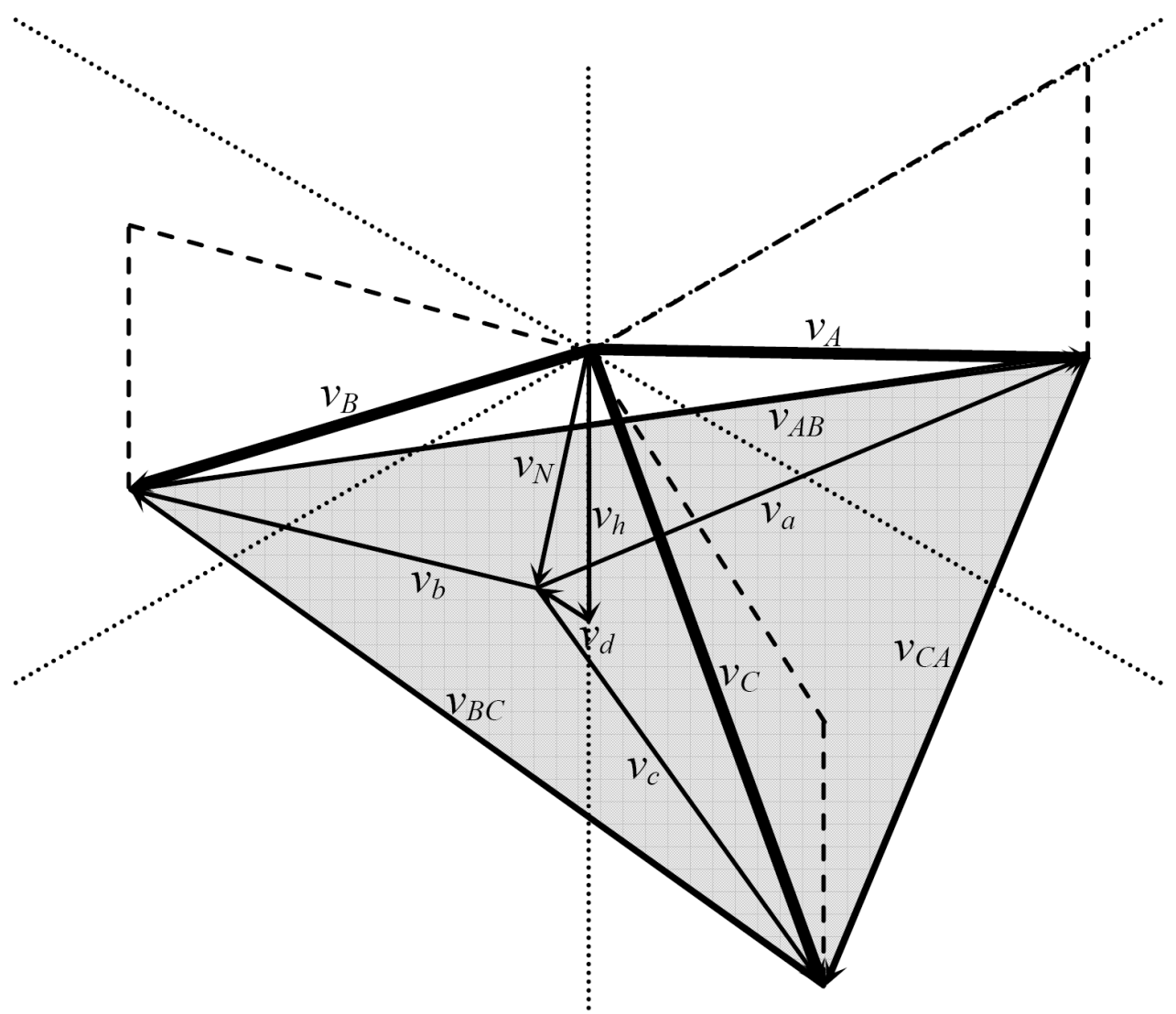

Figura 3.10 - Representação esquemática para as projeções $v_{a}(t), v_{b}(t)$ e $v_{c}(t)$.

Por meio do conceito de projeções, é, portanto possível alcançar a expressão para a projeção de $v_{A}(t)$ sobre a função planar, bem como para as funções $v_{B}(t)$ e $v_{C}(t)$. Dessa maneira, o seguinte conjunto de expressões pode ser utilizado para tais fins.

$$
\begin{aligned}
& v_{a}(t)=\operatorname{proj}_{v_{\|}(t)}\left(v_{A}(t)\right)+\operatorname{proj}_{v_{\perp}(t)}\left(v_{A}(t)\right) \\
& v_{a}(t)=\frac{\left\langle v_{\|}(t), v_{A}(t)\right\rangle}{\left\|v_{\|}(t)\right\|^{2}} v_{\|}(t)+\frac{\left\langle v_{\perp}(t), v_{A}(t)\right\rangle}{\left\|v_{\perp}(t)\right\|^{2}} v_{\perp}(t) \\
& v_{b}(t)=\operatorname{proj}_{v_{\|}(t)}\left(v_{B}(t)\right)+\operatorname{proj}_{v_{\perp}(t)}\left(v_{B}(t)\right)
\end{aligned}
$$




$$
\begin{aligned}
& v_{b}(t)=\frac{\left\langle v_{\|}(t), v_{B}(t)\right\rangle}{\left\|v_{\|}(t)\right\|^{2}} v_{\|}(t)+\frac{\left\langle v_{\perp}(t), v_{B}(t)\right\rangle}{\left\|v_{\perp}(t)\right\|^{2}} v_{\perp}(t) \\
& v_{c}(t)=\operatorname{proj}_{v_{\|}(t)}\left(v_{C}(t)\right)+\operatorname{proj}_{v_{\perp}(t)}\left(v_{C}(t)\right) \\
& v_{c}(t)=\frac{\left\langle v_{\|}(t), v_{C}(t)\right\rangle}{\left\|v_{\|}(t)\right\|^{2}} v_{\|}(t)+\frac{\left\langle v_{\perp}(t), v_{C}(t)\right\rangle}{\left\|v_{\perp}(t)\right\|^{2}} v_{\perp}(t)
\end{aligned}
$$

Para comprovar a coerência das expressões apresentadas se torna útil verificar se as seguintes equivalências são verdadeiras:

$$
v_{A B}(t) \equiv v_{a b}(t) ; v_{B C}(t) \equiv v_{b c}(t) ; v_{C A}(t) \equiv v_{c a}(t)
$$

A fim de demonstrar a validade das equivalências destacadas em (3.66), as expressões (3.63), (3.64) e (3.65) serão empregadas inicialmente para verificação de que $v_{A B}(t)=v_{a b}(t)$ o que será feito por meio do seguinte desenvolvimento:

$$
\begin{aligned}
& v_{a b}(t)=v_{a}(t)-v_{b}(t) \\
& v_{a b}(t)=\frac{\left\langle v_{\|}(t), v_{A}(t)\right\rangle}{\left\|v_{\|}(t)\right\|^{2}} v_{\|}(t)+\frac{\left\langle v_{\perp}(t), v_{A}(t)\right\rangle}{\left\|v_{\perp}(t)\right\|^{2}} v_{\perp}(t)+\cdots \\
& \cdots-\frac{\left\langle v_{\|}(t), v_{B}(t)\right\rangle}{\left\|v_{\|}(t)\right\|^{2}} v_{\|}(t)-\frac{\left\langle v_{\perp}(t), v_{B}(t)\right\rangle}{\left\|v_{\perp}(t)\right\|^{2}} v_{\perp}(t) \\
& v_{a b}(t)=\left(\frac{\left\langle v_{\|}(t), v_{A}(t)\right\rangle}{\left\|v_{\|}(t)\right\|^{2}}-\frac{\left\langle v_{\|}(t), v_{B}(t)\right\rangle}{\left\|v_{\|}(t)\right\|^{2}}\right) v_{\|}(t)+\cdots \\
& \cdots+\left(\frac{\left\langle v_{\perp}(t), v_{A}(t)\right\rangle}{\left\|v_{\perp}(t)\right\|^{2}}-\frac{\left\langle v_{\perp}(t), v_{B}(t)\right\rangle}{\left\|v_{\perp}(t)\right\|^{2}}\right) v_{\perp}(t) \\
& v_{a b}(t)=\frac{\left\langle v_{\|}(t), v_{A}(t)-v_{B}(t)\right\rangle}{\left\|v_{\|}(t)\right\|^{2}} v_{\|}(t)+\frac{\left\langle v_{\perp}(t), v_{A}(t)-v_{B}(t)\right\rangle}{\left\|v_{\perp}(t)\right\|^{2}} v_{\perp}(t) \\
& v_{a b}(t)=\frac{\left\langle v_{\|}(t), v_{A B}(t)\right\rangle}{\left\|v_{\|}(t)\right\|^{2}} v_{\|}(t)+\frac{\left\langle v_{\perp}(t), v_{A B}(t)\right\rangle}{\left\|v_{\perp}(t)\right\|^{2}} v_{\perp}(t)
\end{aligned}
$$


Como $v_{\|}(t)=v_{A B}(t)$ então $\left\langle v_{\|}(t), v_{A B}(t)\right\rangle=\left\|v_{\|}(t)\right\|^{2}$; ao passo que $v_{\perp}(t)$ e $v_{A B}(t)$ são ortogonais entre si pela própria definição de $v_{\perp}(t)$. Dessa forma, $\left\langle v_{\perp}(t), v_{A B}(t)\right\rangle=0$, assim, a expressão (3.67) resultará em:

$$
\begin{aligned}
& v_{a b}(t)=\frac{\left\|v_{\|}(t)\right\|^{2}}{\left\|v_{\|}(t)\right\|^{2}} v_{\|}(t)+\frac{0}{\left\|v_{\perp}(t)\right\|^{2}} v_{\perp}(t) \\
& v_{a b}(t)=v_{A B}(t)
\end{aligned}
$$

A Expressão (3.68) denota a equivalência entre $v_{A B}(t)$ e $v_{a b}(t)$ assim como se deseja verificar. No entanto, a validade das projeções sobre a função planar somente é plenamente afirmativa se as equivalências entre $v_{B C}(t)$ e $v_{b c}(t)$ e entre $v_{C A}(t)$ e $v_{c a}(t)$ forem comprovadas tal como feito para $v_{A B}(t)$ e $v_{a b}(t)$. Nesse sentido, na seqüência será analisado o relacionamento entre $v_{B C}(t)$ e $v_{b c}(t)$, ou seja:

$$
\begin{aligned}
& v_{b c}(t)=v_{b}(t)-v_{c}(t) \\
& v_{b c}(t)=\frac{\left\langle v_{\|}(t), v_{B}(t)\right\rangle}{\left\|v_{\|}(t)\right\|^{2}} v_{\|}(t)+\frac{\left\langle v_{\perp}(t), v_{B}(t)\right\rangle}{\left\|v_{\perp}(t)\right\|^{2}} v_{\perp}(t)+\cdots \\
& \cdots-\frac{\left\langle v_{\|}(t), v_{C}(t)\right\rangle}{\left\|v_{\|}(t)\right\|^{2}} v_{\|}(t)-\frac{\left\langle v_{\perp}(t), v_{C}(t)\right\rangle}{\left\|v_{\perp}(t)\right\|^{2}} v_{\perp}(t) \\
& v_{b c}(t)=\left(\frac{\left\langle v_{\|}(t), v_{B}(t)\right\rangle}{\left\|v_{\|}(t)\right\|^{2}}-\frac{\left\langle v_{\|}(t), v_{C}(t)\right\rangle}{\left\|v_{\|}(t)\right\|^{2}}\right) v_{\|}(t)+\cdots \\
& \cdots+\left(\frac{\left\langle v_{\perp}(t), v_{B}(t)\right\rangle}{\left\|v_{\perp}(t)\right\|^{2}}-\frac{\left.\left.(t), v_{C}(t)\right\rangle\right)}{\left\|v_{\perp}(t)\right\|^{2}}(t)\right. \\
& v_{b c}(t)=\frac{\left\langle v_{\|}(t), v_{B}(t)-v_{C}(t)\right\rangle}{\left\|v_{\|}(t)\right\|^{2}} v_{\|}(t)+\frac{\left\langle v_{\perp}(t), v_{B}(t)-v_{C}(t)\right\rangle}{\left\|v_{\perp}(t)\right\|^{2}} v_{\perp}(t) \\
& v_{b c}(t)=\frac{\left\langle v_{\|}(t), v_{B C}(t)\right\rangle}{\left\|v_{\|}(t)\right\|^{2}} v_{\|}(t)+\frac{\left\langle v_{\perp}(t), v_{B C}(t)\right\rangle}{\left\|v_{\perp}(t)\right\|^{2}} v_{\perp}(t)
\end{aligned}
$$


Da expressão (3.62) e da definição de que $v_{\|}(t)=v_{A B}(t)$ a expressão (3.69) resultará em:

$$
\begin{aligned}
& v_{b c}(t)=\frac{\left\langle v_{A B}(t), v_{B C}(t)\right\rangle}{\left\|v_{A B}(t)\right\|^{2}} v_{A B}(t)+v_{B C}(t)-\frac{\left\langle v_{A B}(t), v_{B C}(t)\right\rangle}{\left\|v_{A B}(t)\right\|^{2}} v_{A B}(t) \\
& v_{b c}(t)=v_{B C}(t)
\end{aligned}
$$

Prosseguindo com a demonstração da equivalência das projeções propostas nesse trabalho, é necessário, por fim, verificar a equivalência entre $v_{C A}(t)$ e $v_{c a}(t)$, ou seja:

$$
\begin{aligned}
& v_{c a}(t)=v_{c}(t)-v_{a}(t) \\
& v_{c a}(t)=\frac{\left\langle v_{\|}(t), v_{C}(t)\right\rangle}{\left\|v_{\|}(t)\right\|^{2}} v_{\|}(t)+\frac{\left\langle v_{\perp}(t), v_{C}(t)\right\rangle}{\left\|v_{\perp}(t)\right\|^{2}} v_{\perp}(t)+\cdots \\
& \cdots-\frac{\left\langle v_{\|}(t), v_{A}(t)\right\rangle}{\left\|v_{\|}(t)\right\|^{2}} v_{\|}(t)-\frac{\left\langle v_{\perp}(t), v_{A}(t)\right\rangle}{\left\|v_{\perp}(t)\right\|^{2}} v_{\perp}(t) \\
& v_{c a}(t)=\left(\frac{\left\langle v_{\|}(t), v_{C}(t)\right\rangle}{\left\|v_{\|}(t)\right\|^{2}}-\frac{\left\langle v_{\|}(t), v_{A}(t)\right\rangle}{\left\|v_{\|}(t)\right\|^{2}}\right) v_{\|}(t)+\cdots \\
& \cdots+\left(\frac{\left\langle v_{\perp}(t), v_{C}(t)\right\rangle}{\left\|v_{\perp}(t)\right\|^{2}}-\frac{\left\langle v_{\perp}(t), v_{A}(t)\right\rangle}{\left\|v_{\perp}(t)\right\|^{2}}\right) v_{\perp}(t) \\
& v_{c a}(t)=\frac{\left\langle v_{\|}(t), v_{C}(t)-v_{A}(t)\right\rangle}{\left\|v_{\|}(t)\right\|^{2}} v_{\|}(t)+\frac{\left\langle v_{\perp}(t), v_{C}(t)-v_{A}(t)\right\rangle}{\left\|v_{\perp}(t)\right\|^{2}} v_{\perp}(t) \\
& v_{c a}(t)=\operatorname{proj}_{v_{\|}(t)}\left(v_{C A}(t)\right)+\operatorname{proj}_{v_{\perp}(t)}\left(v_{C A}(t)\right) \\
& v_{c a}(t)=\frac{\left\langle v_{\|}(t), v_{C A}(t)\right\rangle}{\left\|v_{\|}(t)\right\|^{2}} v_{\|}(t)+\frac{\left\langle v_{\perp}(t), v_{C A}(t)\right\rangle}{\left\|v_{\perp}(t)\right\|_{\perp}^{2}(t)}
\end{aligned}
$$

Como $v_{\|}(t)$ e $v_{\perp}(t)$ constituem as bases ortogonais da função planar que contém $v_{C A}(t)$, então $\operatorname{proj}_{v_{\|}(t)}\left(v_{C A}(t)\right)+\operatorname{proj}_{v_{\perp}(t)}\left(v_{C A}(t)\right)=v_{C A}(t)$ e, portanto:

$$
v_{c a}(t)=v_{C A}(t)
$$


Os resultados alcançados por meio dos desenvolvimentos anteriores e destacados em (3.68), (3.70) e (3.72) comprovam a coerência das projeções $v_{a}(t), v_{b}(t)$ e $v_{c}(t)$ sobre a função planar que contém as funções $v_{A B}(t), v_{B C}(t)$ e $v_{C A}(t)$.

Além das tensões de linha pode-se, por meio das tensões de fase, determinar a tensão de neutro, denotada por $v_{N}(t)$, a qual é resultado da soma das tensões de fase, assim como se destaca na seguinte expressão:

$$
v_{N}(t)=v_{A}(t)+v_{B}(t)+v_{C}(t)
$$

Dessa forma, a função $v_{N}(t)$, descritora da tensão de neutro, passa a ser definida como sendo uma combinação linear das tensões de fase. Como não existe garantia de que as funções $v_{A}(t), \quad v_{B}(t)$ e $v_{C}(t)$ são simultaneamente coplanares, conforme discutido anteriormente, não existe garantia de que $v_{N}(t)$ esteja inteiramente contida na função planar que contém as funções $v_{A B}(t), v_{B C}(t)$ e $v_{C A}(t)$. Dessa forma, torna-se conveniente analisar como se procede a projeção de $v_{N}(t)$, denotada por $v_{d}(t)$, sobre a referida função planar, ou seja:

$$
\begin{aligned}
& v_{d}(t)=\operatorname{proj}_{v_{\|}(t)}\left(v_{N}(t)\right)+\operatorname{proj}_{v_{\perp}(t)}\left(v_{N}(t)\right) \\
& v_{d}(t)=\frac{\left\langle v_{\|}(t), v_{N}(t)\right\rangle}{\left\|v_{\|}(t)\right\|^{2}} v_{\|}(t)+\frac{\left\langle v_{\perp}(t), v_{N}(t)\right\rangle}{\left\|v_{\perp}(t)\right\|^{2}} v_{\perp}(t) \\
& v_{d}(t)=\frac{\left\langle v_{\|}(t), v_{A}(t)+v_{B}(t)+v_{C}(t)\right\rangle}{\left\|v_{\|}(t)\right\|^{2}} v_{\|}(t)+\frac{\left\langle v_{\perp}(t), v_{A}(t)+v_{B}(t)+v_{C}(t)\right\rangle}{\left\|v_{\perp}(t)\right\|^{2}} v_{\perp}(t) \\
& v_{d}(t)=\frac{\left\langle v_{\|}(t), v_{A}(t)\right\rangle+\left\langle v_{\|}(t), v_{B}(t)\right\rangle+\left\langle v_{\|}(t), v_{C}(t)\right\rangle}{\left\|v_{\|}(t)\right\|^{2}} v_{\|}(t)+\cdots \\
& \ldots+\frac{\left.v_{\perp}(t), v_{A}(t)\right\rangle+\left\langle v_{\perp}(t), v_{B}(t)\right\rangle+\left\langle v_{\perp}(t), v_{C}(t)\right\rangle}{\left\|v_{\perp}(t)\right\|^{2}} v_{\perp}(t)
\end{aligned}
$$




$$
\begin{aligned}
& v_{d}(t)=\frac{\left\langle v_{\|}(t), v_{A}(t)\right\rangle}{\left\|v_{\|}(t)\right\|^{2}} v_{\|}(t)+\frac{\left\langle v_{\|}(t), v_{B}(t)\right\rangle}{\left\|v_{\|}(t)\right\|^{2}} v_{\|}(t)+\frac{\left\langle v_{\|}(t), v_{C}(t)\right\rangle}{\left\|v_{\|}(t)\right\|^{2}} v_{\|}(t)+\cdots \\
& \cdots+\frac{\left\langle v_{\perp}(t), v_{A}(t)\right\rangle}{\left\|v_{\perp}(t)\right\|^{2}} v_{\perp}(t)+\frac{\left\langle v_{\perp}(t), v_{B}(t)\right\rangle}{\left\|v_{\perp}(t)\right\|^{2}} v_{\perp}(t)+\frac{\left\langle v_{\perp}(t), v_{C}(t)\right\rangle}{\left\|v_{\perp}(t)\right\|^{2}} v_{\perp}(t) \\
& v_{d}(t)=\operatorname{proj}_{v_{\|}(t)}\left(v_{A}(t)\right)+\operatorname{proj}_{v_{\|}(t)}\left(v_{B}(t)\right)+\operatorname{proj}_{v_{\|}(t)}\left(v_{C}(t)\right)+\cdots \\
& \cdots+\operatorname{proj}_{v_{\perp}(t)}\left(v_{A}(t)\right)+\operatorname{proj}_{v_{\perp}(t)}\left(v_{B}(t)\right)+\operatorname{proj}_{v_{\perp}(t)}\left(v_{C}(t)\right) \\
& v_{d}(t)=\underbrace{\operatorname{pros}_{v_{a}(t)}}_{\operatorname{proj}_{v_{\|}(t)}\left(v_{A}(t)\right)+\operatorname{proj}_{v_{\perp}(t)}\left(v_{A}(t)\right)}+\cdots \\
& \cdots+\underbrace{\operatorname{proj}_{v_{\|}(t)}\left(v_{B}(t)\right)+\operatorname{proj}_{v_{\perp}(t)}\left(v_{B}(t)\right)}_{v_{b}(t)}+\cdots \\
& \cdots+\underbrace{\operatorname{proj}_{v_{\|}(t)}\left(v_{C}(t)\right)+\operatorname{proj}_{v_{\perp}(t)}\left(v_{C}(t)\right)}_{v_{c}(t)} \\
& v_{d}(t)=v_{a}(t)+v_{b}(t)+v_{c}(t)
\end{aligned}
$$

O resultado destacado em (3.74) apresenta a função $v_{d}(t)$, resultante da projeção de $v_{N}(t)$ sobre a função planar, como sendo composta pela combinação linear das funções $v_{a}(t), v_{b}(t)$ e $v_{c}(t)$ as quais, por sua vez, são as projeções das tensões de fase sobre a função planar das tensões de linha.

Ainda com relação à Figura 3.10, a componente $v_{h}(t)$ não fora formulada por meio desse desenvolvimento. Essa componente é resultado da decomposição da função $v_{N}(t)$ de maneira que a seguinte composição é válida:

$$
\begin{aligned}
& v_{N}(t)=v_{d}(t)+v_{h}(t) \\
& v_{h}(t)=v_{N}(t)-v_{d}(t)
\end{aligned}
$$

Por meio da definição empregada para $v_{N}(t)$ e da formulação para $v_{d}(t)$, apresentada em (3.74), a expressão (3.75) poderá ser desenvolvida da seguinte forma:

$$
\begin{aligned}
& v_{h}(t)=v_{A}(t)+v_{B}(t)+v_{C}(t)-v_{a}(t)-v_{b}(t)-v_{c}(t) \\
& v_{h}(t)=v_{A}(t)-v_{a}(t)+v_{B}(t)-v_{b}(t)+v_{C}(t)-v_{c}(t)
\end{aligned}
$$


A Expressão (3.76) mostra de maneira clara como cada uma das tensões contribui para a composição da tensão $v_{h}(t)$, semelhante ao que ocorre para a tensão $v_{d}(t)$, conforme se verifica em (3.74). Outro aspecto a ser mencionado é sobre a ortogonalidade de $v_{h}(t)$ em relação à função planar das tensões de linha. Como $v_{d}(t)$ é uma função contida na função planar formada pelas tensões de linha, a diferença entre a função $v_{N}(t)$ e $v_{d}(t)$ resultará em uma função normal à função planar das tensões de linha, ou seja, a função $v_{h}(t)$ será normal à função planar das tensões de linha.

Uma vez apresentada a conceituação da função planar das tensões de linha e como as tensões de fase se relacionam com essa por meio de suas respectivas projeções ortogonais, o mesmo desenvolvimento pode ser estendido às correntes de fase desse sistema de energia elétrica. Esse desenvolvimento é apresentado por meio da seção seguinte.

\subsection{Formulação Matemática Para a decomposição das CORRENTES DE UM SISTEMA DE ENERGIA ELÉTRICA TRIFÁSICO}

O desenvolvimento dissertado na seção anterior apresentou como a função planar das tensões de linha pode ser empregada para a decomposição das tensões de fase e de neutro por meio da conceituação de projeções ortogonais. Além disso, fora destacado a coerência entre as projeções das tensões de fase e as tensões de linha. Nessa seção, a conceituação abordada será empregada na decomposição das correntes de linha do sistema de energia elétrica trifásico.

Dessa forma, sejam $i_{A}(t), i_{B}(t)$ e $i_{C}(t)$ funções temporais contínuas e periódicas, com periodicidade $T$ constante, as quais descrevem o comportamento das correntes de linha de um sistema de energia elétrica trifásico. A corrente de neutro, tal como a tensão de neutro, pode ser definida da seguinte forma:

$$
i_{N}(t)=i_{A}(t)+i_{B}(t)+i_{C}(t)
$$

A fim de ilustrar o relacionamento entre as componentes de tensão e de corrente, apresenta-se por meio da Figura 3.11 o referido sistema. 
Dessa forma, empregando-se as bases ortogonais $v_{\|}(t)$ e $v_{\perp}(t)$ definidas na seção anterior e apresentadas em (3.78), a projeção da função $i_{A}(t)$, denotada por $i_{a}(t)$, sobre a função planar das tensões de linha pode ser calculada conforme o seguinte desenvolvimento:

$$
\begin{aligned}
& \left\{\begin{array}{l}
v_{\|}(t)=v_{A B}(t) \\
v_{\perp}(t)=v_{B C}(t)-\frac{\left\langle v_{A B}(t), v_{B C}(t)\right\rangle}{\left\|v_{A B}(t)\right\|} v_{A B}(t)
\end{array}\right. \\
& i_{a}(t)=\operatorname{proj}_{v_{\|}(t)}\left(i_{A}(t)\right)+\operatorname{proj}_{v_{\perp}(t)}\left(i_{A}(t)\right) \\
& i_{a}(t)=\frac{\left\langle v_{\|}(t), i_{A}(t)\right\rangle}{\left\|v_{\|}(t)\right\|^{2}} v_{\|}(t)+\frac{\left\langle v_{\perp}(t), i_{A}(t)\right\rangle}{\left\|v_{\perp}(t)\right\|^{2}} v_{\perp}(t)
\end{aligned}
$$

Por analogia à (3.79), as expressões para as projeções de $i_{B}(t)$ e $i_{C}(t)$, denotadas respectivamente por $i_{b}(t)$ e $i_{c}(t)$, sobre a função planar das tensões de linha podem ser apresentadas da seguinte forma:

$$
\begin{aligned}
& i_{b}(t)=\operatorname{proj}_{v_{\|}(t)}\left(i_{B}(t)\right)+\operatorname{proj}_{v_{\perp}(t)}\left(i_{B}(t)\right) \\
& i_{b}(t)=\frac{\left\langle v_{\|}(t), i_{B}(t)\right\rangle}{\left\|v_{\|}(t)\right\|^{2}} v_{\|}(t)+\frac{\left\langle v_{\perp}(t), i_{B}(t)\right\rangle}{\left\|v_{\perp}(t)\right\|^{2}} v_{\perp}(t) \\
& i_{c}(t)=\operatorname{proj}_{v_{\|}(t)}\left(i_{C}(t)\right)+\operatorname{proj}_{v_{\perp}(t)}\left(i_{C}(t)\right) \\
& i_{c}(t)=\frac{\left\langle v_{\|}(t), i_{C}(t)\right\rangle}{\left\|v_{\|}(t)\right\|^{2}} v_{\|}(t)+\frac{\left\langle v_{\perp}(t), i_{C}(t)\right\rangle}{\left\|v_{\perp}(t)\right\|^{2}} v_{\perp}(t)
\end{aligned}
$$

A Figura 3.12 ilustra a representação esquemática da função planar das tensões de linha, bem como das projeções das tensões de fase e das correntes de linha. 


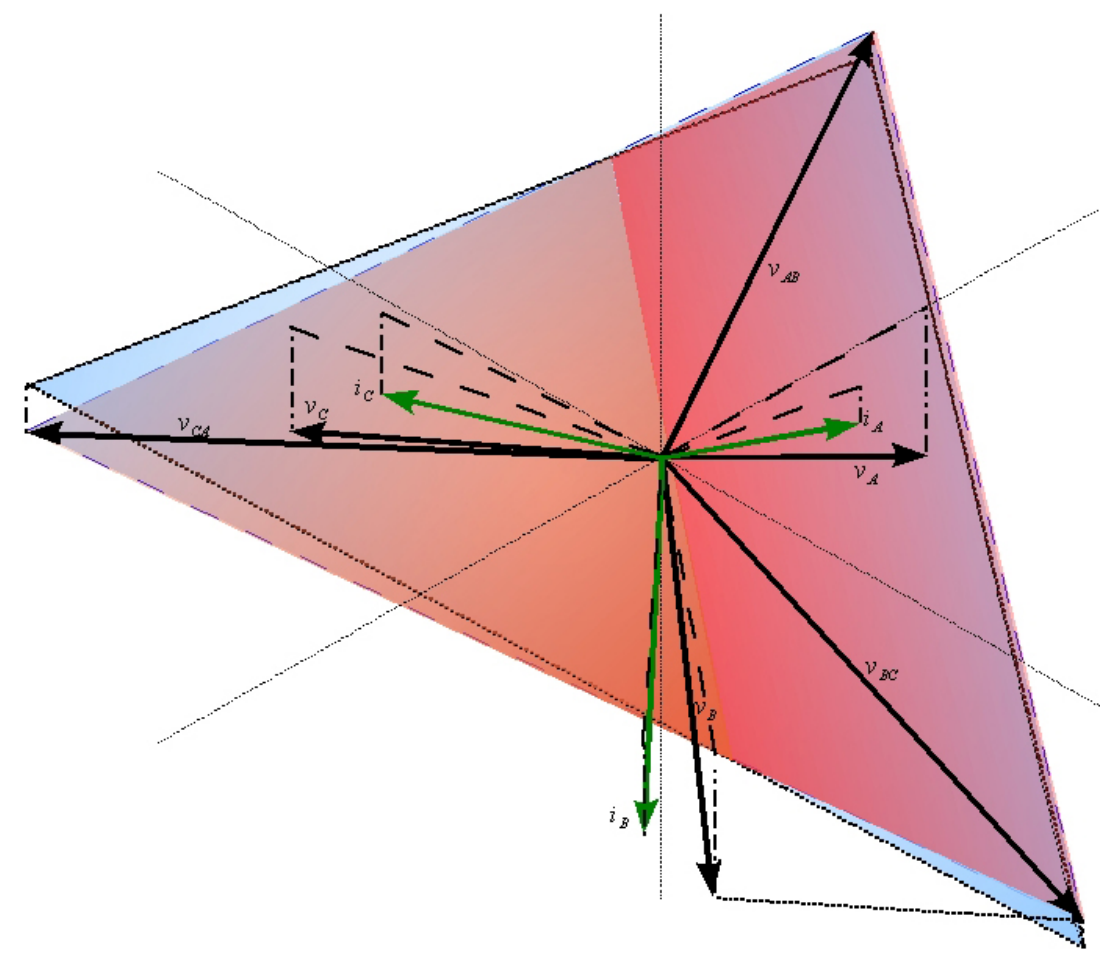

Figura 3.11 - Representação esquemática para as correntes de linha $i_{A}(t), i_{B}(t)$ e $i_{C}(t)$.

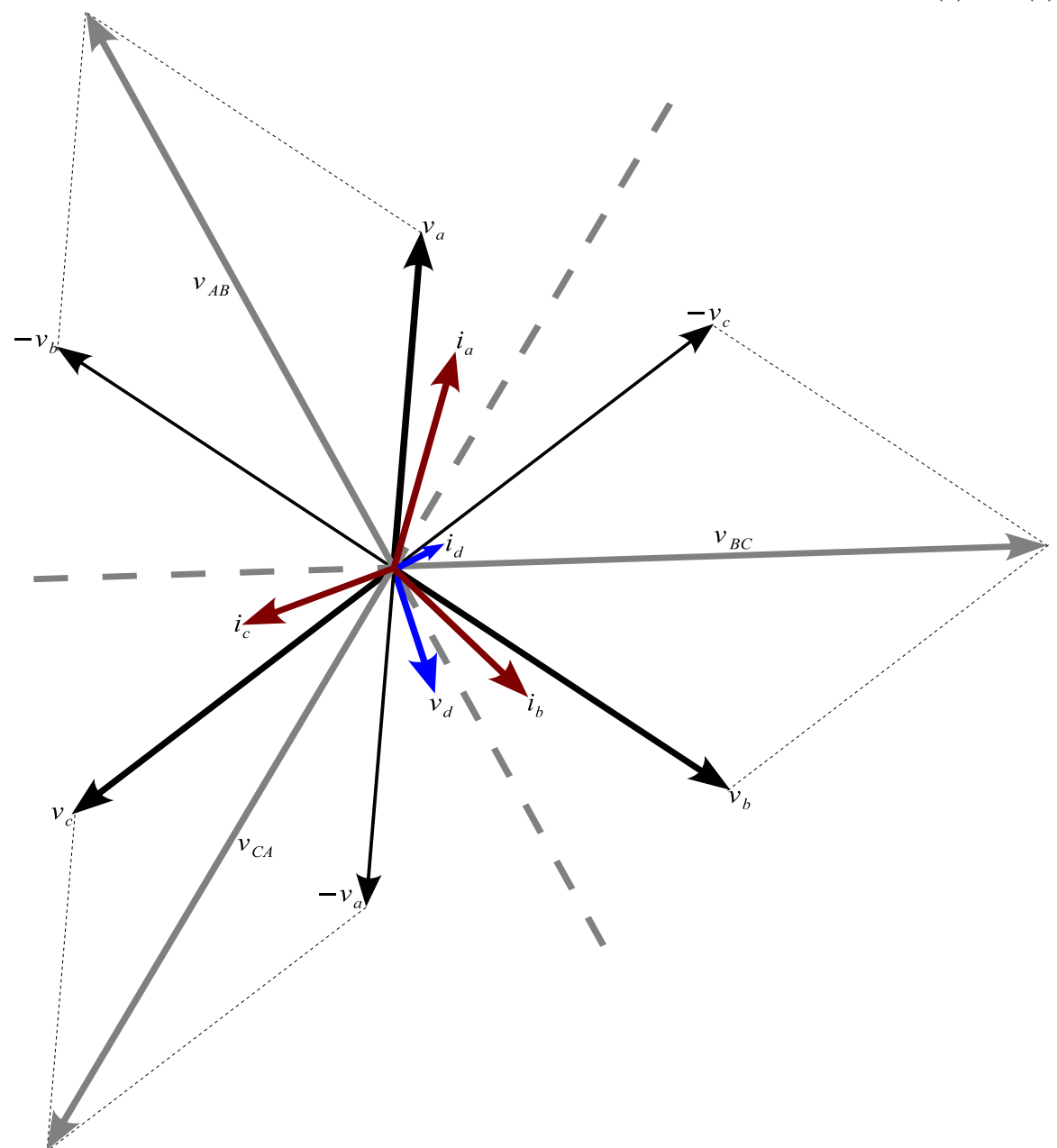

Figura 3.12 - Representação esquemática da função planar das tensões de linha, das projeções das tensões de fase e das projeções das correntes de linha. 
A corrente $i_{d}(t)$ representa a projeção de $i_{N}(t)$ sobre a função planar das tensões de linha. Dessa maneira, empregando-se a equivalência (3.77) o seguinte desenvolvimento é pertinente:

$$
\begin{aligned}
& i_{d}(t)=\operatorname{proj}_{v_{\|}(t)}\left(i_{N}(t)\right)+\operatorname{proj}_{v_{\perp}(t)}\left(i_{N}(t)\right) \\
& i_{d}(t)=\frac{\left\langle v_{\|}(t), i_{N}(t)\right\rangle}{\left\|v_{\|}(t)\right\|^{2}} v_{\|}(t)+\frac{\left\langle v_{\perp}(t), i_{N}(t)\right\rangle}{\left\|v_{\perp}(t)\right\|^{2}} v_{\perp}(t) \\
& i_{d}(t)=\frac{\left\langle v_{\|}(t), i_{A}(t)+i_{B}(t)+i_{C}(t)\right\rangle}{\left\|v_{\|}(t)\right\|^{2}} v_{\|}(t)+\frac{\left\langle v_{\perp}(t), i_{A}(t)+i_{B}(t)+i_{C}(t)\right\rangle}{\left\|v_{\perp}(t)\right\|^{2}} v_{\perp}(t) \\
& i_{d}(t)=\frac{\left\langle v_{\|}(t), i_{A}(t)\right\rangle+\left\langle v_{\|}(t), i_{B}(t)\right\rangle+\left\langle v_{\|}(t), i_{C}(t)\right\rangle}{\left\|v_{\|}(t)\right\|^{2}} v_{\|}(t)+\cdots \\
& \cdots+\frac{\left\langle v_{\perp}(t), i_{A}(t)\right\rangle+\left\langle v_{\perp}(t), i_{B}(t)\right\rangle+\left\langle v_{\perp}(t), i_{C}(t)\right\rangle}{\left\|v_{\perp}(t)\right\|^{2}} v_{\perp}(t) \\
& i_{d}(t)=\frac{\left\langle v_{\|}(t), i_{A}(t)\right\rangle}{\left\|v_{\|}(t)\right\|^{2}} v_{\|}(t)+\frac{\left\langle v_{\|}(t), i_{B}(t)\right\rangle}{\left\|v_{\|}(t)\right\|^{2}} v_{\|}(t)+\frac{\left\langle v_{\|}(t), i_{C}(t)\right\rangle}{\left\|v_{\|}(t)\right\|^{2}} v_{\|}(t)+\cdots \\
& \cdots+\frac{\left\langle v_{\perp}(t), i_{A}(t)\right\rangle}{\left\|v_{\perp}(t)\right\|^{2}} v_{\perp}(t)+\frac{\left\langle v_{\perp}(t), i_{B}(t)\right\rangle}{\left\|v_{\perp}(t)\right\|^{2}} v_{\perp}(t)+\frac{\left\langle v_{\perp}(t), i_{C}(t)\right\rangle}{\left\|v_{\perp}(t)\right\|^{2}} v_{\perp}(t) \\
& i_{d}(t)=\frac{\left\langle v_{\|}(t), i_{A}(t)\right\rangle}{\left\|v_{\|}(t)\right\|^{2}} v_{\|}(t)+\frac{\left\langle v_{\perp}(t), i_{A}(t)\right\rangle}{\left\|v_{\perp}(t)\right\|^{2}} v_{\perp}(t)+\cdots \\
& \cdots+\frac{\left\langle v_{\|}(t), i_{B}(t)\right\rangle}{\left\|v_{\|}(t)\right\|^{2}} v_{\|}(t)+\frac{\left\langle v_{\perp}(t), i_{B}(t)\right\rangle}{\left\|v_{\perp}(t)\right\|^{2}} v_{\perp}(t)+\cdots \\
& \cdots+\frac{\left\langle v_{\|}(t), i_{C}(t)\right\rangle}{\left\|v_{\|}(t)\right\|^{2}} v_{\|}(t)+\frac{\left\langle v_{\perp}(t), i_{C}(t)\right\rangle}{\left\|v_{\perp}(t)\right\|^{2}} v_{\perp}(t) \\
& i_{d}(t)=\underbrace{\operatorname{proj}_{v_{\|}(t)}\left(i_{A}(t)\right)+\operatorname{proj}_{v_{\perp}(t)}\left(i_{A}(t)\right)}_{i_{a}(t)}+\underbrace{\operatorname{proj}_{v_{\|}(t)}\left(i_{B}(t)\right)+\operatorname{proj}_{v_{\perp}(t)}\left(i_{B}(t)\right)}_{i_{b}(t)}+\cdots \\
& \cdots+\underbrace{\operatorname{proj}_{v_{\|}(t)}\left(i_{C}(t)\right)+\operatorname{proj}_{v_{\perp}(t)}\left(i_{C}(t)\right)}_{i_{c}(t)} \\
& i_{d}(t)=i_{a}(t)+i_{b}(t)+i_{c}(t)
\end{aligned}
$$


A Expressão (3.82) apresenta $i_{d}(t)$ como sendo equivalente à somatória das projeções das correntes de linha sobre a função planar das tensões de linha do sistema de energia elétrica trifásico. Por outro lado, a função $i_{h}(t)$, descritora da componente de corrente de neutro normal à função planar das tensões de linha, pode ser obtida da seguinte maneira:

$$
\begin{aligned}
& i_{N}(t)=i_{d}(t)+i_{h}(t) \\
& i_{h}(t)=i_{N}(t)-i_{d}(t)
\end{aligned}
$$

Empregando-se as equivalências de $i_{N}(t)$ e de $i_{d}(t)$ apresentadas anteriormente em (3.77) e (3.82), o seguinte desenvolvimento é possível:

$$
\begin{aligned}
& i_{h}(t)=i_{A}(t)+i_{B}(t)+i_{C}(t)-i_{a}(t)-i_{b}(t)-i_{c}(t) \\
& i_{h}(t)=i_{A}(t)-i_{a}(t)+i_{B}(t)-i_{b}(t)+i_{C}(t)-i_{c}(t)
\end{aligned}
$$

Em função das definições apresentadas, a componente da tensão de neutro $v_{h}(t)$ e a componente da corrente de neutro $i_{h}(t)$ devem ser, necessariamente, colineares entre si. Para demonstrar essa afirmação é necessário mostrar que a função $i_{h}(t)$ é resultante da combinação linear de $v_{h}(t)$, ou seja, deve existir $\alpha \in \mathbb{R}$, tal que:

$$
i_{h}(t)=\alpha v_{h}(t)
$$

Para demonstrar a existência de $\alpha$ o desenvolvimento seguinte é pertinente:

$$
\begin{aligned}
& i_{h}(t)=i_{N}(t)-i_{d}(t) \\
& i_{h}(t)=i_{A}(t)-i_{a}(t)+i_{B}(t)-i_{b}(t)+i_{C}(t)-i_{c}(t)
\end{aligned}
$$




$$
\begin{aligned}
& i_{h}(t)=\underbrace{\operatorname{proj}_{v_{h}(t)}\left(i_{A}(t)\right)+\operatorname{proj}_{v_{\|}(t)}\left(i_{A}(t)\right)+\operatorname{proj}_{v_{\perp}(t)}\left(i_{A}(t)\right)}_{i_{A}(t)}+\cdots \\
& \cdots \underbrace{-\operatorname{proj}_{v_{\|}(t)}\left(i_{A}(t)\right)-\operatorname{proj}_{v_{\perp}(t)}\left(i_{A}(t)\right)}_{i_{a}(t)}+\cdots \\
& \cdots+\underbrace{\operatorname{proj}_{v_{h}(t)}\left(i_{B}(t)\right)+\operatorname{proj}_{v_{\|}(t)}\left(i_{B}(t)\right)+\operatorname{proj}_{v_{\perp}(t)}\left(i_{B}(t)\right)}_{i_{B}(t)}+\cdots \\
& \cdots \underbrace{-\operatorname{proj}_{v_{\|}(t)}\left(i_{B}(t)\right)-\operatorname{proj}_{v_{\perp}(t)}\left(i_{B}(t)\right)}_{i_{b}(t)}+\cdots \\
& \cdots+\underbrace{\operatorname{proj}_{v_{h}(t)}\left(i_{C}(t)\right)+\operatorname{proj}_{v_{\|}(t)}\left(i_{C}(t)\right)+\operatorname{proj}_{v_{\perp}(t)}\left(i_{C}(t)\right)}_{i_{C}(t)}+\cdots \\
& \underbrace{-\operatorname{proj}_{v_{\|}(t)}\left(i_{C}(t)\right)-\operatorname{proj}_{\nu_{\perp}(t)}\left(i_{C}(t)\right)}_{i_{c}(t)} \\
& i_{h}(t)=\operatorname{proj}_{v_{h}(t)}\left(i_{A}(t)\right)+\operatorname{proj}_{v_{h}(t)}\left(i_{B}(t)\right)+\operatorname{proj}_{v_{h}(t)}\left(i_{C}(t)\right) \\
& i_{h}(t)=\frac{\left\langle v_{h}(t), i_{A}(t)\right\rangle}{\left\|v_{h}(t)\right\|^{2}} v_{h}(t)+\frac{\left\langle v_{h}(t), i_{B}(t)\right\rangle}{\left\|v_{h}(t)\right\|^{2}} v_{h}(t)+\frac{\left\langle v_{h}(t), i_{C}(t)\right\rangle}{\left\|v_{h}(t)\right\|^{2}} v_{h}(t) \\
& i_{h}(t)=\left(\frac{\left\langle v_{h}(t), i_{A}(t)\right\rangle}{\left\|v_{h}(t)\right\|^{2}}+\frac{\left\langle v_{h}(t), i_{B}(t)\right\rangle}{\left\|v_{h}(t)\right\|^{2}}+\frac{\left\langle v_{h}(t), i_{C}(t)\right\rangle}{\left\|v_{h}(t)\right\|^{2}}\right) v_{h}(t) \\
& i_{h}(t)=\frac{\left\langle v_{h}(t), i_{A}(t)+i_{B}(t)+i_{C}(t)\right\rangle}{\left\|v_{h}(t)\right\|^{2}} v_{h}(t) \\
& i_{h}(t)=\frac{\left\langle v_{h}(t), i_{N}(t)\right\rangle}{\left\|v_{h}(t)\right\|^{2}} v_{h}(t) \\
& \therefore i_{h}(t)=\alpha v_{h}(t) \Rightarrow \alpha=\frac{\left\langle v_{h}(t), i_{N}(t)\right\rangle}{\left\|v_{h}(t)\right\|^{2}}
\end{aligned}
$$

O resultado destacado em (3.86) demonstra a colinearidade entre as funções $i_{h}(t)$ e $v_{h}(t)$. Sobre o ponto de vista de sistemas de energia elétrica essa constatação é equivalente à afirmação de que $i_{h}(t)$ e $v_{h}(t)$ estão em fase, quando $\alpha>0$, ou defasadas entre si de $\pi$ radianos, quando $\alpha<0$. Essa segunda afirmação, equivalente à primeira, pode ainda ser 
demonstrada garantindo que o módulo da razão entre o produto interno das funções $i_{h}(t)$ e $v_{h}(t)$ pelo produto das normas quadráticas dessas funções seja unitário, ou seja:

$$
\begin{aligned}
& \left|\frac{\left\langle v_{h}(t), i_{h}(t)\right\rangle}{\left\|v_{h}(t)\right\|\left\|i_{h}(t)\right\|}\right|=\left|\frac{\left\langle v_{h}(t), \alpha v_{h}(t)\right\rangle}{\left\|v_{h}(t)\right\|\left\|\alpha v_{h}(t)\right\|}\right| \\
& \left|\frac{\left\langle v_{h}(t), i_{h}(t)\right\rangle}{\left\|v_{h}(t)\right\|\left\|i_{h}(t)\right\|}\right|=\left|\frac{\alpha\left\langle v_{h}(t), v_{h}(t)\right\rangle}{|\alpha|\left\|v_{h}(t)\right\|\left\|v_{h}(t)\right\|}\right| \\
& \left|\frac{\left\langle v_{h}(t), i_{h}(t)\right\rangle}{\left\|v_{h}(t)\right\|\left\|i_{h}(t)\right\|}\right|=\left|\frac{\alpha\left\|v_{h}(t)\right\|^{2}}{|\alpha|\left\|v_{h}(t)\right\|^{2}}\right| \\
& \left|\frac{\left\langle v_{h}(t), i_{h}(t)\right\rangle}{\left\|v_{h}(t)\right\|\left\|i_{h}(t)\right\|}\right|=\left|\frac{\alpha}{|\alpha|}\right| \\
& \left|\frac{\left\langle v_{h}(t), i_{h}(t)\right\rangle}{\left\|v_{h}(t)\right\|\left\|i_{h}(t)\right\|}\right|=\frac{|\alpha|}{|\alpha|} \\
& \left|\frac{\left\langle v_{h}(t), i_{h}(t)\right\rangle}{\left\|v_{h}(t)\right\|\left\|i_{h}(t)\right\|}\right|=1
\end{aligned}
$$

Assim, por meio do apresentado nessa seção, tem-se, portanto, a formulação para a decomposição das correntes de linha em suas componentes planares em relação às tensões de linha. Além disso, verificou-se a colinearidade entre a função $i_{h}(t)$ e a função $v_{h}(t)$ propriedade essa demonstrada por meio das expressões (3.86) e (3.87).

\subsection{ANÁlise da COMPOSIÇÃo da TENSÃo E dA CORRENTE de DESBALANÇO EM SISTEMAS DE ENERGIA ELÉTRICA TRIFÁSICO}

Na Seção 3.5 foi definida a componente de tensão $v_{d}(t)$ como sendo resultante da somatória das projeções das tensões de fase sobre a função planar das correntes de linha, ou seja:

$$
v_{d}(t)=v_{a}(t)+v_{b}(t)+v_{c}(t)
$$


Para verificar a condição de existência da tensão $v_{d}(t)$ será considerado que as projeções $v_{a}(t), v_{b}(t)$ e $v_{c}(t)$ possuem a seguinte formulação:

$$
\left\{\begin{array}{l}
v_{a}(t)=V_{a} \cos (\omega t) \\
v_{b}(t)=V_{b} \cos \left(\omega t-120^{\circ}\right) \\
v_{c}(t)=V_{c} \cos \left(\omega t+120^{\circ}\right)
\end{array}\right.
$$

Assim, tendo como base a proposição em (3.89), a expressão para $v_{d}(t)$ resultante poderá ser dada da seguinte forma:

$$
\begin{aligned}
& v_{d}(t)=v_{a}(t)+v_{b}(t)+v_{c}(t) \\
& v_{d}(t)=V_{a} \cos (\omega t)+V_{b} \cos \left(\omega t-120^{\circ}\right)+V_{c} \cos \left(\omega t+120^{\circ}\right) \\
& v_{d}(t)=V_{a} \cos (\omega t)+V_{b}\left(\cos (\omega t) \cos \left(120^{\circ}\right)+\operatorname{sen}(\omega t) \operatorname{sen}\left(120^{\circ}\right)\right)+\cdots \\
& \cdots+V_{c}\left(\cos (\omega t) \cos \left(120^{\circ}\right)-\operatorname{sen}(\omega t) \operatorname{sen}\left(120^{\circ}\right)\right) \\
& v_{d}(t)=V_{a} \cos (\omega t)+V_{b}\left(-\frac{1}{2} \cos (\omega t)+\frac{\sqrt{3}}{2} \operatorname{sen}(\omega t)\right)+\cdots \\
& \cdots+V_{c}\left(-\frac{1}{2} \cos (\omega t)-\frac{\sqrt{3}}{2} \operatorname{sen}(\omega t)\right) \\
& v_{d}(t)=\left(V_{a}-\frac{V_{b}}{2}-\frac{V_{c}}{2}\right) \cos (\omega t)+\left(\frac{\sqrt{3} V_{b}}{2}-\frac{\sqrt{3} V_{c}}{2}\right) \operatorname{sen}(\omega t)
\end{aligned}
$$

A Expressão (3.90) apresenta a função $v_{d}(t)$ na forma da composição de uma função co-seno e uma função seno. No entanto, torna-se conveniente para análise da condição de existência dessa função assumir $v_{d}(t)$ da seguinte forma:

$$
v_{d}(t)=V_{d} \cos \left(\omega t+\theta_{d}\right)
$$

Desenvolvendo a expressão (3.91) por meio das igualdades trigonométricas, temse:

$$
\begin{aligned}
& v_{d}=V_{d} \cos \left(\omega t+\theta_{d}\right) \\
& v_{d}=V_{d}\left(\cos (\omega t) \cos \left(\theta_{d}\right)-\operatorname{sen}(\omega t) \operatorname{sen}\left(\theta_{d}\right)\right)
\end{aligned}
$$




$$
v_{d}=V_{d} \cos (\omega t) \cos \left(\theta_{d}\right)-V_{d} \operatorname{sen}(\omega t) \operatorname{sen}\left(\theta_{d}\right)
$$

Por comparação da expressão (3.92) com a expressão (3.90), o seguinte sistema de equações pode ser estabelecido:

$$
\left\{\begin{array}{l}
V_{d} \cos \left(\theta_{d}\right)=V_{a}-\frac{V_{b}}{2}-\frac{V_{c}}{2} \\
V_{d} \operatorname{sen}\left(\theta_{d}\right)=\frac{\sqrt{3} V_{c}}{2}-\frac{\sqrt{3} V_{b}}{2}
\end{array}\right.
$$

A resolução do sistema de equação apresentado em (3.93) resultará nos valores para as incógnitas $V_{d}$ e $\theta_{d}$. Para tanto, o seguinte desenvolvimento é necessário:

$$
\begin{aligned}
& V_{d}^{2} \cos ^{2}\left(\theta_{d}\right)+V_{d}^{2} \operatorname{sen}^{2}\left(\theta_{d}\right)=V_{a}^{2}-\frac{1}{2} V_{a} V_{b}-\frac{1}{2} V_{a} V_{c}-\frac{1}{2} V_{a} V_{b}+\frac{1}{4} V_{b}^{2}+\frac{1}{4} V_{b} V_{c}+\cdots \\
& \cdots-\frac{1}{2} V_{a} V_{c}+\frac{1}{4} V_{b} V_{c}+\frac{1}{4} V_{c}^{2}+\frac{3}{4} V_{c}^{2}+\frac{3}{4} V_{b}^{2}-\frac{3}{2} V_{b} V_{c} \\
& V_{d}^{2}\left(\cos ^{2}\left(\theta_{d}\right)+\operatorname{sen}^{2}\left(\theta_{d}\right)\right)=V_{a}^{2}+V_{c}^{2}+V_{b}^{2}-V_{a} V_{b}-V_{b} V_{c}-V_{a} V_{c} \\
& V_{d}^{2}=V_{a}^{2}+V_{c}^{2}+V_{b}^{2}-V_{a} V_{b}-V_{b} V_{c}-V_{a} V_{c}
\end{aligned}
$$

A Expressão (3.94) permite verificar que a magnitude da função $v_{d}(t)$, denotada por $V_{d}$, será nula conforme a seguinte condição:

$$
V_{d}=0 \Leftrightarrow V_{a}=V_{b}=V_{c}
$$

Nessa análise, foi verificada a condição de existência da função $v_{d}(t)$ mediante a amplitude das projeções das tensões de fase sobre a tensão planar das tensões de linha. Por outro lado, é necessário verificar como a magnitude de $v_{d}(t)$ se porta frente à defasagem angular das formas de onda das projeções $v_{a}(t), v_{b}(t)$ e $v_{c}(t)$. Assim, para essa análise será considerada a seguinte representação funcional para as referidas projeções de tensão:

$$
\left\{\begin{array}{l}
v_{a}(t)=V \cos \left(\omega t+\theta_{a}\right) \\
v_{b}(t)=V \cos \left(\omega t+\theta_{b}\right) \\
v_{c}(t)=V \cos \left(\omega t+\theta_{c}\right)
\end{array}\right.
$$

Procedendo de maneira análoga ao efetuado anteriormente, tem-se:

$$
v_{d}(t)=v_{a}(t)+v_{b}(t)+v_{c}(t)
$$




$$
\begin{aligned}
& v_{d}(t)=V \cos \left(\omega t+\theta_{a}\right)+V \cos \left(\omega t+\theta_{b}\right)+V \cos \left(\omega t+\theta_{c}\right) \\
& v_{d}(t)=V\left(\cos (\omega t) \cos \left(\theta_{a}\right)+\operatorname{sen}(\omega t) \operatorname{sen}\left(\theta_{a}\right)+\cos (\omega t) \cos \left(\theta_{b}\right)+\cdots\right. \\
& \left.\cdots+\operatorname{sen}(\omega t) \operatorname{sen}\left(\theta_{b}\right)+\cos (\omega t) \cos \left(\theta_{c}\right)+\operatorname{sen}(\omega t) \operatorname{sen}\left(\theta_{c}\right)\right) \\
& v_{d}(t)=V \cos (\omega t)\left(\cos \left(\theta_{a}\right)+\cos \left(\theta_{b}\right)+\cos \left(\theta_{c}\right)\right)+\cdots \\
& \cdots+V \operatorname{sen}(\omega t)\left(\operatorname{sen}\left(\theta_{a}\right)+\operatorname{sen}\left(\theta_{b}\right)+\operatorname{sen}\left(\theta_{c}\right)\right)
\end{aligned}
$$

Para que a amplitude de $v_{d}(t)$ seja nula a seguinte condição deve ser válida:

$$
\left\{\begin{array}{l}
\cos \left(\theta_{a}\right)+\cos \left(\theta_{b}\right)+\cos \left(\theta_{c}\right)=0 \\
\operatorname{sen}\left(\theta_{a}\right)+\operatorname{sen}\left(\theta_{b}\right)+\operatorname{sen}\left(\theta_{c}\right)=0
\end{array}\right.
$$

Adotando-se $\theta_{a}$ como referência angular, ou seja, $\theta_{a}=0$, a Expressão (3.98) pode ser desenvolvida da seguinte forma:

$$
\begin{aligned}
& 1+\cos \left(\theta_{b}\right)+\cos \left(\theta_{c}\right)=0 \Leftrightarrow \cos \left(\theta_{b}\right)+\cos \left(\theta_{c}\right)=-1 \\
& \operatorname{sen}\left(\theta_{b}\right)+\operatorname{sen}\left(\theta_{c}\right)=0 \Leftrightarrow \operatorname{sen}\left(\theta_{c}\right)=-\operatorname{sen}\left(\theta_{b}\right) \Leftrightarrow \theta_{c}=-\theta_{b}
\end{aligned}
$$

Substituindo (3.100) em (3.99), tem-se:

$$
\begin{aligned}
& \cos \left(\theta_{b}\right)+\cos \left(-\theta_{b}\right)=-1 \\
& \cos \left(\theta_{b}\right)+\cos \left(\theta_{b}\right)=-1 \\
& \cos \left(\theta_{b}\right)=-\frac{1}{2} \\
& \theta_{b}=-120^{\circ} \Leftrightarrow \theta_{c}=120^{\circ}
\end{aligned}
$$

Nessas condições, onde $\theta_{a}=0, \theta_{b}=-120^{\circ}$ e $\theta_{c}=120^{\circ}$, a magnitude de $v_{d}(t)$ será nula para qualquer valor de $t$.

Assim, pode-se verificar, por meio da análise efetuada, que a tensão $v_{d}(t)$ tem origem no desbalanço das tensões de fase tanto no que diz respeito às amplitudes dessas formas de onda quanto na defasagem angular relativa entre elas. Dessa forma, torna-se conveniente definir $v_{d}(t)$ como sendo a tensão de desbalanço do sistema trifásico. 
Para fins de análise, é pertinente verificar que as três componentes das tensões de fase contribuem com a composição de $v_{d}(t)$, ou seja, existe o acoplamento entre as componentes de tensão $v_{a}(t), v_{b}(t), v_{c}(t)$ e $v_{d}(t)$. Para desconsiderar a influência de $v_{d}(t)$ sobre as demais componentes, será então determinada a função $v_{n}(t)$ que, se subtraída às projeções das tensões de fase sobre a função planar das tensões de linha, torna essas projeções equilibradas, ou seja, torna sua somatória nula. Dessa forma, o seguinte desenvolvimento é possível:

$$
\begin{aligned}
& \left(v_{a}(t)-v_{n}(t)\right)+\left(v_{b}(t)-v_{n}(t)\right)+\left(v_{c}(t)-v_{n}(t)\right)=0 \\
& \underbrace{v_{a}(t)+v_{b}(t)+v_{c}(t)}_{v_{d}(t)}-3 v_{n}(t)=0 \\
& v_{n}(t)=\frac{1}{3} v_{d}(t)
\end{aligned}
$$

De maneira semelhante, pode-se pensar na componente $i_{n}(t)$ que subtraída das correntes $i_{a}(t), i_{b}(t), i_{c}(t)$ resultará na anulação de seu somatório que procedendo como feito para $v_{n}(t)$ resultará em:

$$
\begin{aligned}
& \left(i_{a}(t)-i_{n}(t)\right)+\left(i_{b}(t)-i_{n}(t)\right)+\left(i_{c}(t)-i_{n}(t)\right)=0 \\
& \underbrace{i_{a}(t)+i_{b}(t)+i_{c}(t)}_{i_{d}(t)}-3 i_{n}(t)=0 \\
& i_{n}(t)=\frac{1}{3} i_{d}(t)
\end{aligned}
$$

Dessa forma, os resultados conduzidos ao longo desse capítulo permitem a decomposição do sistema trifásico sob análise, destacado por meio da Figura 3.13 em seus respectivos circuitos ortogonais os quais se ilustram por meio da Figura 3.14. 


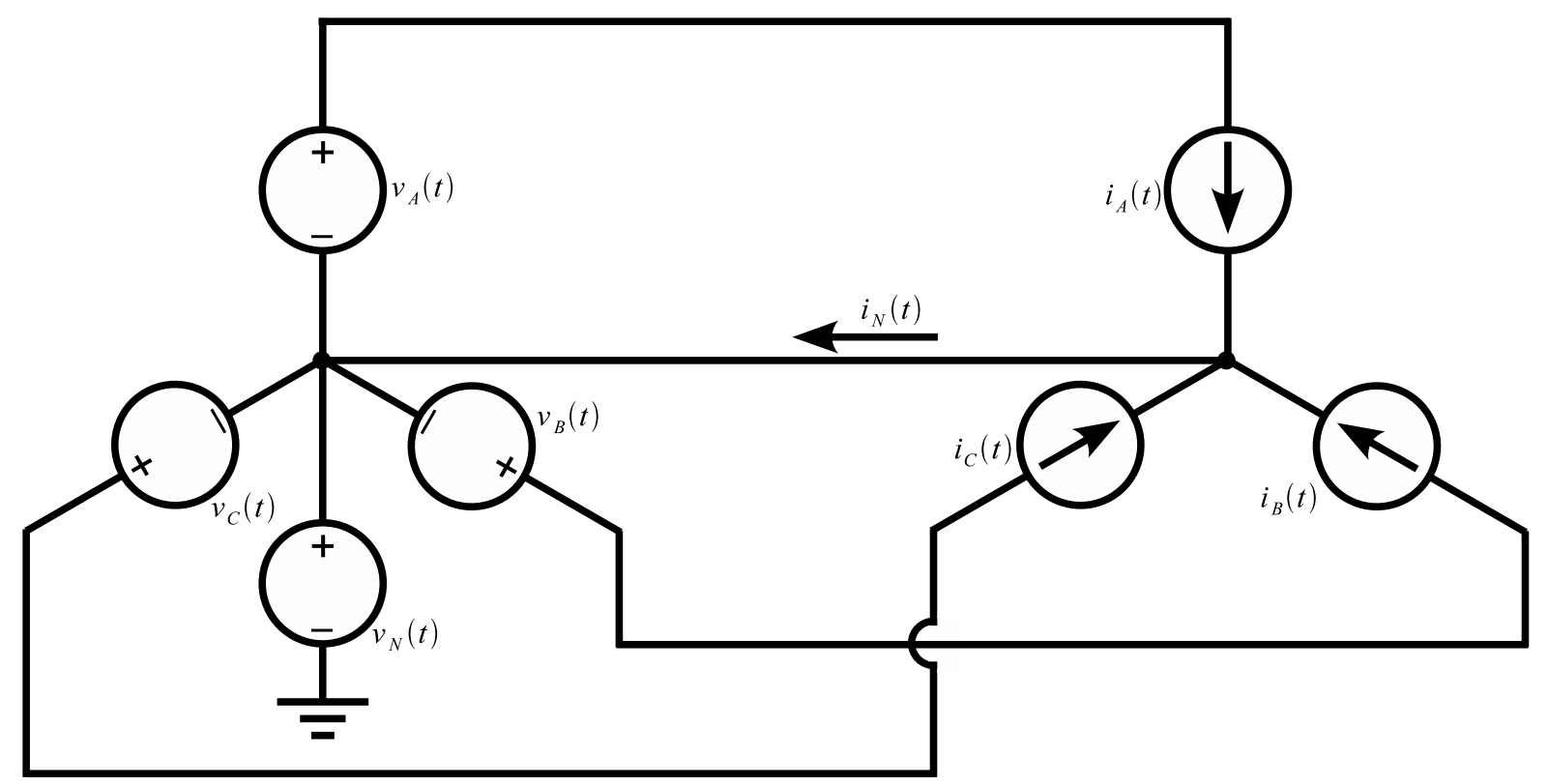

Figura 3.13 - Sistema de energia elétrica sob análise.

Para elucidar a apresentação dos circuitos destacados na Figura 3.14 as seguintes expressões podem ser empregadas:

$$
\begin{aligned}
& \left\{\begin{array}{l}
v_{a}(t)=\frac{\left\langle v_{\|}(t), v_{A}(t)\right\rangle}{\left\|v_{\|}(t)\right\|^{2}} v_{\|}(t)+\frac{\left\langle v_{\perp}(t), v_{A}(t)\right\rangle}{\left\|v_{\perp}(t)\right\|^{2}} v_{\perp}(t) \\
v_{b}(t)=\frac{\left\langle v_{\|}(t), v_{B}(t)\right\rangle}{\left\|v_{\|}(t)\right\|^{2}} v_{\|}(t)+\frac{\left\langle v_{\perp}(t), v_{B}(t)\right\rangle}{\left\|v_{\perp}(t)\right\|^{2}} v_{\perp}(t) \\
v_{c}(t)=\frac{\left\langle v_{\|}(t), v_{C}(t)\right\rangle}{\left\|v_{\|}(t)\right\|^{2}} v_{\|}(t)+\frac{\left\langle v_{\perp}(t), v_{C}(t)\right\rangle}{\left\|v_{\perp}(t)\right\|^{2}} v_{\perp}(t) \\
\left\{\begin{array}{l}
v_{\bar{a}}(t)=v_{A}(t)-v_{a}(t) \\
v_{\bar{b}}(t)=v_{B}(t)-v_{b}(t) \\
v_{\bar{c}}(t)=v_{C}(t)-v_{c}(t) \\
v_{a}(t)=\frac{\left\langle v_{\|}(t), v_{A}(t)\right\rangle}{\left\|v_{\|}(t)\right\|^{2}} v_{\|}(t)+\frac{\left\langle v_{\perp}(t), v_{A}(t)\right\rangle}{\left\|v_{\perp}(t)\right\|^{2}} v_{\perp}(t) \\
v_{c}(t)=\frac{\left\langle v_{\|}(t), v_{C}(t)\right\rangle}{\left\|v_{\|}(t)\right\|^{2}} v_{\|}(t)+\frac{\left\langle v_{\perp}(t), v_{C}(t)\right\rangle}{\left\|v_{\perp}(t)\right\|^{2}} v_{\perp}(t)
\end{array}\right. \\
v_{b}(t)=\frac{\left\langle v_{\|}(t), v_{B}(t)\right\rangle}{\left\|v_{\|}(t)\right\|^{2}} v_{\|}(t)+\frac{\left\langle v_{\perp}(t), v_{B}(t)\right\rangle}{\left\|v_{\perp}(t)\right\|^{2}} v_{\perp}(t)
\end{array}\right.
\end{aligned}
$$




$$
\left\{\begin{array}{l}
v_{\bar{a}}(t)=v_{A}(t)-v_{a}(t) \\
v_{\bar{b}}(t)=v_{B}(t)-v_{b}(t) \\
v_{\bar{c}}(t)=v_{C}(t)-v_{c}(t)
\end{array}\right.
$$

onde

$$
\left\{\begin{array}{l}
v_{\|}(t)=v_{A B}(t) \\
v_{\perp}(t)=v_{B C}(t)-\frac{\left\langle v_{A B}(t), v_{B C}(t)\right\rangle}{\left\|v_{A B}(t)\right\|} v_{A B}(t)
\end{array}\right.
$$

(a)

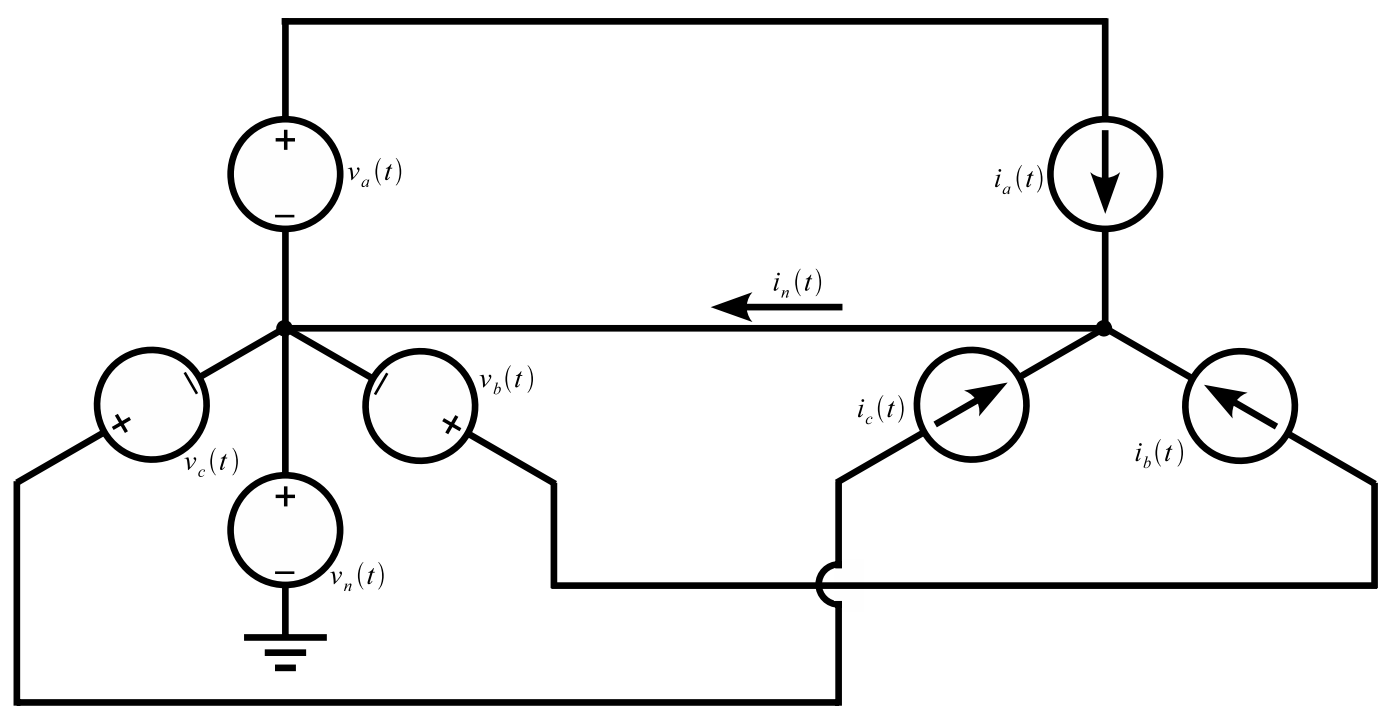

(b)

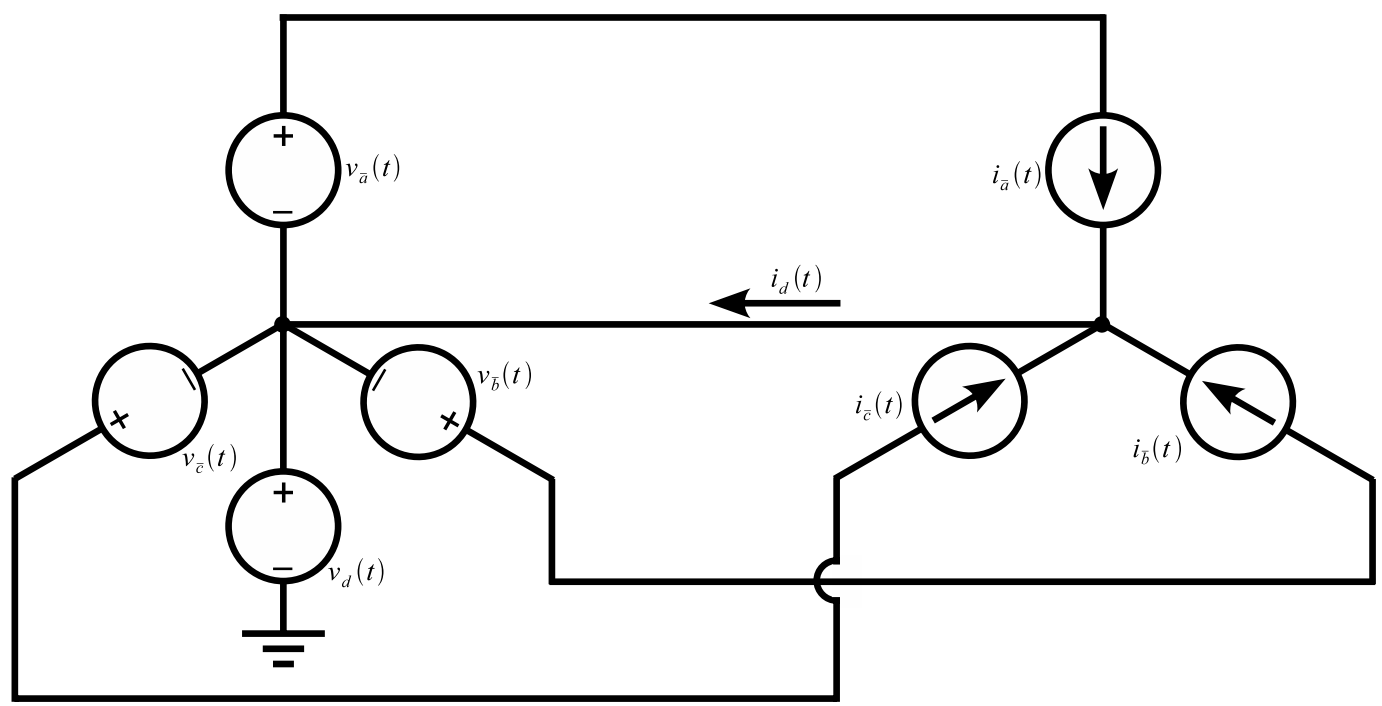

Figura 3.14 - Sistema de energia elétrica decomposto em suas componentes ortogonais; (a) Componentes contidas na função planar das tensões de linha; (b) Componentes ortogonais à função planar das tensões de linha. 


\subsection{CONSIDERAÇões SOBRE O MÉTOdO DE DECOMPOSIÇão EM COMPONENTES ORTOGONAIS}

Ao longo desse capítulo fora apresentada a técnica de decomposição em componentes ortogonais e como a mesma pode ser empregada em sistemas elétricos. A principal característica dessa técnica reside no fato de não se fazer uso de bases para decomposição previamente estabelecidas. Ao contrário disso, a técnica de decomposição em componentes ortogonais, por meio de operações elementares da álgebra linear, emprega as próprias formas de onda para obtenção das bases ortogonais empregadas no processo de decomposição.

Assim, diante de um sistema elétrico trifásico, uma primeira obtenção de componentes ortogonais é realizada, resultando, por sua vez, em dois conjuntos de componentes: um conjunto de componentes contidas na função planar das tensões de linha e outro conjunto de componentes ortogonais à função planar das tensões de linha.

Fazendo uso das componentes resultantes do primeiro processo de decomposição é ainda possível, para cada componente de tensão e a correspondente componente de corrente, realizar um segundo processo de decomposição, o qual resulta em outras oito componentes: quatro para a componente de tensão e outras quatro para a componente de corrente. De forma resumida, tem-se que a partir das quatro componentes de tensão $\left\{v_{A}(t), v_{B}(t), v_{C}(t)\right.$ e $\left.v_{N}(t)\right\}$ e das quatro componentes de corrente $\left\{i_{A}(t), i_{B}(t), i_{C}(t)\right.$ e $\left.i_{N}(t)\right\}$ a primeira etapa da decomposição resulta em oitos componentes para a tensão e outras oito componentes para a corrente, ou ainda, oito pares tensão-corrente. Cada um desses pares, na segunda etapa de decomposição, pode ainda ser decomposto em quatro pares tensão-corrente perfazendo, ao todo, 64 componentes ortogonais a partir das quais é possível reconstruir as formas de onda originais de maneira plena. Dessa forma, pode-se afirmar que as formas de onda originais são sintetizadas completamente pelas componentes oriundas do processo de decomposição.

A maneira pela qual as componentes ortogonais podem ser empregadas no estudo de sistema elétricos é digna de mais estudos e essa tarefa é contemplada quando da pontuação dos trabalhos futuros conseguintes a esse. De forma particular nesta tese, a técnica da decomposição em componentes ortogonais será empregada como ferramenta de préprocessamento de sinais para auxiliar na identificação e localização de faltas do tipo faseterra. O delineamento do referido uso é desenvolvido no Capítulo 5, onde se retrata inclusive como as componentes se portam diante de uma falta, e no Capítulo 6 mostrar-se-á o uso das componentes ortogonais quando da localização e estimação da resistência de falta. 


\section{AJUSTe Automático de Sistemas DE INFERÊNCIA FUZZY}

\subsection{INTRODUÇÃO}

A lógica fuzzy é a lógica que suporta os modos de raciocínio que são aproximados ao invés de exatos, ou ainda, de forma mais abrangente, pode ser aceita como a melhor maneira de representação do raciocínio humano, que é parcial e aproximado em sua essência.

Modelagem e controle fuzzy de sistemas são técnicas para o tratamento de informações qualitativas de uma forma rigorosa. Derivada do conceito de conjuntos fuzzy, a lógica fuzzy constitui a base para o desenvolvimento de métodos e algoritmos de modelagem e controle de processos, permitindo a redução da complexidade de projeto e implementação, tornando-se uma alternativa para a solução de problemas de controle e modelagem de sistemas.

Esta forma de estruturação do raciocínio é capaz de tomar decisões racionais mesmo estando em um ambiente de incertezas e imprecisões, onde dados desta natureza e até mesmo conflitantes são tratados (LEE, 1990). A tecnologia advinda da teoria de conjuntos fuzzy e da lógica fuzzy tem permitido a aplicação destas técnicas em diversas áreas do conhecimento (GOMIDE \& GUDWIN, 1994; HIROTA, 1993), tendo como exemplos os sistemas fuzzy de controle, os quais podem possibilitar um controle mais acurado, além de um desempenho estável e robusto; ou ainda, na modelagem de sistemas, onde através das técnicas 
de sistemas de inferência fuzzy é possível uma representação mais fiel do mesmo e inclusive a extração de informações qualitativas deste.

Como mencionado anteriormente, a lógica fuzzy procura expressar o raciocínio aproximado, ou seja, através da representação do conhecimento por regras se pode responder a um determinado estímulo. Na lógica fuzzy existe a opção adicional de se empregar possibilidades lingüísticas, como por exemplo "provável”, “altamente provável” e "improvável”, interpretados como números fuzzy e manipulados pela aritmética fuzzy. Também em contraste com a lógica modal clássica, o conceito de possibilidade é interpretado utilizando os subconjuntos fuzzy no universo dos reais.

Através da lógica fuzzy, um sistema pode ser representado através de conceitos imprecisos tais como "rápido", "baixo" e "pequeno". Essas propriedades são responsáveis, entre outras, pela facilidade na extração do conhecimento de um sistema a partir de observações realizadas sobre este.

Em um sistema de inferência fuzzy, os valores de entrada são normalizados e convertidos para uma representação fuzzy. Este processo é denominado de fuzzificação das variáveis de entrada. As regras do sistema fuzzy serão executadas em paralelo, conseqüentemente, uma região fuzzy será produzida para cada variável. A criação desta região fuzzy através das regras ativas do sistema é conhecida por agregação. Depois do processamento das regras de inferência, as regiões fuzzy são convertidas em valores não fuzzy, também conhecidas como valores "crisp", determinando assim, o valor de cada variável de saída do sistema. O processo de se converter tal região fuzzy em um valor real é conhecido por defuzzificação.

Um sistema de inferência fuzzy dedicado a uma determinada aplicação necessita, na sua fase de desenvolvimento, da especificação de alguns parâmetros. Dentre os parâmetros relacionados à sua estrutura se pode citar o número de funções de pertinência para cada entrada e para cada saída, o número de regras, bem como a definição de cada uma das regras. A determinação destes parâmetros pode ser realizada por meio de associações empíricas ou através da experiência prática. No entanto, muitos processos não fornecem subsídios adequados à determinação correta dos parâmetros estruturais do sistema fuzzy.

Torna-se então necessário o desenvolvimento de técnicas de sintonia que sejam eficientes na otimização estrutural e paramétrica de sistemas fuzzy. Dessa maneira, esse capítulo esta organizado de maneira a contemplar os fundamentos elementares correlatos aos 
sistemas fuzzy na Seção 4.2. Na Seção 4.3 será dado destaque às principais técnicas de ajuste de sistemas de inferência fuzzy. A fim de delinear corretamente os aspectos propostos, tanto para o ajuste estrutural como para o ajuste paramétrico de sistemas fuzzy, torna-se necessário a apresentação do modelo de sistema fuzzy adotado nesse trabalho, aspecto esse abordado na Seção 4.4. O algoritmo para o ajuste estrutural é delineado na Seção 4.5, tal como a Seção 4.6 conduz à formulação do algoritmo para o ajuste paramétrico. Por fim, na Seção 4.7, algumas considerações sobre a técnica proposta são tecidas.

\subsection{FundaMentos Sobre CONJUNTOS E Lógica FuzZY}

Nesta seção serão apresentados os conceitos básicos relacionados aos conjuntos e à lógica fuzzy, tendo como foco a modelagem de sistemas. Apesar de existir uma complexa base formal sustentando seu uso na modelagem e controle de sistemas, serão evidenciados somente os fundamentos necessários para o entendimento da teoria básica de modelagem fuzzy.

Assim, na teoria de conjuntos clássica, um elemento ou pertence a uma classe ou não. Dado um universo de discurso $U$ e um elemento particular $x \in U$, o grau de pertinência $\mu_{A}(x)$ com relação a um conjunto $A \subseteq U$ é dado por:

$$
\mu_{A}(x)= \begin{cases}1, & \text { se } x \in A \\ 0, & \text { sex } \notin A\end{cases}
$$

A função $\mu_{A}(x): U \rightarrow\{0,1\}$ é chamada de função característica na teoria clássica de conjuntos. Pode-se observar através da Expressão (4.1) que a função característica, assim definida, pode assumir apenas valores discretos.

Freqüentemente, uma generalização desta idéia é utilizada, por exemplo, para manipulação de dados com erros limitados. Todos os números pertencentes a um intervalo pré-definido terão um grau de pertinência 1 , os números que não pertencerem a este intervalo possuirão um grau de pertinência nulo como pode ser observado na Figura 4.1(a). Na Figura 4.1(b) o caso preciso é apresentado e deste se tem que o grau de pertinência é um somente em determinado valor, sendo nulo para os demais valores.

Zadeh (1973) propôs uma caracterização mais ampla, na medida em que sugere que alguns elementos são mais membros de um conjunto do que outros. O grau de pertinência 
pode então assumir qualquer valor entre o intervalo $[0,1]$, sendo que o valor 0 indica uma completa exclusão e um valor 1 representa completa pertinência, ou seja, a função característica passa a ser contínua no seu domínio. Esta generalização aumenta o poder de expressão da função característica. Na Figura 4.1(c), esta abordagem descrita é apresentada na forma de uma função de pertinência triangular com pico em $x$, sugerindo a idéia de que quanto mais próximo de $x$, mais o elemento se identifica com o conceito representado por $x$.
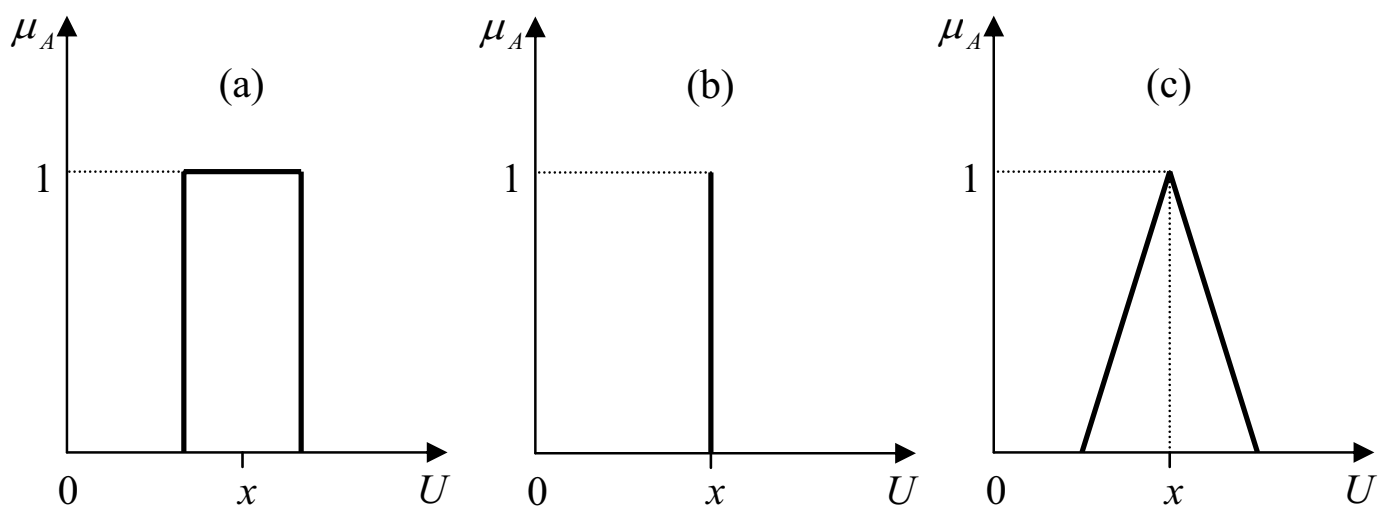

Figura 4.1 - Funções de pertinência.

A partir desta definição, o conceito de elemento e o conceito de conjunto podem ser expandidos e novas denominações mais amplas assumidas, como apresentado a seguir.

Formalmente, seja $U$ uma coleção de objetos denominados genericamente por $\{u\}$. O domínio $U$ é chamado de universo de discurso, podendo ser contínuo ou discreto. Um conjunto fuzzy $A$ em um universo de discurso $U$ é definido por uma função de pertinência $\mu_{A}$ que assume valores em um intervalo [0, 1], como apresentado em (4.2).

$$
\mu_{A}: U \rightarrow[0,1]
$$

O conjunto suporte de um conjunto fuzzy $A$ é o sub-conjunto dos pontos $u$ de $U$ tal que $\mu_{A}(u)>0$. Um conjunto fuzzy cujo conjunto suporte é um único ponto de $U$ com $\mu_{A}=1$ é chamado de um conjunto unitário fuzzy. A partir desta definição, os conjuntos clássicos passam a ser um caso específico na teoria de conjuntos fuzzy. Na Figura 4.1(c) tem-se uma função de pertinência do tipo triangular, no entanto, pode-se utilizar qualquer função $f: \mathbb{R} \rightarrow[0,1]$ para a representação de um determinado conjunto fuzzy. 


\subsubsection{DEFINIÇÃO DE OPERAÇÕES E OPERADORES DA LÓGICA FUZZY}

Sejam $A$ e $B$ dois conjuntos fuzzy definidos em um universo de discurso $U$ com funções de pertinência $\mu_{A}$ e $\mu_{B}$, respectivamente. As operações envolvendo conjuntos fuzzy, tais como a união $(A \cup B)$, a intersecção $(A \cap B)$ e o complemento $(\neg A)$ são definidas respectivamente de maneira formal pelas expressões (4.3), (4.4) e (4.5).

$$
\begin{aligned}
& \mu_{A \cup B}(u)=\mu_{A}(u) \& \mu_{B}(u) \\
& \mu_{A \cap B}(u)=\mu_{A}(u) \Gamma \mu_{B}(u) \\
& \mu_{\neg A}(u)=1-\mu_{A}(u)
\end{aligned}
$$

onde $\Gamma$ é uma norma triangular ( $t$-norma) e \& é uma co-norma triangular ( $s$-norma).

Como exemplo de $s$-norma tem-se a Expressão (4.6) e como exemplo da $t$-norma tem-se a Expressão (4.7).

$$
\begin{aligned}
& \mu_{A \cup B}=\max \left\{\mu_{A}(u), \mu_{B}(u)\right\} \\
& \mu_{A \cap B}=\min \left\{\mu_{A}(u), \mu_{B}(u)\right\}
\end{aligned}
$$

O emprego do operador "max" representando a s-norma e o emprego do operador "min" representando a $t$-norma foi proposto inicialmente por Zadeh (1965). No entanto, inúmeras outras $s$-norma e $t$-norma podem ser empregadas na definição dos sistemas fuzzy (PEDRYCZ \& GOMIDE, 1998).

\subsubsection{REGRAS DE INFERÊNCIA FUZZY}

Para expressar conceitos ou relacionamentos através de elementos da linguagem natural é muito comum o uso de elementos qualitativos ao invés de valores quantitativos. Elementos lingüísticos típicos incluem expressões do tipo "mais ou menos", "alto", "não muitos", "médios", etc. Estas idéias são capturadas pela definição de variáveis lingüísticas. Uma variável lingüística tem por característica assumir valores dentro de um conjunto de termos lingüísticos, ou seja, palavras ou frases. Assim, ao invés de assumir instâncias numéricas, estas variáveis assumem instâncias lingüísticas. Por exemplo, uma variável lingüística "Temperatura" poderá assumir como valor um dos termos do conjunto \{"baixa", "média", "alta"\}. Para se atribuir um significado aos termos lingüísticos, associa-se a cada um 
destes ternos um conjunto fuzzy definido sobre um universo de discurso comum, que neste exemplo será a "Temperatura". A Figura 4.2 ilustra três possíveis termos lingüísticos para variável lingüística representando a temperatura.

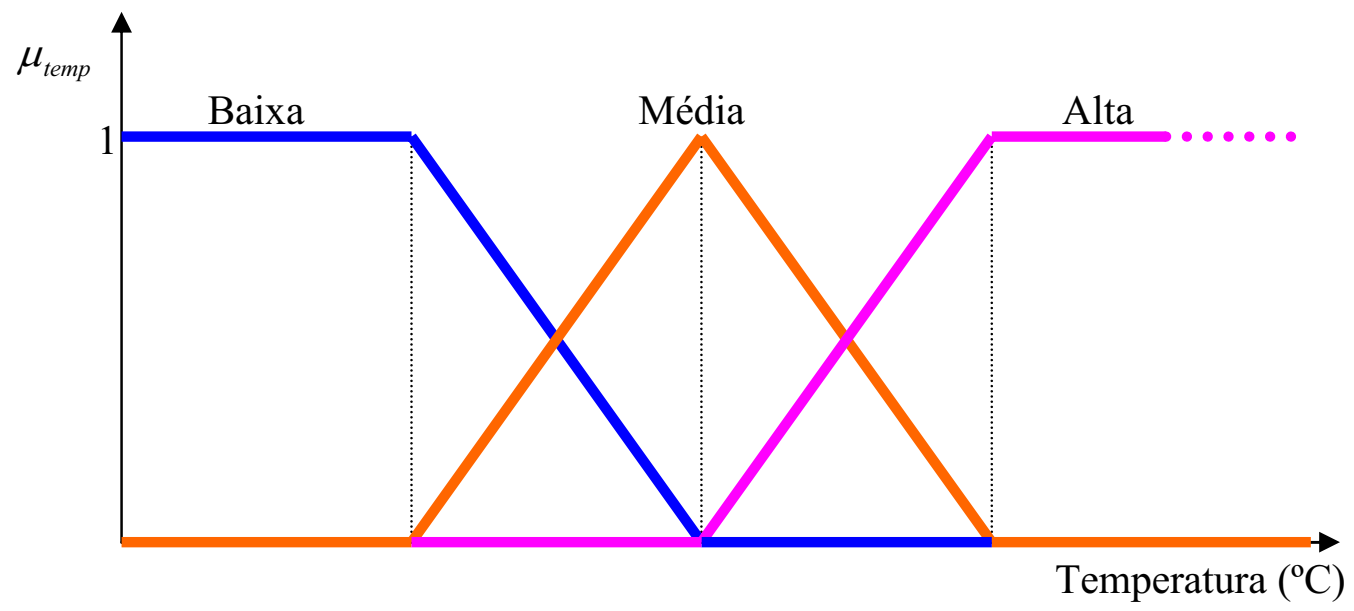

Figura 4.2 - Representação da variável lingüística temperatura.

A forma mais comum de expressar o conhecimento é por meio de regras do tipo condição-ação. Neste tipo de regra, um conjunto de condições descrevendo uma parcela observável das entradas do processo é associado com uma ação de saída que irá manter ou levar o sistema às condições desejadas, ou ainda, expressar o conhecimento especialista envolvido em um sistema e permitir que a modelagem seja mais flexível e comporte informações qualitativas do processo.

Tipicamente, uma condição é uma proposição lingüística (envolvendo variáveis lingüísticas) sobre o valor de alguma das variáveis de entrada, como por exemplo "o erro é grande e positivo". Da mesma maneira, uma ação típica de controle é uma descrição lingüística, como por exemplo "aumente um pouco a vazão". A idéia embutida junto às regras fuzzy de representar o conhecimento por meio de um conjunto de termos lingüísticos associados às variáveis de saída e entrada do processo é absorvida pelos sistemas de inferência fuzzy. As ações de controle ou as saídas do modelo são expressas de forma similar para cada variável de controle (saídas). Regras do tipo se-então são freqüentemente chamadas de declarações condicionais fuzzy ou simplesmente regras fuzzy. Dependendo do propósito, controle ou modelagem, podem ser chamadas ainda de regras de controle fuzzy ou regras de modelagem fuzzy. Uma regra fuzzy típica pode ser dada por:

$$
\mu_{R_{i}}=\mu_{\left(A_{i} \text { and } B_{i} \rightarrow C_{i}\right)}(u, v, w)
$$




$$
\mu_{R_{i}}=\left[\mu_{A_{i}}(u) \text { and } \mu_{B_{i}}(v)\right] \rightarrow \mu_{C_{i}}(w)
$$

onde $A_{i}, B_{i}$ e $C_{i}$ são conjuntos fuzzy pertencentes respectivamente aos universos de discursos $U, V$ e $W$, e o operador $(\rightarrow)$ denota uma função de implicação fuzzy.

Utilizando a regra de inferência composicional de Zadeh (ZADEH, 1973) para uma relação do tipo $R_{A \rightarrow B}$, onde $A \in U$ e $B \in V$, e dado um conjunto fuzzy de $U$ denotado por $A$ e um conjunto fuzzy $B$ 'de $V$, a inferência de $A$ 'é dada pela seguinte função de pertinência:

$$
\mu_{B^{\prime}}(v)=\max _{u}\left\{\min \left(\mu_{A^{\prime}}(u), \mu_{R}(u, v)\right)\right\} ; u \in U, v \in V
$$

A ação de controle consistirá então da união de todas as funções fuzzy ativadas. $\mathrm{O}$ valor final, ou seja, aquele que será apresentado pelas saídas do sistema fuzzy, será determinado pelo processo de defuzzificação. Uma descrição detalhada dos processos envolvidos com a inferência fuzzy pode ser encontrada em Pedrycz \& Gomide (1998).

\subsubsection{AGREGAÇÃO}

Em uma base de regras, quando mais de uma regra é acionada, as contribuições das diversas regras após a inferência são combinadas pelo operador de agregação. Por exemplo, supondo-se que $B_{1}^{\prime}, \ldots, B_{n}^{\prime}$ são todos os resultados derivados das diversas regras acionadas, todos relacionados a uma mesma variável lingüística, o resultado da implicação de todas as regras $B$ 'será:

$$
B^{\prime}=\bigcup_{i}^{n} B_{i}^{\prime}
$$

onde o símbolo $U$ representa o operador agregação. Um exemplo de função para o operador agregação é o operador união.

A Figura 4.3 ilustra o processo de inferência max-min quando existem duas regras, $A_{i} \rightarrow B_{i}$ e $A_{j} \rightarrow B_{j}$. $A$ 'é o fato de entrada, representado como um conjunto fuzzy. 

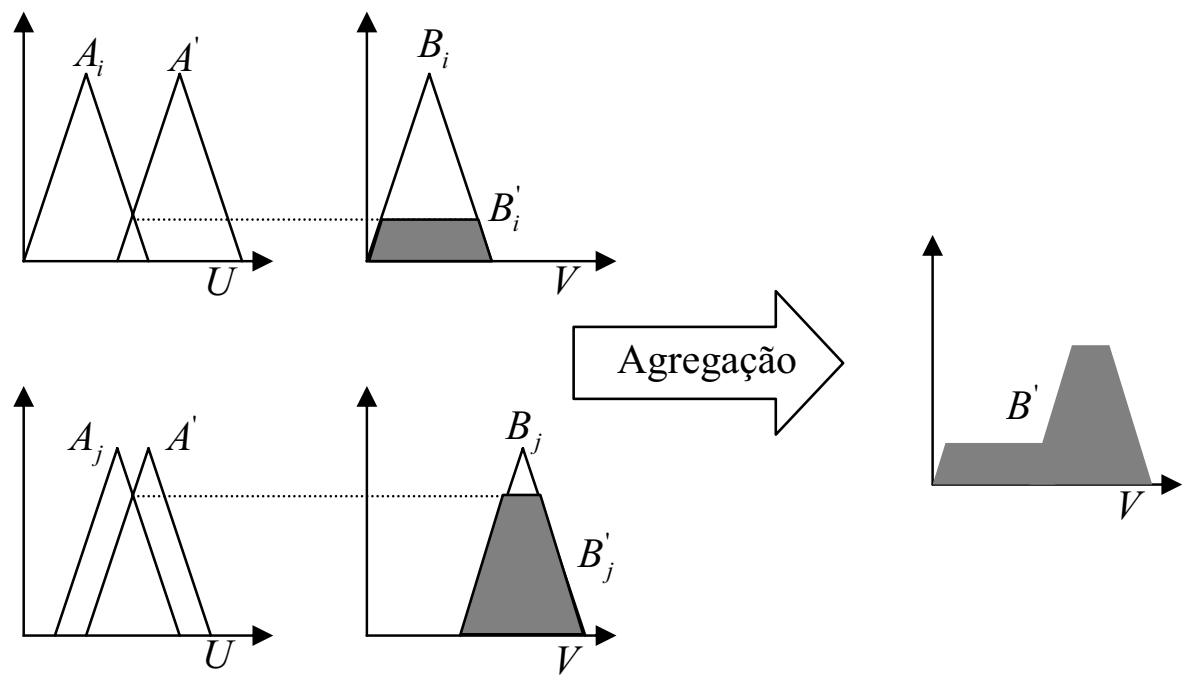

Figura 4.3 - Mecanismo de inferência fuzzy.

\subsection{Técnicas Para o ajuste estrutural e Paramétrico DE SISTEMAS DE INFERÊNCIA FUZZY}

Nos últimos anos se pôde observar um grande e crescente interesse nas aplicações envolvendo lógica fuzzy. As aplicações envolvendo lógica fuzzy estão compreendidas desde produtos ao consumidor, tais como câmeras fotográficas, filmadoras, máquinas de lavar e fornos de microondas, até aplicações industriais como controle de processos, instrumentação médica e sistemas de suporte à decisão (RAMOT et al, 2003).

Dentro da teoria compreendida pela lógica fuzzy e da teoria associada aos conjuntos fuzzy, uma das implementações mais usuais e que mais se destacam são os sistemas de inferência fuzzy (GUILLAUME, 2001). Os sistemas de inferência fuzzy desempenham grande importância em tarefas como nas de reconhecimentos de padrões, nas simulações e diagnósticos de processos, identificação de sistemas, etc.

De uma maneira geral, os sistemas de inferência fuzzy possuem propriedades peculiares que os tornam atrativos em diversas aplicações como exposto anteriormente. Além de serem capazes de incorporar conceitos lingüísticos, os sistemas de inferência fuzzy são também aproximadores universais, capazes de mapearem as relações entre as entradas e saídas de um dado sistema.

Estas duas propriedades podem ser empregadas para designarem dois tipos principais de sistemas de inferência fuzzy (GUILLAUME, 2001). 
O primeiro tipo de sistema de inferência fuzzy possui seu foco direcionado para a habilidade de modelar a linguagem natural, inerente à lógica fuzzy (MANDANI \& ASSILIAN, 1975). Este tipo de sistema de inferência contém regras fuzzy definidas a partir de uma base de conhecimento especialista. Tais sistemas são conhecidos como sistemas fuzzy especialistas ou controladores fuzzy, dependendo da finalidade ser modelagem ou controle, respectivamente.

O emprego deste primeiro tipo de sistema de inferência fuzzy, devido à sua estruturação, vem a oferecer uma robustez adequada aos propósitos desejados, pois os mesmos permitem a incorporação gradual de regras à sua base de conhecimento sem que haja perda ou inconsistência no resultado final (GUILLAUME, 2001).

Ainda com relação a este tipo de sistema fuzzy, pode-se observar que estes oferecem um alto nível semântico e uma boa capacidade de generalização. Porém, a complexidade de sistemas de médio até grande porte pode acarretar em uma insuficiência de precisão nos resultados de simulação, acarretando assim em um pobre desempenho (GUILLAUME, 2001).

Um outro tipo de sistema de inferência fuzzy pode ser identificado como sendo aqueles que incorporam o aprendizado através de um conjunto de dados onde estão paralelizados as variáveis de entrada com suas respectivas saídas. Desta forma, pode-se observar que este segundo tipo de sistema de inferência fuzzy é definido com base nos dados coletados do sistema ao qual se deseja modelar; diferenciando-se do primeiro tipo, onde o sistema fuzzy era definido se relacionando o conhecimento especialista adquirido pela observação do sistema.

Takagi \& Sugeno (1985) foram um dos primeiros pesquisadores a proporem estruturas de sistemas de inferência fuzzy próprio à agregação de algoritmos de sintonia, ou seja, sistemas de inferência fuzzy baseada em um conjunto de padrões de ajuste para a sua definição.

De uma forma genérica, esses métodos de ajuste de sistemas de inferência fuzzy podem ser interpretados como sendo compostos de técnicas de geração de regras através dos dados disponíveis para o ajuste (ou treinamento) e de técnicas dedicadas ao ajuste dos parâmetros livres do sistema fuzzy.

O processo de geração das regras de inferência pode ser decomposto em dois passos principais: 
* Indução das regras.

- Otimização da base de regras.

Em pequenos sistemas, praticamente não existe a necessidade de se otimizar a base de regras induzidas no primeiro passo, pois esta possui um tamanho reduzido devido às próprias características do sistema. Em sistemas mais complexos, a otimização da base de regras induzidas se faz necessária, pois a base de regras se torna muito grande e a descrição de cada uma das regras é muito complexa devido ao número de variáveis. Desta forma, a interpretabilidade das regras pode ficar comprometida (GUILLAUME, 2001).

A fim de contornar o problema da interpretabilidade das regras, procura-se referenciar as regras em função das variáveis mais ponderantes, assim, o conhecimento armazenado no sistema poderá ser mais bem compreendido e o número de regras se tornará menor.

Pode-se observar que a indução de regras e a respectiva redução da base de regras são, assim, dois importantes passos no processo de geração das regras. A agregação destes dois processos é usualmente referenciada como otimização estrutural do sistema fuzzy.

Além da otimização estrutural, um sistema de inferência fuzzy possui muitos outros parâmetros que podem ser otimizados como, por exemplo, os parâmetros das funções de inferência e a ponderação de cada regra fuzzy. Este processo de otimização é conhecido como otimização paramétrica do sistema de inferência fuzzy.

A otimização paramétrica de sistemas de inferência fuzzy é objetivo de estudo de diversos autores como pode ser observado em Roger Jang et al. (1997) e Glorennec (1999).

Com relação à otimização estrutural se pode mencionar que existem dois tipos de métodos para a indução de regras. O primeiro tipo utiliza o particionamento do espaço multidimensional. O particionamento pode ser realizado baseado nos dados disponíveis, ou, definidos pelo conhecimento especialista. O processo de particionamento implica na definição do número de conjuntos fuzzy para cada variável do sistema e pressupõe que estas serão compartilhadas por todas as regras. O objetivo, neste caso, da técnica de ajuste é de otimizar a estrutura de particionamento.

A segunda família de métodos para a indução de regras é conhecida como clustering. Nestes métodos, os pares de dados (entradas - saídas) são reunidos em grupos homogêneos e existe uma regra associada a cada grupo. Nestes métodos os conjuntos fuzzy 
não são compartilhados por todas as regras, mas sim, cada um destes conjuntos fuzzy é associado a uma regra em específico.

Ainda com relação a estes métodos, pode-se citar uma outra família denominada de métodos híbridos. Tem-se nestes métodos o intenso uso de técnicas computacionais, principalmente envolvendo outras abordagens da inteligência computacional; além disso, são mais heterogêneos do que os demais e seus resultados são altamente dependentes da implementação e da codificação empregada.

Dentro da primeira família de métodos para indução de regras em sistemas fuzzy é conveniente mencionar os principais. Desta forma, tem-se:

* IMPlementaÇão de tOdas AS Regras. Em Ishibuchi et al. (1994), um sistema de inferência fuzzy com múltiplas entradas e uma única saída é considerado. As regras são inferidas considerando todas as combinações possíveis dos conjuntos fuzzy de cada entrada. Trabalhos como o de Nozaki et al. (1997) propõe formas para o cálculo da ponderação das regras utilizando técnicas heurísticas. A partir desta abordagem, pôde-se perceber que, dentro da base de regras do sistema de inferência fuzzy, existiriam regras que nunca seriam ativadas pelos padrões de ajuste disponíveis.

Número de Conjuntos Fuzzy Dinamicamente Escolhidos. A escolha do número de conjuntos fuzzy associados a cada variável do sistema acarreta em conseqüências significantes. Se este número for muito pequeno, o sistema não será capaz de mapear o relacionamento implícito, acarretando em perda de precisão. Por outro lado, torna-se complicado aumentar o número de conjuntos fuzzy devido às seguintes razões: 1) Se este número for muito grande, os conjuntos fuzzy tendem a ser muito específico, resultando em uma perda da generalização; 2) À medida que se incrementa o número de conjuntos fuzzy, o número de regras tende a ser muito grande (GUILLAUME, 2001). Para evitar o uso de um número fixo de conjuntos fuzzy, alguns autores propõem metodologias para extração do número de conjuntos fuzzy a partir dos dados disponíveis para o ajuste. Dentre estes métodos, pode-se destacar:

- Refino do Particionamento. Dado um sistema de inferência fuzzy, inicialmente se atribui a cada uma de suas variáveis dois conjuntos fuzzy. A cada iteração, um novo conjunto fuzzy é adicionado na entrada 
que é responsável pela maior parte do erro. Maiores detalhes sobre esta técnica podem ser encontrados em Bortolet (1998).

* Uso de Algoritmos Genéticos. Em Ishibuchi et al. (1995), problemas de classificação são tratados. Para atingir esses objetivos, diferentes partições fuzzy são geradas. Algoritmos genéticos são utilizados para selecionar o melhor particionamento de acordo com os dados disponíveis. Todas as regras correspondentes a um dado particionamento são consideradas. A função objetivo do algoritmo genético leva em consideração tanto o desempenho do sistema como a dimensão da base de regras.

- Uma Única Regra por Par de Dados. Este método foi introduzido por Wang \& Mendel (1992), aonde o número de regras é limitado ao número de padrões de treinamento. Esta metodologia independe do nível de particionamento, e a mesma agrega características adaptativas ao sistema, visto que as regras competem entre si.

* ÁRvores de Decisão. As árvores de decisão foram propostas por Quinlan (1986) e metodologias alternativas para a sua implementação também podem ser encontradas em Ichihashi et al. (1996). O objetivo desta técnica é de encontrar caminhos que levem a níveis puros, ou seja, regras com o mínimo de antecedentes, de tal forma que regras incompletas possam ser geradas. A árvore de decisão vem a representar o subespaço de todas as regras possíveis.

Dentre a segunda família de métodos para a indução de regras, os seguintes métodos podem ser destacados:

Fuzzy C-Means Clustering. Este método foi introduzido por Dunn (1973). Bezdek demonstrou suas propriedades e a proposição do primeiro critério para a sua validação (BEZDEK, 1981; RUNKLER \& BEZDEK, 1999). A aplicação desta técnica possui diferentes implementações como aquelas propostas em Sugeno \& Yasukawa (1993) e em Emami et al. (1998), onde a categorização é realizada no espaço das variáveis de saída. As premissas das regras, neste caso, são definidas pelas projeções dos clusters no espaço de entrada (GUILLAUME, 2001). 
* Cluster Validity. Desde os primeiros trabalhos de Bezdek, muitos grupos de pesquisadores estão envolvidos em pesquisas cujo foco se concentra em encontrar o número ótimo de conjuntos fuzzy. Este problema também é conhecido como problema da validação categorizada. Como exemplos de trabalhos realizados nesta área, pode-se citar o de Xie \& Beni (1991), Emani et al. (1998), Yager \& Filev (1994), Chiu (1994) e mais ainda Burrough (2000).

Como mencionado anteriormente, o conjunto de métodos classificados como métodos híbridos procura integrar entre si muitas ferramentas diferentes. Dentre estas ferramentas, as que mais se tem destacados são os algoritmos genéticos e as redes neurais artificiais.

Dentre as principais abordagens que usam métodos híbridos neuro-fuzzy destacase o algoritmo ANFIS (Adaptive-Network-based Fuzzy Inference Systems) proposto por Roger Jang (1993). Tal algoritmo de sintonia é aplicável a arquiteturas fuzzy que possuem funções reais polinomiais como conseqüentes das regras fuzzy. Como exemplo deste tipo de arquitetura, destaca-se aquela proposta em Takagi \& Sugeno (1985) e em Sugeno \& Kang (1988). No entanto, a representação de um processo através destas arquiteturas acarreta na perda de interpretabilidade junto à base de regras criadas, uma vez que os membros conseqüentes serão expressos, não por variáveis lingüísticas, mas sim por funções polinomiais conforme descrito anteriormente.

Torna-se assim interessante o desenvolvimento de algoritmos de ajuste de sistemas de inferência fuzzy baseados em arquiteturas Mandani, nos quais os membros conseqüentes das regras fuzzy sejam representados por uma variável lingüística. A abordagem fuzzy multicamadas proposta nesta tese foi desenvolvida com o intuito de atender a este quesito.

Desta forma, em relação ao problema tratado neste trabalho, aplicando-se a abordagem fuzzy multicamadas para mapear o relacionamento existente entre as tensões e correntes oscilografadas na subestação de distribuição de energia elétrica, torna-se possível a obtenção de uma estrutura fuzzy com alto grau de interpretabilidade do mapeamento realizado, pois os membros antecedentes e membros conseqüentes das regras serão definidos por variáveis lingüísticas. Em outras palavras, o sistema fuzzy desenvolvido poderá fornecer informações qualitativas sobre o inter-relacionamento entre as componentes ortogonais das tensões e das correntes com a ocorrência ou não de uma falta, bem como relacionar as 
referidas grandezas com a distância relativa de sua ocorrência. Esse aspecto, ou seja, da capacidade dos sistemas fuzzy representarem o relacionamento entre o espaço das entradas com o espaço das saídas de forma verbal, pode ser pontuado como um dos aspectos motivadores para se empregar os sistemas fuzzy nos desenvolvimentos retratados nesse trabalho.

\subsection{MOdelo do Sistema Fuzzy Multicamadas}

Os sistemas de inferência fuzzy podem ser tratados como sistemas que empregam os conceitos e operações definidas pela teoria de conjuntos fuzzy, bem como fazem uso do processo de inferência fuzzy a fim de desempenhar suas funções operacionais. Basicamente, estas funções operacionais compreendem a fuzzificação das entradas do sistema, a inferência das regras associadas ao mesmo, a agregação das regras e a posterior defuzzificação do resultado da agregação, na qual vem a ser a saída, ou saídas, do sistema fuzzy.

Pode-se observar com isso, que os sistemas de inferência fuzzy possuem funções distintas e claramente definidas. Assim, pode-se interpretar tais sistemas através da representação por um modelo multicamadas.

Tendo em vista as funções operacionais desempenhadas pelos sistemas de inferência fuzzy, é conveniente a representação dos mesmos por um modelo de três camadas. Logo, o sistema de inferência fuzzy proposto nesta tese pode ser dado pela composição seqüencial da camada de entrada, da camada de inferência das regras fuzzy e da camada de saída.

A camada de entrada tem por funcionalidade a conexão às variáveis de entrada (advindas do meio externo), com o sistema de inferência fuzzy, bem como a fuzzificação dessas utilizando para isso as funções de pertinência associadas a cada entrada.

Na camada de inferência das regras fuzzy, ou simplesmente camada de inferência, as variáveis de entrada fuzzificadas são combinadas entre si, segundo as regras definidas, utilizando como suporte as operações definidas na teoria de conjuntos fuzzy.

Os resultados de cada regra individual são agregados, segundo algum método específico, compondo desta maneira o conjunto fuzzy de saída. Esse conjunto então é defuzzificado resultando na saída do sistema de inferência fuzzy. O processo de agregação e o processo de defuzzificação do conjunto fuzzy de saída são executados pela camada de saída. É importante observar, com relação à camada de saída, que apesar desta executar os dois 
processos acima descritos, ela é responsável também por armazenar as funções de pertinência das variáveis de saída.

Nas subseções que seguem, são apresentados mais detalhes das três camadas envolvidas com o sistema fuzzy multicamadas proposto.

\subsubsection{CAMADA DE ENTRADA}

Como apresentado anteriormente, a camada de entrada do sistema de inferência fuzzy tem por finalidade a conexão das entradas advindas do mundo real com o sistema fuzzy, bem como a fuzzificação destas entradas segundo as funções de pertinência associadas ao sistema fuzzy.

A fuzzificação das entradas do sistema tem por finalidade a determinação do grau de pertinência de cada entrada em relação aos conjuntos fuzzy associados a cada variável de entrada. À cada variável de entrada do sistema fuzzy podem estar associados tantos conjuntos fuzzy quanto necessários. Desta forma, dado um sistema fuzzy com uma única entrada e, a esta entrada, associadas $N$ funções de pertinência, ou seja, $N$ conjuntos fuzzy que definem a referida entrada, a saída da camada de entrada será um vetor coluna com $N$ elementos representando os graus de pertinência da entrada em relação a estes conjuntos fuzzy.

Se for definida a entrada deste sistema fuzzy, de uma única entrada, pelo escalar $x$, a saída da camada de entrada do sistema fuzzy será o vetor $\boldsymbol{Y}$, ou seja:

$$
\boldsymbol{Y}(x)=\boldsymbol{p}(x)=\left[\begin{array}{c}
p_{1}(x) \\
p_{2}(x) \\
\vdots \\
p_{N}(x)
\end{array}\right]
$$

onde $p_{k}($.) representa a função de pertinência definida para a entrada $x$ referente ao $k$-ésimo conjunto fuzzy associado a esta entrada.

A generalização do conceito de camada de entrada para um sistema fuzzy possuindo $m$ variáveis de entrada é realizada se cada uma dessas entradas do sistema fuzzy for modelada como uma subcamada da camada de entrada. Assim, o vetor de saída da camada de entrada $\boldsymbol{Y}(\boldsymbol{x})$ pode ser dado como apresentado em (4.12), ou seja: 


$$
\boldsymbol{Y}(\boldsymbol{x})=\left[\begin{array}{c}
\boldsymbol{Y}^{(1)} \\
\boldsymbol{Y}^{(2)} \\
\vdots \\
\boldsymbol{Y}^{(\boldsymbol{m})}
\end{array}\right]=\left[\begin{array}{c}
\boldsymbol{p}^{(1)}\left(x_{1}\right) \\
\boldsymbol{p}^{(2)}\left(x_{2}\right) \\
\vdots \\
\boldsymbol{p}^{(\boldsymbol{m})}\left(x_{m}\right)
\end{array}\right]
$$

onde $x_{i}$ é a $i$-ésima entrada do sistema fuzzy, $\boldsymbol{p}^{(k)}($.) é o $k$-ésimo vetor de função de inferência fuzzy associado à entrada $x_{k}$ e $\boldsymbol{Y}^{(k)}$. Cada subcamada possui seus conjuntos fuzzy definidos pelo vetor de funções de inferência fuzzy $\boldsymbol{p}^{(k)}($.$) .$

Portanto, o vetor $\boldsymbol{Y}(\boldsymbol{x})$ dado em (4.11) passa a ser definido como a concatenação vetorial dos vetores $\boldsymbol{Y}^{(1)}, \boldsymbol{Y}^{(2)}, \ldots, \boldsymbol{Y}^{(m)}$. Para um sistema constituído de duas variáveis de entrada, a expressão (4.12) seria dada por:

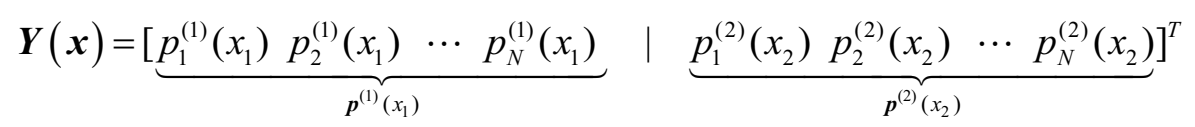

Como exemplo, a Figura 4.4 ilustra os conjuntos fuzzy associados a um sistema de duas entradas, $x_{1}$ e $x_{2}$, com três conjuntos fuzzy em cada uma.
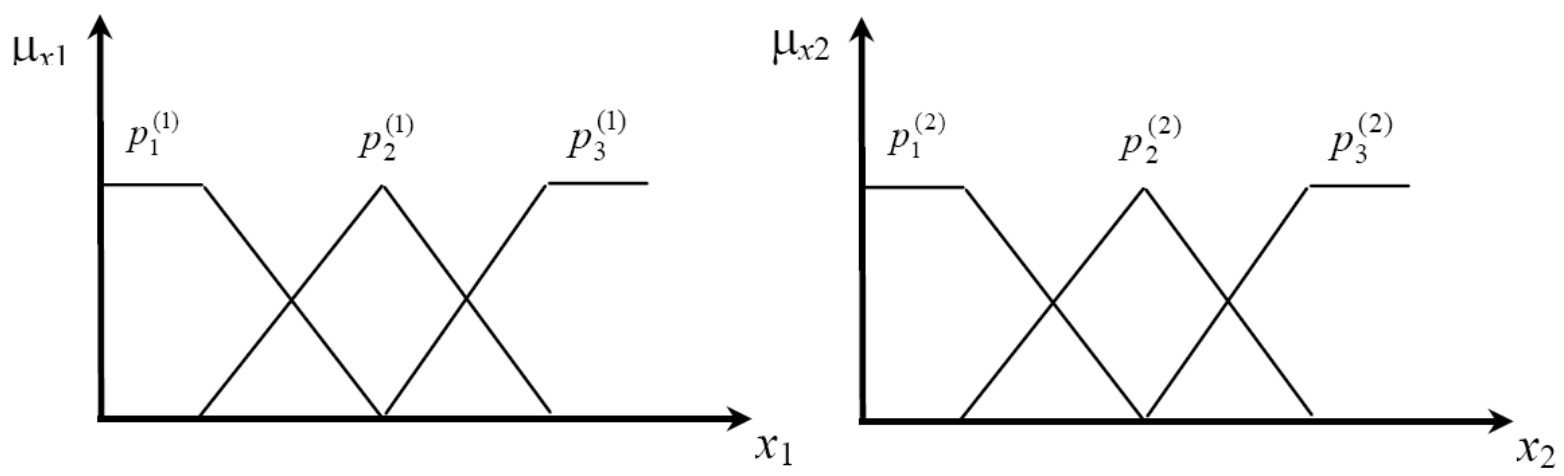

Figura 4.4 - Representação das entradas do sistema fuzzy multicamadas.

Como mencionado anteriormente, as funções de pertinência têm a propriedade de definirem os conjuntos fuzzy associados a cada entrada. Na camada de entrada, são as funções de pertinência que determinam o grau de pertinência de cada variável em relação ao conjunto fuzzy que essas definem.

As funções de pertinência podem ser definidas através de qualquer função. $O$ único requisito para tais funções é que as mesmas estejam definidas no domínio fechado [0,1]. Porém, é desejável que as funções de pertinência sejam definidas de forma simples e convenientemente para a respectiva implementação computacional, tendo como objetivo uma maior velocidade de processamento e uso racional de memória. 


\subsubsection{CAMADA DE INFERÊNCIA}

A camada de inferência de um sistema fuzzy tem por funcionalidade o processamento das regras de inferência fuzzy definidas para o mesmo. Outra funcionalidade da camada de inferência é de proporcionar uma base de conhecimento sobre o processo em questão. Da mesma forma como as subcamadas da camada de entrada, as regras de inferência são processadas de forma conjunta.

Dentro deste contexto, a definição deste conjunto de regras é de fundamental importância para o correto funcionamento do sistema de inferência fuzzy. Diversos são os métodos para extração das regras fuzzy a partir do conjunto de dados de ajuste.

A ponderação das regras de inferência é uma forma adequada de representar no sistema fuzzy as regras mais importantes ou mesmo permitir que regras conflitantes se relacionem sem que haja perda de completude verbal das regras.

Desta forma, pode-se expressar a $i$-ésima regra fuzzy como em (4.14), ou seja:

$$
R_{i}(\boldsymbol{Y}(\boldsymbol{x}))=w_{i} r_{i}(\boldsymbol{Y}(\boldsymbol{x}))
$$

onde $R_{i}($.$) é a função que representa o valor ponderado da i$-ésima regra fuzzy, $w_{i}$ é o fator de ponderação da $i$-ésima regra fuzzy e $r_{i}$ (.) representa o valor fuzzy da $i$-ésima regra fuzzy.

\subsubsection{CAMADA DE SAÍDA}

A camada de saída do sistema de inferência fuzzy tem por finalidade a agregação das regras de inferência, bem como a defuzzificação do conjunto fuzzy gerado pela agregação das regras de inferência.

No projeto de sistemas de inferência fuzzy, a escolha tanto do método de agregação como do método de defuzzificação constitui em uma decisão importante. O método de agregação das regras de inferência fuzzy deve ser tal que, o conjunto fuzzy resultante da agregação seja capaz de inferir adequadamente o conhecimento explicitado pelo conjunto de regras fuzzy do mesmo. De forma análoga, o método escolhido para a defuzzificação deve ser capaz de expressar, em um valor não fuzzy, o conjunto fuzzy resultante da agregação fuzzy.

Além destes aspectos operacionais, os métodos de agregação e defuzzificação devem atender os requisitos de desempenho computacional, a fim de reduzir o esforço computacional necessário ao processamento do sistema fuzzy. Neste trabalho, utiliza-se como 
método de agregação o operador "máximo" e para a defuzzificação o método "centro de área" (PEDRYCZ \& GOMIDE, 1998), o qual produzirá a única saída defuzzificada do sistema.

Neste trabalho, a camada de saída do sistema fuzzy também é ajustada, sendo a mesma representada por conjuntos fuzzy da camada de saída. O ajuste desta camada ocorre de forma semelhante ao da camada de entrada. A Figura 4.5 apresenta um diagrama esquemático do modelo fuzzy multicamadas para um sistema composto de duas entradas e três regras de inferência ativadas.

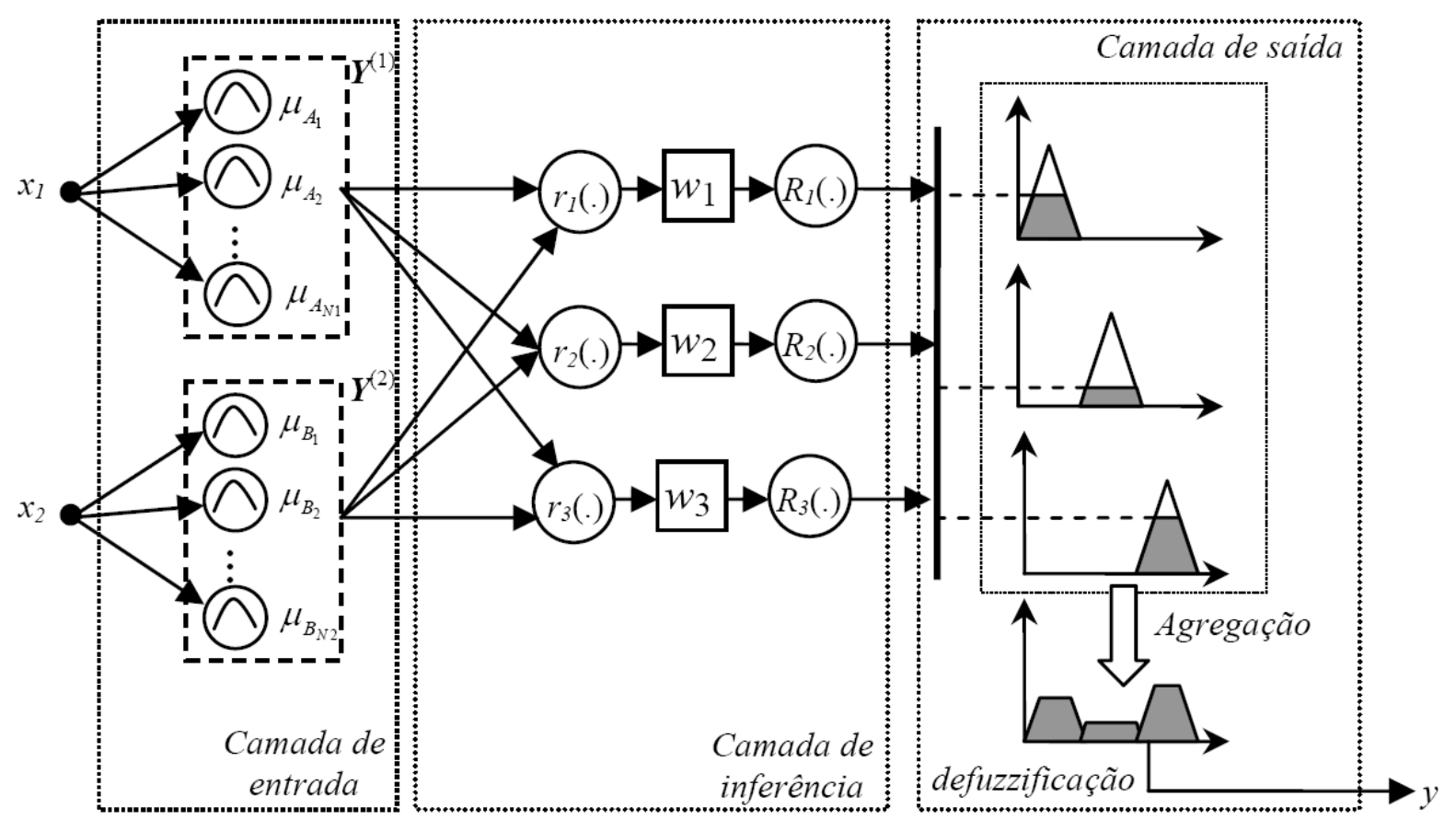

Figura 4.5 - Sistema fuzzy multicamada.

\subsection{AJUSTE ESTRUTURAL DE SISTEMAS DE INFERÊNCIA FUZZY}

De uma forma genérica, em aplicações envolvendo identificação de sistemas e modelagem fuzzy, é conveniente empregar funções custo que expressem o desvio entre os resultados desejados e os resultados fornecidos pelo sistema fuzzy. Desta forma, esta função pode ser explicitada em termos do erro quadrático médio entre a saída do sistema fuzzy e os resultados desejados, os quais são fornecidos na forma de um conjunto de treinamento, semelhante às redes neurais artificiais com treinamento supervisionado. Além do erro quadrático médio, pode-se ser acrescentado à função custo alguns indicadores de regularização dos dados, auxiliando assim, na melhoria da resposta do sistema na presença de ruídos nos dados de treinamento. 
Apesar de acrescentar uma nova tarefa no processo de criação de um sistema de inferência fuzzy, a definição da função custo associada ao sistema, em conjunto com as técnicas delineadas neste trabalho, vêm a poupar esforço do projetista nas etapas de sintonia das funções de pertinência e inclusive na criação das regras de inferência fuzzy.

O algoritmo de criação de base de regras empregado neste trabalho é baseado no algoritmo de otimização Hill Clibing (ROGER JANG et al, 1997). Assim, o procedimento desenvolvido tem o objetivo de realizar uma busca em um determinado espaço válido. Formalmente, dado um espaço de busca $S$ e um conjunto factível $F, F \subseteq S$, deve-se encontrar $r^{*}$ tal que a expressão (4.15) seja verdadeira, ou seja:

$$
\xi\left(r^{*}\right) \leq \xi(r) ; \quad \forall r \in F
$$

onde $\xi($.) representa a função custo associada ao sistema fuzzy, $r$ é uma determinada base de regras pertencente ao conjunto de todas as bases de regras válidas e $r^{*}$ configura a base de regras que fornece o menor valor para a função custo em relação à região factível $F$.

No entanto, a busca de uma base de regras que minimize a função custo $\xi$ configura uma sistemática complexa visto que o universo $F$ representando todas as bases de regras factíveis possui inúmeras possibilidades. Além disso, a superfície definida por $\xi$ é composta de pontos de mínimos e de máximos, comprometendo assim a busca por uma solução que satisfaça a condição de mínimo global.

Desta forma, torna-se conveniente a adoção de estratégias de busca que operem localmente. Assim, a expressão (4.15) pode ser modificada conforme apresentado a seguir:

$$
\xi\left(r^{(1)}\right) \leq \xi\left(r^{(2)}\right) ; \forall r^{(2)} \in N\left(r^{l}\right)
$$

onde:

$$
N\left(r^{(1)}\right)=\left\{r^{(2)} \in F: \operatorname{dist}\left(r^{(1)}, r^{(2)}\right) \leq \varepsilon\right\}
$$

onde $\operatorname{dist}\left(r^{(1)}, r^{(2)}\right)$ é uma função que determina a distância entre $r^{(1)} \mathrm{e} r^{(2)}$, e $\varepsilon$ é uma constante que define o raio da função vizinhança $N($.$) .$

Portanto, devido à complexidade do processo de busca de uma base de regras que satisfaça a condição (4.16), o algoritmo de otimização estrutural proposto neste trabalho opera em duas fases distintas. Na primeira fase são sorteadas diversas bases de regras. A base de regras que fornecer o menor custo é aceita. Desta maneira, o espaço de busca ficará restrito a 
uma determinada região definida pelo conjunto $N\left(r^{(1)}\right)$, onde $r^{(1)}$ representa a base de regras sorteada que apresentou o menor custo frente às demais.

Tendo como ponto inicial a base de regras $r^{(1)}$ escolhida na primeira fase, tem-se na segunda fase a realização do ajuste local através da inserção de pequenas perturbações na base de regras original. Caso a perturbação inserida proporcione uma redução do custo, tal perturbação é aceita e o processo continua até que não se observe melhoria significativa no sistema por um determinado número de iterações. O algoritmo de extração de regras baseado na abordagem descrita é apresentado na Figura 4.6.

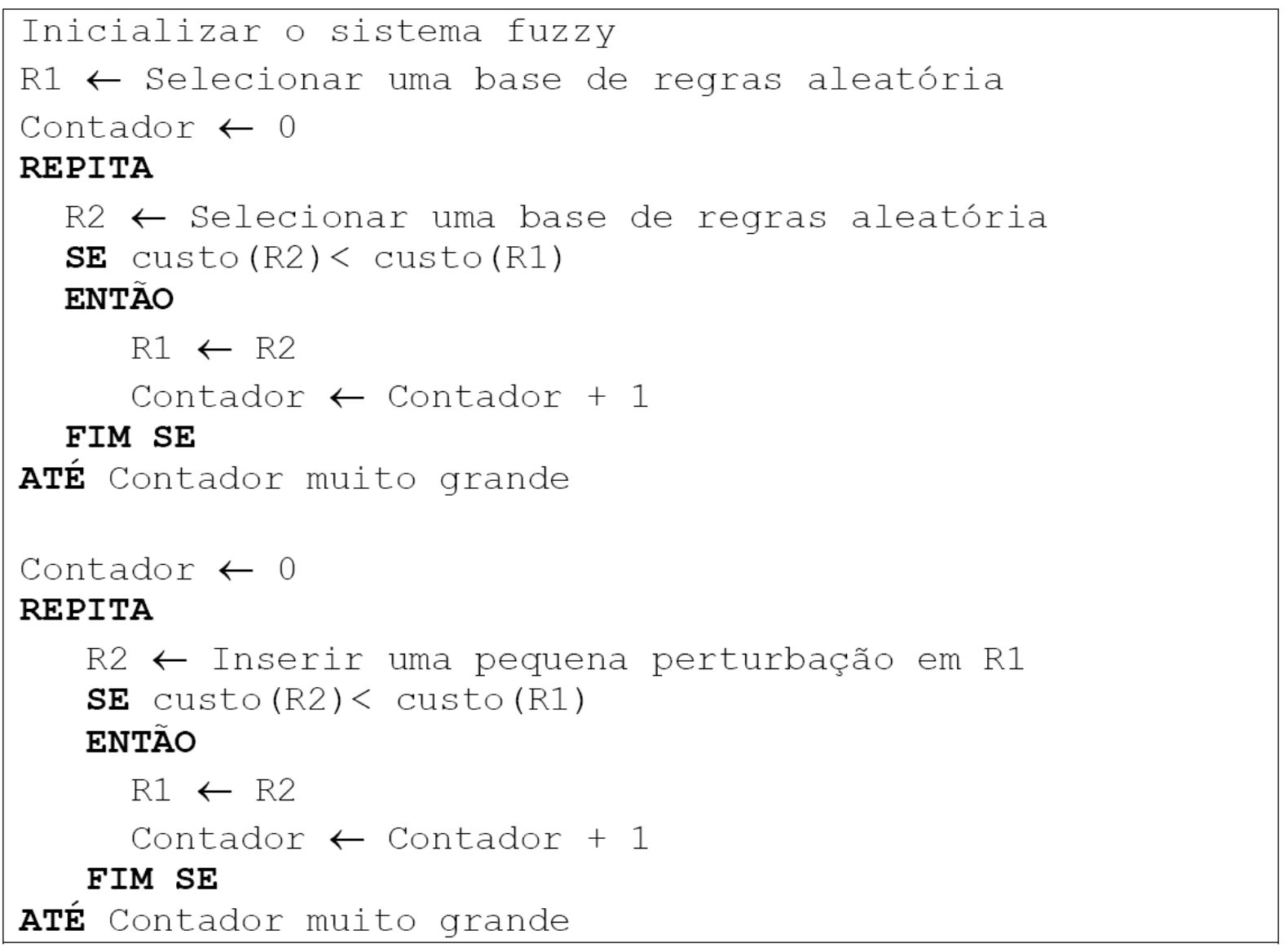

Figura 4.6 - Algoritmo de extração de regras fuzzy.

\subsection{AJUSte Paramétrico de Sistemas de InferênCia FUZZY}

Nesta seção será apresentado um método de sintonia de sistemas de inferência fuzzy baseado em algoritmos de retropropagação de erro e técnicas de otimização. Este método tem por objetivo a minimização de uma função custo associada ao sistema de inferência fuzzy. 
A formalização de um sistema de inferência fuzzy na forma de um sistema multicamadas, como apresentado na Seção 4.5, pode ser justificada não só pela divisão operacional distinta de cada uma destas camadas, mas também, pela presença em cada qual de parâmetros livres distintos. Como apresentado anteriormente, tem-se na camada de entrada os parâmetros das funções de pertinência dos conjuntos fuzzy do espaço de entrada do sistema, na camada de inferência fuzzy se tem a ponderação das regras e na camada de saída os parâmetros das funções de pertinência dos conjuntos fuzzy do espaço de saída.

Considerando que o conjunto de ajuste $\{\boldsymbol{x}, y\}$ é fixo durante todo o processo de ajuste, então a função custo responsável pela sintonia dos parâmetros livres do mapeamento fuzzy $g: x \rightarrow y$ pode ser escrita da seguinte forma:

$$
\xi_{g}=\xi\left(\boldsymbol{h}^{(1)}, \boldsymbol{h}^{(2)}, \boldsymbol{h}^{(3)}\right)
$$

onde $\boldsymbol{h}^{(1)}, \boldsymbol{h}^{(2)}$ e $\boldsymbol{h}^{(3)}$ representam respectivamente os vetores dos parâmetros das funções de pertinência de entrada, o vetor da ponderação das regras de inferência e o vetor dos parâmetros das funções de pertinência de saída.

Assim, após a minimização da função custo $\xi_{g}$, os diversos parâmetros livres incorporados nos vetores $\boldsymbol{h}^{(1)}, \boldsymbol{h}^{(2)}$ e $\boldsymbol{h}^{(3)}$ corresponderão aos valores que minimizam a respectiva função custo.

Logo, o problema de ajuste paramétrico de um sistema de inferência fuzzy pode ser interpretado como sendo um problema de otimização irrestrita, podendo este ser resolvido por qualquer método disponível para tal. Neste trabalho utilizou o método do gradiente descendente para a minimização da função custo e o cálculo do gradiente foi estimado através do emprego do método de equações às diferenças.

Para elucidar este processo de ajuste, considera-se um sistema fuzzy tendo na camada de entrada uma variável com duas funções de pertinência gaussiana, a camada de inferência composta de três regras e a camada de saída com uma variável composta por duas funções de pertinência gaussiana. Assim sendo, os vetores de parâmetros $\boldsymbol{h}^{(1)}, \boldsymbol{h}^{(2)}$ e $\boldsymbol{h}^{(3)}$ serão dados por:

$$
\begin{aligned}
\boldsymbol{h}^{(1)} & =\left[\begin{array}{lllll}
\mu_{1}^{e} & \sigma_{1}^{e} & \vdots & \mu_{2}^{e} & \sigma_{2}^{e}
\end{array}\right]^{T} \\
\boldsymbol{h}^{(2)} & =\left[\begin{array}{llll}
w_{1} & w_{2} & w_{3}
\end{array}\right]^{T} \\
\boldsymbol{h}^{(3)} & =\left[\begin{array}{lllll}
\mu_{1}^{s} & \sigma_{1}^{s} & \vdots & \mu_{2}^{s} & \sigma_{2}^{s}
\end{array}\right]^{T}
\end{aligned}
$$


onde $\mu_{i}^{e}$ e $\sigma_{i}^{e}$ são respectivamente a média e a variância da $i$-ésima função de pertinência de entrada; $w_{1}, w_{2}$ e $w_{3}$ são os fatores de ponderação das regras fuzzy; $\mu_{\mathrm{i}}^{s}$ e $\sigma_{i}^{s}$ são respectivamente a média e a variância da $i$-ésima função de pertinência de saída.

Para o caso de ajuste camada a camada, basta aplicar então o método do gradiente descendente em cada uma delas. Para o caso da segunda camada, representando os fatores de ponderação das regras, tem-se a seguinte expressão:

$$
\boldsymbol{h}^{(2)}(k)=\boldsymbol{h}^{(2)}(k-1)+\eta \cdot \nabla \xi\left(\boldsymbol{h}^{(2)}(k-1)\right)
$$

sendo $\eta$ a taxa de aprendizagem. Neste caso, o vetor gradiente $\nabla \xi\left(\boldsymbol{h}^{(\cdot)}\right)$ pode ser dado de forma genérica por:

$$
\nabla \xi\left(\boldsymbol{h}^{(.)}\right)=\left[\begin{array}{llll}
\frac{\partial \xi}{\partial h_{1}^{(.)}} & \frac{\partial \xi}{\partial h_{2}^{(.)}} & \cdots & \frac{\partial \xi}{\partial h_{n}^{(.)}}
\end{array}\right]^{T}
$$

onde $h_{i}^{(.)}$representa o $i$-ésimo elemento do vetor de parâmetros $\boldsymbol{h}^{(.)}$e $n$ é o número de elementos deste vetor. Neste caso, como a expressão analítica do vetor gradiente é de difícil obtenção, utiliza-se a aproximação numérica do mesmo através do método de equações às diferenças (DENNIS \& SCHNABEL, 1983), ou seja:

$$
\frac{\partial \xi}{\partial h_{i}^{(.)}} \cong \frac{\xi\left(\boldsymbol{h}^{(.)}+\rho \cdot \boldsymbol{e}_{i}\right)-\xi\left(\boldsymbol{h}^{(.)}\right)}{\rho}
$$

onde $\rho$ é um valor muito pequeno e $\boldsymbol{e}_{i}=\left[\begin{array}{llll}0 & 0 \ldots & \ldots . .0\end{array}\right]^{T}$, sendo que o elemento igual a 1 ocupa a posição $i$.

A função custo $\xi_{g}$ neste caso é a própria função erro quadrático médio em relação aos $p$ padrões de sintonia, ou seja:

$$
\xi_{g}=\frac{1}{p} \sum_{k=1}^{p} \xi_{g(k)}
$$

sendo que $\xi_{g(k)}$ é o erro quadrático em relação ao $k$-ésimo padrão de treinamento, ou seja:

$$
\xi_{g(k)}=\left(d_{k}-y_{k}\right)^{2}
$$

onde $d_{k}$ é o valor da saída desejada em relação ao $k$-ésimo padrão de treinamento e $y_{k}$ é a saída fornecida pelo sistema fuzzy também em relação ao $k$-ésimo padrão de treinamento. 
A Figura 4.7 ilustra o algoritmo de sintonia paramétrica proposto neste trabalho quando aplicado na otimização da camada $\boldsymbol{h}^{(2)}$.

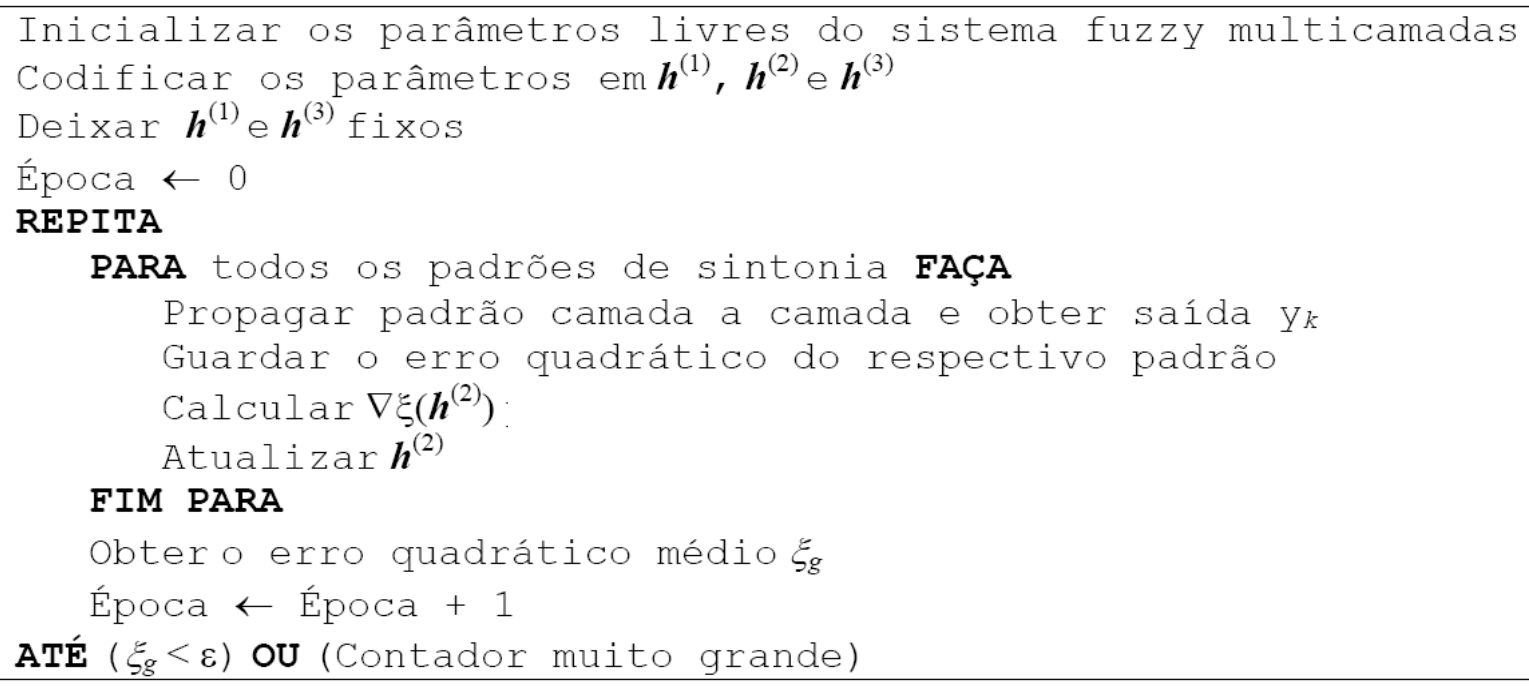

Figura 4.7 - Algoritmo de sintonia paramétrica.

Os procedimentos para os ajustes das camadas $\boldsymbol{h}^{(1)}$ e $\boldsymbol{h}^{(3)}$ são similares a aqueles fornecidos na Figura 4.7.

\subsection{CONSIDERAÇÕES SOBRE O SISTEMA FUZZY MULTICAMADAS}

A especificação do sistema fuzzy multicamadas proposto neste trabalho pode então ser realizada se definindo, além do número de entradas do mesmo, o número de funções de pertinência associadas a cada uma destas entradas e o número de funções de pertinência para a saída do mesmo.

Assim, como exemplo do sistema fuzzy multicamadas proposto, toma-se um sistema de duas entradas e para cada uma das entradas se tem três funções de pertinência gaussiana associadas. Supõe-se ainda que a variável de saída tem duas funções de pertinência gaussiana associadas e uma base de regras composta de cinco regras. Admitindo-se que a cada função gaussiana possui dois parâmetros livres de ajuste, a média e a variância, então a camada de entrada possuirá 12 parâmetros livres de ajuste, da mesma maneira que a camada de saída possuirá 4 parâmetros de ajuste. Como cada regra possui um fator de ponderação, a base de regras possuirá cinco parâmetros de ajuste. Desta forma, tem-se que o número total de parâmetros livres a serem ajustados será 21 .

Valendo-se de uma nova abordagem do ponto de vista de definição, o sistema fuzzy passa a ser definido na forma de um modelo de três camadas. Cada uma destas camadas 
vem a representar as tarefas desempenhadas pelo sistema de inferência fuzzy, ou seja, as tarefas de fuzzificação, inferência das regras fuzzy e defuzzificação.

O ajuste do sistema de inferência fuzzy, proposto neste trabalho, é desempenhado através da adaptação dos parâmetros livres de cada uma destas camadas com o objetivo de minimizar a função custo definida inicialmente.

Em princípio, o ajuste paramétrico pode ser efetuado camada a camada separadamente, não impedindo, no entanto, que este venha a ser realizado em todas as camadas a cada iteração. A distinção operacional de cada camada, onde o ajuste dos parâmetros de uma camada pouco influi no desempenho das demais, permite o ajuste individual das camadas. Desta forma, a rotina de sintonia do sistema de inferência fuzzy adquire uma maior flexibilidade quando comparada ao processo de treinamento empregado em redes neurais artificiais.

Desta maneira, o algoritmo de ajuste proposto neste trabalho possui duas etapas distintas de operação. Na primeira etapa, a base de regras é gerada de forma a minimizar a função custo associada ao sistema. Na segunda etapa, a sintonia fina do sistema é realizada através da adequação dos parâmetros livres do sistema, ou seja, nesta etapa os parâmetros das funções de pertinência das entradas e das saídas, bem como a ponderação de cada regra é alterada de forma a otimizar o sistema fuzzy. 


\section{APÍTULO 5}

\section{SISTEMA IDENTIFICADOR DE FALTA E SISTEMA DISCRIMINADOR DE FASE FALTOSA}

\subsection{INTRODUÇÃO}

As faltas de alta impedância fase-terra são caracterizadas por correntes com magnitudes inferiores à da corrente de carga, fato esse que decorre na inoperância de elos fusíveis instalados ao longo dos alimentadores do sistema de distribuição. Além disso, em muitas vezes, a magnitude da corrente de neutro não é capaz de sensibilizar as proteções de neutro da subestação fazendo com que a falta permaneça no sistema, colocando em risco pedestres, animais e construções civis e comprometendo, ainda, a qualidade do fornecimento de energia elétrica aos consumidores do referido sistema de distribuição de energia elétrica.

Dessa maneira, tendo na melhoria da segurança e na garantia da qualidade de fornecimento os aspectos motivadores para pesquisas de aplicação prática, inúmeros centros de pesquisa tornaram esse tema uma linha de investigação central no contexto de sistemas de distribuição de energia elétrica. Algumas das contribuições desses grupos de pesquisa e de seus respectivos pesquisadores foram pontuadas ainda no Capítulo 1, sendo o Capítulo 2 dedicado a uma visão geral sobre os mesmos. No entanto, mesmo sendo esse tema foco de investigação desde meados da década de 1970, seu fechamento não constitui em um desmembramento previsível. Pelo contrário, sob o ponto de vista da técnica, o advento de 
novas ferramentas computacionais e a aplicação de ferramentas matemáticas contemporâneas faz crescer a busca por metodologias que contornem, mesmo que de forma parcial, o problema abordado nessa tese. Em colaboração com os aspectos motivadores desse trabalho tem-se a crescente necessidade e preocupação com aspectos referentes à segurança e à qualidade do fornecimento de energia elétrica.

Mesmo existindo uma grande diversidade de abordagens tanto para o problema da identificação como para o de localização de faltas de alta impedância, retratadas resumidamente no Capítulo 2, pode-se, contudo, extrair dessas um modelo comum para a execução de ambas as tarefas. Esse modelo comum, quando analisado sob um ponto de vista amplo, é constituído por dois blocos de processamento. O primeiro desses módulos é responsável por receber as formas de onda de tensão e de corrente e dessas extrair características que permitam que o segundo bloco de processamento identifique ou localize a falta de alta impedância. De forma esquemática, esse modelo comum pode ser representado como se faz por meio da Figura 5.1.

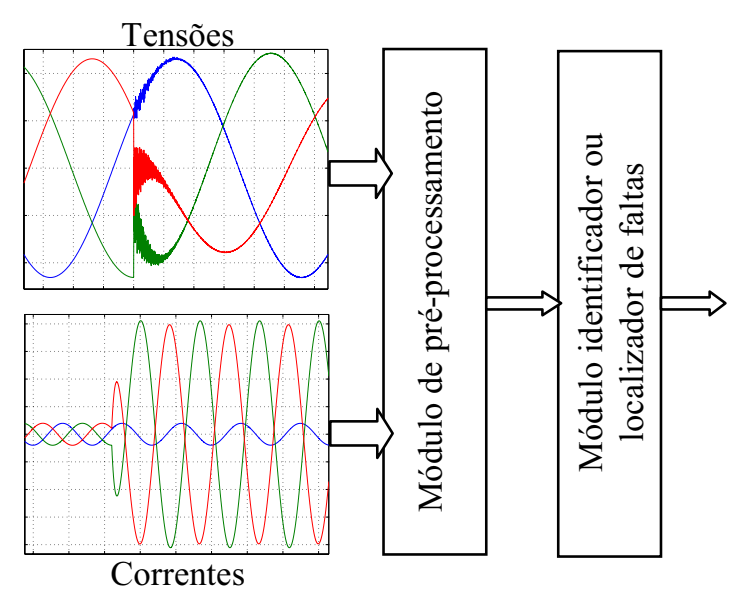

Figura 5.1 - Diagrama esquemático para o modelo comum de sistemas identificadores/localizadores de faltas de alta impedância.

Assim, diante da identificação do modelo comum, retratado na Figura 5.1, esse trabalho conduziu o desenvolvimento de duas propostas. A primeira dessas, delineada ao longo do Capítulo 3, e intitulada por decomposição em componentes ortogonais, apresentou como a partir das formas de onda de tensão e de corrente é possível extrair componentes, ortogonais entre si, ou seja, descorrelacionadas, capazes de sintetizar o comportamento do sistema elétrico sob estudo. Dessa forma, almeja-se empregar essa ferramenta matemática como módulo de pré-processamento para o modelo de sistema identificador de faltas apresentado nesse capítulo e para o modelo de sistema localizador de faltas proposto no Capítulo 6. A segunda proposta conduzida nessa tese e tema do Capítulo 4 constitui em uma 
proposição para o ajuste automático de sistemas de inferência fuzzy. Dessa forma, por meio de simulações computacionais de faltas de alta impedância e dos dados pré-processados, segundo os dizeres da decomposição em componentes ortogonais, almeja-se, nesse capítulo, constituir um primeiro sistema fuzzy que seja eficaz na identificação, em tempo hábil, de faltas de alta impedância. Além disso, ainda nesse capítulo, será conduzido o ajuste de um segundo sistema fuzzy capaz de informar qual das fases participou da falta. Prosseguindo com os desenvolvimentos desse trabalho, no Capítulo 6, fazendo uso novamente das características obtidas via decomposição por componentes ortogonais, serão ajustados outros dois sistemas fuzzy. O primeiro sistema fuzzy estimará a distância, relativa à subestação, que a falta de alta impedância ocorrera, enquanto que o segundo sistema fuzzy estimará a possível resistência dessa falta.

Atendo-se por agora nos objetivos desse capítulo, ou seja, na identificação e na determinação da fase participante da falta, apresenta-se na Figura 5.2 o diagrama esquemático do sistema desenvolvido para tais finalidades.

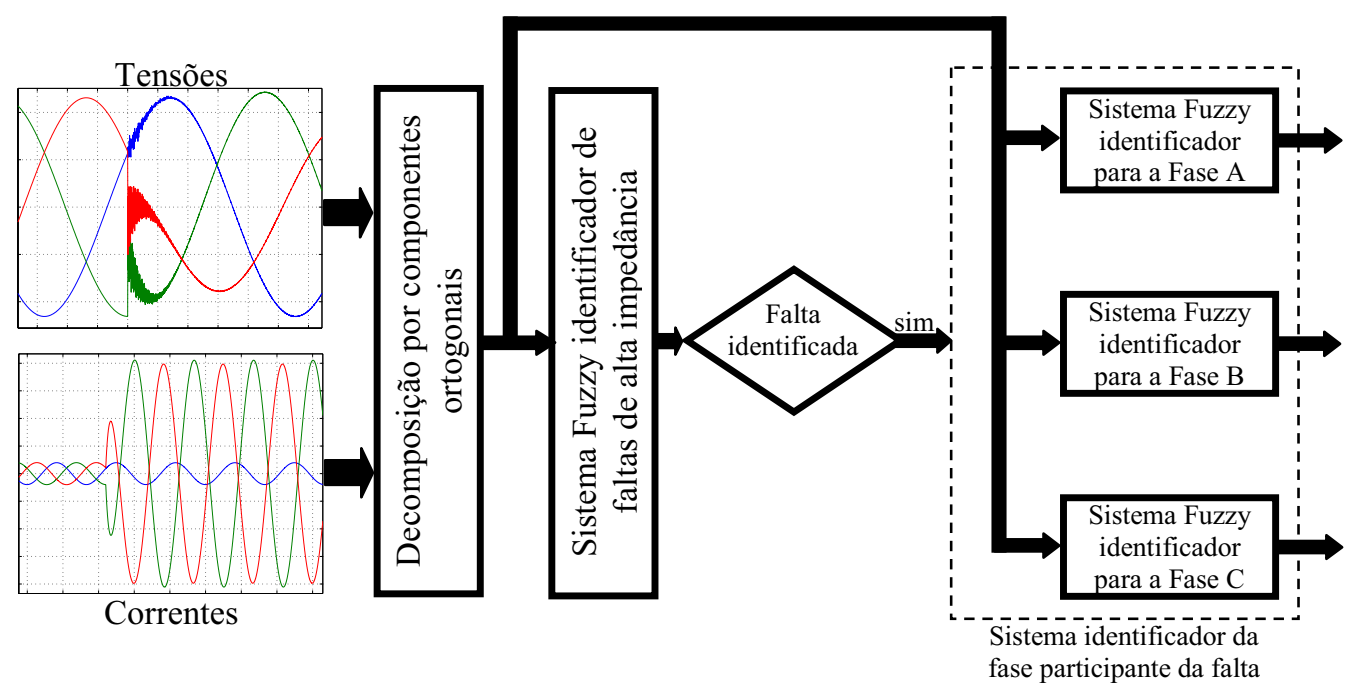

Figura 5.2 - Diagrama esquemático para o modelo proposto de sistema identificador de faltas de alta impedância e identificador da fase participante na falta.

Por meio do digrama esquemático apresentado por meio da Figura 5.2 é possível verificar que tanto o sistema identificador de faltas como o sistema identificador da fase participante da falta fazem uso dos dados providos pelo bloco de pré-processamento de dados os quais desempenham suas tarefas por meio da técnica da decomposição por componentes ortogonais. Ainda, vale ressaltar que o sistema identificador da fase participante da falta é composto por três sistemas fuzzy, um para a identificação de cada fase, os quais se tornam operantes apenas diante do indicativo da ocorrência de uma falta. Assim, nesse capítulo serão apresentados todos os detalhes relativos ao alimentador empregado nas simulações 
computacionais, detalhes esses expressos na Seção 5.2. Na Seção 5.3, a partir das simulações computacionais conduzidas segundo o descrito na Seção 5.2, será apresentada a implementação do sistema de pré-processamento de dados e como o mesmo se porta frente às formas de onda de tensão e de corrente. A implementação e os resultados relativos ao sistema identificador de falta serão tema da Seção 5.3, enquanto que a implementação e os resultados para o sistema identificador da fase participante da falta serão foco para a Seção 5.4. Por fim, na Seção 5.5, as considerações pertinentes ao expresso nesse capítulo serão tecidas.

\subsection{MODELAGEM COMPUTACIONAL DO AlimentAdoR PiLOTO}

Conforme descrito inicialmente nesse capítulo, serão empregadas simulações computacionais para, a partir dos resultados providos pelas mesmas, extrair características que permitam nesse primeiro momento ajustar o sistema fuzzy responsável por identificar a ocorrência de uma falta de alta impedância. Além disso, essas mesmas simulações computacionais serão empregadas para o ajuste dos sistemas fuzzy constituintes do sistema identificador da fase participante da falta.

Assim, fora escolhido um alimentador de um sistema de distribuição de energia elétrica de forma que as proposições desse trabalho fossem passíveis de estudo. O referido alimentador piloto empregado nas simulações computacionais é apresentado por meio da disposição geográfica de sua rede primária assim como ilustrado por meio da Figura 5.3.

O alimentador apresentado por meio da Figura 5.3 fora modelado por intermédio da linguagem descritiva ATP/EMTP, a qual é reconhecidamente uma ferramenta adequada para simulação de transitórios eletromagnéticos, tendo como suporte para a modelagem o ambiente gráfico ATPDraw. O sistema de transmissão fora modelado por meio de seu equivalente Thévenin o qual fora representado por uma fonte de tensão trifásica com tensão de linha de $138 \mathrm{kV}$ à $60 \mathrm{~Hz}$ e impedância série modelada por um ramo resistivo-indutivo série com resistência de 3,7444 $\Omega$ e indutância de 29,68 $\mathrm{mH}$, perfazendo uma impedância de $3,7444+j 11,1891 \Omega$ por fase. A Figura 5.4 apresenta o sistema de transmissão equivalente modelado por meio do ATPDraw. 


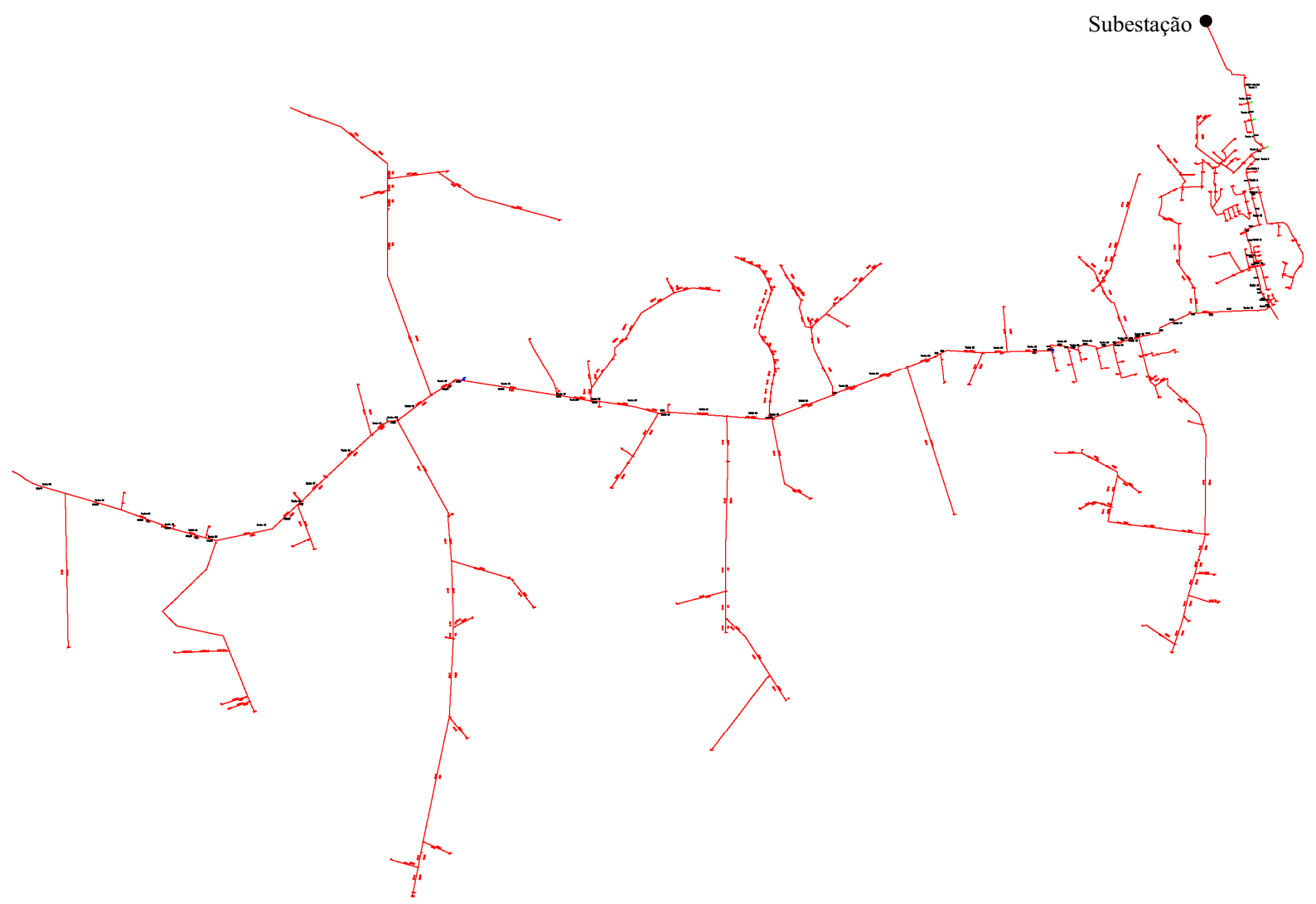

Figura 5.3 - Mapa dos trechos primários do alimentador piloto modelado computacionalmente.

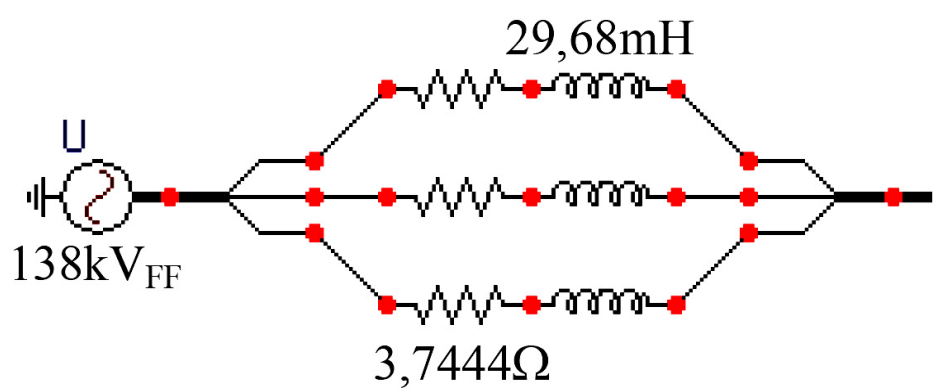

Figura 5.4 - Modelagem do sistema equivalente de transmissão feito por meio do ATPDraw.

O transformador da subestação de distribuição fora considerado como sendo possuidor de uma potência nominal de 33,3MVA trifásica e dois enrolamentos. O enrolamento de alta tensão com ligação delta e tensão nominal de $138 \mathrm{kV}$, enquanto que o enrolamento de média tensão com ligação estrela aterrada e defasagem angular de $30^{\circ}$ com tensão nominal de linha de $13,8 \mathrm{kV}$. O aterramento do enrolamento de média tensão fora modelado por meio de uma resistência de $10 \Omega$. Os parâmetros de modelagem foram informados por meio dos resultados dos ensaios à vazio e em curto-circuito do transformador os quais são apresentados por meio da Tabela 5.1. Em complemento, para a realização da modelagem do transformador foi empregado o módulo BCTRAN do ATP. 
Tabela 5.1 - Dados de ensaio do transformador da subestação.

\begin{tabular}{llll}
\hline \hline \multicolumn{2}{c}{$\begin{array}{c}\text { Ensaio em Vazio (enrolamento de } \\
\text { média tensão) }\end{array}$} & \multicolumn{2}{c}{ Ensaio em curto-circuito } \\
\hline \hline Tensão & $13,8 \mathrm{kV}$ & Impedância percentual & $13,9059 \%$ \\
\hline Corrente de excitação & $0,0861 \%$ & Potência & 33,3 \\
\hline Perdas & $19,9056 \mathrm{~kW}$ & Perdas & $141,1261 \mathrm{~kW}$ \\
\hline
\end{tabular}

A rede primária do alimentador piloto fora modelado possuindo um total de 277 barramentos de forma a auxiliar, com obtenção de dados representativos de faltas, os procedimentos de simulações computacionais as quais fizeram uso da modelagem computacional realizada por meio da linguagem descritiva do ATP/EMTP. Além de contribuir para a geração de uma base de dados significativa sobre faltas, essa modelagem auxiliou na setorização do alimentador padrão. O critério de determinação setorial se valeu da disposição geográfica do alimentador identificando, a princípio, o alimentador principal o qual é responsável por suprir energia elétrica a todos os ramais constituintes do mesmo. Assim, tem-se como primeiro setor o alimentador principal conforme se destaca por meio da Figura 5.5.

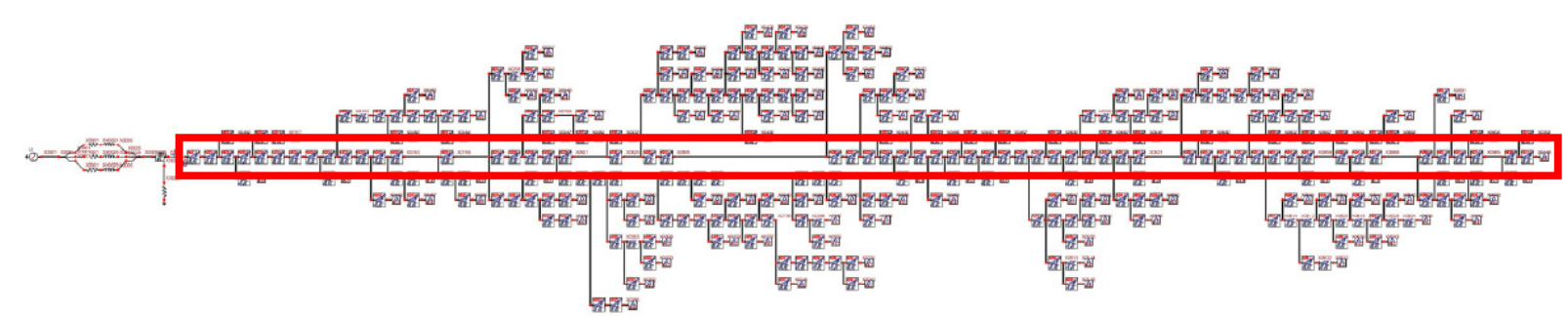

Figura 5.5 - Destaque para o alimentador principal no diagrama de blocos do modelo computacional do alimentador piloto.

Da mesma maneira, cada um dos ramais fora identificado e os trechos primários que o constitui foram catalogados. De forma semelhante, apresenta-se por meio da Figura 5.6 o Ramal 01, o Ramal 02 e Ramal 03.

A fim de delinear corretamente os trechos é nós que constituem o Ramal 01, o Ramal 02 e o Ramal 03, apresenta-se por meio da Tabela 5.2 tais informações. Prosseguindo com apresentação da setorização do alimentador padrão, apresenta-se na Figura 5.7 a representação em diagrama de blocos do Ramal 04, do Ramal 05, do Ramal 06, do Ramal 07 e do Ramal 08. Na seqüência, tem-se na Tabela 5.3 os trechos primários que compõem os ramais destacados na Figura 5.7. 


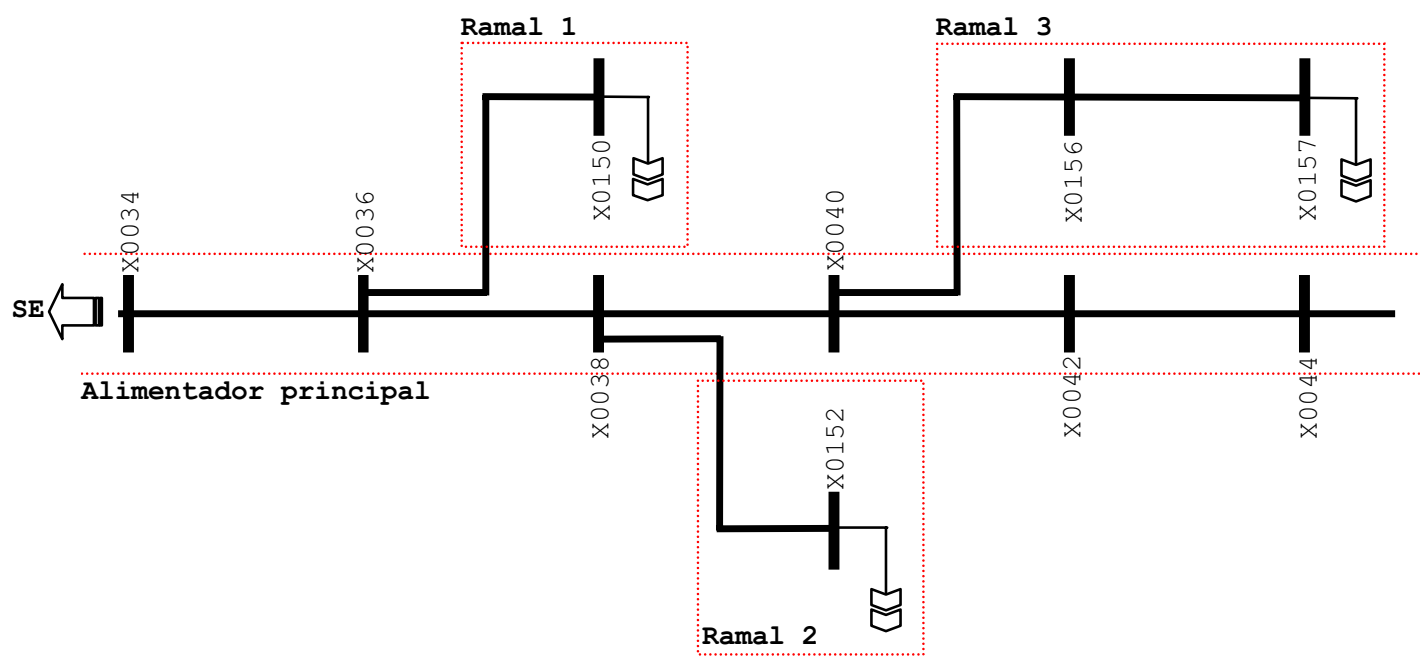

Figura 5.6 - Destaque para o Ramal 01, Ramal 02 e Ramal 03.

Tabela 5.2 - Trechos constituintes do Ramal 01, Ramal 02 e Ramal 03.

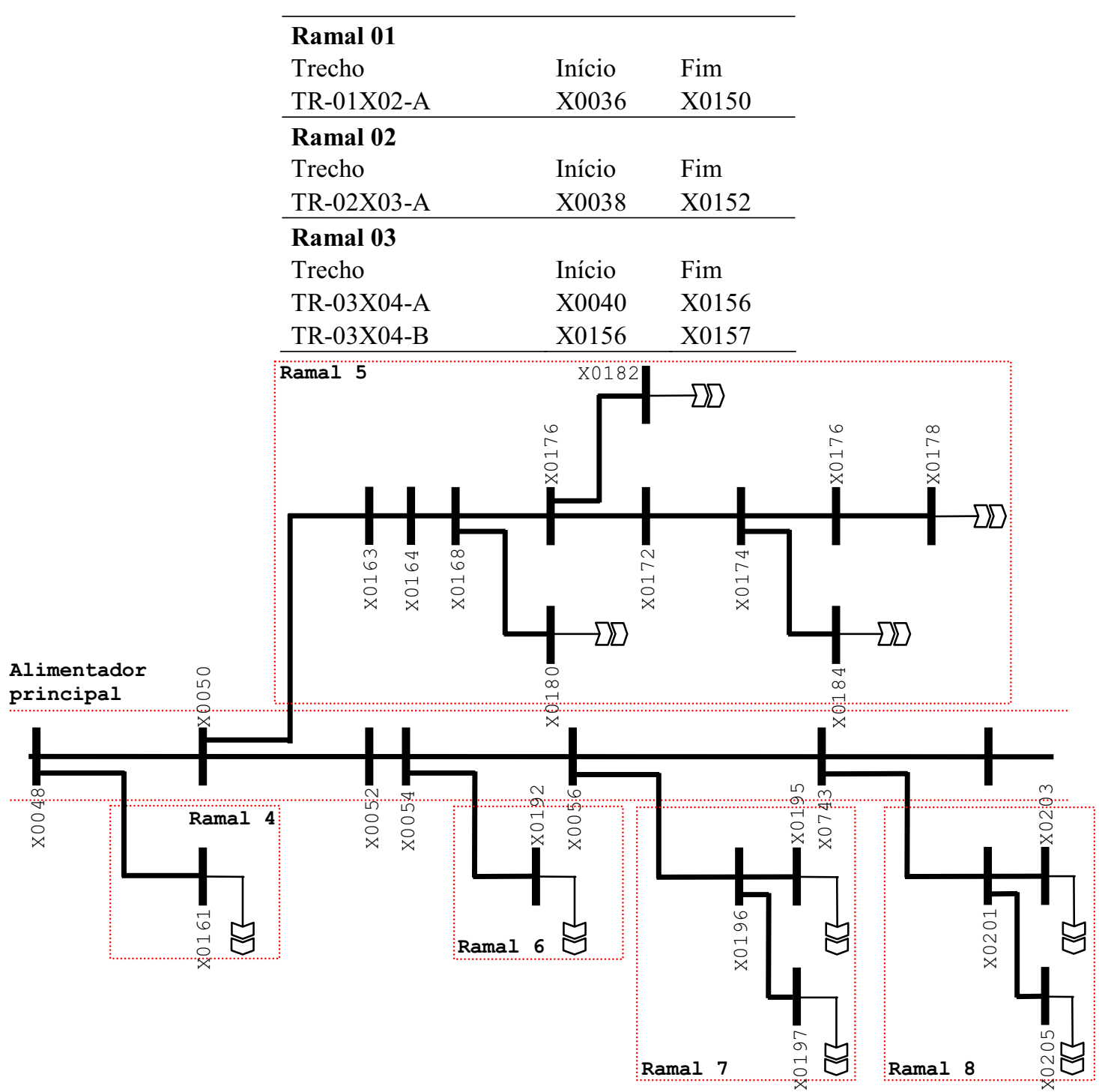

Figura 5.7 - Destaque para o Ramal 04, Ramal 05, Ramal 06, Ramal 07 e Ramal 08. 
O Ramal 09 é ilustrado por meio da Figura 5.8 onde se destaca sua disposição em relação ao alimentador principal. Conforme se pode observar por meio dessa figura, esse ramal é constituído por duas parcelas que possuem origem em um mesmo nó. Assim, a impedância equivalente nesse nó é compartilhada por ambas as parcelas, fato esse motivador para a setorização dessas como sendo um único ramal. Caso contrário, ou seja, se houvesse a classificação por meio de dois ramais originários no mesmo nó do alimentador padrão a localização de faltas poderia ficar comprometida o que deterioraria a robustez global do sistema especialista para localização de faltas. Complementando o digrama de blocos apresentado na Figura 5.8, destaca-se na Tabela 5.4 os trechos que constituem o Ramal 09.

Tabela 5.3 - Trechos constituintes do Ramal 04, Ramal 05, Ramal 6, Ramal 7 e Ramal 08.

\begin{tabular}{lll}
\hline $\begin{array}{l}\text { Ramal 04 } \\
\text { Trecho }\end{array}$ & Início & Fim \\
TR-07X08-A & X0048 & X0161 \\
\hline Ramal 05 & & \\
Trecho & Início & Fim \\
TR-08X09-B & X0163 & X0164 \\
TR-08X09-A & X0050 & X0163 \\
TR-08X09-C & X0164 & X0168 \\
TR-08X09-D & X0168 & X0170 \\
TR-08X09-E & X0170 & X0172 \\
TR-08X09-F & X0172 & X0174 \\
TR-08X09-G & X0174 & X0176 \\
TR-08X09-H & X0176 & X0178 \\
TR-08X09-CXD-A & X0168 & X0180 \\
TR-08X09-DXE-A & X0170 & X0182 \\
TR-08X09-FXG-A & X0174 & X0184 \\
\hline Ramal 06 & & \\
Trecho & Início & Fim \\
TR-11X12-A & X0056 & X0190 \\
TR-11X12-B & X0190 & X0195 \\
TR-11X12-AXB-A & X0190 & X0197 \\
\hline Ramal 07 & & \\
Trecho & Início & Fim \\
TR-10X11-A & X0054 & X0192 \\
\hline Ramal 08 & & \\
Trecho & Início & Fim \\
TR-12X13-A & X0747 & X0201 \\
TR-12X13-B & X0201 & X0203 \\
TR-12X13-AXB-A & X0201 & X0205 \\
\hline & & \\
\hline & &
\end{tabular}


Tabela 5.4 - Trechos constituintes do Ramal 09.

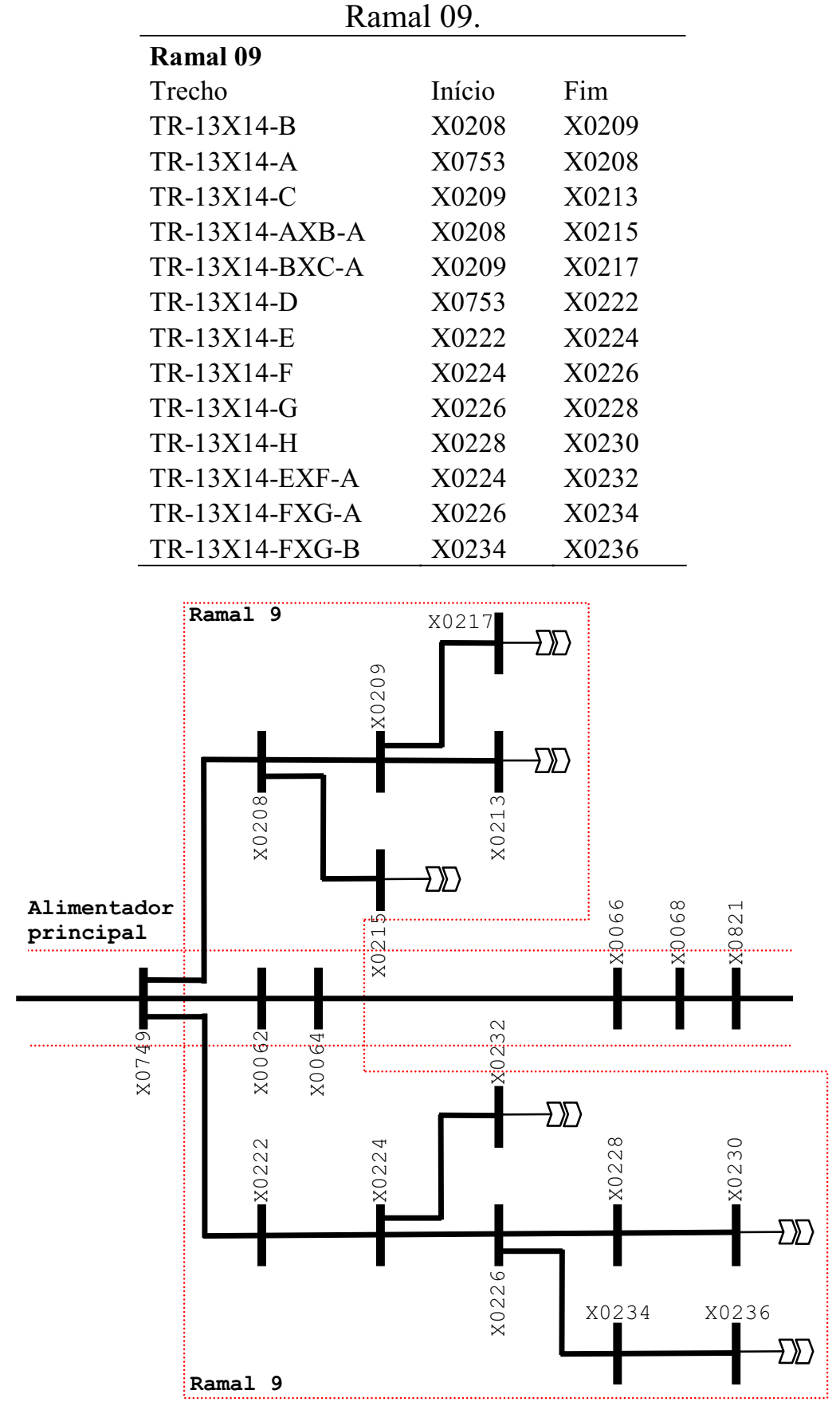

Figura 5.8 - Destaque para o Ramal 09 em relação à disposição do alimentador principal.

A Figura 5.9 destaca o Ramal 10 e o Ramal 12, bem como indica, por meio do diagrama de blocos do alimentador padrão, a origem do Ramal 11 junto ao alimentador principal. 


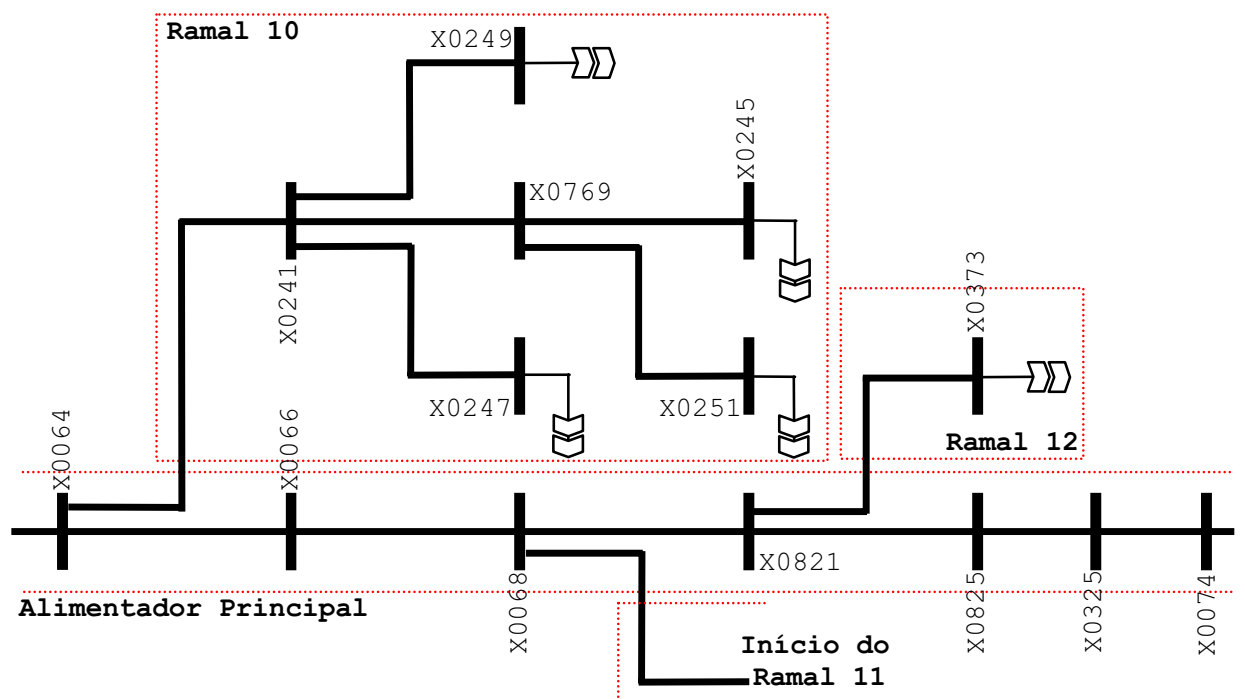

Figura 5.9 - Destaque para o Ramal 10 e Ramal 12 em relação à disposição do alimentador principal.

A relação dos trechos que compõem o Ramal 10 e o Ramal 12 é apresentada por meio da Tabela 5.5.

Tabela 5.5 - Trechos constituintes do Ramal 10 e do Ramal 12.

\begin{tabular}{lll}
\hline Ramal 10 & & \\
Trecho & Início & Fim \\
TR-15X16-A & X0064 & X0241 \\
TR-15X16-B & X0241 & X0773 \\
TR-15X16-C & X0773 & X0245 \\
TR-15X16-AXB-A & X0241 & X0247 \\
TR-15X16-AXB-B & X0241 & X0249 \\
TR-15X16-BXC-A & X0773 & X0251 \\
\hline Ramal 12 & & \\
Trecho & Início & Fim \\
TR-18X19-A & X0825 & X0373 \\
\hline
\end{tabular}

O Ramal 11, em função de sua extensão geográfica, é modelado computacionalmente por meio de diversos trechos primários. A disposição desse ramal em relação ao alimentador principal é ilustrada por meio da Figura 5.10. Além disso, essa figura apresenta os pontos dos quais outros ramais se originam. Complementando, tem-se na Tabela 5.6 a relação dos trechos primários que constituem o Ramal 11. 


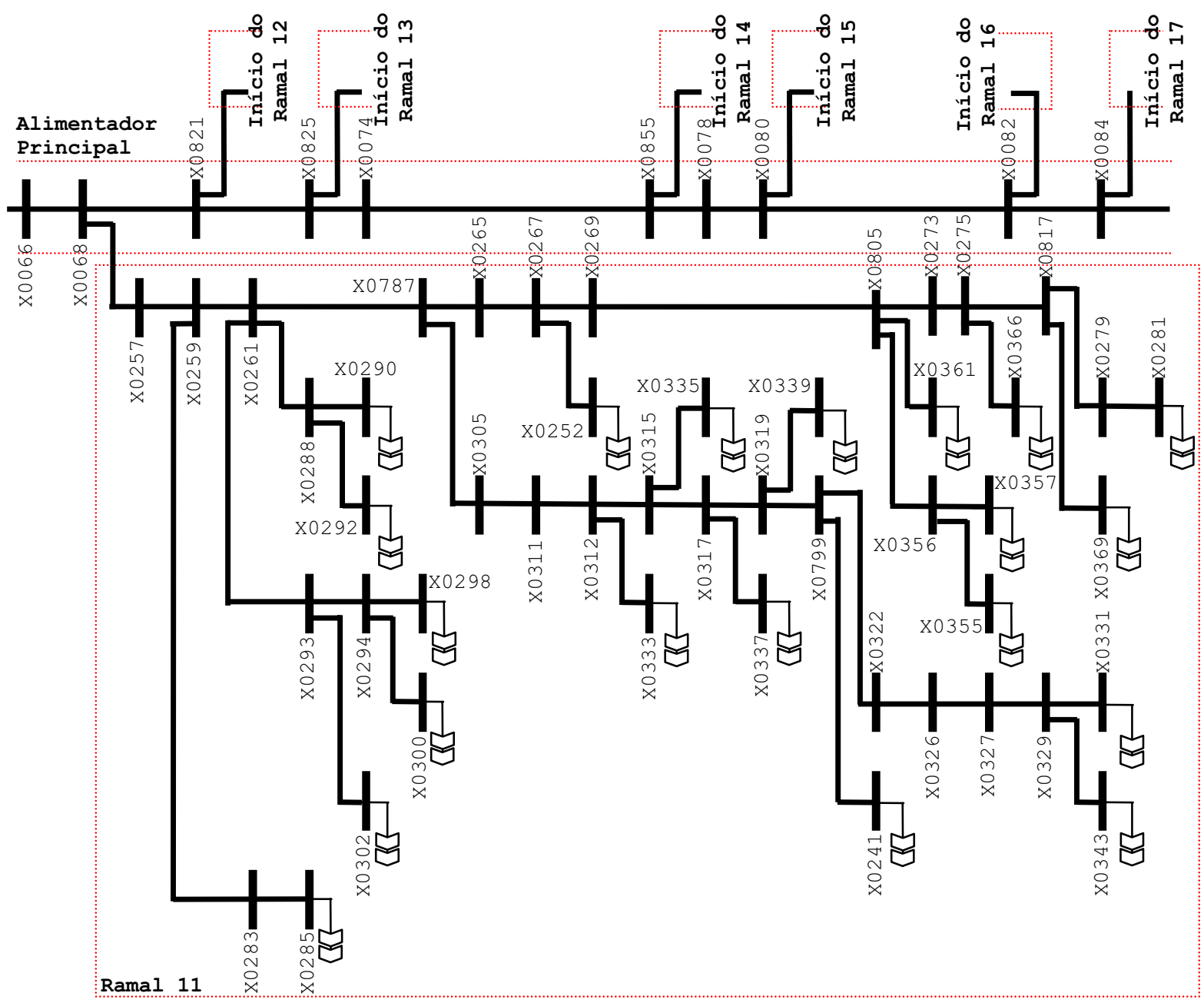

Figura 5.10 - Destaque para o Ramal 11 em relação à disposição do alimentador principal.

Tabela 5.6 - Trechos constituintes do Ramal 11.

\begin{tabular}{lll|lll}
\hline \multicolumn{7}{l}{} & \multicolumn{2}{c}{ Ramal 11 } & & \\
Trecho & Início & Fim & $\mid$ Trecho & Início & Fim \\
TR-17X18-A & X0068 & X0257 & TR-17X18-DXE-B & X0309 & X0311 \\
TR-17X18-B & X0257 & X0259 & TR-17X18-DXE-C & X0311 & X0313 \\
TR-17X18-C & X0259 & X0261 & TR-17X18-DXE-D & X0313 & X0315 \\
TR-17X18-D & X0261 & X0791 & TR-17X18-DXE-E & X0315 & X0317 \\
TR-17X18-E & X0791 & X0265 & TR-17X18-DXE-F & X0317 & X0319 \\
TR-17X18-F & X0265 & X0267 & TR-17X18-DXE-G & X0319 & X0803 \\
TR-17X18-G & X0267 & X0269 & TR-17X18-DXE-H & X0803 & X0323 \\
TR-17X18-H & X0269 & X0809 & TR-17X18-DXE-I & X0323 & X0325 \\
TR-17X18-I & X0809 & X0273 & TR-17X18-DXE-J & X0325 & X0327 \\
TR-17X18-J & X0273 & X0275 & TR-17X18-DXE-K & X0327 & X0329 \\
TR-17X18-K & X0275 & X0821 & TR-17X18-DXE-L & X0329 & X0331 \\
TR-17X18-L & X0821 & X0279 & TR-17X18-DXE-CXD-A & X0313 & X0333 \\
TR-17X18-M & X0279 & X0281 & TR-17X18-DXE-DXE-A & X0315 & X0335 \\
TR-17X18-BXC-A & X0259 & X0283 & TR-17X18-DXE-EXF-A & X0317 & X0337 \\
TR-17X18-BXC-B & X0283 & X0285 & TR-17X18-DXE-FXG-A & X0319 & X0339 \\
TR-17X18-CXD-A & X0261 & X0288 & TR-17X18-DXE-GXH-A & X0803 & X0341 \\
TR-17X18-CXD-B & X0288 & X0290 & TR-17X18-DXE-KXL-A & X0329 & X0343 \\
TR-17X18-CXD-AXB-A & X0288 & X0292 & TR-17X18-FXG-A & X0267 & X0352 \\
TR-17X18-CXD-D & X0293 & X0294 & Tr-17X18-HXI-BXC-A & X0356 & X0355 \\
TR-17X18-CXD-C & X0261 & X0293 & TR-17X18-HXI-C & X0356 & X0357 \\
TR-17X18-CXD-E & X0294 & X0298 & TR-17X18-HXI-B & X0809 & X0356 \\
TR-17X18-CXD-DXE-A & X0294 & X0300 & TR-17X18-HXI-A & X0809 & X0361 \\
TR-17X18-CXD-CXD-A & X0293 & X0302 & TR-17X18-JXK-A & X0275 & X0366 \\
TR-17X18-DXE-A & X0791 & X0309 & TR-17X18-KXL-A & X0821 & X0369 \\
\hline
\end{tabular}


O Ramal 13 até o Ramal 19 são ilustrados por meio da Figura 5.11, a qual também é responsável por indicar o início do Ramal 20 e do Ramal 21. A Tabela 5.7 apresenta os trechos constituintes dos referidos ramais.

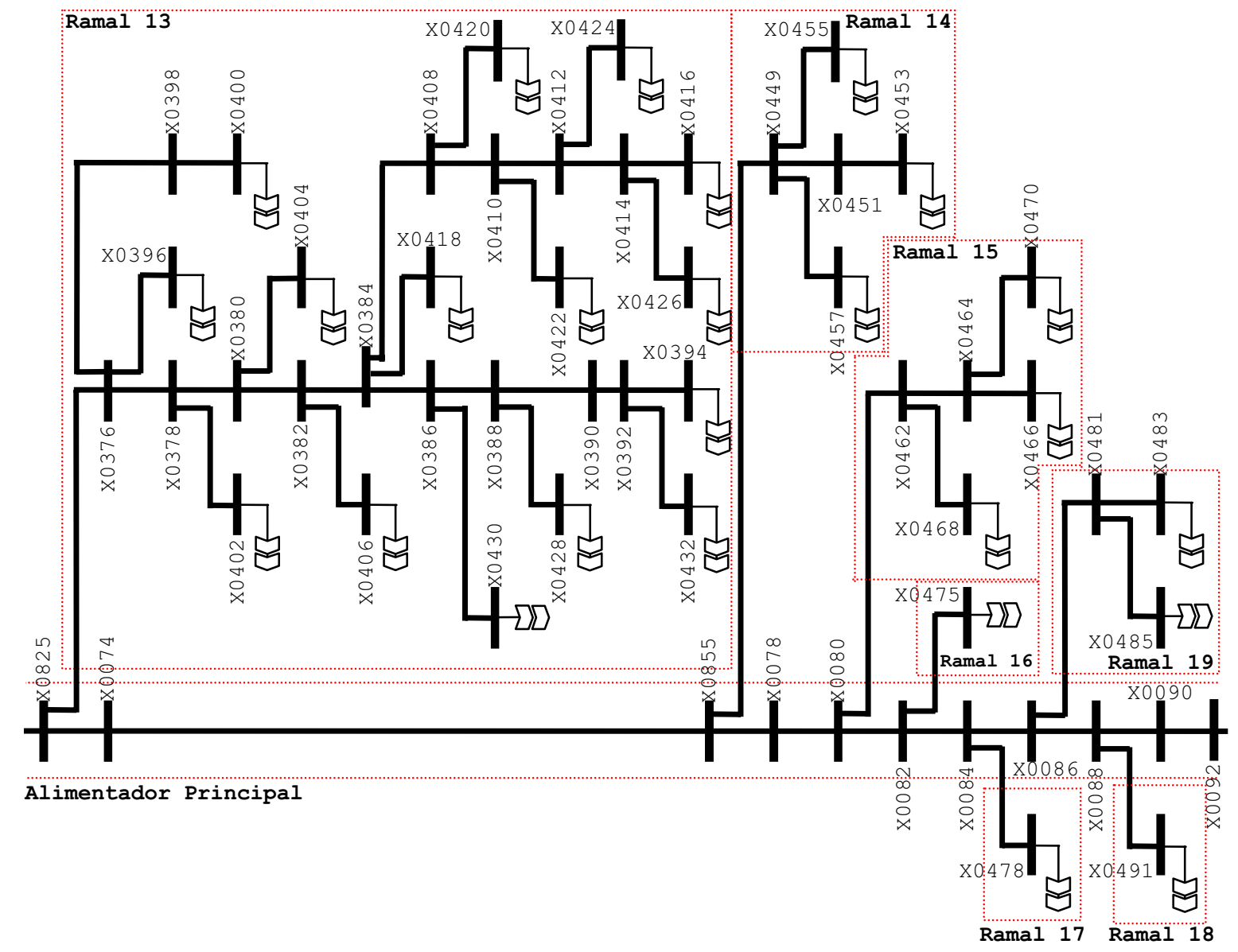

Figura 5.11 - Destaque para o Ramal 13 até o Ramal 19 em relação à disposição do alimentador principal.

Prosseguindo com a apresentação da setorização do alimentador padrão, tem-se por meio da Figura 5.12 destaque para o Ramal 20 até o Ramal 30 em relação ao alimentador principal. Ainda com relação a esses ramais, tem-se na Tabela 5.8 a relação dos trechos que constituem cada um desses ramais. 
Tabela 5.7 - Trechos constituintes do Ramal 13 até o Ramal 19.

\begin{tabular}{|c|c|c|c|c|c|}
\hline \multicolumn{3}{|l|}{ Ramal 13} & \multicolumn{3}{|l|}{ Ramal 14} \\
\hline Trecho & Início & Fim & Trecho & Início & Fim \\
\hline TR-19X20-A & X0829 & X0376 & TR-21X22-A & X0859 & X0449 \\
\hline TR-19X20-B & X0376 & X0378 & TR-21X22-B & X0449 & X0451 \\
\hline TR-19X20-C & X0378 & X0380 & TR-21X22-C & X0451 & X0453 \\
\hline TR-19X20-D & X0380 & X0382 & TR-21X22-AXB-A & X0449 & $\mathrm{X} 0455$ \\
\hline TR-19X20-E & X0382 & X0384 & TR-21X22-AXB-B & X0449 & $\mathrm{X} 0457$ \\
\hline TR-19X20-F & X0384 & X0386 & Ramal 15 & & \\
\hline TR-19X20-G & X0386 & X0388 & Trecho & Início & Fim \\
\hline TR-19X20-H & X0388 & X0390 & TR-23X24-A & X0080 & X0462 \\
\hline TR-19X20-I & X0390 & X0392 & TR-23X24-B & X0462 & X0464 \\
\hline TR-19X20-J & X0392 & X0394 & TR-23X24-C & X0464 & X0466 \\
\hline TR-19X20-AXB-A & X0376 & X0396 & TR-23X24-AXB-A & X0462 & X0468 \\
\hline TR-19X20-AXB-B & X0376 & X0398 & TR-23X24-BXC-A & X0464 & $\mathrm{X} 0470$ \\
\hline TR-19X20-AXB-C & X0398 & X0400 & Ramal 16 & & \\
\hline TR-19X20-BXC-A & X0378 & X0402 & Trecho & Início & Fim \\
\hline TR-19X20-CXD-A & X0380 & X0404 & TR-24X25-A & X0082 & $\mathrm{X} 0475$ \\
\hline TR-19X20-DXE-A & X0382 & X0406 & Ramal 17 & & \\
\hline TR-19X20-EXF-B & X0384 & X0408 & Trecho & Início & Fim \\
\hline TR-19X20-EXF-C & X0408 & X0410 & TR-25X26-A & X0084 & $\mathrm{X} 0478$ \\
\hline TR-19X20-EXF-D & X0410 & X0412 & Ramal 18 & & \\
\hline TR-19X20-EXF-E & X0412 & X0414 & Trecho & Início & Fim \\
\hline TR-19X20-EXF-F & X0414 & X0416 & TR-26X27-A & X0086 & X0481 \\
\hline TR-19X20-EXF-A & X0384 & X0418 & TR-26X27-B & X0481 & X0483 \\
\hline TR-19X20-EXF-BXC-A & X0408 & X0420 & TR-26X27-AXB-A & X0481 & $\mathrm{X} 0485$ \\
\hline TR-19X20-EXF-CXD-A & $\mathrm{X} 0410$ & X0422 & Ramal 19 & & \\
\hline TR-19X20-EXF-DXE-A & X0412 & X0424 & Trecho & Início & Fim \\
\hline TR-19X20-EXF-EXF-A & X0414 & X0426 & TR-28X30-A & X0090 & X0489 \\
\hline TR-19X20-GXH-A & X0388 & X0428 & & & \\
\hline TR-19X20-FXG-A & X0386 & X0430 & & & \\
\hline TR-19X20-IXJ-A & X0392 & X0432 & & & \\
\hline
\end{tabular}

A setorização do Ramal 31 ao Ramal 39 é apresentada por meio da Figura 5.13 sob a forma do diagrama de blocos da modelagem computacional do alimentador padrão. $\mathrm{Na}$ seqüência, a Tabela 5.9 destaca os trechos primários que compõem os referidos ramais.

Conforme se verifica por meio do diagrama de blocos da Figura 5.13, os trechos primários referentes ao ramal 35 estão omitidos. No entanto, a fim de complementar a apresentação da setorização desse ramal, tem-se na Figura 5.14 os trechos primários que o constitui. 


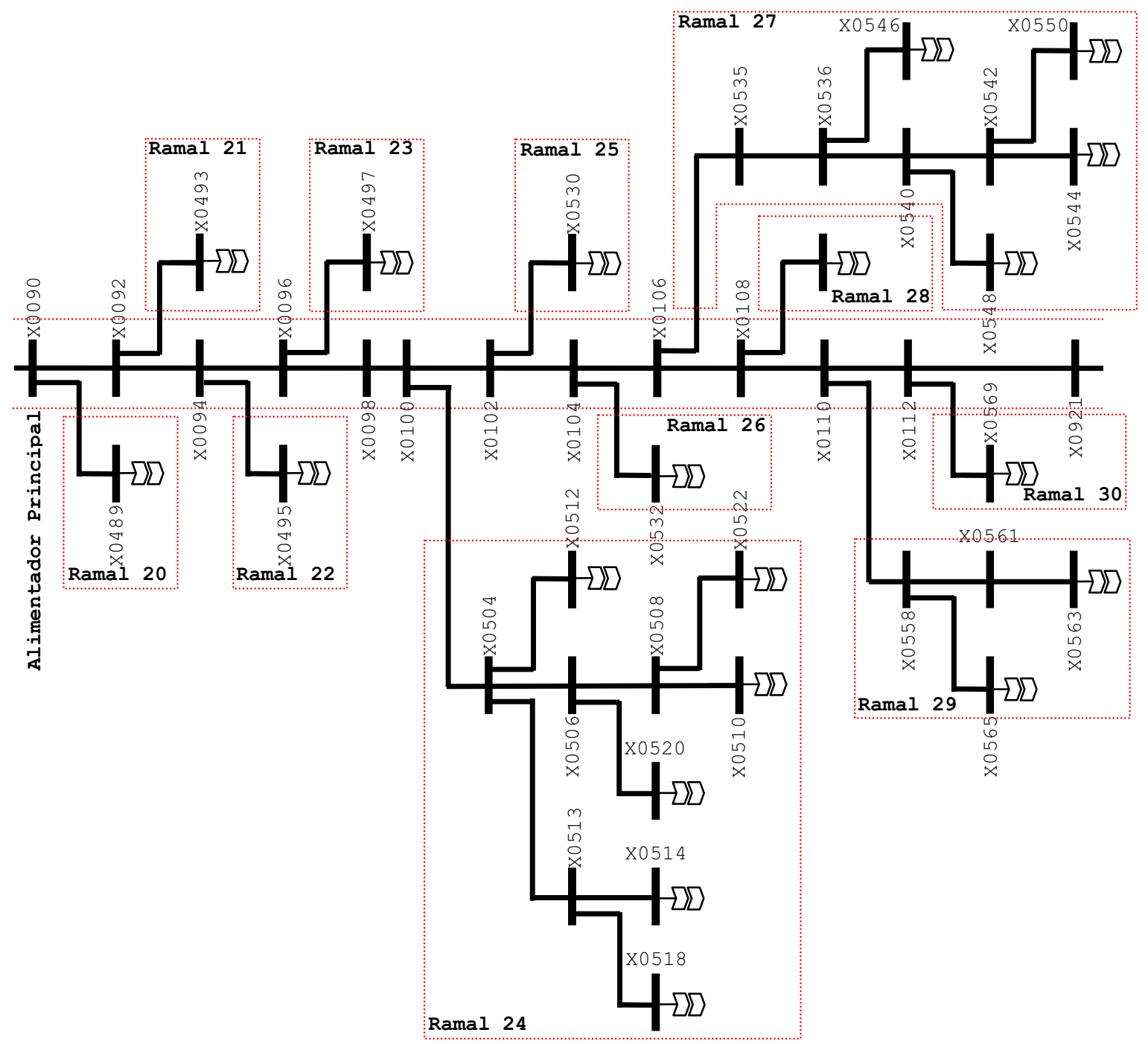

Figura 5.12 - Destaque para o Ramal 20 até o Ramal 30 em relação à disposição do alimentador principal. 
Tabela 5.8 - Trechos constituintes do Ramal 20 até o Ramal 21.

\begin{tabular}{|c|c|c|c|c|c|}
\hline Ramal 20 & & & Ramal 26 & & \\
\hline Trecho & Início & Fim & Trecho & Início & Fim \\
\hline TR-27X28-A & X0088 & X0491 & TR-36X37-B & X0535 & X0536 \\
\hline Ramal 21 & & & TR-36X37-A & X0106 & X0535 \\
\hline Trecho & Início & Fim & TR-36X37-C & X0536 & X0540 \\
\hline TR-29X30-A & X0092 & X0493 & TR-36X37-D & X0540 & X0542 \\
\hline Ramal 22 & & & TR-36X37-E & X0542 & X0544 \\
\hline Trecho & Início & Fim & TR-36X37-BXC-A & X0536 & X0546 \\
\hline TR-30X31-A & X0094 & X0495 & TR-36X37-CXD-A & X0540 & X0548 \\
\hline TR-30X31-A & X0096 & X0497 & TR-36X37-DXE-A & X0542 & X0550 \\
\hline Ramal 23 & & & Ramal 27 & & \\
\hline Trecho & Início & Fim & Trecho & Início & Fim \\
\hline TR-33X34-A & X0100 & X0504 & TR-37X38-A & X0108 & X0552 \\
\hline TR-33X34-B & X0504 & X0506 & Ramal 28 & & \\
\hline TR-33X34-C & X0506 & X0508 & Trecho & Início & Fim \\
\hline TR-33X34-D & X0508 & X0510 & TR-38X39-A & X0110 & X0559 \\
\hline TR-33X34-AXB-A & X0504 & X0512 & TR-38X39-B & X0559 & X0561 \\
\hline TR-33X34-AXB-C & X0513 & X0514 & TR-38X39-C & X0561 & X0563 \\
\hline TR-33X34-AXB-B & X0504 & X0513 & TR-38X39-AXB-A & X0559 & X0565 \\
\hline TR-33X34-AXB-BXC-A & X0513 & X0518 & Ramal 29 & & \\
\hline TR-33X34-BXC-A & X0506 & X0520 & Trecho & Início & Fim \\
\hline TR-33X34-CXD-A & X0508 & X0522 & TR-39X40-A & X0112 & X0569 \\
\hline Ramal 24 & & & Ramal 30 & & \\
\hline Trecho & Início & Fim & Trecho & Início & Fim \\
\hline TR-34X35-A & X0102 & X0530 & TR-40X41-A & X0925 & X0572 \\
\hline Ramal 25 & & & TR-40X41-B & X0572 & X0574 \\
\hline Trecho & Início & Fim & TR-40X41-C & X0574 & X0576 \\
\hline TR-35X36-A & X0104 & X0532 & TR-40X41-D & X0576 & X0578 \\
\hline & & & TR-40X41-E & X0578 & X0580 \\
\hline & & & TR-40X41-AXB-A & X0572 & X0582 \\
\hline & & & TR-40X41-DXE-A & X0578 & X0584 \\
\hline
\end{tabular}

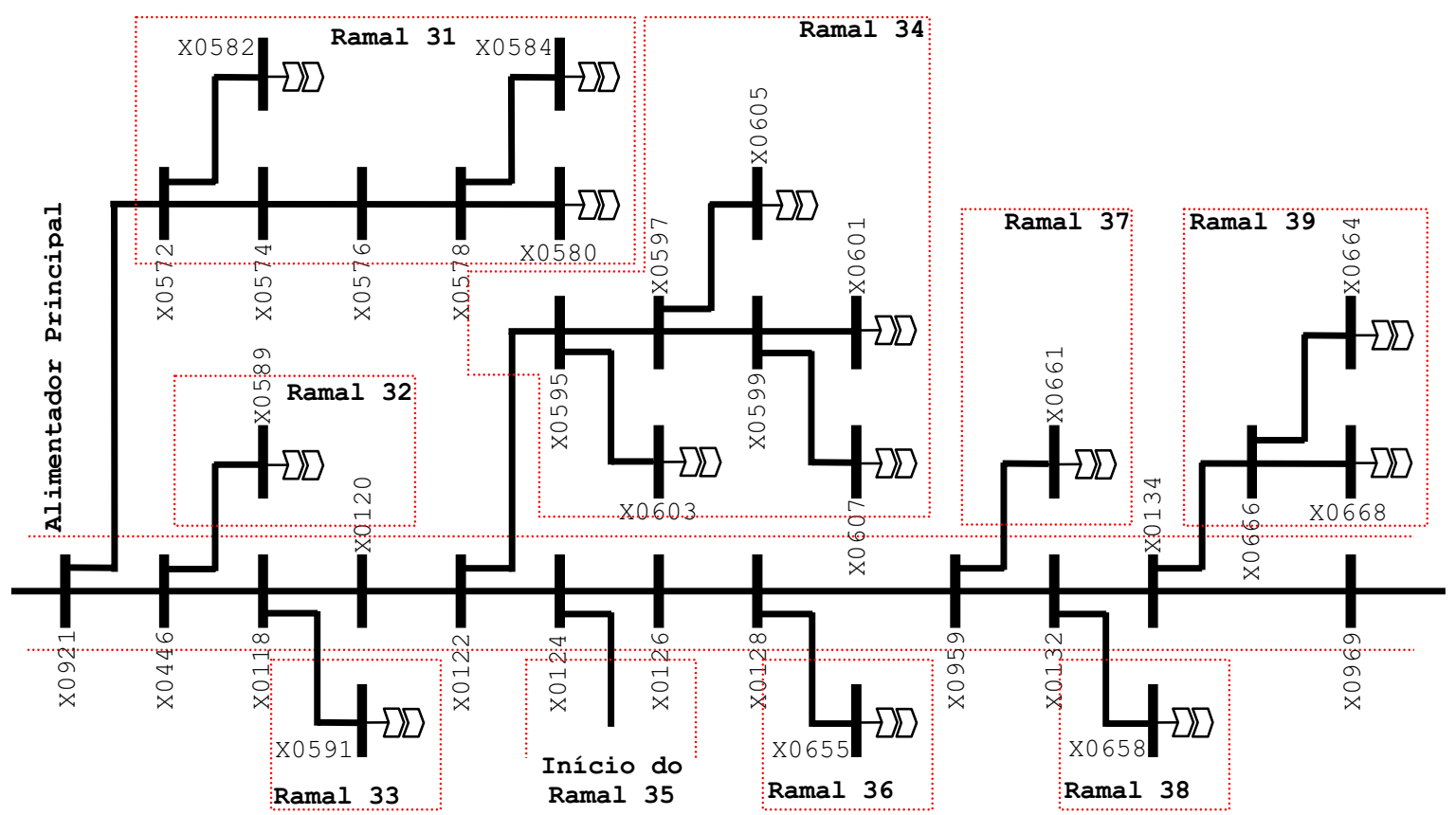

Figura 5.13 - Destaque para o Ramal 31 até o Ramal 39 em relação à disposição do alimentador principal. 


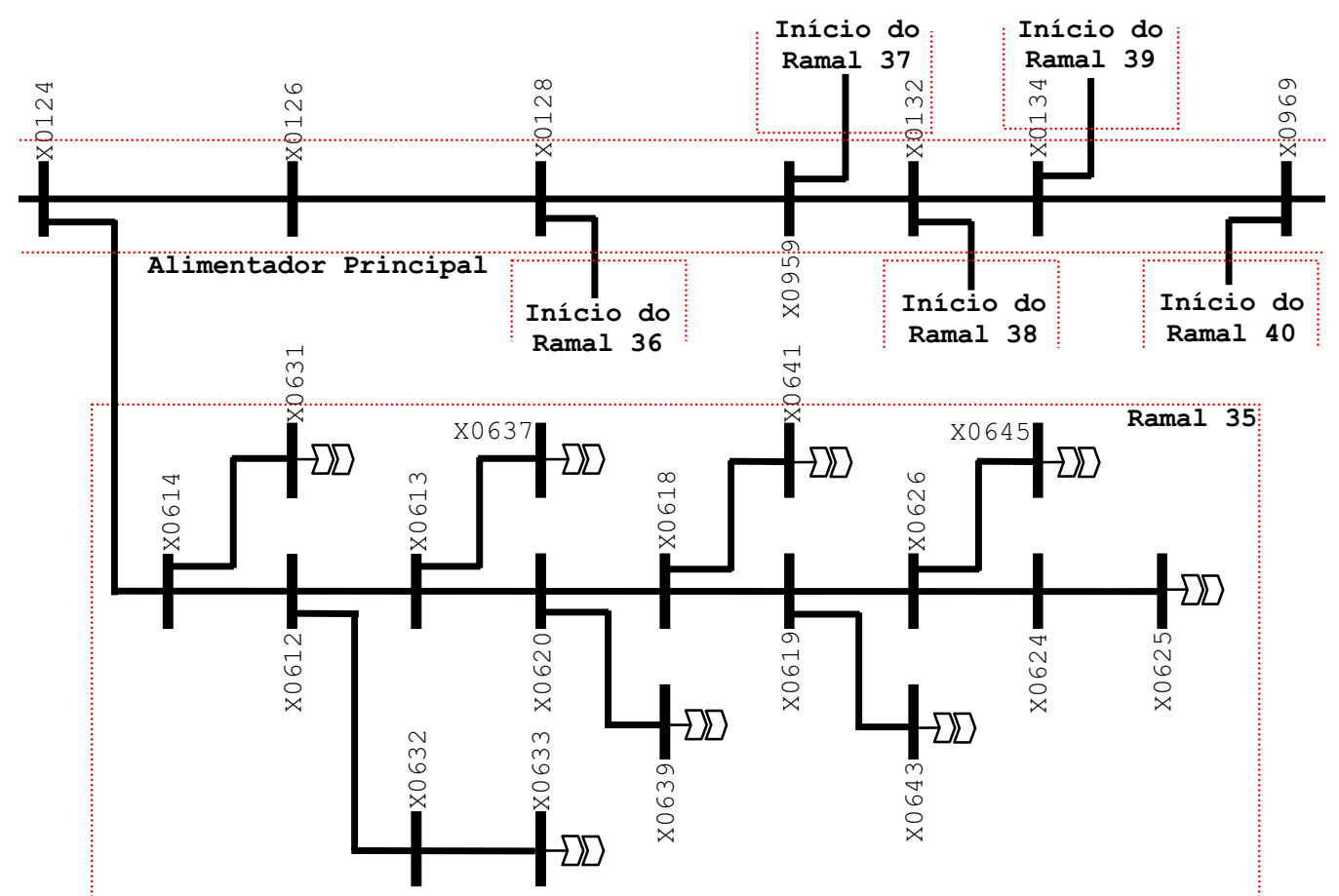

Figura 5.14 - Destaque para o Ramal 35 em relação à disposição do alimentador principal.

Tabela 5.9 - Trechos constituintes do Ramal 31 até o Ramal 39.

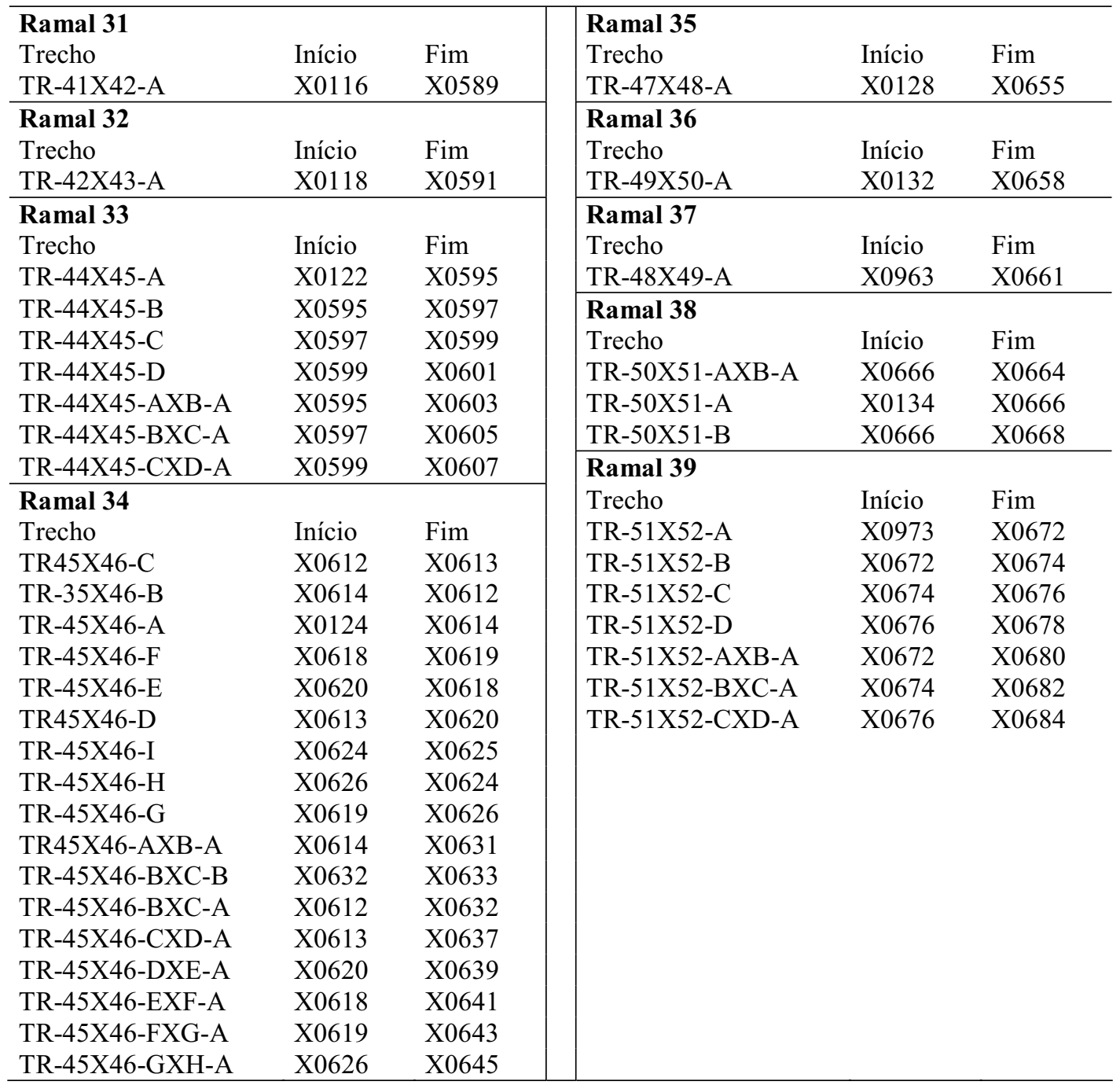


Por fim, o Ramal 40 até o Ramal 44 são apresentados esquematicamente por meio da Figura 5.15, assim como os trechos primários que contem tais ramais são destacados na Tabela 5.10.

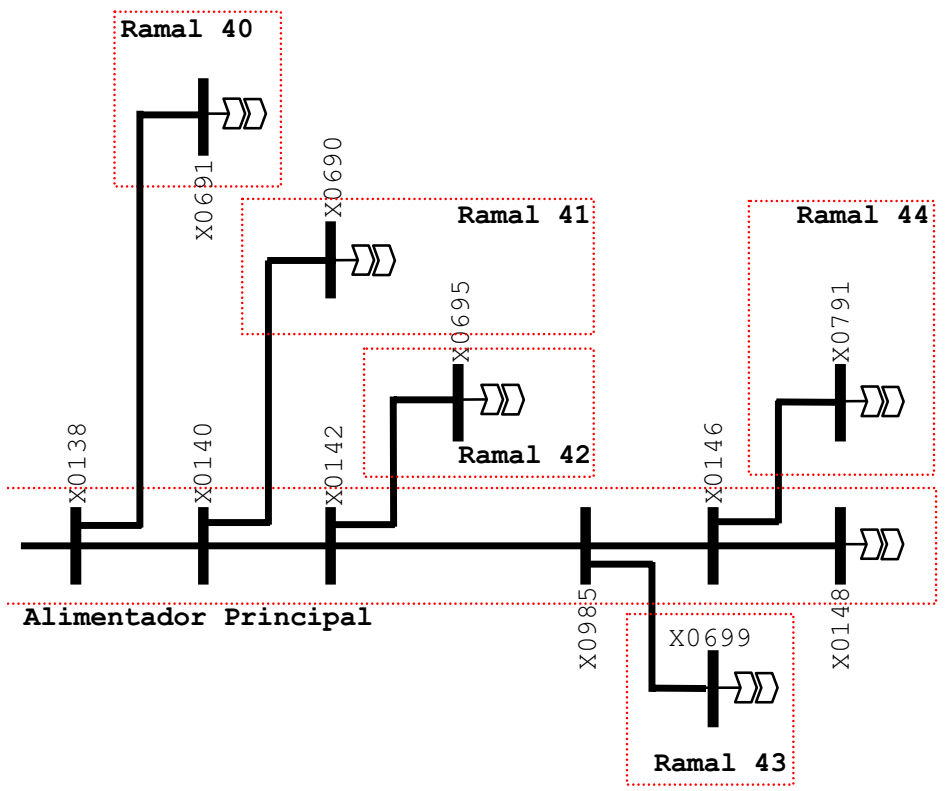

Figura 5.15 - Destaque para o Ramal 40 até o Ramal 44 em relação à disposição do alimentador principal.

Tabela 5.10 - Trechos constituintes do

\begin{tabular}{lcl}
\multicolumn{3}{c}{ Ramal 40 até o Ramal 44.} \\
\hline $\begin{array}{l}\text { Ramal 40 } \\
\text { Trecho }\end{array}$ & Início & Fim \\
TR-53X54-A & X0140 & X0690 \\
\hline $\begin{array}{l}\text { Ramal 41 } \\
\text { Trecho }\end{array}$ & Início & Fim \\
TR-52X53-A & X0138 & X0691 \\
\hline Ramal 42 & & \\
Trecho & Início & Fim \\
TR-54X55-A & X0142 & X0695 \\
\hline Ramal 43 & & \\
Trecho & Início & Fim \\
TR-55X56-A & X0989 & X0699 \\
\hline Ramal 44 & & \\
Trecho & Início & Fim \\
TR-56X57-A & X0146 & X0701 \\
\hline
\end{tabular}

Cada um dos trechos primários destacados nessa seção foram modelados considerando um altura média de instalação de 6,5 metros. A distância entre os condutores fase fora de 0,95 metros para as fase A e B, enquanto que a distância entre as fase B e C foi de 0,85 metros. Complementando a descrição do alimentador empregado nas simulações computacionais, apresenta-se, por meio da Tabela 5.11, a identificação dos barramentos e sua respectiva distância em relação à barra de média tensão da subestação. 
Tabela 5.11 - Distâncias dos barramentos relativas à subestação.

\begin{tabular}{|c|c|}
\hline Barramento & Distância (km) \\
\hline $\mathrm{x} 0019$ & 0,0000 \\
\hline $\mathrm{x} 0034$ & 0,8000 \\
\hline $\mathrm{x} 0036$ & 1,7705 \\
\hline $\mathrm{x} 0038$ & 1,8451 \\
\hline $\mathrm{X} 0040$ & 2,0134 \\
\hline $\mathrm{x} 0042$ & 2,3233 \\
\hline $\mathrm{X} 0044$ & 2,4558 \\
\hline $\mathrm{X} 0046$ & 2,5860 \\
\hline $\mathrm{x} 0048$ & 2,6858 \\
\hline $\mathrm{x} 0050$ & 2,8540 \\
\hline $\mathrm{x} 0052$ & 3,7700 \\
\hline $\mathrm{x} 0054$ & 4,2005 \\
\hline $\mathrm{x} 0056$ & 4,4091 \\
\hline $\mathrm{x} 0062$ & 6,0812 \\
\hline $\mathrm{x} 0064$ & 6,1772 \\
\hline $\mathrm{x} 0066$ & 6,2235 \\
\hline $\mathrm{x} 0068$ & 6,9881 \\
\hline $\mathrm{x} 0074$ & 7,6957 \\
\hline $\mathrm{x} 0078$ & 7,8752 \\
\hline $\mathrm{x} 0080$ & 7,9336 \\
\hline X0082 & 8,1062 \\
\hline $\mathrm{x} 0084$ & 8,3512 \\
\hline $\mathrm{x} 0086$ & 8,4678 \\
\hline $\mathrm{x} 0088$ & 8,7017 \\
\hline X0090 & 9,1549 \\
\hline $\mathrm{x} 0092$ & 9,4051 \\
\hline X0094 & 9,8406 \\
\hline X0096 & 10,2088 \\
\hline X0098 & 10,7813 \\
\hline $\mathrm{x} 0100$ & 11,0160 \\
\hline $\mathrm{x} 0102$ & 11,6739 \\
\hline $\mathrm{x} 0104$ & 11,6995 \\
\hline $\mathrm{x} 0106$ & 12,1353 \\
\hline X0108 & 12,7366 \\
\hline $\mathrm{x} 0110$ & 12,8371 \\
\hline $\mathrm{x} 0112$ & 13,4479 \\
\hline X0116 & 13,8726 \\
\hline $\mathrm{x} 0118$ & 13,8876 \\
\hline $\mathrm{x} 0120$ & 14,9346 \\
\hline $\mathrm{x} 0122$ & 15,1962 \\
\hline $\mathrm{x} 0124$ & 15,6124 \\
\hline $\mathrm{x} 0126$ & 15,7159 \\
\hline $\mathrm{x} 0128$ & 15,9275 \\
\hline $\mathrm{x} 0132$ & 16,8768 \\
\hline $\mathrm{x} 0134$ & 16,9268 \\
\hline $\mathrm{x} 0138$ & 17,9655 \\
\hline $\mathrm{x} 0140$ & 18,3080 \\
\hline $\mathrm{x} 0142$ & 18,4230 \\
\hline $\mathrm{x} 0146$ & 19,4585 \\
\hline $\mathrm{x} 0148$ & 20,0339 \\
\hline x0150 & 1,7836 \\
\hline $\mathrm{x} 0152$ & 1,9311 \\
\hline x0156 & 2,0435 \\
\hline X0157 & 2,2028 \\
\hline $\mathrm{x} 0161$ & 2,7759 \\
\hline X0163 & 2,9959 \\
\hline $\mathrm{X} 0164$ & 3,3497 \\
\hline $\mathrm{x} 0168$ & 3,4089 \\
\hline $\mathrm{x} 0170$ & 3,6781 \\
\hline X0172 & 3,9648 \\
\hline $\mathrm{X} 0174$ & 4,0979 \\
\hline$x 0176$ & 4,2188 \\
\hline $\mathrm{x} 0178$ & 4,3468 \\
\hline $\mathrm{x} 0180$ & 3,5303 \\
\hline $\mathrm{x} 0182$ & 3,7103 \\
\hline $\mathrm{X0184}$ & 4,2440 \\
\hline X0190 & 4,4364 \\
\hline X0192 & 4,2592 \\
\hline X0195 & 4,5289 \\
\hline X0197 & 4,4746 \\
\hline
\end{tabular}

\begin{tabular}{|c|c|}
\hline Barramento & Distância (km) \\
\hline $\mathrm{X} 0201$ & 5,3647 \\
\hline $\mathrm{x} 0203$ & 5,4583 \\
\hline $\mathrm{x} 0205$ & 5,3997 \\
\hline $\mathrm{X} 0208$ & 5,8593 \\
\hline X0209 & 5,9865 \\
\hline $\mathrm{x} 0213$ & 6,1138 \\
\hline $\mathrm{x} 0215$ & 5,8862 \\
\hline $\mathrm{x} 0217$ & 6,0104 \\
\hline X0222 & 5,8300 \\
\hline X0224 & 5,8717 \\
\hline$\times 0226$ & 5,9575 \\
\hline $\mathrm{x} 0228$ & 6,0509 \\
\hline $\mathrm{x} 0230$ & 6,2381 \\
\hline $\mathrm{X} 0232$ & 6,0613 \\
\hline X0234 & 6,2313 \\
\hline$\times 0236$ & 6,3835 \\
\hline $\mathrm{x} 0241$ & 6,2102 \\
\hline X0245 & 6,2917 \\
\hline $\mathrm{X} 0247$ & 6,2571 \\
\hline $\mathrm{X} 0249$ & 6,2650 \\
\hline X0251 & 6,2935 \\
\hline$\times 0257$ & 7,1128 \\
\hline$\times 0259$ & 7,3308 \\
\hline $\mathrm{x} 0261$ & 7,3949 \\
\hline$\times 0265$ & 7,5470 \\
\hline$\times 0265$ & 7,5470 \\
\hline $\mathrm{X} 0267$ & 7,6210 \\
\hline$\times 0269$ & 7,7192 \\
\hline $\mathrm{x} 0273$ & 8,1441 \\
\hline$\times 0275$ & 8,6932 \\
\hline $\mathrm{x} 0279$ & 9,3514 \\
\hline X0281 & 9,3714 \\
\hline $\mathrm{X} 0283$ & 7,4060 \\
\hline $\mathrm{x} 0285$ & 7,4835 \\
\hline $\mathrm{X} 0288$ & 7,9015 \\
\hline $\mathrm{x} 0290$ & 7,9915 \\
\hline X0292 & 8,0571 \\
\hline X0293 & 7,4452 \\
\hline X0294 & 7,4704 \\
\hline X0298 & 7,7413 \\
\hline $\mathrm{x} 0300$ & 7,5951 \\
\hline$\times 0302$ & 7,5763 \\
\hline X0309 & 7,5129 \\
\hline $\mathrm{x} 0311$ & 7,7010 \\
\hline$\times 0313$ & 7,8022 \\
\hline X0315 & 7,8716 \\
\hline $\mathrm{x} 0317$ & 8,0278 \\
\hline X0319 & 8,0984 \\
\hline$\times 0323$ & 8,2648 \\
\hline$\times 0325$ & 8,4791 \\
\hline X0327 & 8,5941 \\
\hline$\times 0329$ & 8,6811 \\
\hline X0331 & 8,8672 \\
\hline $\mathrm{X} 0333$ & 7,9382 \\
\hline $\mathrm{x} 0335$ & 8,0489 \\
\hline$\times 0337$ & 8,1028 \\
\hline$\times 0339$ & 8,1943 \\
\hline $\mathrm{X} 0341$ & 8,2437 \\
\hline X0343 & 8,6961 \\
\hline$\times 0352$ & 7,7068 \\
\hline X0355 & 8,2158 \\
\hline X0356 & 8,2110 \\
\hline$\times 0357$ & 8,5732 \\
\hline X0361 & 8,1856 \\
\hline X0366 & 8,7016 \\
\hline$\times 0369$ & 9,1533 \\
\hline $\mathrm{X} 0373$ & 7,0721 \\
\hline$\times 0376$ & 7,8447 \\
\hline$\times 0378$ & 8,1060 \\
\hline $\mathrm{x} 0380$ & 8,1728 \\
\hline
\end{tabular}

\begin{tabular}{|c|c|}
\hline Barramento & Distância (km) \\
\hline X0382 & 8,9164 \\
\hline$\times 0384$ & 9,9611 \\
\hline$\times 0386$ & 11,1019 \\
\hline X0388 & 11,3991 \\
\hline $\mathrm{X0390}$ & 11,6854 \\
\hline X0392 & 11,8509 \\
\hline$\times 0394$ & 12,1209 \\
\hline X0396 & 7,8819 \\
\hline X0398 & 8,0133 \\
\hline $\mathrm{X} 0400$ & 8,2226 \\
\hline $\mathrm{x} 0402$ & 8,1763 \\
\hline $\mathrm{X} 0404$ & 8,2900 \\
\hline $\mathrm{X} 0406$ & 9,0658 \\
\hline $\mathrm{X0408}$ & 10,3547 \\
\hline $\mathrm{X} 0410$ & 10,5761 \\
\hline $\mathrm{x} 0412$ & 10,7823 \\
\hline$\times 0414$ & 11,0576 \\
\hline $\mathrm{x} 0416$ & 11,1430 \\
\hline $\mathrm{X} 0418$ & 9,9811 \\
\hline $\mathrm{x} 0420$ & 10,5450 \\
\hline $\mathrm{x} 0422$ & 10,8846 \\
\hline$\times 0424$ & 10,8470 \\
\hline X0426 & 11,4406 \\
\hline $\mathrm{X} 0428$ & 11,6700 \\
\hline $\mathrm{x} 0430$ & 11,4448 \\
\hline$\times 0432$ & 11,8809 \\
\hline$\times 0449$ & 8,3977 \\
\hline X0451 & 8,7074 \\
\hline$\times 0453$ & 9,5266 \\
\hline$\times 0455$ & 8,7380 \\
\hline$\times 0457$ & 8,5040 \\
\hline $\mathrm{x} 0462$ & 8,1154 \\
\hline$\times 0464$ & 8,2253 \\
\hline $\mathrm{X} 0466$ & 8,2689 \\
\hline $\mathrm{X} 0468$ & 8,1664 \\
\hline$\times 0470$ & 8,4150 \\
\hline X0475 & 8,3412 \\
\hline$\times 0478$ & 8,4832 \\
\hline $\mathrm{X} 0481$ & 8,6351 \\
\hline $\mathrm{X} 0483$ & 8,6766 \\
\hline$\times 0485$ & 8,8502 \\
\hline $\mathrm{X} 0489$ & 9,5867 \\
\hline X0491 & 8,9089 \\
\hline X0493 & 9,7454 \\
\hline$\times 0495$ & 10,1232 \\
\hline X0497 & 11,6190 \\
\hline $\mathrm{X0504}$ & 11,7142 \\
\hline$\times 0506$ & 11,9128 \\
\hline$\times 0508$ & 12,0259 \\
\hline X0510 & 12,6435 \\
\hline $\mathrm{x} 0512$ & 11,7554 \\
\hline $\mathrm{X} 0513$ & 12,4249 \\
\hline$\times 0514$ & 12,5677 \\
\hline$\times 0518$ & 12,6274 \\
\hline$\times 0520$ & 12,1616 \\
\hline X0522 & 12,0509 \\
\hline $\mathrm{x} 0530$ & 12,6027 \\
\hline $\mathrm{X} 0532$ & 13,5095 \\
\hline$\times 0535$ & 12,5654 \\
\hline$\times 0536$ & 13,8057 \\
\hline$\times 0540$ & 14,0657 \\
\hline $\mathrm{X} 0542$ & 14,7663 \\
\hline X0544 & 15,0556 \\
\hline $\mathrm{X} 0546$ & 14,3200 \\
\hline $\mathrm{X} 0548$ & 14,1957 \\
\hline $\mathrm{X} 0550$ & 15,7060 \\
\hline X0552 & 12,8066 \\
\hline$\times 0559$ & 13,3231 \\
\hline X0561 & 13,4047 \\
\hline X0563 & 13,6951 \\
\hline
\end{tabular}

\begin{tabular}{|c|c|}
\hline Barramento & Distância (km) \\
\hline $\mathrm{x} 0565$ & 13,4650 \\
\hline$\times 0569$ & 13,4979 \\
\hline$\times 0572$ & 13,6634 \\
\hline $\mathrm{X0574}$ & 14,0134 \\
\hline$\times 0576$ & 14,2705 \\
\hline $\mathrm{X0578}$ & 14,9501 \\
\hline $\mathrm{X} 0580$ & 15,4086 \\
\hline $\mathrm{X} 0582$ & 13,9265 \\
\hline $\mathrm{X} 0584$ & 15,1047 \\
\hline X0589 & 13,9126 \\
\hline X0591 & 14,5026 \\
\hline X0595 & 17,2384 \\
\hline X0597 & 17,3584 \\
\hline $\mathrm{X} 0599$ & 17,8719 \\
\hline X0601 & 19,2095 \\
\hline$x 0603$ & 17,5174 \\
\hline X0605 & 18,6359 \\
\hline X0607 & 17,9625 \\
\hline $\mathrm{x} 0612$ & 17,0968 \\
\hline $\mathrm{x} 0613$ & 17,7272 \\
\hline X0614 & 16,6654 \\
\hline$\times 0618$ & 18,5783 \\
\hline X0619 & 19,8083 \\
\hline $\mathrm{x} 0620$ & 17,8372 \\
\hline X0624 & 20,2995 \\
\hline $\mathrm{x} 0625$ & 20,3399 \\
\hline x0626 & 20,0574 \\
\hline X0631 & 16,7061 \\
\hline $\mathrm{X} 0632$ & 17,6986 \\
\hline $\mathrm{x} 0633$ & 18,0846 \\
\hline X0637 & 17,9377 \\
\hline X0639 & 17,9178 \\
\hline $\mathrm{X} 0641$ & 18,8556 \\
\hline $\mathrm{x} 0643$ & 20,1001 \\
\hline $\mathrm{x} 0645$ & 20,3461 \\
\hline X0655 & 16,4276 \\
\hline X0658 & 16,9909 \\
\hline X0661 & 16,5598 \\
\hline $\mathrm{X} 0664$ & 17,3801 \\
\hline $\mathrm{x} 0666$ & 17,2756 \\
\hline$x 0668$ & 17,4756 \\
\hline X0672 & 19,5952 \\
\hline $\mathrm{x} 0674$ & 20,0667 \\
\hline $\mathrm{x} 0676$ & 20,1191 \\
\hline $\mathrm{X} 0678$ & 20,3432 \\
\hline $\mathrm{x} 0680$ & 20,1595 \\
\hline $\mathrm{X} 0682$ & 20,3474 \\
\hline $\mathrm{X} 0684$ & 20,2261 \\
\hline X0690 & 18,3380 \\
\hline $\mathrm{x} 0691$ & 18,0752 \\
\hline X0695 & 18,4410 \\
\hline X0699 & 19,0290 \\
\hline $\mathrm{x} 0701$ & 20,9256 \\
\hline X0747 & 5,3431 \\
\hline $\mathrm{X} 0753$ & 5,8061 \\
\hline $\mathrm{x} 0773$ & 6,2565 \\
\hline X0791 & 7,4587 \\
\hline $\mathrm{x} 0803$ & 8,1468 \\
\hline X0809 & 8,0541 \\
\hline $\mathrm{x} 0821$ & 9,0933 \\
\hline $\mathrm{x} 0825$ & 7,0691 \\
\hline $\mathrm{X} 0829$ & 7,6644 \\
\hline X0859 & 7,7721 \\
\hline X0925 & 13,5380 \\
\hline X0963 & 16,5371 \\
\hline X0973 & 17,8544 \\
\hline X0989 & 18,8701 \\
\hline
\end{tabular}




\subsection{Simulações Computacionais Para Faltas de Alta IMPEDÂNCIA}

Assim como descrito ainda no Capítulo 1 e reforçado pelas abordagens apresentadas no Capítulo 2, as faltas de alta impedância são caracterizadas por possuírem correntes de falta inferiores à corrente de carga de um alimentador quando o escopo de estudo se concentra nos sistemas de distribuição de energia elétrica. Mais do que isso, pode-se inferir que as faltas de alta impedância são aquelas onde a magnitude de corrente de falta não é capaz de sensibilizar as proteções do alimentador, estando essas localizadas seja na subestação ou mesmo ao longo do alimentador. Essa conceituação para as faltas de alta impedância pode ser complementada se classificarmos as referidas faltas como sendo ou do tipo passivas ou ativas.

As faltas de alta impedância ativas são aquelas onde, no ponto de sua ocorrência, a corrente de falta se faz circular por meio de arco-elétrico. A existência de um arco-elétrico decorre na corrupção da corrente de falta por componentes harmônicas e inter-harmônicas e a identificação dessas é premissa para as abordagens dedicadas à sua identificação. Por outro lado, as faltas de alta impedância passivas não apresentam o arco-elétrico observável nas faltas ativas. Assim, o comprometimento da forma de onda da corrente de falta não é observado quando o sistema retoma seu regime permanente. Em função dessa característica, as faltas de alta impedância passivas possuem uma identificação mais complexa do que aquela necessária para identificação das faltas ativas. Dessa maneira, almejando contribuir para essa carência no que se diz respeito à identificação e localização de faltas de alta impedância passivas, as simulações computacionais conduzidas para constituição de uma base de conhecimento ampla o suficiente para ajustes dos sistemas de identificação e localização de faltas contemplaram fundamentalmente as faltas de alta impedância.

Ao todo, foram realizadas 3000 simulações computacionais onde a distância de ocorrência da falta, a resistência de falta e a fase faltante foram parâmetros variáveis. Dessas variáveis, pode-se pontuar a resistência de falta como sendo a principal variável determinante para a falta ser ou não de alta impedância, e a distância da ocorrência da falta variável secundária nessa determinação. Assim, o total de simulações fora dividido em três grupos, cada qual caracterizado por uma faixa para a resistência de falta tal como se apresenta por meio da Tabela 5.12. Os demais parâmetros, ou seja, a distância de ocorrência da falta e a fase faltante, foram igualmente aleatórios para os três grupos de simulações. 
Tabela 5.12 - Faixa de variação da resistência de falta para cada grupo de simulações.

\begin{tabular}{lcr}
\hline \hline Grupo & $\begin{array}{r}\text { Número de } \\
\text { simulações }\end{array}$ & $\begin{array}{r}\text { Faixa de variação para } \\
\text { a resistência de falta }\end{array}$ \\
\hline \hline 1 & 1000 & $10 \rightarrow 100 \Omega$ \\
\hline 2 & 1000 & $100 \rightarrow 1000 \Omega$ \\
\hline 3 & 1000 & $1.000 \rightarrow 10.000 \Omega$ \\
\hline
\end{tabular}

Como o processo de geração das simulações de falta operou de forma a garantir a aleatoriedade dos parâmetros relativos à distância de ocorrência da falta e da fase faltante, o número de faltas que a fase $\mathrm{A}$ experimentou fora diferente do número experimentado pelas fases B e C. A fim de apresentar o número de faltas simuladas para as fases constituintes do sistema elétrico sob estudo, tem-se na Tabela 5.13 o número de simulações realizadas para cada uma das fases do referido sistema.

Tabela 5.13 - Número de simulações de falta por fase.

\begin{tabular}{lr}
\hline \hline $\begin{array}{l}\text { Fase } \\
\text { faltosa }\end{array}$ & $\begin{array}{l}\text { Número de } \\
\text { Simulações }\end{array}$ \\
\hline \hline $\mathrm{A}$ & 975 \\
\hline $\mathrm{B}$ & 999 \\
\hline $\mathrm{C}$ & 1026 \\
\hline
\end{tabular}

A fim de complementar as informações relativas às simulações computacionais empregadas no estudo relatado nesta tese, apresenta-se por meio da Figura 5.16 o histograma do número de simulações em função da distância de ocorrência das faltas.

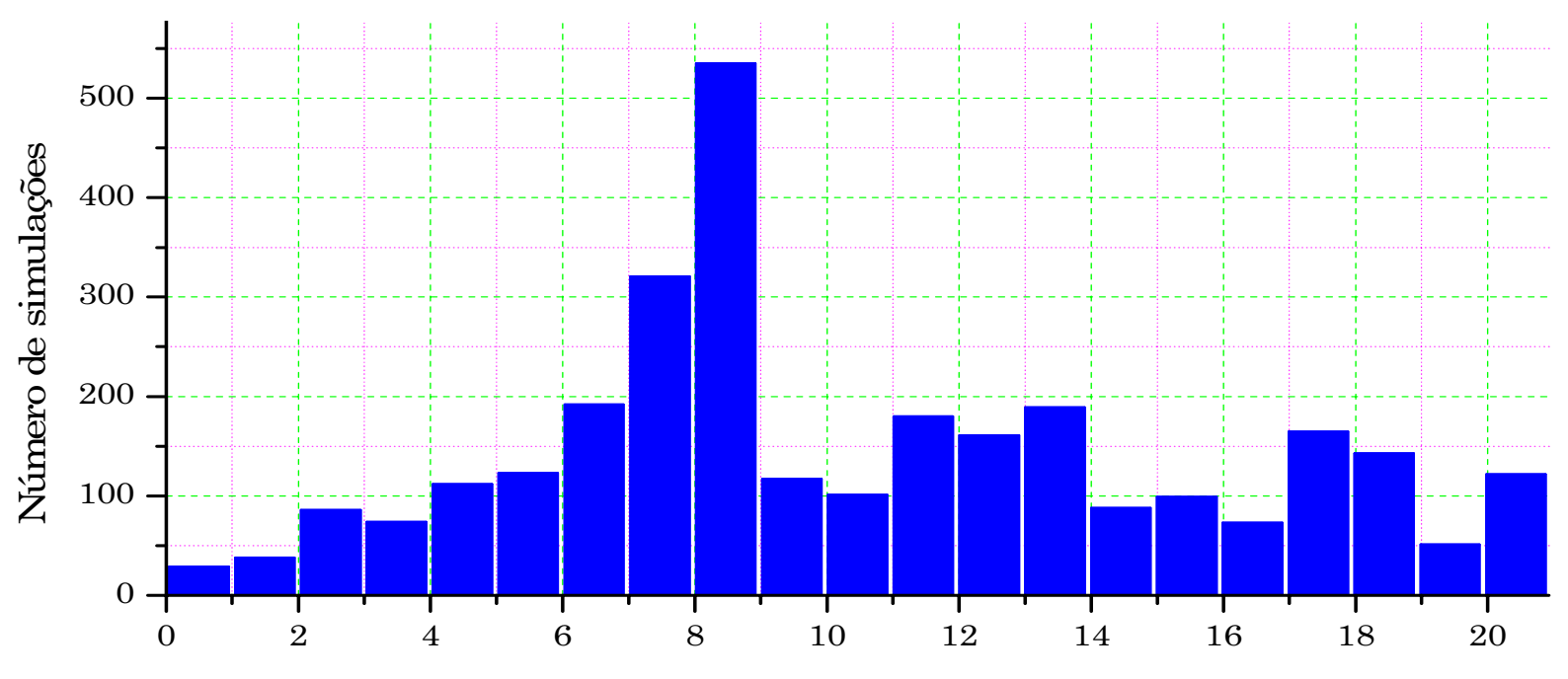

Distância de ocorrência da falta $(\mathrm{km})$

Figura 5.16 - Relacionamento entre o número de simulações e a distância de ocorrência da falta. 


\subsection{DETERminaÇÃo das VARiáVEIS Pertinentes À IDENTIFICAÇÃO DE FALTAS de ALTA IMPEDÂNCIA}

Na Seção 5.2 fora apresentada a descrição do alimentador empregado nas simulações computacionais realizadas segundo o estabelecido por meio da Seção 5.3. Assim, de posse das formas de onda de tensão e de corrente registrados na subestação, constitui-se objetivo dessa seção determinar as variáveis que possam permitir a identificação da referida falta de maneira independente da fase onde a mesma ocorreu e de sua respectiva distância em relação à subestação.

Das variáveis disponíveis para a identificação da ocorrência de uma falta de alta impedância, encontravam-se aquelas disponíveis pela técnica da decomposição em componentes ortogonais. A técnica denotada por decomposição em componentes ortogonais, apresentada em seus detalhes por meio do Capítulo 3, fornece, em um primeiro momento, as formas de onda tanto para as tensões quanto para as correntes que se fazem contidas na função planar das tensões de linha, bem como as formas de onda de tensão e de corrente que se encontram ortogonais a essa função planar. Em segundo momento, ainda valendo-se dos conceitos desenvolvidos para a técnica de decomposição em componentes ortogonais, é possível decompor cada par tensão corrente em outras oito componentes: quatro para as tensões e quatro para as correntes. Assim, considerando-se um sistema trifásico e desse disponível as formas de onda para as tensões de fase e para as correntes de linha, são possíveis, considerando-se também as formas de onda para $v_{N}(t)$ e para $i_{N}(t)$, a obtenção de um total de 64 formas de onda: 32 para as tensões e 32 para as correntes. A fim de melhor delinear cada uma dessas formas de onda, apresenta-se na Figura 5.17 um diagrama esquemático ilustrativo do processo de decomposição em componentes ortogonais.

Resumindo, a partir da Figura 5.17 se tem, após o emprego da decomposição por componentes ortogonais, 64 componentes. A fim de colaborar com a definiçãa de cada uma dessas componentes, por meio de (5.1), apresenta-se a formulação matemática para determinação das componentes do conjunto $\left\{v_{a}(t), v_{b}(t), v_{c}(t), v_{n}(t)\right\}$, bem como, por meio de (5.2), faz o mesmo para os elementos do conjunto $\left\{i_{a}(t), i_{b}(t), i_{c}(t), i_{n}(t)\right\}$. Ambos os conjuntos $\left\{v_{a}(t), v_{b}(t), v_{c}(t), v_{n}(t)\right\}$ e $\left\{i_{a}(t), i_{b}(t), i_{c}(t), i_{n}(t)\right\}$ representam as componentes de tensão e de corrente, respectivamente, as quais estão contidas na função planar das tensões de linha. 


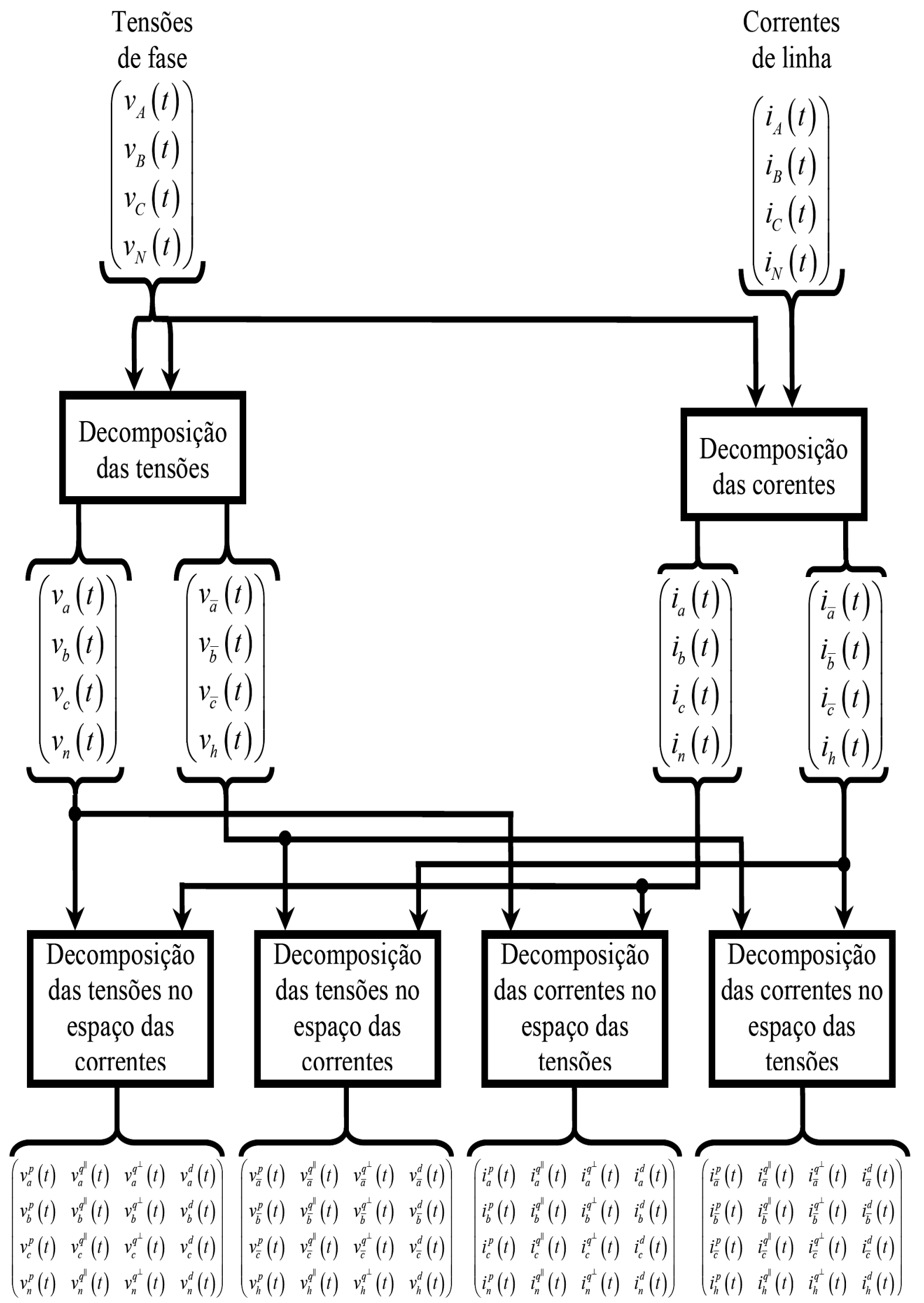

Figura 5.17 - Diagrama esquemático do processo de decomposição por componentes ortogonais 


$$
\begin{aligned}
& \left\{\begin{array}{l}
v_{a}(t)=\frac{\left\langle v_{\|}(t), v_{A}(t)\right\rangle}{\left\|v_{\|}(t)\right\|^{2}} v_{\|}(t)+\frac{\left\langle v_{\perp}(t), v_{A}(t)\right\rangle}{\left\|v_{\perp}(t)\right\|^{2}} v_{\perp}(t) \\
v_{b}(t)=\frac{\left\langle v_{\|}(t), v_{B}(t)\right\rangle}{\left\|v_{\|}(t)\right\|^{2}} v_{\|}(t)+\frac{\left\langle v_{\perp}(t), v_{B}(t)\right\rangle}{\left\|v_{\perp}(t)\right\|^{2}} v_{\perp}(t) \\
v_{c}(t)=\frac{\left\langle v_{\|}(t), v_{C}(t)\right\rangle}{\left\|v_{\|}(t)\right\|^{2}} v_{\|}(t)+\frac{\left\langle v_{\perp}(t), v_{C}(t)\right\rangle}{\left\|v_{\perp}(t)\right\|^{2}} v_{\perp}(t) \\
v_{n}(t)=v_{a}(t)+v_{b}(t)+v_{c}(t) \\
i_{a}(t)=\frac{\left\langle v_{\|}(t), i_{A}(t)\right\rangle}{\left\|v_{\|}(t)\right\|^{2}} v_{\|}(t)+\frac{\left\langle v_{\perp}(t), i_{A}(t)\right\rangle}{\left\|v_{\perp}(t)\right\|^{2}} v_{\perp}(t) \\
i_{b}(t)=\frac{\left\langle v_{\|}(t), i_{B}(t)\right\rangle}{\left\|v_{\|}(t)\right\|^{2}} v_{\|}(t)+\frac{\left\langle v_{\perp}(t), i_{B}(t)\right\rangle}{\left\|v_{\perp}(t)\right\|^{2}} v_{\perp}(t) \\
i_{c}(t)=\frac{\left\langle v_{\|}(t), i_{C}(t)\right\rangle}{\left\|v_{\|}(t)\right\|^{2}} v_{\|}(t)+\frac{\left\langle v_{\perp}(t), i_{C}(t)\right\rangle}{\left\|v_{\perp}(t)\right\|^{2}} v_{\perp}(t) \\
i_{n}(t)=i_{a}(t)+i_{b}(t)+i_{c}(t)
\end{array}\right.
\end{aligned}
$$

onde:

$$
\left\{\begin{array}{l}
v_{\|}(t)=v_{A B}(t) \\
v_{\perp}(t)=v_{B C}(t)-\frac{\left\langle v_{A B}(t), v_{B C}(t)\right\rangle}{\left\|v_{A B}(t)\right\|^{2}} v_{A B}(t)
\end{array}\right.
$$

O conjunto $\left\{v_{\bar{a}}(t), v_{\bar{b}}(t), v_{\bar{c}}(t), v_{h}(t)\right\}$, referente às tensões, bem como o conjunto $\left\{i_{\bar{a}}(t), i_{\bar{b}}(t), i_{\bar{c}}(t), i_{h}(t)\right\}$, referente às componentes de corrente, representam aquelas componentes ortogonais à função planar das tensões de linha e podem ser calculadas por meio da Expressão (5.4) e da Expressão (5.5), respectivamente.

$$
\left\{\begin{array}{l}
v_{\bar{a}}(t)=v_{A}(t)-v_{a}(t) \\
v_{\bar{b}}(t)=v_{B}(t)-v_{b}(t) \\
v_{\bar{c}}(t)=v_{C}(t)-v_{c}(t) \\
v_{h}(t)=v_{\bar{a}}(t)+v_{\bar{b}}(t)+v_{\bar{c}}(t)
\end{array}\right.
$$




$$
\left\{\begin{array}{l}
i_{\bar{a}}(t)=i_{A}(t)-i_{a}(t) \\
i_{\bar{b}}(t)=i_{B}(t)-i_{b}(t) \\
i_{\bar{c}}(t)=i_{C}(t)-i_{c}(t) \\
i_{h}(t)=i_{\bar{a}}(t)+i_{\bar{b}}(t)+i_{\bar{c}}(t)
\end{array}\right.
$$

As componentes $v_{x}^{p}(t)$ representam as componentes colineares com as funções $i_{x}(t)$, bem como as componentes $i_{x}^{p}(t)$ denotam as componentes colineares com as funções $v_{x}(t), \operatorname{com} x=a, b, c, n, \bar{a}, \bar{b}, \bar{c}, h$, e podem ser calculadas da seguinte maneira:

$$
\left\{\begin{array}{l}
v_{x}^{p}(t)=\frac{\left\langle v_{x}(t), i_{x}(t)\right\rangle}{\left\|i_{x}(t)\right\|^{2}} i_{x}(t) \\
i_{x}^{p}(t)=\frac{\left\langle i_{x}(t), v_{x}(t)\right\rangle}{\left\|v_{x}(t)\right\|^{2}} v_{x}(t)
\end{array}\right.
$$

De maneira semelhante, as componentes $v_{x}^{q^{\| \prime}}(t)$ representam as componentes colineares com as funções $i_{x}(t)$, bem como as componentes $i_{x}^{q^{\prime \prime}}(t)$ denotam as componentes colineares com as funções $\dot{v}_{x}(t)$, com $x=a, b, c, n, \bar{a}, \bar{b}, \bar{c}, h$, e podem ser obtidas por meio do seguinte equacionamento:

$$
\left\{\begin{array}{l}
v_{x}^{q^{\prime \prime}}(t)=\frac{\left\langle v_{x}(t), \dot{i}_{x}(t)\right\rangle}{\left\|\dot{i}_{x}(t)\right\|^{2}} \dot{i}_{x}(t) \\
i_{x}^{q^{\prime \prime}}(t)=\frac{\left\langle i_{x}(t), \dot{v}_{x}(t)\right\rangle}{\left\|\dot{v}_{x}(t)\right\|^{2}} \dot{v}_{x}(t)
\end{array}\right.
$$

As componentes $v_{x}^{q^{\perp}}(t)$ denotam as componentes de tensão colineares às funções $i_{x}^{\perp}(t)=\tilde{i}_{x}(t)-\left\langle\tilde{i}_{x}(t), i_{x}(t)\right\rangle /\left\|i_{x}(t)\right\|^{2} i_{x}(t)$ assim como as funções $i_{x}^{q^{\perp}}(t)$ são as componentes de corrente colineares com as funções $v_{x}^{\perp}(t)=\tilde{v}_{x}(t)-\left\langle\tilde{v}_{x}(t), \dot{v}_{x}(t)\right\rangle /\left\|\dot{v}_{x}(t)\right\|^{2} \dot{v}_{x}(t)$, com $x=a, b, c, n, \bar{a}, \bar{b}, \bar{c}, h$, e são calculadas se fazendo uso do seguinte conjunto de equações: 


$$
\left\{\begin{array}{l}
v_{x}^{q^{\perp}}(t)=\frac{\left\langle v_{x}(t), i_{x}^{\perp}(t)\right\rangle}{\left\|i_{x}^{\perp}(t)\right\|^{2}} i_{x}^{\perp}(t) \\
i_{x}^{q^{\perp}}(t)=\frac{\left\langle i_{x}(t), v_{x}^{\perp}(t)\right\rangle}{\left\|v_{x}^{\perp}(t)\right\|^{2}} v_{x}^{\perp}(t)
\end{array}\right.
$$

Além de ilustrar o processo por meio do diagrama esquemático descritivo de sua operação, feito por meio da Figura 5.17, será ainda apresentado como os valores eficazes das formas de onda resultantes da decomposição em componentes ortogonais se comportam temporalmente quando da ocorrência de uma falta fase-terra. Assim, diante de toda a base de simulações constituída, fora eleita uma simulação de falta de maneira aleatória com a finalidade de ilustrar o comportamento das componentes ortogonais diante da ocorrência de uma falta.

A simulação empregada nessa ilustração decorreu de uma simulação de falta na fase $\mathrm{C}$ e com uma resistência de falta de $61,75 \Omega$. A falta simulada, nesse caso teve início no instante 0,13 segundos e término no instante 0,61 segundos. Antes, no entanto, de apresentar como os valores eficazes das componentes ortogonais variam temporalmente, será apresentado por meio da Figura 5.18 as formas de onda de tensão e de corrente, registradas na subestação de distribuição, as quais foram empregadas no processo de decomposição por componentes ortogonais. Ainda, para fins de identificação e classificação da fase faltante, tem-se que as formas de onda de tensão e de corrente foram corrompidas por um ruído branco, simulando assim os ruídos decorrentes do processo de aquisição de dados. 

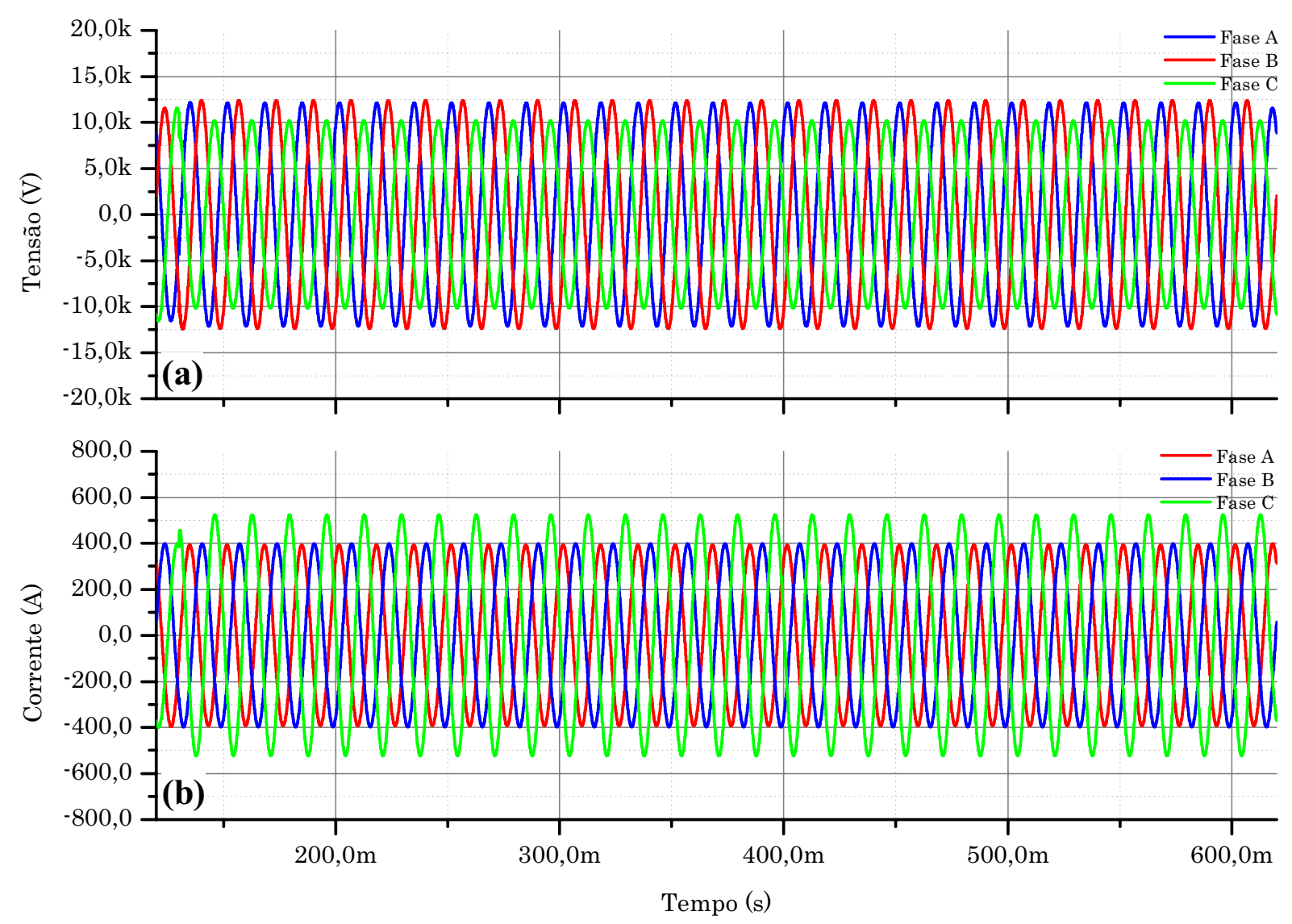

Figura 5.18 - Gráficos para as forma de onda obtidas por simulação computacional; (a) Formas de onda para as tensões de fase; (b) Formas de onda para as correntes de linha.

Processando as formas de onda fruto da simulação computacional a fim de se obter o valor eficaz das formas de onda das funções resultado da decomposição em componentes ortogonais, apresenta-se por meio da Figura 5.19 tanto o comportamento temporal para o valor eficaz das funções de tensão $v_{a}^{p}(t), v_{b}^{p}(t)$ e $v_{c}^{p}(t)$ como as correntes $i_{a}^{p}(t), i_{b}^{p}(t)$ e $i_{c}^{p}(t)$. Na seqüência, por meio da Figura 5.20, tem-se o comportamento temporal do valor eficaz para das funções $v_{n}^{p}(t)$ e $i_{n}^{p}(t)$. 

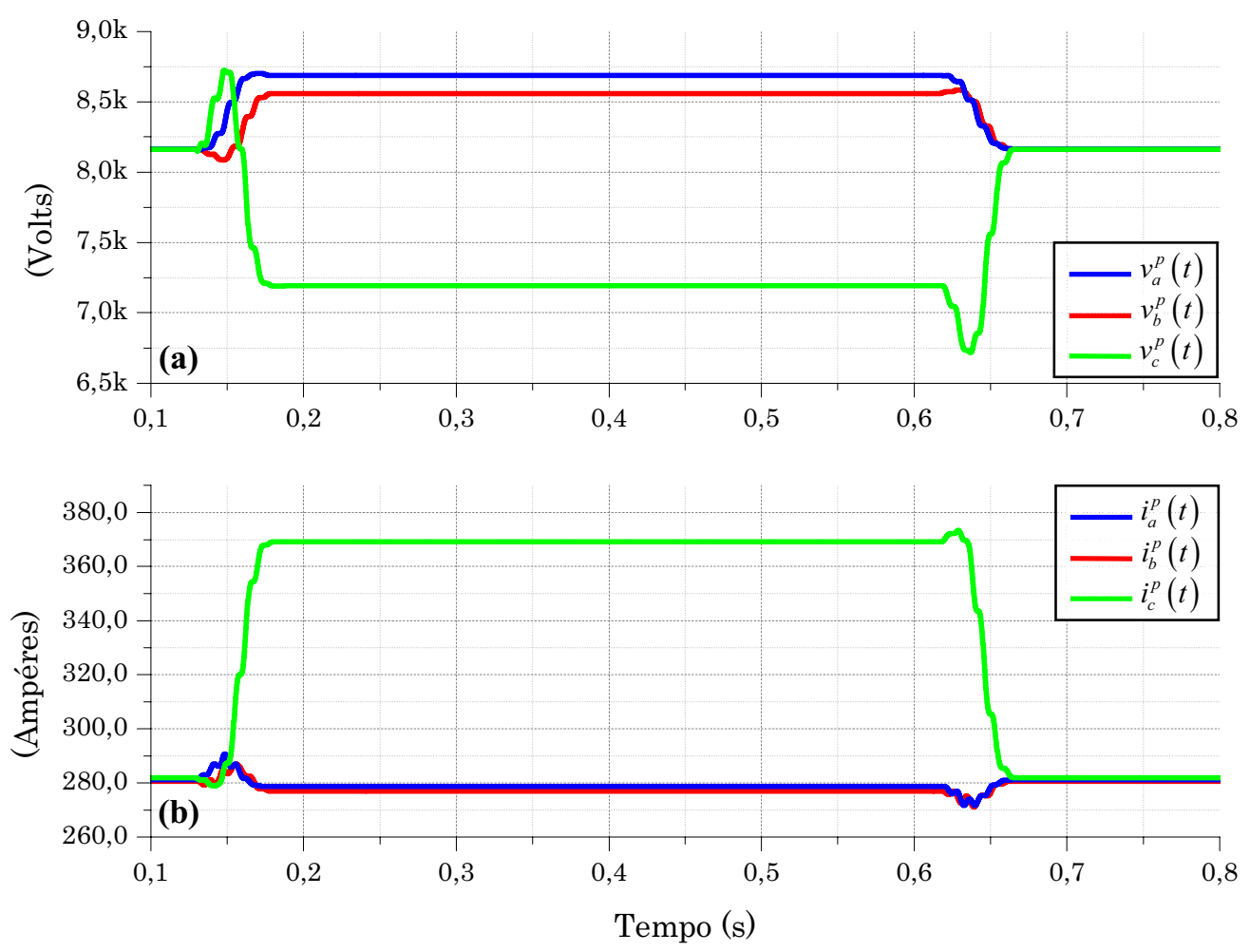

Figura 5.19 - Gráficos para os valores eficazes das componentes ortogonais; (a) Valores eficazes para as funções $v_{a}^{p}(t), v_{b}^{p}(t)$ e $v_{c}^{p}(t) ;(\mathbf{b})$ Valores eficazes para as funções $i_{a}^{p}(t)$, $i_{b}^{p}(t)$ e $i_{c}^{p}(t)$.

Prosseguindo com a apresentação dos valores eficazes das formas de onda resultantes da decomposição em componentes ortogonais, tem-se na Figura $5.21 \mathrm{o}$ comportamento temporal desse parâmetro para as funções $v_{a}^{q^{\prime \prime}}(t), v_{b}^{q^{\prime \prime}}(t)$ e $v_{c}^{q^{\prime \prime}}(t)$ em conjunto com as funções $i_{a}^{q^{\prime \prime}}(t), i_{b}^{q^{\prime \prime}}(t)$ e $i_{c}^{q^{\prime \prime}}(t)$ e assim como feito anteriormente, por meio da Figura 5.22 apresenta-se o comportamento temporal para o valor eficaz tanto da função $v_{n}^{q^{\|}}(t)$ como para $i_{n}^{q^{\|}}(t)$. 

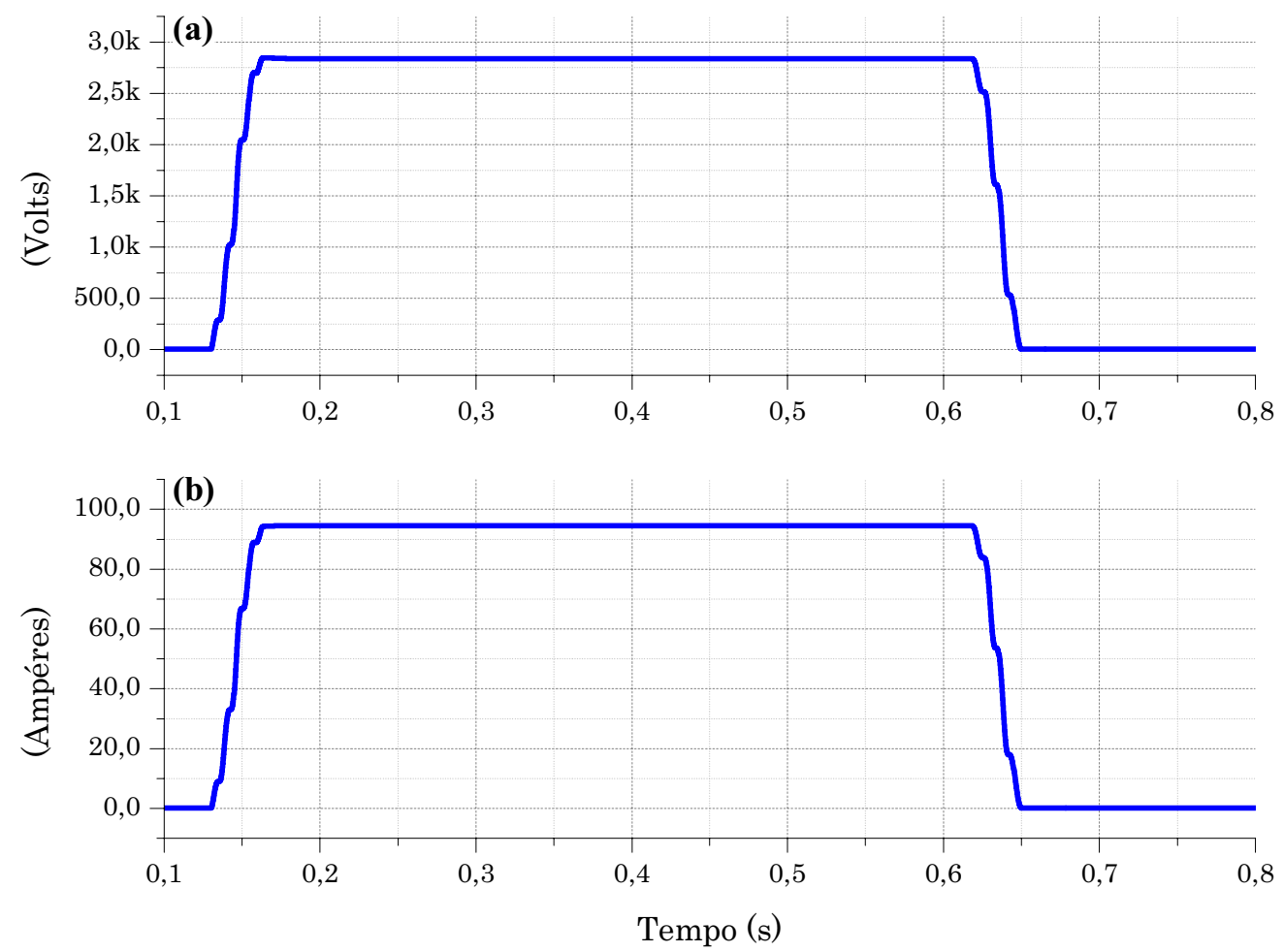

Figura 5.20 - Gráficos para os valores eficazes das componentes ortogonais; (a) Valor eficaz para a função $v_{n}^{p}(t)$; (b) Valor eficaz para a função $i_{n}^{p}(t)$.

Conforme é possível se observar por meio dos gráficos apresentados por intermédio da Figura 5.19 até a Figura 5.22, o valor eficaz das funções apresentadas nesses gráficos ilustram de forma clara a ocorrência da falta simulada. Dessa forma, o valor eficaz dessas projeções ortogonais são candidatas à identificação da ocorrência de uma falta de alta impedância. Além da identificação, observando-se os gráficos da Figura 5.19 e da Figura 5.21, vislumbra-se a possibilidade de se empregar os respectivos valores eficazes na identificação da fase faltosa.

Dando continuidade a ilustração do comportamento do valor eficaz das projeções ortogonais diante da ocorrência de um falta fase-terra, apresenta-se por meio da Figura 5.23 o comportamento dessa característica para as funções $v_{a}^{q^{\perp}}(t), v_{b}^{q^{\perp}}(t)$ e $v_{c}^{q^{\perp}}(t)$, bem como para as funções $i_{a}^{q^{\perp}}(t), i_{b}^{q^{\perp}}(t)$ e $i_{c}^{q^{\perp}}(t)$. Na seqüência, por meio da Figura 5.24, destaca-se o comportamento temporal do valor eficaz para as projeções $v_{n}^{q^{\perp}}(t)$ e $i_{n}^{q^{\perp}}(t)$. 

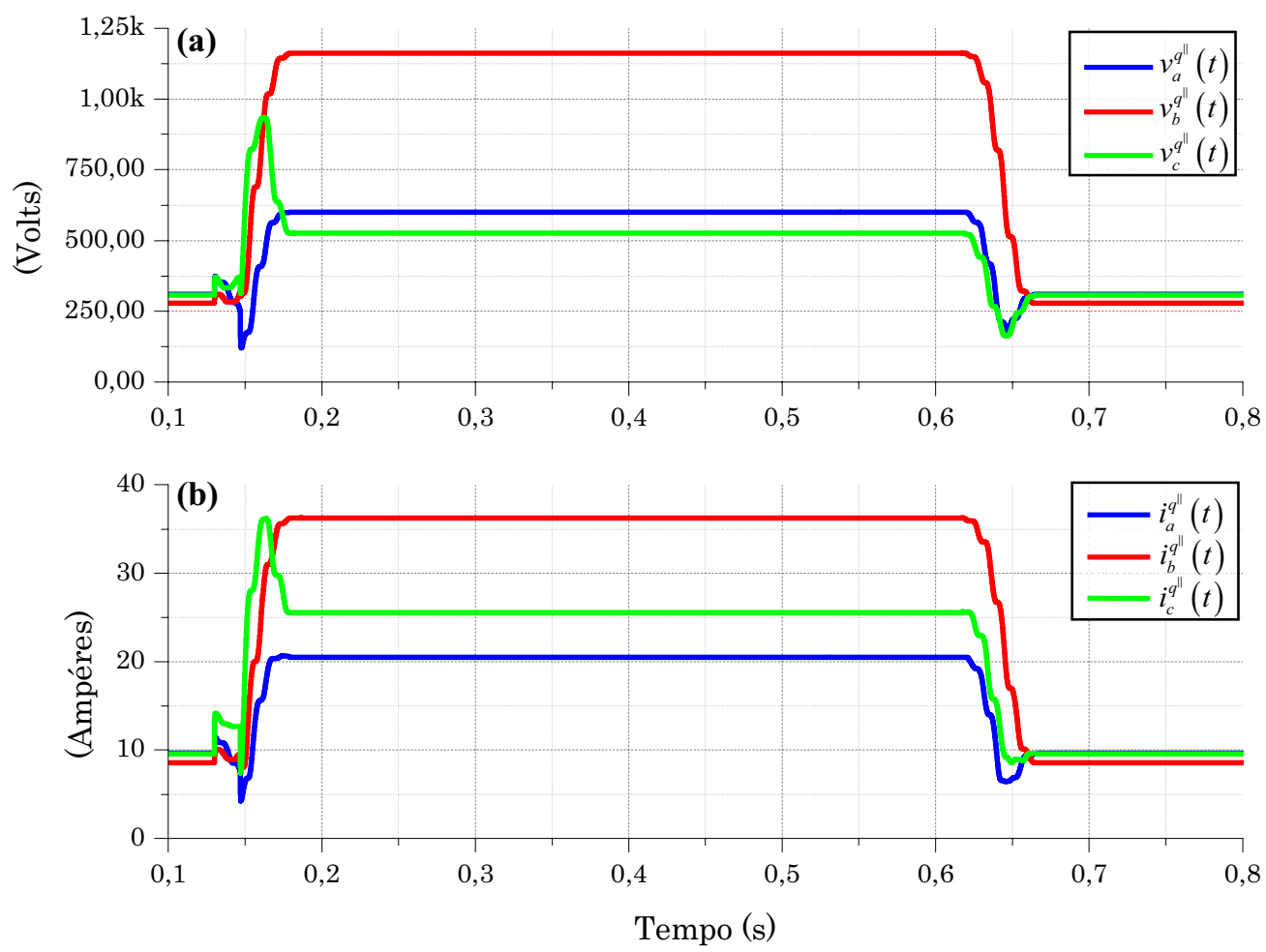

Figura 5.21 - Gráficos para os valores eficazes das componentes ortogonais; (a) Valores eficazes para as funções $v_{a}^{q^{\|}}(t), v_{b}^{q^{\|}}(t)$ e $v_{c}^{q^{\|}}(t)$; (b) Valores eficazes para as funções $i_{a}^{q^{\| \prime}}(t)$, $i_{b}^{q^{\prime \prime}}(t)$ e $i_{c}^{q^{\prime \prime}}(t)$.
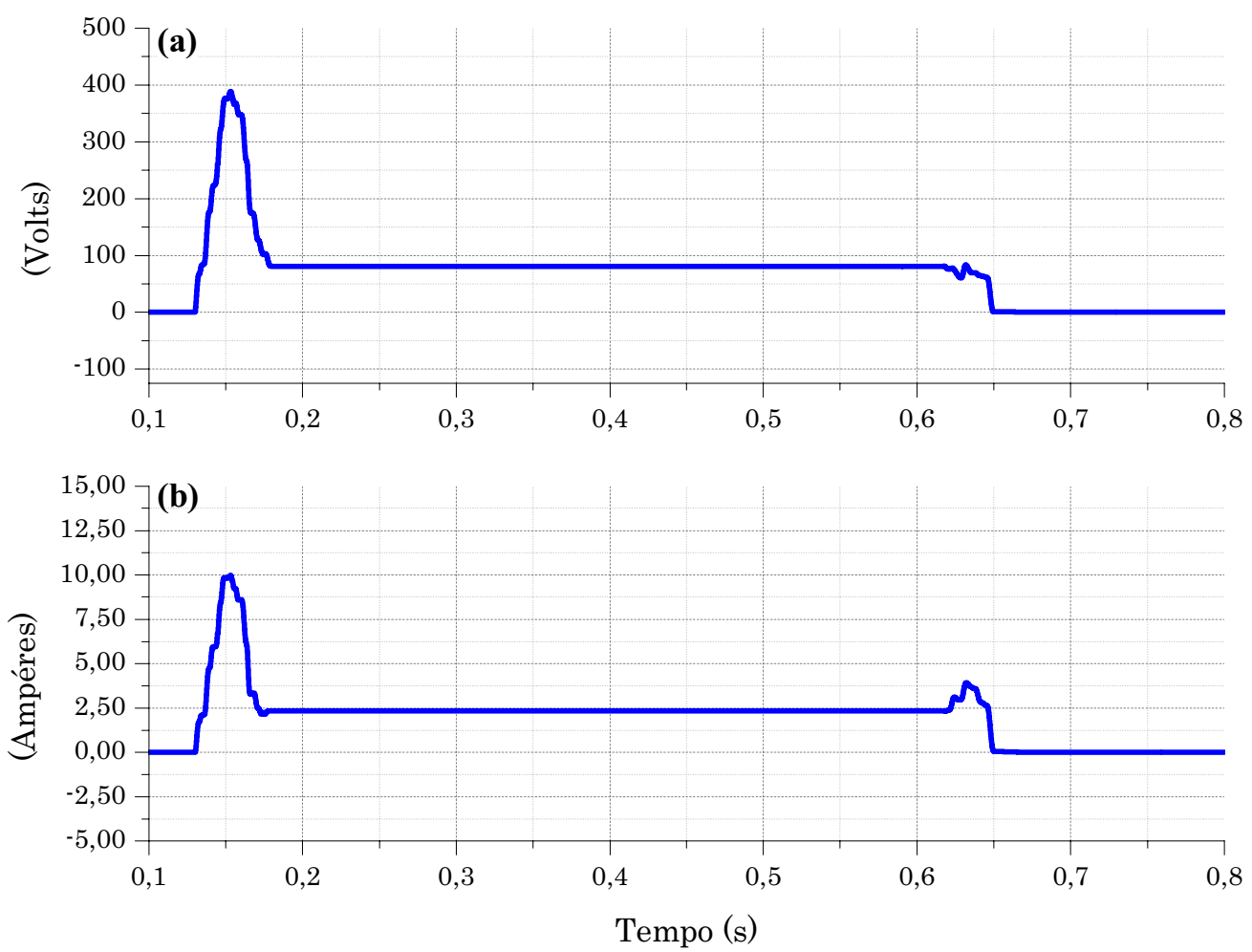

Figura 5.22 - Gráficos para os valores eficazes das componentes ortogonais; (a) Valor eficaz para a função $v_{n}^{q^{\|}}(t) ;$ (b) Valor eficaz para a função $i_{n}^{q^{\|}}(t)$. 

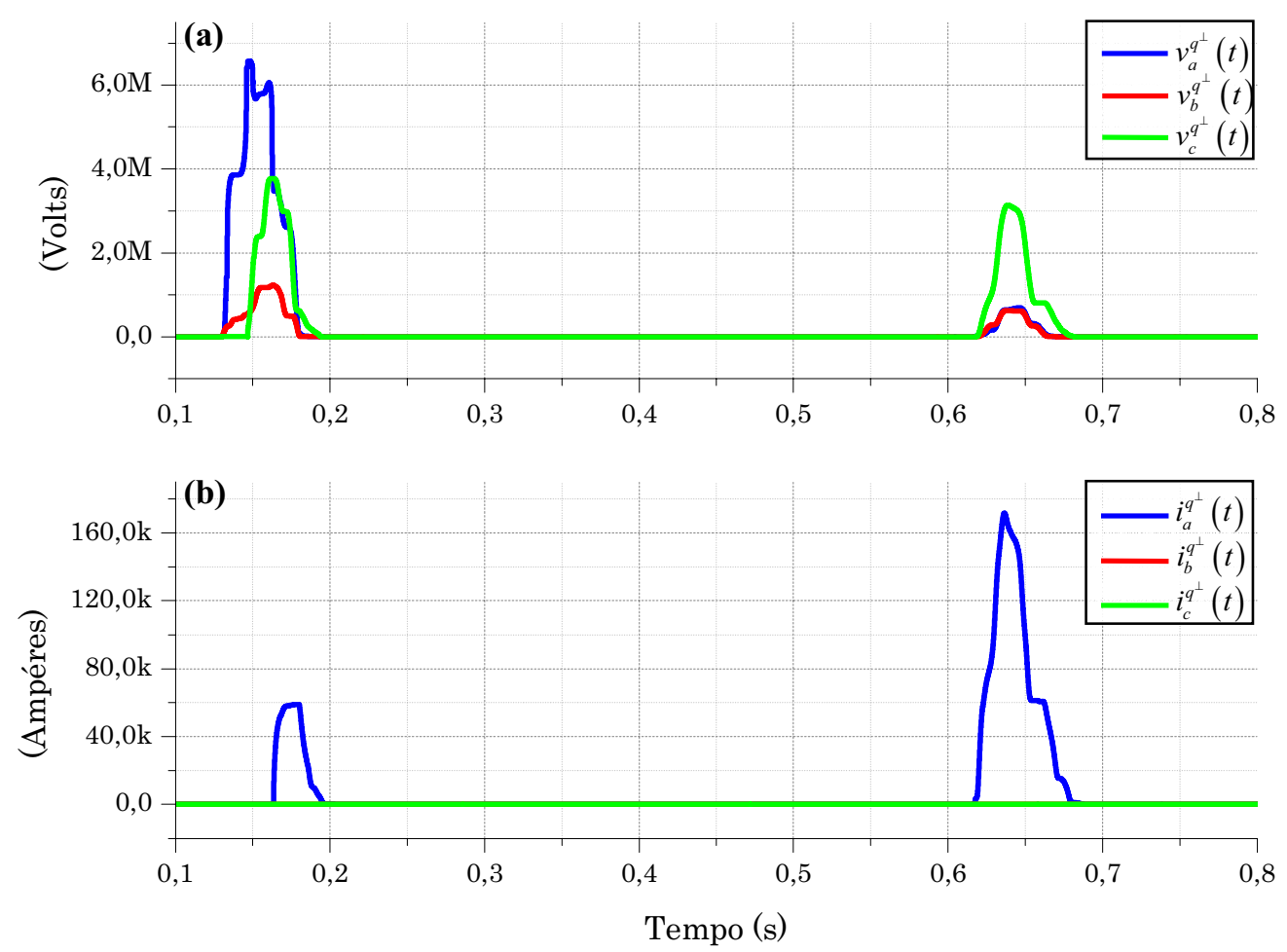

Figura 5.23 - Gráficos para os valores eficazes das componentes ortogonais; (a) Valores eficazes para as funções $v_{a}^{q^{\perp}}(t), v_{b}^{q^{\perp}}(t)$ e $v_{c}^{q^{\perp}}(t)$; (b) Valores eficazes para as funções $i_{a}^{q^{\perp}}(t)$, $i_{b}^{q^{\perp}}(t)$ e $i_{c}^{q^{\perp}}(t)$.
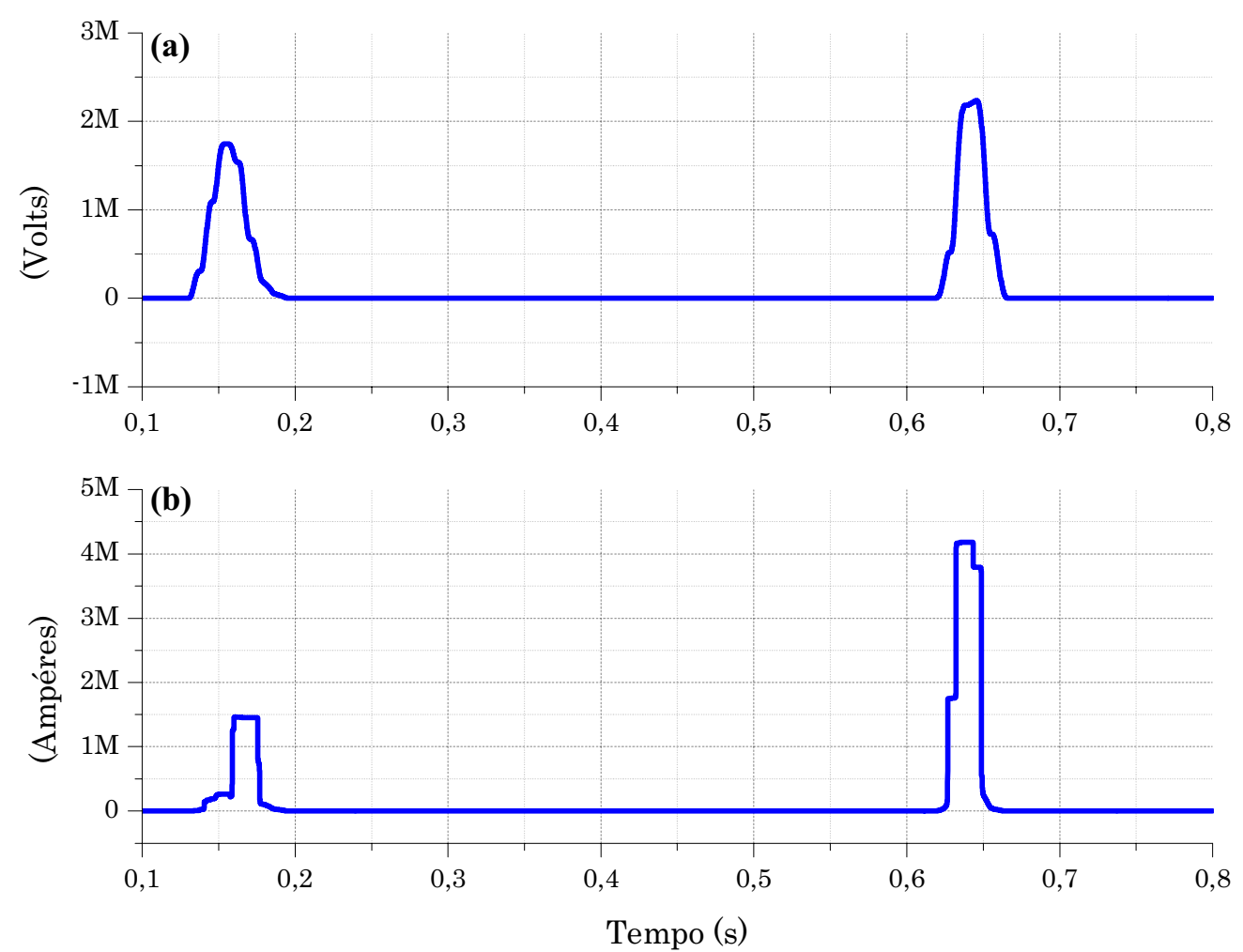

Figura 5.24 - Gráficos para os valores eficazes das componentes ortogonais; (a) Valor eficaz para a função $v_{n}^{q^{\perp}}(t)$; (b) Valor eficaz para a função $i_{n}^{q^{\perp}}(t)$. 
Diferentemente do observado para as projeções $f^{p}(t)$ e $f^{q^{\|}}(t)$, apresentadas por meio do comportamento temporal dos respectivos valores eficazes na Figura 5.19 até a Figura 5.22, as projeções $f^{q^{\perp}}(t)$, apresentadas por meio da Figura 5.23 e Figura 5.24, não informam sobre o intervalo de tempo de ocorrência da falta simulada. Observa-se sim, apenas seu instante inicial e o respectivo término da falta, sendo as mesmas amorfas durante o transcorrer da falta, momento no qual a ocorrência se manteve em regime permanente. Em outras palavras, pode-se constatar que as projeções $f^{q^{\perp}}(t)$ possuem valores não nulos significativos apenas quando da ocorrência de transitórios no sistema elétrico sob análise.

Ainda focando a apresentação das componentes ortogonais contidas na função planar das tensões de linha, destaca-se na Figura 5.25 o valor eficaz das projeções $v_{a}^{d}(t)$, $v_{b}^{d}(t)$ e $v_{c}^{d}(t)$, assim como para as funções $i_{a}^{d}(t), i_{b}^{d}(t)$ e $i_{c}^{d}(t)$. Assim como feito anteriormente, por meio da Figura 5.26, apresenta-se também o comportamento temporal para o valor eficaz das projeções $v_{n}^{d}(t)$ e $i_{n}^{d}(t)$.
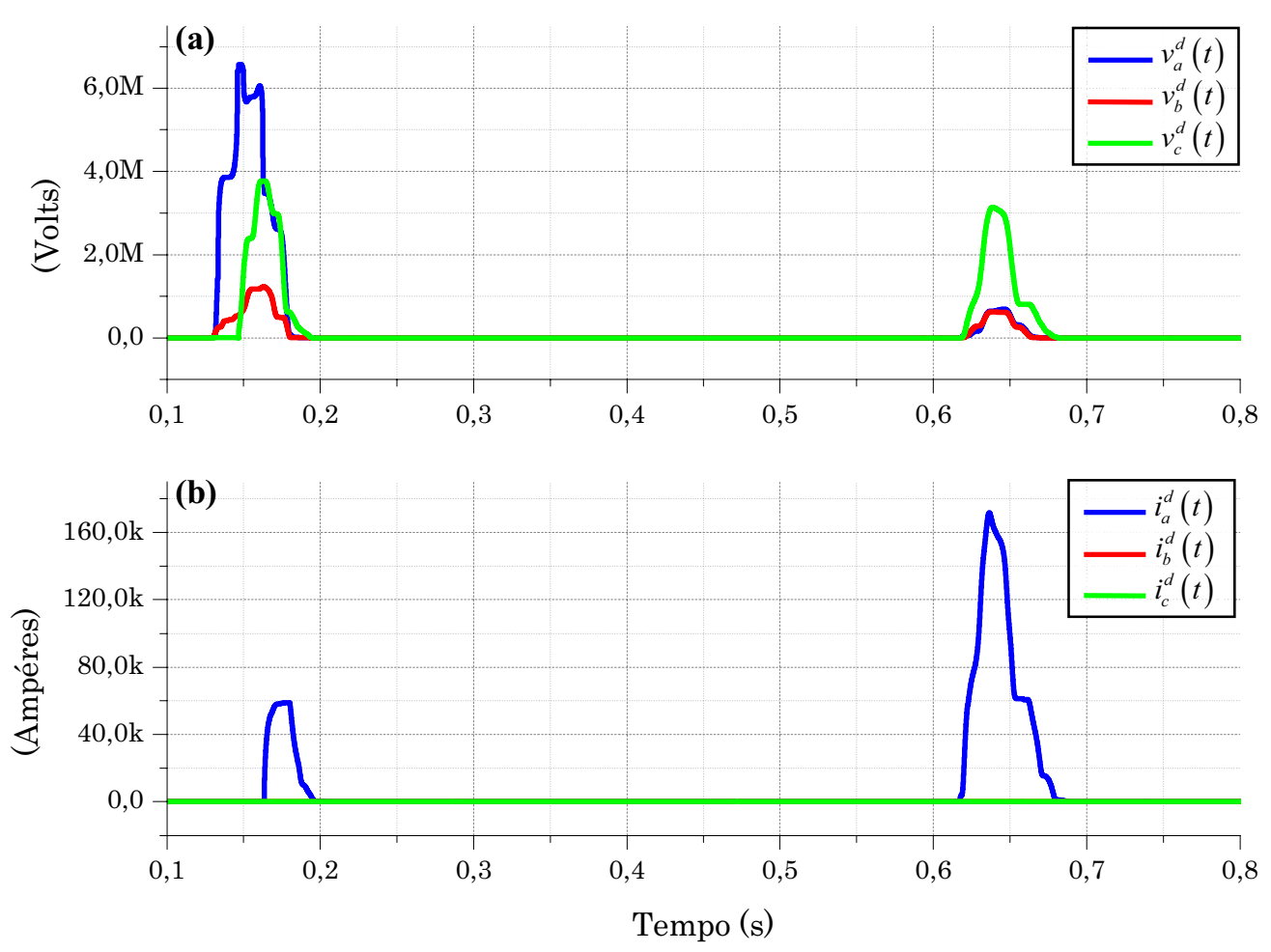

Figura 5.25 - Gráficos para os valores eficazes das componentes ortogonais; (a) Valores eficazes para as funções $v_{a}^{d}(t), v_{b}^{d}(t)$ e $v_{c}^{d}(t)$; (b) Valores eficazes para as funções $i_{a}^{d}(t)$,

$$
i_{b}^{d}(t) \text { e } i_{c}^{d}(t)
$$



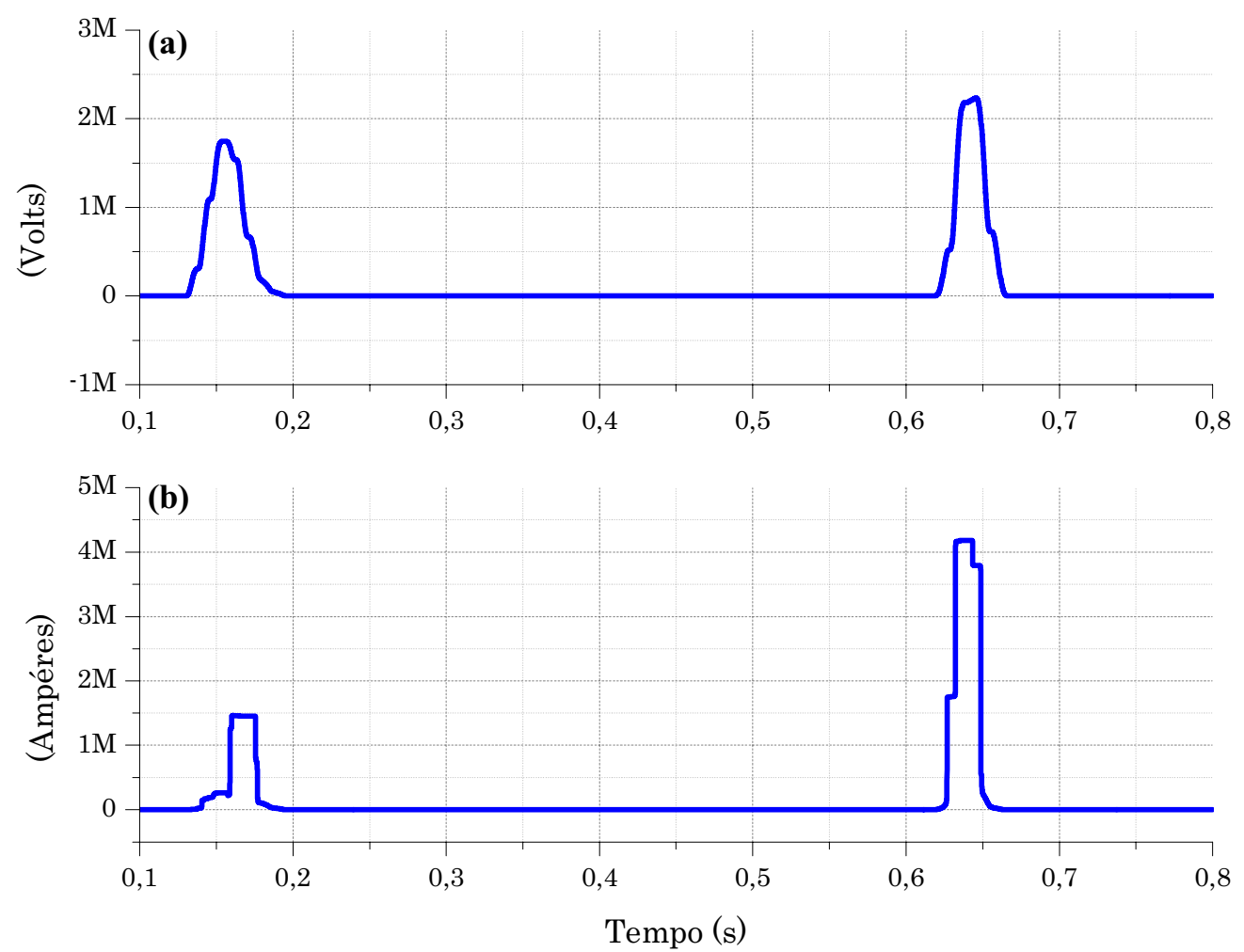

Figura 5.26 - Gráficos para os valores eficazes das componentes ortogonais; (a) Valor eficaz para a função $v_{n}^{d}(t)$; (b) Valor eficaz para a função $i_{n}^{d}(t)$.

Assim como verificado para as projeções $f^{q^{\perp}}(t)$, constata-se que as projeções $f^{d}(t)$ são inóculas quando de um regime permanente mesmo que esse seja referente a uma condição de falta. Os gráficos da Figura 5.25 e Figura 5.26, os quais apresentam o comportamento temporal das projeções $f^{d}(t)$, consubstanciam essa afirmação. Dessa maneira, verifica-se que, das projeções contidas na função planar das tensões de linha, ou seja, $f^{p}(t), f^{q^{\|}}(t), f^{q^{\perp}}(t)$ e $f^{d}(t)$, condensam informações sobre o intervalo de tempo de ocorrência de uma falta fase-terra somente as projeções $f^{p}(t), f^{q^{\prime \prime}}(t)$. Não se atendo apenas às projeções contidas na função planar das tensões de linha, apresenta-se por meio dos gráficos da Figura 5.27 os valores eficazes das funções de tensão $v_{\bar{a}}^{p}(t), v_{\bar{b}}^{p}(t)$ e $v_{\bar{c}}^{p}(t)$, assim como as correntes $i_{\bar{a}}^{p}(t), i_{\bar{b}}^{p}(t)$ e $i_{\bar{c}}^{p}(t)$. Na seqüência, por meio da Figura 5.28, tem-se o comportamento temporal do valor eficaz para das funções $v_{h}^{p}(t)$ e $i_{h}^{p}(t)$. 

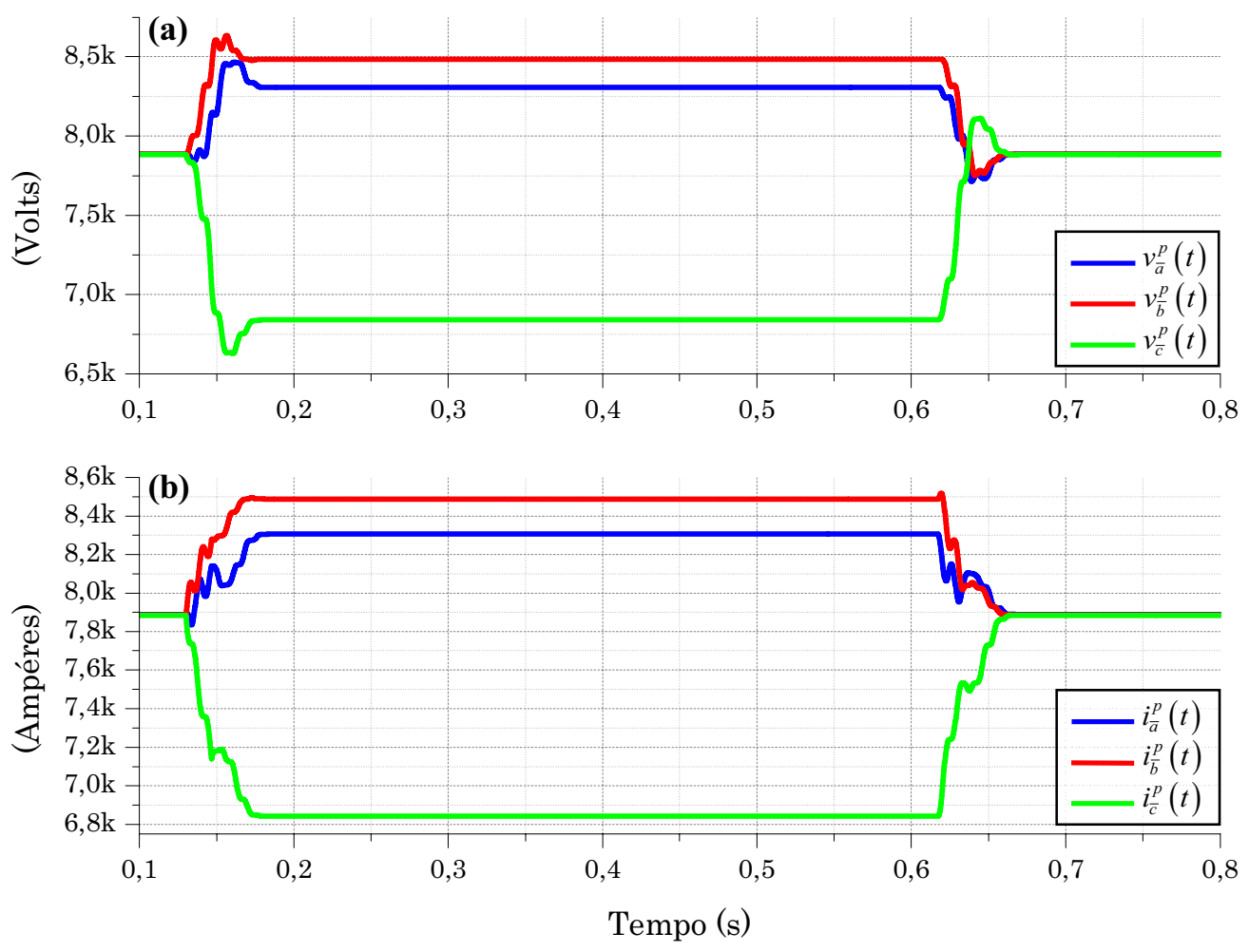

Figura 5.27 - Gráficos para os valores eficazes das componentes ortogonais; (a) Valores eficazes para as funções $v_{\bar{a}}^{p}(t), v_{\bar{b}}^{p}(t)$ e $v_{\bar{c}}^{p}(t) ;(\mathbf{b})$ Valores eficazes para as funções $i_{\bar{a}}^{p}(t)$, $i_{\bar{b}}^{p}(t)$ e $i_{\bar{c}}^{p}(t)$.
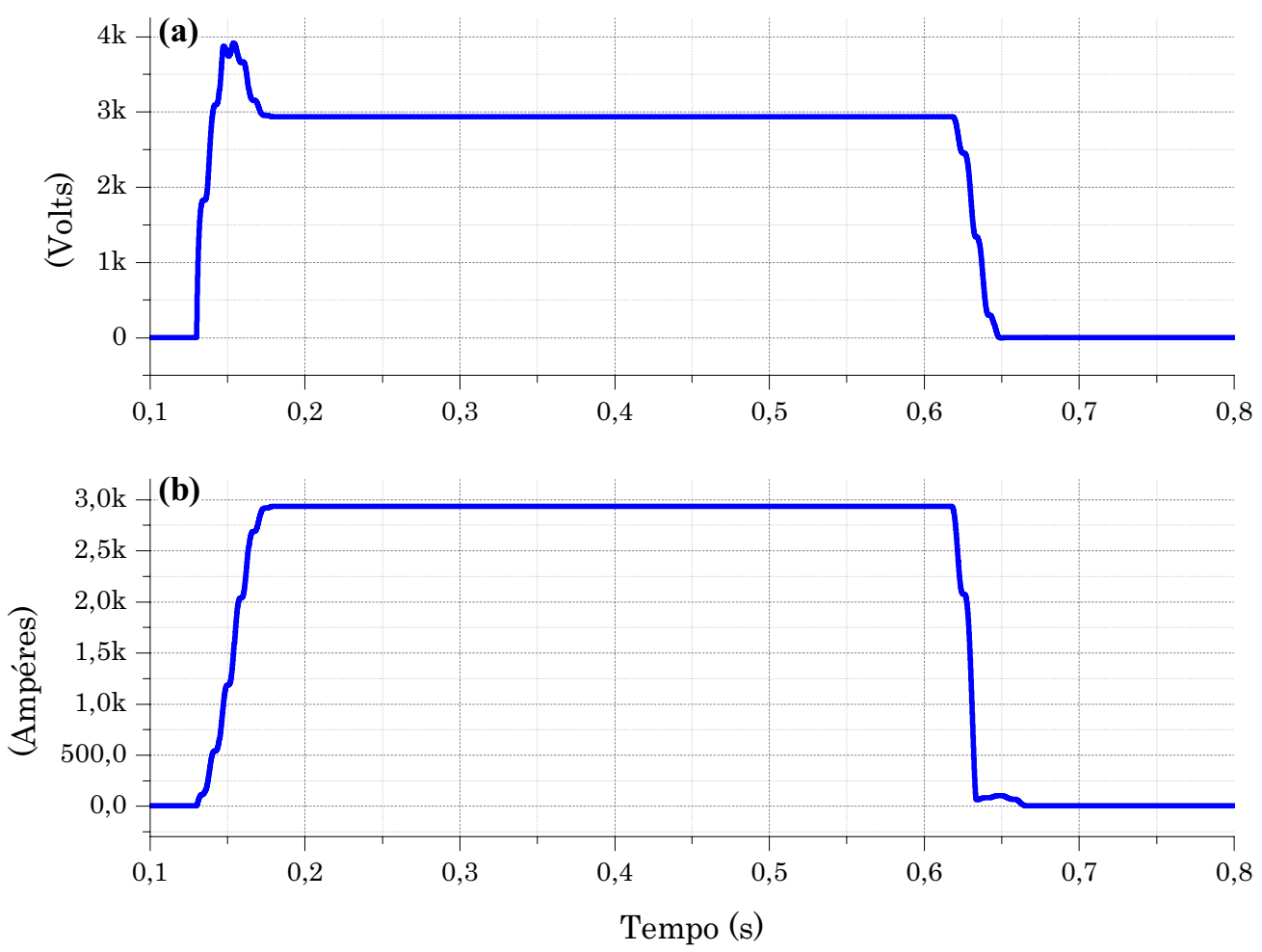

Figura 5.28 - Gráficos para os valores eficazes das componentes ortogonais; (a) Valor eficaz para a função $v_{h}^{p}(t)$; (b) Valor eficaz para a função $i_{h}^{p}(t)$. 
Por meio dos gráficos para as componentes ortogonais de corrente apresentado na Figura 5.27 é possível verificar que o valor eficaz para a corrente da fase faltosa, nesse caso a componentes $i_{\bar{c}}^{p}(t)$, apresenta magnitude sensivelmente superior àquela observada para as fase sãs. Esse aspecto pode contribuir para identificação da fase faltosa. No entanto, no que se refere à identificação da falta, tem-se que as componentes ortogonais retratadas na Figura 5.27 e Figura 5.28 pouco contribuem para a identificação de faltas almejadas. Esse mesmo aspecto, ou seja, a insensibilidade diante do regime permanente, seja para uma operação normal ou faltosa, também pode ser observado por meio das componentes $v_{\bar{a}}^{q^{\|}}(t), v_{\bar{b}}^{q^{\|}}(t)$ e $v_{\bar{c}}^{q^{\|}}(t)$, em conjunto com as funções $i_{\bar{a}}^{q^{\|}}(t), i_{\bar{b}}^{q^{\|}}(t)$ e $i_{\bar{c}}^{q^{\|}}(t)$, apresentadas em termos de seus valores eficazes na Figura 5.29 e Figura 5.30, na qual se tem o valor eficaz para as funções $v_{h}^{q^{\prime \prime}}(t)$ e $i_{h}^{q^{\|}}(t)$
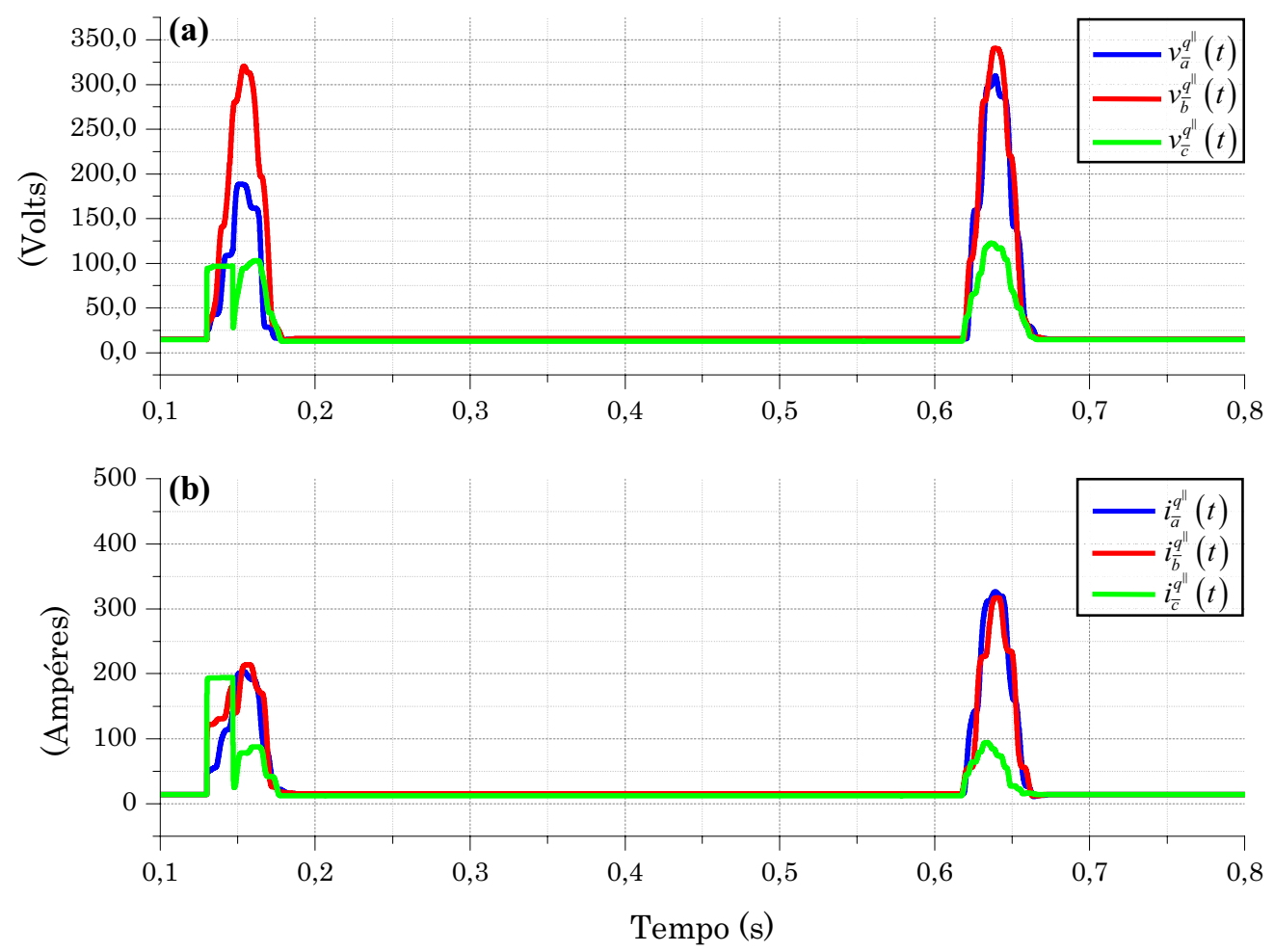

Figura 5.29 - Gráficos para os valores eficazes das componentes ortogonais; (a) Valores eficazes para as funções $v_{\bar{a}}^{q^{\|}}(t), v_{\bar{b}}^{q^{\| \prime}}(t)$ e $v_{\bar{c}}^{q^{\prime \prime}}(t)$; (b) Valores eficazes para as funções $i_{\bar{a}}^{q^{\prime \prime}}(t)$, $i_{\bar{b}}^{q^{\prime \prime}}(t)$ e $i_{\bar{c}}^{q^{\prime \prime}}(t)$.

Assim como a projeção $i_{\bar{c}}^{p}(t)$ fora classificada como potencial na identificação da fase participante da falta, pode-se inferir semelhante classificação para a projeção $i_{\bar{c}}^{q^{\|}}(t)$ a 
qual, por ser sensivelmente distinta às componentes $i_{\bar{a}}^{q^{\prime \prime}}(t)$ e $i_{\bar{b}}^{q^{\prime \prime}}(t)$, pode colaborar na identificação da fase faltosa. No entanto, as projeções retratadas na Figura 5.29 e Figura 5.30 não informam sobre a duração da falta tal como citado anteriormente. Continuando com a apresentação do comportamento do valor eficaz das componentes ortogonais ao plano das tensões de linha, tem-se na Figura 5.31 o destaque para as componentes de tensão $v_{\bar{a}}^{q^{\perp}}(t)$, $v_{\frac{q^{\perp}}{b}}^{q^{2}}(t)$ e $v_{\bar{c}}^{q^{\perp}}(t)$, assim como para as componentes de corrente $i_{\bar{a}}^{q^{\perp}}(t), i_{\frac{q^{\perp}}{b}}^{\perp^{2}}(t)$ e $i_{\bar{c}}^{q^{\perp}}(t)$. Na seqüência, por meio da Figura 5.32, tem-se o comportamento do valor eficaz para as funções $v_{h}^{q^{\perp}}(t)$ e $i_{h}^{q^{\perp}}(t)$.
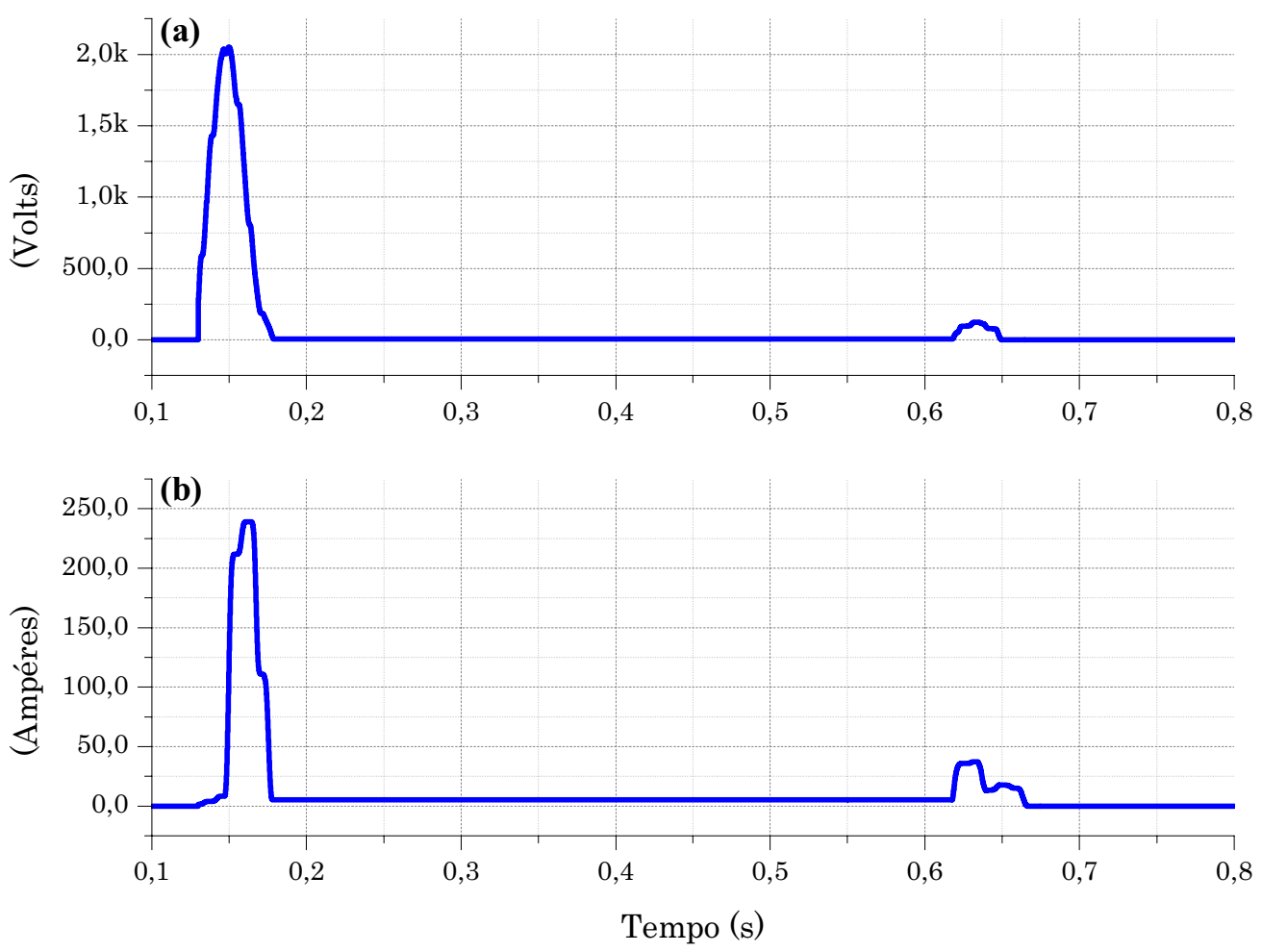

Figura 5.30 - Gráficos para os valores eficazes das componentes ortogonais; (a) Valor eficaz para a função $v_{h}^{q^{\prime \prime}}(t) ;(\mathbf{b})$ Valor eficaz para a função $i_{h}^{q^{\prime \prime}}(t)$. 

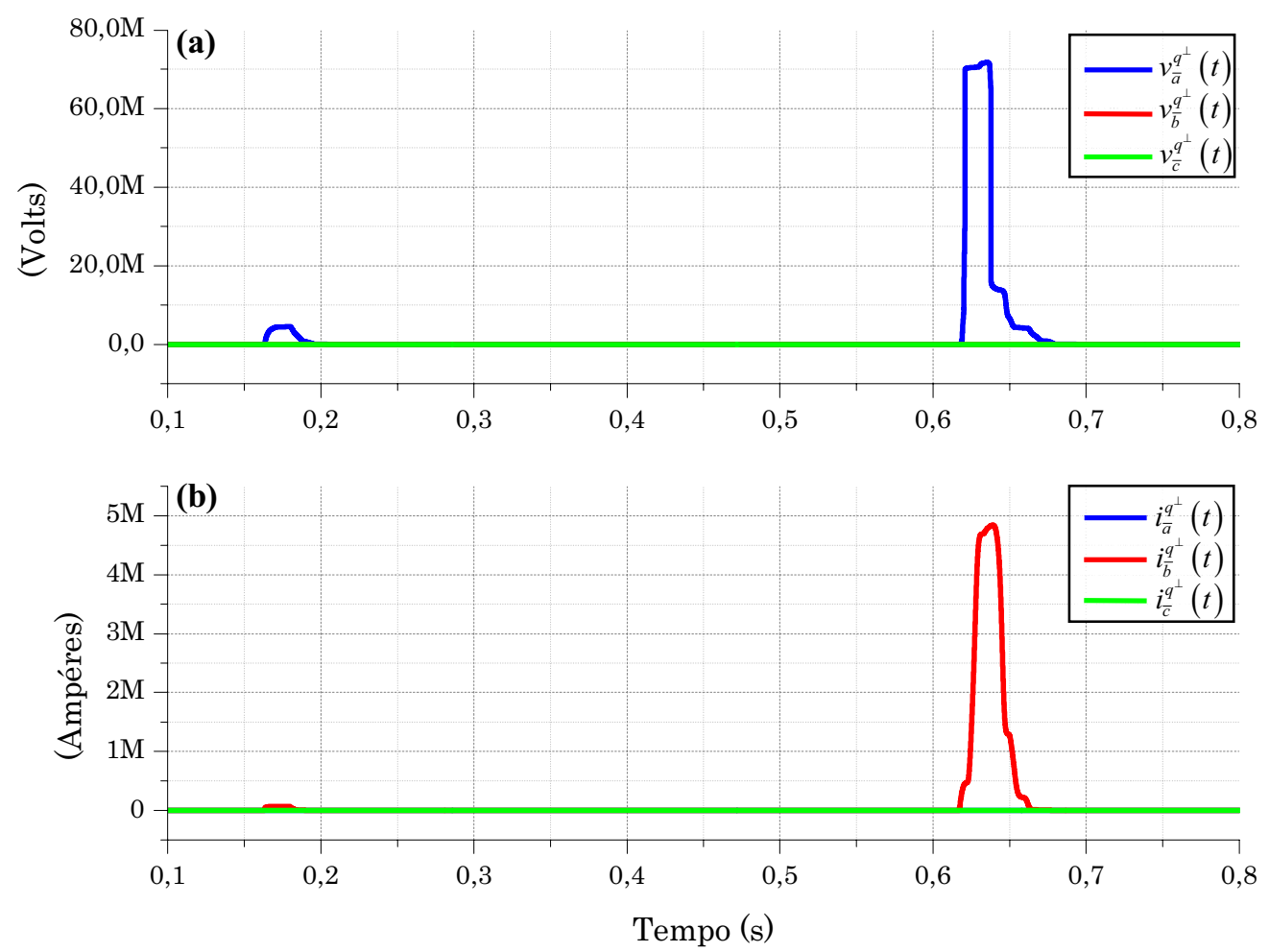

Figura 5.31 - Gráficos para os valores eficazes das componentes ortogonais; (a) Valores eficazes para as funções $v_{\bar{a}}^{q^{\perp}}(t), v_{\bar{b}}^{q^{\perp}}(t)$ e $v_{\bar{c}}^{q^{\perp}}(t)$; (b) Valores eficazes para as funções $i_{\bar{a}}^{q^{\perp}}(t)$, $i_{\frac{q^{\perp}}{b}}(t)$ e $i_{\bar{c}}^{q^{\perp}}(t)$.
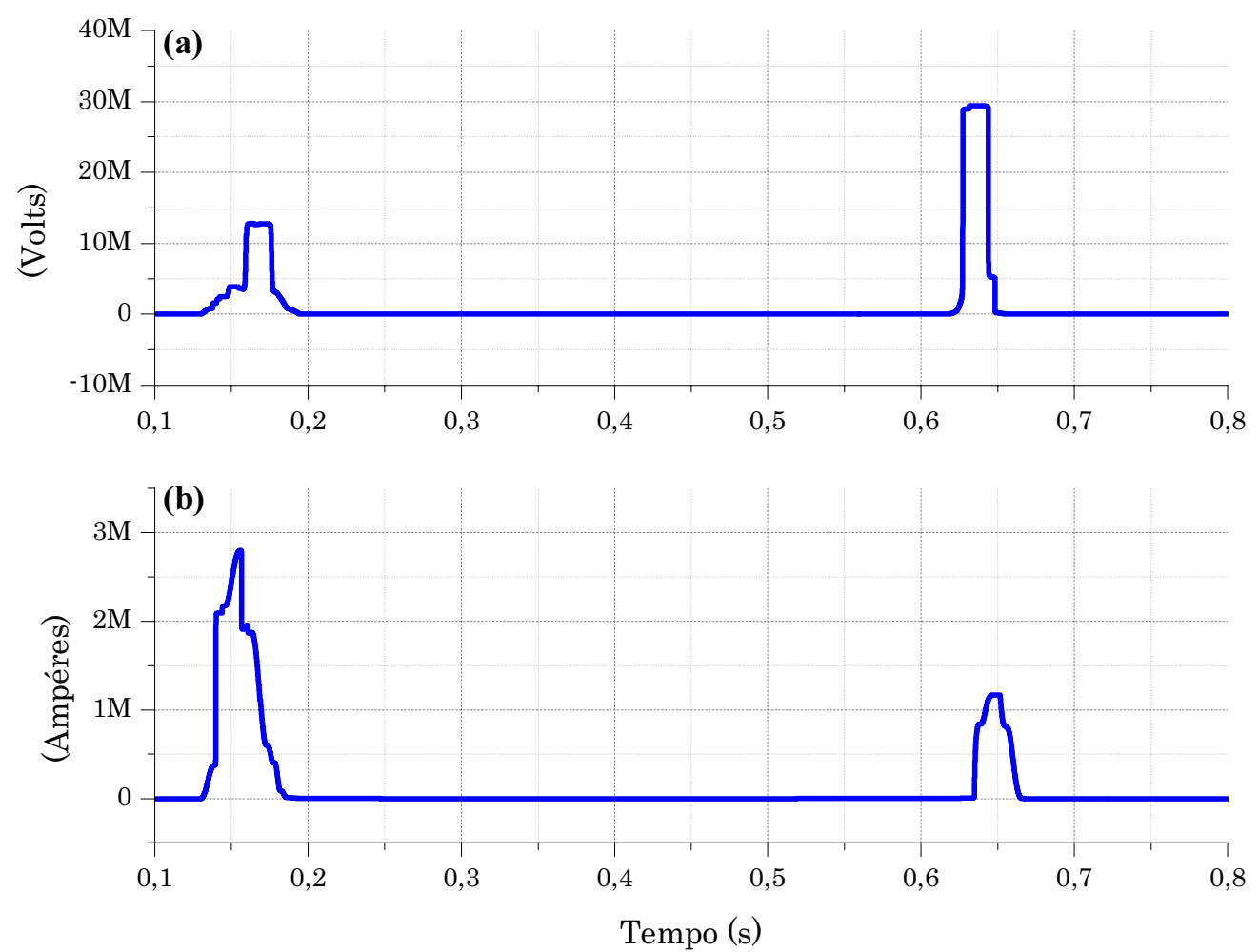

Figura 5.32 - Gráficos para os valores eficazes das componentes ortogonais; (a) Valor eficaz para a função $v_{h}^{q^{\prime \prime}}(t)$; (b) Valor eficaz para a função $i_{h}^{q^{\prime \prime}}(t)$. 
Findando a apresentação do comportamento temporal dos valores eficazes das componentes ortogonais à função planar das tensões de linha, apresenta-se por meio da Figura 5.33 a referida característica para as projeções de tensão $v_{\bar{a}}^{d}(t), v_{\bar{b}}^{d}(t)$ e $v_{\bar{c}}^{d}(t)$, bem como para as componentes de corrente $i_{\bar{a}}^{d}(t), i_{\bar{b}}^{d}(t)$ e $i_{\bar{c}}^{d}(t)$, assim como a Figura 5.34 apresentará as componentes $v_{h}^{d}(t)$ e $i_{h}^{d}(t)$.
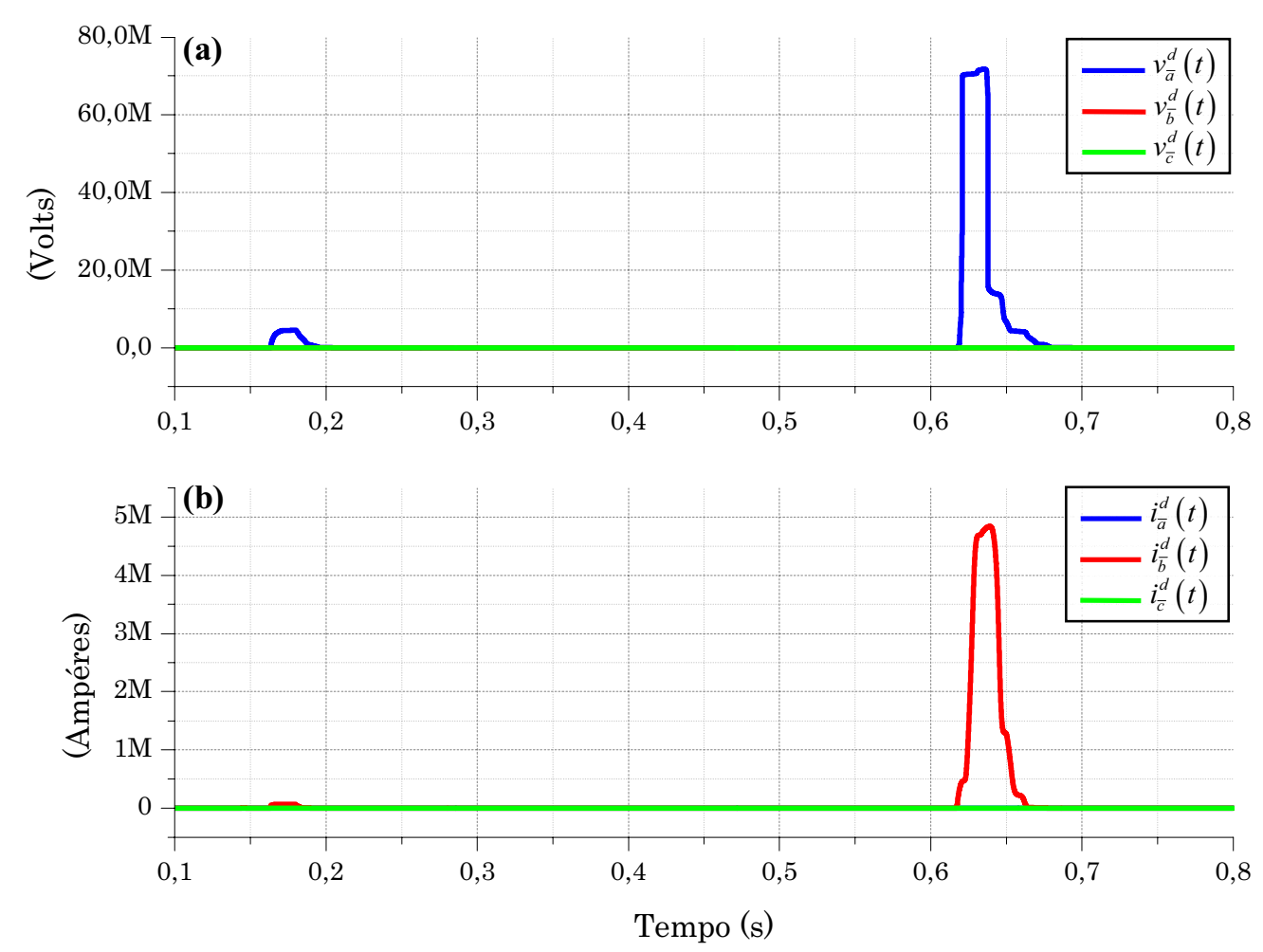

Figura 5.33 - Gráficos para os valores eficazes das componentes ortogonais; (a) Valores eficazes para as funções $v_{\bar{a}}^{d}(t), v_{\bar{b}}^{d}(t)$ e $v_{\bar{c}}^{d}(t)$; (b) Valores eficazes para as funções $i_{\bar{a}}^{d}(t)$, $i_{\bar{b}}^{d}(t)$ e $i_{\bar{c}}^{d}(t)$

No entanto, a simples observação visual de como o valor eficaz das componentes ortogonais se porta frente às condições normais e faltosas não constitui em uma metodologia científica para inferir sobre quais dessas componentes diretamente colaboram para a identificação da ocorrência de uma condição faltosa tal como se almeja por meio dessa seção. Partindo-se dessa impossibilidade de inferência, foram então analisadas todas as componentes ortogonais tanto diante dos instantes de operação normal como frente às condições de falta. A referida análise contemplou o cálculo da correlação entre o valor eficaz das componentes oriundas do processo de decomposição com as condições de falta ou operação normal. Não apenas focando no valor médio da correlação existente, fora feito o teste de hipótese dessa correlação ser significativa. 

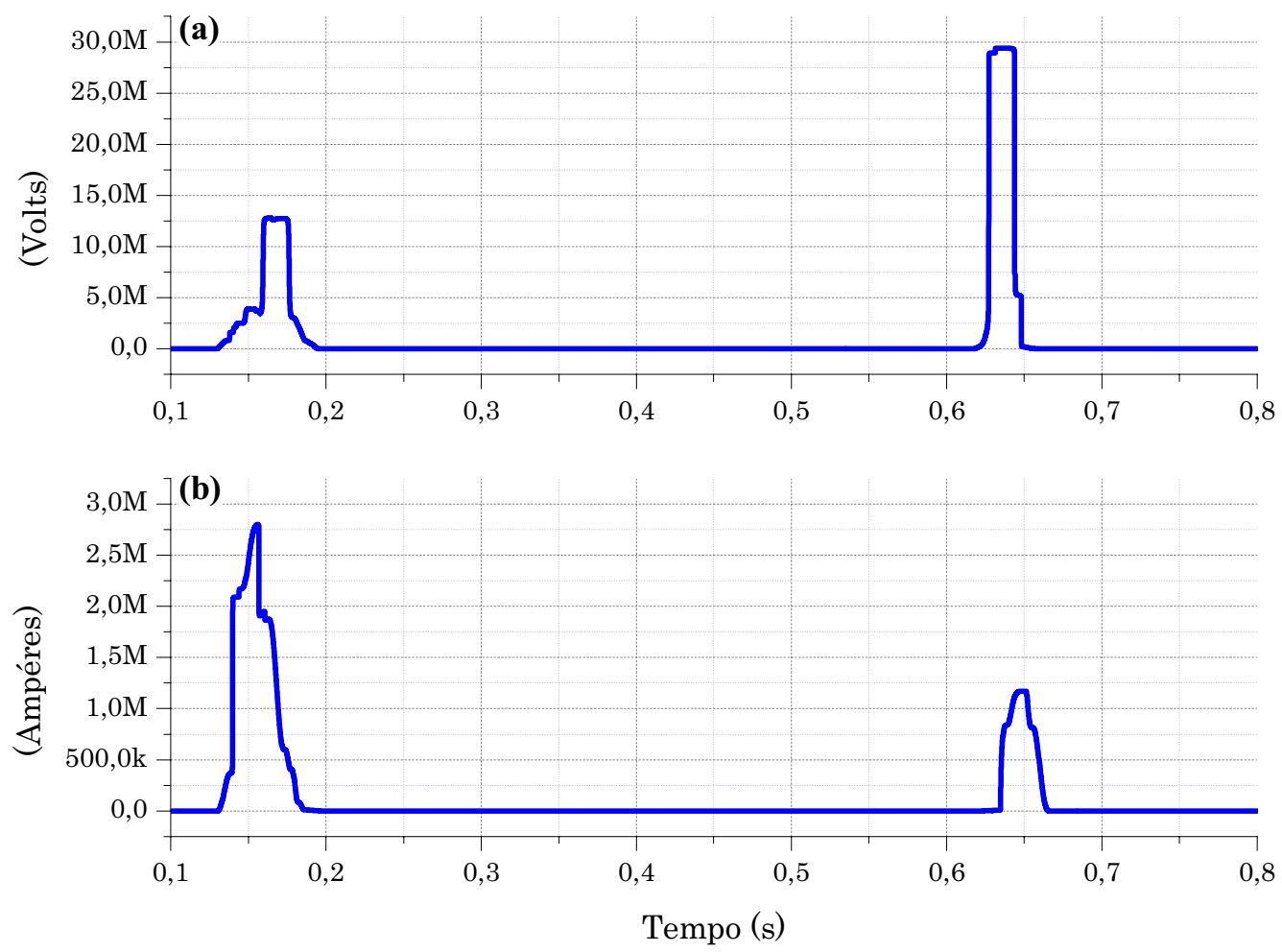

Figura 5.34 - Gráficos para os valores eficazes das componentes ortogonais; (a) Valor eficaz para a função $v_{h}^{d}(t)$; (b) Valor eficaz para a função $i_{h}^{d}(t)$.

Assim, no intuito de colaborar com a interpretabilidade dos resultados obtidos, o conjunto de correlações e testes de hipóteses foram subdivididos em dois grupos: um relativo às componentes contidas na função planar das tensões de linha e o segundo contemplando as componentes ortogonais a essa função planar. Dessa forma, por meio da Tabela 5.14 apresenta-se a relação das projeções contidas na função planar das tensões de linha associadas à sua correlação média com a discriminação entre condições normais e condições faltosas. Além disso, a Tabela 5.14 associa as variáveis com o resultado do teste de hipótese dessa variável não vir a informar sobre a ocorrência de uma condição de falta. A Tabela 5.15, por sua vez, apresenta a correlação entre as projeções ortogonais à função planar das tensões de linha e a identificação de faltas do tipo fase-terra, bem como o resultado do teste de hipótese, responsável por mensurar o quão significativa é a correlação, dessa característica não vir a informar sobre a ocorrência de uma condição de falta.

Para fins de análise gráfica, os valores de correlação e teste de hipótese destacados na Tabela 5.14 são apresentados na Figura 5.35, assim como a Figura 5.36 o faz para os resultados apresentado por meio da Tabela 5.15. 
Tabela 5.14 - Correlação e teste de hipótese para as projeções contidas na função planar das tensões de linha.

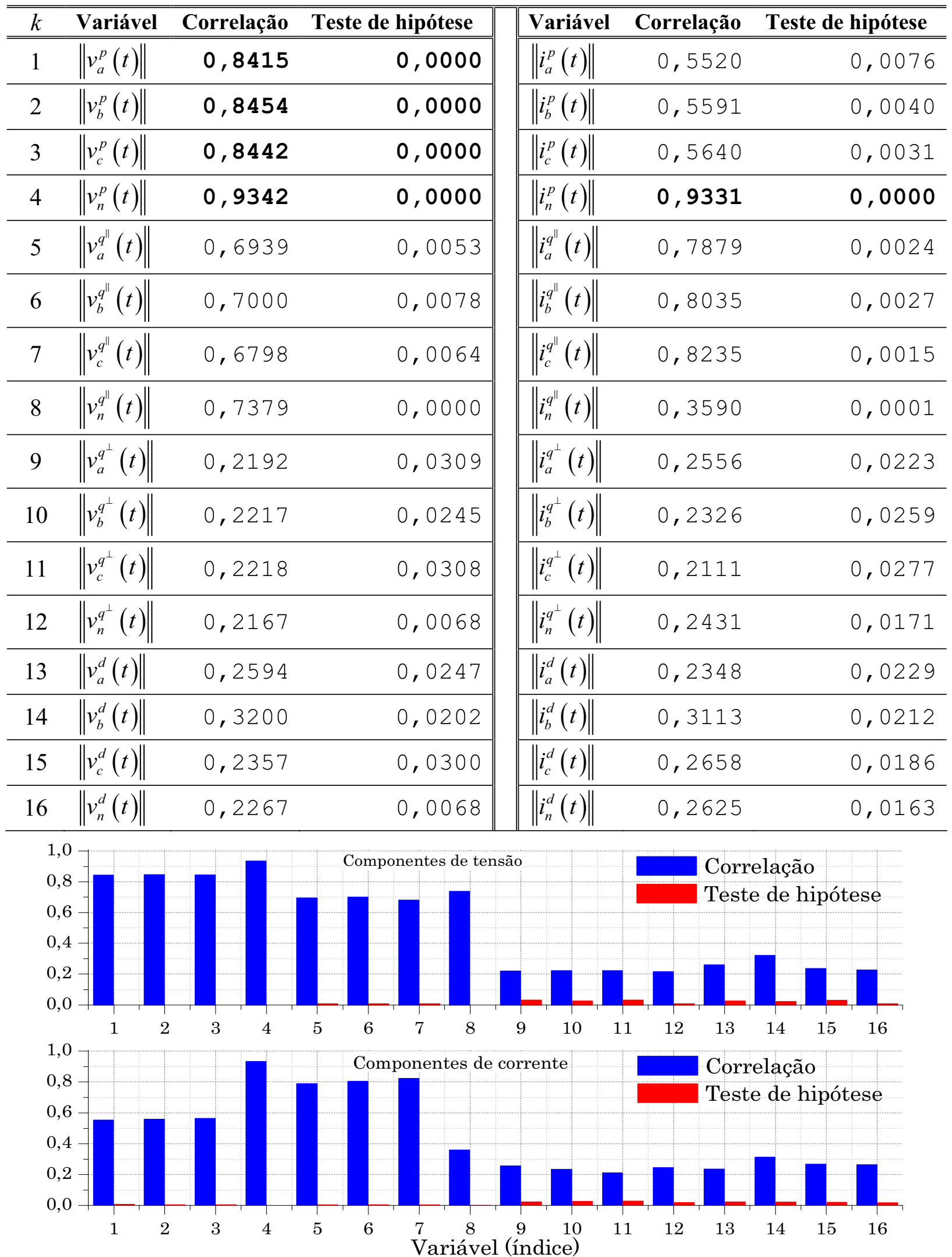

Figura 5.35 - Correlação e teste de hipótese para as projeções contidas na função planar das tensões de linha com relação à identificação de falta fase-terra. 
Tabela 5.15 - Correlação e teste de hipótese para as projeções ortogonais à função planar das tensões de linha.

\begin{tabular}{|c|c|c|c|c|c|c|}
\hline$k$ & Variável & Correlação & Teste de hipótese & Variável & Correlaçãa & Teste de hipótese \\
\hline 1 & $\left\|v_{\bar{a}}^{p}(t)\right\|$ & 0,1870 & 0,0260 & $\left\|i_{\bar{a}}^{p}(t)\right\|$ & 0,1818 & 0,0289 \\
\hline 2 & $\left\|v \frac{p}{b}(t)\right\|$ & 0,1961 & 0,0261 & $\left\|i \frac{p}{b}(t)\right\|$ & 0,1921 & 0,0244 \\
\hline 3 & $\left\|v_{\bar{c}}^{p}(t)\right\|$ & 0,1962 & 0,0203 & $\left\|i_{\bar{c}}^{p}(t)\right\|$ & 0,1957 & 0,0237 \\
\hline 4 & $\left\|v_{h}^{p}(t)\right\|$ & 0,2115 & 0,0020 & $\left\|i_{h}^{p}(t)\right\|$ & 0,2115 & 0,0020 \\
\hline 5 & $\left\|v_{\bar{a}}^{q^{\prime \prime}}(t)\right\|$ & 0,1916 & 0,0217 & $\left\|i^{q^{\|}}(t)\right\|$ & 0,2166 & 0,0154 \\
\hline 6 & $\left\|v \frac{q^{\prime \prime}}{b}(t)\right\|$ & 0,1688 & 0,0369 & $\left\|i^{\frac{q^{\|}}{b}}(t)\right\|$ & 0,1802 & 0,0379 \\
\hline 7 & $\left\|v \frac{q^{\prime \prime}}{c}(t)\right\|$ & 0,1874 & 0,0301 & $\left\|i_{\bar{c}}^{q^{\|}}(t)\right\|$ & 0,2041 & 0,0256 \\
\hline 8 & $\left\|v_{h}^{q^{\prime \prime}}(t)\right\|$ & 0,2117 & 0,0145 & $\left\|i_{h}^{q^{\|}}(t)\right\|$ & 0,2114 & 0,0145 \\
\hline 9 & $\left\|v_{\bar{a}}^{q^{\perp}}(t)\right\|$ & 0,1754 & 0,0364 & $\left\|i_{\frac{q^{\perp}}{a}}(t)\right\|$ & 0,2154 & 0,0131 \\
\hline 10 & $\left\|v^{q^{\perp}}(t)\right\|$ & 0,1716 & 0,0329 & $\left\|i^{q^{\perp}}(t)\right\|$ & 0,2296 & 0,0131 \\
\hline 11 & $\left\|v_{\frac{q^{\perp}}{c}}(t)\right\|$ & 0,1768 & 0,0324 & $\left\|i_{\frac{q^{\perp}}{c}}(t)\right\|$ & 0,2438 & 0,0133 \\
\hline 12 & $\left\|v_{h}^{q^{\perp}}(t)\right\|$ & 0,2114 & 0,0075 & $\left\|i_{h}^{q^{\perp}}(t)\right\|$ & 0,0000 & 1,0000 \\
\hline 13 & $\left\|v_{\bar{a}}^{d}(t)\right\|$ & 0,1771 & 0,0351 & $\left\|i_{\bar{a}}^{d}(t)\right\|$ & 0,2096 & 0,0156 \\
\hline 14 & $\left\|v_{\bar{b}}^{d}(t)\right\|$ & 0,1756 & 0,0323 & $\left\|i_{\bar{b}}^{d}(t)\right\|$ & 0,2032 & 0,0339 \\
\hline 15 & $\left\|v_{c}^{d}(t)\right\|$ & 0,1829 & 0,0302 & $\left\|i_{\bar{c}}^{\frac{d}{c}}(t)\right\|$ & 0,2352 & 0,0190 \\
\hline 16 & $\left\|v_{h}^{d}(t)\right\|$ & 0,2115 & 0,0074 & $\left\|i_{h}^{d}(t)\right\|$ & 0,2670 & 0,0099 \\
\hline
\end{tabular}
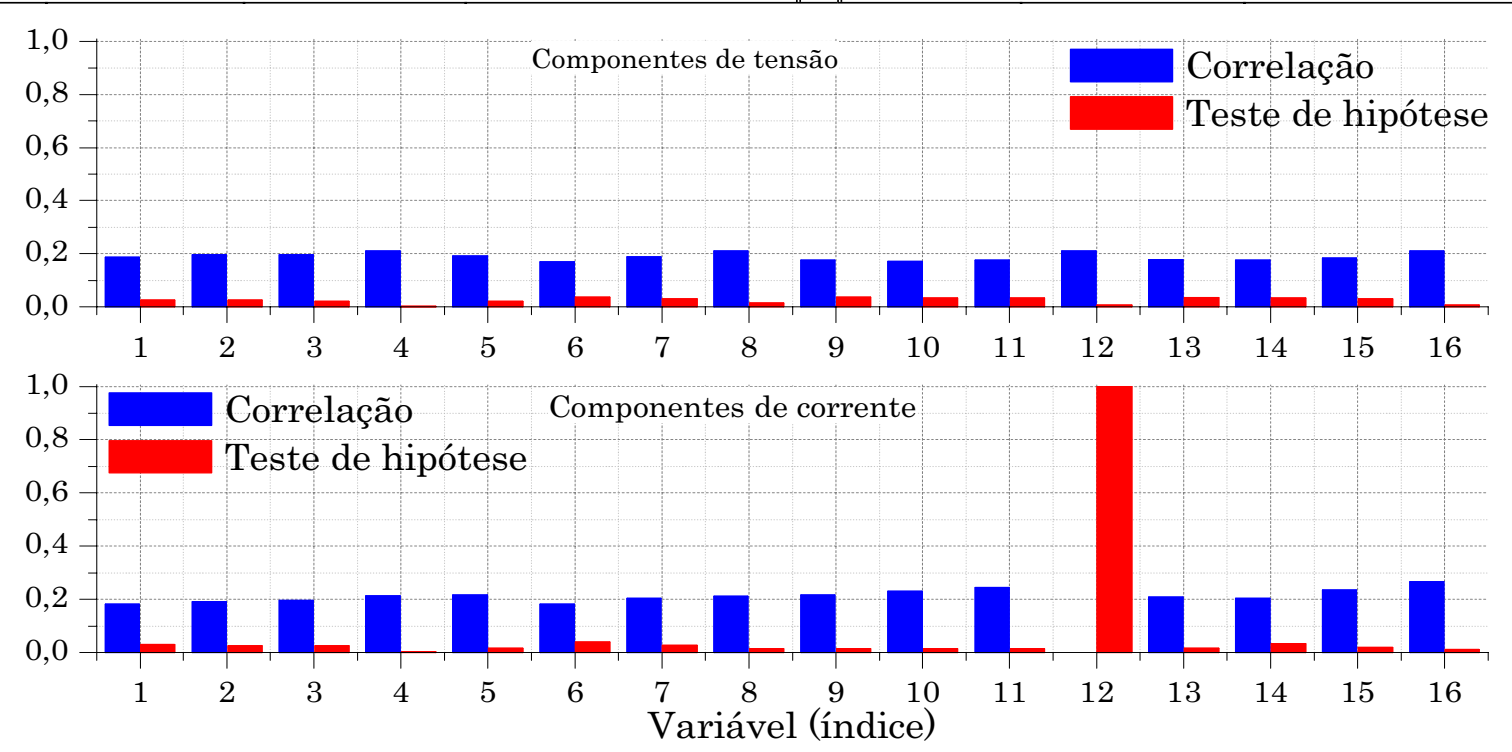

Figura 5.36 - Correlação e teste de hipótese para as projeções ortogonais à função planar das tensões de linha com relação à identificação de falta fase-terra. 
Por meio dos valores apresentados na Tabela 5.14 e na Tabela 5.15 se verifica, valendo-se dos resultados para o teste de hipótese relativa à significância da variável quanto a identificação da ocorrência de uma falta fase-terra, que o valor eficaz para as componentes $v_{n}^{p}(t), i_{n}^{p}(t), v_{a}^{p}(t), v_{b}^{p}(t)$ e $v_{c}^{p}(t)$ portam nos seus valores informações de grande pertinência. Não apenas possuindo valores que denotam a respectiva significância, essas variáveis são dotadas de grande correlação com a ocorrência de uma falta do tipo fase-terra. Essa verificação pode ser mais bem contemplada por meio da Tabela 5.16, a qual sumariza os valores da correlação e do teste de hipótese para as variáveis eleitas.

Tabela 5.16 - Relação das variáveis eleitas como parâmetros no processo de identificação de falta fase-terra.

\begin{tabular}{ccc}
\hline \hline Variável & Correlação & Teste de hipótese \\
\hline$\left\|v_{n}^{p}(t)\right\|$ & 0,9342 & 0,0000 \\
\hline$\left\|i_{n}^{p}(t)\right\|$ & 0,9331 & 0,0000 \\
\hline$\left\|v_{a}^{p}(t)\right\|$ & 0,8415 & 0,0000 \\
\hline$\left\|v_{b}^{p}(t)\right\|$ & 0,8454 & 0,0000 \\
\hline$\left\|v_{c}^{p}(t)\right\|$ & 0,8442 & 0,0000 \\
\hline
\end{tabular}

Os valores expressos na Tabela 5.16 denotam valores médios, os quais foram calculados sobre todo o conjunto de simulações realizadas. Complementando essa primeira análise, apresenta-se por meio da Figura 5.37 a função densidade probabilidade empírica para as funções $\left\|v_{n}^{p}(t)\right\|$ e $\left\|i_{n}^{p}(t)\right\|$ enquanto que, por meio da Figura 5.38 se faz o mesmo para as funções $\left\|v_{a}^{p}(t)\right\|,\left\|v_{b}^{p}(t)\right\| \mathrm{e}\left\|v_{c}^{p}(t)\right\|$.

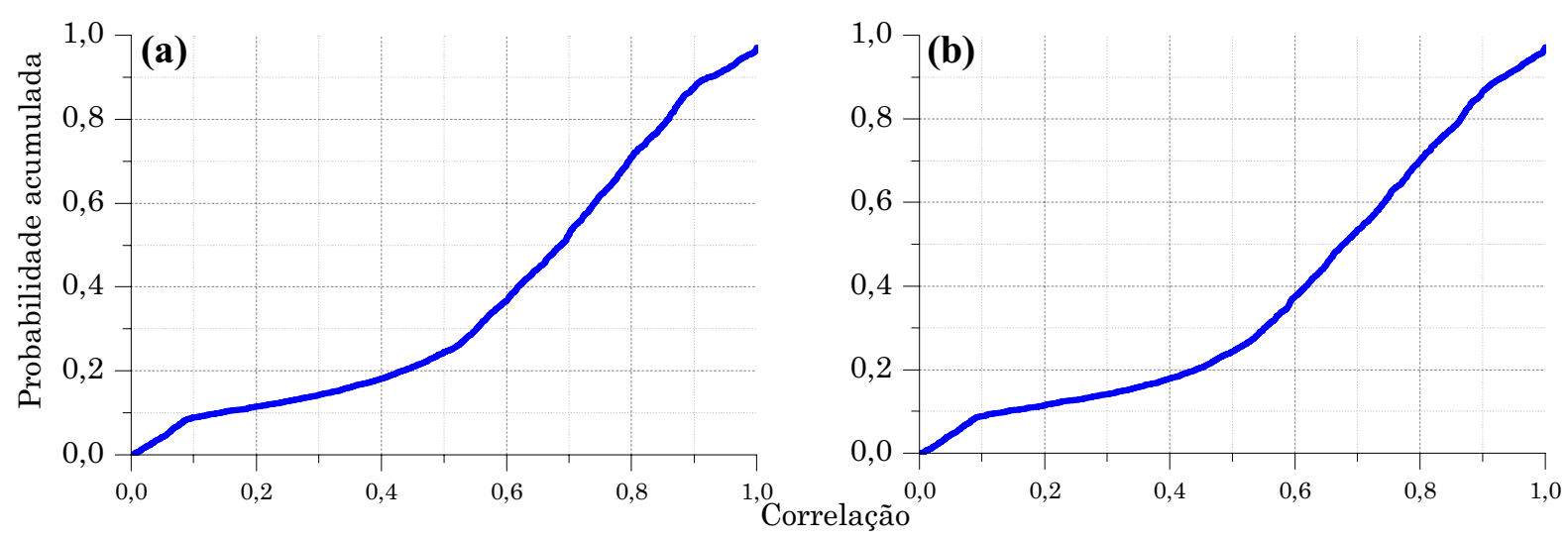

Figura 5.37 - Função densidade probabilidade empírica para as funções eleitas; (a) Função densidade probabilidade para $\left\|v_{n}^{p}(t)\right\|$; (b) Função densidade probabilidade para $\left\|i_{n}^{p}(t)\right\|$. 

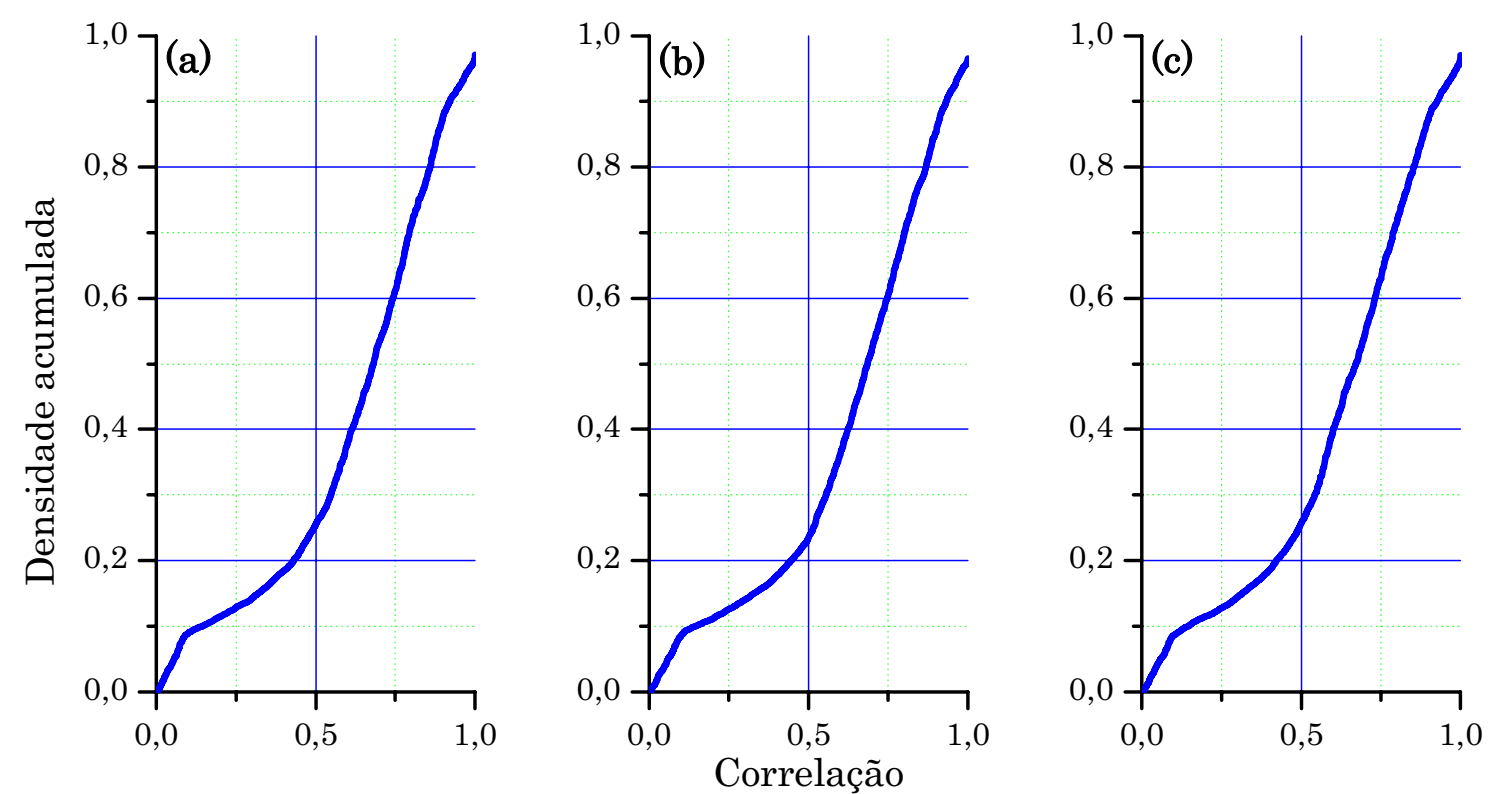

Figura 5.38 - Função densidade probabilidade empírica para as funções eleitas; (a) Função densidade probabilidade para $\left\|v_{a}^{p}(t)\right\|$; (b) Função densidade probabilidade para $\left\|v_{b}^{p}(t)\right\|$; (c) Função densidade probabilidade para $\left\|v_{c}^{p}(t)\right\|$.

Pode-se verificar por meio dos gráficos da Figura 5.37 que, para a grande maioria das faltas simuladas, a correlação entre as variáveis $\left\|v_{n}^{p}(t)\right\|$ e $\left\|i_{n}^{p}(t)\right\|$ e a ocorrência da falta é alta sendo, em ambos os casos, superiores à 0,9 . Comportamento semelhante, porém menos intenso, é observável para as funções $\left\|v_{a}^{p}(t)\right\|,\left\|v_{b}^{p}(t)\right\|$ e $\left\|v_{c}^{p}(t)\right\|$ por meio dos gráficos da Figura 5.38. Em função desse comportamento as referidas variáveis foram eleitas como variáveis no processo de identificação da ocorrência de faltas do tipo fase-terra.

\subsection{AJUSTE do SiSTEMA de INFERÊNCIA FUZZY PARA IDENTIFICAÇÃO de FALTAS dE ALTA IMPEDÂNCIA}

Na Seção 5.4, além de se apresentar como as projeções ortogonais se portam, em termos de seus valores eficazes, frente à operação normal e faltoso do alimentador padrão empregado nesse estudo, realizou-se a determinação de quais dessas projeções seriam empregadas como variáveis de entrada para o sistema de inferência fuzzy responsável pela identificação de faltas do tipo fase-terra. O procedimento descrito na referida seção resultou na seleção de cinco potenciais variáveis $\left\{\left\|v_{n}^{p}(t)\right\|,\left\|i_{n}^{p}(t)\right\|,\left\|v_{a}^{p}(t)\right\|,\left\|v_{b}^{p}(t)\right\|,\left\|v_{c}^{p}(t)\right\|\right\}$ de um universo de 64 parâmetros disponibilizados pela técnica da decomposição em componentes ortogonais a qual fora desenvolvida nessa pesquisa e retratada ao longo do Capítulo 3. Assim, 
diante dessas variáveis eleitas e de todo o conjunto de dados disponibilizados pelas simulações, nessa seção será apresentado o processo de ajuste do sistema de inferência fuzzy empregado na identificação de falta fase-terra, bem como os detalhes estruturais e paramétricos do sistema fuzzy resultante.

O algoritmo de ajuste paramétrico e estrutural para sistemas de inferência fuzzy proposto nesse trabalho e detalhado conforme feito no Capítulo 4 prevê a execução de duas etapas distintas e seqüênciais de ajuste. A primeira dessas etapas realiza, a partir dos pares entrada-saída, a extração da base de regras de inferência, ou seja, as regras que modelam o relacionamento existente entre o espaço fuzzy das entradas e o espaço fuzzy de saída. Uma vez constituída a base de regras, a segunda etapa de ajuste, etapa essa não de ajuste estrutural como a primeira e sim de ajuste paramétrico, atua de maneira a parametrizar as funções de pertinência contidas nos universos de discurso das entradas e da saída, bem como ponderando as regras de inferência obtidas na primeira etapa.

No entanto, independente da etapa de ajuste ser a primeira ou ser a segunda, fazse necessário a constituição de um conjunto de ajuste representativo do processo que se deseja modelar ou identificar. Nesse caso, o interesse é de ajustar um sistema de inferência que seja capaz de identificar a ocorrência de uma falta fase-terra, tendo como entradas os valores para as variáveis $\left\|v_{n}^{p}(t)\right\|,\left\|i_{n}^{p}(t)\right\|,\left\|v_{a}^{p}(t)\right\|,\left\|v_{b}^{p}(t)\right\|$ e $\left\|v_{c}^{p}(t)\right\|$. Assim, diante dessa necessidade, ou seja, da constituição de um conjunto de ajuste para o sistema fuzzy dedicado à identificação de faltas de alta impedância, todo o conjunto de simulações, um total de 3.000, fora processado de maneira a extrair as componentes $\left\|v_{n}^{p}(t)\right\|,\left\|i_{n}^{p}(t)\right\|,\left\|v_{a}^{p}(t)\right\|,\left\|v_{b}^{p}(t)\right\| \mathrm{e}$ $\left\|v_{c}^{p}(t)\right\|$. Nesse processamento, um conjunto constituído por 818.277 pares entrada-saída fora constituído, número esse excessivo para o ajuste de um sistema de inferência fuzzy em função do grande esforço necessário para o processamento de todos esses dados. A fim de contornar essa limitação um conjunto de ajuste secundário fora elaborado com 1.894 pares entradassaída, cerca de $2,3 \%$ do total disponível, conjunto esse empregado para o ajuste do sistema fuzzy dedicado à identificação de falta fase-terra. $\mathrm{O}$ conjunto de ajuste secundário fora constituído escolhendo-se aleatoriamente pares entrada-saída do conjunto principal. O número de pares empregados nesse processo de construção possuiu a correlação como parâmetro restritivo, ou seja, o conjunto de ajuste secundário fora incrementado iterativamente até que o mesmo possuísse correlação diferente em no máximo $0,1 \%$ daquelas apresentadas na Tabela 5.16. 
Assim, partindo-se desse conjunto secundário de ajuste, o sistema fuzzy fora iniciado possuindo um número máximo de três funções de pertinência por universo de discurso, fosse ele de entrada ou de saída. Além dessa imposição, o número de regras fuzzy fora limitado em apenas cinco. Dessa forma e por meio do algoritmo proposto para extração de regras apresentado no Capítulo 4, o sistema fuzzy fora submetido à primeira etapa de ajuste, decorrendo, por sua vez, na redução progressiva do erro quadrático médio ao longo das iterações de ajuste. A forma como o sistema fora se ajustando, iteração a iteração, nessa primeira etapa de ajuste é ilustrada por meio da Figura 5.39. Por intermédio do gráfico do comportamento do erro quadrático médio em função das iterações apresentado na Figura 5.39, é possível observar que no início do processo de ajuste, ou seja, quando o sistema fuzzy fora criado, o erro quadrático médio observado era próximo à unidade, enquanto que ao término da primeira etapa de ajuste esse erro passou a ser de aproximadamente à 0,3. Essa evolução na redução do erro quadrático médio ao longo das iterações do algoritmo de ajuste reflete, primeiramente, a grande correlação entre as variáveis eleitas $\left\{\left\|v_{n}^{p}(t)\right\|,\left\|i_{n}^{p}(t)\right\|,\left\|v_{a}^{p}(t)\right\|\right.$, $\left.\left\|v_{b}^{p}(t)\right\|,\left\|v_{c}^{p}(t)\right\|\right\}$ e a ocorrência de uma falta do tipo fase-terra, assim como antes verificado. Como segundo aspecto merecedor de citação, tem-se a eficiência do algoritmo de ajuste em obter as regras fuzzy que melhor representam o processo de identificação de faltas.

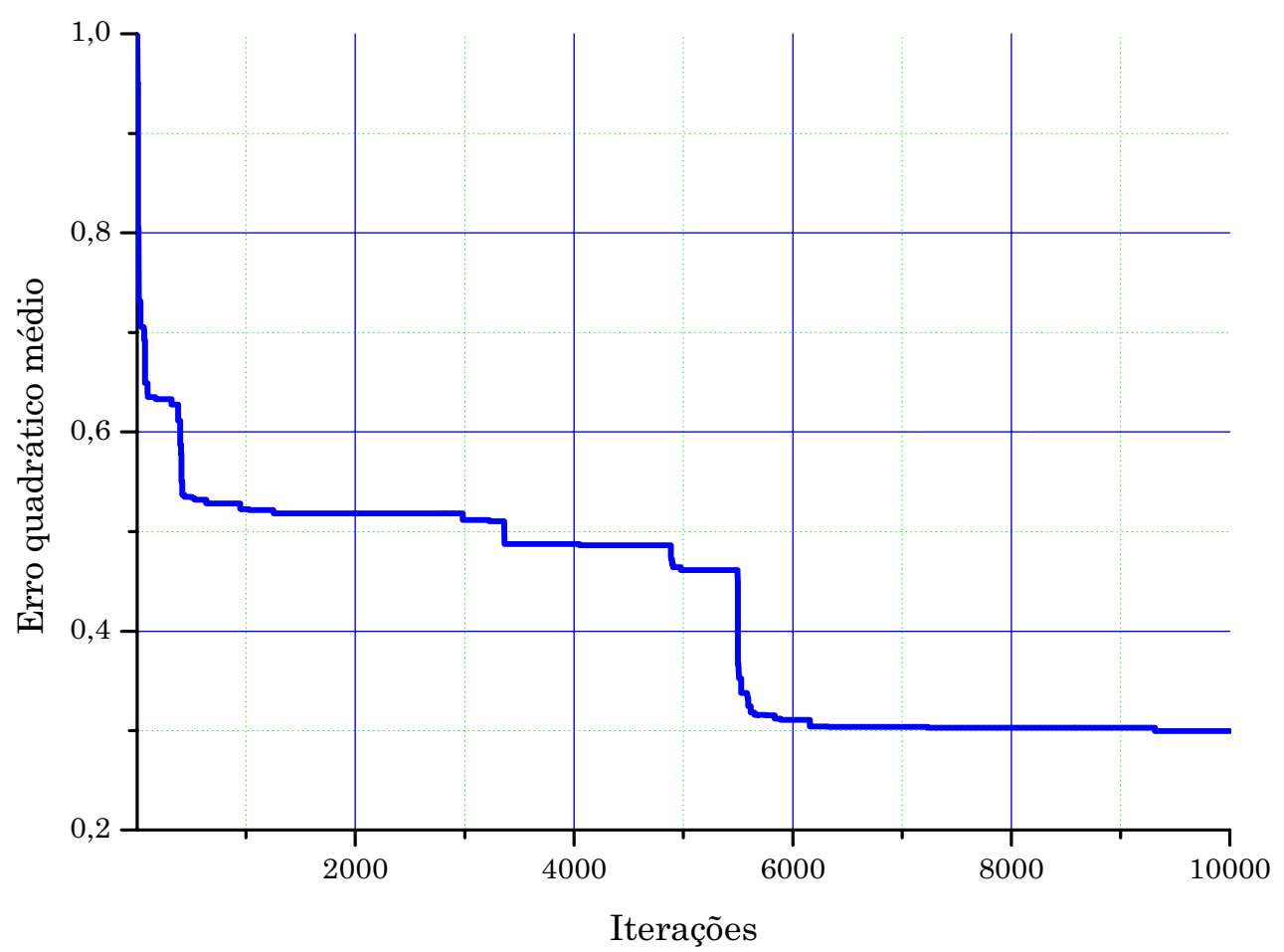

Figura 5.39 - Comportamento do erro quadrático médio ao longo das iterações da primeira etapa de ajuste do sistema de inferência fuzzy para identificação de falta fase-terra. 
Conforme delineado no Capítulo 4 e reforçado nessa seção, o objetivo da primeira etapa de ajuste para o sistema fuzzy é de, a partir dos pares entradas-saídas disponibilizados por meio do conjunto de ajuste, determinar a base de regras fuzzy que melhor relacione o espaço fuzzy das entradas com o espaço fuzzy da saída. Assim, como resultado dessa primeira etapa de ajuste, tem-se as regras fuzzy apresentadas por meio da Figura 5.40.

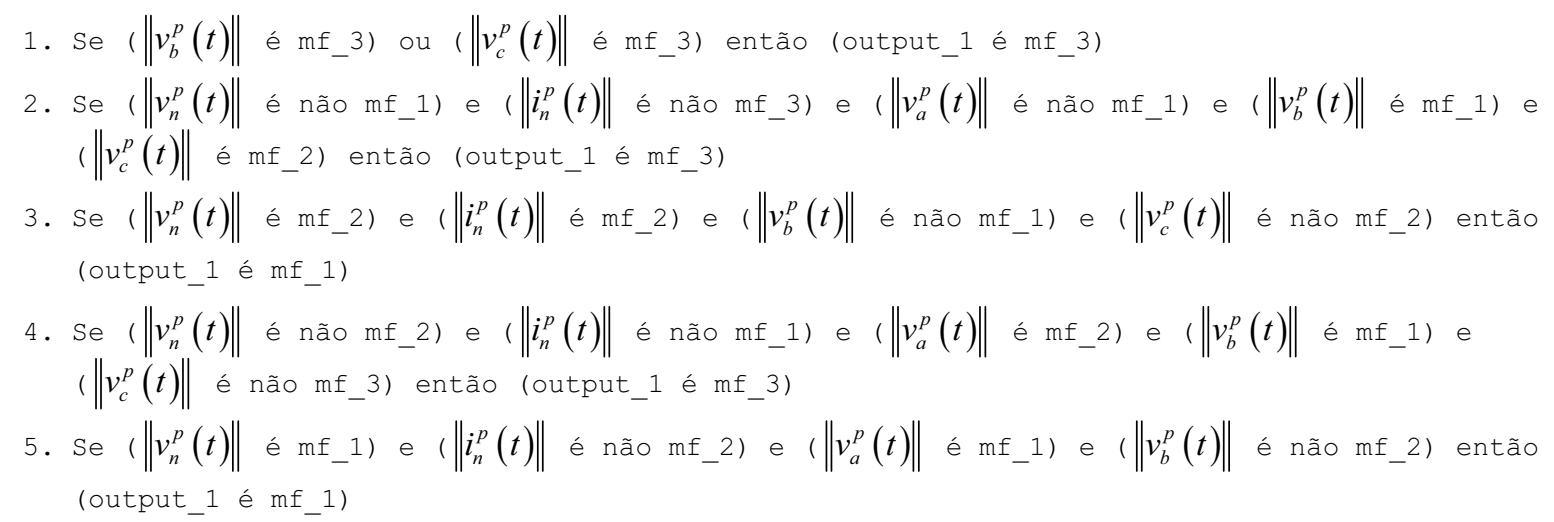

Figura 5.40 - Base de regras fuzzy determinadas pela primeira etapa de ajuste.

Na Figura 5.40 tem-se em cada regra, a identificação das variáveis empregadas no processo de identificação de faltas, bem como a nomeação das funções de pertinência contidas em cada universo de discurso. Essas funções de pertinência serão adequadamente apresentadas quando do delineamento dos resultados advindos após o término da segunda etapa de ajuste.

Após a obtenção da base de regras, o sistema de inferência fuzzy deve ser submetido à segunda etapa de ajuste a fim de que os parâmetros das funções de pertinência dos universos de discursos das entradas e da saída, bem como a ponderação das regras, sejam ajustados com o objetivo de otimizar, de forma paramétrica, o sistema fuzzy. Dessa forma, valendo-se do mesmo conjunto de ajuste empregado na primeira etapa, o sistema de inferência fuzzy fora submetido à segunda etapa de ajuste. Assim como feito anteriormente, por meio da Figura 5.41, apresenta-se como o erro quadrático médio se reduz ao longo das iterações da segunda etapa de ajuste.

Analisando-se o gráfico da Figura 5.41 é possível verificar que o erro quadrático médio no início dessa etapa de ajuste fora de aproximadamente 0,3 , enquanto que ao término do processo esse erro passou a apresentar valores inferiores à 0,03 , ou seja, uma redução do erro quadrático médio em cerca de dez vezes. A redução do erro quadrático proferida pela segunda etapa de ajuste se dá pela parametrização das funções de pertinência do sistema fuzzy, assim como pela ponderação das regras de inferência como já citado, e para retratar os 
resultados sobre o sistema fuzzy, tem-se, primeiramente por meio da Figura 5.42, como cada uma das regras de inferência, apresentadas na Figura 5.40, foram parametrizadas. Assim, por meio da Figura 5.42 é possível observar que a regra de número 4 recebeu ponderação sensivelmente superior às demais, o que compromete a visualização da parametrização conferida às demais regras. Contornando essa limitação de visualização, na Tabela 5.17 temse o valor numérico para a ponderação de cada regra.

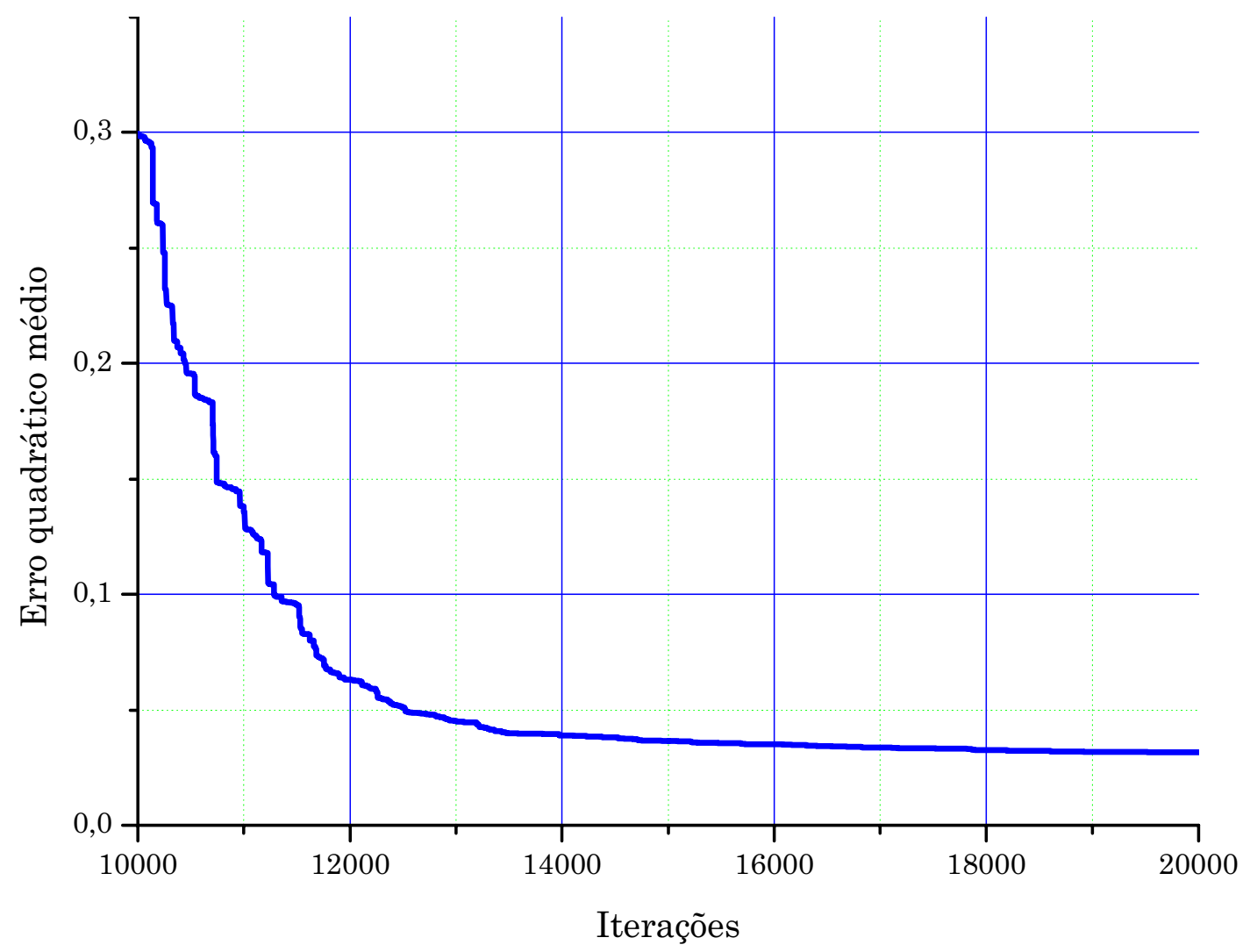

Figura 5.41 - Comportamento do erro quadrático médio ao longo das iterações da segunda etapa de ajuste do sistema de inferência fuzzy para identificação de faltas fase-terra.

Tabela 5.17 - Ponderação das regras fuzzy.

\begin{tabular}{lr}
\hline \hline Índice & Ponderação \\
\hline \hline 1 & 0,0051 \\
\hline 2 & 0,0414 \\
\hline 3 & 0,1359 \\
\hline 4 & 126,9303 \\
\hline 5 & 0,9114 \\
\hline
\end{tabular}

Por meio da Tabela 5.17 e do gráfico da Figura 5.42 é possível verificar a grande importância da regra índice número 4. Prosseguindo com a apresentação do sistema fuzzy dedicado à determinação da ocorrência de uma falta, tem-se por meio da Figura 5.43 as 
funções de pertinência para o universo de discurso da variável $\left\|v_{n}^{p}(t)\right\|$. Na Figura 5.44, temse as funções de pertinência para a variável $\left\|i_{n}^{p}(t)\right\|$, assim como na Figura 5.45 se tem o mesmo para a variável $\left\|v_{a}^{p}(t)\right\|$. As funções de pertinência para as variáveis $\left\|v_{b}^{p}(t)\right\| \mathrm{e}\left\|v_{c}^{p}(t)\right\|$ são apresentadas, respectivamente, por meio da Figura 5.46 e Figura 5.47.

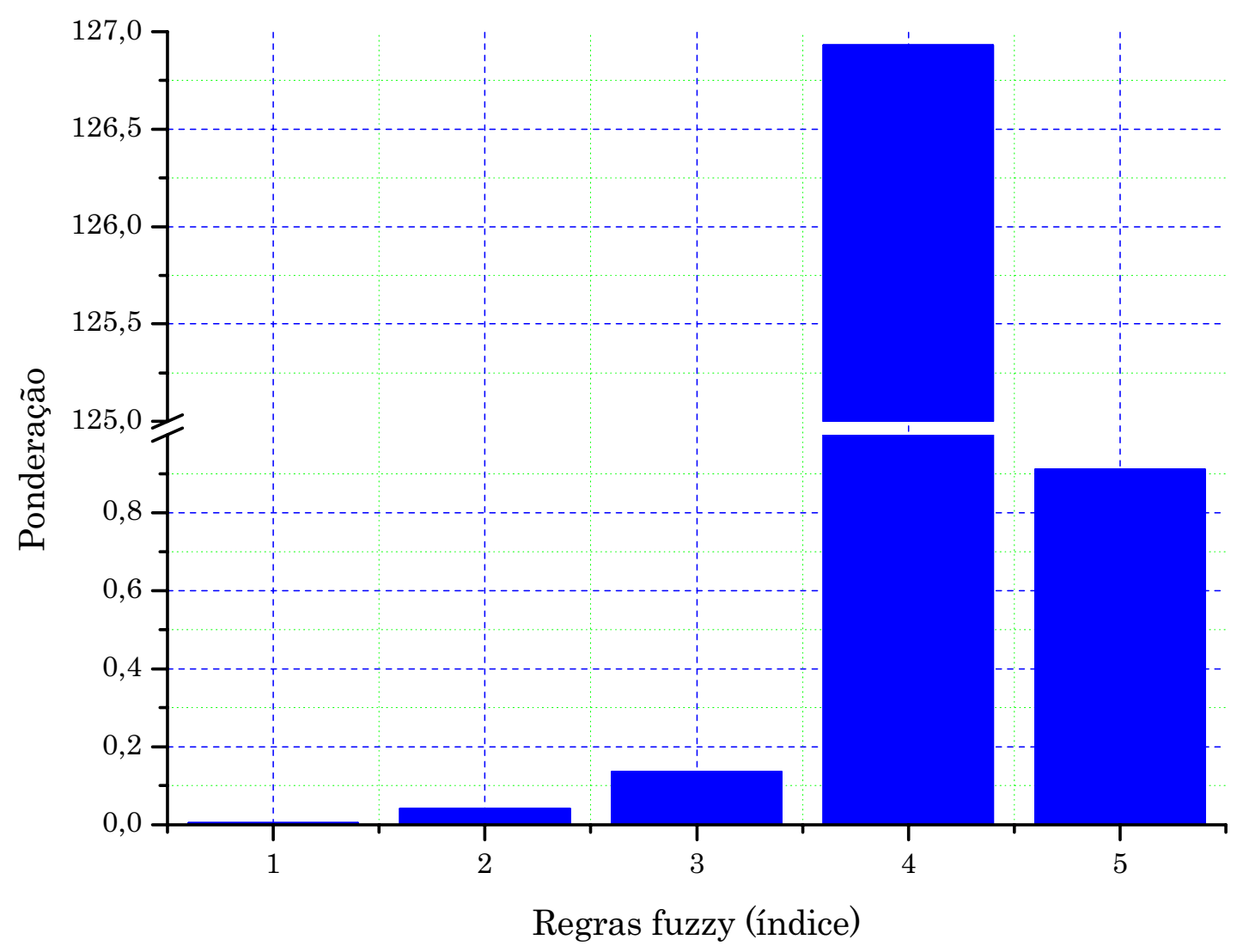

Figura 5.42 - Ponderação para as regras fuzzy obtida ao término da segunda etapa de ajuste.

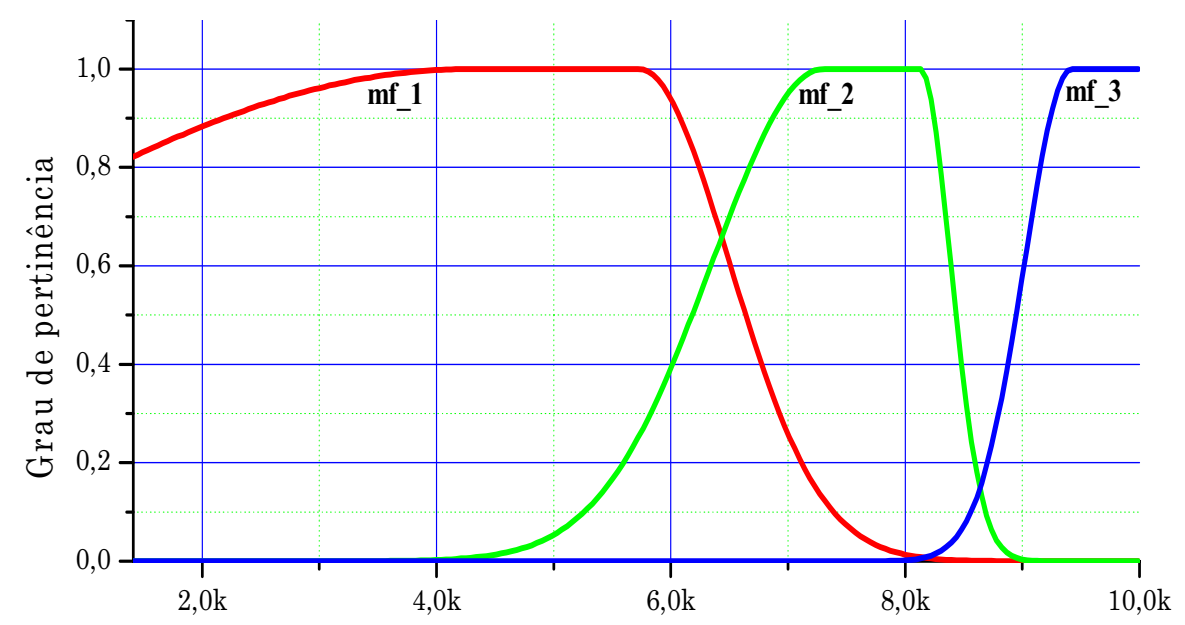

Universo de discurso

Figura 5.43 - Funções de pertinência para o universo de discurso da variável $\left\|v_{n}^{p}(t)\right\|$. 


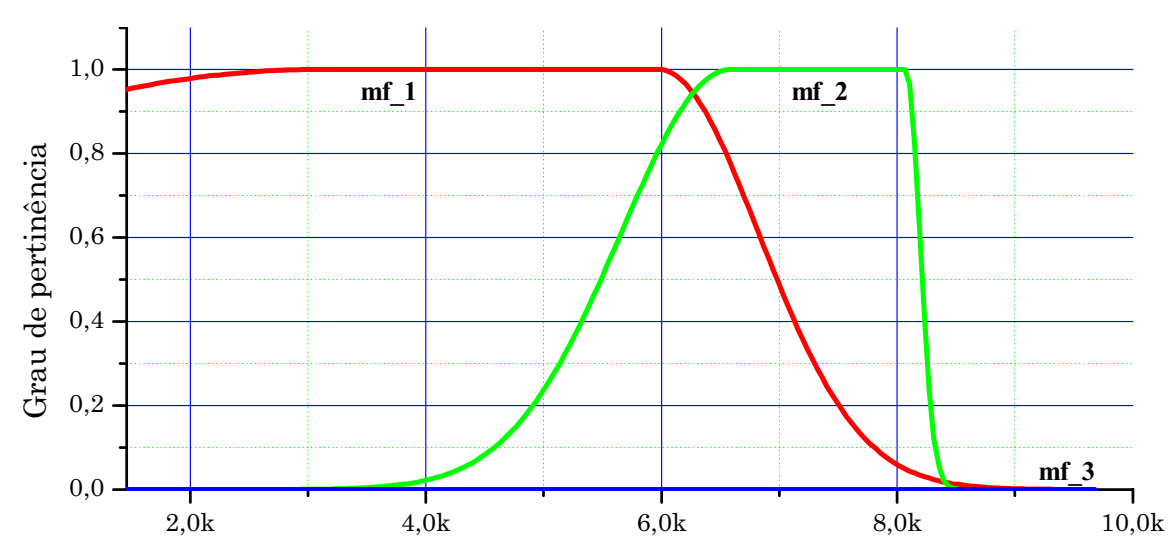

Universo de discurso

Figura 5.44 - Funções de pertinência para o universo de discurso da variável $\left\|i_{n}^{p}(t)\right\|$.

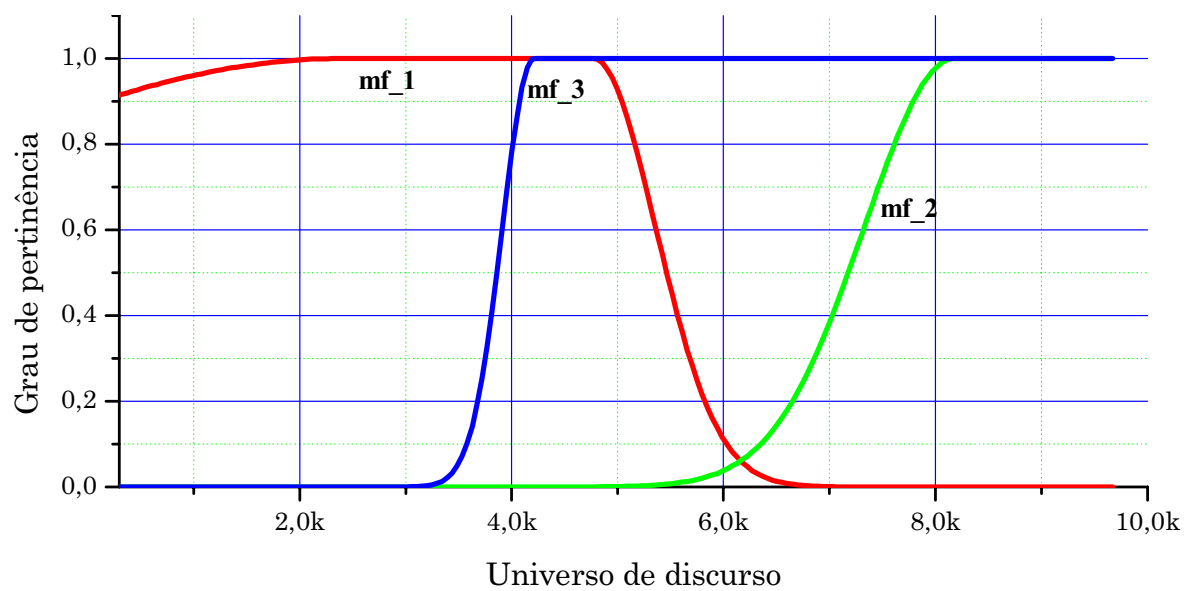

Figura 5.45 - Funções de pertinência para o universo de discurso da variável $\left\|v_{a}^{p}(t)\right\|$.

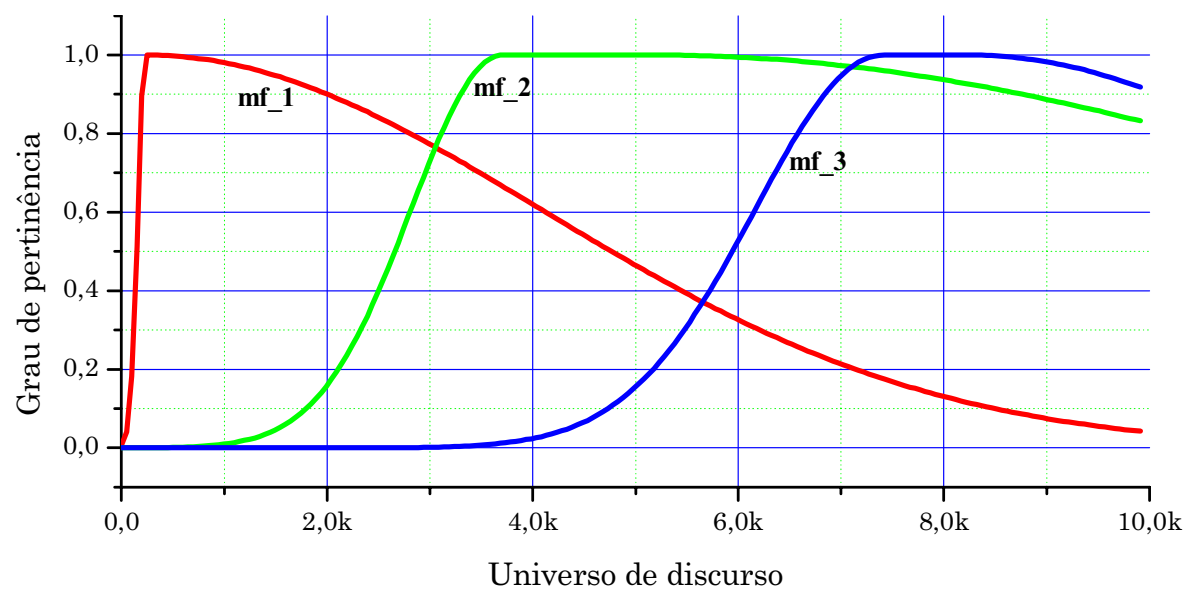

Figura 5.46 - Funções de pertinência para o universo de discurso da variável $\left\|v_{b}^{p}(t)\right\|$.

O sistema de inferência fuzzy descrito por meio de sua base de regras, de suas funções de pertinência e da ponderação das regras é dedicado à identificação da ocorrência de faltas fase-terra, e o mesmo foi fruto do ajuste desempenhado sobre um conjunto de ajuste de reduzida dimensão relativa ao todo disponível. O conjunto de ajuste empregado fora constituído por cerca de $2,3 \%$ dos dados disponíveis para a finalidade de identificação. Assim, 
para validar a operação do sistema fuzzy o mesmo fora testado frente à $100 \%$ das situações disponíveis, ou seja, para as 3000 condições de falta simuladas.

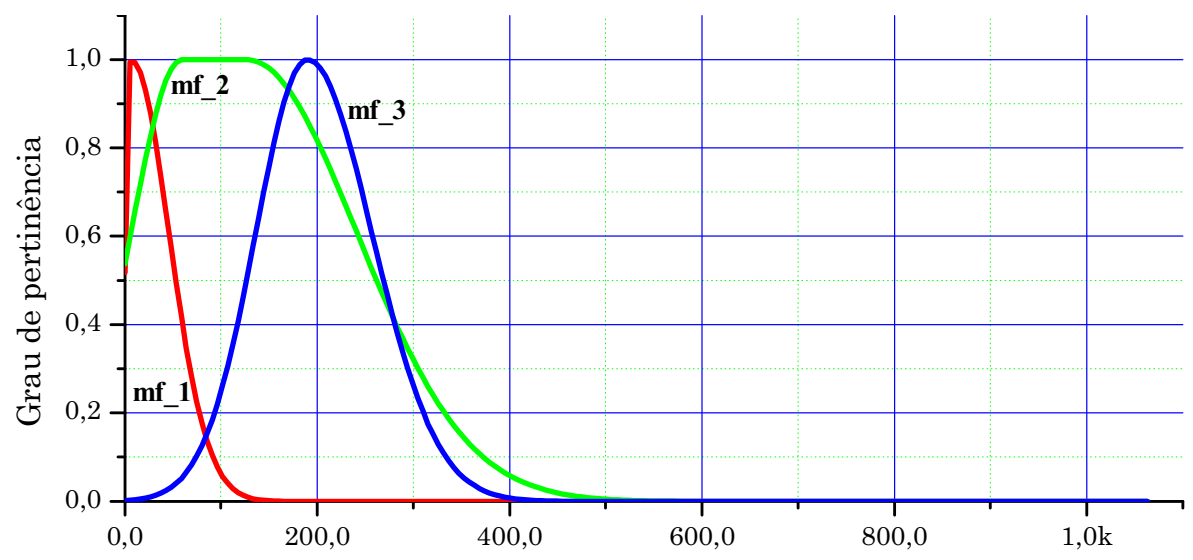

Universo de discurso

Figura 5.47 - Funções de pertinência para o universo de discurso da variável $\left\|v_{c}^{p}(t)\right\|$.

Como resultado direto do processo de identificação de faltas fase-terra, tem-se que o sistema fuzzy dedicado para tal finalidade fora capaz de identificar todas as ocorrências. No entanto, no contexto de identificação de faltas não apenas o fato de identificar é merecedor de importância, devendo-se o tempo de detecção ser igualmente considerado. Assim, ilustrando o tempo de detecção de faltas fase-terra, tem-se na Figura 5.48 o histograma do percentual de detecção, relativo a todo o conjunto de simulações, em função das faixas temporais para detecção.

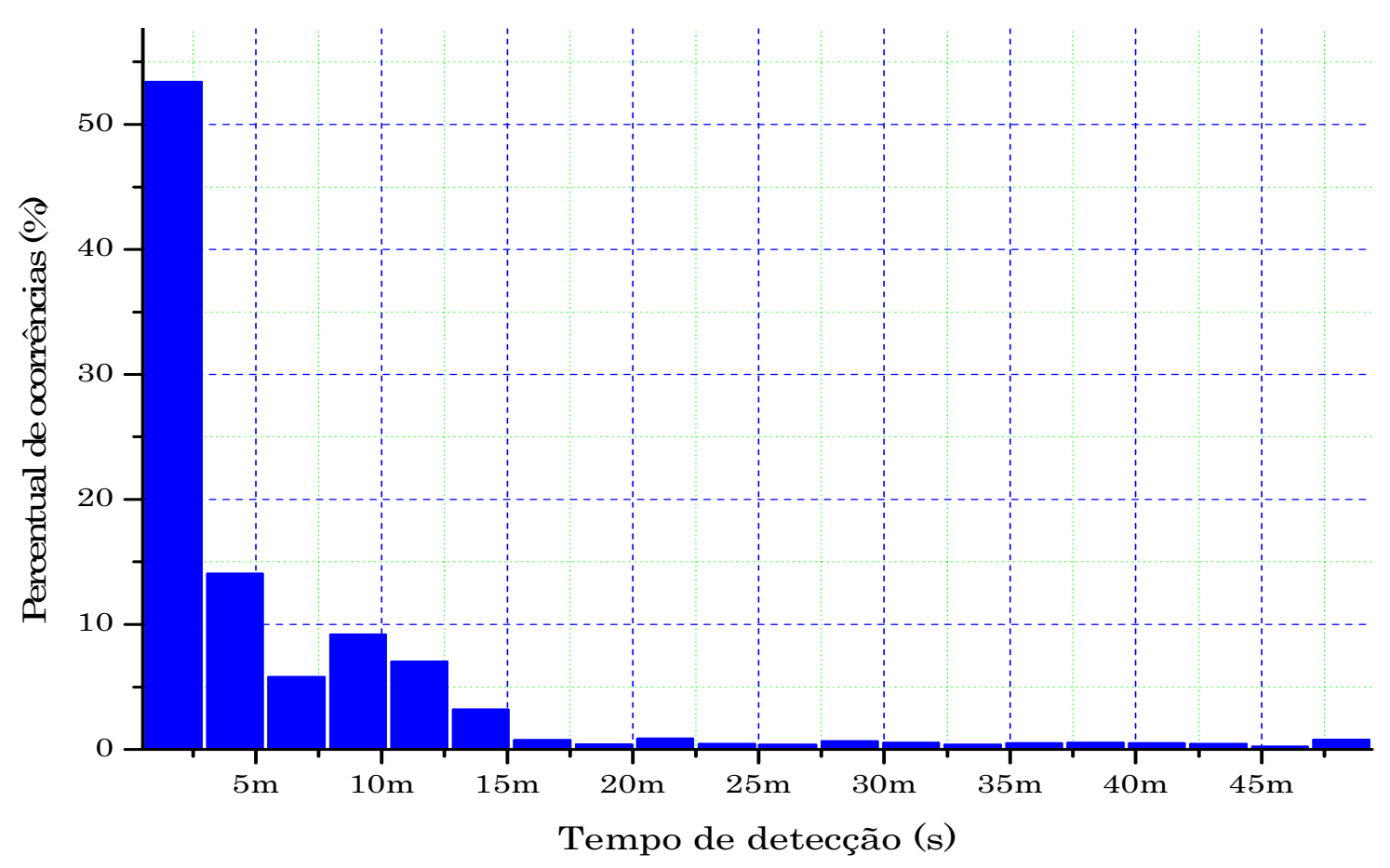

Figura 5.48 - Histograma do percentual de detecção para cada faixa temporal. 
Pode-se, por meio da Figura 5.48, verificar que um grande percentual das faltas, mais do que $50 \%$, são identificadas em tempo inferior à 5 milisegundos. Ainda com relação à Figura 5.48, tem-se que aproximadamente $93 \%$ das faltas são identificadas em um tempo inferior a um ciclo de senóide à $60 \mathrm{~Hz}$, ou seja, a grande maioria das faltas são identificadas antes que essas se estabeleçam e danos pessoais, materiais e comprometimentos severos da qualidade do fornecimento de energia elétrica sejam significativamente observados. Para complementar a apresentação dos resultados apresentados pelo sistema fuzzy dedicado à identificação de faltas, tem-se na Figura 4.49 o gráfico da função densidade de probabilidade empírica para o tempo de detecção.

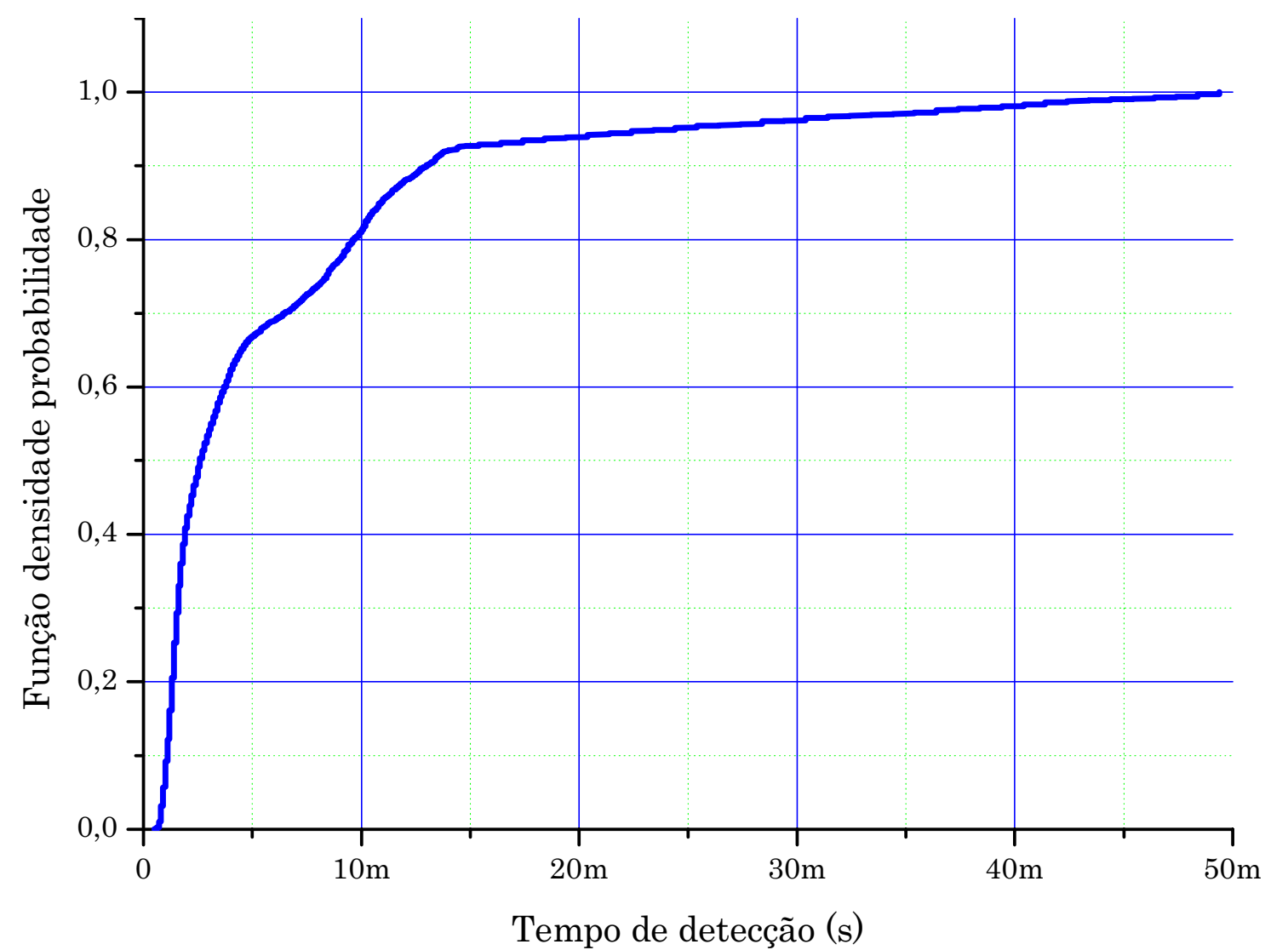

Figura 5.49 - Função densidade probabilidade para o tempo de detecção de faltas.

Assim, é possível observar que $100 \%$ das faltas fase-terra foram identificadas com tempo inferior à 50 milisegundos, ou seja, três ciclos de forma de onda, enquanto que mais de 90\% desse universo de faltas foram identificadas em tempo inferior a um ciclo da forma de onda.

Os resultados apresentados para o sistema identificador de faltas foram frutos obtidos a partir de um conjunto de 3000 simulações, onde foram parâmetros de variabilidade a resistência de falta e a distância de ocorrência da falta. Assim, fora avaliado como o tempo de 
detecção pode ser comprometido em função desses parâmetros. Para tanto, apresenta-se na Figura 5.50 o comportamento do tempo de detecção em função da resistência de falta para cada uma das simulações.

O gráfico da Figura 5.50 apresenta como o tempo de identificação de falta varia em função da resistência de falta. Observa-se por meio desse que o tempo de identificação tende a crescer com o aumento da resistência de falta. A forma como o tempo de identificação varia em termos da distância de falta é retratada no gráfico da Figura 5.51.

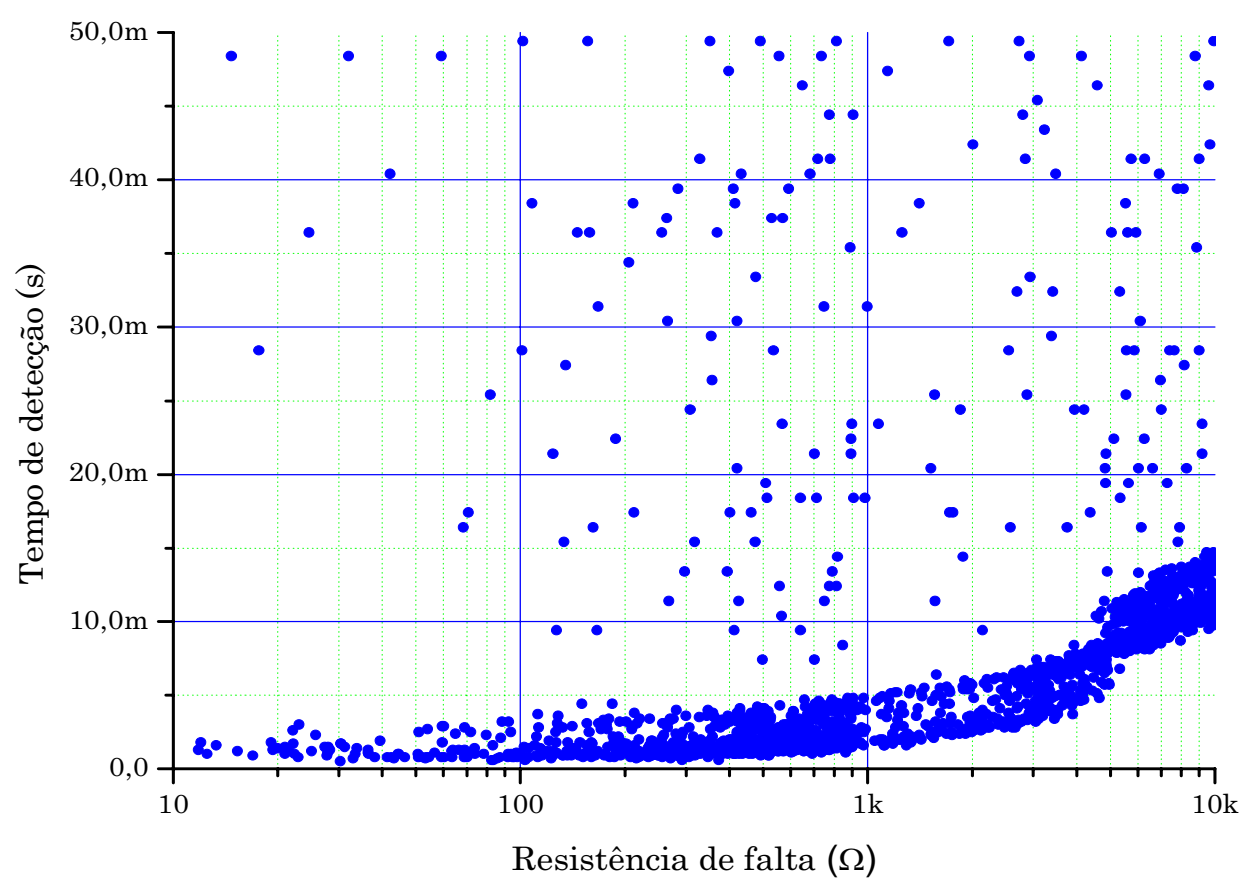

Figura 5.50 - Comportamento do tempo de detecção em função da resistência de falta para todo o conjunto de simulações.

O tempo de identificação de falta tende a aumentar com o aumento da distância de ocorrência de falta, tal como se verifica por meio da Figura 5.51, porém de maneira menos intensa do que ocorre quando comparado com variação proporcionada pela resistência de falta. Por fim, para quantificar a influência da resistência de falta e da distância de ocorrência da falta, apresenta-se na Tabela 5.18 a correlação entre essas variáveis e o tempo de detecção.

Tabela 5.18 - Correlação entre as variáveis de simulação e o tempo de detecção de faltas.

\begin{tabular}{lc}
\hline \hline Variável & Correlação \\
\hline Resistência de falta & 0,0865 \\
\hline Distância de ocorrência da falta & 0,0246 \\
\hline
\end{tabular}

Os valores expressos na Tabela 5.18 confirmam as observações feitas quando da análise visual dos gráficos da Figura 5.50 e Figura 5.51, ou seja, de que o tempo de 
identificação da falta é dependente tanto da resistência de falta quanto da distância da ocorrência da mesma. Além disso, os valores expressos na Tabela 5.18 mostram que a influência da resistência de falta é sensivelmente superior à influência que a distância de ocorrência de falta exerce sobre o processo de identificação.

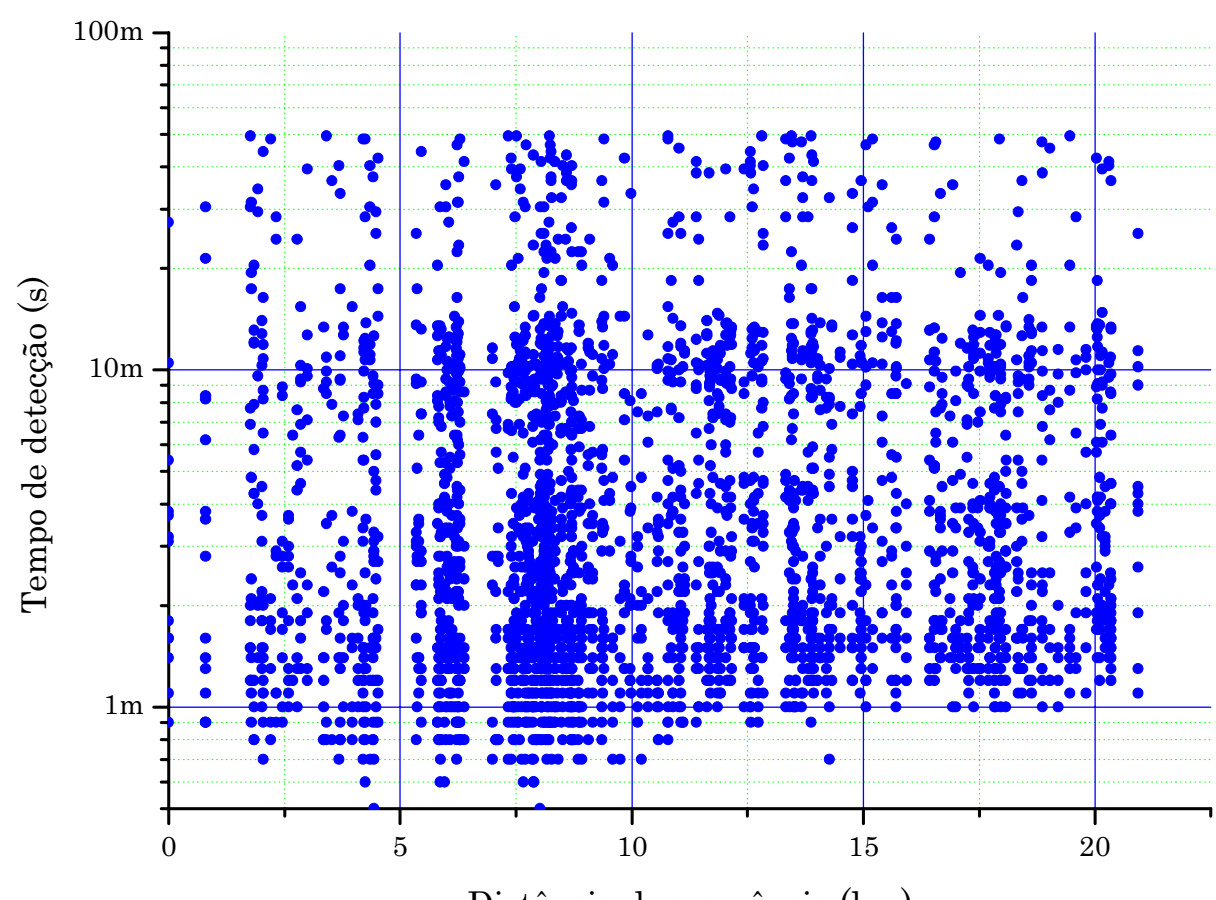

Figura 5.51 - Comportamento do tempo de detecção em função da distância da falta em relação à subestação para todo o conjunto de simulações.

\subsection{AJUSTE dO SISTEMA DE INFERÊNCIA FUZZY PARA IDENTIFICAÇÃO dA FASE PARTICIPANTE dA FALTA}

Na seção anterior fora apresentado como por meio das componentes ortogonais, para fins de pré-processamento, e de sistemas de inferência fuzzy, para propósitos de identificação, é possível identificar a ocorrência de faltas fase-terra. Contudo, o objetivo desse capítulo não se restringe apenas na identificação da ocorrência desse tipo de evento, mas também se tem a meta de se inferir sobre qual é a fase participante da falta. Assim, permeando as metas delineadas nessa seção será apresentada como a identificação da fase faltosa pode ser feita por meio dos desenvolvimentos anteriormente estabelecidos.

Dessa maneira, organizando a apresentação dos desenvolvimentos realizados, essa seção será organizada em três subseções cada qual responsável pela descrição do processo de identificação de fase faltosa para cada fase, ou seja, na Subseção 5.6.1 a fase A será foco, 
enquanto que a fase B e a Fase C serão abordadas, respectivamente, na Subseção 5.62 e Subseção 5.63.

\subsubsection{Sistema IdenTIFICAdOR de FALTAS COM PARTICIPAÇÃo DA FASE A}

Assim como feito para determinação das variáveis que mais se correlacionavam com a ocorrência de uma falta fase-terra, para a determinação da fase participante da fase ora identificada, fora avaliada a correlação entre o valor eficaz das componentes ortogonais com a identificação da fase participante da falta. No entanto, diferente do que feito na seção anterior, nessa seção, foram considerados os valores médios durante a perduração da falta dos valores eficazes para as componentes ortogonais oriundas do processo de decomposição.

A fim de apresentar como cada componente pode vir a colaborar com a determinação da fase faltosa, fora feito o cálculo da correlação dos valores eficazes com o propósito de determinar se a fase A participara da falta. Os valores da correlação e o teste de hipótese são apresentados na Tabela 5.19, onde se destaca os referidos valores para as componentes contidas na função planar das tensões de linha e, na Tabela 5.20, onde se faz o mesmo para as componentes ortogonais à função planar das tensões de linha. Para fins de comparação visual, apresenta-se por meio da Figura 5.52 os valores da Tabela 5.19, enquanto que os da Tabela 5.20, são apresentados na Figura 5.53.

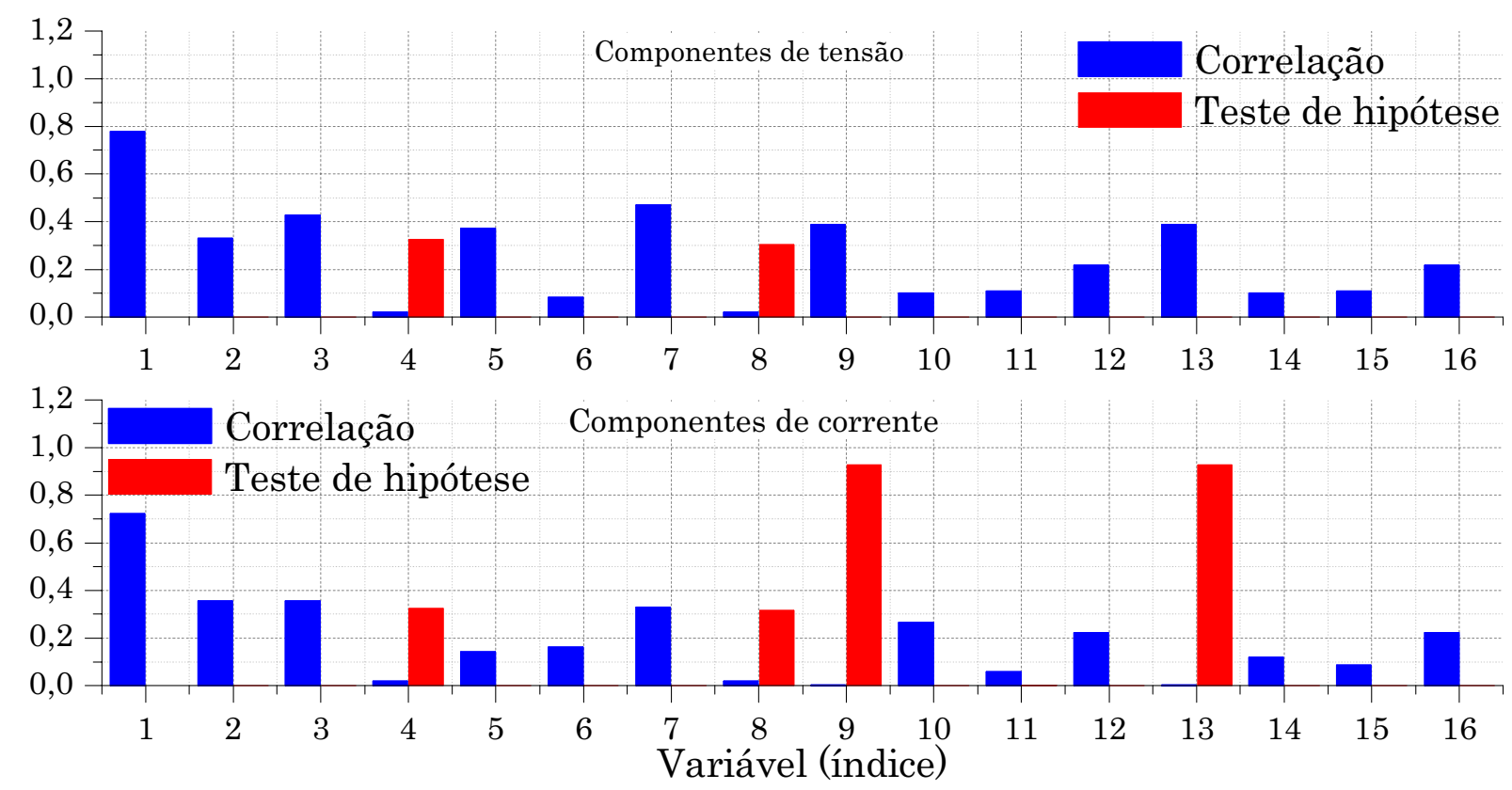

Figura 5.52 - Correlação e teste de hipótese para as projeções contidas na função planar das tensões de linha com relação à identificação da fase A. 
Tabela 5.19 - Correlação e teste de hipótese para as projeções contidas na função planar das tensões de linha.

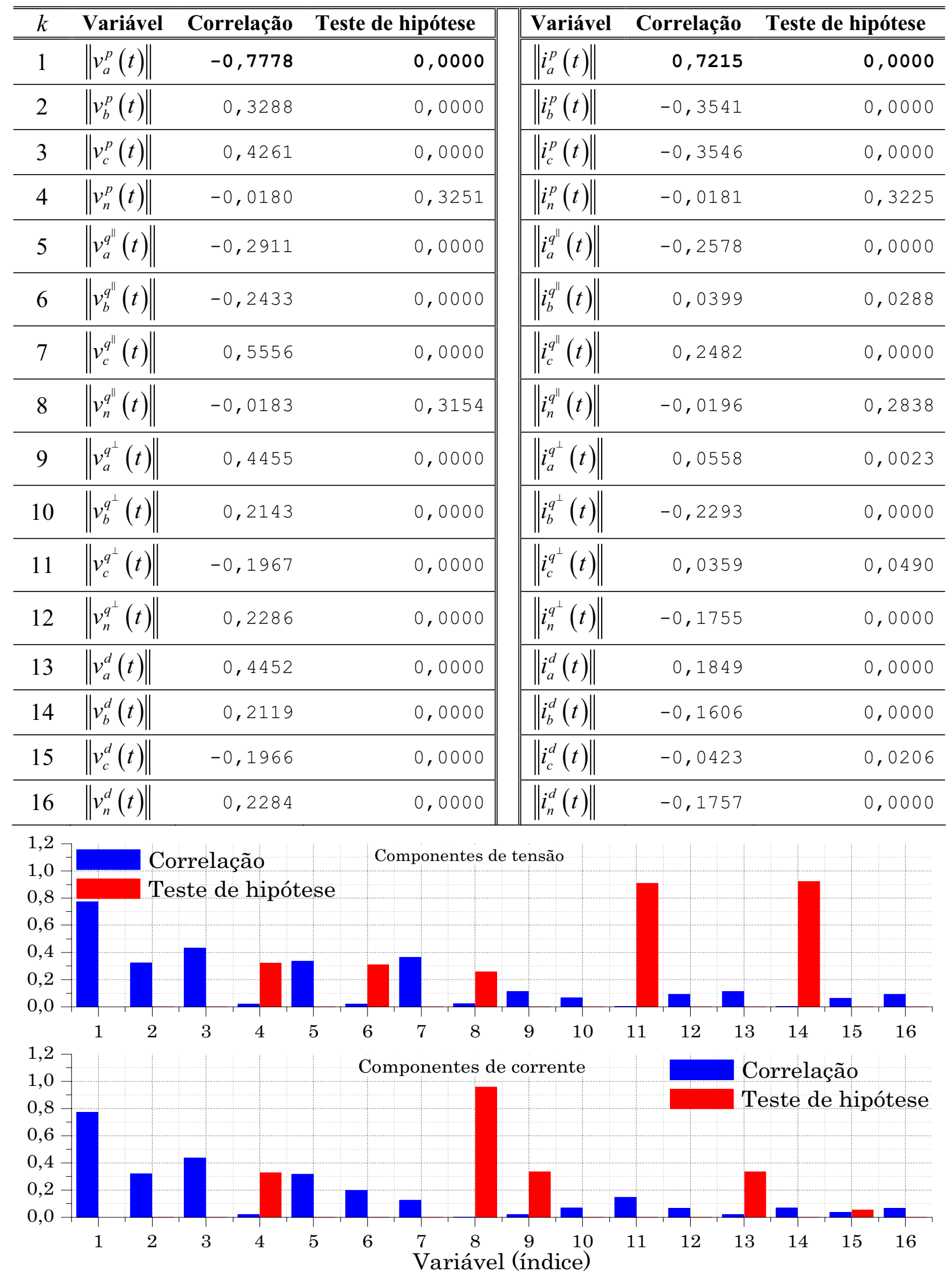

Figura 5.53 - Correlação e teste de hipótese para as projeções ortogonais à função planar das tensões de linha com relação à identificação da fase A. 
Tabela 5.20 - Correlação e teste de hipótese para as projeções ortogonais à função planar das tensões de linha.

\begin{tabular}{|c|c|c|c|c|c|c|}
\hline$k$ & Variável & Correlação & Teste de hipótese & Variável & Correlação & Teste de hipótese \\
\hline 1 & $\left\|v_{\bar{a}}^{p}(t)\right\|$ & $-0,7720$ & 0,0000 & $\left\|i_{\bar{a}}^{p}(t)\right\|$ & $-0,7713$ & 0,0000 \\
\hline 2 & $\left\|v_{\bar{b}}^{p}(t)\right\|$ & 0,3213 & 0,0000 & $\left\|i_{\bar{b}}^{p}(t)\right\|$ & 0,3170 & 0,0000 \\
\hline 3 & $\left\|v_{\bar{c}}^{p}(t)\right\|$ & 0,4318 & 0,0000 & $\left\|i_{\bar{c}}^{p}(t)\right\|$ & 0,4348 & 0,0000 \\
\hline 4 & $\left\|v_{h}^{p}(t)\right\|$ & $-0,0182$ & 0,3199 & $\left\|i_{h}^{p}(t)\right\|$ & $-0,0179$ & 0,3266 \\
\hline 5 & $\left\|v_{\bar{a}}^{q^{\|}}(t)\right\|$ & $-0,6031$ & 0,0000 & $\left\|i_{a}^{q^{\|}}(t)\right\|$ & $-0,6404$ & 0,0000 \\
\hline 6 & $\left\|v_{\bar{b}}^{q^{\| \prime}}(t)\right\|$ & 0,0380 & 0,0376 & $\left\|i \frac{q^{\prime \prime}}{b}(t)\right\|$ & 0,4903 & 0,0000 \\
\hline 7 & $\left\|v_{\bar{c}}^{q^{\|}}(t)\right\|$ & 0,5772 & 0,0000 & $\left\|i_{c}^{q^{\|}}(t)\right\|$ & 0,1583 & 0,0000 \\
\hline 8 & $\left\|v_{h}^{q^{\prime \prime}}(t)\right\|$ & $-0,0178$ & 0,3306 & $\left\|i_{h}^{q^{\|}}(t)\right\|$ & $-0,0211$ & 0,2469 \\
\hline 9 & $\left\|v_{\bar{a}}^{q^{\perp}}(t)\right\|$ & 0,0085 & 0,6404 & $\left\|i_{\bar{a}}^{q^{\perp}}(t)\right\|$ & $-0,1356$ & 0,0000 \\
\hline 10 & $\left\|v_{\frac{q^{\perp}}{b}}^{\perp}(t)\right\|$ & $-0,0027$ & 0,8829 & $\left\|i_{\bar{b}}^{q^{\perp}}(t)\right\|$ & $-0,2057$ & 0,0000 \\
\hline & $\left\|v_{\bar{c}}^{q^{\perp}}(t)\right\|$ & $-0,0331$ & 0,0701 & $\left\|i_{\bar{c}}^{q^{\perp}}(t)\right\|$ & 0,0568 & 0,0018 \\
\hline & $\left\|v_{h}^{q^{\perp}}(t)\right\|$ & $-0,0605$ & 0,0009 & $\left\|i_{h}^{q^{\perp}}(t)\right\|$ & 0,2066 & 0,0000 \\
\hline & $\left\|v_{\bar{a}}^{d}(t)\right\|$ & $-0,2086$ & 0,0000 & $\left\|i_{\bar{a}}^{d}(t)\right\|$ & $-0,2329$ & 0,0000 \\
\hline 14 & $\left\|v_{\bar{b}}^{d}(t)\right\|$ & 0,0890 & 0,0000 & $\left\|i_{\bar{b}}^{d}(t)\right\|$ & 0,0115 & 0,5291 \\
\hline 15 & $\left\|v_{\bar{c}}^{d}(t)\right\|$ & 0,1908 & 0,0000 & $\left\|i_{\bar{c}}^{d}(t)\right\|$ & 0,0911 & 0,0000 \\
\hline & $\left\|v_{h}^{d}(t)\right\|$ & $-0,0615$ & 0,0007 & $\left\|i_{h}^{d}(t)\right\|$ & 0,2067 & 0,0000 \\
\hline
\end{tabular}

Por meio da Tabela 5.19 e Tabela 5.20 é possível verificar que as variáveis que mais se correlacionam com a identificação da Fase A como participante de uma condição de falta foram as variáveis $\left\|v_{a}^{p}(t)\right\|,\left\|v_{\bar{a}}^{p}(t)\right\|,\left\|i_{\bar{a}}^{p}(t)\right\| \mathrm{e}\left\|i_{a}^{p}(t)\right\|$. Essas variáveis foram empregadas na constituição do conjunto de ajuste para o sistema fuzzy responsável por identificar a Fase A quando essa participar de uma falta. O referido conjunto de ajuste fora constituído por 1000 pares entrada-saída de um total de 3000 existentes. Frente ao conjunto de treinamento, o sistema de inferência fuzzy fora ajustado segundo as duas etapas previstas para tal finalidade. A forma como o erro quadrático se reduziu ao longo da primeira etapa de ajuste, etapa essa responsável pela determinação da base de regras de inferência, é apresentada por meio da Figura 5.54. 


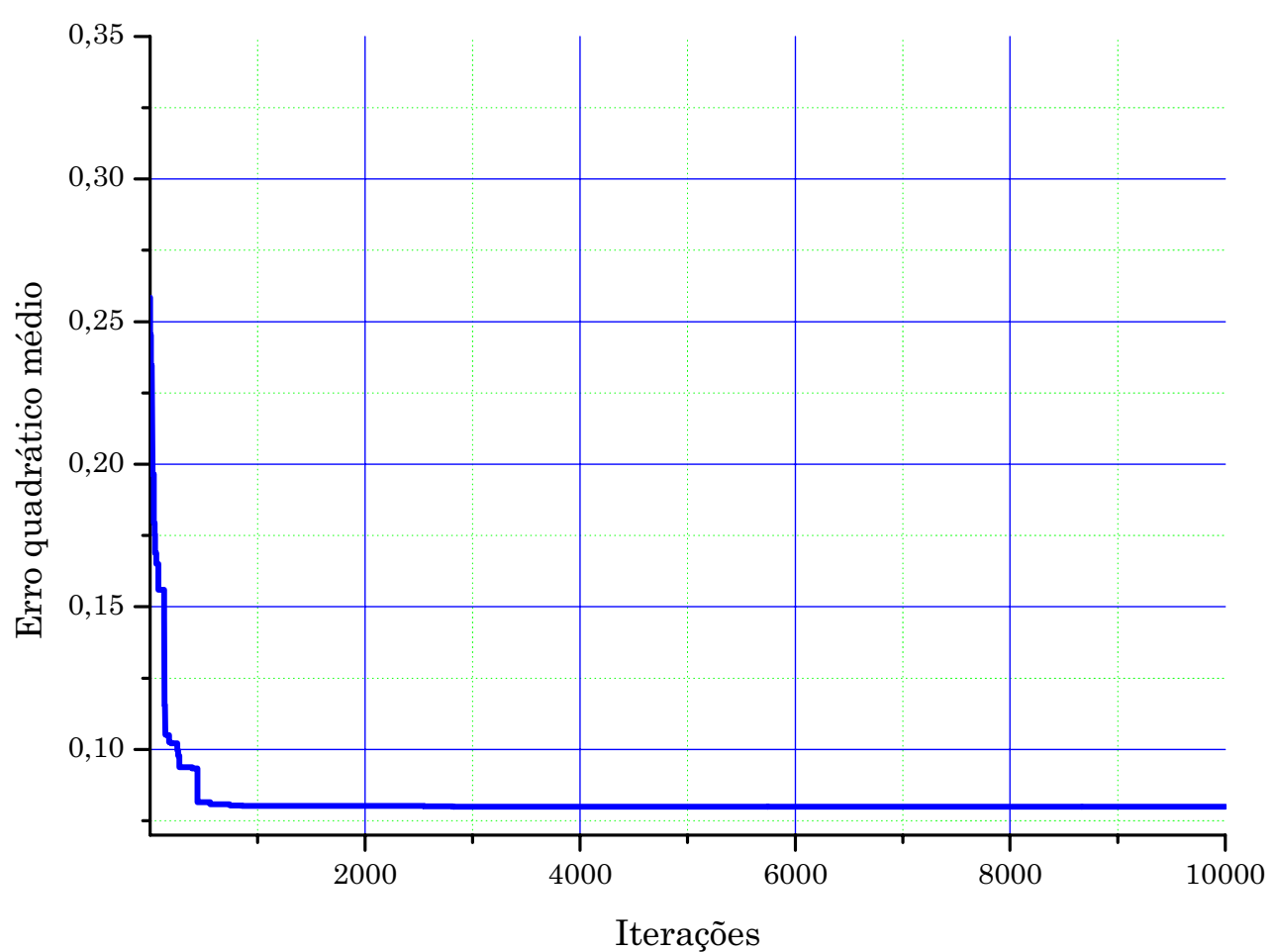

Figura 5.54 - Comportamento do erro quadrático médio ao longo das iterações da primeira etapa de ajuste do sistema de inferência fuzzy para identificação da fase A.

Por meio do gráfico da Figura 5.54 é possível verificar que a base de regras responsável por identificar a Fase A quando essa participar da ocorrência de uma falta faseterra rapidamente fora determinada. Essa rápida determinação reflete a eficiência do algoritmo desenvolvido e a grande correlação entre as variáveis empregadas para o objetivo proposto. Ao término da primeira etapa de ajuste, a base de regras determinada fora aquela apresentada por meio da Figura 5.55.

$$
\begin{aligned}
& \text { 1. Se }\left(\| v _ { a } ^ { p } ( t ) \| \text { é mf_3) e } \left(\| v _ { \overline { a } } ^ { p } ( t ) \| \text { é mf_3) e } ( \| i _ { \overline { a } } ^ { p } ( t ) \| \text { é mf_3 } 3 ) \text { e } \left(\left\|i_{a}^{p}(t)\right\|\right.\right.\right. \text { é mf_2) } \\
& \text { Então (Fase_A é não mf_3) } \\
& \text { 2. Se }\left(\left\|v_{a}^{p}(t)\right\| \text { é mf_3 }\right) \text { e }\left(\left\|v_{\bar{a}}^{p}(t)\right\| \text { é não mf_2 }\right) \text { e }\left(\left\|i_{\bar{a}}^{p}(t)\right\| \text { é não } \mathrm{mf}_{-} 2\right) \text { e }\left(\left\|i_{a}^{p}(t)\right\|\right. \text { é não mf_1) } \\
& \text { Então (Fase_A é não mf_3) } \\
& \text { 3. Se }\left(\left\|v_{a}^{p}(t)\right\| \text { é mf_1 }\right) \text { e }\left(\| v _ { \overline { a } } ^ { p } ( t ) \| \text { é não mf_3) e } \left(\left\|i_{a}^{p}(t)\right\|\right.\right. \text { é não mf_1) } \\
& \text { Então (Fase_A é não mf_2) } \\
& \text { 4. Se }\left(\left\|v_{a}^{p}(t)\right\| \text { é não } \mathrm{mf}_{-} 1\right) \text { e }\left(\| v _ { \overline { a } } ^ { p } ( t ) \| \text { é mf_3) e } ( \| i _ { \overline { a } } ^ { p } ( t ) \| \text { é } \mathrm { mf } _ { - } 3 ) \text { e } \left(\left\|i_{a}^{p}(t)\right\|\right.\right. \text { é não mf_1) } \\
& \text { Então (Fase_A é não mf_3) } \\
& \text { 5. Se }\left(\| v _ { a } ^ { p } ( t ) \| \text { é mf_3) e } \left(\| v _ { \overline { a } } ^ { p } ( t ) \| \text { é mf_1) e } \left(\| i _ { \overline { a } } ^ { p } ( t ) \| \text { é mf_1) e } \left(\left\|i_{a}^{p}(t)\right\|\right.\right.\right.\right. \text { é não mf_1) } \\
& \text { Então (Fase_A é não mf_2) }
\end{aligned}
$$

Figura 5.55 - Base de regras fuzzy determinadas pela primeira etapa de ajuste para o sistema identificador para a Fase A.

Após o término da primeira etapa de ajuste, o qual culminou na base de regras apresentadas por meio da Figura 5.55, o sistema de inferência fuzzy fora ajustado de forma 
paramétrica, ou seja, os parâmetros das funções de pertinência e a ponderação das regras de inferência foram ajustados de forma a conferir uma maior redução do erro quadrático médio. A Figura 5.56 apresenta como o erro quadrático médio evoluiu iteração a iteração ao longo da segunda etapa de ajuste.

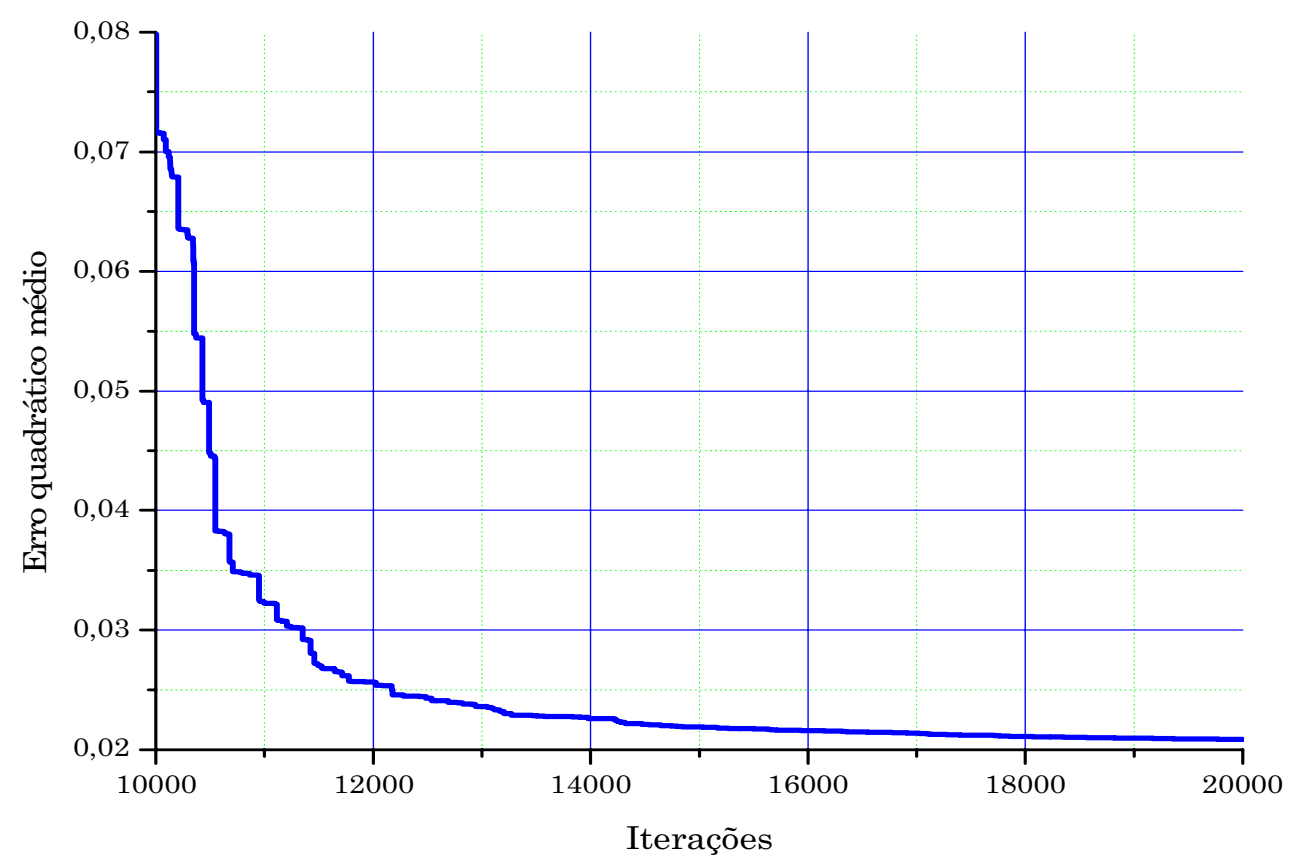

Figura 5.56 - Comportamento do erro quadrático médio ao longo das iterações da segunda etapa de ajuste do sistema de inferência fuzzy para identificação da fase A.

Conforme é possível verificar por meio do gráfico da Figura 5.56, o erro quadrático médio ao término da segunda etapa de ajuste fora cerca de três vezes inferior àquele observado no início do processo. Retratando a forma pela qual as funções de pertinência foram ajustadas pela segunda etapa, apresenta-se por meio da Figura 5.57 os gráficos das funções de pertinência constituintes do espaço de entrada do sistema fuzzy. $\mathrm{Na}$ Figura 5.58 apresenta-se as funções de pertinência contidas no universo de discurso da saída.

Complementando a apresentação do sistema fuzzy empregado para identificação da Fase A quando essa participar de uma falta fase-terra, tem-se na Tabela 5.21 as ponderações atribuídas a cada uma das regras destacadas na Figura 5.55.

Tabela 5.21 - Ponderação das regras fuzzy.

\begin{tabular}{lr}
\hline \hline Índice & Ponderação \\
\hline \hline 1 & 35,0125 \\
\hline 2 & 0,0727 \\
\hline 3 & 0,0097 \\
\hline 4 & 0,0919 \\
\hline 5 & 0,0766 \\
\hline
\end{tabular}



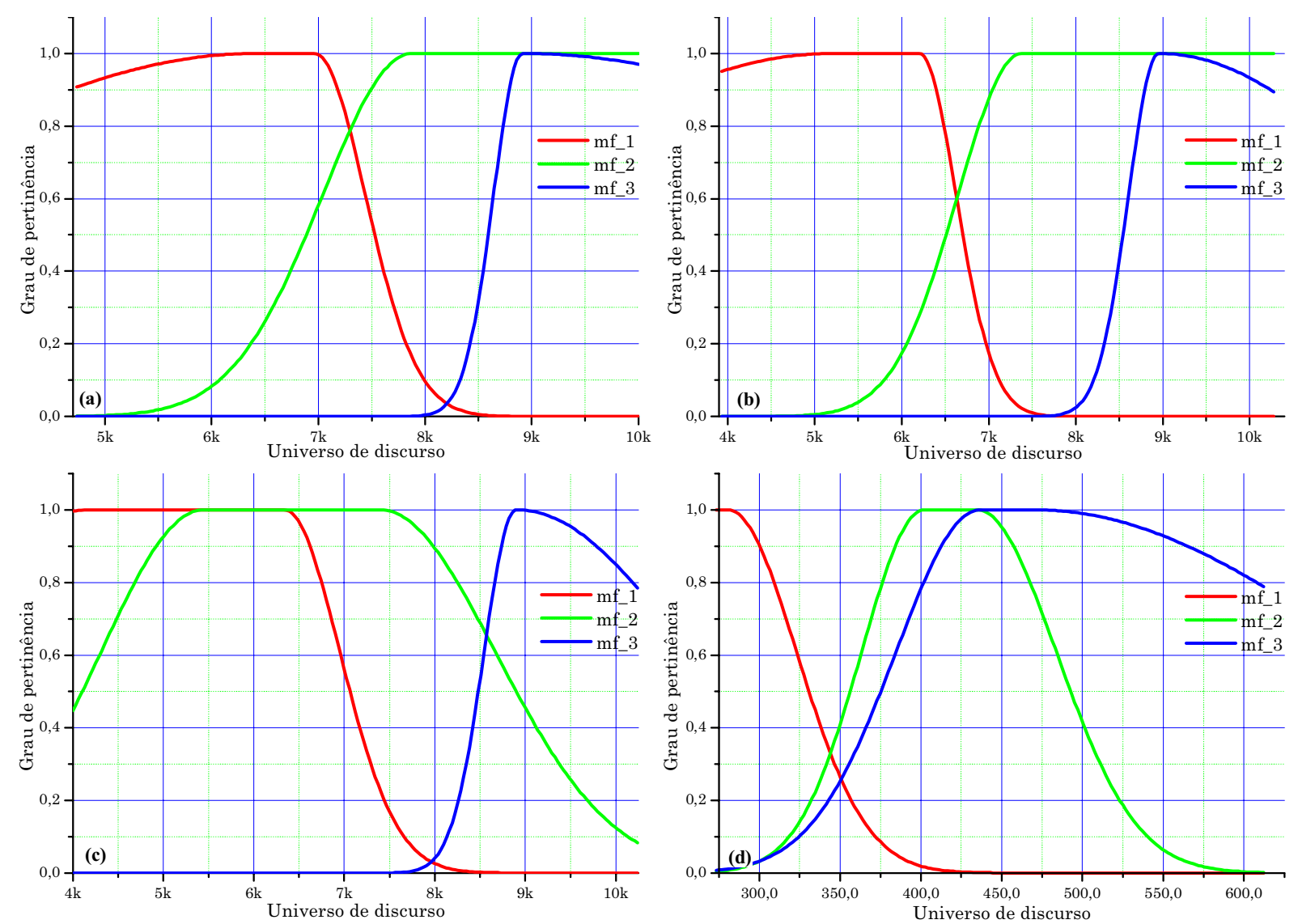

Figura 5.57 - Funções de pertinência para as entradas do sistema fuzzy identificador da Fase A; (a) Funções de pertinência para a variável $\left\|v_{a}^{p}(t)\right\|$; (b) Funções de pertinência para a variável $\left\|\nu_{\bar{a}}^{p}(t)\right\|$; (c) Funções de pertinência para a variável $\left\|i_{\bar{a}}^{p}(t)\right\|$; (d) Funções de pertinência para a variável $\left\|i_{a}^{p}(t)\right\|$;

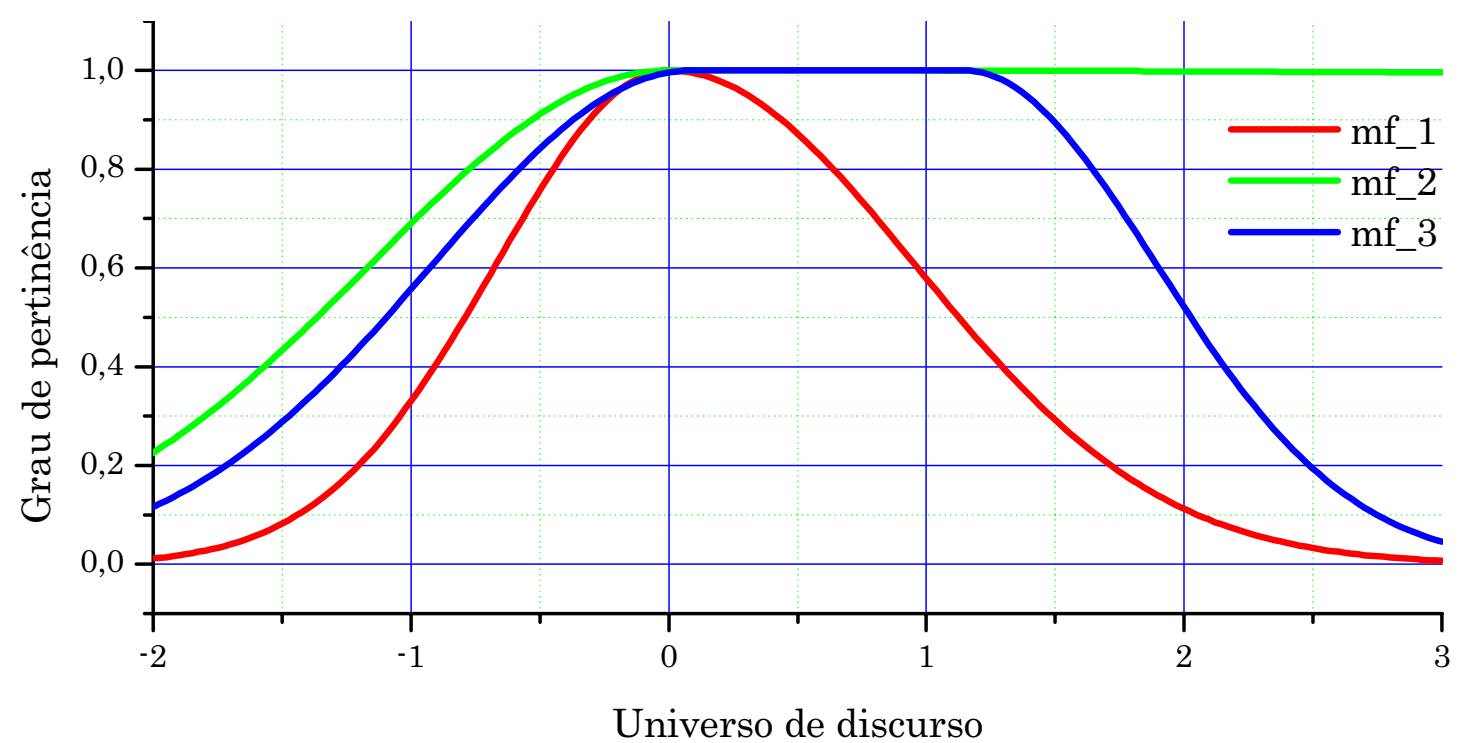

Figura 5.58 - Funções de pertinência para o universo de discurso da saída do sistema fuzzy identificador da Fase A 
A implementação do ajuste do sistema fuzzy fora feito tendo auxílio de um conjunto de teste com dimensão reduzida se comparado com o todo disponível. A fim de validar o comportamento do sistema fuzzy apresentado nessa subseção, o mesmo fora testado para todas as simulações disponíveis, ou seja, 3000 condições de falta. Como resultado do processo de identificação da Fase A como participante de uma falta, o sistema fuzzy respondeu com acerto de $100 \%$ dos casos, o que destaca a eficiência do sistema fuzzy na execução da tarefa.

\subsubsection{Sistema IdentificAdor de FAltas COM PARTICIPAÇÃo DA FASE B}

A identificação das variáveis que mais influenciam no processo de identificação da fase participante da falta por meio da análise de correlação e de teste de hipótese de significância se mostrou adequado em função dos resultados destacados na Subseção 5.6.1. Assim, o mesmo procedimento será empregado na determinação das variáveis que mais podem colaborar em identificar a Fase B como participante de uma falta do tipo fase-terra quando assim o for. Dessa maneira, igualmente ao realizado na Subseção 5.6.1, nessa subseção foram considerados os valores médios (durante a perduração da falta) dos valores eficazes para as componentes ortogonais oriundas do processo de decomposição.

A fim de apresentar como cada componente pode vir a colaborar com a determinação da fase faltosa, fora então feito o cálculo da correlação dos valores eficazes com o propósito de determinar se a Fase B participara da falta. Os valores da correlação e o teste de hipótese são apresentados na Tabela 5.22, onde se destaca o referido para as componentes contidas na função planar das tensões de linha e, na Tabela 5.23, onde se faz o mesmo para as componentes ortogonais à função planar das tensões de linha. Para fins de comparação visual, apresenta-se por meio da Figura 5.59 os valores da Tabela 5.22, enquanto que os da Tabela 5.25 são apresentados na Figura 5.60. 
Tabela 5.22 - Correlação e teste de hipótese para as projeções contidas na função planar das tensões de linha.

\begin{tabular}{|c|c|c|c|c|c|c|}
\hline$k$ & Variável & Correlação & Teste de hipótese & Variável & Correlação & Teste de hipótese \\
\hline 1 & $\left\|v_{a}^{p}(t)\right\|$ & 0,4235 & 0,0000 & $\left\|i_{a}^{p}(t)\right\|$ & $-0,3488$ & 0,0000 \\
\hline 2 & $\left\|v_{b}^{p}(t)\right\|$ & $-0,7740$ & 0,0000 & $\left\|i_{b}^{p}(t)\right\|$ & 0,7099 & 0,0000 \\
\hline 3 & $\left\|v_{c}^{p}(t)\right\|$ & 0,3627 & 0,0000 & $\left\|i_{c}^{p}(t)\right\|$ & $-0,3704$ & 0,0000 \\
\hline 4 & $\left\|v_{n}^{p}(t)\right\|$ & 0,0080 & 0,6630 & $\left\|i_{n}^{p}(t)\right\|$ & 0,0081 & 0,6594 \\
\hline 5 & $\left\|v_{a}^{q^{\|}}(t)\right\|$ & 0,5628 & 0,0000 & $\left\|i_{a}^{q \|}(t)\right\|$ & 0,2497 & 0,0000 \\
\hline 6 & $\left\|v_{b}^{q^{\| \prime}}(t)\right\|$ & $-0,3260$ & 0,0000 & $\left\|i_{b}^{q^{\|}}(t)\right\|$ & $-0,2918$ & 0,0000 \\
\hline 7 & $\left\|v_{c}^{q^{\| \prime}}(t)\right\|$ & $-0,2396$ & 0,0000 & $\left\|i_{c}^{q^{\|}}(t)\right\|$ & 0,0279 & 0,1263 \\
\hline 8 & $\left\|v_{n}^{q^{\|}}(t)\right\|$ & 0,0070 & 0,7015 & $\left\|i_{n}^{q^{\prime \prime}}(t)\right\|$ & 0,0037 & 0,8391 \\
\hline 9 & $\left\|v_{a}^{q^{\perp}}(t)\right\|$ & $-0,1882$ & 0,0000 & $\left\|i_{a}^{q^{\perp}}(t)\right\|$ & 0,1041 & 0,0000 \\
\hline 10 & $\left\|v_{b}^{q^{\perp}}(t)\right\|$ & $-0,1050$ & 0,0000 & $\left\|i_{b}^{q^{\perp}}(t)\right\|$ & 0,1761 & 0,0000 \\
\hline 11 & $\left\|v_{c}^{q^{\perp}}(t)\right\|$ & $-0,1931$ & 0,0000 & $\left\|i_{c}^{q^{\perp}}(t)\right\|$ & $-0,2033$ & 0,0000 \\
\hline 12 & $\left\|v_{n}^{q^{\perp}}(t)\right\|$ & $-0,0574$ & 0,0017 & $\left\|i_{n}^{q^{\perp}}(t)\right\|$ & $-0,0881$ & 0,0000 \\
\hline 13 & $\left\|v_{a}^{d}(t)\right\|$ & $-0,1882$ & 0,0000 & $\left\|i_{a}^{d}(t)\right\|$ & $-0,0544$ & 0,0029 \\
\hline 14 & $\left\|v_{b}^{d}(t)\right\|$ & $-0,1041$ & 0,0000 & $\left\|i_{b}^{d}(t)\right\|$ & 0,1919 & 0,0000 \\
\hline 15 & $\left\|v_{c}^{d}(t)\right\|$ & $-0,1933$ & 0,0000 & $\left\|i_{c}^{d}(t)\right\|$ & $-0,1586$ & 0,0000 \\
\hline 16 & $\left\|v_{n}^{d}(t)\right\|$ & $-0,0574$ & 0,0017 & $\left\|i_{n}^{d}(t)\right\|$ & $-0,0879$ & 0,0000 \\
\hline
\end{tabular}
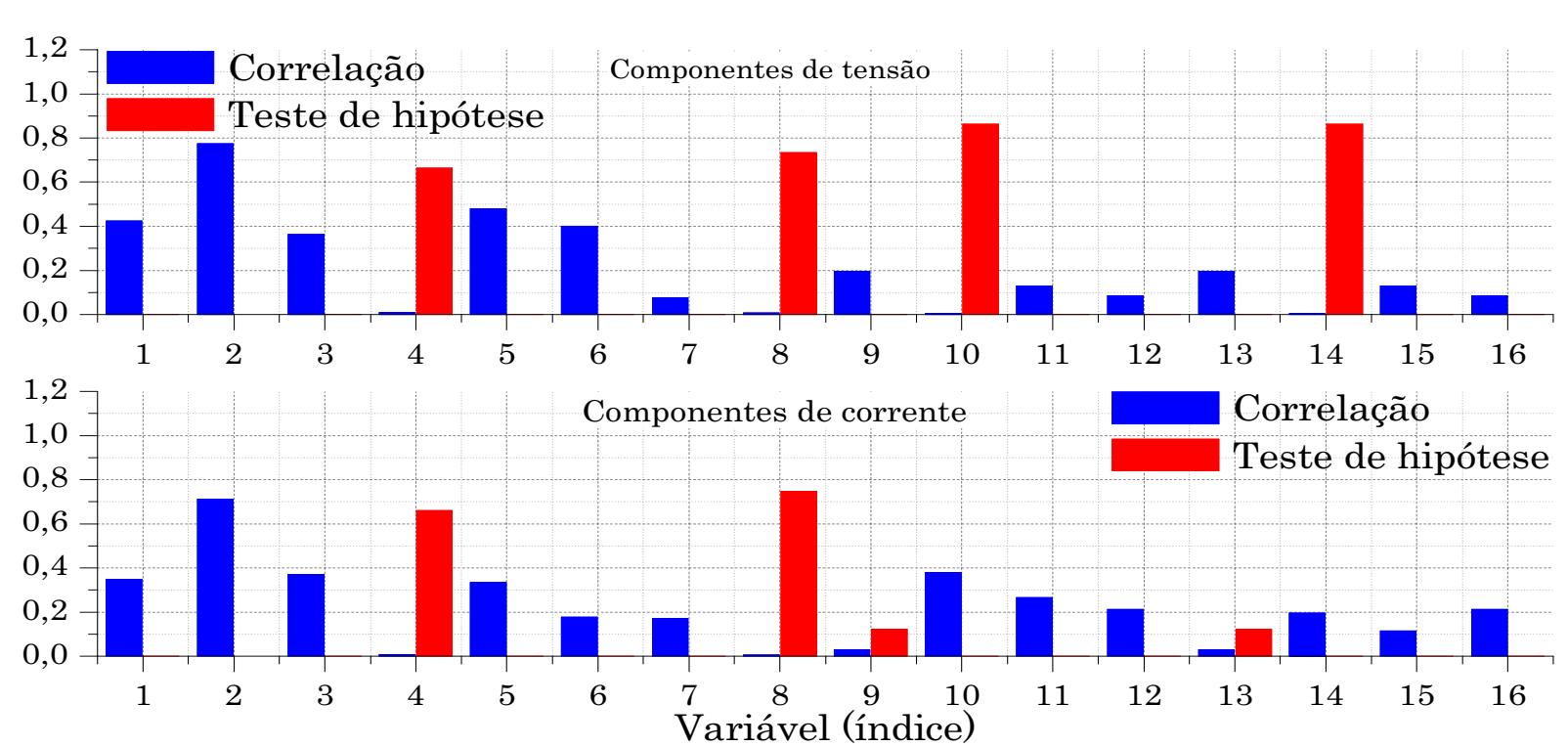

Figura 5.59 - Correlação e teste de hipótese para as projeções contidas na função planar das tensões de linha com relação à identificação da Fase B. 
Tabela 5.23 - Correlação e teste de hipótese para as projeções ortogonais à função planar das tensões de linha.

\begin{tabular}{|c|c|c|c|c|c|c|}
\hline k & Variável & Correlação & Teste de hipótese & Variável & Correlação & Teste de hipótese \\
\hline 1 & $\left\|\nu_{\bar{a}}^{p}(t)\right\|$ & 0,4302 & 0,0000 & $\left\|i_{\bar{a}}^{p}(t)\right\|$ & 0,4342 & 0,0000 \\
\hline 2 & $\left\|v_{\bar{b}}^{p}(t)\right\|$ & $-0,7707$ & 0,0000 & $\left\|i_{\bar{b}}^{p}(t)\right\|$ & $-0,7697$ & 0,0000 \\
\hline 3 & $\left\|v_{\bar{c}}^{p}(t)\right\|$ & 0,3532 & 0,0000 & $\left\|i_{\bar{c}}^{p}(t)\right\|$ & 0,3490 & 0,0000 \\
\hline 4 & $\left\|v_{h}^{p}(t)\right\|$ & 0,0077 & 0,6737 & $\left\|i_{h}^{p}(t)\right\|$ & 0,0080 & 0,6620 \\
\hline 5 & $\left\|v_{\bar{a}}^{q^{\|}}(t)\right\|$ & 0,5713 & 0,0000 & $\left\|i_{\bar{a}}^{q^{\|}}(t)\right\|$ & 0,1390 & 0,0000 \\
\hline 6 & $\left\|v_{\frac{q^{\|}}{b}}(t)\right\|$ & $-0,6274$ & 0,0000 & $\left\|i_{\frac{q}{b}}^{\|}(t)\right\|$ & $-0,6672$ & 0,0000 \\
\hline 7 & $\left\|v_{\bar{c}}^{q^{\|}}(t)\right\|$ & 0,0672 & 0,0002 & $\left\|i_{c}^{q^{\|}}(t)\right\|$ & 0,5229 & 0,0000 \\
\hline 8 & $\left\|v_{h}^{q^{\|}}(t)\right\|$ & 0,0109 & 0,5495 & $\left\|i_{h}^{q^{\|}}(t)\right\|$ & 0,0100 & 0,5855 \\
\hline 9 & $\left\|v_{\bar{a}}^{q^{\perp}}(t)\right\|$ & $-0,1023$ & 0,0000 & $\left\|i_{\bar{a}}^{q^{\perp}}(t)\right\|$ & $-0,0644$ & 0,0004 \\
\hline 10 & $\left\|v_{\bar{b}}^{q^{\perp}}(t)\right\|$ & $-0,0071$ & 0,6969 & $\left\|i_{\frac{q^{\perp}}{b}}(t)\right\|$ & $-0,0308$ & 0,0912 \\
\hline 11 & $\left\|v_{\bar{c}}^{q^{\perp}}(t)\right\|$ & 0,0453 & 0,0132 & $\left\|i_{\bar{c}}^{q^{\perp}}(t)\right\|$ & $-0,0059$ & 0,7485 \\
\hline 12 & $\left\|v_{h}^{q^{\perp}}(t)\right\|$ & $-0,1587$ & 0,0000 & $\left\|i_{h}^{q^{\perp}}(t)\right\|$ & $-0,1373$ & 0,0000 \\
\hline 13 & $\left\|v_{\bar{a}}^{d}(t)\right\|$ & 0,1207 & 0,0000 & $\left\|i_{\bar{a}}^{d}(t)\right\|$ & 0,0765 & 0,0000 \\
\hline 14 & $\left\|v_{\bar{b}}^{d}(t)\right\|$ & $-0,3260$ & 0,0000 & $\left\|i_{\frac{d}{b}}^{d}(t)\right\|$ & $-0,1931$ & 0,0000 \\
\hline 15 & $\left\|v_{\bar{c}}^{d}(t)\right\|$ & 0,1161 & 0,0000 & $\left\|i_{\bar{c}}^{d}(t)\right\|$ & 0,1208 & 0,0000 \\
\hline 16 & $\left\|v_{h}^{d}(t)\right\|$ & $-0,1567$ & 0,0000 & $\left\|i_{h}^{d}(t)\right\|$ & $-0,1380$ & 0,0000 \\
\hline
\end{tabular}
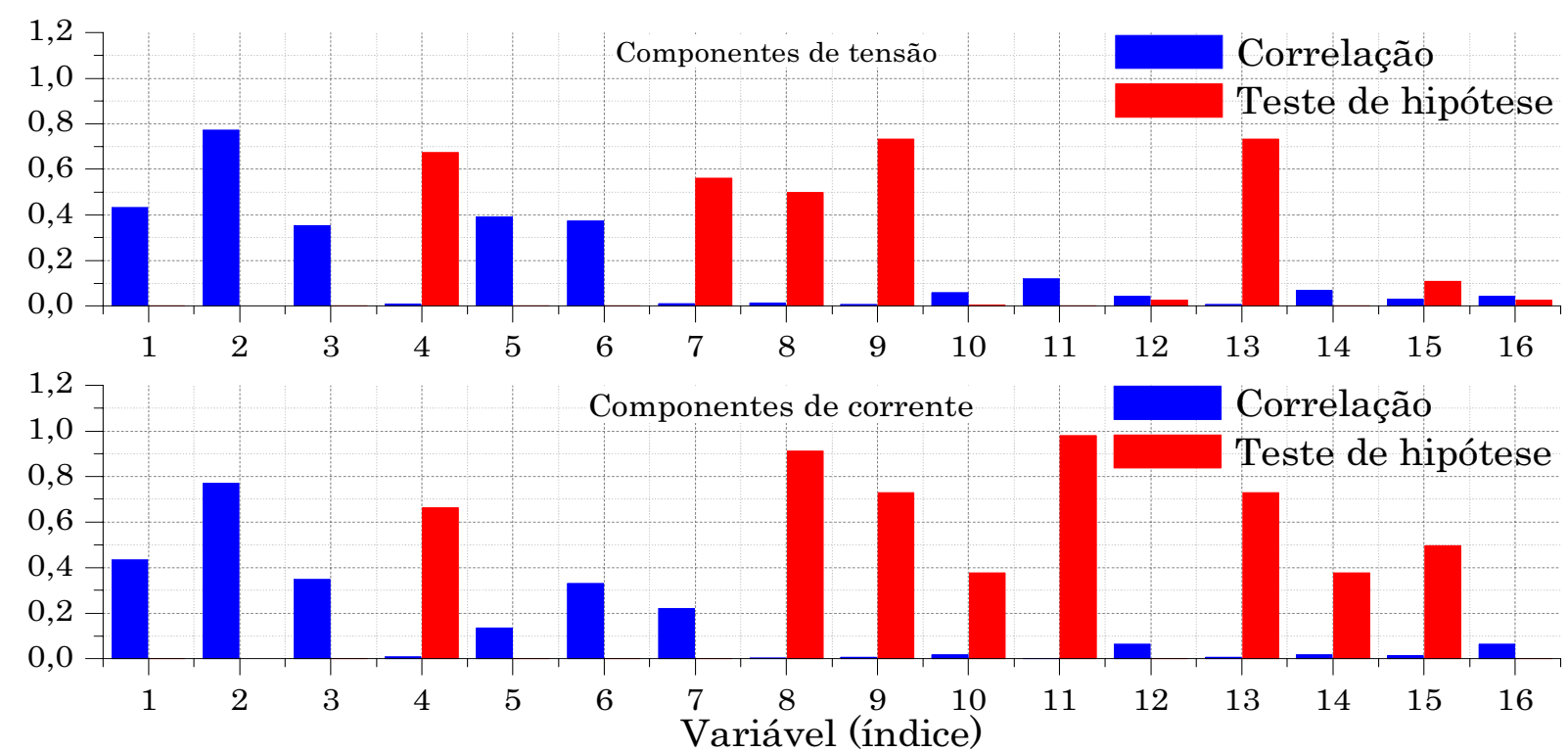

Figura 5.60 - Correlação e teste de hipótese para as projeções contidas na função planar das tensões de linha com relação à identificação da Fase B. 
Por meio da Tabela 5.22 e Tabela 5.23 é possível verificar que as variáveis que mais se correlacionam com a identificação da Fase B como participante de uma condição de falta foram as variáveis $\left\|v_{b}^{p}(t)\right\|,\left\|v_{\bar{b}}^{p}(t)\right\|,\left\|i_{\bar{b}}^{p}(t)\right\| \mathrm{e}\left\|i_{b}^{p}(t)\right\|$. Essas variáveis foram empregadas na constituição do conjunto de ajuste para o sistema fuzzy responsável por identificar a Fase B quando essa participar de uma falta. O referido conjunto de ajuste fora constituído por 1000 pares entrada-saída de um total de 3000 existentes. Frente ao conjunto de treinamento, o sistema de inferência fuzzy fora ajustado segundo as duas etapas previstas para tal finalidade. A forma como o erro quadrático se reduziu ao longo da primeira etapa de ajuste, etapa essa responsável pela determinação da base de regras de inferência, é apresentada por meio da Figura 5.61.

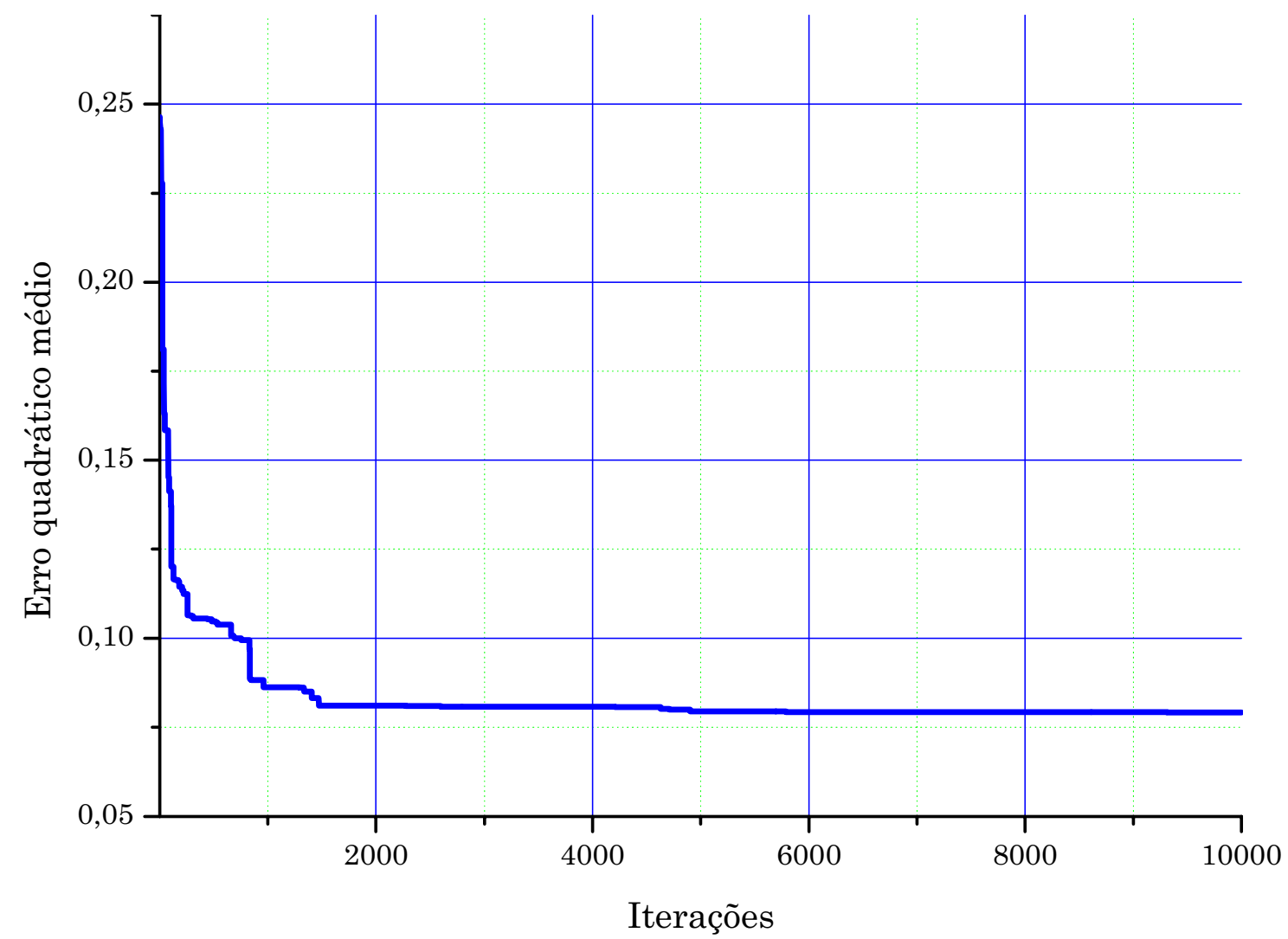

Figura 5.61 - Comportamento do erro quadrático médio ao longo das iterações da primeira etapa de ajuste do sistema de inferência fuzzy para identificação da Fase B.

Por meio do gráfico da Figura 5.61 é possível verificar que a base de regras responsável por identificar a Fase B, quando essa participar da ocorrência de uma falta faseterra, rapidamente fora determinada. Essa rápida determinação reflete a eficiência do algoritmo desenvolvido e a grande correlação entre as variáveis empregadas para o objetivo proposto. Ao término da primeira etapa de ajuste, a base de regras determinada fora aquela apresentada por meio da Figura 5.62. 


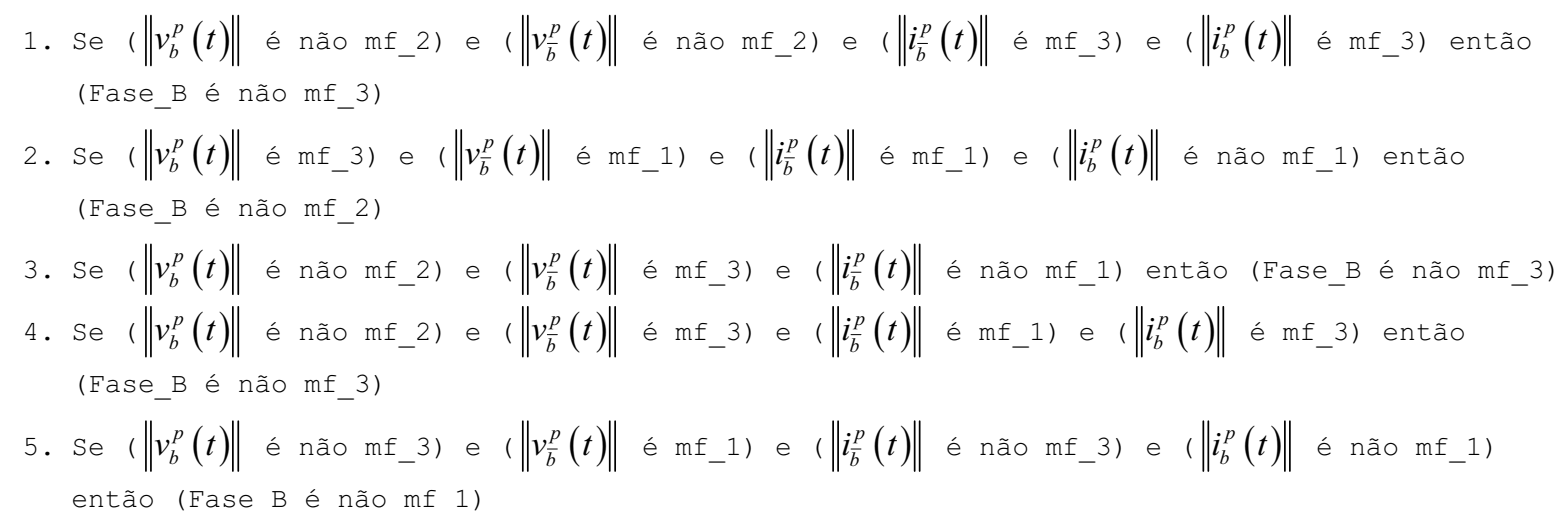

Figura 5.62 - Base de regras fuzzy determinadas pela primeira etapa de ajuste para o sistema identificador para a Fase B.

Após o término da primeira etapa de ajuste o qual culminou na base de regras apresentadas por meio da Figura 5.62 o sistema de inferência fuzzy fora ajustado de forma paramétrica, ou seja, os parâmetros das funções de pertinência e a ponderação das regras de inferência foram ajustados de forma a conferir uma maior redução do erro quadrático médio. A Figura 5.63 apresenta como o erro quadrático médio evoluiu iteração a iteração ao longo da segunda etapa de ajuste.

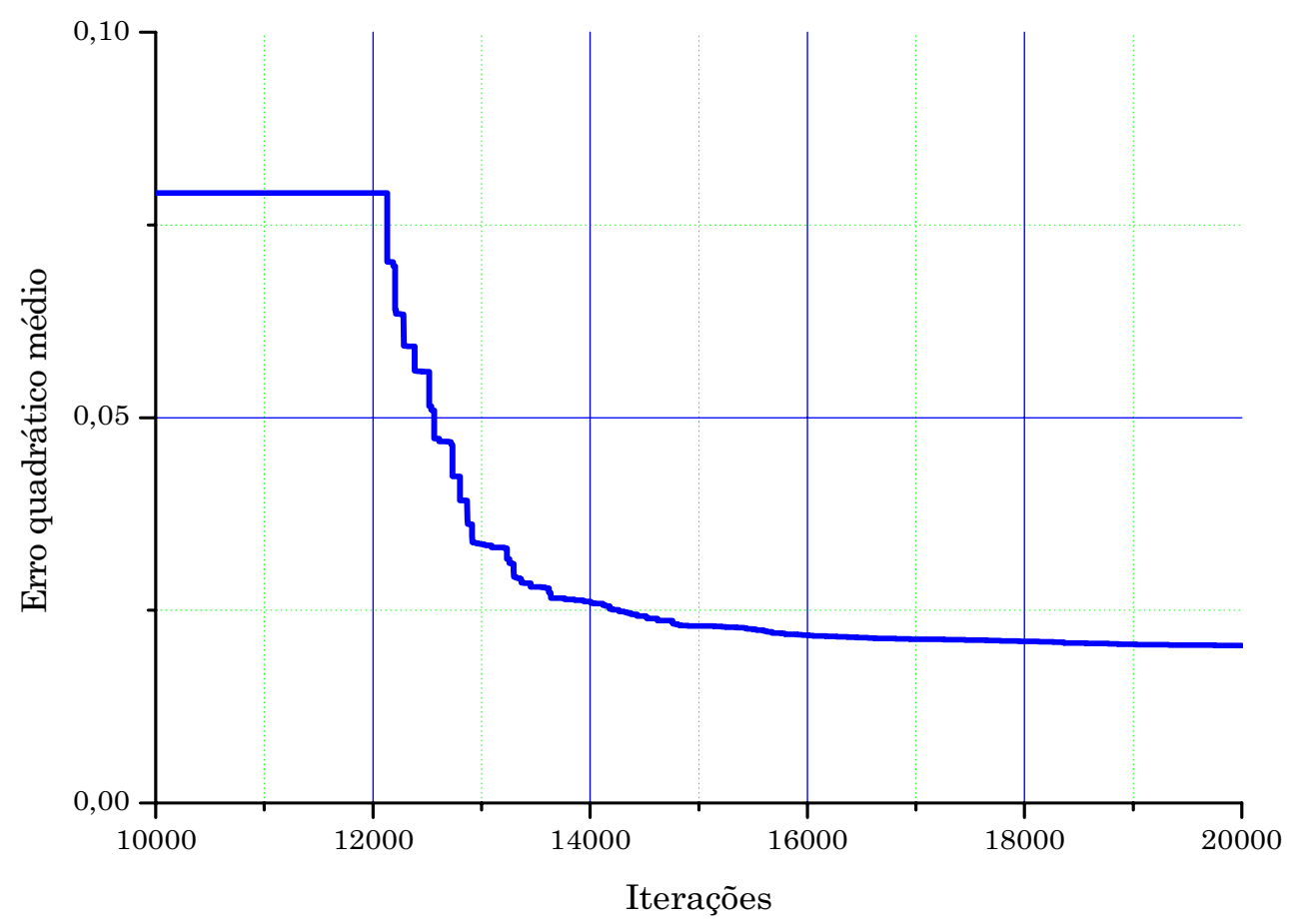

Figura 5.63 - Comportamento do erro quadrático médio ao longo das iterações da segunda etapa de ajuste do sistema de inferência fuzzy para identificação da fase B.

Conforme é possível verificar por meio do gráfico da Figura 5.63, o erro quadrático médio ao término da segunda etapa de ajuste fora cerca de três vezes inferior àquele observado no início do processo. Retratando a forma pela qual as funções de pertinência foram ajustadas pela segunda etapa, apresenta-se por meio da Figura 5.64 os 
gráficos das funções de pertinência constituintes do espaço de entrada do sistema fuzzy. Na Figura 5.65 apresenta-se as funções de pertinência contida no universo de discurso da saída.
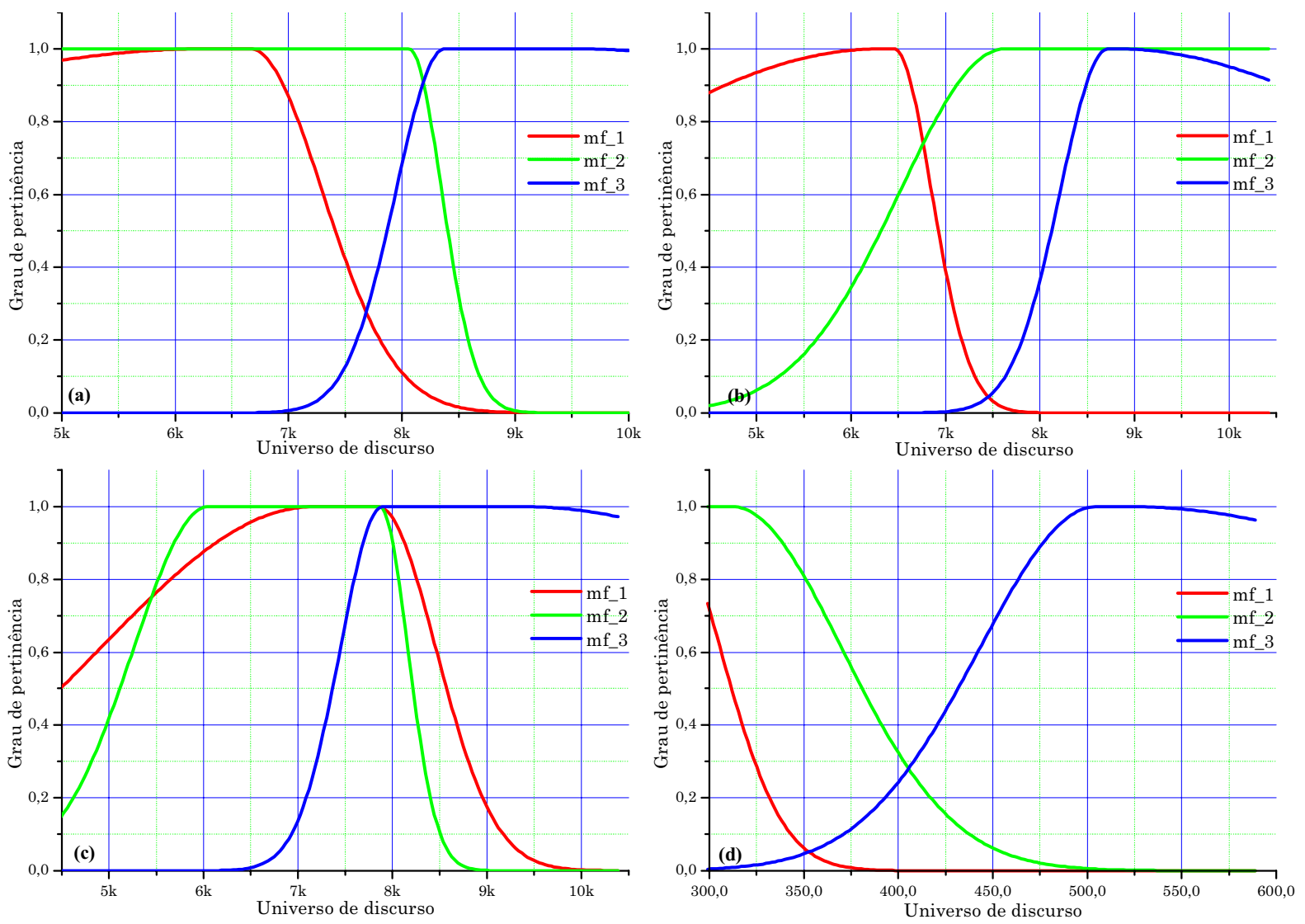

Figura 5.64 - Funções de pertinência para as entradas do sistema fuzzy identificador da Fase B; (a) Funções de pertinência para a variável $\left\|v_{b}^{p}(t)\right\|$; (b) Funções de pertinência para a variável $\left\|v_{\bar{b}}^{p}(t)\right\|$; (c) Funções de pertinência para a variável $\left\|i_{\bar{b}}^{p}(t)\right\|$; (d) Funções de pertinência para a variável $\left\|i_{b}^{p}(t)\right\|$;

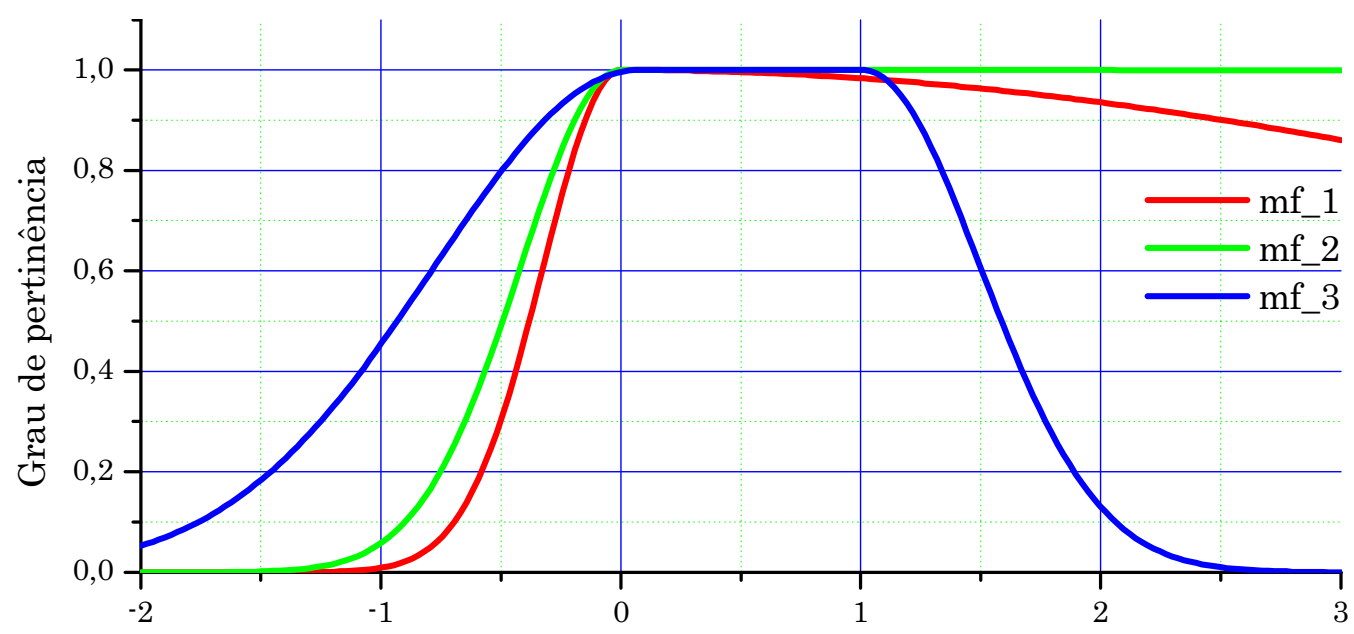

Universo de discurso

Figura 5.65 - Funções de pertinência para o universo de discurso da saída do sistema fuzzy identificador da Fase B. 
Complementando a apresentação do sistema fuzzy empregado para identificação da Fase B quando essa participar de uma falta fase-terra, tem-se na Tabela 5.26 as ponderações atribuídas a cada uma das regras destacadas na Figura 5.62.

Tabela 5.24 - Ponderação das regras fuzzy.

\begin{tabular}{lr}
\hline Índice & Ponderação \\
\hline \hline 1 & 0,3309 \\
\hline 2 & $\approx 0$ \\
\hline 3 & 2291,1233 \\
\hline 4 & 0,0387 \\
\hline 5 & 1,2551 \\
\hline
\end{tabular}

A implementação do ajuste do sistema fuzzy fora feito tendo auxílio de um conjunto de teste com dimensão reduzida se comparado com o todo disponível. A fim de validar o comportamento do sistema fuzzy apresentado nessa subseção, o mesmo fora testado para todas as simulações disponíveis, ou seja, 3000 condições de falta. Como resultado do processo de identificação da Fase B como participante de uma falta, o sistema fuzzy respondeu com acerto de $100 \%$ dos casos, o que destaca a eficiência do sistema fuzzy na execução da tarefa.

\subsubsection{Sistema IdENTIFICAdOR DE FALTAS COM PARTICIPAÇÃo DA FASE C}

A identificação das variáveis que mais influenciam no processo de identificação da fase participante da falta por meio da análise de correlação e de teste de hipótese de significância se mostrou adequado tanto quando do foco da Fase A quanto da Fase B. Assim, o mesmo procedimento será empregado na determinação das variáveis que mais podem colaborar em identificar a Fase C como participante de uma falta do tipo fase-terra quando assim o for. Dessa maneira, igualmente ao realizado na Subseção 5.6.1 e Subseção 5.6.2, nessa subseção, foram considerados os valores médios (durante a perduração da falta) dos valores eficazes para as componentes ortogonais oriundas do processo de decomposição.

Os valores da correlação e o teste de hipótese são apresentados na Tabela 5.25, onde se destaca o referido para as componentes contidas na função planar das tensões de linha e na Tabela 5.26, onde se faz o mesmo para as componentes ortogonais à função planar das tensões de linha. Para fins de comparação visual, apresenta-se por meio da Figura 5.66 os valores da Tabela 5.25, enquanto que os da Tabela 5.26 são apresentados na Figura 5.67. 
Tabela 5.25 - Correlação e teste de hipótese para as projeção contidas na função planar das tensões de linha.

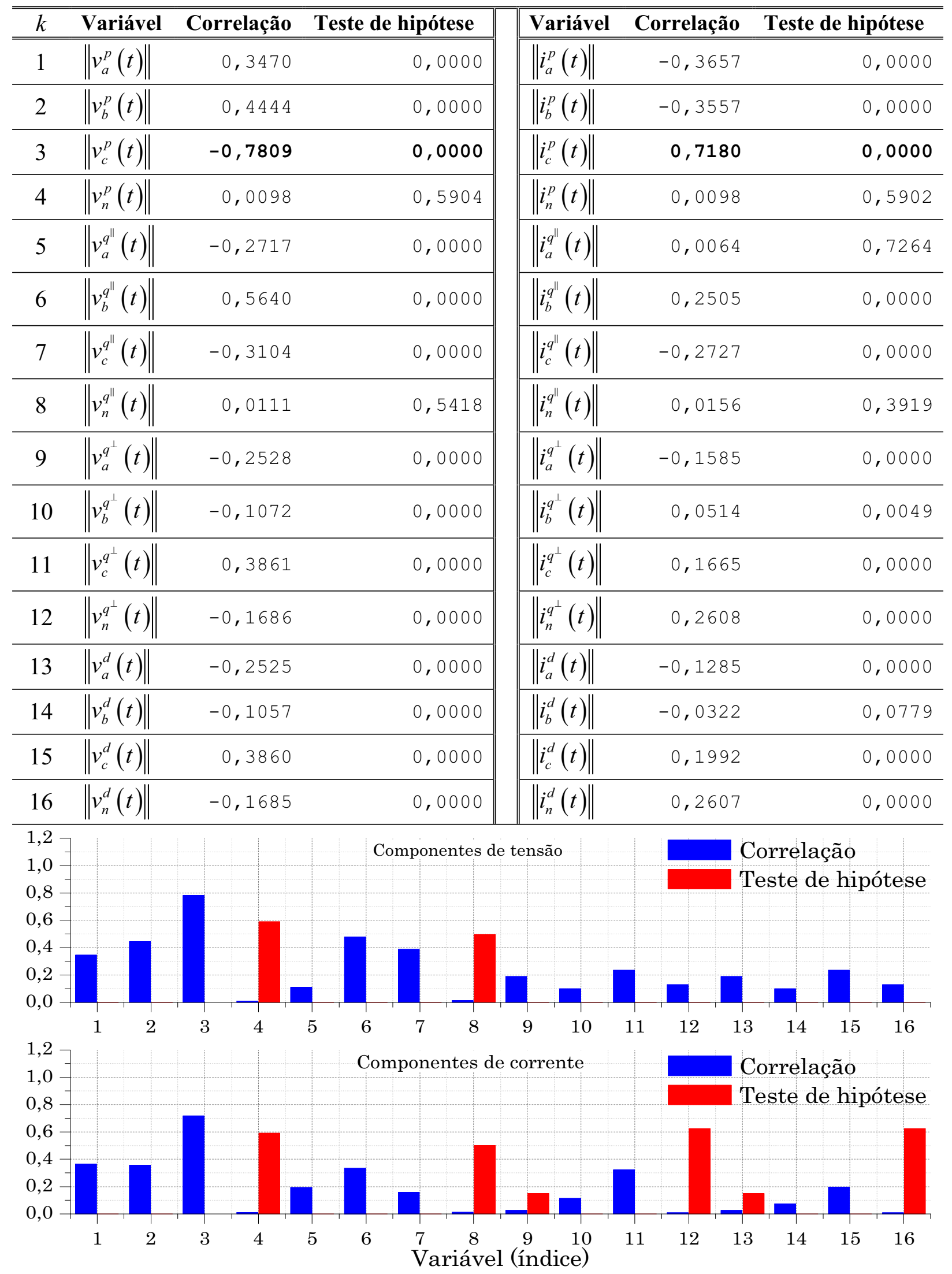

Figura 5.66 - Correlação e teste de hipótese para as projeções contidas na função planar das tensões de linha com relação à identificação da Fase C. 
Tabela 5.26 - Correlação e teste de hipótese para as projeções ortogonais à função planar das tensões de linha.

\begin{tabular}{|c|c|c|c|c|c|c|}
\hline$k$ & Variável & Correlação & Teste de hipótese & Variável & Correlação & Teste de hipótese \\
\hline 1 & $\left\|v_{\bar{a}}^{p}(t)\right\|$ & 0,3346 & 0,0000 & $\left\|i_{\bar{a}}^{p}(t)\right\|$ & 0,3300 & 0,0000 \\
\hline 2 & $\left\|v_{\bar{b}}^{p}(t)\right\|$ & 0,4486 & 0,0000 & $\left\|i_{\bar{b}}^{p}(t)\right\|$ & 0,4517 & 0,0000 \\
\hline 3 & $\left\|\nu_{\bar{c}}^{p}(t)\right\|$ & 0,7771 & 0,0000 & $\left\|i_{\bar{c}}^{p}(t)\right\|$ & 0,7759 & 0,0000 \\
\hline 4 & $\left\|v_{h}^{p}(t)\right\|$ & 0,0103 & 0,5740 & $\left\|i_{h}^{p}(t)\right\|$ & 0,0097 & 0,5956 \\
\hline 5 & $\left\|v_{\bar{a}}^{q^{\|}}(t)\right\|$ & 0,0571 & 0,0018 & $\left\|i_{\bar{a}}^{q^{\|}}(t)\right\|$ & 0,1777 & 0,0000 \\
\hline 6 & $\left\|v_{\frac{q^{\prime \prime}}{b}}(t)\right\|$ & 0,3897 & 0,0000 & $\left\|i_{\bar{b}}^{q^{\|}}(t)\right\|$ & 0,1335 & 0,0000 \\
\hline 7 & $\left\|\nu_{\bar{c}}^{q^{\|}}(t)\right\|$ & 0,3677 & 0,0000 & $\left\|i_{c}^{q^{\|}}(t)\right\|$ & 0,3383 & 0,0000 \\
\hline 8 & $\left\|v_{h}^{q^{\|}}(t)\right\|$ & 0,0081 & 0,6568 & $\left\|i_{h}^{q^{\|}}(t)\right\|$ & 0,0011 & 0,9515 \\
\hline 9 & $\left\|v_{\bar{a}}^{q^{\perp}}(t)\right\|$ & 0,1172 & 0,0000 & $\left\|i_{\bar{a}}^{q^{\perp}}(t)\right\|$ & 0,0237 & 0,1940 \\
\hline 10 & $\left\|v_{\frac{q^{\perp}}{b}}(t)\right\|$ & 0,0062 & 0,7326 & $\left\|i_{\frac{q^{\perp}}{}}^{\perp}(t)\right\|$ & 0,0491 & 0,0072 \\
\hline 11 & $\left\|v_{\bar{c}}^{q^{\perp}}(t)\right\|$ & 0,1188 & 0,0000 & $\left\|i_{\bar{c}}^{q^{\perp}}(t)\right\|$ & 0,1425 & 0,0000 \\
\hline 12 & $\left\|v_{h}^{q^{\perp}}(t)\right\|$ & 0,0478 & 0,0089 & $\left\|i_{h}^{q^{\perp}}(t)\right\|$ & 0,0013 & 0,9437 \\
\hline 13 & $\left\|v_{\bar{a}}^{d}(t)\right\|$ & 0,1172 & 0,0000 & $\left\|i_{\bar{a}}^{d}(t)\right\|$ & 0,0237 & 0,1941 \\
\hline 14 & $\left\|v_{\bar{b}}^{d}(t)\right\|$ & 0,0691 & 0,0002 & $\left\|i_{\frac{d}{b}}^{d}(t)\right\|$ & 0,0491 & 0,0072 \\
\hline 15 & $\left\|v_{\bar{c}}^{d}(t)\right\|$ & 0,0912 & 0,0000 & $\left\|i_{\bar{c}}^{d}(t)\right\|$ & 0,0473 & 0,0096 \\
\hline 16 & $\left\|v_{h}^{d}(t)\right\|$ & 0,0478 & 0,0089 & $\left\|i_{h}^{d}(t)\right\|$ & 0,0013 & 0,9436 \\
\hline
\end{tabular}
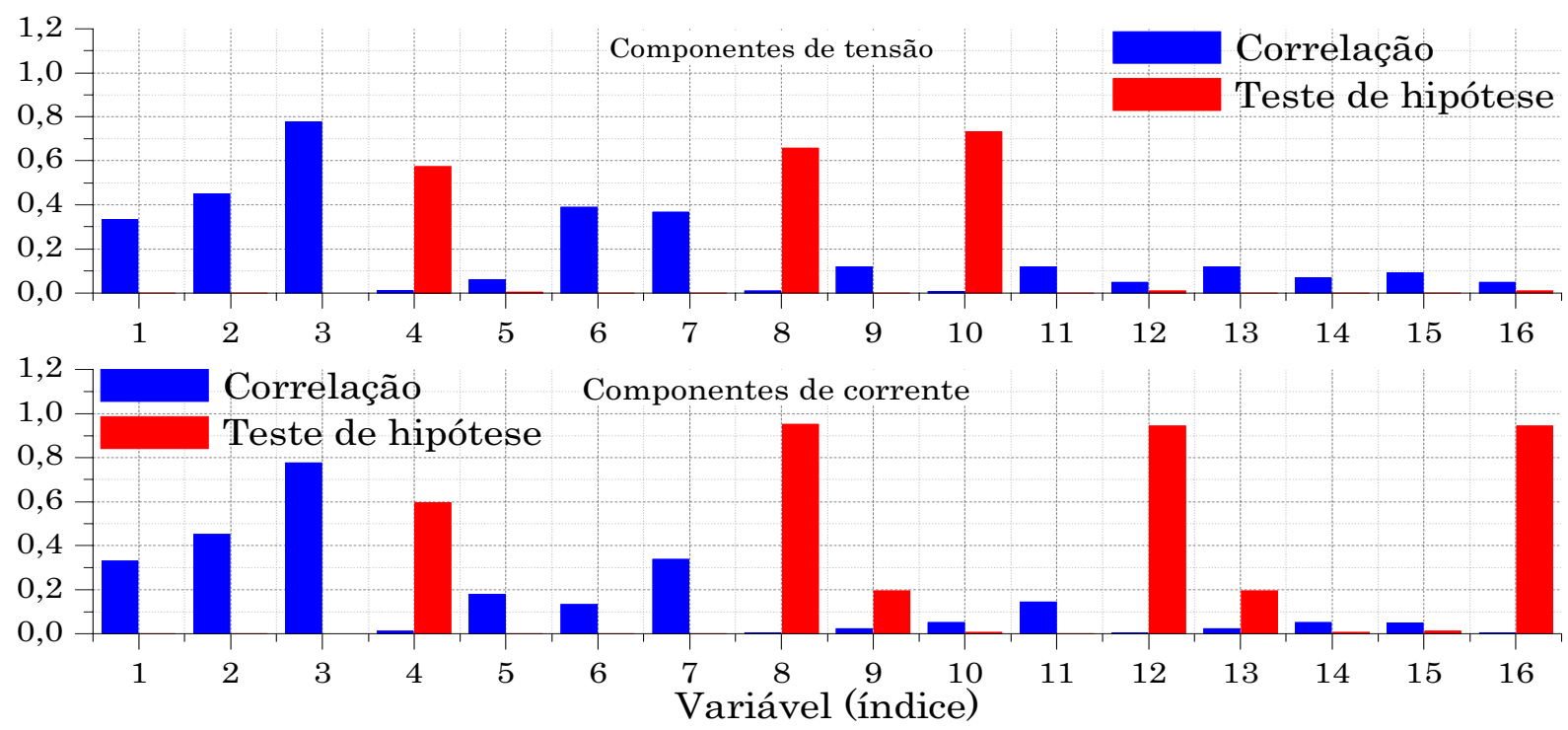

Figura 5.67 - Correlação e teste de hipótese para as projeções contidas na função planar das tensões de linha com relação à identificação da Fase C. 
Por meio da Tabela 5.25 e Tabela 5.26 é possível verificar que as variáveis que mais se correlacionam com a identificação da Fase C como participante de uma condição de falta foram as variáveis $\left\|v_{c}^{p}(t)\right\|,\left\|\nu_{\bar{c}}^{p}(t)\right\|,\left\|i_{\bar{c}}^{p}(t)\right\| \mathrm{e}\left\|i_{c}^{p}(t)\right\|$. Essas variáveis foram empregadas na constituição do conjunto de ajuste para o sistema fuzzy responsável por identificar a Fase C quando essa participar de uma falta. O referido conjunto de ajuste fora constituído por 1000 pares entrada-saída de um total de 3000 existentes. Frente ao conjunto de treinamento, o sistema de inferência fuzzy fora ajustado segundo as duas etapas previstas para tal finalidade. A forma como o erro quadrático se reduziu ao longo da primeira etapa de ajuste, etapa essa responsável pela determinação da base de regras de inferência, é apresentada por meio da Figura 5.68.

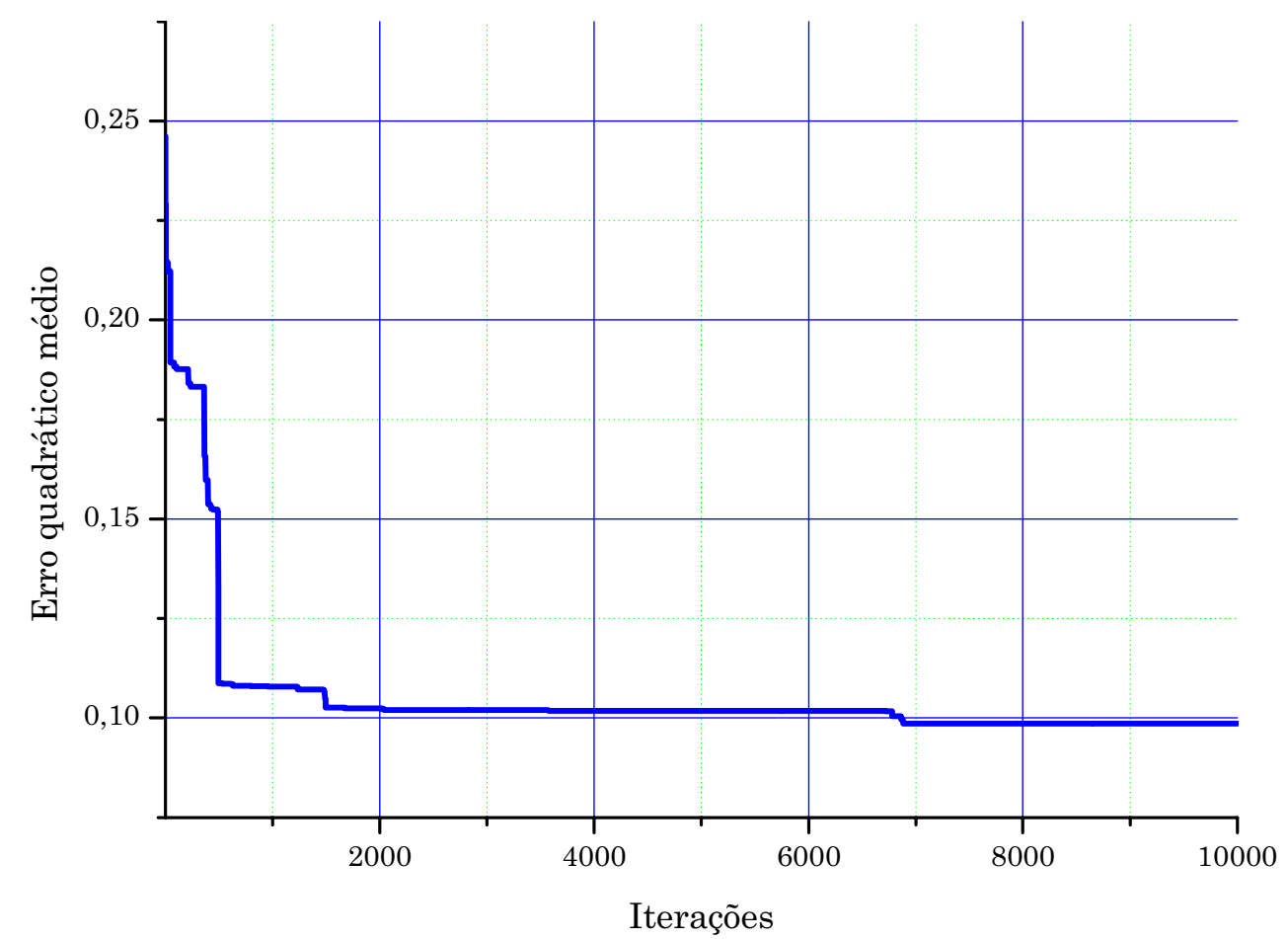

Figura 5.68 - Comportamento do erro quadrático médio ao longo das iterações da primeira etapa de ajuste do sistema de inferência fuzzy para identificação da Fase C.

Por meio do gráfico da Figura 5.68 é possível verificar que a base de regras responsável por identificar a Fase C quando essa participar da ocorrência de uma falta faseterra rapidamente fora determinada. Essa rápida determinação reflete a eficiência do algoritmo desenvolvido e a grande correlação entre as variáveis empregadas para o objetivo proposto. Ao término da primeira etapa de ajuste, a base de regras determinada fora aquela apresentada por meio da Figura 5.69. 


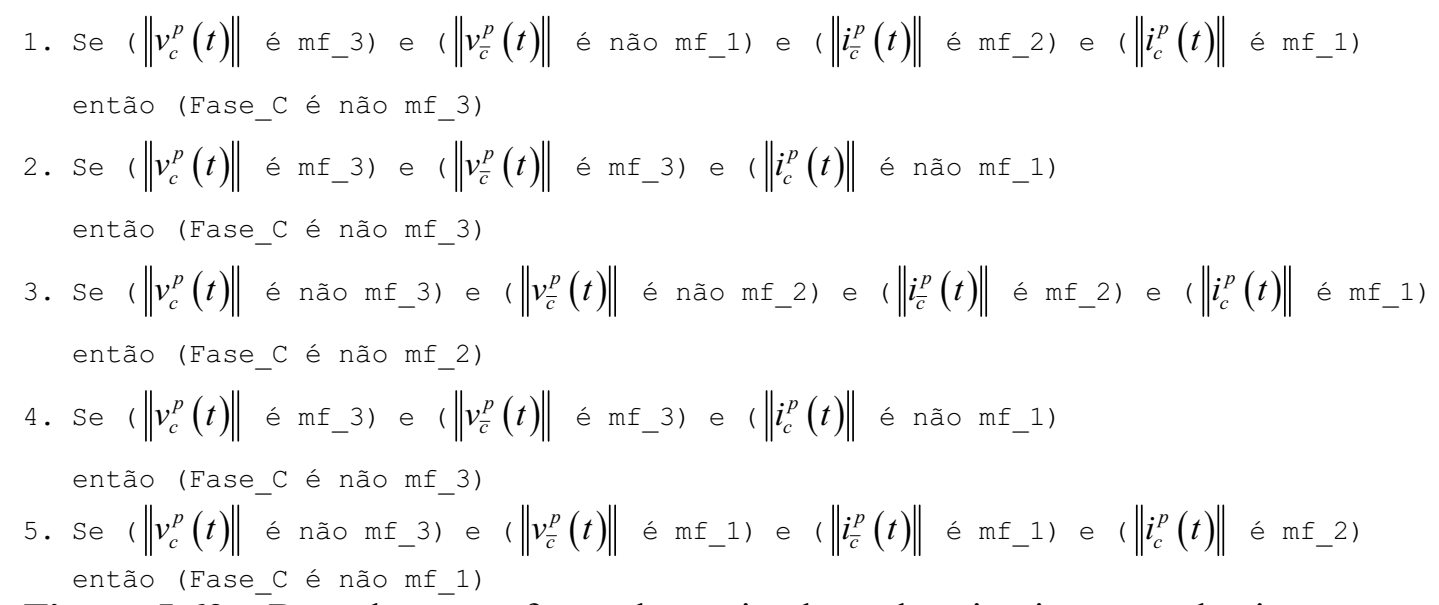

Figura 5.69 - Base de regras fuzzy determinadas pela primeira etapa de ajuste para o sistema identificador para a Fase C.

Após o término da primeira etapa de ajuste, o qual culminou na base de regras apresentadas por meio da Figura 5.69, o sistema de inferência fuzzy fora ajustado de forma paramétrica, ou seja, os parâmetros das funções de pertinência e a ponderação das regras de inferência foram ajustados de forma a conferir uma maior redução do erro quadrático médio. A Figura 5.70 apresenta como o erro quadrático médio evoluiu iteração a iteração ao longo da segunda etapa de ajuste.

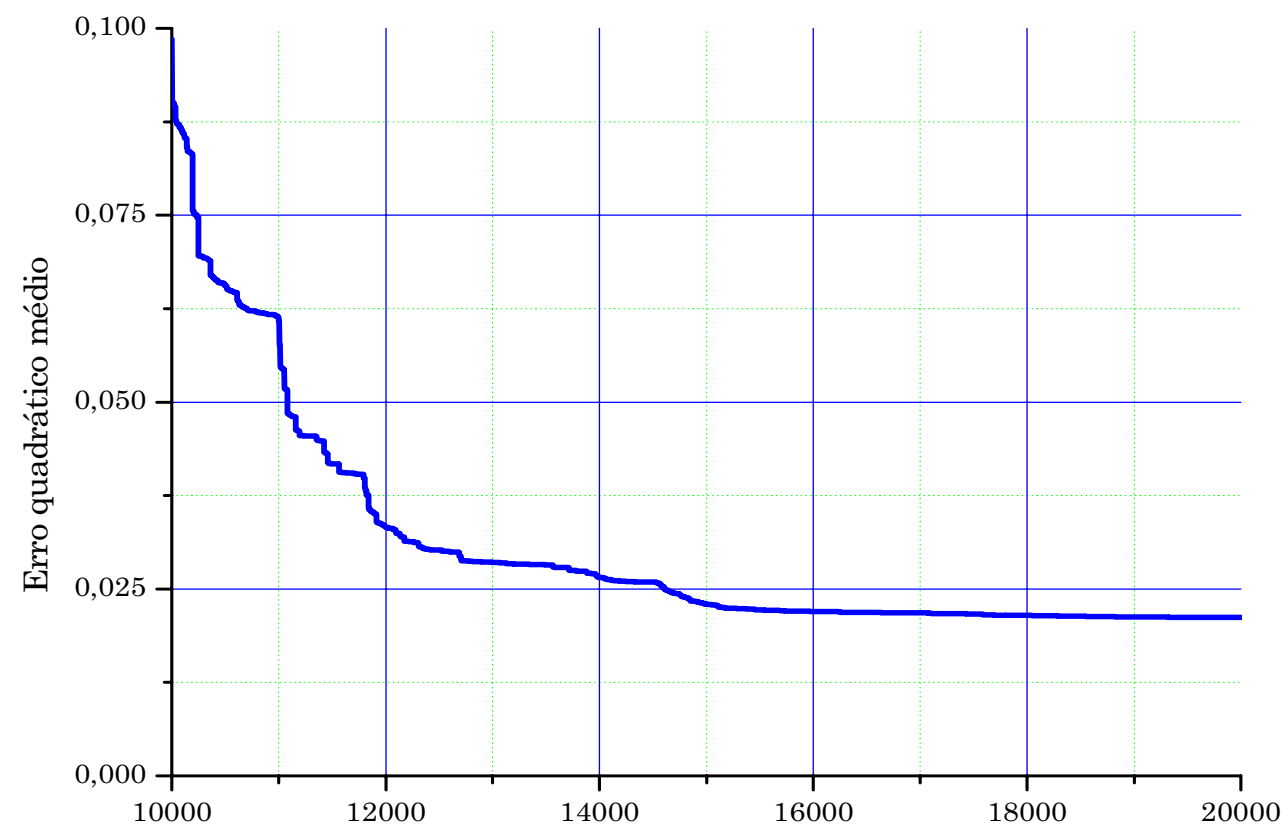

Iterações

Figura 5.70 - Comportamento do erro quadrático médio ao longo das iterações da segunda etapa de ajuste do sistema de inferência fuzzy para identificação da Fase C.

Conforme é possível verificar por meio do gráfico da Figura 5.70, o erro quadrático médio ao término da segunda etapa de ajuste fora cerca de três vezes inferior àquele observado no início do processo. Retratando a forma pela qual as funções de 
pertinência foram ajustadas pela segunda etapa, apresenta-se por meio da Figura 5.71 os gráficos das funções de pertinência constituintes do espaço de entrada do sistema fuzzy. $\mathrm{Na}$ Figura 5.72 apresenta-se as funções de pertinência contida no universo de discurso da saída.
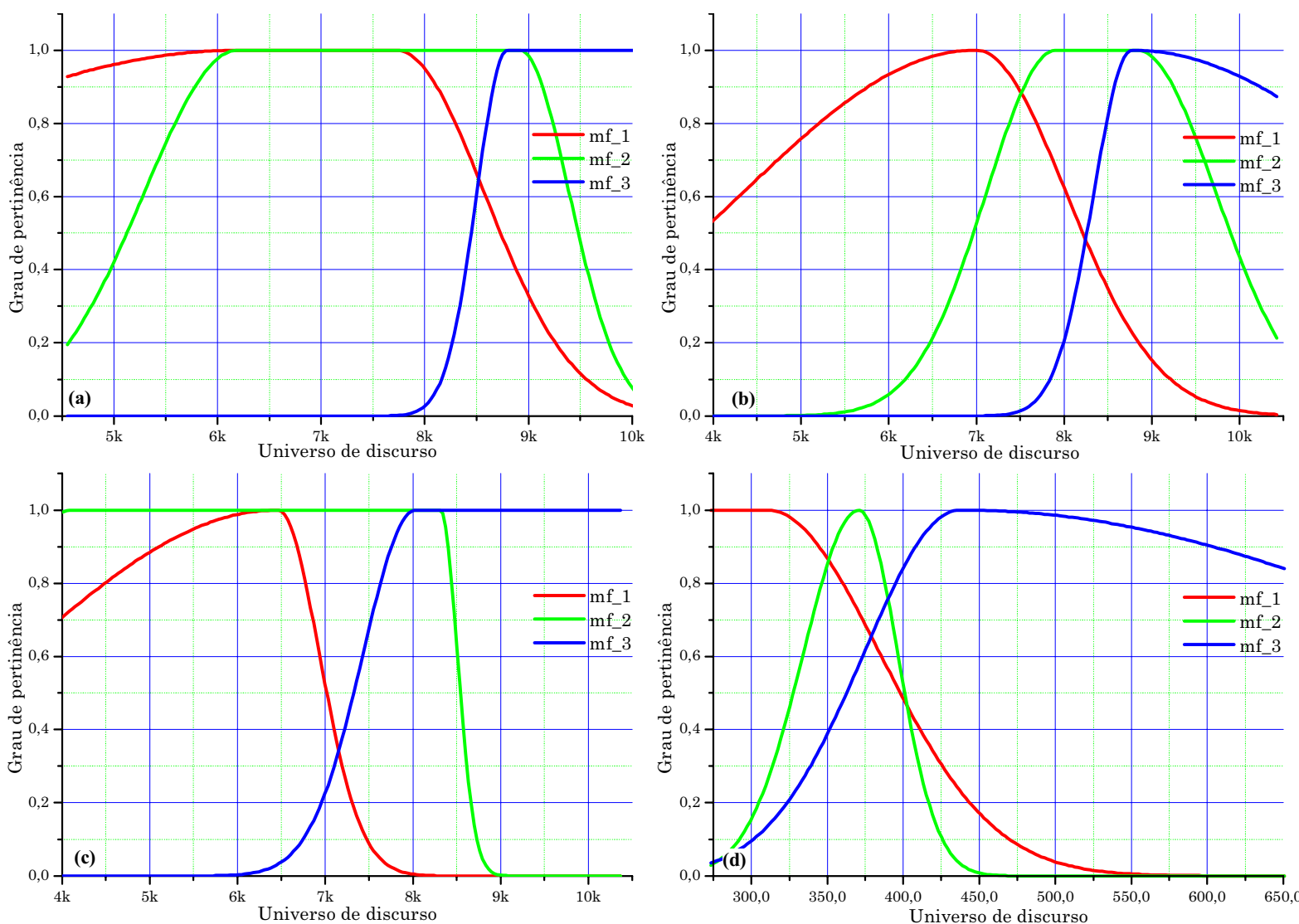

Figura 5.71 - Funções de pertinência para as entradas do sistema fuzzy identificador da Fase C; (a) Funções de pertinência para a variável $\left\|v_{c}^{p}(t)\right\|$; (b) Funções de pertinência para a variável $\left\|\nu_{\bar{c}}^{p}(t)\right\|$; (c) Funções de pertinência para a variável $\left\|i_{\bar{c}}^{p}(t)\right\|$; (d) Funções de pertinência para a variável $\left\|i_{c}^{p}(t)\right\|$;

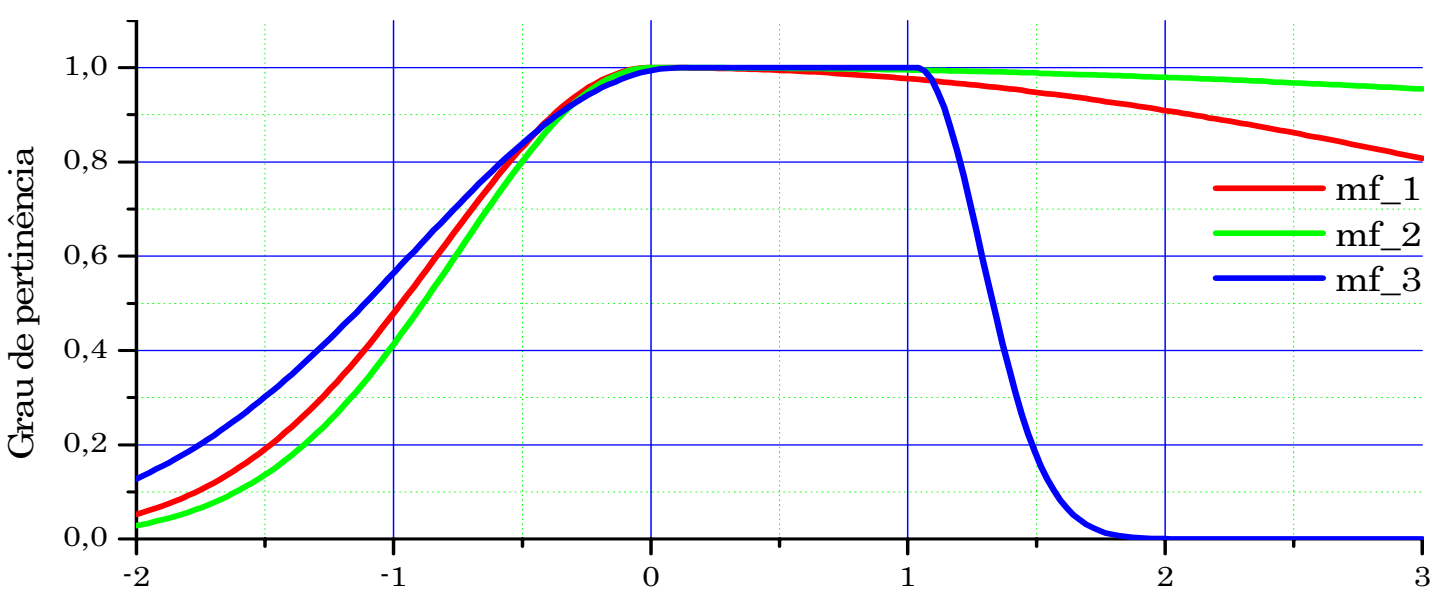

Universo de discurso

Figura 5.72 - Funções de pertinência para o universo de discurso da saída do sistema fuzzy identificador da Fase C. 
Complementando a apresentação do sistema fuzzy empregado para identificação da Fase C quando essa participar de uma falta fase-terra, tem-se na Tabela 5.27 as ponderações atribuídas a cada uma das regras destacadas na Figura 5.69.

Tabela 5.27 - Ponderação das regras fuzzy.

\begin{tabular}{lr}
\hline \hline Índice & Ponderação \\
\hline \hline 1 & 0.4607 \\
\hline 2 & 0.0002 \\
\hline 3 & 947.1593 \\
\hline 4 & 1919.2908 \\
\hline 5 & 0.0010 \\
\hline
\end{tabular}

A implementação do ajuste do sistema fuzzy fora feito tendo auxílio de um conjunto de teste com dimensão reduzida se comparado com o todo disponível. A fim de validar o comportamento do sistema fuzzy apresentado nessa subseção, o mesmo fora testado para todas as simulações disponíveis, ou seja, 3000 condições de falta. Como resultado do processo de identificação da Fase $\mathrm{C}$, como participante de uma falta, o sistema fuzzy respondeu com acerto de $100 \%$ dos casos, o que destaca a eficiência do sistema fuzzy na execução da tarefa.

\subsection{CONSIDERAÇÕES SOBRE O SISTEMA IDENTIFICADOR DE FALTAS E Discriminador da FASE PARTICIPANTE}

Ao longo desse capítulo foram apresentados os desenvolvimentos realizados para a elaboração do sistema identificador de faltas do tipo fase-terra e dos sistemas discriminadores de fase participante da falta. Inicialmente, por meio da Figura 5.2, fora proposto um modelo geral para os sistemas almejados. Esse sistema como um todo foi foco desse capítulo onde, por meio das seções constituintes, os detalhes envolvidos foram abordados.

Por meio dos resultados apresentados, podem-se tecer algumas observações preliminares. Como primeira colocação, tem-se a forma pela qual as componentes ortogonais podem proferir dados de grande valia, tanto para a identificação de faltas, como para a discriminação da fase participante dessa. Além disso, os sistemas fuzzy, valendo-se do algoritmo proposto para seu ajuste, desempenharam as tarefas conferidas de maneira coerente e adequada. Assim, no quesito identificação, os sistemas de inferência fuzzy ajustados pela técnica desenvolvida se mostraram eficientes. Com relação ao quesito mapeamento de 
funções, esse será verificado no próximo capítulo, onde se fará a estimação da distância de ocorrência da falta, ora identificada, bem como será conduzida a estimação da resistência de falta da mesma. 


\section{APÍTULO 6}

\section{Sistema PARA LoCAlizaÇão de Faltas e Sistema Para EstimaÇão DA RESISTÊNCIA DE FALTA}

\subsection{INTRODUÇÃO}

A identificação de faltas de alta impedância é de fundamental importância na operação de um sistema de distribuição de energia elétrica visto que diante dessa ocorrência se encontram comprometidas, em primeira instância, a segurança de pessoas, animais e construções civis e, em segunda instância, a qualidade do fornecimento da energia elétrica. Os aspectos da identificação, bem como a discriminação da fase participante da falta foram focos do Capítulo 5. No entanto, a identificação da ocorrência de uma falta de natureza fase-terra decorre na interrupção do fornecimento de energia elétrica à todos, ou em parte, dos consumidores conectados ao alimentador possuidor da falta. Essa interrupção do fornecimento se faz necessária a fim de que a segurança do fornecimento e sua qualidade não mais sejam prejudicadas.

Ocorrendo a identificação da falta e a posterior interrupção do fornecimento, as equipes de manutenção são acionadas a fim de localizar o ponto de ocorrência da falta e proceder com os reparos necessários. Uma vez que essas tarefas estejam concluídas se pode proceder com o restabelecimento do fornecimento de energia elétrica. No entanto, a localização do ponto de ocorrência da falta, em grande parte dos casos, é realizada por meio 
de inspeção visual e a estimativa inicial sobre o local de onde se iniciar essa busca é baseada na experiência do corpo técnico da operação e manutenção do sistema de distribuição. Assim, o emprego dessa metodologia convencional pode decorrer, em muitos casos, num tempo de restabelecimento alto o suficiente para provocar incômodos aos consumidores residenciais e prejuízos de ordem econômica aos consumidores comerciais e industriais.

Faz-se, portanto, necessário o desenvolvimento de técnicas que auxiliem na localização dos potenciais pontos onde a falta ocorrera a fim de minimizar o tempo de restabelecimento do fornecimento de energia elétrica. Focando tal necessidade, esse capítulo se desenvolve e, não apenas focando na localização da falta, mas também determinando a possível resistência de falta. A estimação da resistência de falta tem por meta auxiliar na identificação do ponto de ocorrência de falta, pois, mesmo diante dos prováveis pontos de ocorrência da falta, a inspeção visual ainda se faz necessária e, com auxílio da resistência de falta estimada, se pode inferir sobre as prováveis causas dessa ocorrência.

Assim, para fins de uma visão ampla dos desenvolvimentos a serem realizados, por meio da Figura 6.1, apresenta-se o diagrama esquemático do sistema localizador de faltas e de estimação da resistência de falta propostos.

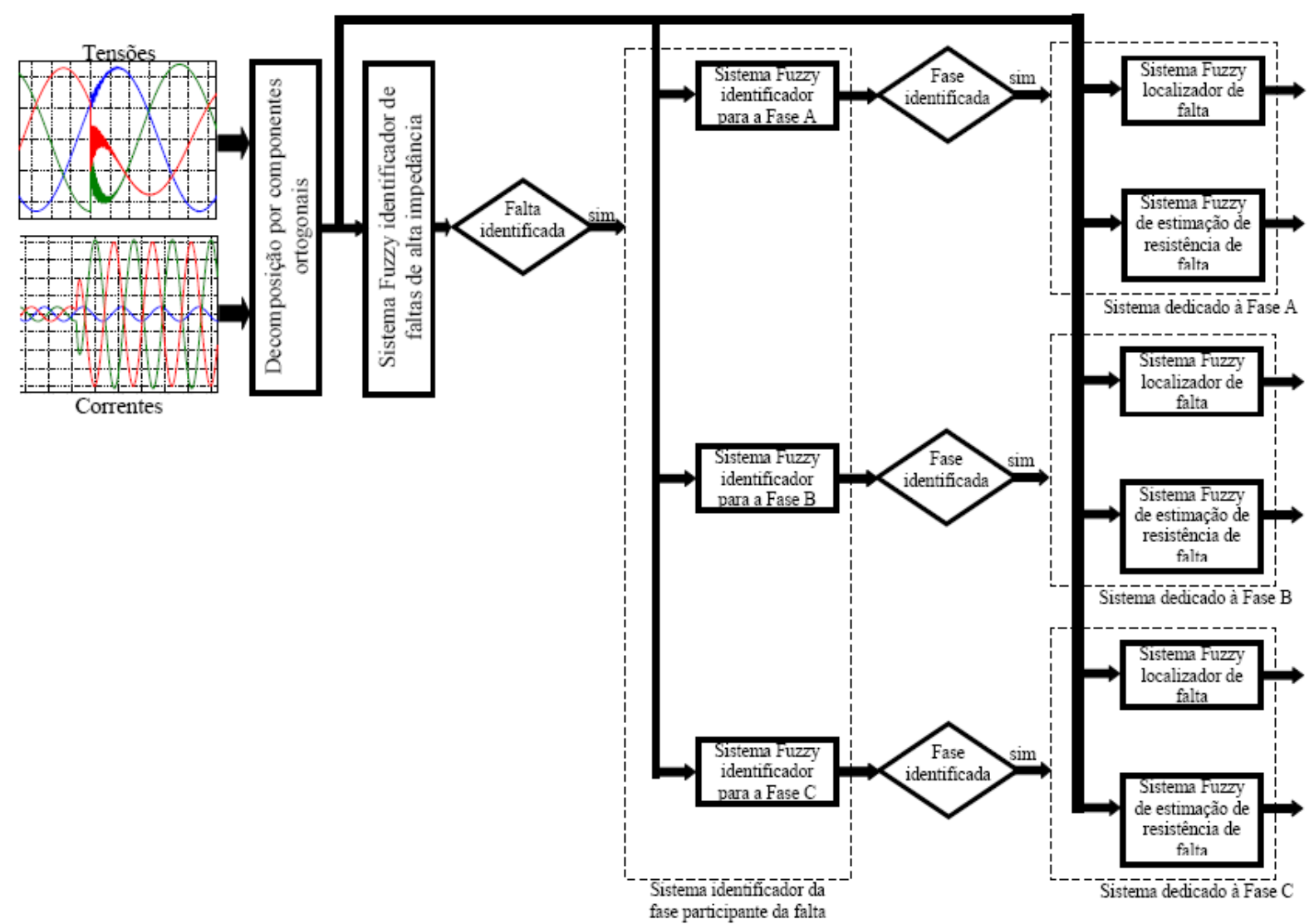

Figura 6.1 - Diagrama esquemático para o sistema localizador de faltas e de estimação da resistência de falta. 


\subsection{SiSTEMA de INFERÊNCIA FUZZY PARA LOCALIZAÇÃo dE FALTAS}

As possíveis causas para a ocorrência de faltas em sistemas elétricos de potência são inúmeras e as variáveis que culminam na mesma são tantas que a grande maioria dessas faltas pode ser interpretada como sendo de origem aleatória. Assim, mesmo diante de ações preventivas, como aquelas praticadas pela equipe técnica de manutenção, os fatores que resultam em uma condição faltosa não são passíveis de sua plena eliminação. Um exemplo de fatores que não podem ser completamente contornados são aqueles de origem climática e que sabidamente estão presentes em um número expressivo de faltas em sistemas elétricos de potência.

Sendo a eliminação de todos os fatores que decorrem em condições faltosas impossível, atenção especial deve ser dedicada à localização do ponto de ocorrência da falta, pois assim, a eliminação da condição faltosa pode ser procedida e a condição normal de operação do sistema volte a imperar.

Quando o foco se dá sobre os sistemas de distribuição de energia elétrica, convencionalmente, a localização do ponto de ocorrência de uma falta é realizada pela inspeção visual da rede aérea de distribuição primária, bem como pela verificação da possível atuação dos dispositivos de proteção instalados ao longo da rede de distribuição, tal como anteriormente citado. Essa prática, muito empregada para localização de faltas, não apenas requer avidez da equipe de manutenção de rede como também faz da experiência dessa equipe fator de redução do tempo necessário à localização e, conseqüentemente, melhoria dos indicadores de desempenho do sistema. Esses aspectos motivadores, resumidamente citados nessa seção, foram abordados de maneira mais ampla ainda nos capítulos introdutórios desta tese e reforçados ao longo de todo o texto.

Assim, com o intuito de colaborar com a tarefa de localização do ponto de ocorrência de falta, os sistemas descritos nessa seção, em conjunto com os resultados retratados, foram elaborados e, como referido na introdução desse capítulo, para cada fase um sistema para localização de faltas fora constituído. Dessa maneira, essa seção fora organizada de forma a contemplar na Subseção 6.2.1 o sistema para localização de faltas quando essa ocorrer na Fase A, a localização de faltas na Fase B é tema da Seção 6.2.2, tal como se faz na Subseção 6.2.3 para quando da ocorrência de faltas fase-terra na Fase C. 


\subsubsection{SiSTEMA de INFERÊNCIA FUZZY PARA LOCALIZAÇÃo de FALTAS NA FASE A}

No Capítulo 5, onde foram abordadas a identificação de faltas e a discriminação da fase participante da falta, empregaram-se os valores eficazes das componentes ortogonais como variáveis determinantes da ocorrência ou não de uma falta fase-terra, bem como da fase participante da falta. A localização de faltas também fará uso dessas variáveis, porém, em virtude da tarefa mais complexa que a localização é, não apenas os valores médios das componentes serão testados, mas também seus valores máximos e mínimos durante o intervalo de ocorrência da falta serão verificados quanto à sua correlação com a distância de ocorrência da falta.

Para apresentar como cada componente advinda do resultado da decomposição ortogonal se correlaciona com a distância de ocorrência da falta, apresentam-se por meio da Tabela 6.1 as correlações e os testes de hipótese, que mensuram o quão significativo são as correlações das componentes de tensões contidas na função planar das tensões de linha com a distância de ocorrência da falta quando essa for observada na Fase A. Os valores contidos na Tabela 6.1 são graficamente apresentados por meio da Figura 6.2.

Por meio da Tabela 6.2 se apresentam as correlações das componentes de corrente contidas na função planar das tensões de linha com a distância de ocorrência da falta, assim como por meio da Figura 6.3 se tem a representação gráfica dos valores contidos nessa Tabela.

A correlação das componentes de tensão ortogonais à função planar das tensões de linha com a distância de ocorrência de falta é apresentada na Tabela 6.3 e tais valores para as componentes de corrente ortogonais à função planar das tensões de linha são conteúdo da Tabela 6.4. A representação dos valores expressos na Tabela 6.3 e Tabela 6.4 é realizada por meio da Figura 6.4 e da Figura 6.5, respectivamente. 
Tabela 6.1 - Correlação das componentes de tensão contidas na função planar das tensões de linha com relação à distância de ocorrência de falta na Fase A.

\begin{tabular}{|c|c|c|c|c|c|c|c|}
\hline \multirow[b]{2}{*}{$k$} & \multirow[b]{2}{*}{ Variável } & \multicolumn{2}{|c|}{ Média } & \multicolumn{2}{|c|}{ Máximo } & \multicolumn{2}{|c|}{ Mínimo } \\
\hline & & Correlação & $\begin{array}{l}\text { Teste de } \\
\text { hipótese }\end{array}$ & Correlação & $\begin{array}{l}\text { Teste de } \\
\text { hipótese } \\
\end{array}$ & Correlação & $\begin{array}{l}\text { Teste de } \\
\text { hipótese }\end{array}$ \\
\hline 1 & $\left\|v_{a}^{p}(t)\right\|$ & 0,0990 & 0,0020 & 0,1515 & 0,0000 & 0,1083 & 0,0007 \\
\hline 2 & $\left\|v_{b}^{p}(t)\right\|$ & 0,2242 & 0,0000 & 0,2108 & 0,0000 & 0,0122 & 0,7045 \\
\hline 3 & $\left\|v_{c}^{p}(t)\right\|$ & 0,0507 & 0,1135 & 0,0536 & 0,0946 & 0,0122 & 0,7048 \\
\hline 4 & $\left\|v_{n}^{p}(t)\right\|$ & 0,1109 & 0,0005 & 0,1112 & 0,0005 & 0,0114 & 0,7214 \\
\hline 5 & $\left\|v_{a}^{q^{\prime \prime}}(t)\right\|$ & 0,4970 & 0,0000 & 0,2999 & 0,0000 & 0,6844 & 0,0000 \\
\hline 6 & $\left\|v_{b}^{q^{\| \prime}}(t)\right\|$ & 0,0441 & 0,1691 & 0,0549 & 0,0867 & 0,3495 & 0,0000 \\
\hline 7 & $\left\|v_{c}^{q^{\|}}(t)\right\|$ & 0,0945 & 0,0032 & 0,1031 & 0,0013 & 0,5274 & 0,0000 \\
\hline 8 & $\left\|v_{n}^{q^{\|}}(t)\right\|$ & 0,0996 & 0,0019 & 0,0574 & 0,0733 & 0,0404 & 0,2078 \\
\hline 9 & $\left\|v_{a}^{q^{\perp}}(t)\right\|$ & 0,1595 & 0,0000 & 0,1231 & 0,0001 & 0,0151 & 0,6385 \\
\hline 10 & $\left\|v_{b}^{q^{\perp}}(t)\right\|$ & 0,0890 & 0,0054 & 0,1087 & 0,0007 & 0,2364 & 0,0000 \\
\hline 11 & $\left\|v_{c}^{q^{\perp}}(t)\right\|$ & 0,2862 & 0,0000 & 0,3038 & 0,0000 & 0,3699 & 0,0000 \\
\hline 12 & $\left\|v_{n}^{q^{\perp}}(t)\right\|$ & 0,1661 & 0,0000 & 0,1115 & 0,0005 & 0,0617 & 0,0542 \\
\hline 13 & $\left\|v_{a}^{d}(t)\right\|$ & 0,1595 & 0,0000 & 0,1231 & 0,0001 & 0,0542 & 0,0911 \\
\hline 14 & $\left\|v_{b}^{d}(t)\right\|$ & 0,0890 & 0,0054 & 0,1087 & 0,0007 & 0,2227 & 0,0000 \\
\hline 15 & $\left\|v_{c}^{d}(t)\right\|$ & 0,2862 & 0,0000 & 0,3038 & 0,0000 & 0,3642 & 0,0000 \\
\hline 16 & $\left\|v_{n}^{d}(t)\right\|$ & 0,1661 & 0,0000 & 0,1115 & 0,0005 & 0,0638 & 0,0465 \\
\hline
\end{tabular}
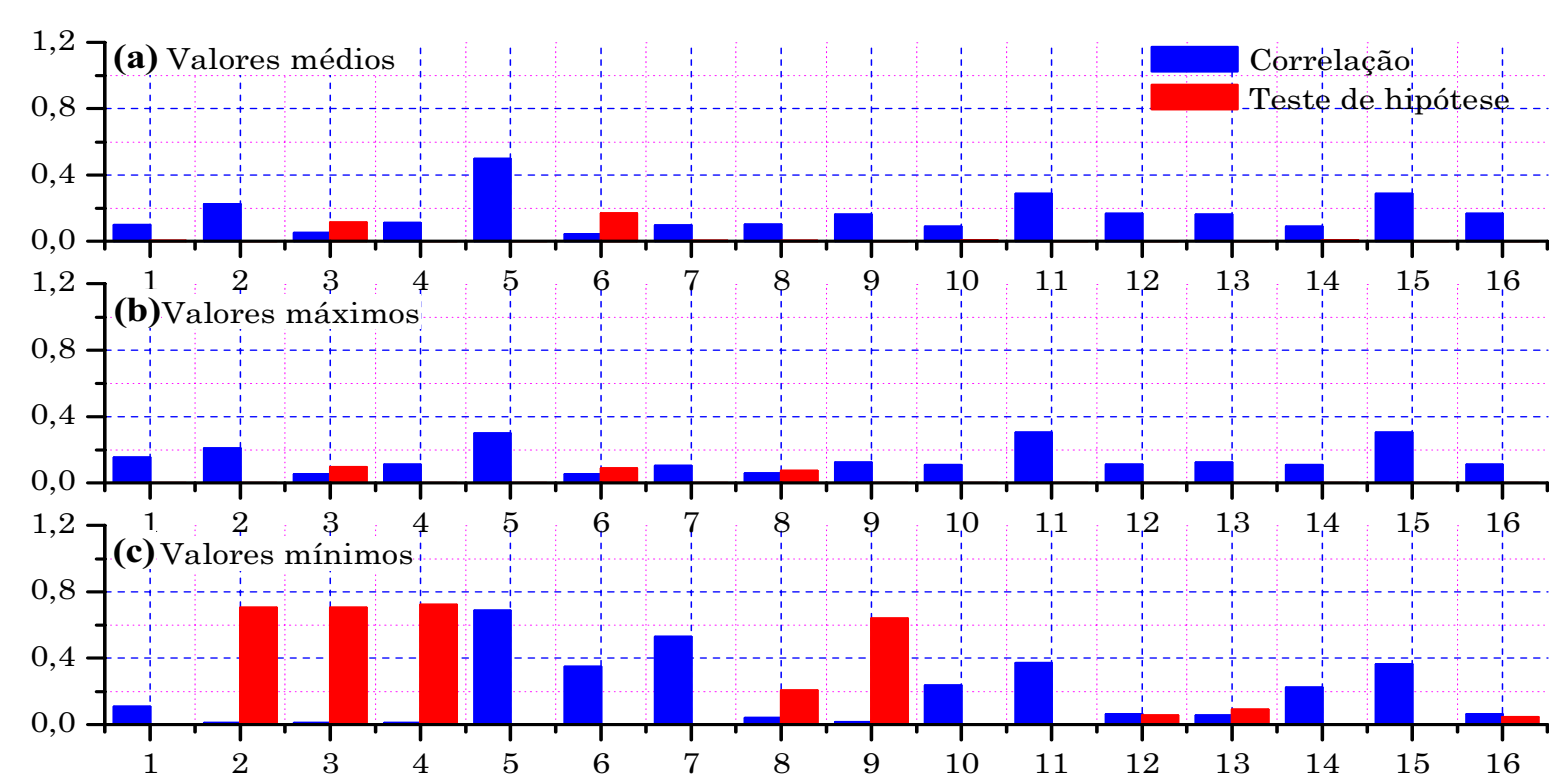

Variável (índice)

Figura 6.2 - Correlação e teste de hipótese para as componentes de tensão contidas na função planar das tensões de linha com a distância de ocorrência de falta na Fase A; (a) Correlação e teste de hipótese para os valores médios; (b) Correlação e teste de hipótese para os valores máximos; (c) Correlação e teste de hipótese para os valores mínimos. 
Tabela 6.2 - Correlação das componentes de corrente contidas na função planar das tensões de linha com relação à distância de ocorrência de falta na Fase A.

\begin{tabular}{|c|c|c|c|c|c|c|c|}
\hline \multirow[b]{2}{*}{$k$} & \multirow[b]{2}{*}{ Variável } & \multicolumn{2}{|c|}{ Média } & \multicolumn{2}{|c|}{ Máximo } & \multicolumn{2}{|c|}{ Mínimo } \\
\hline & & Correlação & $\begin{array}{l}\text { Teste de } \\
\text { hipótese } \\
\end{array}$ & Correlação & $\begin{array}{l}\text { Teste de } \\
\text { hipótese } \\
\end{array}$ & Correlação & $\begin{array}{l}\text { Teste de } \\
\text { hipótese }\end{array}$ \\
\hline 1 & $\left\|i_{a}^{p}(t)\right\|$ & 0,1462 & 0,0000 & 0,0470 & 0,1425 & 0,0549 & 0,0869 \\
\hline 2 & $\left\|i_{b}^{p}(t)\right\|$ & 0,0441 & 0,1689 & 0,0164 & 0,6083 & 0,0321 & 0,3163 \\
\hline 3 & $\left\|i_{c}^{p}(t)\right\|$ & 0,0162 & 0,6126 & 0,0208 & 0,5166 & 0,0511 & 0,1108 \\
\hline 4 & $\left\|i_{n}^{p}(t)\right\|$ & 0,1109 & 0,0005 & 0,1111 & 0,0005 & 0,0281 & 0,3802 \\
\hline 5 & $\left\|i_{a}^{q^{\|}}(t)\right\|$ & 0,2640 & 0,0000 & 0,0180 & 0,5741 & 0,6244 & 0,0000 \\
\hline 6 & $\left\|i_{b}^{q^{\|}}(t)\right\|$ & 0,0366 & 0,2535 & 0,0448 & 0,1622 & 0,3537 & 0,0000 \\
\hline 7 & $\left\|i_{c}^{q^{\|}}(t)\right\|$ & 0,1007 & 0,0016 & 0,1105 & 0,0006 & 0,5205 & 0,0000 \\
\hline 8 & $\left\|i_{n}^{q^{\| \prime}}(t)\right\|$ & 0,1013 & 0,0015 & 0,0600 & 0,0612 & 0,0123 & 0,7013 \\
\hline 9 & $\left\|i_{a}^{q^{\perp}}(t)\right\|$ & 0,2071 & 0,0000 & 0,2037 & 0,0000 & 0,4942 & 0,0000 \\
\hline 10 & $\left\|i_{b}^{q^{\perp}}(t)\right\|$ & 0,4086 & 0,0000 & 0,4228 & 0,0000 & 0,0000 & 1,0000 \\
\hline 11 & $\left\|i_{c}^{q^{\perp}}(t)\right\|$ & 0,3892 & 0,0000 & 0,3840 & 0,0000 & 0,0000 & 1,0000 \\
\hline 12 & $\left\|i_{n}^{q^{\perp}}(t)\right\|$ & 0,1526 & 0,0000 & 0,1019 & 0,0015 & 0,0448 & 0,1622 \\
\hline 13 & $\left\|i_{a}^{d}(t)\right\|$ & 0,2070 & 0,0000 & 0,2037 & 0,0000 & 0,4485 & 0,0000 \\
\hline 14 & $\left\|i_{b}^{d}(t)\right\|$ & 0,0581 & 0,0698 & 0,0208 & 0,5175 & 0,0000 & 1,0000 \\
\hline 15 & $\left\|i_{c}^{d}(t)\right\|$ & 0,0807 & 0,0118 & 0,0274 & 0,3922 & 0,0000 & 1,0000 \\
\hline 16 & $\left\|i_{n}^{d}(t)\right\|$ & 0,1526 & 0,0000 & 0,1019 & 0,0015 & 0,0447 & 0,1635 \\
\hline
\end{tabular}

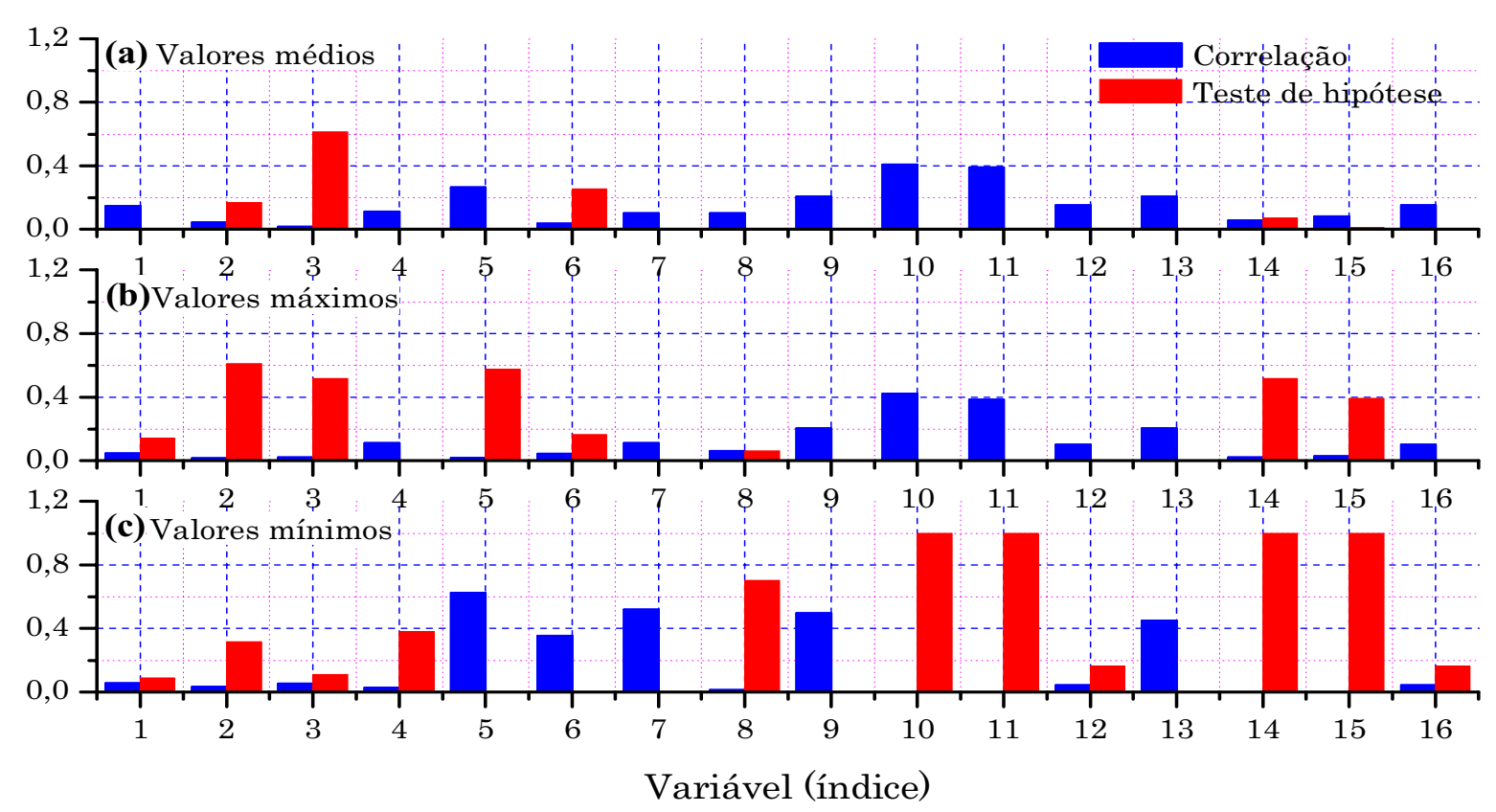

Figura 6.3 - Correlação e teste de hipótese para as componentes de corrente contidas na função planar das tensões de linha com a distância de ocorrência de falta na Fase A; (a) Correlação e teste de hipótese para os valores médios; (b) Correlação e teste de hipótese para os valores máximos; (c) Correlação e teste de hipótese para os valores mínimos. 
Tabela 6.3 - Correlação das componentes de tensão ortogonais à função planar das tensões de linha com relação à distância de ocorrência de falta na Fase A.

\begin{tabular}{|c|c|c|c|c|c|c|c|}
\hline \multirow[b]{2}{*}{$k$} & \multirow[b]{2}{*}{ Variável } & \multicolumn{2}{|c|}{ Média } & \multicolumn{2}{|c|}{ Máximo } & \multicolumn{2}{|c|}{ Mínimo } \\
\hline & & Correlação & $\begin{array}{l}\text { Teste de } \\
\text { hipótese }\end{array}$ & Correlação & $\begin{array}{l}\text { Teste de } \\
\text { hipótese }\end{array}$ & Correlação & $\begin{array}{l}\text { Teste de } \\
\text { hipótese }\end{array}$ \\
\hline 1 & $\left\|v_{\bar{a}}^{p}(t)\right\|$ & 0,1156 & 0,0003 & 0,0396 & 0,2166 & 0,1153 & 0,0003 \\
\hline 2 & $\left\|v_{\bar{b}}^{\frac{p}{b}}(t)\right\|$ & 0,1896 & 0,0000 & 0,1827 & 0,0000 & 0,0291 & 0,3636 \\
\hline 3 & $\left\|v_{\bar{c}}^{p}(t)\right\|$ & 0,0619 & 0,0534 & 0,0626 & 0,0508 & 0,0021 & 0,9489 \\
\hline 4 & $\left\|v_{h}^{p}(t)\right\|$ & 0,1122 & 0,0005 & 0,1124 & 0,0004 & 0,0109 & 0,7346 \\
\hline 5 & $\left\|v_{\bar{a}}^{q^{\| \prime}}(t)\right\|$ & 0,1459 & 0,0000 & 0,1361 & 0,0000 & 0,0315 & 0,3260 \\
\hline 6 & $\left\|v q^{q^{\prime \prime}}(t)\right\|$ & 0,0980 & 0,0022 & 0,0574 & 0,0735 & 0,1281 & 0,0001 \\
\hline 7 & $\left\|v_{\bar{c}}^{q^{\prime \prime}}(t)\right\|$ & 0,0312 & 0,3312 & 0,0163 & 0,6105 & 0,1304 & 0,0000 \\
\hline 8 & $\left\|v_{h}^{q^{\|}}(t)\right\|$ & 0,0656 & 0,0408 & 0,0476 & 0,1379 & 0,4452 & 0,0000 \\
\hline 9 & $\left\|v_{\bar{a}}^{q^{\perp}}(t)\right\|$ & 0,1936 & 0,0000 & 0,2243 & 0,0000 & 0,4165 & 0,0000 \\
\hline 10 & $\left\|v \frac{q^{\perp}}{b}(t)\right\|$ & 0,2683 & 0,0000 & 0,2282 & 0,0000 & 0,0000 & 1,0000 \\
\hline 11 & $\left\|v_{\frac{q^{\perp}}{c}}(t)\right\|$ & 0,2985 & 0,0000 & 0,2582 & 0,0000 & 0,0000 & 1,0000 \\
\hline 12 & $\left\|v_{h}^{q^{\perp}}(t)\right\|$ & 0,0890 & 0,0055 & 0,0762 & 0,0174 & 0,1651 & 0,0000 \\
\hline 13 & $\left\|v_{\bar{a}}^{d}(t)\right\|$ & 0,1936 & 0,0000 & 0,2243 & 0,0000 & 0,4788 & 0,0000 \\
\hline 14 & $\left\|v_{\bar{b}}^{d}(t)\right\|$ & 0,1777 & 0,0000 & 0,0762 & 0,0173 & 0,1150 & 0,0003 \\
\hline 15 & $\left\|v_{\bar{c}}^{d}(t)\right\|$ & 0,1830 & 0,0000 & 0,0846 & 0,0083 & 0,2421 & 0,0000 \\
\hline & $\left\|v_{h}^{d}(t)\right\|$ & 0,0890 & 0,0055 & 0,0762 & 0,0174 & 0,1848 & 0,0000 \\
\hline
\end{tabular}
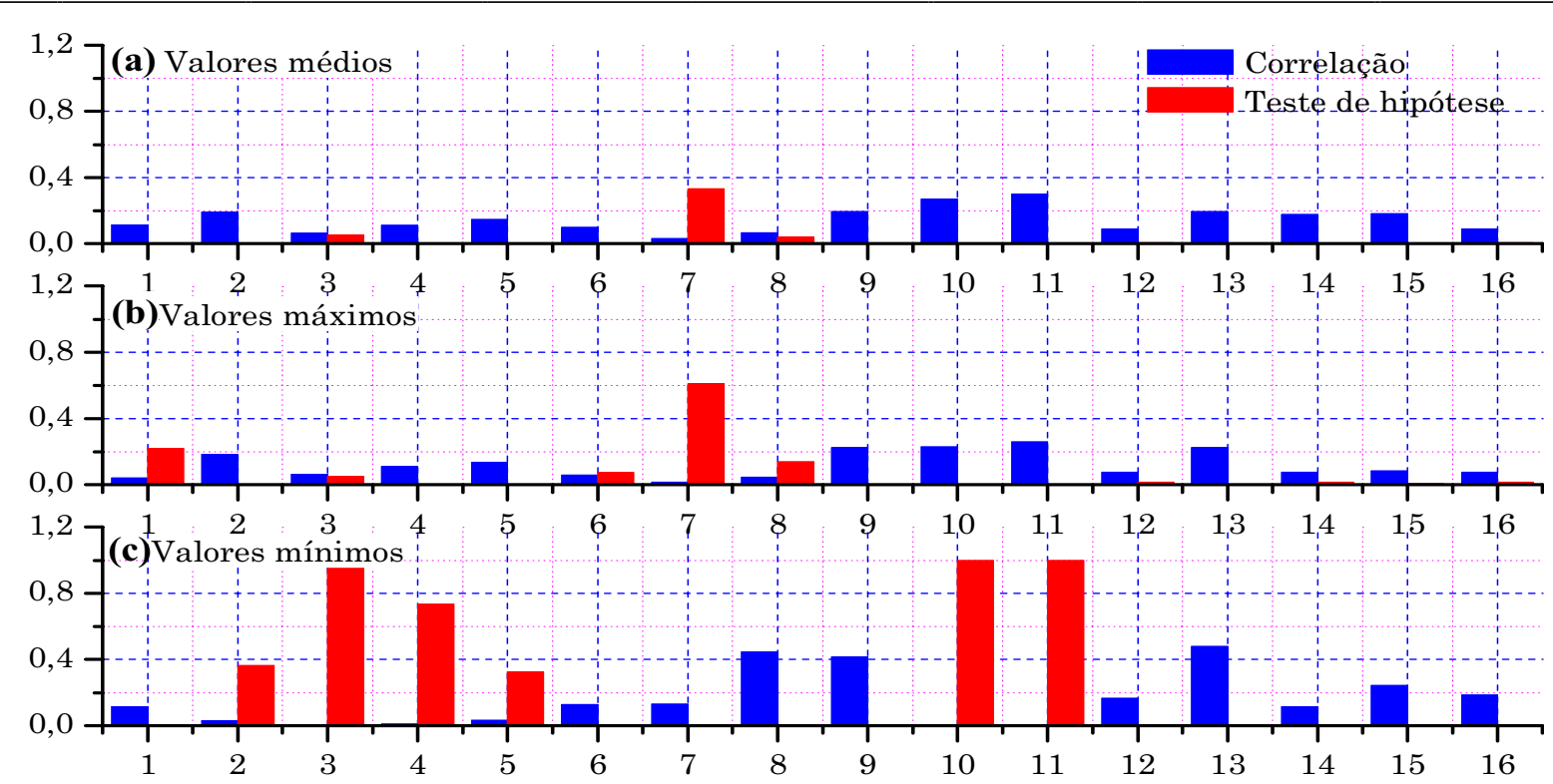

Variável (índice)

Figura 6.4 - Correlação e teste de hipótese para as componentes de tensão ortogonais à função planar das tensões de linha com a distância de ocorrência de falta na Fase A; (a) Correlação e teste de hipótese para os valores médios; (b) Correlação e teste de hipótese para os valores máximos; (c) Correlação e teste de hipótese para os valores mínimos. 
Tabela 6.4 - Correlação das componentes de corrente ortogonais à função planar das tensões de linha com relação à distância de ocorrência de falta na Fase A.

\begin{tabular}{|c|c|c|c|c|c|c|c|}
\hline \multirow[b]{2}{*}{$k$} & \multirow[b]{2}{*}{ Variável } & \multicolumn{2}{|c|}{ Média } & \multicolumn{2}{|c|}{ Máximo } & \multicolumn{2}{|c|}{ Mínimo } \\
\hline & & Correlação & $\begin{array}{l}\text { Teste de } \\
\text { hipótese } \\
\end{array}$ & Correlação & $\begin{array}{l}\text { Teste de } \\
\text { hipótese } \\
\end{array}$ & Correlação & $\begin{array}{l}\text { Teste de } \\
\text { hipótese }\end{array}$ \\
\hline 1 & $\left\|i_{\bar{a}}^{p}(t)\right\|$ & 0,1158 & 0,0003 & 0,0434 & 0,1756 & 0,1196 & 0,0002 \\
\hline 2 & $\left\|i_{\frac{p}{b}}^{p}(t)\right\|$ & 0,1897 & 0,0000 & 0,1896 & 0,0000 & 0,0103 & 0,7491 \\
\hline 3 & $\left\|i_{\frac{1}{c}}^{p}(t)\right\|$ & 0,0613 & 0,0557 & 0,0692 & 0,0308 & 0,0313 & 0,3285 \\
\hline 4 & $\left\|i_{h}^{p}(t)\right\|$ & 0,1102 & 0,0006 & 0,1111 & 0,0005 & 0,0810 & 0,0114 \\
\hline 5 & $\left\|i_{a}^{q^{\|}}(t)\right\|$ & 0,0997 & 0,0018 & 0,1458 & 0,0000 & 0,3774 & 0,0000 \\
\hline 6 & $\left\|i^{q^{\prime \prime}}(t)\right\|$ & 0,1010 & 0,0016 & 0,0187 & 0,5609 & 0,1177 & 0,0002 \\
\hline 7 & $\left\|i_{c}^{q^{\|}}(t)\right\|$ & 0,0299 & 0,3505 & 0,0462 & 0,1496 & 0,0658 & 0,0400 \\
\hline 8 & $\left\|i_{h}^{q^{\|}}(t)\right\|$ & 0,0899 & 0,0050 & 0,0732 & 0,0224 & 0,0358 & 0,2641 \\
\hline 9 & $\left\|i_{\bar{a}}^{q^{\perp}}(t)\right\|$ & 0,2686 & 0,0000 & 0,2159 & 0,0000 & 0,0000 & 1,0000 \\
\hline 10 & $\left\|i \frac{q^{\perp}}{b}(t)\right\|$ & 0,1671 & 0,0000 & 0,1606 & 0,0000 & 0,1840 & 0,0000 \\
\hline 11 & $\left\|i_{c}^{q^{\perp}}(t)\right\|$ & 0,2815 & 0,0000 & 0,2382 & 0,0000 & 0,0000 & 1,0000 \\
\hline 12 & $\left\|i_{h}^{q^{\perp}}(t)\right\|$ & 0,0274 & 0,3930 & 0,0781 & 0,0147 & 0,0498 & 0,1202 \\
\hline 13 & $\left\|i_{\bar{a}}^{d}(t)\right\|$ & 0,1890 & 0,0000 & 0,0932 & 0,0036 & 0,0300 & 0,3503 \\
\hline 14 & $\left\|i_{\bar{b}}^{d}(t)\right\|$ & 0,1670 & 0,0000 & 0,1605 & 0,0000 & 0,2422 & 0,0000 \\
\hline 15 & $\left\|i_{\bar{c}}^{d}(t)\right\|$ & 0,1743 & 0,0000 & 0,0956 & 0,0028 & 0,2640 & 0,0000 \\
\hline 16 & $\left\|i_{h}^{d}(t)\right\|$ & 0,0274 & 0,3934 & 0,0781 & 0,0147 & 0,0552 & 0,0851 \\
\hline
\end{tabular}
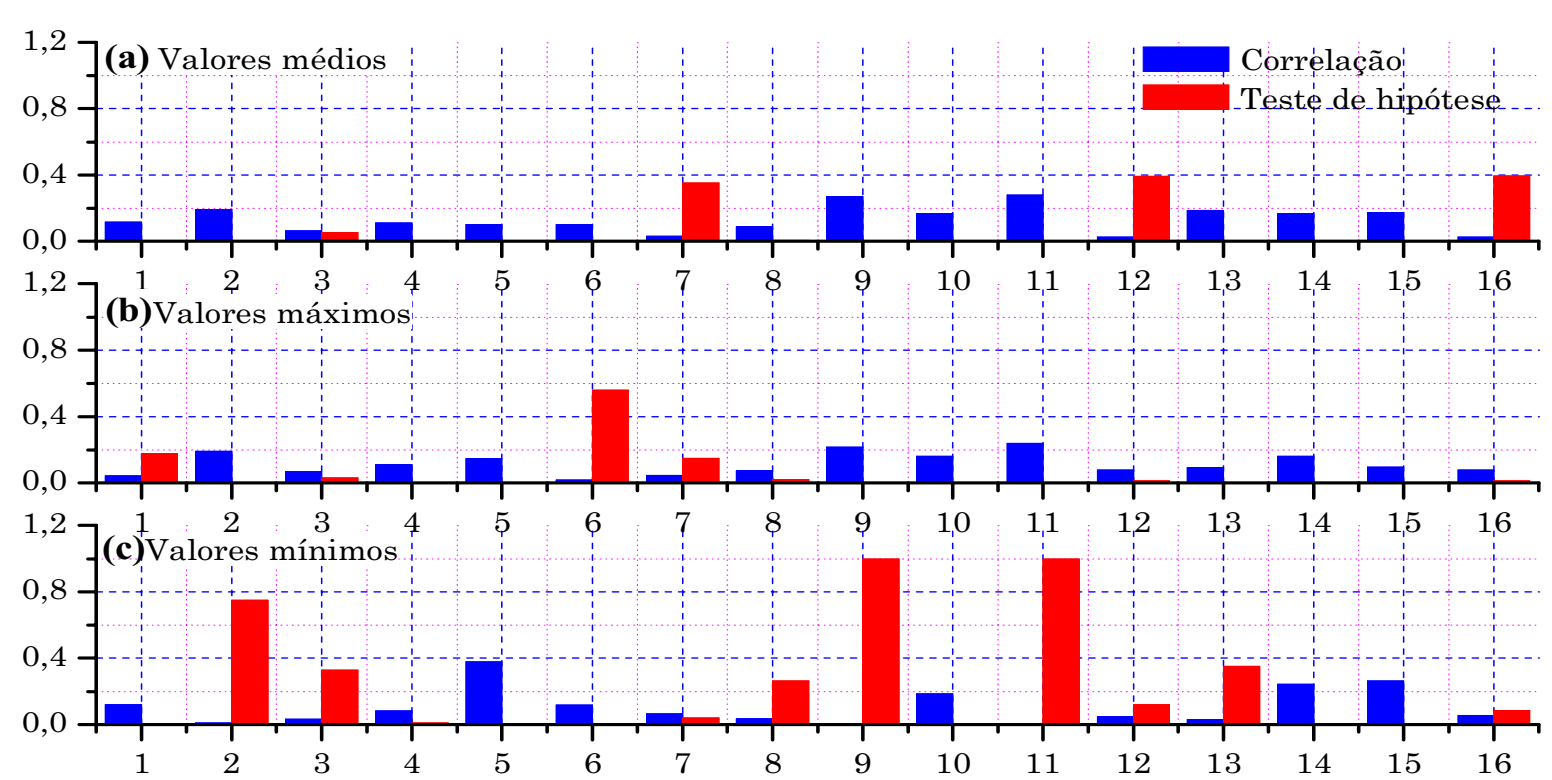

Variável (índice)

Figura 6.5 - Correlação e teste de hipótese para as componentes de corrente ortogonais à função planar das tensões de linha com a distância de ocorrência de falta na Fase A; (a) Correlação e teste de hipótese para os valores médios; (b) Correlação e teste de hipótese para os valores máximos; (c) Correlação e teste de hipótese para os valores mínimos. 
Por meio dos valores de correlação apresentados nas tabelas anteriores é possível verificar que as doze variáveis mais correlacionadas com a distância de ocorrência de faltas na Fase A são aquelas destacadas na Tabela 6.5, a qual destaca também as referidas correlações. Ao todo foram consideradas doze variáveis, pois com esse número se tem, para o caso da localização de faltas, correlações mínimas muito próximas à 0,4. Esse mínimo valor de correlação se mostrou adequado quando das simulações computacionais preliminares.

Tabela 6.5 - Variáveis mais correlatas à localização de faltas faseterra na Fase A.

\begin{tabular}{|c|c|c|c|c|}
\hline Índice & Variável & Característica & Símbolo & Correlação \\
\hline 1 & $\left\|v_{a}^{q^{\prime}}(t)\right\|$ & Mínimo & $\left\|v_{a}^{q^{\prime}}(t)\right\|^{\min }$ & 0,6844 \\
\hline 2 & $\left\|a_{a}^{q^{\prime \prime}}(t)\right\|$ & Mínimo & \|\|$_{a}^{q^{\prime \prime}}(t) \|^{\min }$ & 0,6244 \\
\hline 3 & $\left\|v_{c}^{q^{\| \prime}}(t)\right\|$ & Mínimo & $\left\|v_{c}^{q^{\prime \prime}}(t)\right\|^{\min }$ & 0,5274 \\
\hline 4 & $\left\|q_{c}^{q^{\prime \prime}}(t)\right\|$ & Mínimo & \|\|$_{c}^{q^{\prime \prime}}(t) \|^{\min }$ & 0,5205 \\
\hline 5 & $\left\|q_{a}^{q^{\prime \prime}}(t)\right\|$ & Médio & $\| \overline{\left\|q_{a}^{\prime \prime}(t)\right\|}$ & 0,4970 \\
\hline 6 & $\left\|q_{a}^{q^{a^{\prime}}}(t)\right\|$ & Mínimo & \|\|$_{a}^{q^{+}}(t) \|^{\min }$ & 0,4942 \\
\hline 7 & $\left\|v_{\bar{a}}^{\frac{d}{a}}(t)\right\|$ & Mínimo & $\left\|v_{\bar{a}}^{d}(t)\right\|^{\min }$ & 0,4788 \\
\hline 8 & $\left\|i_{a}^{d}(t)\right\|$ & Mínimo & $\left\|i_{a}^{d}(t)\right\|^{\min }$ & 0,4485 \\
\hline 9 & $\left\|v_{h}^{q^{\prime \prime}}(t)\right\|$ & Mínimo & $\left\|v_{h}^{q^{\prime \prime}}(t)\right\|^{\min }$ & 0,4452 \\
\hline 10 & $\left\|i_{b}^{a^{a}}(t)\right\|$ & Máximo & $\left\|i_{b}^{q^{+}}(t)\right\|^{\max }$ & 0,4228 \\
\hline 11 & $\left\|v_{\frac{q^{\prime}}{a}}(t)\right\|$ & Mínimo & $\left\|v_{a}^{q^{+}}(t)\right\|^{\min }$ & 0,4165 \\
\hline 12 & $\left\|i_{b}^{a^{a}}(t)\right\|$ & Médio & $\overline{\left\|i_{b}^{q^{\perp}}(t)\right\|}$ & 0,4086 \\
\hline
\end{tabular}

As variáveis apresentadas na Tabela 6.5 representam as variáveis mais correlatas com a distância de ocorrência da falta quando essa envolver a Fase A. Além de constituírem as variáveis mais correlatas, essas foram aquelas empregadas como entrada do sistema fuzzy responsável pela estimação da distância de ocorrência da falta. O sistema fuzzy responsável pela estimação da distância de ocorrência da falta fora constituído por 40 regras de inferência, número esse de regras que, durante os testes computacionais, se mostrou adequado na estimação da distância.

O sistema fuzzy fora ajustado segundo o algoritmo delineado no Capítulo 4 e fazendo uso de um conjunto de ajuste constituído por 975 pares entrada-saída. Todo o 
conjunto de ajuste fora construído se fazendo uso das simulações computacionais descritas no Capítulo 5 referentes às faltas fase-terra com participação da Fase A.

O algoritmo de ajuste delineado no Capítulo 4 é composto de duas etapas principais de ajuste. A primeira dessas etapas responde pelo ajuste estrutural do sistema fuzzy que, conforme abordado, é dedicado à extração das regras de inferência fuzzy que melhor correlacionam o espeço fuzzy das entradas com o espaço fuzzy da saída. Dessa forma, tem-se como produto da primeira etapa de ajuste a base de regra do sistema fuzzy que, nesse caso, será responsável pela estimação da distância de ocorrência da falta quando a mesma envolver a Fase A.

A fim de apresentar como o erro quadrático médio do sistema fuzzy se portou ao longo das iterações do processo de ajuste estrutural, retrata-se à Figura 6.6, onde tal comportamento é ilustrado.

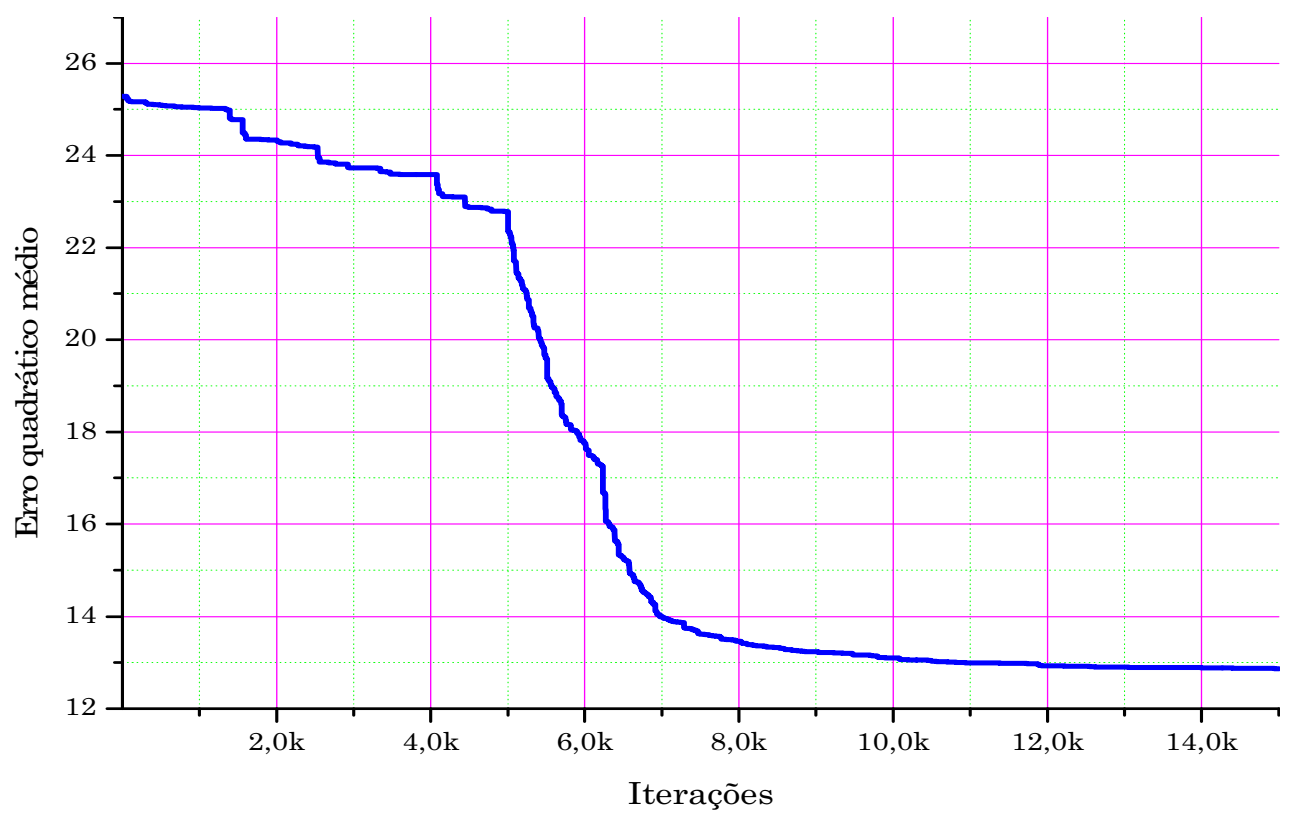

Figura 6.6 - Comportamento do erro quadrático médio do sistema fuzzy dedicado à estimação da distância de ocorrência da falta quando essa envolver a Fase A ao longo das iterações da primeira etapa de ajuste.

O gráfico da Figura 6.6 apresenta a sensível redução do erro quadrático médio ao longo das iterações da primeira etapa de ajuste para o sistema fuzzy responsável pela estimação da distância de ocorrência de uma falta fase-terra quando essa envolver a Fase A. Ao término dessa primeira etapa de ajuste, assim como anteriormente citado, tem-se como produto a base de regras responsável pelo relacionamento entre o espaço fuzzy das variáveis de entrada com o espaço fuzzy da variável de saída. Retratando a base de regras determinada por essa etapa de ajuste, apresenta-se a Figura 6.7. 


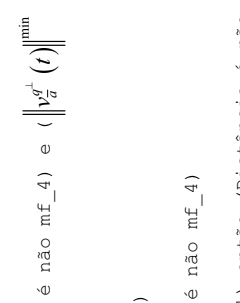

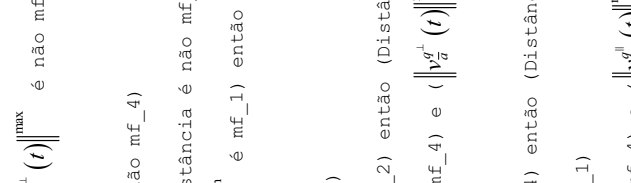

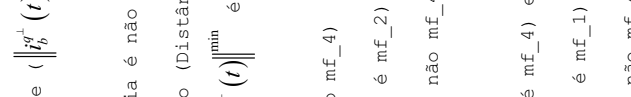

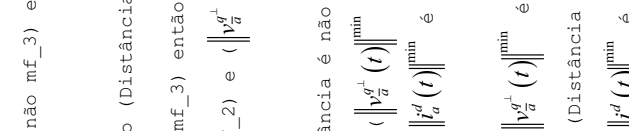

高

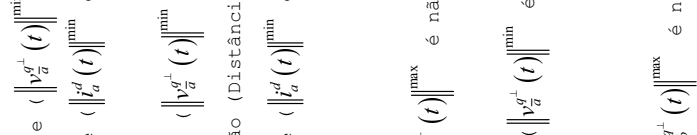

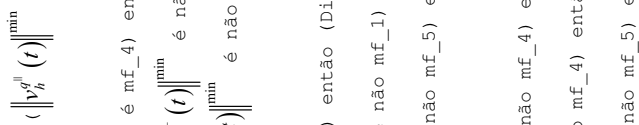

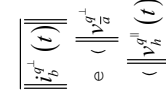

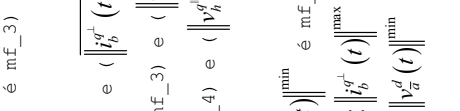

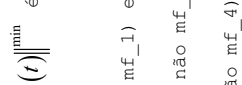

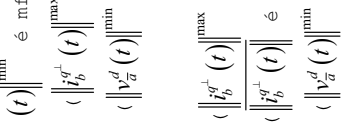

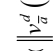

重

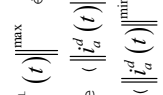

$\sqrt{3+10}$

(.)

崖峲

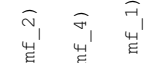

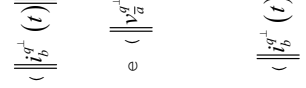

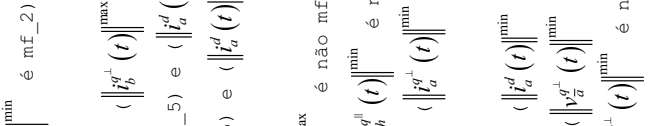

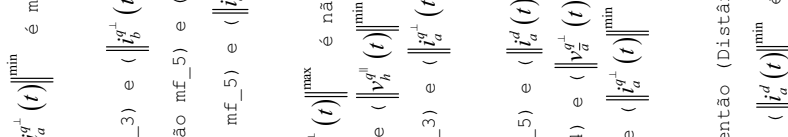

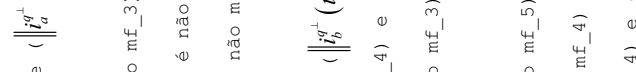

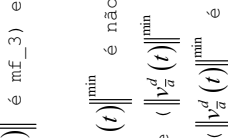

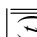

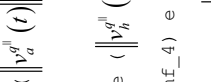

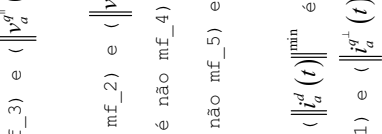

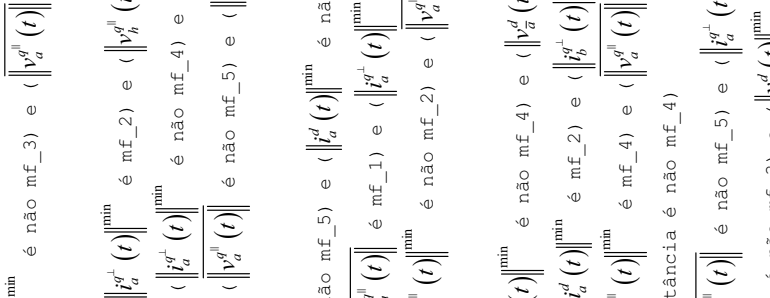

恶

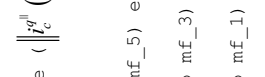

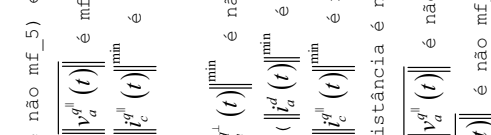

高

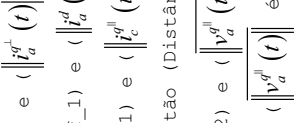

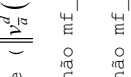

高垔

(a)

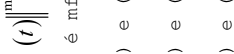

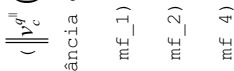

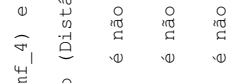

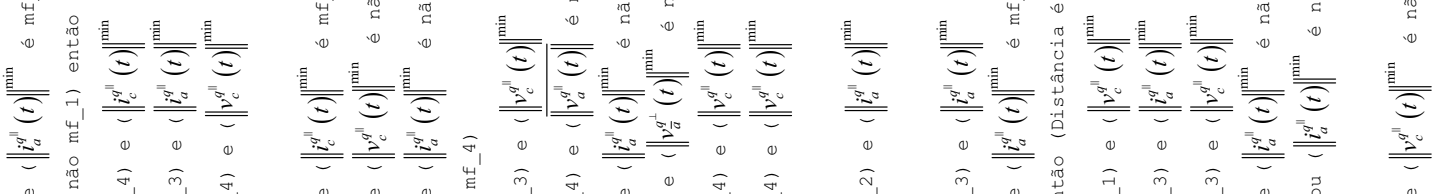

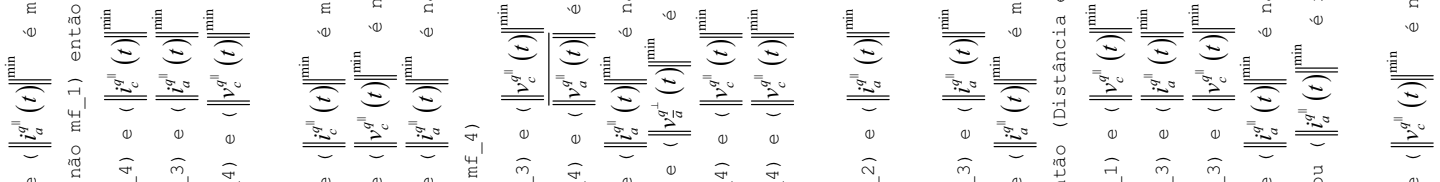

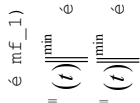

$\sqrt{\overline{2}} \stackrel{\sqrt{20}}{=}$

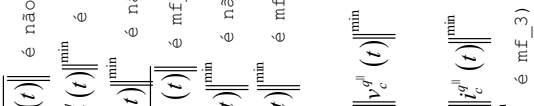

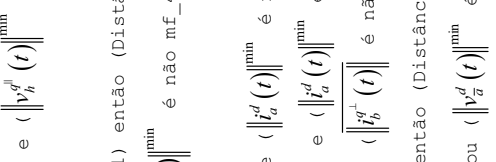

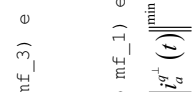

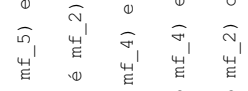

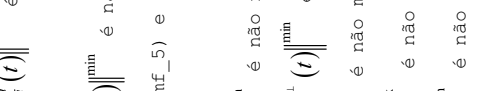

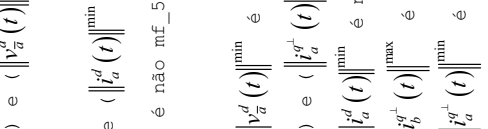

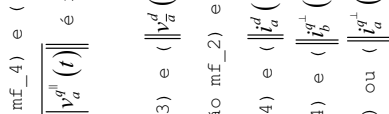

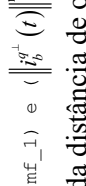

$=0$

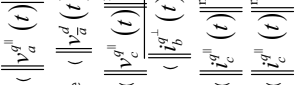

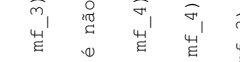

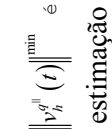

a 0

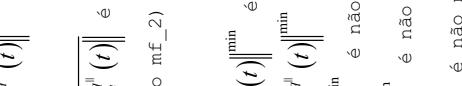

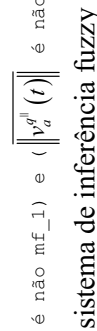

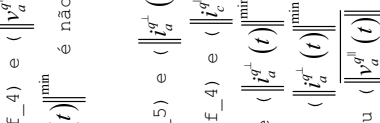

崖

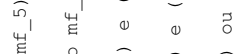

Е

贾

崖苞

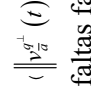

万人

至

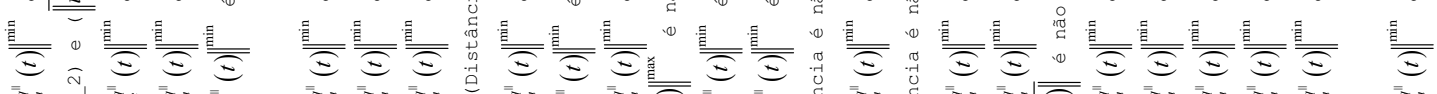

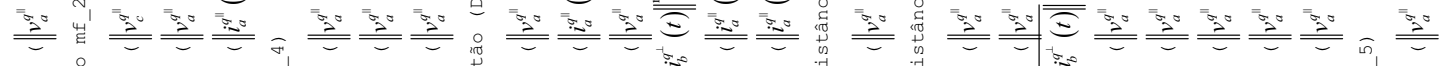
め) 


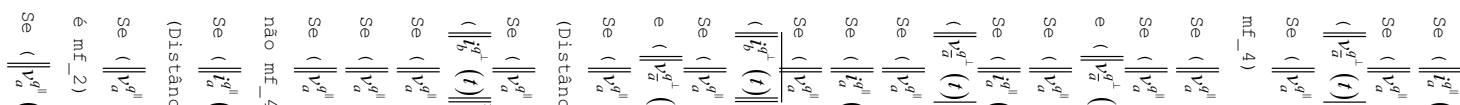

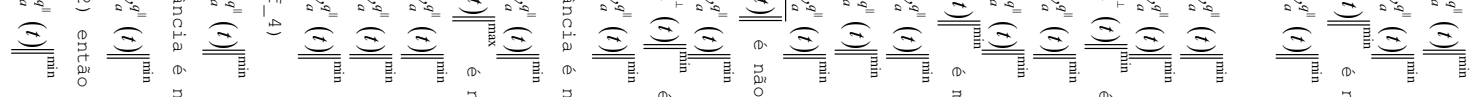

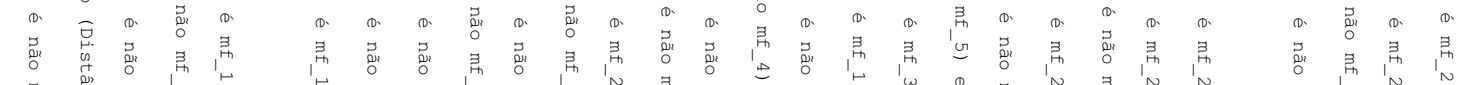

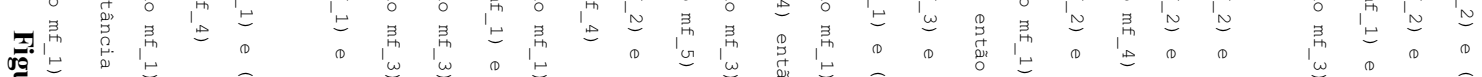

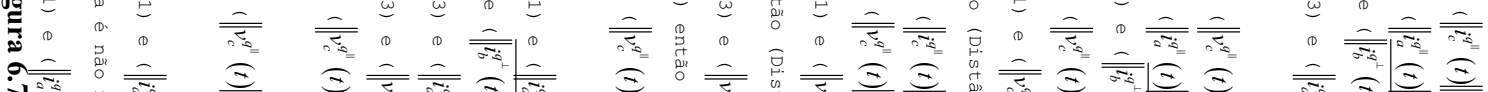

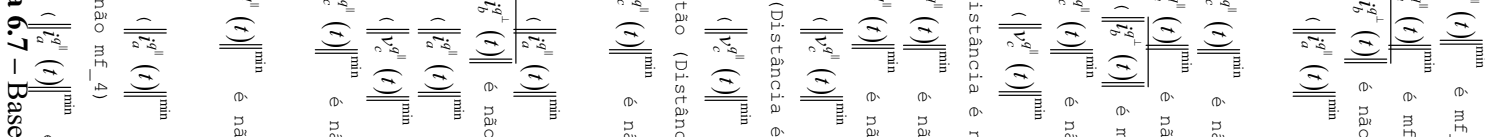

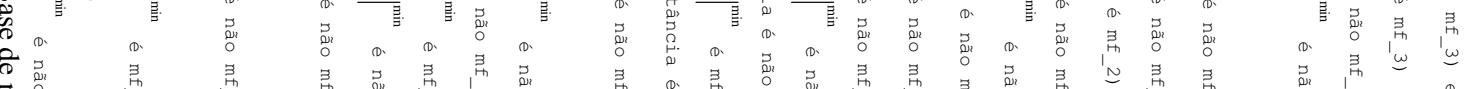

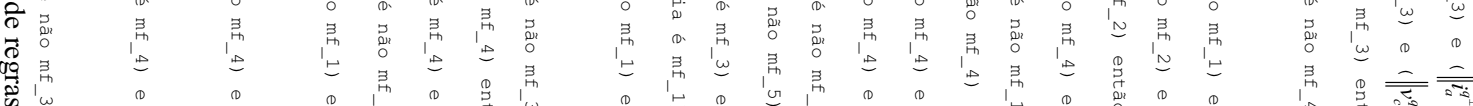

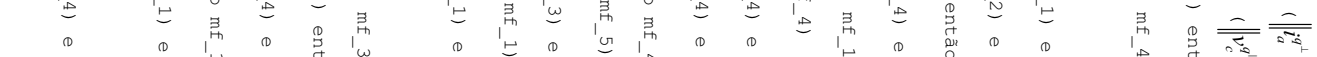

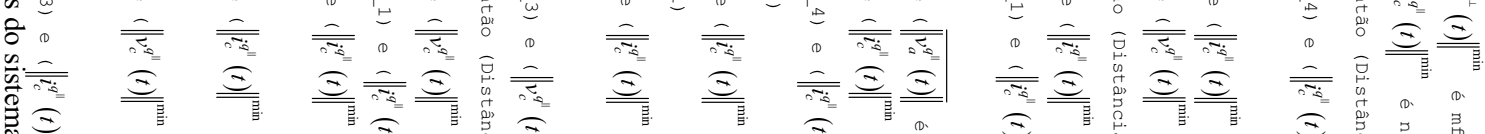

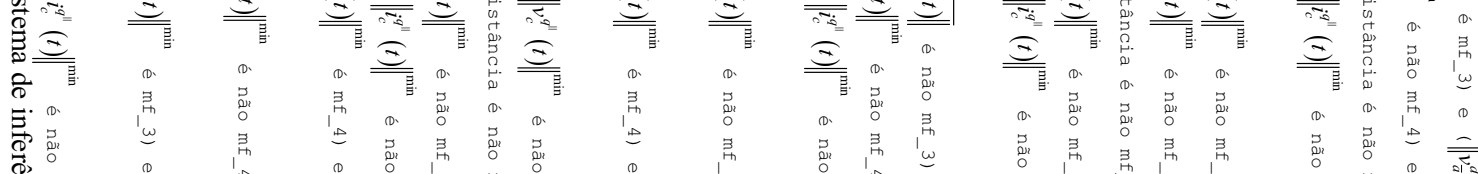
帛

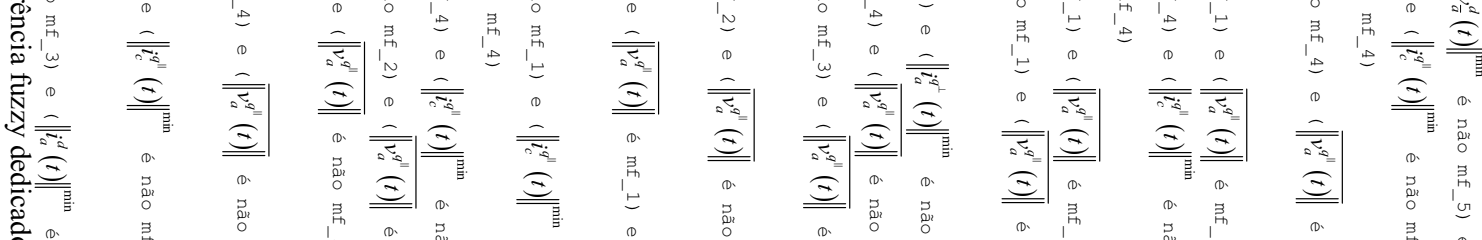

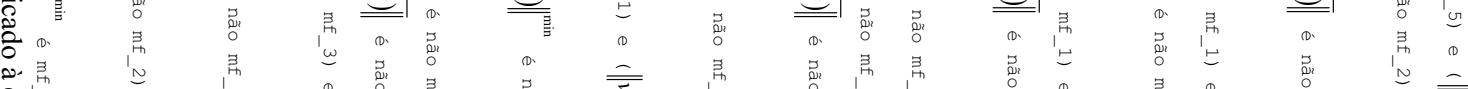

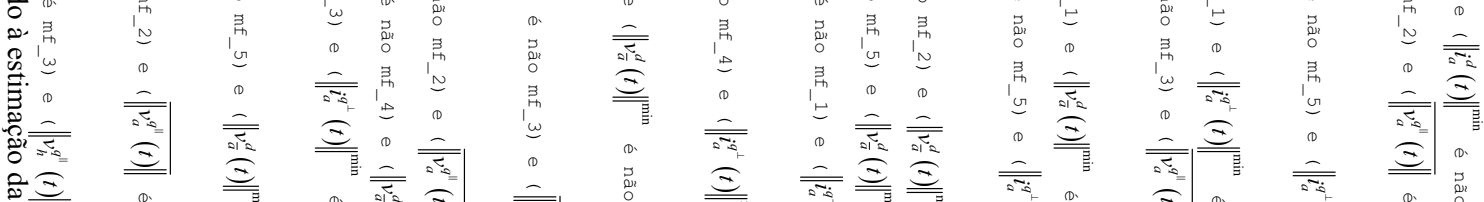

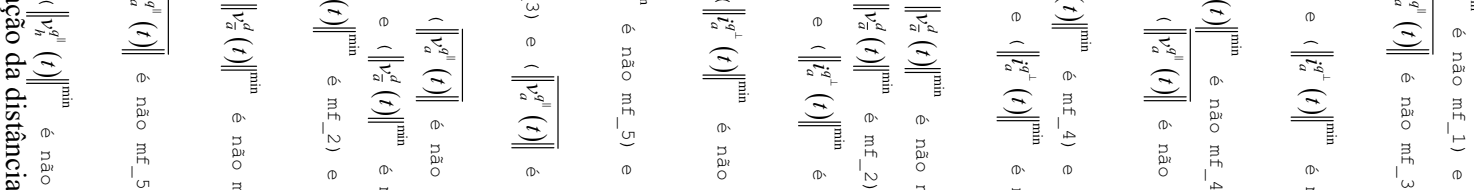

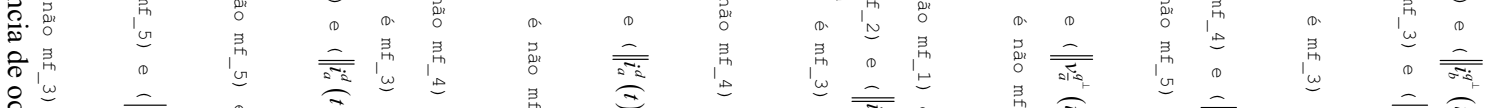

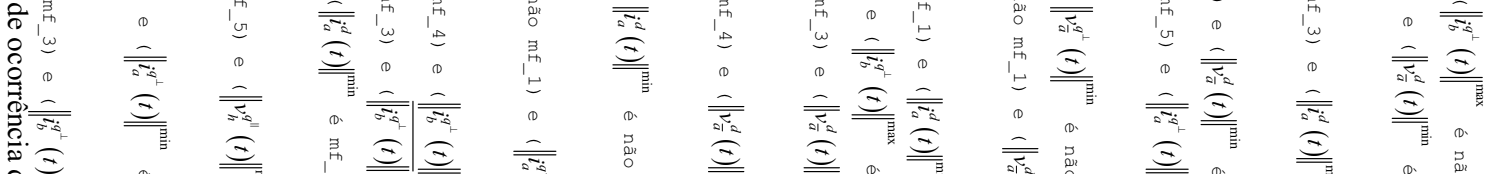

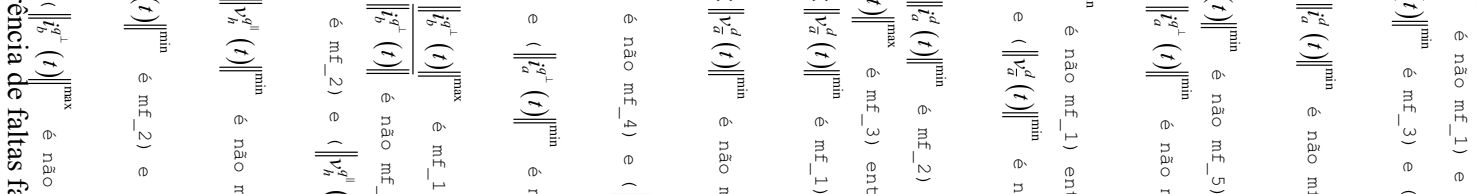

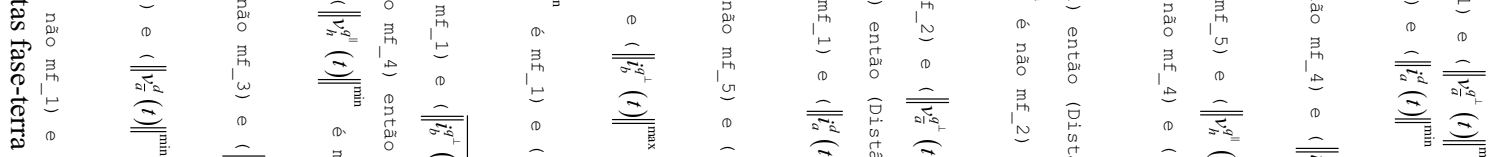

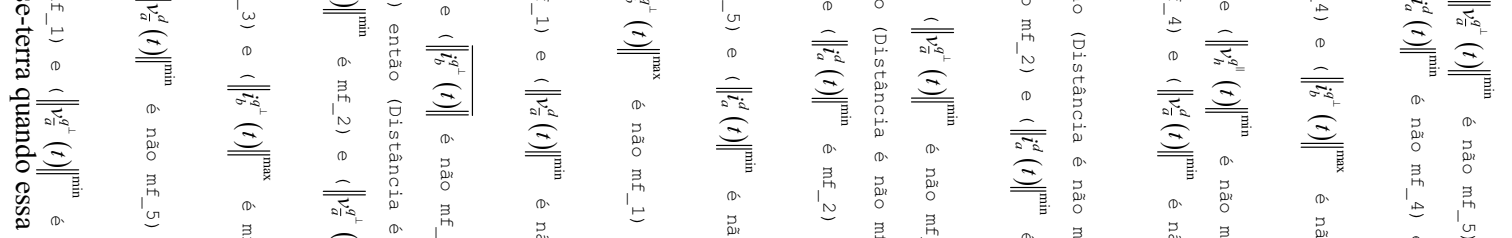

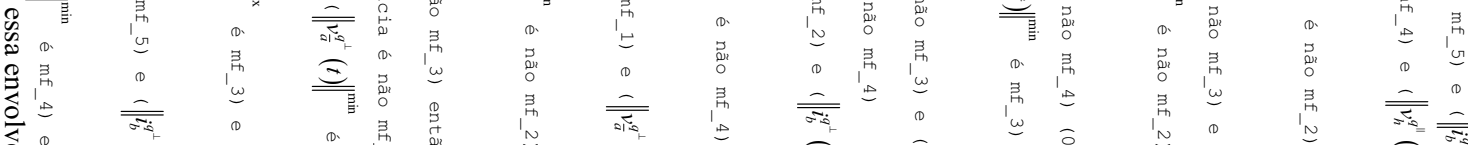

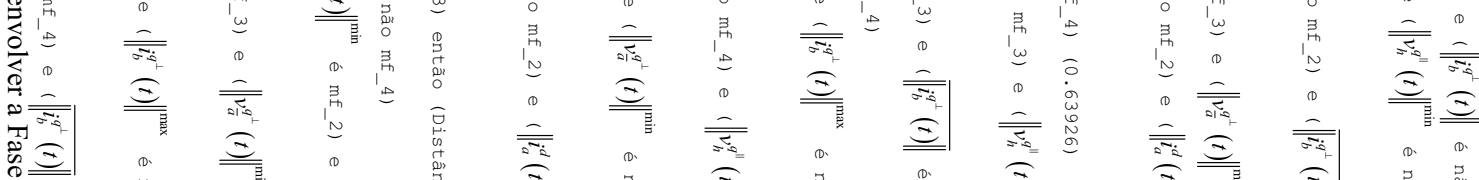

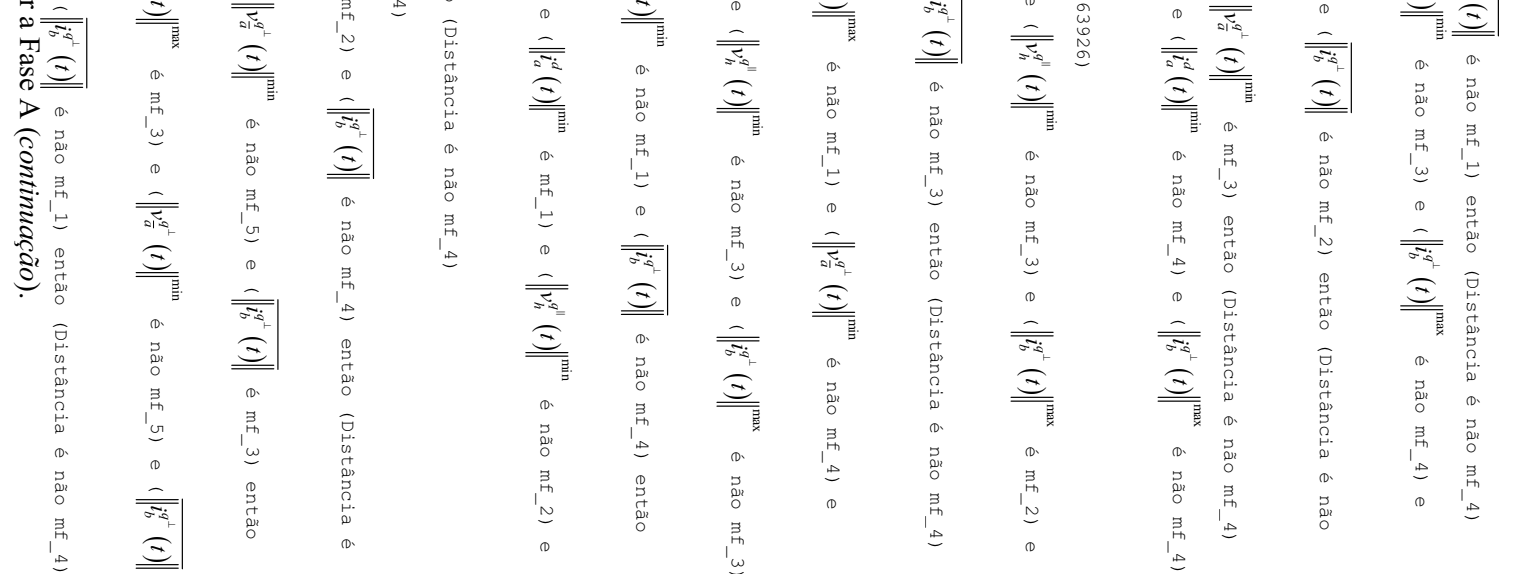


Após a determinação da base de regras, representada por meio da Figura 6.7, o sistema de inferência fuzzy fora submetido à segunda etapa de ajuste a qual é dedicada ao ajuste paramétrico do sistema. $\mathrm{O}$ ajuste paramétrico tem por meta prosseguir com a redução do erro quadrático iniciada na primeira etapa. Para tanto, a segunda etapa de ajuste, denotada por ajuste paramétrico, modifica os parâmetros que definem as funções de pertinência das entradas e da saída, bem como procede com a ponderação das regras fuzzy ora obtidas na primeira etapa de ajuste. Apresentando como o erro quadrático médio se portou ao longo das iterações dessa segunda etapa de ajuste, tem-se a Figura 6.8.

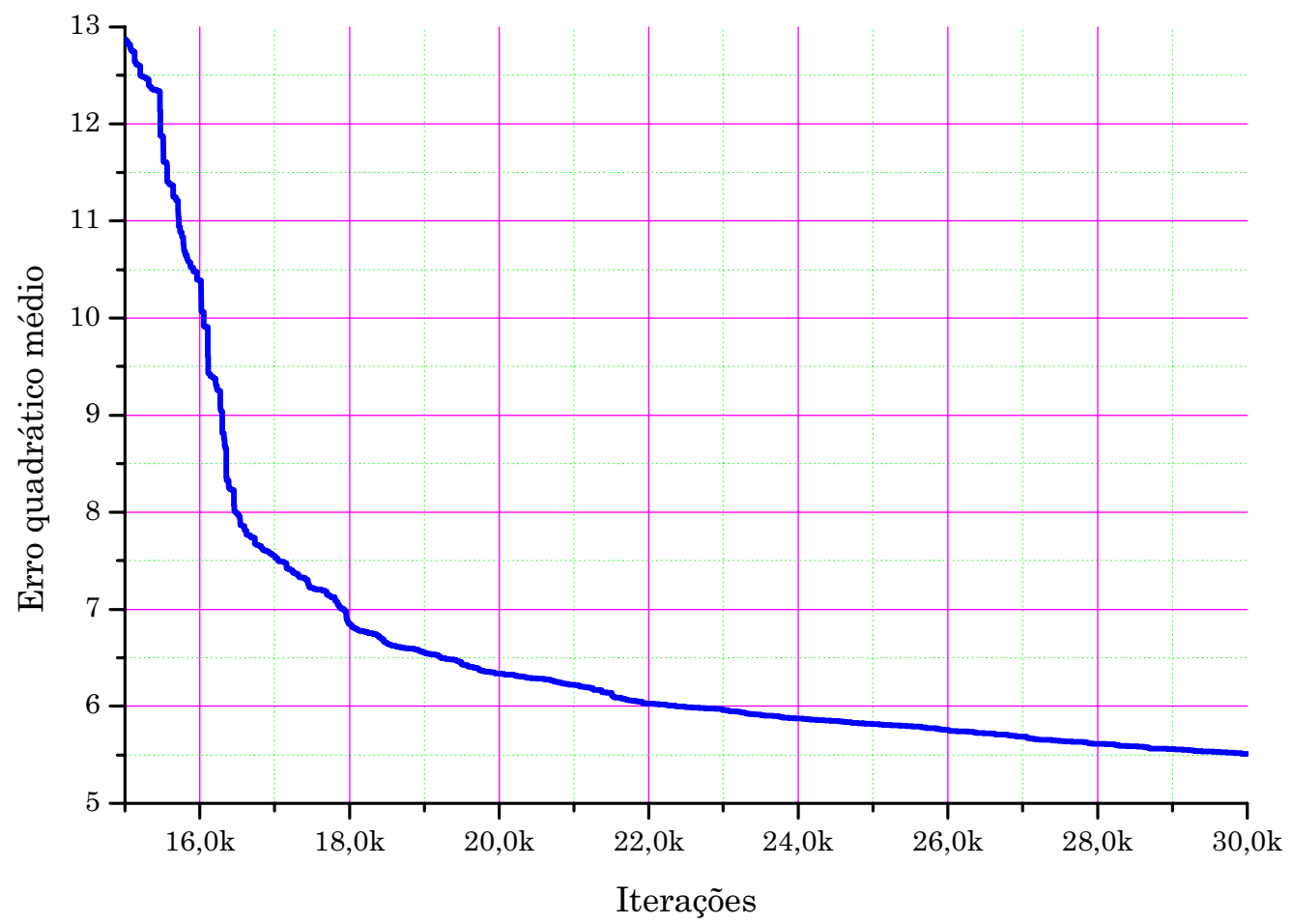

Figura 6.8 - Comportamento do erro quadrático médio do sistema fuzzy dedicado à estimação da distância de ocorrência da falta quando essa envolver a Fase A ao longo das iterações da segunda etapa de ajuste.

Por meio da Figura 6.8 é possível verificar o quão o erro quadrático médio se reduz ao longo da etapa de ajuste paramétrico. Essa etapa, assim como já referenciado, é responsável por ajustar as funções de pertinência das entradas e da saída, além de ponderar as regras de inferência fuzzy. Complementando, a apresentação dos resultados advindos do processo de ajuste paramétrico, ilustra-se por meio da Figura 6.9 as funções de pertinência ajustadas para as seis primeiras entradas, ou seja, para as entradas $\left\|v_{a}^{q^{\| \prime}}(t)\right\|^{\min },\left\|i_{a}^{q^{\| \prime}}(t)\right\|^{\min }$, $\left\|v_{c}^{q^{\|}}(t)\right\|^{\min },\left\|i_{c}^{q^{\|}}(t)\right\|^{\min }, \overline{\left\|v_{a}^{q^{\|}}(t)\right\|}$ e $\left\|i_{a}^{q^{\perp}}(t)\right\|^{\min }$. Da mesma maneira, por meio da Figura $6.10 \mathrm{se}$ tem as funções de pertinência para as outras seis entradas, ou seja, para as entradas $\left\|v_{\bar{a}}^{d}(t)\right\|^{\min }$, $\left\|i_{a}^{d}(t)\right\|^{\min },\left\|v_{h}^{q^{\|}}(t)\right\|^{\min },\left\|i_{b}^{q^{\perp}}(t)\right\|^{\max },\left\|v_{\bar{a}}^{q^{\perp}}(t)\right\|^{\min } \mathrm{e} \overline{{\left\|i_{b}^{q^{\perp}}(t)\right\|} .}$ 

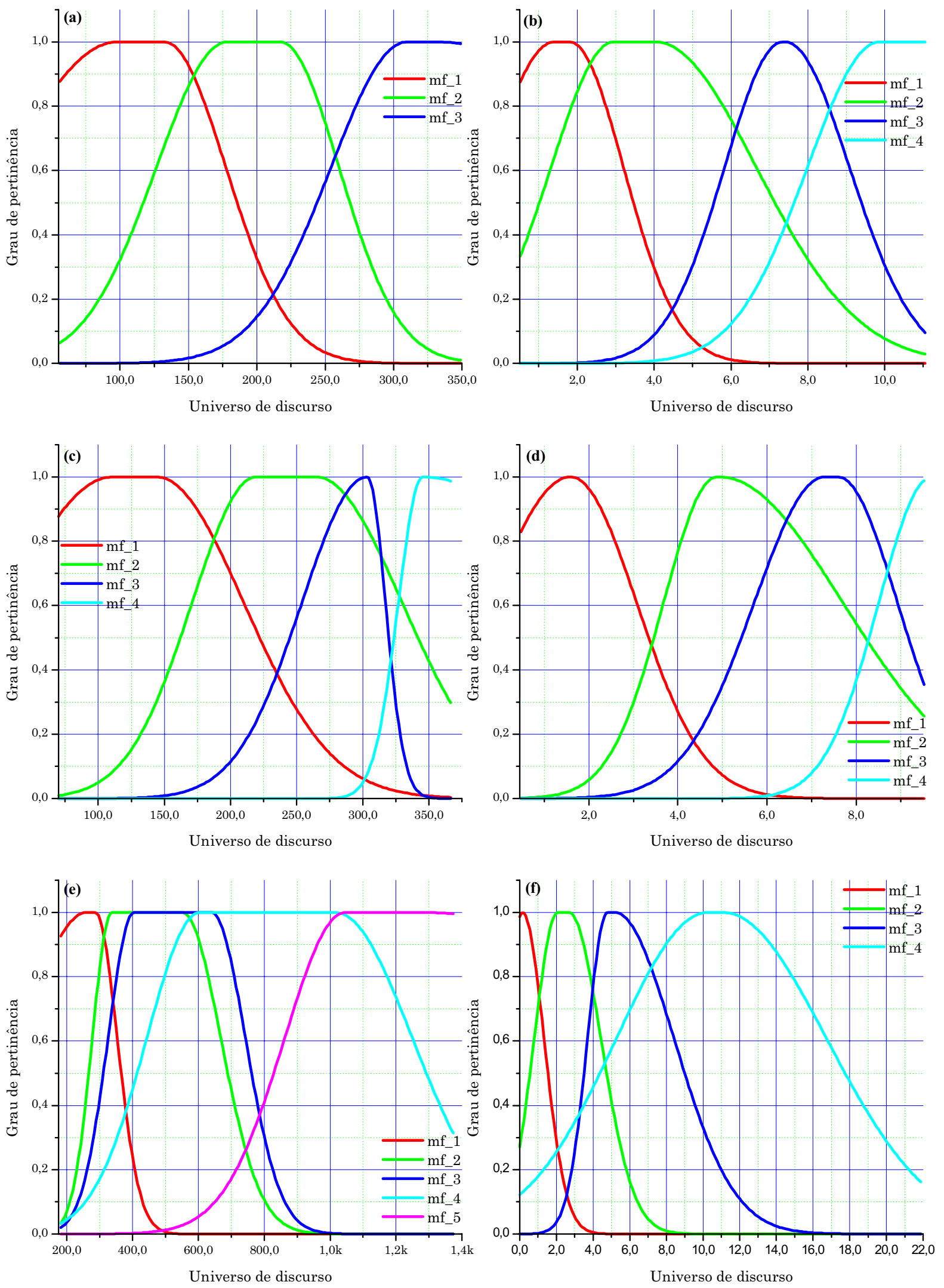

Figura 6.9 - Funções de pertinência ajustadas para as seis primeiras entradas; (a) Entrada $\left\|v_{a}^{q^{\prime \prime}}(t)\right\|^{\min }$; (b) Entrada $\left\|i_{a}^{q^{\prime \prime}}(t)\right\|^{\min } ;$ (c) Entrada $\left\|v_{c}^{q^{\prime \prime}}(t)\right\|^{\min } ;$ (d) Entrada $\left\|i_{c}^{q^{\prime \prime}}(t)\right\|^{\min } ;$ (e) Entrada $\overline{\left\|v_{a}^{q^{\prime \prime}}(t)\right\|} ;$ (f) Entrada $\left\|i_{a}^{a^{+}}(t)\right\|^{\min }$. 

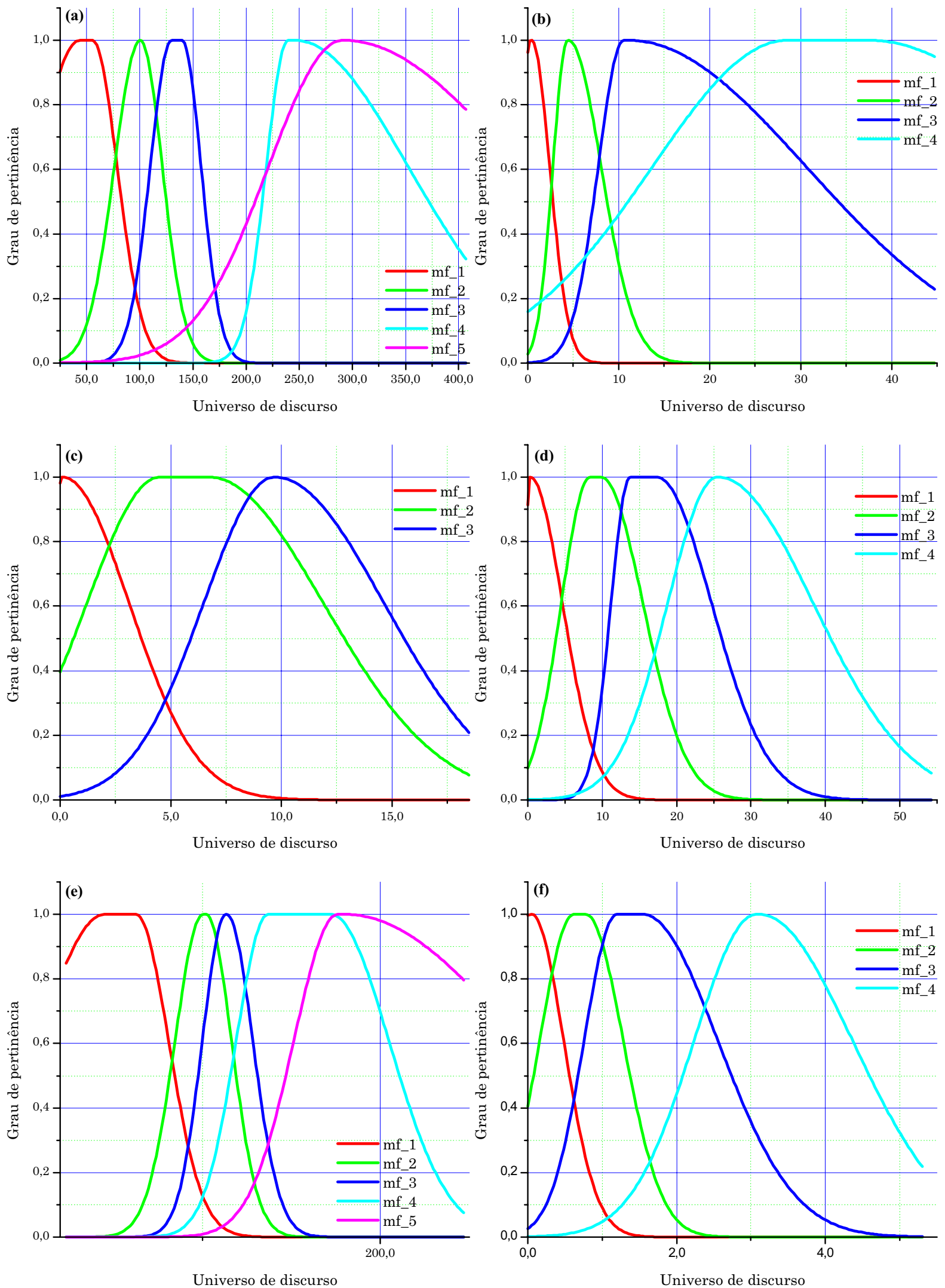

Figura 6.10 - Funções de pertinência ajustadas para as seis primeiras entradas; (a) Entrada $\left\|v_{\bar{a}}^{d}(t)\right\|^{\min } ;$ (b) Entrada $\left\|i_{a}^{d}(t)\right\|^{\min } ;$ (c) Entrada $\left\|v_{h}^{q^{\prime \prime}}(t)\right\|^{\min } ;$ (d) Entrada $\left\|i_{b}^{q^{\perp}}(t)\right\|^{\max } ;$ (e) Entrada $\left\|v_{\bar{a}}^{q^{\perp}}(t)\right\|^{\min } ;$ (f) Entrada $\overline{\overline{\left\|i_{b}^{q^{\perp}}(t)\right\|}}$. 
A etapa de ajuste paramétrico não apenas sintoniza as funções de pertinência do espaço das entradas como também ajusta as funções de pertinência da saída. Assim, por meio da Figura 6.11 se apresentam as funções de pertinência da saída, saída essa que representa a distância de ocorrência da falta em relação à subestação.

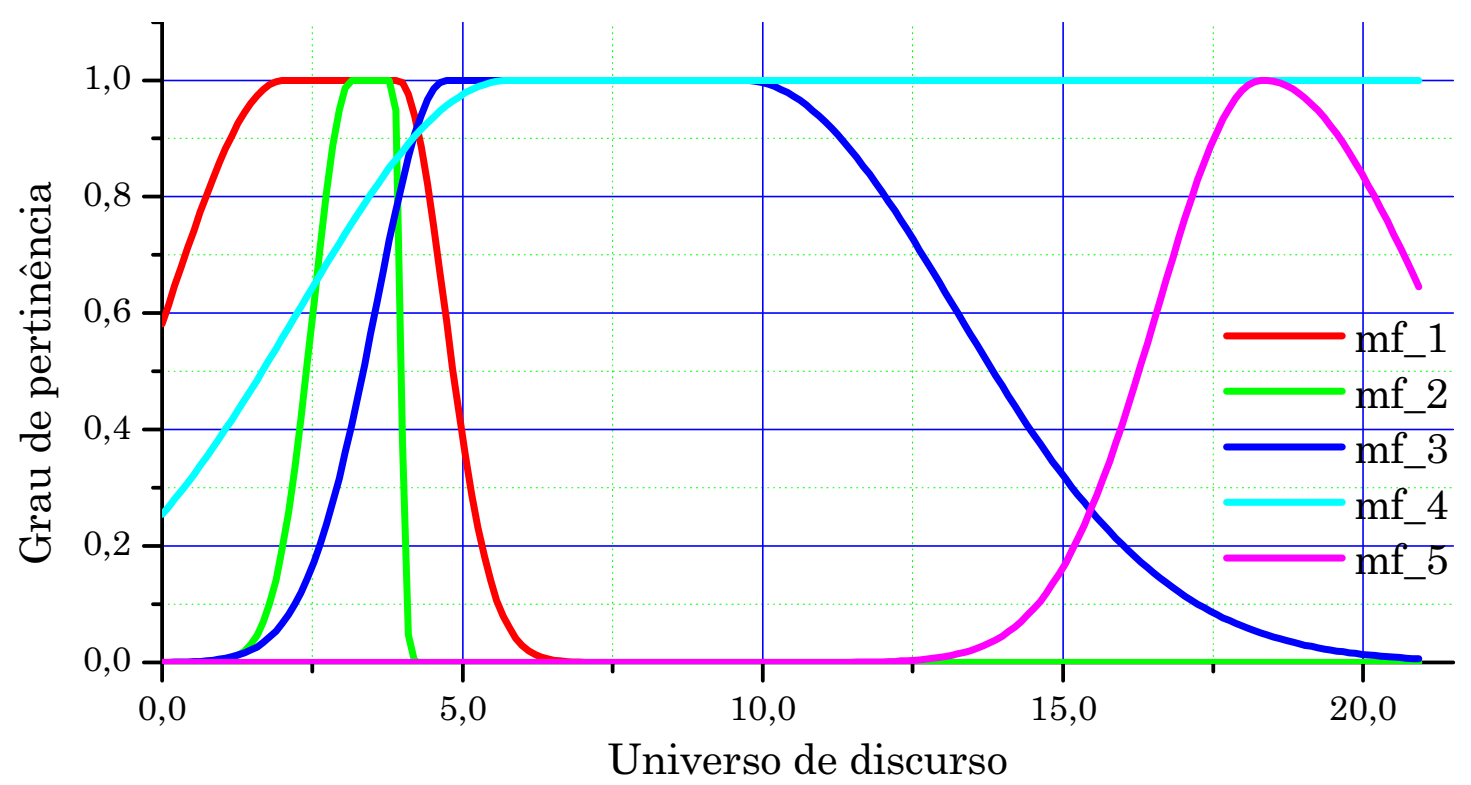

Figura 6.11 - Funções de pertinência associadas à distância de ocorrência de faltas fase-terra na Fase A.

Findando a apresentação do sistema fuzzy dedicado à estimação da distância de ocorrência da falta quando de sua ocorrência na Fase A, tem-se na Figura 6.12 a maneira pela qual as regras fuzzy, destacadas na sua forma verbal por meio da Figura 6.7, foram ponderadas pela etapa de ajuste paramétrico.

O sistema fuzzy ajustado para fins de estimação da distância de ocorrência de faltas fase-terra na Fase A fora ajustado, tanto estrutural como parametricamente, tendo como base os resultados providos por um conjunto de 974 simulações de faltas ocorridas na Fase A. Tais simulações computacionais, apresentadas em detalhes no Capítulo 5, possuíram como variáveis independentes a distância de ocorrência da falta, a resistência de falta, o instante inicial da falta e a duração das mesma. Assim, após o processo de ajuste é primordial a verificação da eficácia do sistema no desempenho da tarefa de estimação da distância de ocorrência da falta.

Para tanto, o sistema fuzzy fora, inicialmente, testado com os dados advindos das simulações empregadas na constituição do conjunto de ajuste do mesmo. Apresentando como o erro relativo se porta para a estimação da distância de ocorrência da falta, tem-se o gráfíco da Figura 6.13, onde se destaca o histograma do referido erro. 


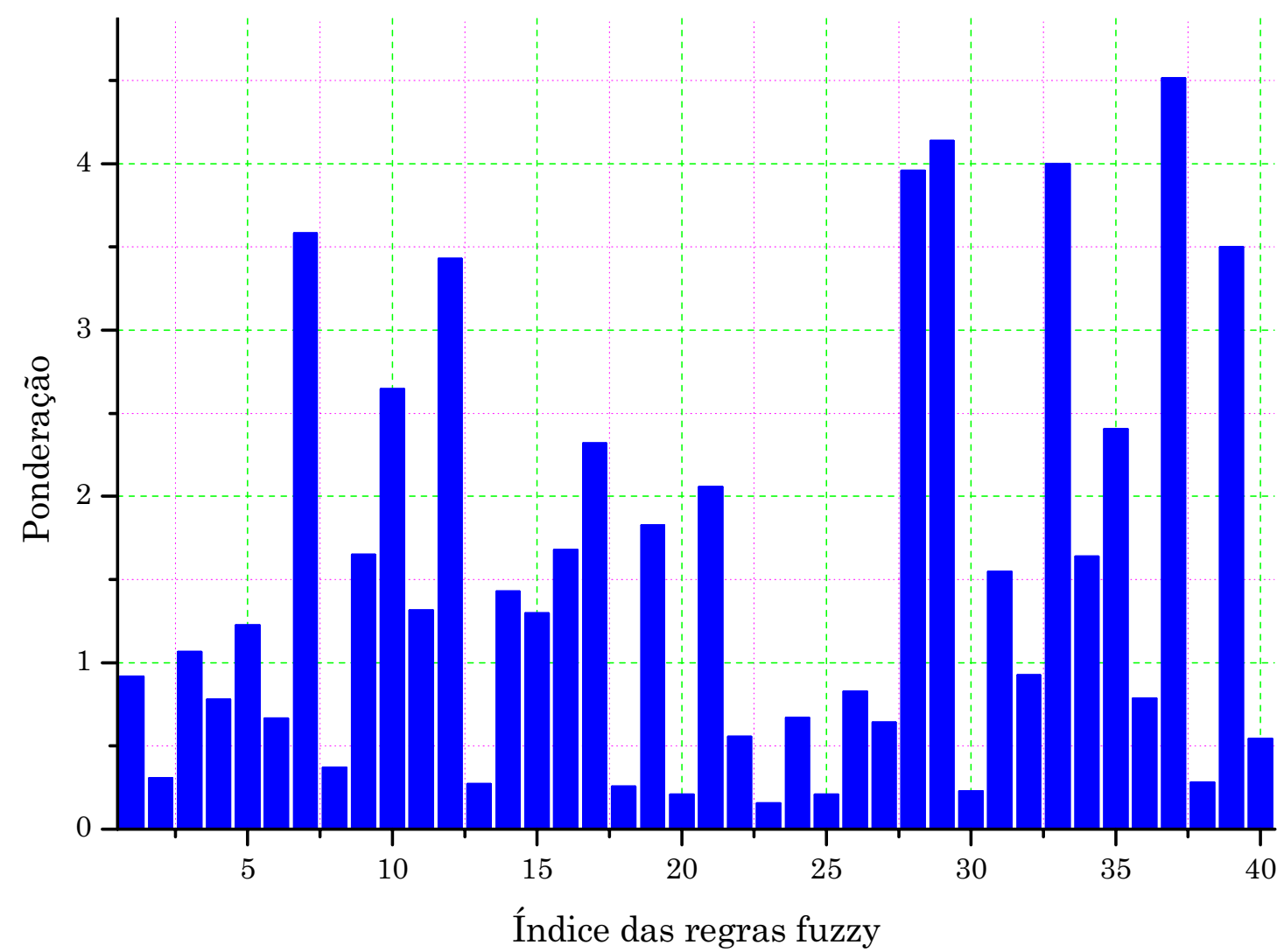

Figura 6.12 - Ponderação das regras fuzzy do sistema de inferência fuzzy dedicado à estimação da distância de ocorrência de faltas fase-terra na Fase A.

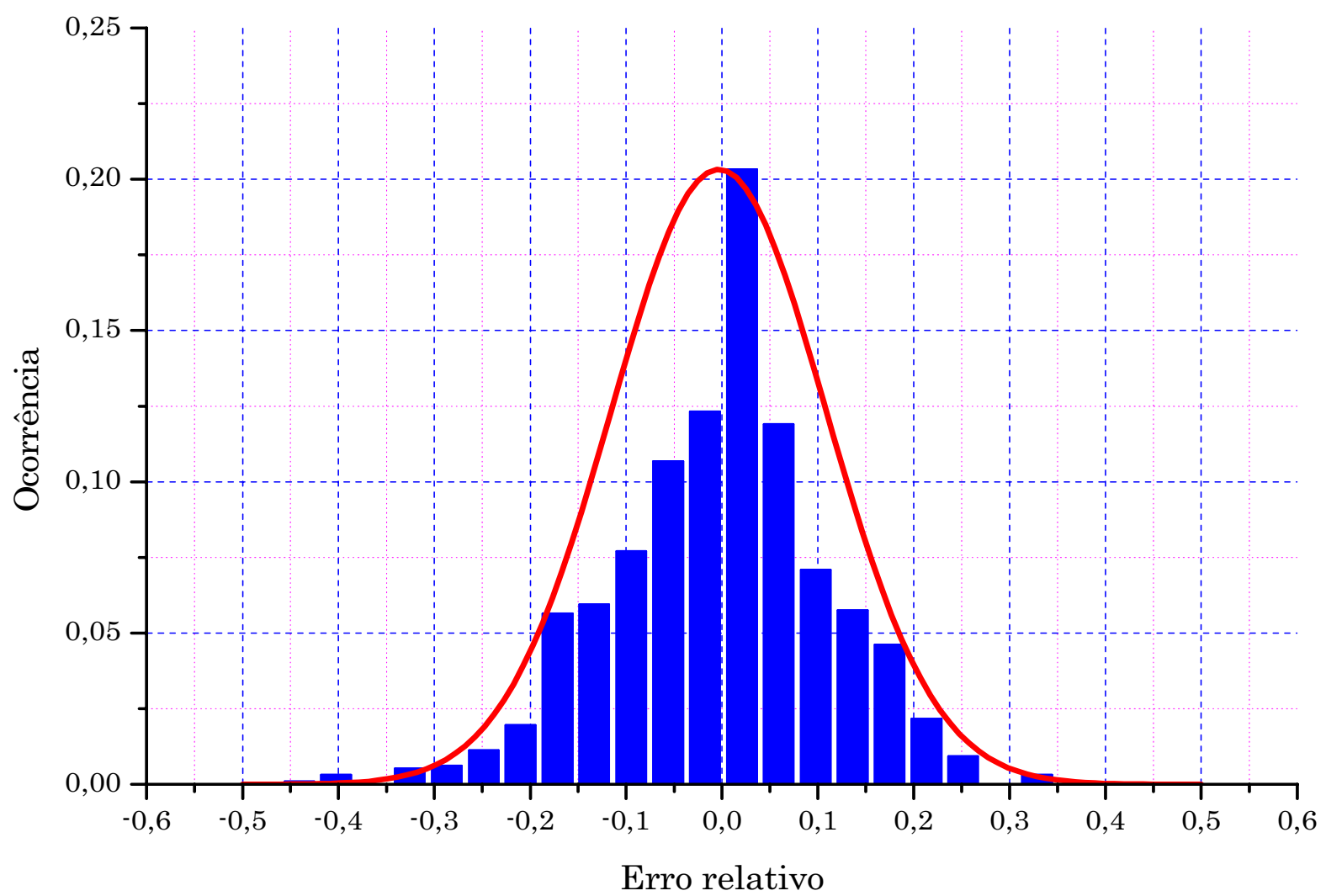

Figura 6.13 - Histograma do erro relativo de estimação da distância de ocorrência de faltas fase-terra ma Fase A. 
Por meio do gráfico apresentado na Figura 6.13, além de destacar o histograma do erro relativo de estimação da distância de ocorrência da falta, tem-se o gráfico da distribuição normal que mais se aproxima desse. A distribuição normal do erro relativo possui média de -0,0034 e desvio padrão de 0,1122, ou seja, em 68,25\% dos casos, a estimação da distância de ocorrência da falta é realizada possuindo o erro relativo de estimação posicionado entre $-0,1122$ e 0,1122 .

Complementando a análise do erro relativo de estimação da distância de ocorrência da falta, apresenta-se na Tabela 6.6 a correlação entre o erro relativo e as variáveis independentes das simulações computacionais, ou seja, a correlação entre o erro relativo e a distância de ocorrência da falta, a resistência de falta, o ângulo de falta e a duração da falta.

Tabela 6.6 - Correlação entre o erro relativo e as variáveis independentes das simulações computacionais.

\begin{tabular}{lr}
\hline \hline $\begin{array}{l}\text { Variável independente da } \\
\text { simulação }\end{array}$ & $\begin{array}{r}\text { Correlação com erro } \\
\text { relativo de estimação }\end{array}$ \\
\hline \hline Distância de ocorrência da falta & 0.4960 \\
\hline Resistência de falta & 0.0033 \\
\hline Ângulo da falta & 0.0912 \\
\hline Duração da falta & 0.0178 \\
\hline \hline
\end{tabular}

Por meio da Tabela 6.6 é possível verificar a forte dependência do erro relativo com a distância de ocorrência da falta, ou seja, com a própria variável de estimação. Ainda, verifica-se a correlação do erro com o ângulo da falta, sendo que as correlações existentes entre o erro e a resistência de falta e a duração da mesma é ínfima. A fim de ilustrar a forte correlação do erro de estimação da distância com a distância real de ocorrência se apresenta o gráfico da Figura 6.14.

Verifica-se pelo gráfico da Figura 6.14 a tendência tanto do máximo erro quanto do mínimo erro aumentarem com o aumento da distância de ocorrência da falta. No entanto, a faixa de erro, a distância entre o máximo erro e o mínimo erro, tende a permanecer constante em relação à distância de ocorrência da falta. A Figura 6.15 apresenta o relacionamento do erro relativo para as demais variáveis independentes das simulações computacionais. 


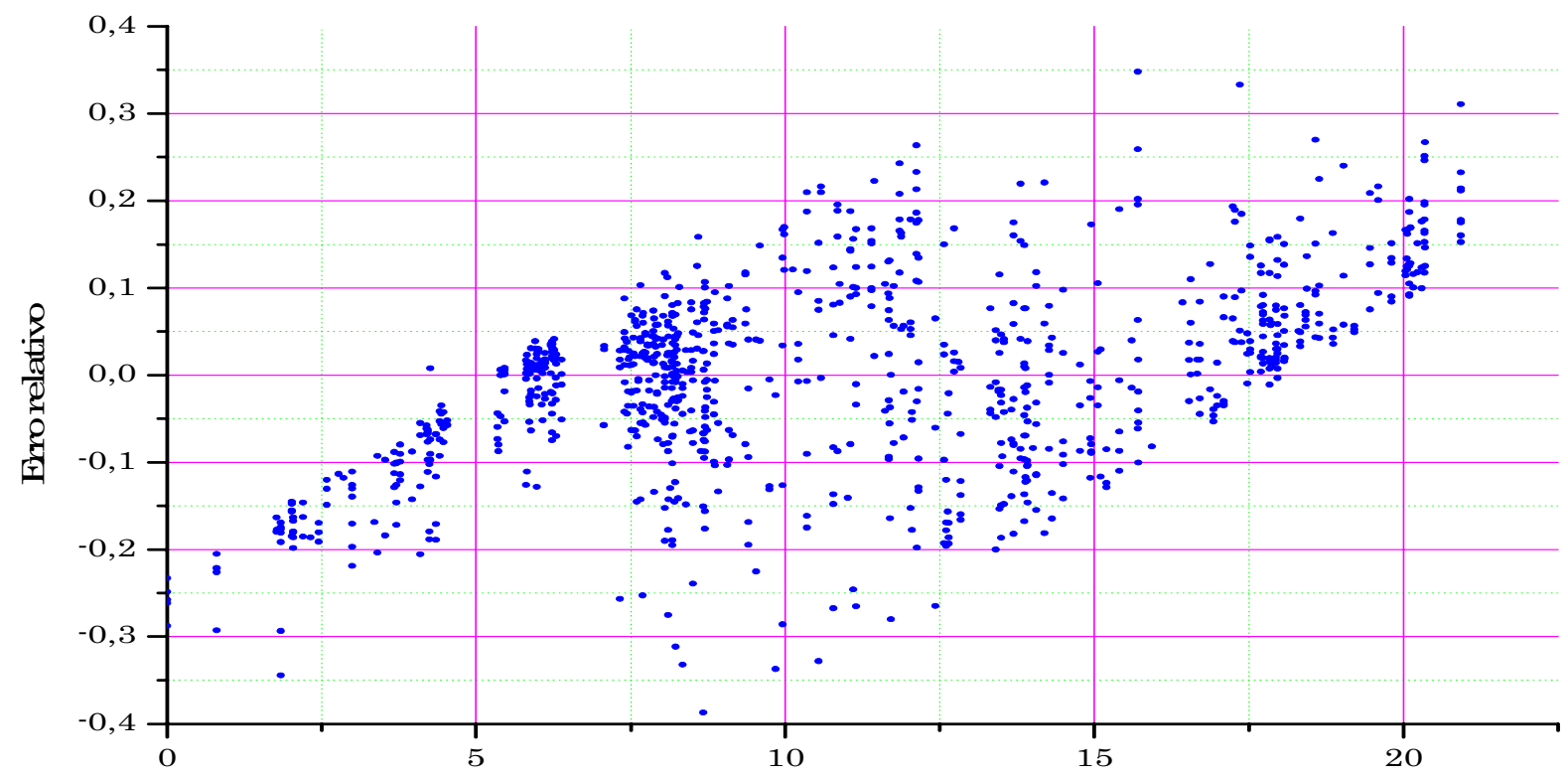

Distância de ocorrência da falta $(\mathrm{km})$

Figura 6.14 - Relacionamento entre o erro relativo e a distância de ocorrência da falta.

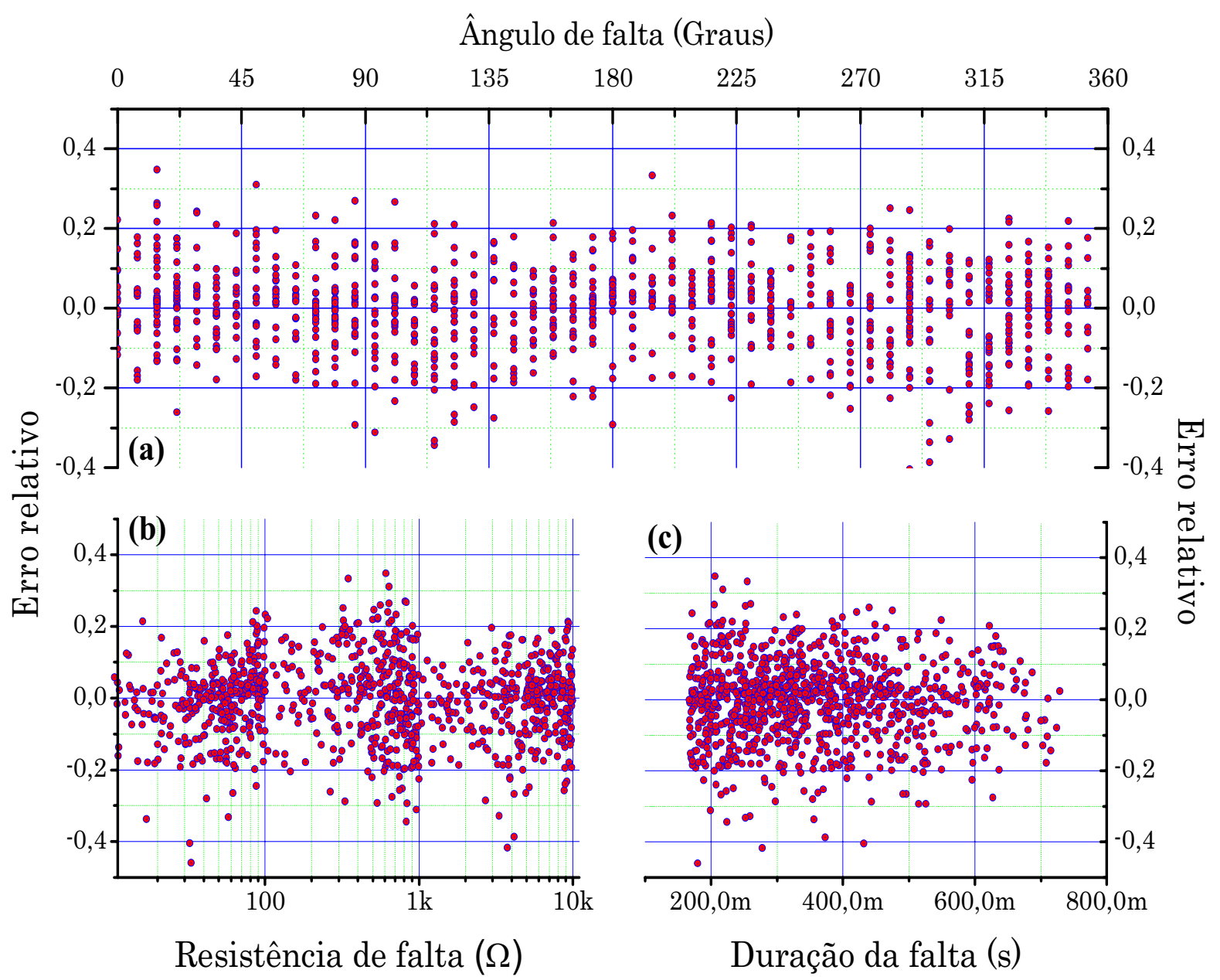

Figura 6.15 - Relacionamento entre o erro relativo e as demais variáveis independentes de simulação; (a) Relacionamento entre o erro relativo e o ângulo de falta; (b) Relacionamento entre o erro relativo e a resistência de falta; (c) Relacionamento entre o erro relativo e a duração da falta. 
O sistema fuzzy dedicado à estimação da distância de ocorrência da falta, além de ser testado com os dados provenientes do conjunto de ajuste, fora também testado com dados advindos de simulações computacionais não contidos no conjunto de ajuste. Assim, um total de 269 situações de falta na Fase A foram simuladas e os resultados dessas simulações foram submetidos à técnica de decomposição em componentes ortogonais. De posse dos valores eficazes das componentes ortogonais, as variáveis mais correlatas à localização de faltas na Fase A, apresentadas na Tabela 6.5, foram selecionadas e apresentadas ao sistema fuzzy previamente ajustado. Os resultados obtidos para a localização de faltas quando de sua ocorrência na Fase A são apresentados por meio da Figura 6.16 na forma de histograma do erro relativo.

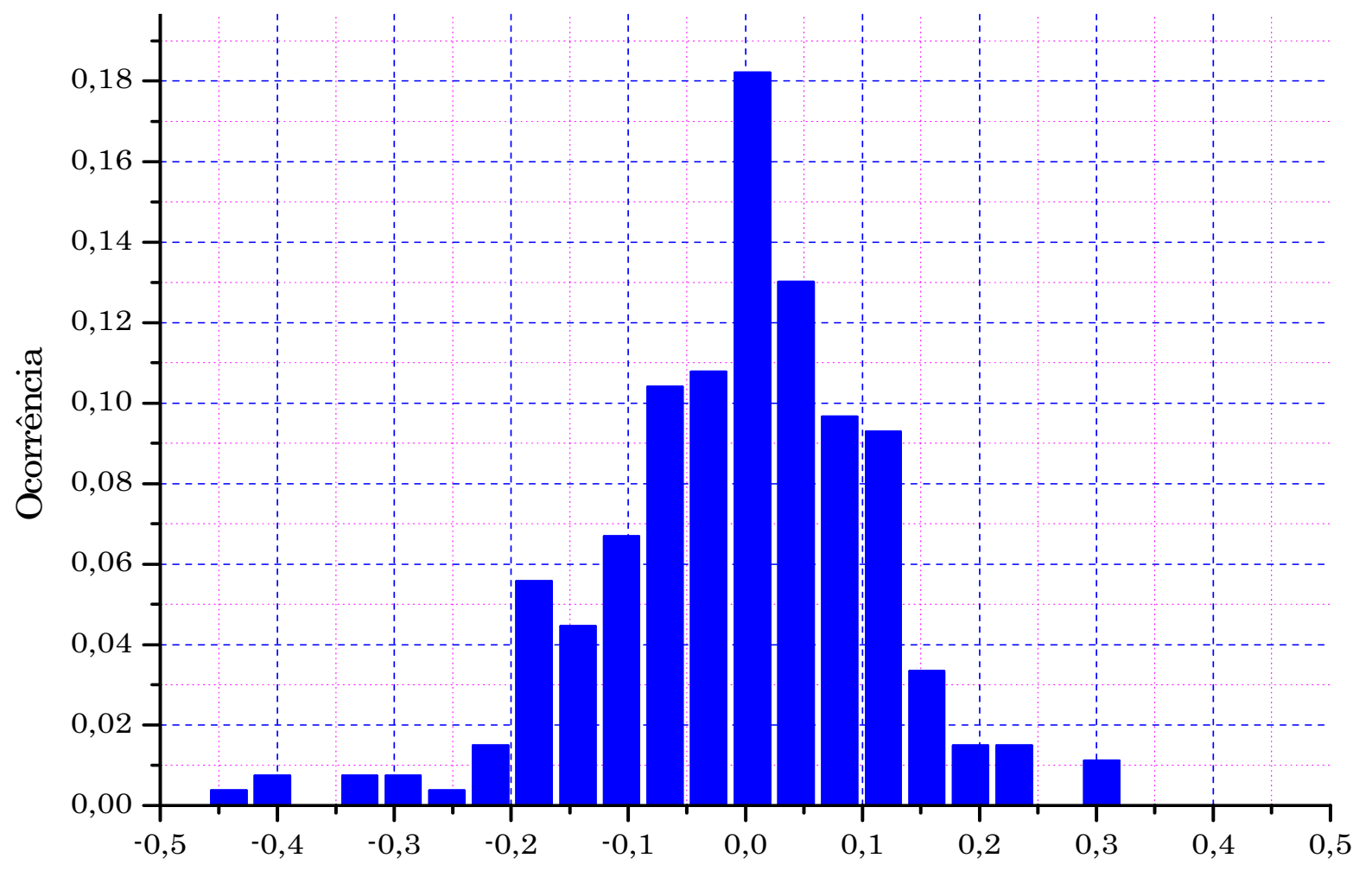

Erro relativo

Figura 6.16 - Histograma do erro relativo de estimação da distância de ocorrência de faltas fase-terra na Fase A para os dados do conjunto de teste.

Assim como a distribuição do erro relativo para os dados de ajuste se assemelha a uma distribuição normal, o mesmo pode ser verificado para o erro relativo apresentado para o conjunto de teste. A fim de ilustrar como a distribuição estatística do erro relativo para os dados de ajuste é semelhante à distribuição do erro verificado para os dados de teste, apresenta-se a Figura 6.17, onde ambas as distribuições estatísticas são confrontadas para propósitos comparativos. 


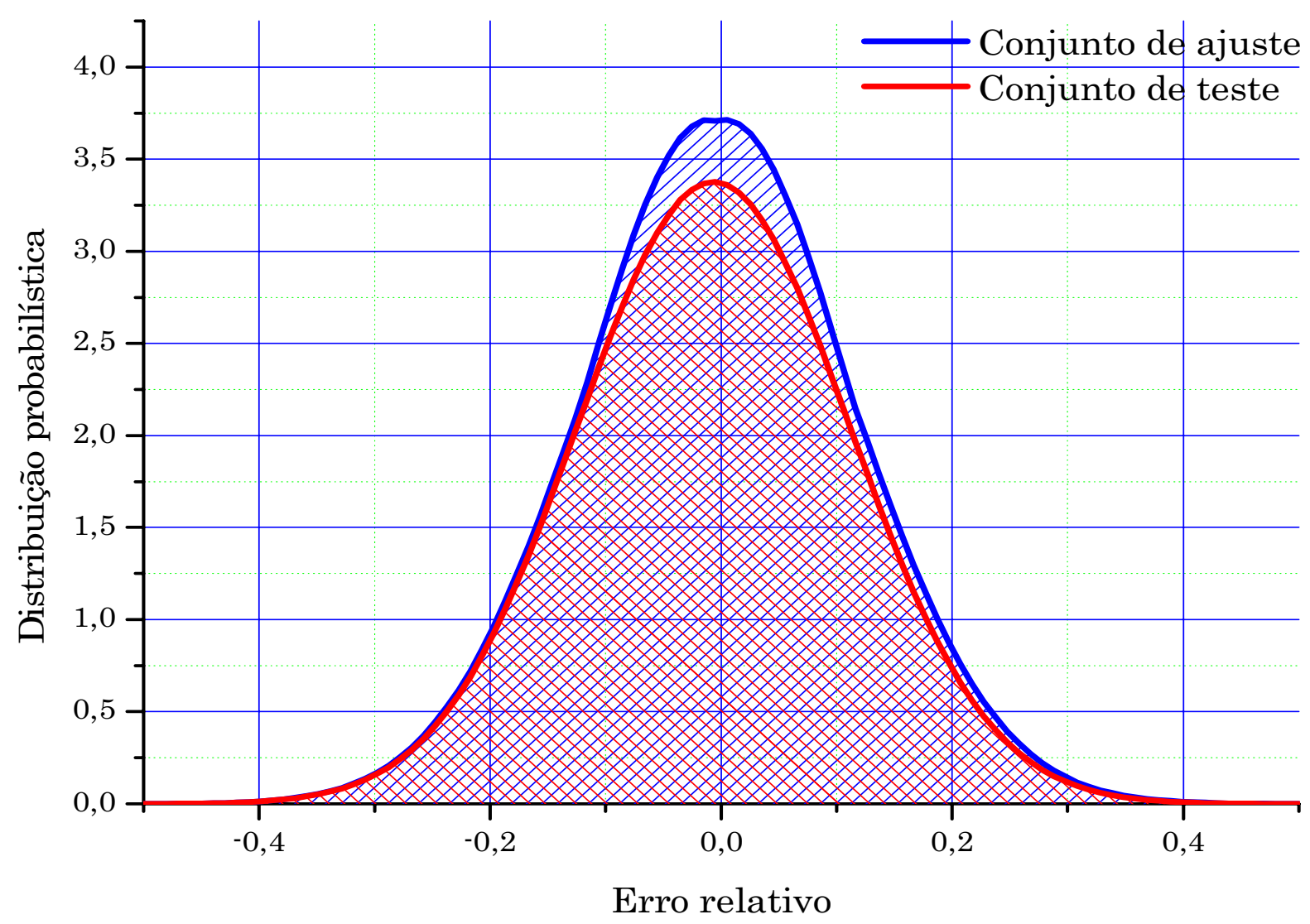

Figura 6.17 - Distribuição normal para o conjunto de ajuste e para o conjunto de teste quando da localização de falta na Fase A.

Por meio da Figura 6.17 é possível verificar que a distribuição normal verificada para os dados de teste se enquadrou com aquela verificada quando da modelagem do erro observado para os dados de ajuste. Ainda, quando da distribuição normal apresentada na Figura 6.17, tem-se que sua média fora de $-0,0067$ e o desvio padrão de 0,1182 .

Complementando, tem-se que por meio dos resultados obtidos para os dados de teste, os quais não constituíram o conjunto de ajuste, o desempenho do sistema fuzzy na estimação da distância de ocorrência fora adequado, evidenciando que o relacionamento das variáveis de entrada com a distância de ocorrência da falta ocorreu de maneira adequada por meio do sistema de inferência fuzzy ajustado segundo o algoritmo proposto para essa finalidade.

\subsubsection{SistemA de INFERÊNCIA FUZZY PARA LOCALIZAÇÃo de FALTAS NA FASE B}

Na Subseção 6.2.1 a estimação da distância de ocorrência de faltas fase-terra quando de sua ocorrência na Fase A fora realizada, primeiramente, selecionando-se as componentes ortogonais mais correlatas à essa distância e, posteriormente à essa seleção, 
ajustando o sistema de inferência fuzzy dedicado a esse propósito. O sistema fuzzy resultante do processo de ajuste fora avaliado por meio do erro que o mesmo apresentou frente ao conjunto de ajuste constituído, bem como frente ao conjunto de teste. Em ambos os casos, ou seja, para os dados provenientes do conjunto de ajuste e para o conjunto de teste, o comportamento estatístico do erro se deu de maneira semelhante. Essa semelhança na distribuição probabilística do erro permite inferir que o relacionamento realizado pelo sistema fuzzy entre as variáveis de entrada e a distância de ocorrência da falta se deu de maneira adequada. Em outras palavras, pode-se constatar que o comportamento verificado para os dados de teste é replicável a outras situações de falta não pertencentes ao conjunto de ajuste, assim como verificado para o conjunto de teste.

Essas observações não apenas validam a metodologia desenvolvida como também motivam sua aplicação quando da implementação dos sistemas fuzzy dedicados à localização de faltas nas demais fases do sistema. Dessa maneira, a referida metodologia será, nessa subseção, empregada na constituição do sistema de inferência fuzzy responsável pela estimação da distância de ocorrência de faltas fase-terra na Fase B.

Prosseguindo, para apresentar como cada componente advinda do resultado da decomposição ortogonal se correlaciona com a distância de ocorrência da falta, apresentam-se por meio da Tabela 6.7 as correlações e os testes de hipótese, que mensuram o quão significativo são as correlações das componentes de tensões contidas na função planar das tensões de linha com a distância de ocorrência da falta quando essa for observada na Fase B. Os valores contidos na Tabela 6.7 são graficamente apresentados por meio da Figura 6.18.

Por meio da Tabela 6.8 se apresentam as correlações das componentes de corrente contidas na função planar das tensões de linha com a distância de ocorrência da falta, assim como por meio da Figura 6.19 se tem a representação gráfica dos valores contidos nessa tabela.

A correlação das componentes de tensão ortogonais à função planar das tensões de linha com a distância de ocorrência de falta é apresentada na Tabela 6.9 e tais valores para as componentes de corrente ortogonais à função planar das tensões de linha são conteúdo da Tabela 6.10. A representação dos valores expressos na Tabela 6.9 e Tabela 6.10 é realizada por meio da Figura 6.20 e da Figura 6.21, respectivamente. 
Tabela 6.7 - Correlação das componentes de tensão contidas na função planar das tensões de linha com relação à distância de ocorrência de falta na Fase B.

\begin{tabular}{|c|c|c|c|c|c|c|c|}
\hline \multirow[b]{2}{*}{$k$} & \multirow[b]{2}{*}{ Variável } & \multicolumn{2}{|c|}{ Média } & \multicolumn{2}{|c|}{ Máximo } & \multicolumn{2}{|c|}{ Mínimo } \\
\hline & & Correlação & $\begin{array}{l}\text { Teste de } \\
\text { hipótese } \\
\end{array}$ & Correlação & $\begin{array}{l}\text { Teste de } \\
\text { hipótese }\end{array}$ & Correlação & $\begin{array}{l}\text { Teste de } \\
\text { hipótese }\end{array}$ \\
\hline 1 & $\left\|v_{a}^{p}(t)\right\|$ & 0,0860 & 0,0066 & 0,0847 & 0,0074 & 0,0310 & 0,3284 \\
\hline 2 & $\left\|v_{b}^{p}(t)\right\|$ & 0,1319 & 0,0000 & 0,1583 & 0,0000 & 0,0969 & 0,0022 \\
\hline 3 & $\left\|v_{c}^{p}(t)\right\|$ & 0,2425 & 0,0000 & 0,2262 & 0,0000 & 0,0354 & 0,2642 \\
\hline 4 & $\left\|v_{n}^{p}(t)\right\|$ & 0,1405 & 0,0000 & 0,1393 & 0,0000 & 0,0104 & 0,7416 \\
\hline 5 & $\left\|v_{a}^{q^{\prime \prime}}(t)\right\|$ & 0,1267 & 0,0001 & 0,1297 & 0,0000 & 0,4963 & 0,0000 \\
\hline 6 & $\left\|v_{b}^{q^{\|}}(t)\right\|$ & 0,5119 & 0,0000 & 0,3182 & 0,0000 & 0,6438 & 0,0000 \\
\hline 7 & $\left\|v_{c}^{q^{\|}}(t)\right\|$ & 0,0939 & 0,0030 & 0,1070 & 0,0007 & 0,3075 & 0,0000 \\
\hline 8 & $\left\|v_{n}^{q^{\prime \prime}}(t)\right\|$ & 0,1204 & 0,0001 & 0,0803 & 0,0111 & 0,0503 & 0,1119 \\
\hline 9 & $\left\|v_{a}^{q^{\perp}}(t)\right\|$ & 0,0354 & 0,2635 & 0,0074 & 0,8153 & 0,3171 & 0,0000 \\
\hline 10 & $\left\|v_{b}^{q^{\perp}}(t)\right\|$ & 0,0624 & 0,0487 & 0,0577 & 0,0685 & 0,3978 & 0,0000 \\
\hline 11 & $\left\|v_{c}^{q^{\perp}}(t)\right\|$ & 0,1914 & 0,0000 & 0,2292 & 0,0000 & 0,3456 & 0,0000 \\
\hline 12 & $\left\|v_{n}^{q^{\perp}}(t)\right\|$ & 0,0075 & 0,8118 & 0,0156 & 0,6215 & 0,0590 & 0,0625 \\
\hline 13 & $\left\|v_{a}^{d}(t)\right\|$ & 0,0354 & 0,2635 & 0,0074 & 0,8153 & 0,3165 & 0,0000 \\
\hline 14 & $\left\|v_{b}^{d}(t)\right\|$ & 0,0624 & 0,0488 & 0,0577 & 0,0685 & 0,3048 & 0,0000 \\
\hline 15 & $\left\|v_{c}^{d}(t)\right\|$ & 0,1914 & 0,0000 & 0,2292 & 0,0000 & 0,3481 & 0,0000 \\
\hline 16 & $\left\|v_{n}^{d}(t)\right\|$ & 0,0075 & 0,8118 & 0,0156 & 0,6215 & 0,0607 & 0,0551 \\
\hline
\end{tabular}
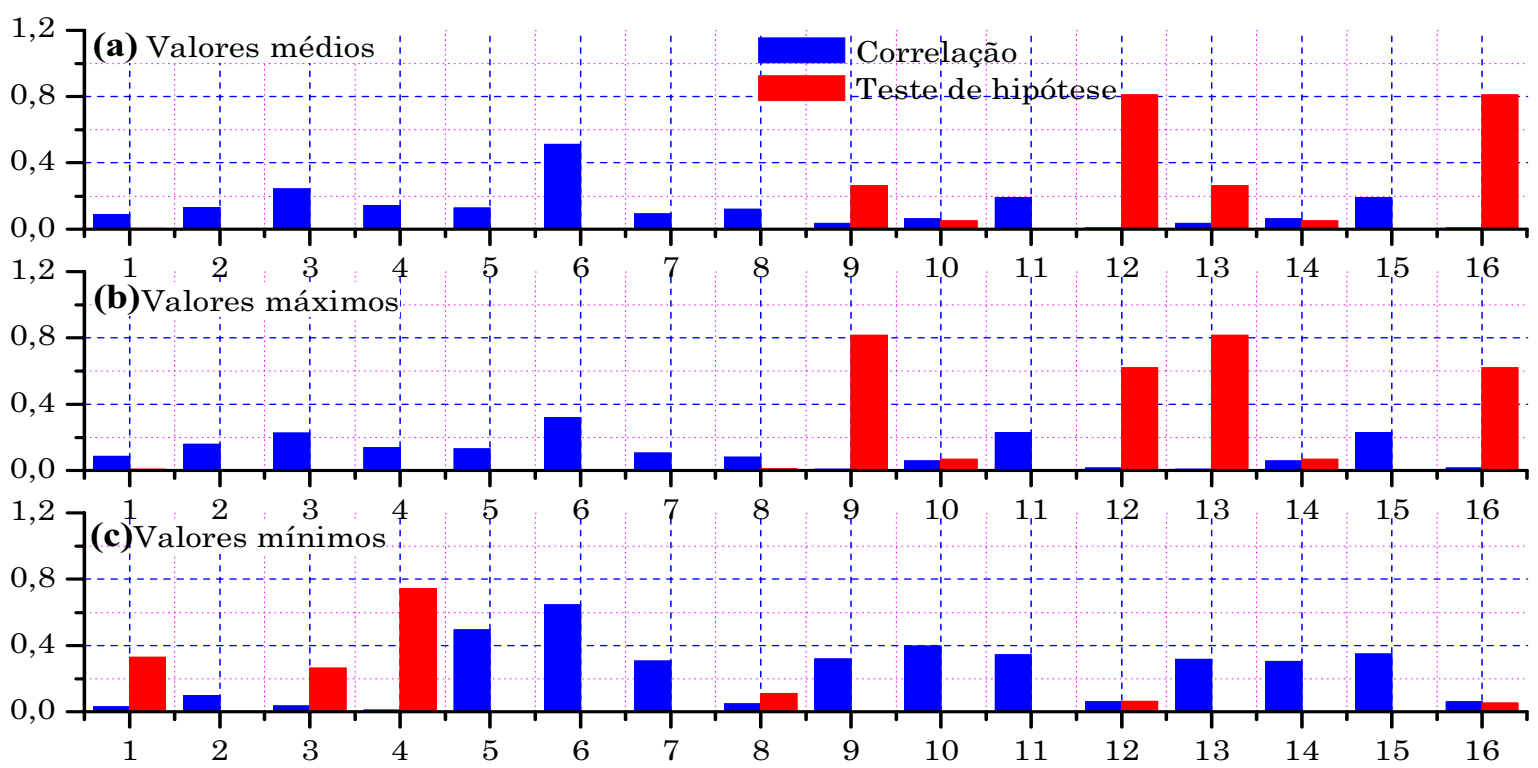

Variável (índice)

Figura 6.18 - Correlação e teste de hipótese para as componentes de tensão contidas na função planar das tensões de linha com a distância de ocorrência de falta na Fase B; (a) Correlação e teste de hipótese para os valores médios; (b) Correlação e teste de hipótese para os valores máximos; (c) Correlação e teste de hipótese para os valores mínimos. 
Tabela 6.8 - Correlação das componentes de corrente contidas na função planar das tensões de linha com relação à distância de ocorrência de falta na Fase B.

\begin{tabular}{|c|c|c|c|c|c|c|c|}
\hline \multirow[b]{2}{*}{$k$} & \multirow[b]{2}{*}{ Variável } & \multicolumn{2}{|c|}{ Média } & \multicolumn{2}{|c|}{ Máximo } & \multicolumn{2}{|c|}{ Mínimo } \\
\hline & & Correlação & $\begin{array}{l}\text { Teste de } \\
\text { hipótese }\end{array}$ & Correlação & $\begin{array}{l}\text { Teste de } \\
\text { hipótese }\end{array}$ & Correlação & $\begin{array}{l}\text { Teste de } \\
\text { hipótese }\end{array}$ \\
\hline 1 & $\left\|i_{a}^{p}(t)\right\|$ & 0,0234 & 0,4596 & 0,0362 & 0,2528 & 0,0666 & 0,0353 \\
\hline 2 & $\left\|i_{b}^{p}(t)\right\|$ & 0,1696 & 0,0000 & 0,0093 & 0,7680 & 0,0988 & 0,0018 \\
\hline 3 & $\left\|i_{c}^{p}(t)\right\|$ & 0,0045 & 0,8880 & 0,0386 & 0,2223 & 0,0439 & 0,1652 \\
\hline 4 & $\left\|i_{n}^{p}(t)\right\|$ & 0,1404 & 0,0000 & 0,1240 & 0,0001 & 0,0044 & 0,8900 \\
\hline 5 & $\left\|i_{a}^{q^{\prime \prime}}(t)\right\|$ & 0,1238 & 0,0001 & 0,0118 & 0,7103 & 0,5051 & 0,0000 \\
\hline 6 & $\left\|i_{b}^{q^{\prime \prime}}(t)\right\|$ & 0,2449 & 0,0000 & 0,1923 & 0,0000 & 0,5938 & 0,0000 \\
\hline 7 & $\left\|i_{c}^{q^{\prime \prime}}(t)\right\|$ & 0,0810 & 0,0105 & 0,0934 & 0,0031 & 0,3449 & 0,0000 \\
\hline 8 & $\left\|i_{n}^{q^{\prime \prime}}(t)\right\|$ & 0,1229 & 0,0001 & 0,0872 & 0,0058 & 0,0462 & 0,1447 \\
\hline 9 & $\left\|i_{a}^{q^{\perp}}(t)\right\|$ & 0,1052 & 0,0009 & 0,0835 & 0,0083 & 0,1769 & 0,0000 \\
\hline 10 & $\left\|i_{b}^{q^{\perp}}(t)\right\|$ & 0,1894 & 0,0000 & 0,2107 & 0,0000 & 0,0000 & 1,0000 \\
\hline 11 & $\left\|i_{c}^{q^{\perp}}(t)\right\|$ & 0,3540 & 0,0000 & 0,2747 & 0,0000 & 0,0000 & 1,0000 \\
\hline 12 & $\left\|i_{n}^{q^{\perp}}(t)\right\|$ & 0,2642 & 0,0000 & 0,1618 & 0,0000 & 0,0000 & 1,0000 \\
\hline 13 & $\left\|i_{a}^{d}(t)\right\|$ & 0,1052 & 0,0009 & 0,0835 & 0,0083 & 0,1612 & 0,0000 \\
\hline 14 & $\left\|i_{b}^{d}(t)\right\|$ & 0,0632 & 0,0457 & 0,0194 & 0,5398 & 0,0000 & 1,0000 \\
\hline 15 & $\left\|i_{c}^{d}(t)\right\|$ & 0,0259 & 0,4141 & 0,0354 & 0,2637 & 0,0000 & 1,0000 \\
\hline 16 & $\overline{\left\|i_{n}^{d}(t)\right\|}$ & 0,2642 & 0,0000 & 0,1618 & 0,0000 & 0,0000 & 1,0000 \\
\hline
\end{tabular}
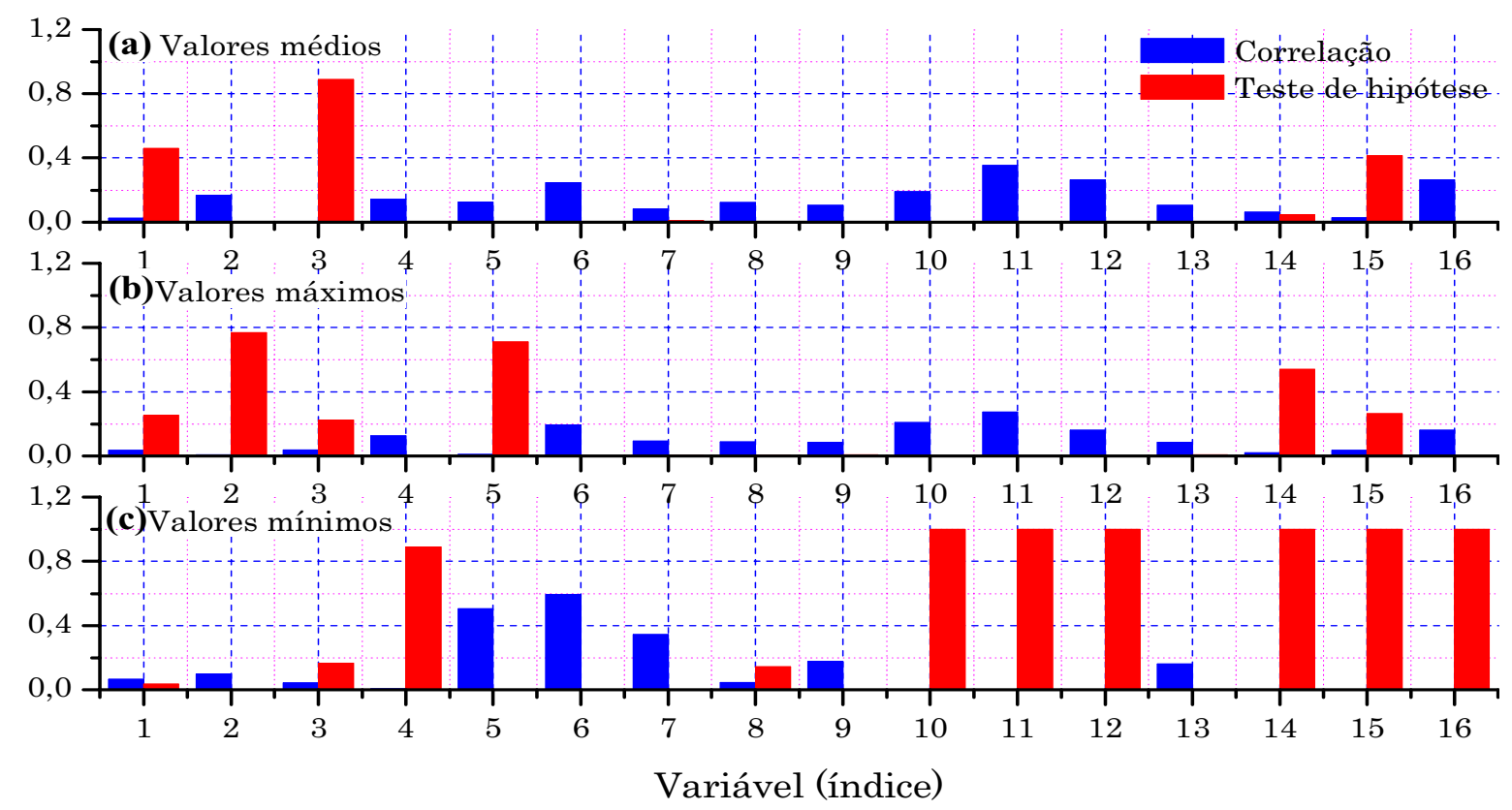

Figura 6.19 - Correlação e teste de hipótese para as componentes de corrente contidas na função planar das tensões de linha com a distância de ocorrência de falta na Fase B; (a) Correlação e teste de hipótese para os valores médios; (b) Correlação e teste de hipótese para os valores máximos; (c) Correlação e teste de hipótese para os valores mínimos. 
Tabela 6.9 - Correlação das componentes de tensão ortogonais à função planar das tensões de linha com relação à distância de ocorrência de falta na Fase B.

\begin{tabular}{|c|c|c|c|c|c|c|c|}
\hline \multirow[b]{2}{*}{$k$} & \multirow[b]{2}{*}{ Variável } & \multicolumn{2}{|c|}{ Média } & \multicolumn{2}{|c|}{ Máximo } & \multicolumn{2}{|c|}{ Mínimo } \\
\hline & & Correlação & $\begin{array}{l}\text { Teste de } \\
\text { hipótese }\end{array}$ & Correlação & $\begin{array}{l}\text { Teste de } \\
\text { hipótese }\end{array}$ & Correlação & $\begin{array}{l}\text { Teste de } \\
\text { hipótese }\end{array}$ \\
\hline 1 & $\left\|v_{\bar{a}}^{p}(t)\right\|$ & 0,0978 & 0,0020 & 0,0951 & 0,0026 & 0,0302 & 0,3411 \\
\hline 2 & $\left\|v_{\bar{b}}^{p}(t)\right\|$ & 0,1443 & 0,0000 & 0,0164 & 0,6049 & 0,1407 & 0,0000 \\
\hline 3 & $\left\|v_{\bar{c}}^{p}(t)\right\|$ & 0,2151 & 0,0000 & 0,2041 & 0,0000 & 0,0326 & 0,3026 \\
\hline 4 & $\left\|v_{h}^{p}(t)\right\|$ & 0,1400 & 0,0000 & 0,1384 & 0,0000 & 0,0155 & 0,6247 \\
\hline 5 & $\left\|v_{\bar{a}}^{q^{\prime \prime}}(t)\right\|$ & 0,0269 & 0,3954 & 0,0016 & 0,9601 & 0,0726 & 0,0218 \\
\hline 6 & $\left\|v q^{q^{\prime \prime}}(t)\right\|$ & 0,1519 & 0,0000 & 0,2272 & 0,0000 & 0,0405 & 0,2007 \\
\hline 7 & $\left\|v_{\bar{c}}^{q^{\prime \prime}}(t)\right\|$ & 0,1072 & 0,0007 & 0,0269 & 0,3956 & 0,0891 & 0,0048 \\
\hline 8 & $\left\|v_{h}^{q^{\| \prime}}(t)\right\|$ & 0,0548 & 0,0834 & 0,0691 & 0,0290 & 0,4362 & 0,0000 \\
\hline 9 & $\left\|v_{\bar{a}}^{q^{\perp}}(t)\right\|$ & 0,3517 & 0,0000 & 0,3402 & 0,0000 & 0,1093 & 0,0005 \\
\hline 10 & $\left\|v_{\frac{q^{\perp}}{b}}^{\perp}(t)\right\|$ & 0,0956 & 0,0025 & 0,1275 & 0,0001 & 0,0000 & 1,0000 \\
\hline 11 & $\left\|v_{\bar{c}}^{q^{\perp}}(t)\right\|$ & 0,2523 & 0,0000 & 0,2433 & 0,0000 & 0,0000 & 1,0000 \\
\hline 12 & $\left\|v_{h}^{q^{\perp}}(t)\right\|$ & 0,2473 & 0,0000 & 0,2317 & 0,0000 & 0,2887 & 0,0000 \\
\hline 13 & $\left\|v_{\bar{a}}^{d}(t)\right\|$ & 0,3517 & 0,0000 & 0,3402 & 0,0000 & 0,2638 & 0,0000 \\
\hline 14 & $\left\|v_{\bar{b}}^{d}(t)\right\|$ & 0,1419 & 0,0000 & 0,0329 & 0,2986 & 0,0039 & 0,9011 \\
\hline 15 & $\left\|v_{\bar{c}}^{d}(t)\right\|$ & 0,1552 & 0,0000 & 0,0160 & 0,6140 & 0,1453 & 0,0000 \\
\hline 16 & $\left\|v_{h}^{d}(t)\right\|$ & 0,2473 & 0,0000 & 0,2317 & 0,0000 & 0,3171 & 0,0000 \\
\hline
\end{tabular}
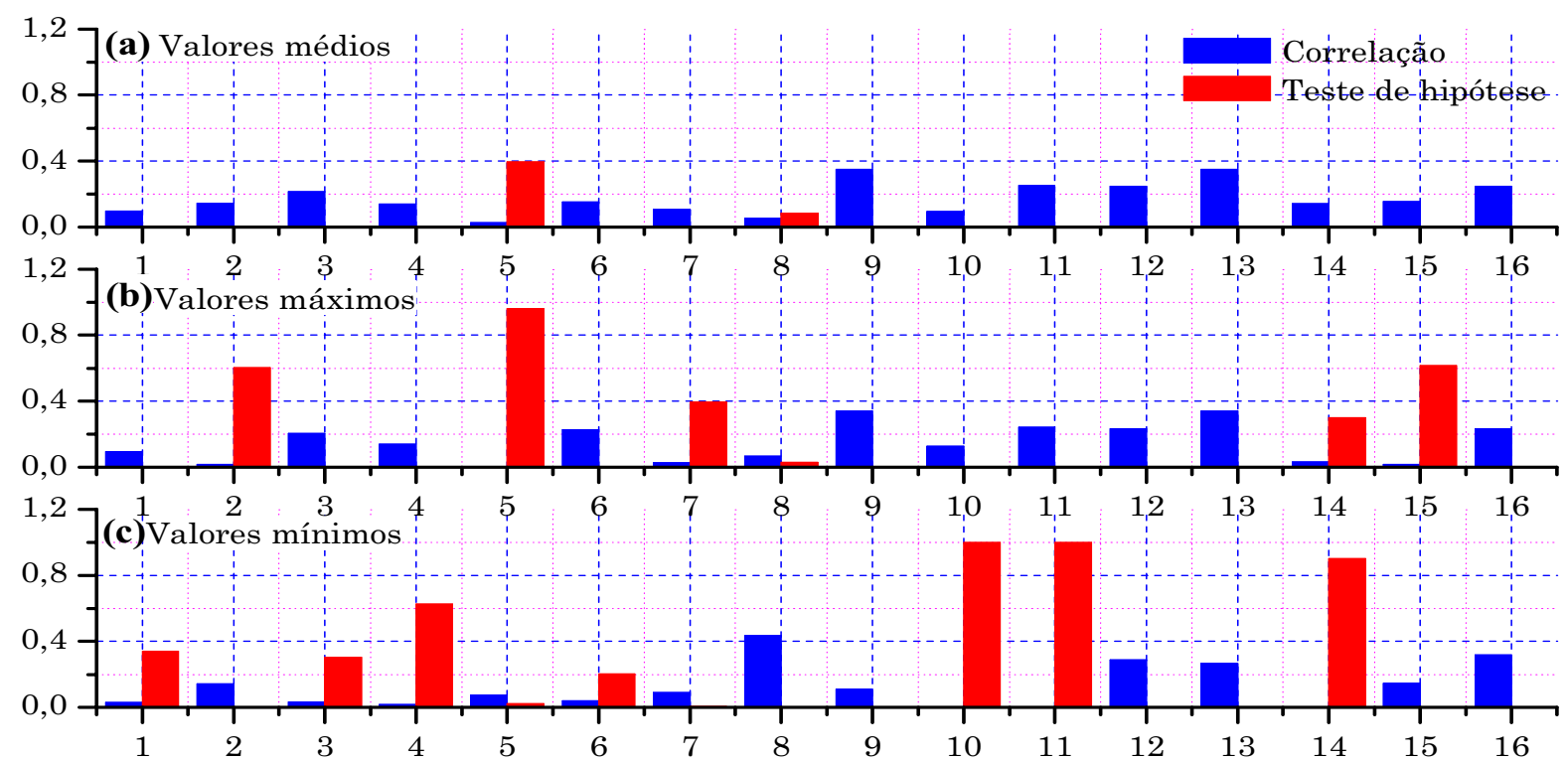

Variável (índice)

Figura 6.20 - Correlação e teste de hipótese para as componentes de tensão ortogonais à função planar das tensões de linha com a distância de ocorrência de falta na Fase B; (a) Correlação e teste de hipótese para os valores médios; (b) Correlação e teste de hipótese para os valores máximos; (c) Correlação e teste de hipótese para os valores mínimos. 
Tabela 6.10 - Correlação das componentes de corrente ortogonais à função planar das tensões de linha com relação à distância de ocorrência de falta na Fase B.

\begin{tabular}{|c|c|c|c|c|c|c|c|}
\hline \multirow[b]{2}{*}{$k$} & \multirow[b]{2}{*}{ Variável } & \multicolumn{2}{|c|}{ Média } & \multicolumn{2}{|c|}{ Máximo } & \multicolumn{2}{|c|}{ Mínimo } \\
\hline & & Correlação & $\begin{array}{l}\text { Teste de } \\
\text { hipótese }\end{array}$ & Correlação & $\begin{array}{l}\text { Teste de } \\
\text { hipótese }\end{array}$ & Correlação & $\begin{array}{l}\text { Teste de } \\
\text { hipótese }\end{array}$ \\
\hline 1 & $\left\|i_{\bar{a}}^{p}(t)\right\|$ & 0,0989 & 0,0018 & 0,1032 & 0,0011 & 0,0347 & 0,2738 \\
\hline 2 & $\left\|i_{i}^{p}(t)\right\|$ & 0,1450 & 0,0000 & 0,0269 & 0,3956 & 0,1365 & 0,0000 \\
\hline 3 & $\left\|i_{\frac{i}{c}}^{p}(t)\right\|$ & 0,2169 & 0,0000 & 0,2138 & 0,0000 & 0,0382 & 0,2277 \\
\hline 4 & $\left\|i_{h}^{p}(t)\right\|$ & 0,1409 & 0,0000 & 0,1393 & 0,0000 & 0,0232 & 0,4635 \\
\hline 5 & $\left\|i_{a}^{q^{\|}}(t)\right\|$ & 0,0338 & 0,2857 & 0,0266 & 0,4014 & 0,0324 & 0,3057 \\
\hline 6 & $\left\|i^{q^{\prime \prime}}(t)\right\|$ & 0,0726 & 0,0217 & 0,1796 & 0,0000 & 0,3907 & 0,0000 \\
\hline 7 & $\left\|i_{\frac{q^{\|}}{c}}(t)\right\|$ & 0,1230 & 0,0001 & 0,0033 & 0,9162 & 0,0402 & 0,2039 \\
\hline 8 & $\left\|i_{h}^{q^{\|}}(t)\right\|$ & 0,0932 & 0,0032 & 0,0419 & 0,1861 & 0,0575 & 0,0692 \\
\hline 9 & $\left\|i_{\bar{a}}^{q^{\perp}}(t)\right\|$ & 0,0500 & 0,1146 & 0,0512 & 0,1057 & 0,0797 & 0,0118 \\
\hline 10 & $\left\|i^{q^{\perp}}(t)\right\|$ & 0,1023 & 0,0012 & 0,1134 & 0,0003 & 0,1915 & 0,0000 \\
\hline 11 & $\left\|i_{c}^{q^{\perp}}(t)\right\|$ & 0,3133 & 0,0000 & 0,2835 & 0,0000 & 0,0000 & 1,0000 \\
\hline 12 & $\left\|i_{h}^{q^{\perp}}(t)\right\|$ & 0,0140 & 0,6593 & 0,0552 & 0,0813 & 0,0730 & 0,0210 \\
\hline 13 & $\left\|i_{\bar{a}}^{d}(t)\right\|$ & 0,0498 & 0,1155 & 0,0511 & 0,1063 & 0,0587 & 0,0639 \\
\hline 14 & $\left\|i_{\bar{b}}^{d}(t)\right\|$ & 0,1023 & 0,0012 & 0,1134 & 0,0003 & 0,1655 & 0,0000 \\
\hline 15 & $\left\|i_{\bar{c}}^{d}(t)\right\|$ & 0,1669 & 0,0000 & 0,0594 & 0,0605 & 0,2505 & 0,0000 \\
\hline 16 & $\left\|i_{h}^{d}(t)\right\|$ & 0,0140 & 0,6592 & 0,0552 & 0,0813 & 0,0958 & 0,0024 \\
\hline
\end{tabular}
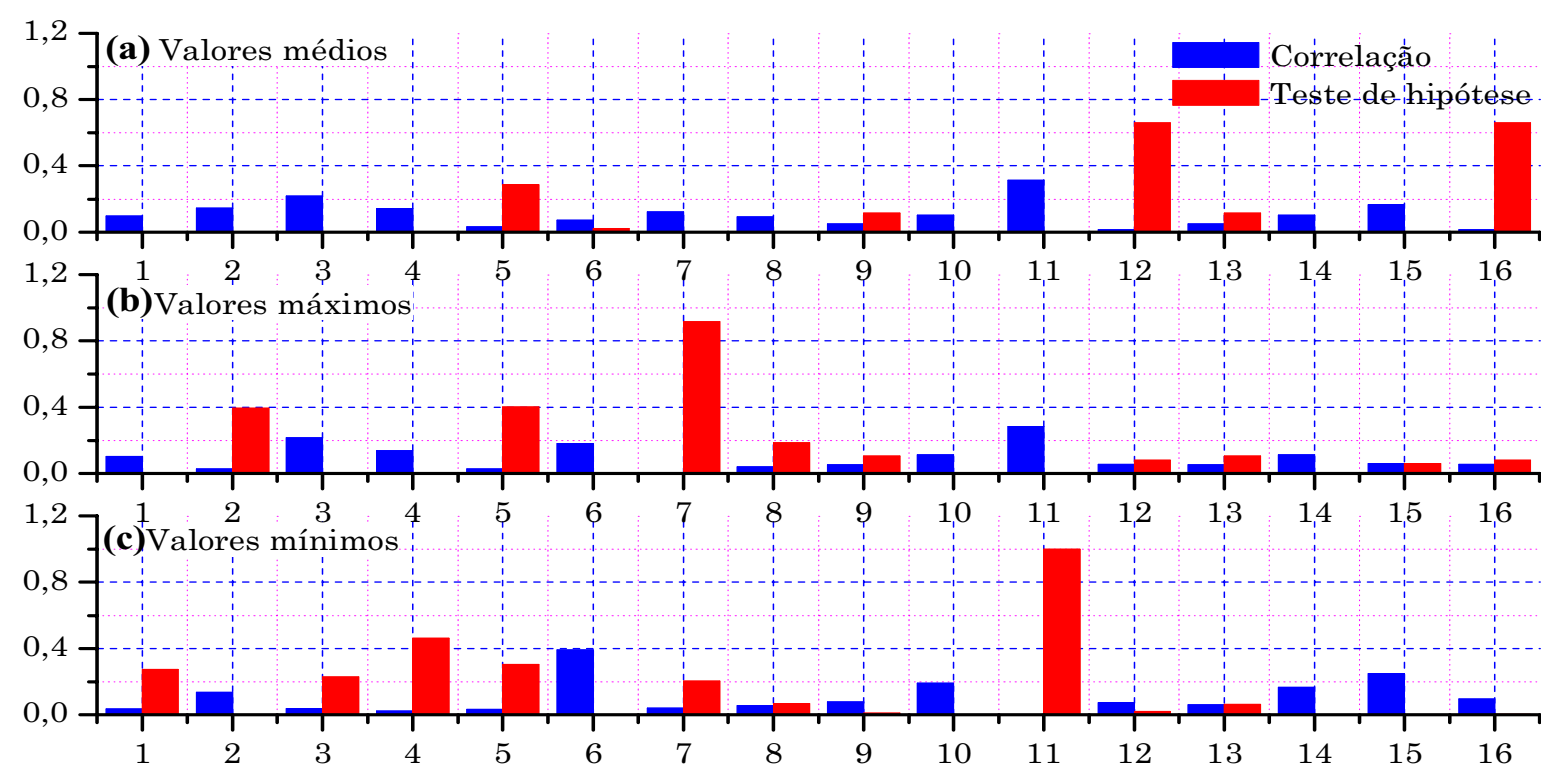

Variável (índice)

Figura 6.21 - Correlação e teste de hipótese para as componentes de corrente ortogonais à função planar das tensões de linha com a distância de ocorrência de falta na Fase B; (a) Correlação e teste de hipótese para os valores médios; (b) Correlação e teste de hipótese para os valores máximos; (c) Correlação e teste de hipótese para os valores mínimos. 
Por meio dos valores de correlação apresentados nas tabelas anteriores é possível verificar que as doze variáveis mais correlacionadas com a distância de ocorrência de faltas na Fase B são aquelas destacadas na Tabela 6.11, a qual destaca também as referidas correlações.

Tabela 6.11 - Variáveis mais correlatas à localização de faltas fase-terra na Fase B.

\begin{tabular}{ccccc}
\hline \hline Índice & Variável & Característica & Símbolo & Correlação \\
\hline \hline 1 & $\left\|v_{b}^{q^{\prime \prime}}(t)\right\|$ & Mínimo & $\left\|v_{b}^{q^{\prime \prime}}(t)\right\|^{\min }$ & 0,6438 \\
\hline 2 & $\left\|i_{b}^{q^{\prime}}(t)\right\|$ & Mínimo & $\left\|i_{b}^{q^{\prime \prime}}(t)\right\|^{\min }$ & 0,5938 \\
\hline 3 & $\left\|v_{b}^{q^{\prime \prime}}(t)\right\|$ & Média & $\left\|v_{b}^{q^{\prime \prime}}(t)\right\|$ & 0,5119 \\
\hline 4 & $\left\|i_{a}^{q^{\prime}}(t)\right\|$ & Mínimo & $\left\|i_{a}^{q^{\prime \prime}}(t)\right\|^{\min }$ & 0,5051 \\
\hline 5 & $\left\|v_{a}^{q^{\prime \prime}}(t)\right\|$ & Mínimo & $\left\|v_{a}^{q^{\prime \prime}}(t)\right\|^{\min }$ & 0,4963 \\
\hline 6 & $\left\|v_{h}^{q^{\prime \prime}}(t)\right\|$ & Mínimo & $\left\|v_{h}^{q^{\prime \prime}}(t)\right\|^{\min }$ & 0,4362 \\
\hline 7 & $\left\|v_{b}^{q^{\perp}}(t)\right\|$ & Mínimo & $\left\|v_{b}^{q^{\perp}}(t)\right\|^{\min }$ & 0,3978 \\
\hline 8 & $\left\|i_{\bar{b}}^{q^{\prime}}(t)\right\|$ & Mínimo & $\left\|i_{\frac{q^{\prime}}{b}}(t)\right\|^{\min }$ & 0,3907 \\
\hline 9 & $\left\|i_{c}^{q^{\perp}}(t)\right\|$ & Média & $\overline{\left\|i_{c}^{q^{\perp}}(t)\right\|}$ & 0,3540 \\
\hline 10 & $\left\|v_{\bar{a}}^{q^{\perp}}(t)\right\|$ & Média & $\overline{\left\|v_{\bar{a}}^{q^{\perp}}(t)\right\|}$ & 0,3517 \\
\hline 11 & $\left\|v_{\bar{a}}^{d}(t)\right\|$ & Média & $\left\|v_{a}^{d}(t)\right\|$ & 0,3517 \\
\hline 12 & $\left\|v_{c}^{d}(t)\right\|$ & Mínimo & $\left\|v_{c}^{d}(t)\right\|^{\min }$ & 0,3481 \\
\hline \hline
\end{tabular}

As variáveis apresentadas na Tabela 6.11 representam as variáveis mais correlatas com a distância de ocorrência da falta quando essa envolver a Fase B. Além de constituírem as variáveis mais correlatas, essas foram aquelas empregadas como entrada do sistema fuzzy responsável pela estimação da distância de ocorrência da falta. O sistema fuzzy responsável pela estimação da distância de ocorrência da falta fora constituído por 40 regras de inferência, número esse de regras que, durante os testes computacionais, se mostrou adequado na estimação da distância.

O sistema fuzzy fora ajustado segundo o algoritmo delineado no Capítulo 4 e fazendo uso de um conjunto de ajuste constituído por 999 pares entrada-saída. Todo o conjunto de ajuste fora construído se fazendo uso das simulações computacionais descritas no Capítulo 5 referentes às faltas fase-terra com participação da Fase B. 
O algoritmo de ajuste delineado no Capítulo 4 é composto de duas etapas de ajuste. A primeira dessas etapas responde pelo ajuste estrutural do sistema fuzzy que, conforme abordado, é dedicado à extração das regras de inferência fuzzy que melhor correlacionam o espaço fuzzy das entradas com o espaço fuzzy da saída. Dessa forma, tem-se como produto da primeira etapa de ajuste a base de regra do sistema fuzzy que, nesse caso, será responsável pela estimação da distância de ocorrência da falta quando a mesma envolver a Fase B.

A fim de apresentar como o erro quadrático médio do sistema fuzzy se portou ao longo das iterações do processo de ajuste estrutural, retrata-se à Figura 6.22, onde tal comportamento é ilustrado.

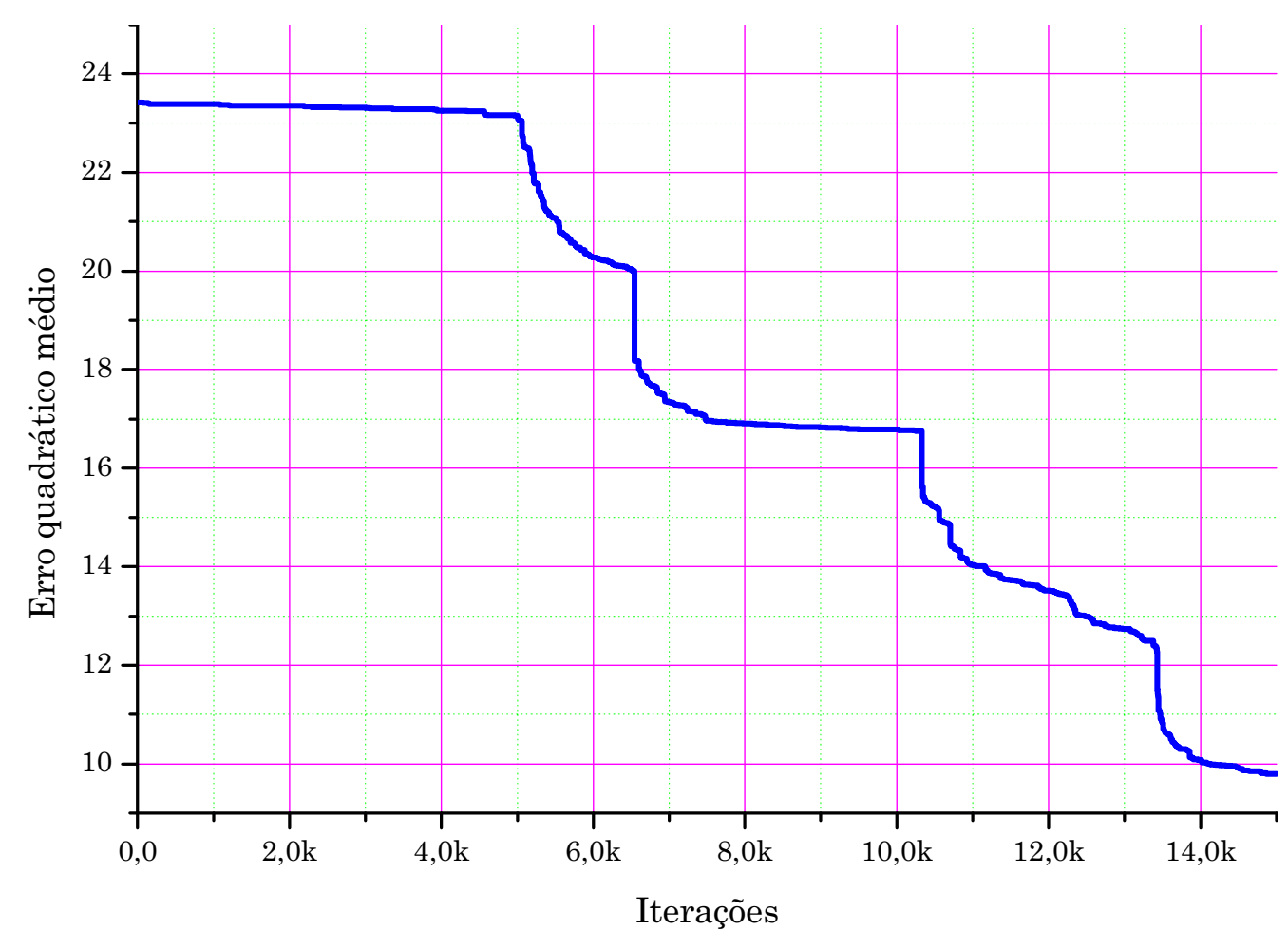

Figura 6.22 - Comportamento do erro quadrático médio do sistema fuzzy dedicado à estimação da distância de ocorrência da falta quando essa envolver a Fase B ao longo das iterações da primeira etapa de ajuste.

O gráfico da Figura 6.22 apresenta a sensível redução do erro quadrático médio ao longo das iterações da primeira etapa de ajuste para o sistema fuzzy responsável pela estimação da distância de ocorrência de uma falta fase-terra quando essa envolver a Fase B. Ao término dessa primeira etapa de ajuste, assim como anteriormente citado, tem-se como produto a base de regras responsável pelo relacionamento entre o espaço fuzzy das variáveis de entrada com o espaço fuzzy da variável de saída. Retratando a base de regras determinada por essa etapa de ajuste, apresenta-se a Figura 6.23. 


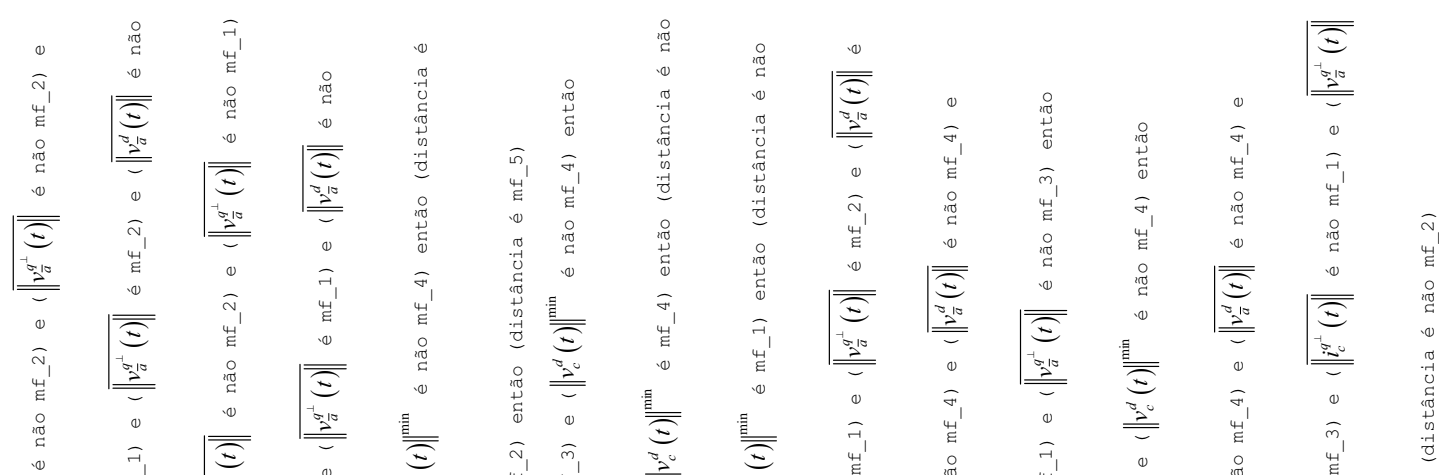

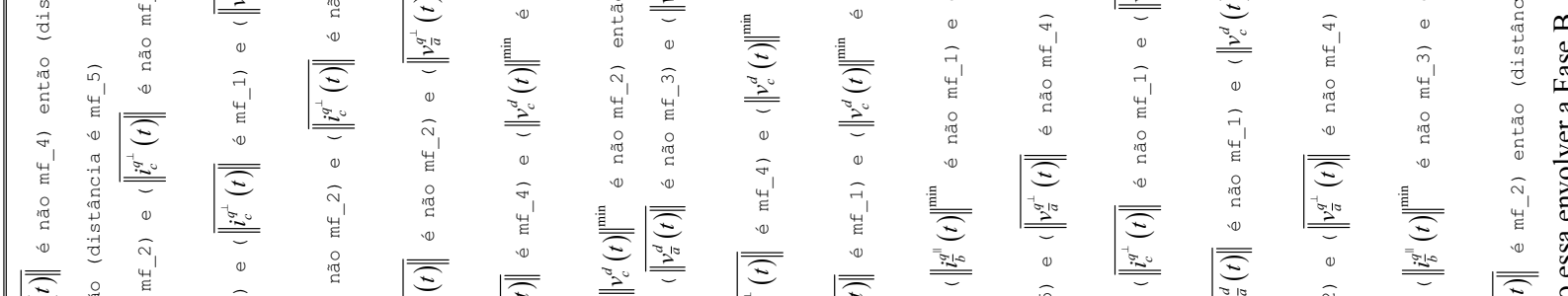

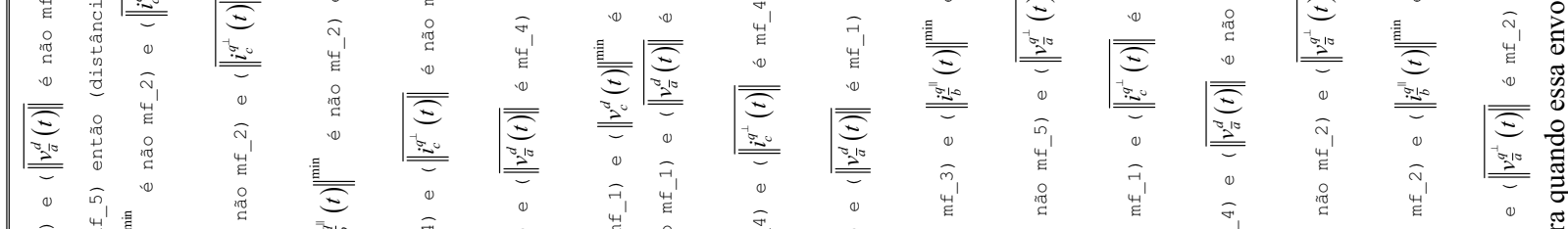

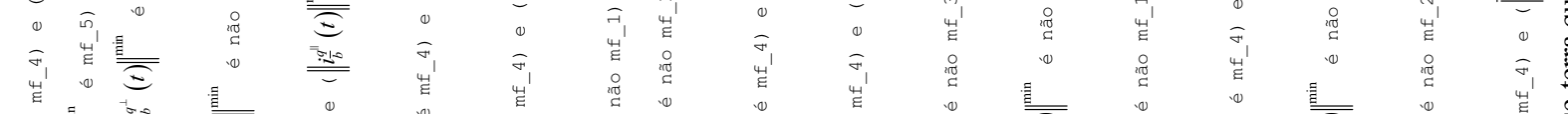

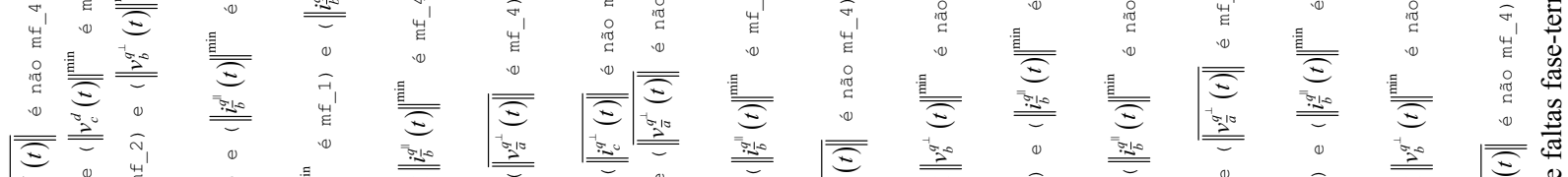

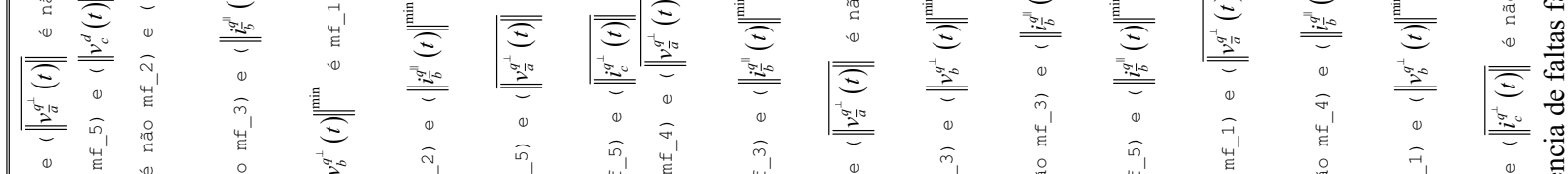

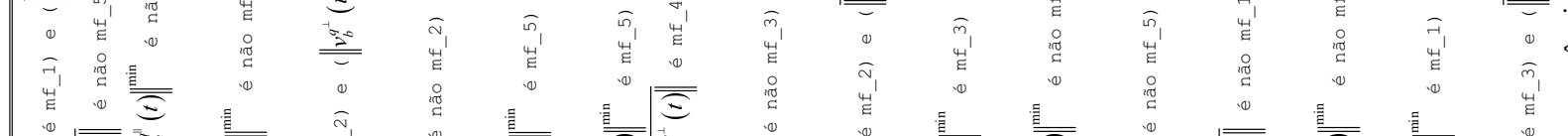

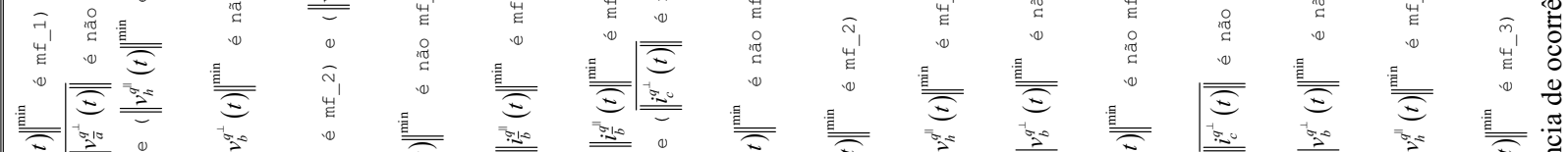

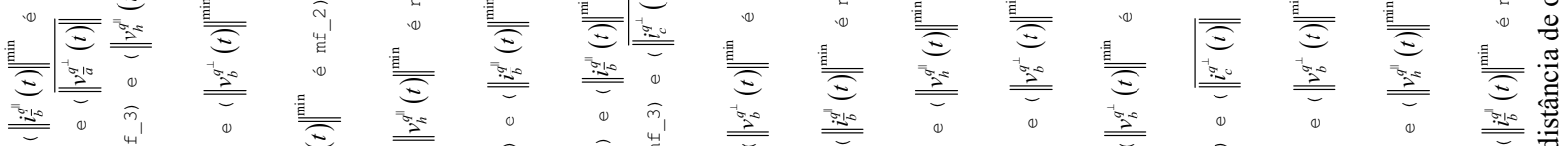

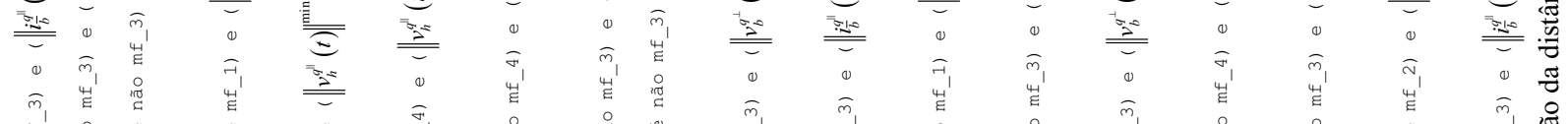

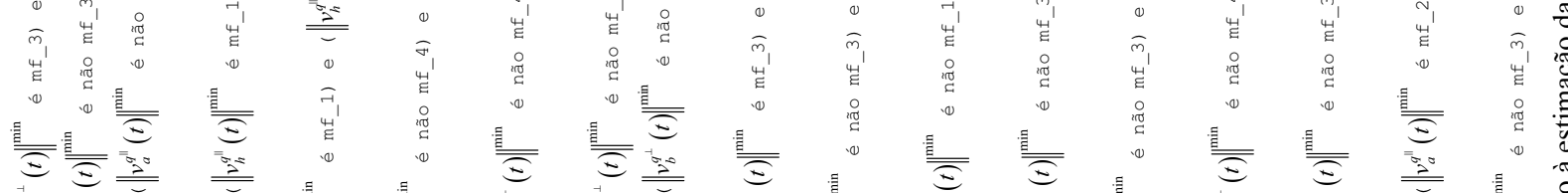

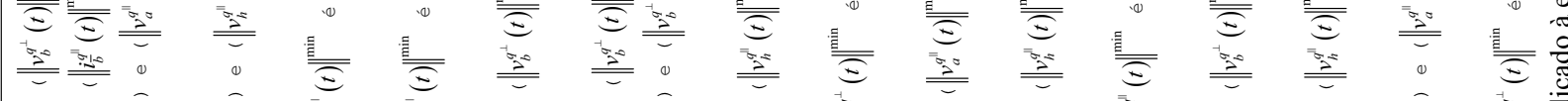

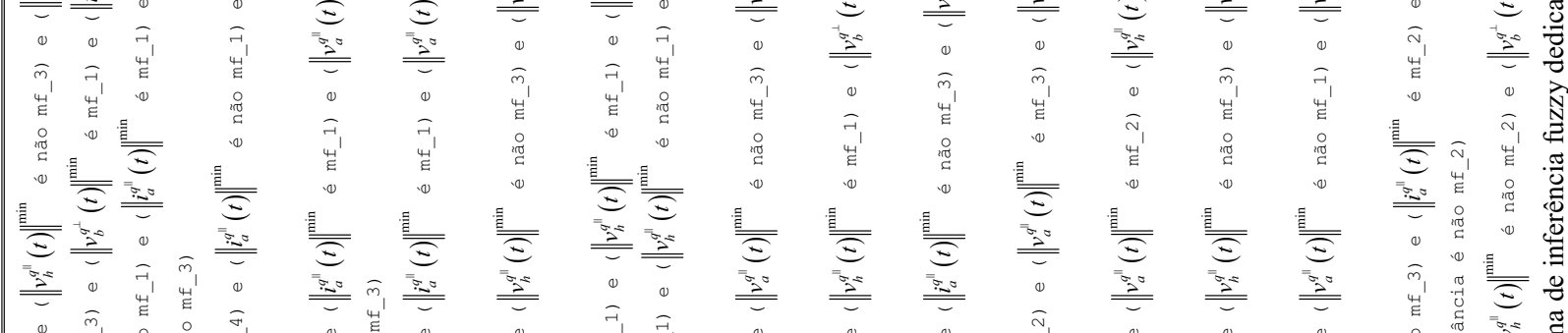

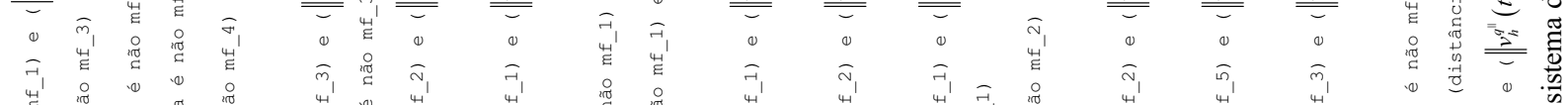

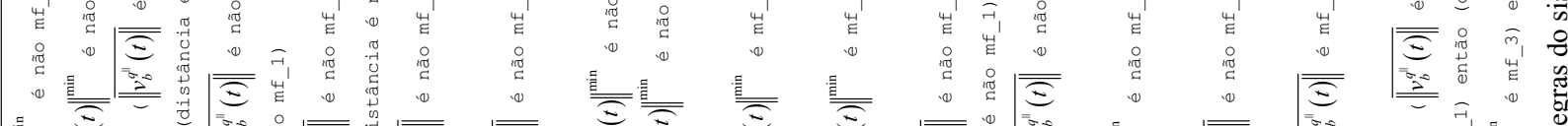

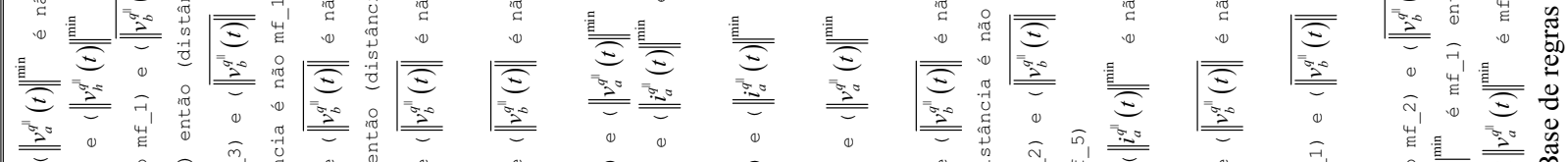

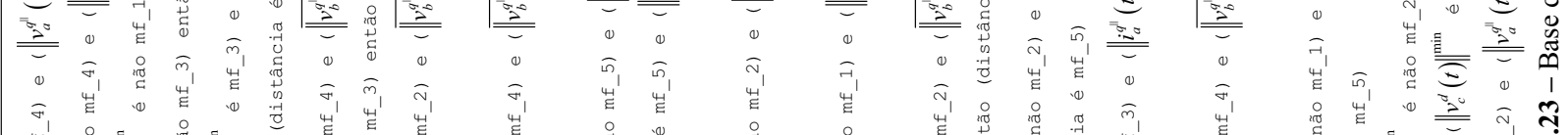

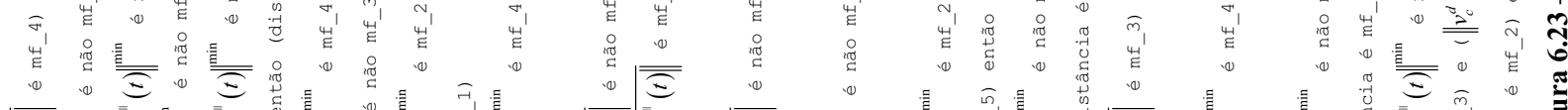

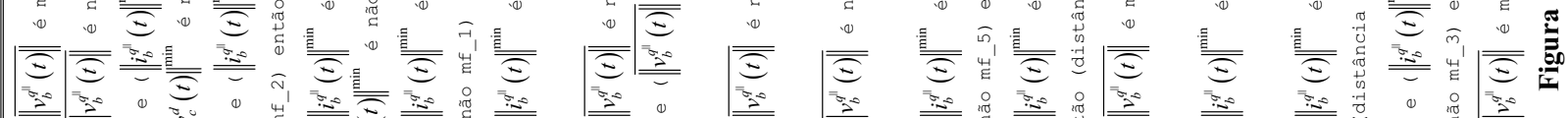

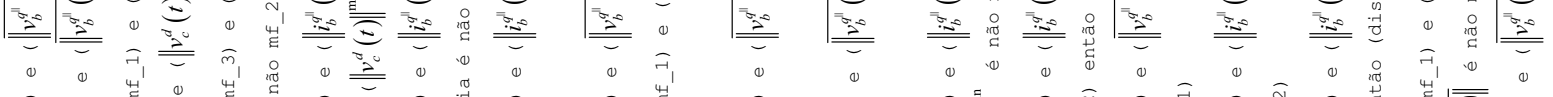

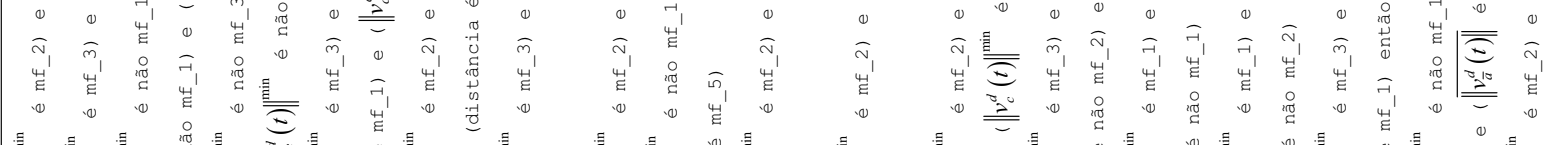

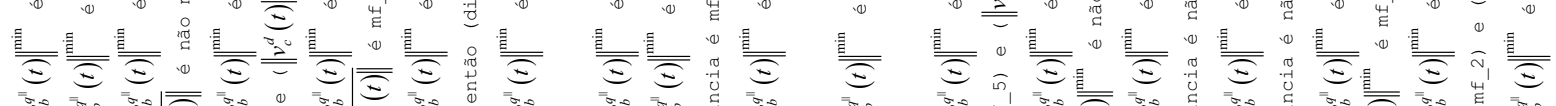

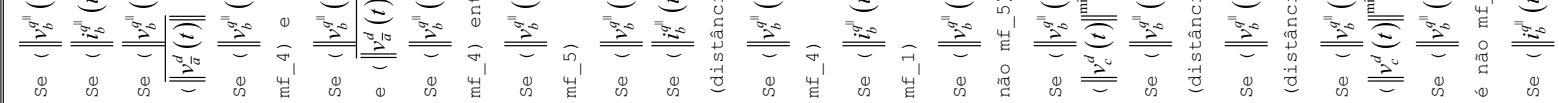




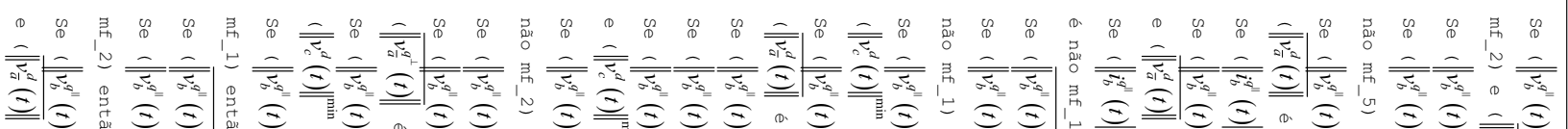

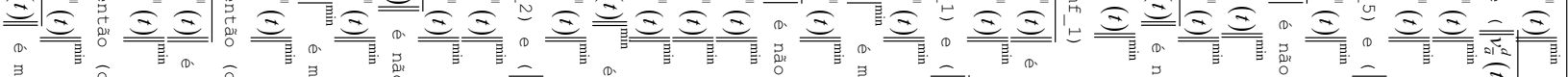

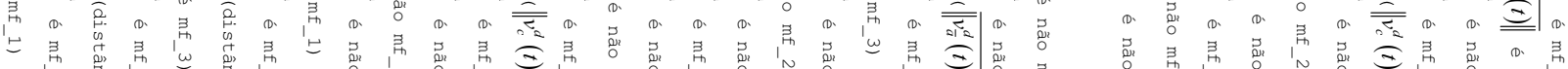

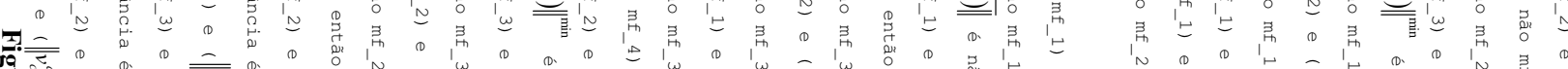

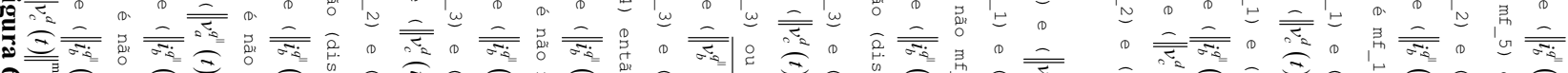

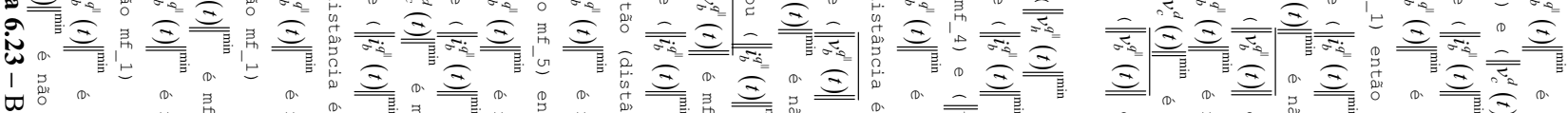

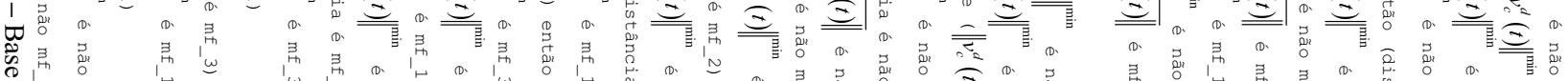

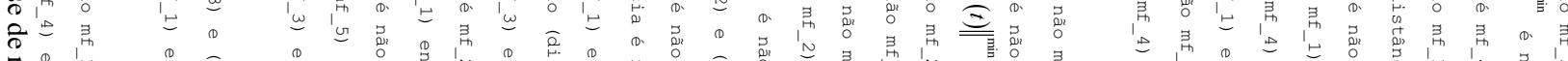

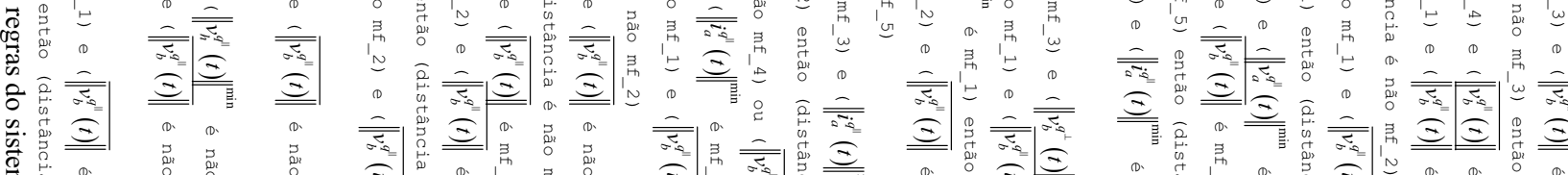

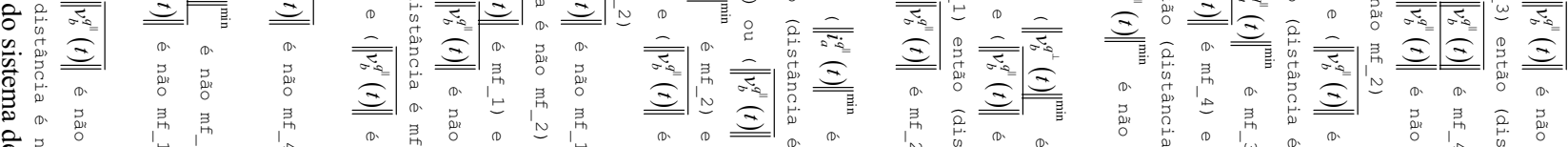

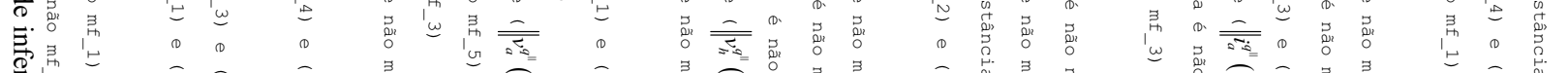

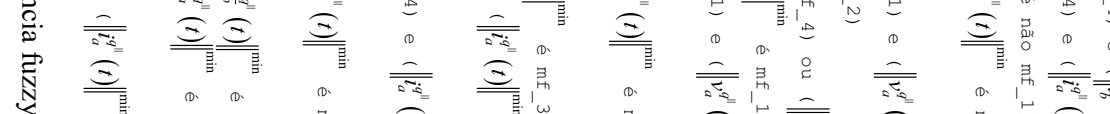

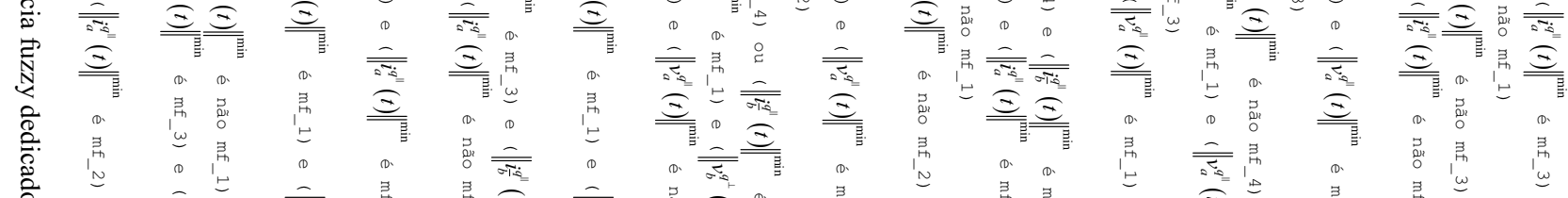

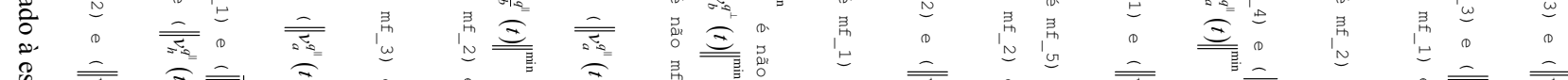

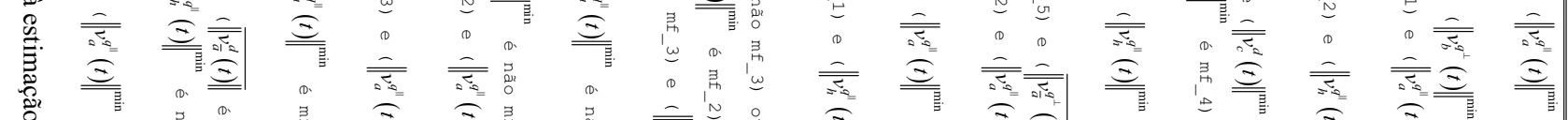

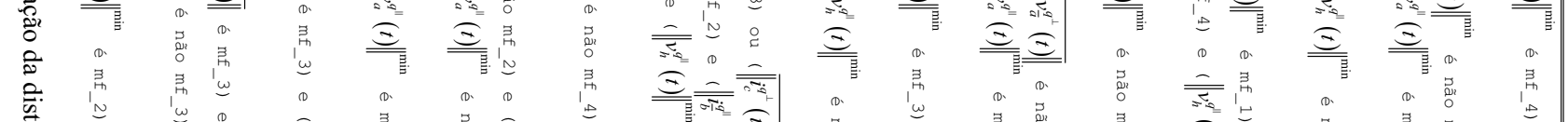

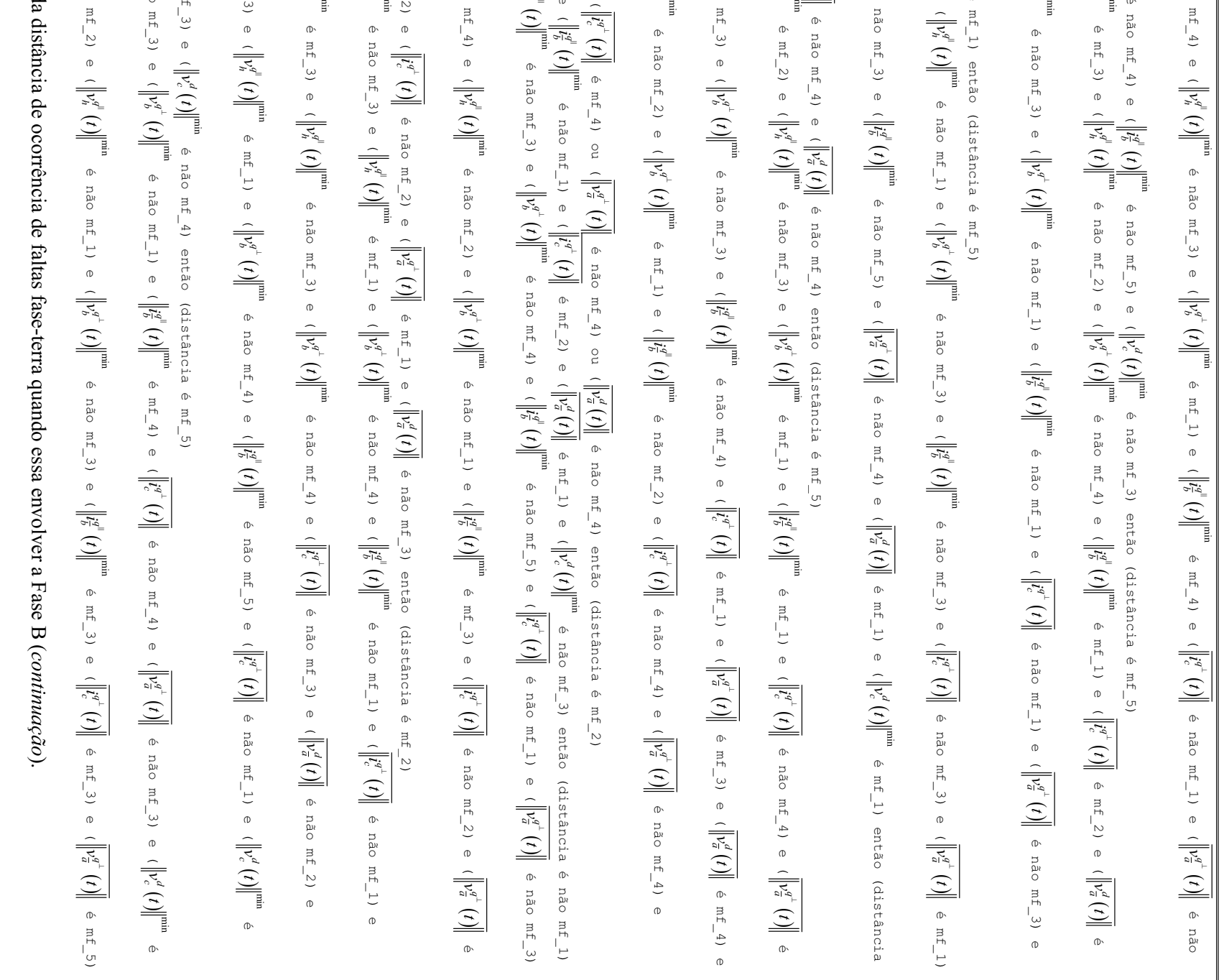


Após a determinação da base de regras, representada por meio da Figura 6.23, o sistema de inferência fuzzy fora submetido à segunda etapa de ajuste o qual é dedicado ao ajuste paramétrico do sistema. O ajuste paramétrico tem por meta prosseguir com a redução do erro quadrático iniciada na primeira etapa. Para tanto, a segunda etapa de ajuste, denotada por ajuste paramétrico, modifica os parâmetros que definem as funções de pertinência das entradas e da saída, bem como procede com a ponderação das regras fuzzy ora obtidas na primeira etapa de ajuste. Apresentando como o erro quadrático médio se portou ao longo das iterações dessa segunda etapa de ajuste, tem-se a Figura 6.24.

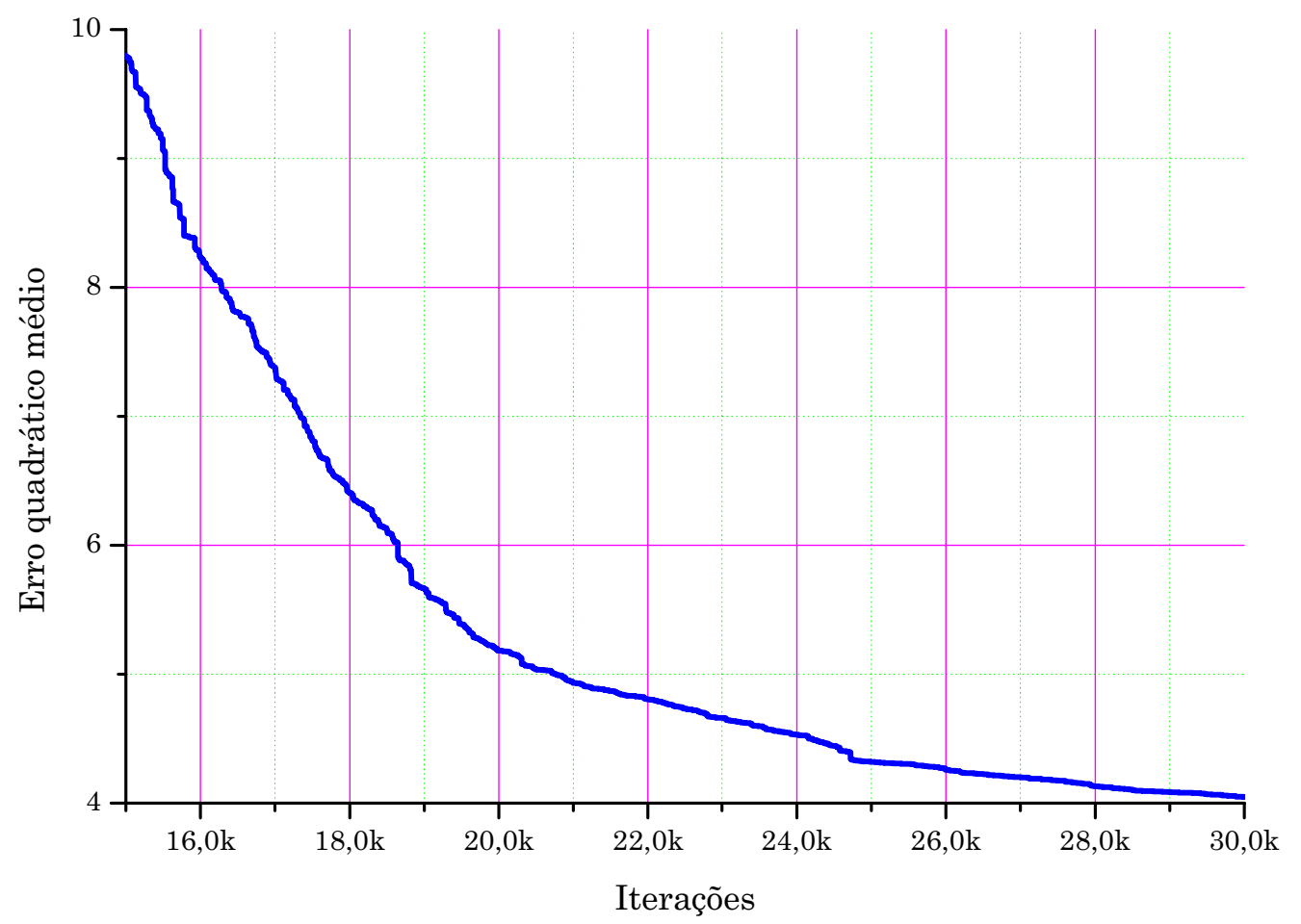

Figura 6.24 - Comportamento do erro quadrático médio do sistema fuzzy dedicado à estimação da distância de ocorrência da falta quando essa envolver a Fase B ao longo das iterações da segunda etapa de ajuste.

Por meio da Figura 6.24 é possível verificar o quão o erro quadrático médio se reduz ao longo da etapa de ajuste paramétrico. Essa etapa, assim como já referenciado, é responsável por ajustar as funções de pertinência das entradas e da saída, além de ponderar as regras de inferência fuzzy. Complementando, a apresentação dos resultados advindos do processo de ajuste paramétrico, ilustra-se por meio da Figura 6.25 as funções de pertinência ajustadas para as seis primeiras entradas, ou seja, para as entradas $\left\|v_{b}^{q^{\prime \prime}}(t)\right\|^{\text {min }},\left\|i_{b}^{q^{\prime \prime}}(t)\right\|^{\min }$, $\overline{\left\|v_{b}^{q^{\prime \prime}}(t)\right\|},\left\|i_{a}^{q^{\prime \prime}}(t)\right\|^{\min },\left\|v_{a}^{q^{\prime \prime}}(t)\right\|^{\min } \mathrm{e}\left\|v_{h}^{q^{\prime \prime}}(t)\right\|^{\min }$. Da mesma maneira, por meio da Figura 6.26 temse as funções de pertinência para as outras seis entradas, ou seja, para as entradas $\left\|v_{b}^{q^{\perp}}(t)\right\|^{\min },\left\|i_{\frac{q^{\prime}}{}}(t)\right\|^{\min }, \overline{\left\|i_{c}^{q^{\perp}}(t)\right\|} \|, \overline{\left\|v_{\bar{a}}^{q^{\perp}}(t)\right\|}, \overline{\left\|v_{\bar{a}}^{d}(t)\right\|}$ e $\left\|v_{c}^{d}(t)\right\|^{\min }$. 

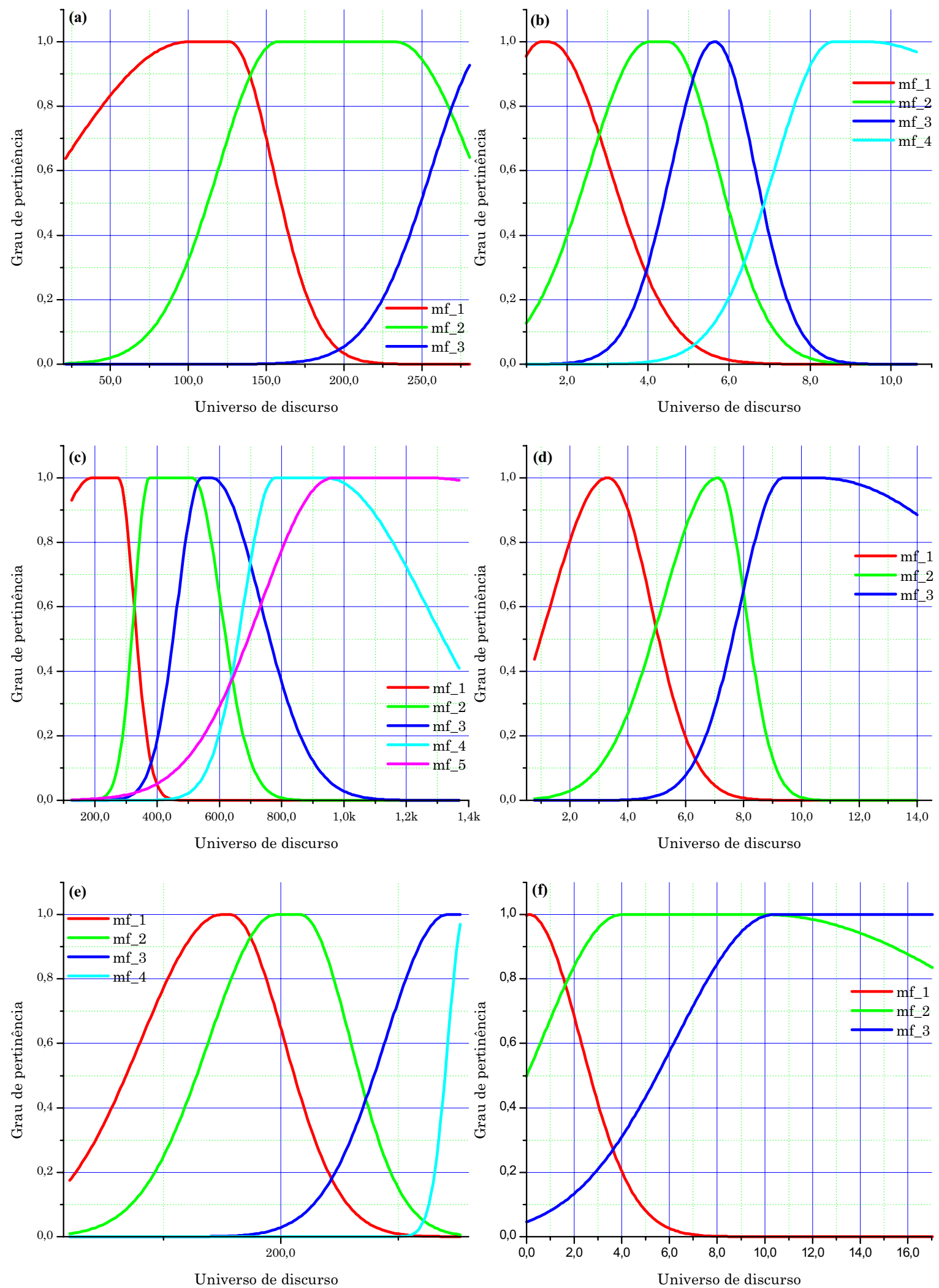

Figura 6.25 - Funções de pertinência ajustadas para as seis primeiras entradas; (a) Entrada $\left\|v_{b}^{q^{\prime}}(t)\right\|^{\text {min }}$; (b) Entrada $\left\|i_{b}^{q^{\prime \prime}}(t)\right\|^{\min }$; (c) Entrada $\overline{\left\|v_{b}^{q^{\prime \prime}}(t)\right\|} \|$; (d) Entrada $\left\|i_{a}^{q^{\prime \prime}}(t)\right\|^{\min }$; (e) Entrada $\left\|v_{a}^{q^{\prime}}(t)\right\|^{\min } ;$ (f) Entrada $\left\|v_{h}^{q^{\prime \prime}}(t)\right\|^{\min }$. 

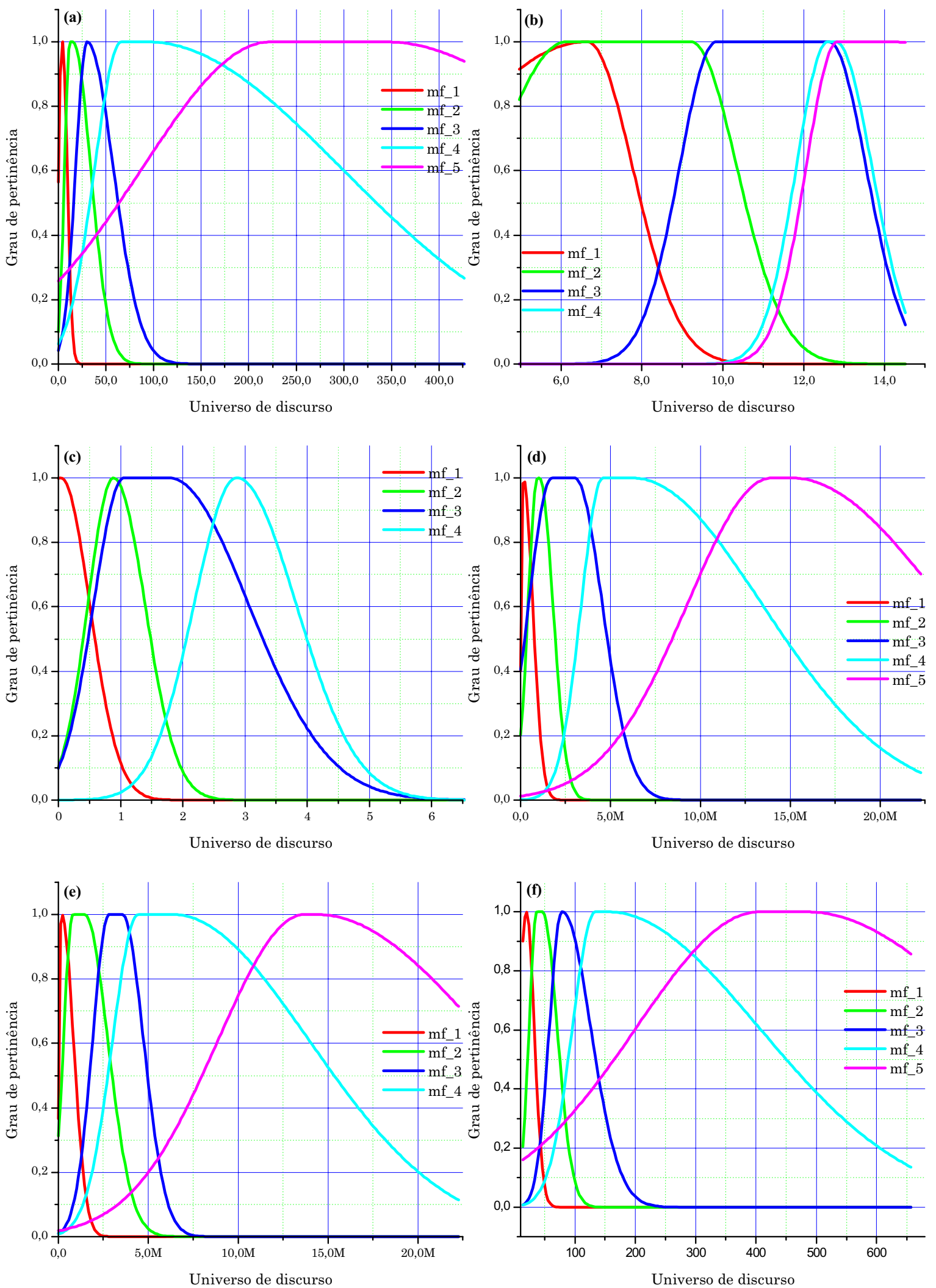

Figura 6.26 - Funções de pertinência ajustadas para as seis primeiras entradas; (a) Entrada $\left\|v_{b}^{q^{\perp}}(t)\right\|^{\min }$; (b) Entrada $\left\|i_{\frac{q^{\prime \prime}}{b}}(t)\right\|^{\min }$; (c) Entrada $\overline{\left\|i_{c}^{q^{\perp}}(t)\right\|}$; (d) Entrada $\overline{\left\|v_{\bar{a}}^{q^{\perp}}(t)\right\|}$; (e) Entrada $\overline{\left\|v_{\bar{a}}^{d}(t)\right\|} ;$ (f) Entrada $\left\|v_{c}^{d}(t)\right\|^{\min }$. 
A etapa de ajuste paramétrico não apenas sintoniza as funções de pertinência do espaço das entradas como também ajusta as funções de pertinência da saída. Assim, por meio da Figura 6.27 apresentam-se as funções de pertinência da saída, que nesse caso representa a distância de ocorrência da falta em relação à subestação.

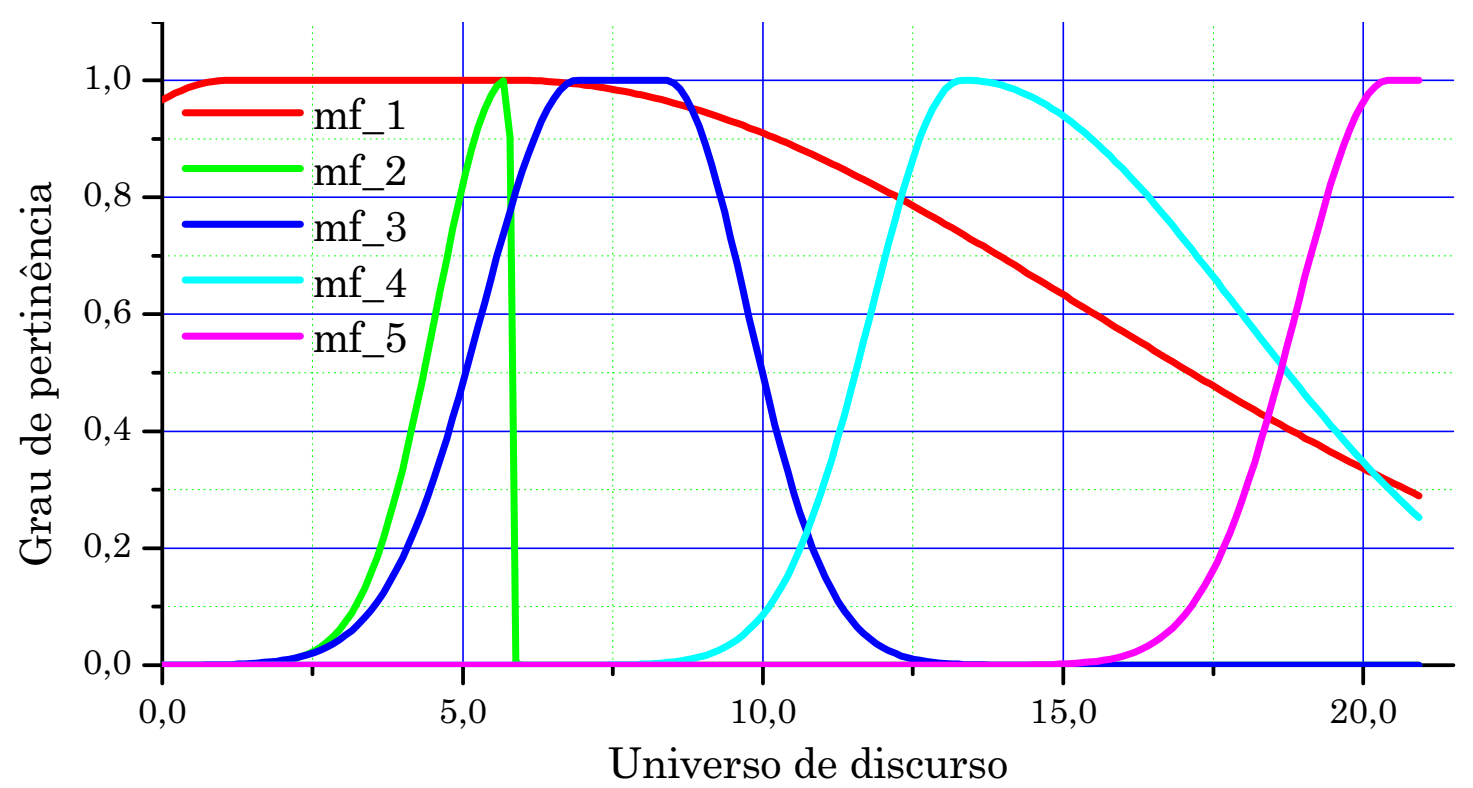

Figura 6.27 - Funções de pertinência associadas à distância de ocorrência de faltas fase-terra na Fase B.

Findando a apresentação do sistema fuzzy dedicado à estimação da distância de ocorrência da falta quando de sua ocorrência na Fase B, tem-se na Figura 6.28 a maneira pela qual as regras fuzzy, destacadas na sua forma verbal por meio da Figura 6.23, foram ponderadas pela etapa de ajuste paramétrico.

O sistema fuzzy ajustado para fins de estimação da distância de ocorrência de faltas fase-terra na Fase B fora ajustado, tanto estrutural como parametricamente, tendo como base os resultados providos por um conjunto de 999 simulações de faltas ocorridas na Fase B. Tais simulações computacionais, apresentadas em detalhes no Capítulo 5, possuíram como variáveis independentes a distância de ocorrência da falta, a resistência de falta, o instante inicial da falta e a duração das mesma. Assim, após o processo de ajuste é primordial a verificação da eficácia do sistema no desempenho da tarefa de estimação da distância de ocorrência da falta.

Para tanto, o sistema fuzzy fora, inicialmente, testado com os dados advindos das simulações empregadas na constituição do conjunto de ajuste do mesmo. Apresentando como o erro relativo se porta para a estimação da distância de ocorrência da falta, tem-se o gráfico da Figura 6.29 onde se destaca o histograma do referido erro. 


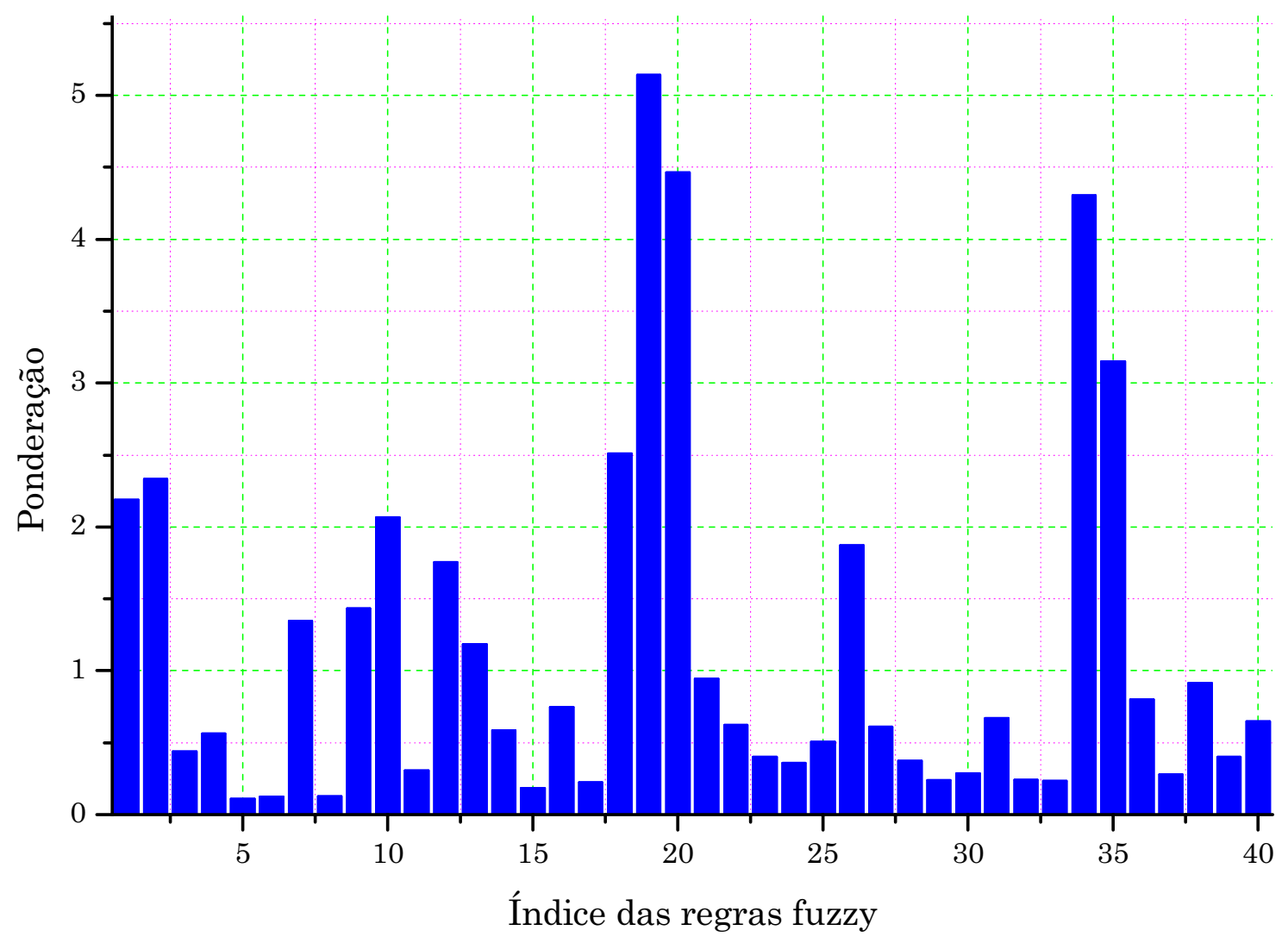

Figura 6.28 - Ponderação das regras fuzzy do sistema de inferência fuzzy dedicado à estimação da distância de ocorrência de faltas fase-terra na Fase B.

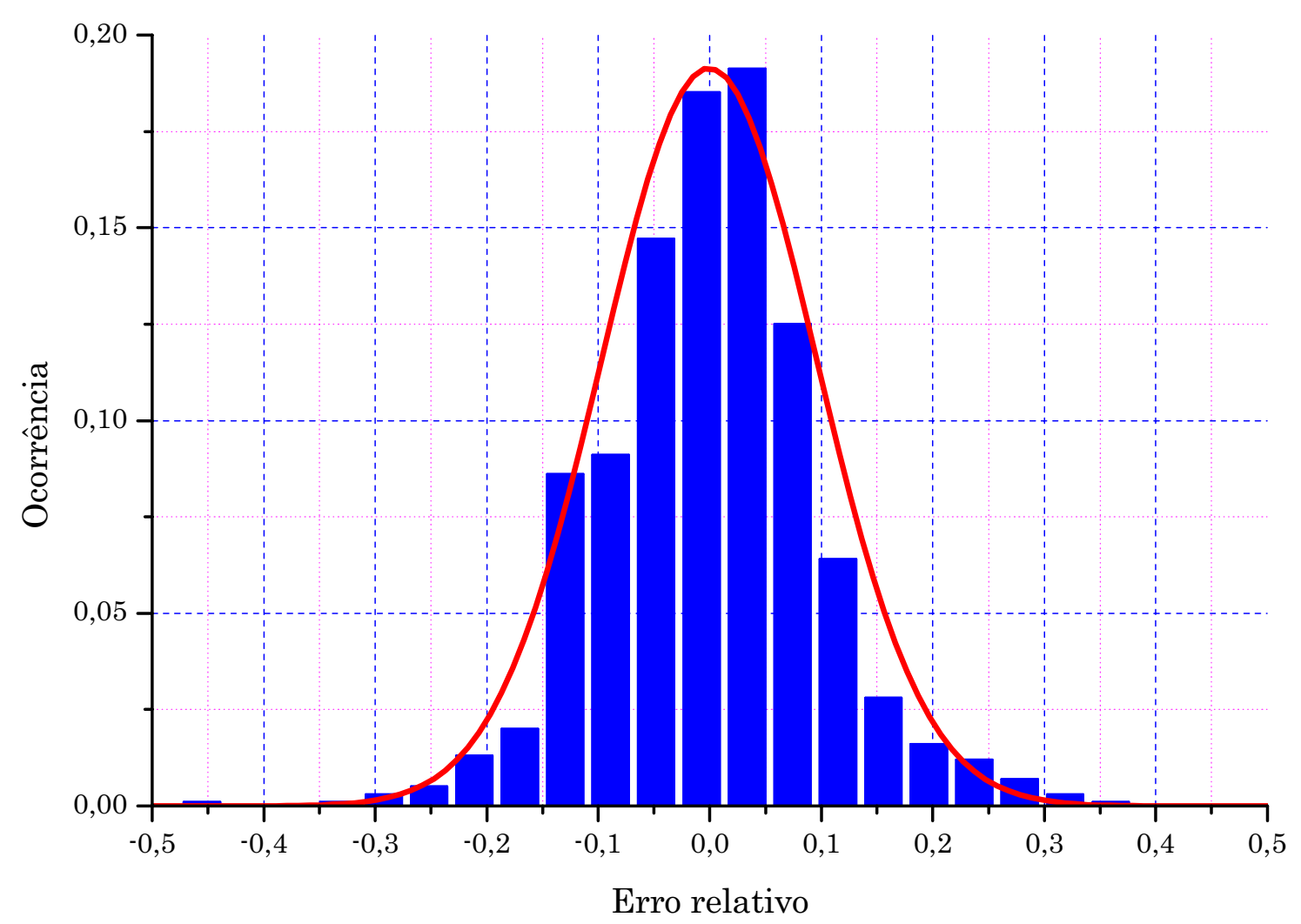

Figura 6.29 - Histograma do erro relativo de estimação da distância de ocorrência de faltas fase-terra na Fase B. 
Por meio do gráfico apresentado na Figura 6.29, além de destacar o histograma do erro relativo de estimação da distância de ocorrência da falta, tem-se o gráfico da distribuição normal que mais se aproxima. A distribuição normal do erro relativo possui média de $-6,2 \times 10^{-4}$ e desvio padrão de 0,0962 , ou seja, em $68,25 \%$ dos casos, a estimação da distância de ocorrência da falta é realizada possuindo o erro relativo de estimação posicionado entre $-0,0962$ e 0,0962 .

Complementando a análise do erro relativo de estimação da distância de ocorrência da falta, apresenta-se na Tabela 6.12 a correlação entre o erro relativo e as variáveis independentes das simulações computacionais, ou seja, a correlação entre o erro relativo e a distância de ocorrência da falta, a resistência de falta, o ângulo de falta e a duração da falta.

Tabela 6.12 - Correlação entre o erro relativo e as variáveis independentes das simulações computacionais.

\begin{tabular}{lr}
\hline \hline $\begin{array}{l}\text { Variável independente da } \\
\text { simulação }\end{array}$ & $\begin{array}{r}\text { Correlação com erro } \\
\text { relativo de estimação }\end{array}$ \\
\hline \hline Distância de ocorrência da falta & 0.5354 \\
\hline Resistência de falta & 0.0487 \\
\hline Ângulo da falta & 0.0092 \\
\hline Duração da falta & 0.0534 \\
\hline \hline
\end{tabular}

Por meio da Tabela 6.12 é possível verificar a forte dependência do erro relativo com a distância de ocorrência da falta, ou seja, com a própria variável de estimação. Ainda, verifica-se a correlação do erro com a resistência de falta e com a duração da mesma, sendo que a correlação existente entre o erro e o ângulo de falta é pequena. A fim de ilustrar a forte correlação do erro de estimação da distância com a distância real de ocorrência se apresenta o gráfico da Figura 6.30 .

Verifica-se pelo gráfico da Figura 6.30 a tendência tanto do máximo erro quanto do mínimo erro aumentarem com o aumento da distância de ocorrência da falta. No entanto, a faixa de erro, a distância entre o máximo erro e o mínimo erro, tende a permanecer constante em relação à distância de ocorrência da falta. A Figura 6.31 apresenta o relacionamento do erro relativo para as demais variáveis independentes das simulações computacionais. 


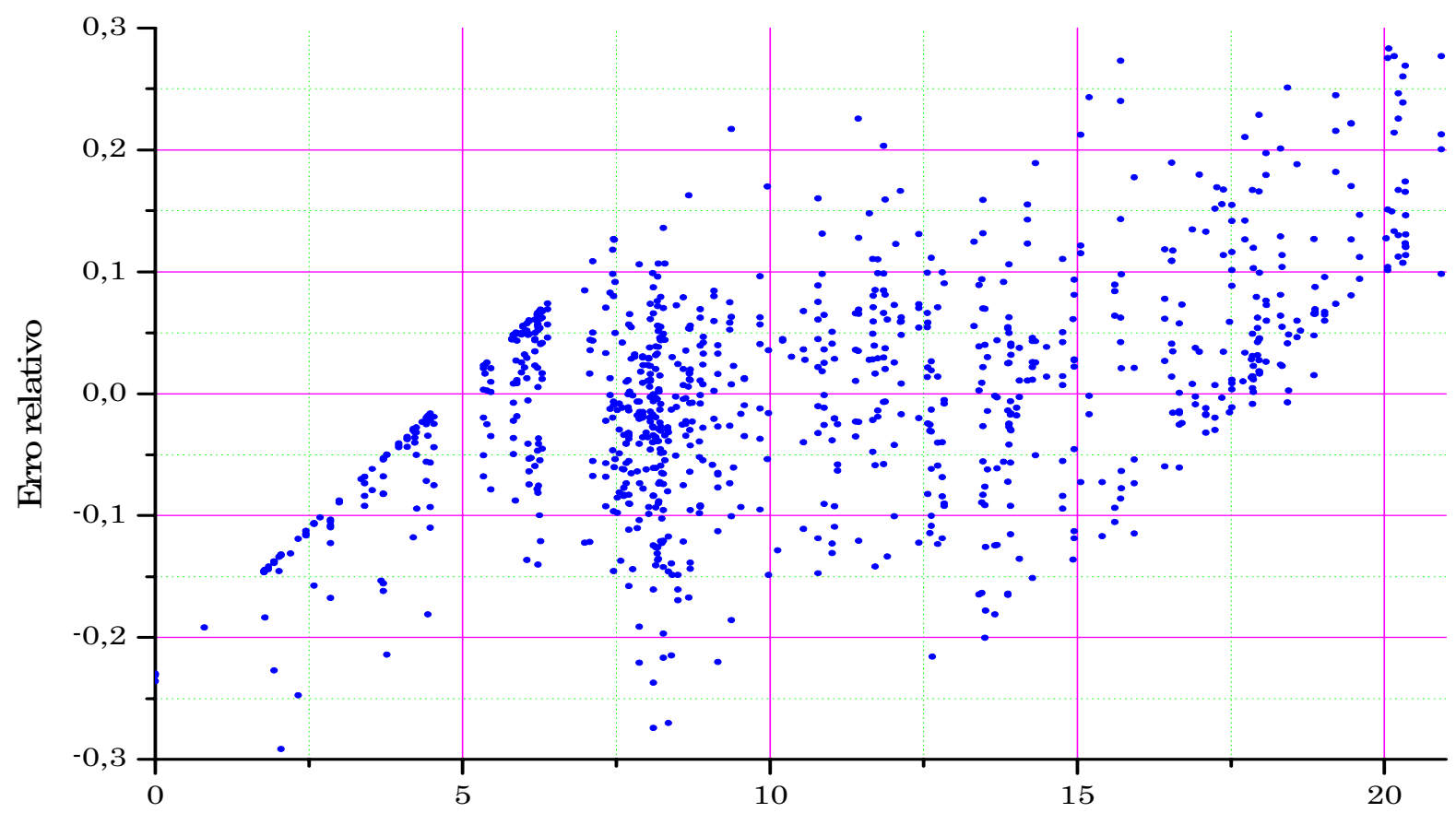

Distância de ocorrência da falta $(\mathrm{km})$

Figura 6.30 - Relacionamento entre o erro relativo e a distância de ocorrência da falta.

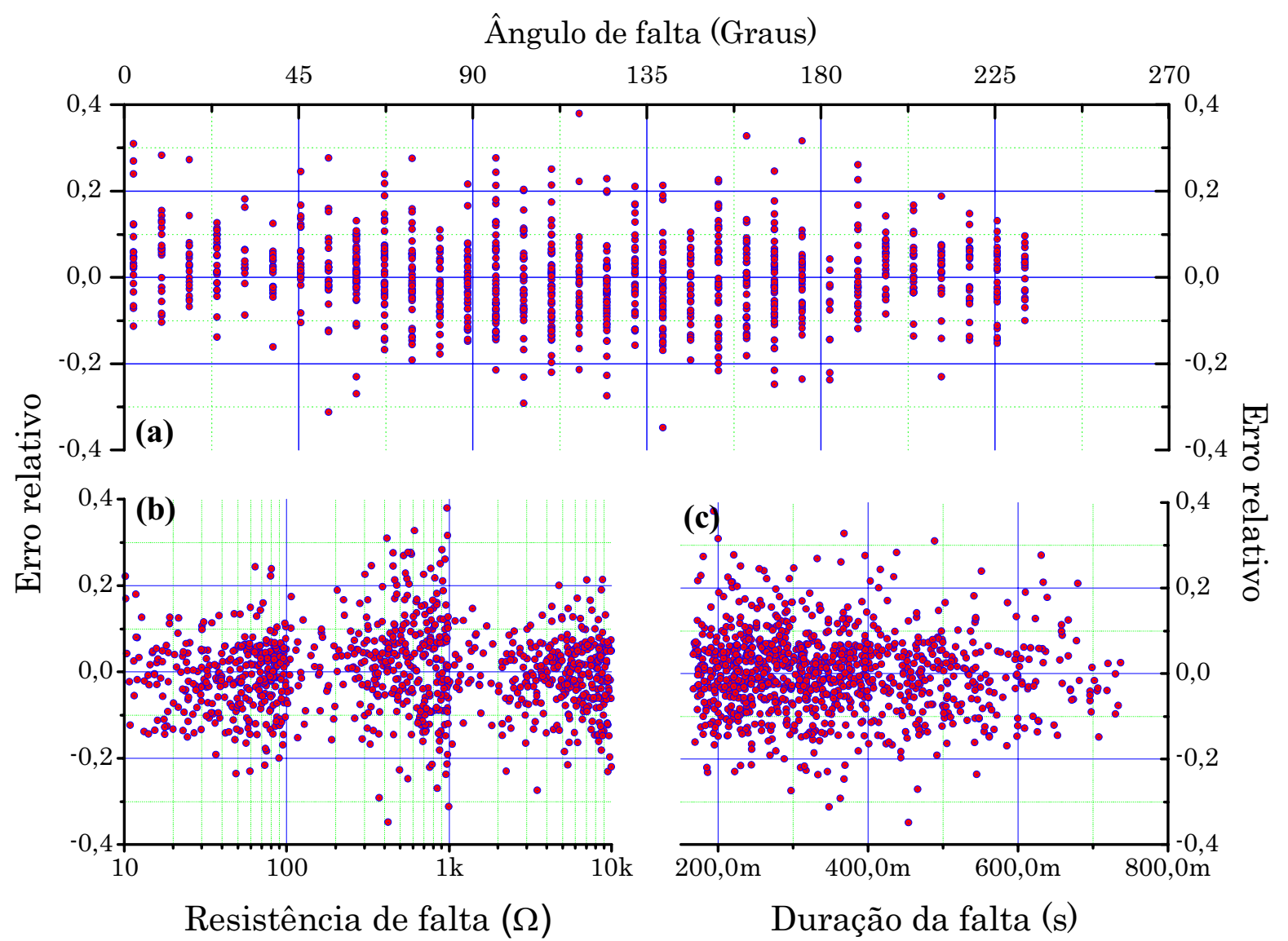

Figura 6.31 - Relacionamento entre o erro relativo e as demais variáveis independentes de simulação; (a) Relacionamento entre o erro relativo e o ângulo de falta; (b) Relacionamento entre o erro relativo e a resistência de falta; (c) Relacionamento entre o erro relativo e a duração da falta. 
O sistema fuzzy dedicado à estimação da distância de ocorrência da falta, além de ser testado com os dados provenientes do conjunto de ajuste, fora também testado com dados advindos de simulações computacionais não contidos no conjunto de ajuste. Assim, um total de 272 situações de falta na Fase B foram simuladas e os resultados dessas simulações foram submetidos à técnica de decomposição em componentes ortogonais. De posse dos valores eficazes das componentes ortogonais, as variáveis mais correlatas à localização de faltas na Fase B, apresentadas na Tabela 6.11, foram selecionadas e apresentadas ao sistema fuzzy previamente ajustado. Os resultados obtidos para a localização de faltas quando de sua ocorrência na Fase B são apresentados por meio da Figura 6.32 na forma de histograma do erro relativo.

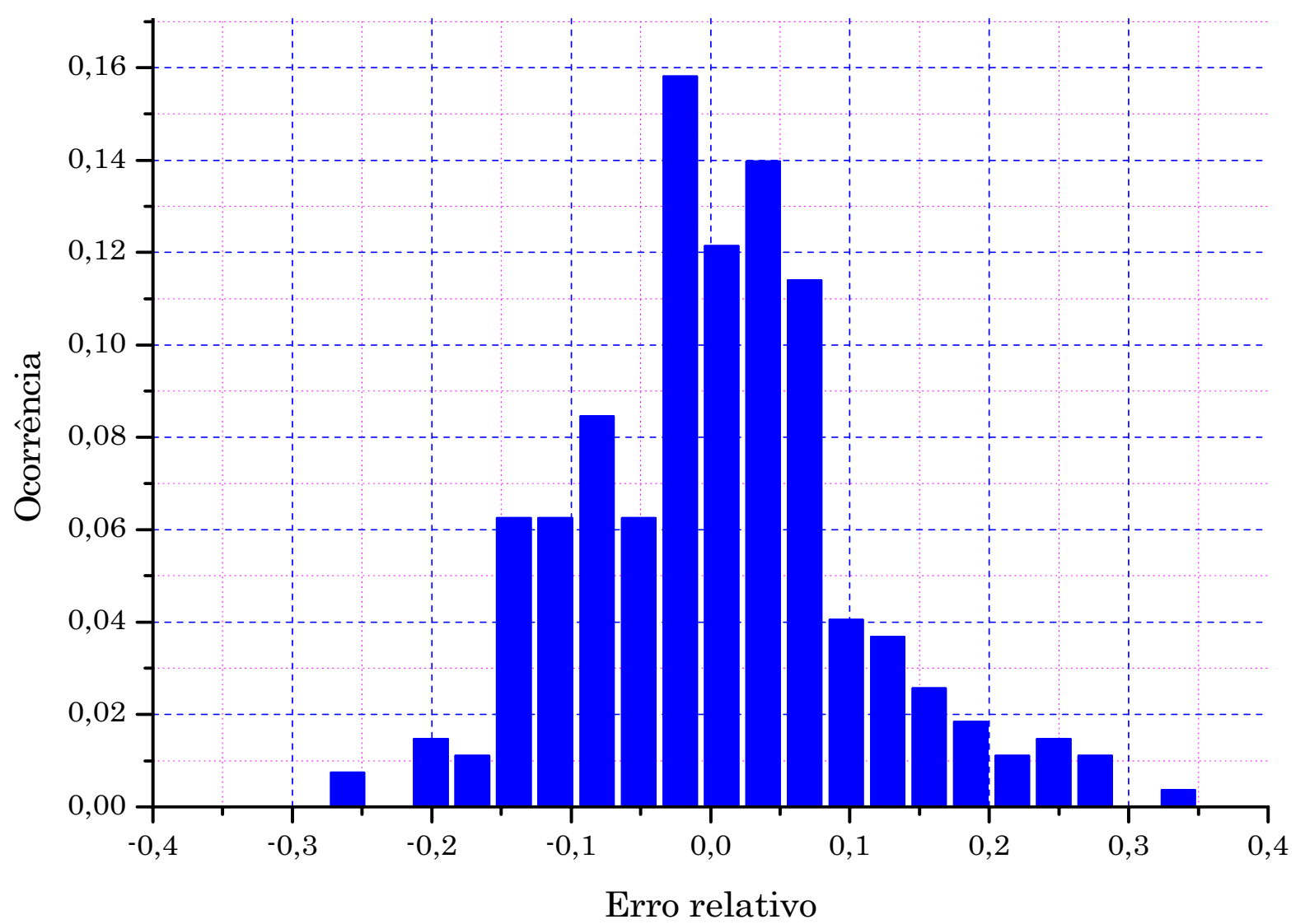

Figura 6.32 - Histograma do erro relativo de estimação da distância de ocorrência de faltas fase-terra na Fase B para os dados do conjunto de teste.

Assim como a distribuição do erro relativo para os dados de ajuste se assemelha a uma distribuição normal, o mesmo pode ser verificado para o erro relativo apresentado para o conjunto de teste. A fim de ilustrar como a distribuição estatística do erro relativo para os dados de ajuste é semelhante à distribuição do erro verificado para os dados de teste, apresenta-se a Figura 6.33 onde ambas as distribuições estatísticas são confrontadas para propósitos comparativos. 


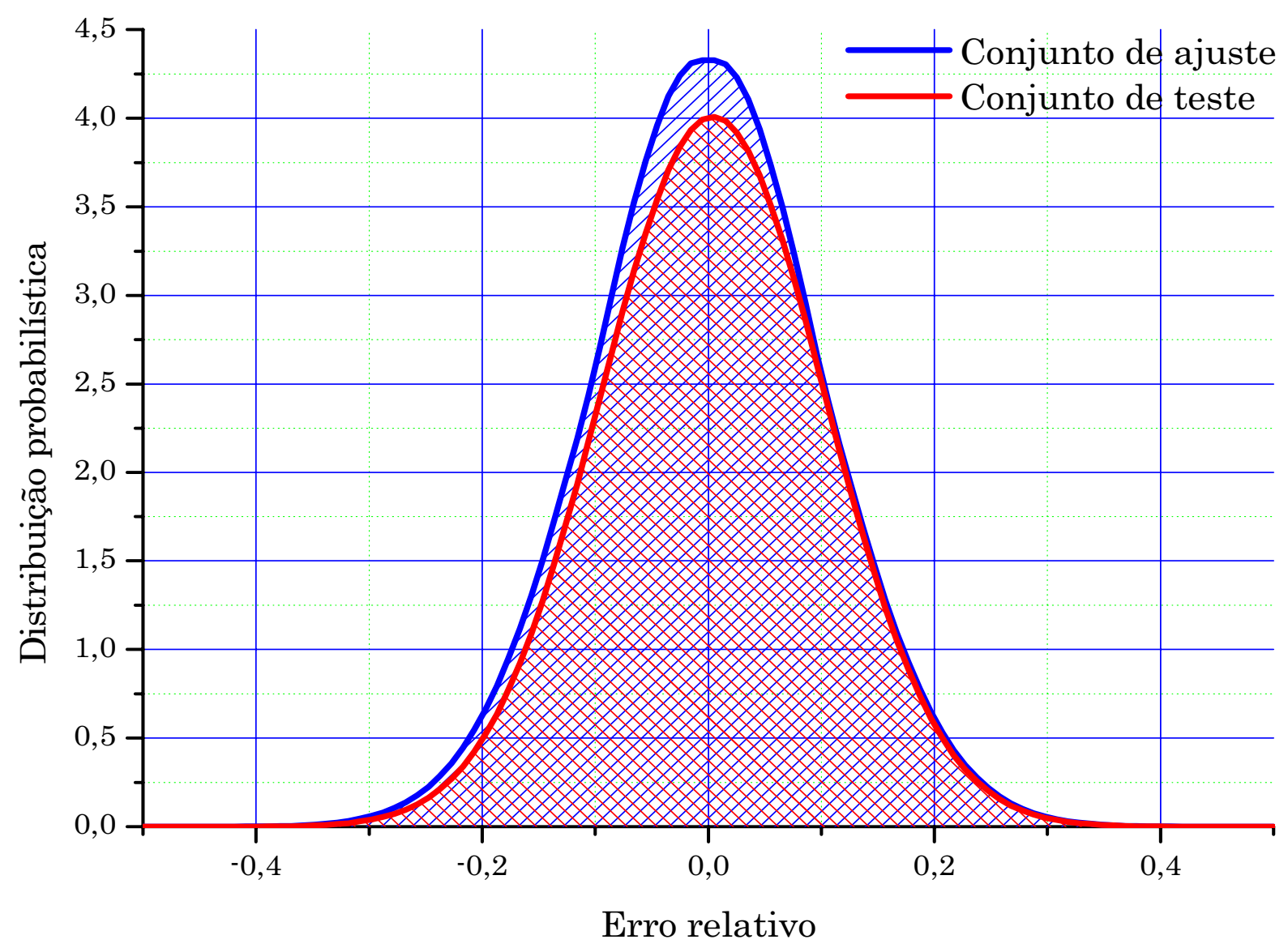

Figura 6.33 - Distribuição normal para o conjunto de ajuste e para o conjunto de teste quando da localização de falta na Fase B.

Por meio da Figura 6.33 é possível verificar que a distribuição normal verificada para os dados de teste se enquadrou com aquela verificada quando da modelagem do erro observado para os dados de ajuste. Ainda, quando da distribuição normal apresentada na Figura 6.33, tem-se que sua média fora de 0,0040 e o desvio padrão de 0,0995.

\subsubsection{SiSTEMA de INFERÊNCIA FuZZY PARA LOCALIZAÇÃo de FALTAS NA FASE C}

Na Subseção 6.2.1 e Subseção 6.2.2 a estimação da distância de ocorrência de faltas fase-terra fora realizada tanto para a Fase A como para a Fase B. Em ambos os casos, a seleção das variáveis levou em consideração as doze mais correlatas com a distância de ocorrência da falta. Após a seleção das variáveis mais correlatas os respectivos sistemas fuzzy foram ajustados por meio do algoritmo desenvolvido e apresentado no Capítulo 4. Assim, a mesma metodologia fora aplicada na implementação do sistema fuzzy dedicado à estimação da distância de ocorrência de faltas fase-terra quando essa envolver a Fase C. 
Dessa forma, para apresentar como cada componente advinda do resultado da decomposição ortogonal se correlaciona com a distância de ocorrência da falta, apresentam-se por meio da Tabela 6.13 as correlações e os testes de hipótese, que mensura o quão significativo são as correlações, das componentes de tensões contidas na função planar das tensões de linha com a distância de ocorrência da Falta quando essa for observada na Fase C. Os valores contidos na Tabela 6.13 são graficamente apresentados por meio da Figura 6.34.

Por meio da Tabela 6.14 se apresentam as correlações das componentes de corrente contidas na função planar das tensões de linha com a distância de ocorrência da falta, assim como por meio da Figura 6.35 se tem a representação gráfica dos valores contidos nessa tabela.

A correlação das componentes de tensão ortogonais à função planar das tensões de linha com a distância de ocorrência de falta é apresentada na Tabela 6.15 e tais valores para as componentes de corrente ortogonais à função planar das tensões de linha são conteúdo da Tabela 6.16. A representação dos valores expressos na Tabela 6.15 e Tabela 6.16 é realizada por meio da Figura 6.36 e da Figura 6.37, respectivamente. 
Tabela 6.13 - Correlação das componentes de tensão contidas na função planar das tensões de linha com relação à distância de ocorrência de falta na Fase C.

\begin{tabular}{|c|c|c|c|c|c|c|c|}
\hline \multirow[b]{2}{*}{$k$} & \multirow[b]{2}{*}{ Variável } & \multicolumn{2}{|c|}{ Média } & \multicolumn{2}{|c|}{ Máximo } & \multicolumn{2}{|c|}{ Mínimo } \\
\hline & & Correlação & $\begin{array}{l}\text { Teste de } \\
\text { hipótese }\end{array}$ & Correlação & $\begin{array}{l}\text { Teste de } \\
\text { hipótese } \\
\end{array}$ & Correlação & $\begin{array}{l}\text { Teste de } \\
\text { hipótese } \\
\end{array}$ \\
\hline 1 & $\left\|v_{a}^{p}(t)\right\|$ & 0,2692 & 0,0000 & 0,2468 & 0,0000 & 0,0135 & 0,6651 \\
\hline 2 & $\left\|v_{b}^{p}(t)\right\|$ & 0,0959 & 0,0021 & 0,0964 & 0,0020 & 0,0149 & 0,6325 \\
\hline 3 & $\left\|v_{c}^{p}(t)\right\|$ & 0,1473 & 0,0000 & 0,1879 & 0,0000 & 0,1394 & 0,0000 \\
\hline 4 & $\left\|v_{n}^{p}(t)\right\|$ & 0,1567 & 0,0000 & 0,1559 & 0,0000 & 0,0588 & 0,0597 \\
\hline 5 & $\left\|v_{a}^{q^{\|}}(t)\right\|$ & 0,0986 & 0,0016 & 0,1158 & 0,0002 & 0,3702 & 0,0000 \\
\hline 6 & $\left\|v_{b}^{q^{\| \prime}}(t)\right\|$ & 0,1435 & 0,0000 & 0,1486 & 0,0000 & 0,4207 & 0,0000 \\
\hline 7 & $\left\|v_{c}^{q^{\| \prime}}(t)\right\|$ & 0,5345 & 0,0000 & 0,3192 & 0,0000 & 0,6915 & 0,0000 \\
\hline 8 & $\left\|v_{n}^{q^{\| \prime}}(t)\right\|$ & 0,1387 & 0,0000 & 0,1036 & 0,0009 & 0,0197 & 0,5285 \\
\hline 9 & $\left\|v_{a}^{q^{\perp}}(t)\right\|$ & 0,0449 & 0,1505 & 0,0405 & 0,1945 & 0,2658 & 0,0000 \\
\hline 10 & $\left\|v_{b}^{q^{\perp}}(t)\right\|$ & 0,3352 & 0,0000 & 0,3767 & 0,0000 & 0,3975 & 0,0000 \\
\hline 11 & $\left\|v_{c}^{q^{\perp}}(t)\right\|$ & 0,0766 & 0,0142 & 0,0669 & 0,0321 & 0,1395 & 0,0000 \\
\hline 12 & $\left\|v_{n}^{q^{\perp}}(t)\right\|$ & 0,1247 & 0,0001 & 0,1543 & 0,0000 & 0,0821 & 0,0085 \\
\hline 13 & $\left\|v_{a}^{d}(t)\right\|$ & 0,0449 & 0,1505 & 0,0405 & 0,1945 & 0,2752 & 0,0000 \\
\hline 14 & $\left\|v_{b}^{d}(t)\right\|$ & 0,3352 & 0,0000 & 0,3767 & 0,0000 & 0,3516 & 0,0000 \\
\hline 15 & $\left\|v_{c}^{d}(t)\right\|$ & 0,0766 & 0,0142 & 0,0669 & 0,0321 & 0,0981 & 0,0016 \\
\hline 16 & $\left\|v_{n}^{d}(t)\right\|$ & 0,1246 & 0,0001 & 0,1543 & 0,0000 & 0,0930 & 0,0029 \\
\hline
\end{tabular}
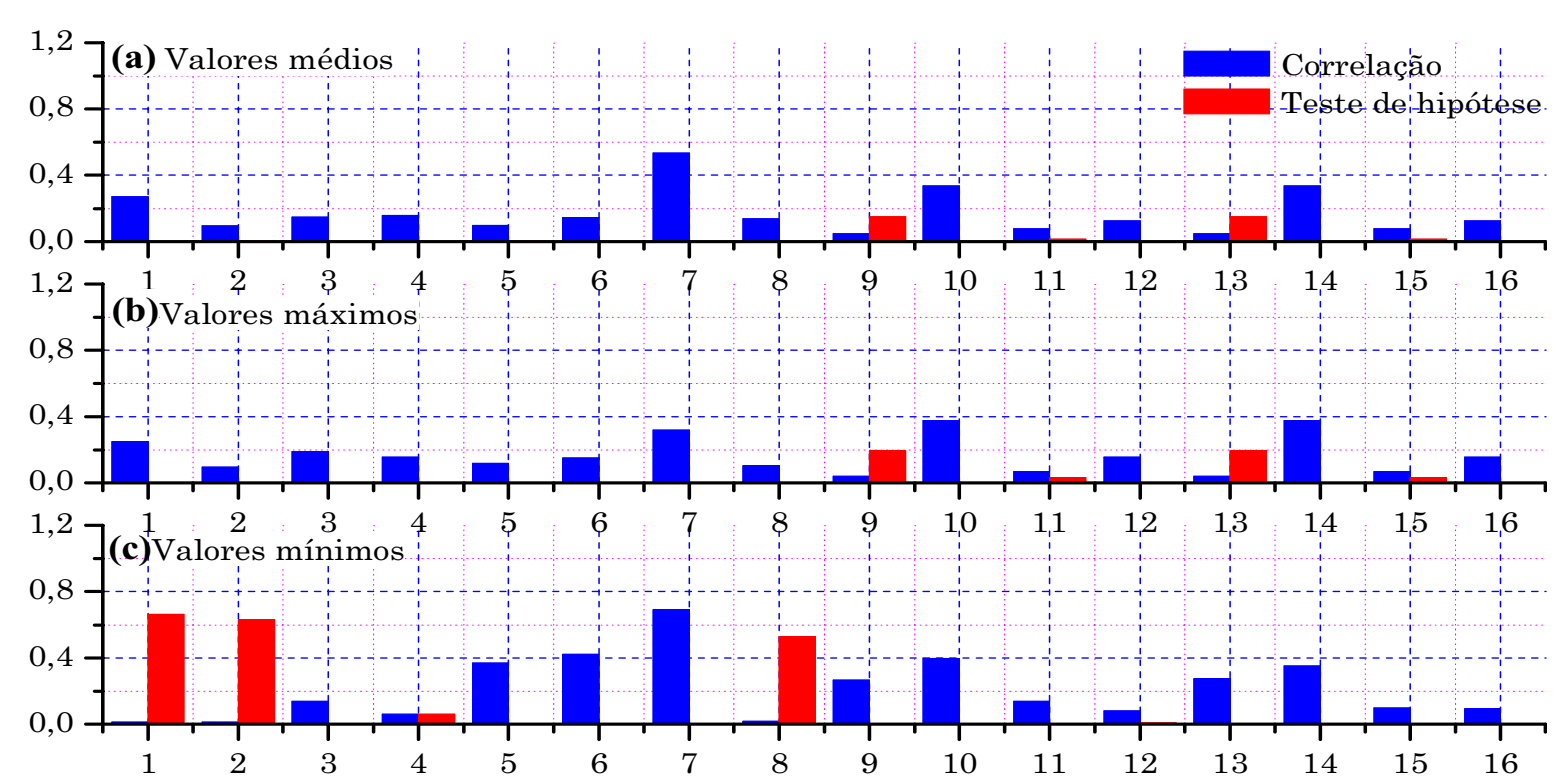

Variável (índice)

Figura 6.34 - Correlação e teste de hipótese para as componentes de tensão contidas na função planar das tensões de linha com a distância de ocorrência de falta na Fase C; (a) Correlação e teste de hipótese para os valores médios; (b) Correlação e teste de hipótese para os valores máximos; (c) Correlação e teste de hipótese para os valores mínimos. 
Tabela 6.14 - Correlação das componentes de corrente contidas na função planar das tensões de linha com relação à distância de ocorrência de falta na Fase C.

\begin{tabular}{|c|c|c|c|c|c|c|c|}
\hline \multirow[b]{2}{*}{$k$} & \multirow[b]{2}{*}{ Variável } & \multicolumn{2}{|c|}{ Média } & \multicolumn{2}{|c|}{ Máximo } & \multicolumn{2}{|c|}{ Mínimo } \\
\hline & & Correlação & $\begin{array}{l}\text { Teste de } \\
\text { hipótese }\end{array}$ & Correlação & $\begin{array}{l}\text { Teste de } \\
\text { hipótese }\end{array}$ & Correlação & $\begin{array}{l}\text { Teste de } \\
\text { hipótese }\end{array}$ \\
\hline 1 & $\left\|i_{a}^{p}(t)\right\|$ & 0,0417 & 0,1824 & 0,0174 & 0,5788 & 0,0702 & 0,0245 \\
\hline 2 & $\left\|i_{b}^{p}(t)\right\|$ & 0,0133 & 0,6708 & 0,0214 & 0,4938 & 0,1011 & 0,0012 \\
\hline 3 & $\left\|i_{c}^{p}(t)\right\|$ & 0,1906 & 0,0000 & 0,0467 & 0,1351 & 0,0814 & 0,0091 \\
\hline 4 & $\left\|i_{n}^{p}(t)\right\|$ & 0,1568 & 0,0000 & 0,1586 & 0,0000 & 0,0489 & 0,1177 \\
\hline 5 & $\left\|i_{a}^{q^{\|}}(t)\right\|$ & 0,0899 & 0,0040 & 0,0231 & 0,4607 & 0,3965 & 0,0000 \\
\hline 6 & $\left\|i_{b}^{q^{\prime \prime}}(t)\right\|$ & 0,1480 & 0,0000 & 0,1533 & 0,0000 & 0,4750 & 0,0000 \\
\hline 7 & $\left\|i_{c}^{q^{\|}}(t)\right\|$ & 0,2651 & 0,0000 & 0,1966 & 0,0000 & 0,6234 & 0,0000 \\
\hline 8 & $\left\|i_{n}^{q^{\|}}(t)\right\|$ & 0,1413 & 0,0000 & 0,1060 & 0,0007 & 0,0503 & 0,1076 \\
\hline 9 & $\left\|i_{a}^{q^{\perp}}(t)\right\|$ & 0,2784 & 0,0000 & 0,2575 & 0,0000 & 0,4572 & 0,0000 \\
\hline 10 & $\left\|i_{b}^{q^{\perp}}(t)\right\|$ & 0,4028 & 0,0000 & 0,4071 & 0,0000 & 0,0000 & 1,0000 \\
\hline 11 & $\left\|i_{c}^{q^{\perp}}(t)\right\|$ & 0,2423 & 0,0000 & 0,2309 & 0,0000 & 0,0000 & 1,0000 \\
\hline 12 & $\left\|i_{n}^{q^{\perp}}(t)\right\|$ & 0,2402 & 0,0000 & 0,1846 & 0,0000 & 0,0727 & 0,0198 \\
\hline 13 & $\left\|i_{a}^{d}(t)\right\|$ & 0,2783 & 0,0000 & 0,2575 & 0,0000 & 0,4673 & 0,0000 \\
\hline 14 & $\left\|i_{b}^{d}(t)\right\|$ & 0,0717 & 0,0215 & 0,0247 & 0,4291 & 0,0000 & 1,0000 \\
\hline 15 & $\left\|i_{c}^{d}(t)\right\|$ & 0,1008 & 0,0012 & 0,0347 & 0,2666 & 0,0000 & 1,0000 \\
\hline 16 & $\left\|i_{n}^{d}(t)\right\|$ & 0,2402 & 0,0000 & 0,1846 & 0,0000 & 0,0728 & 0,0196 \\
\hline
\end{tabular}
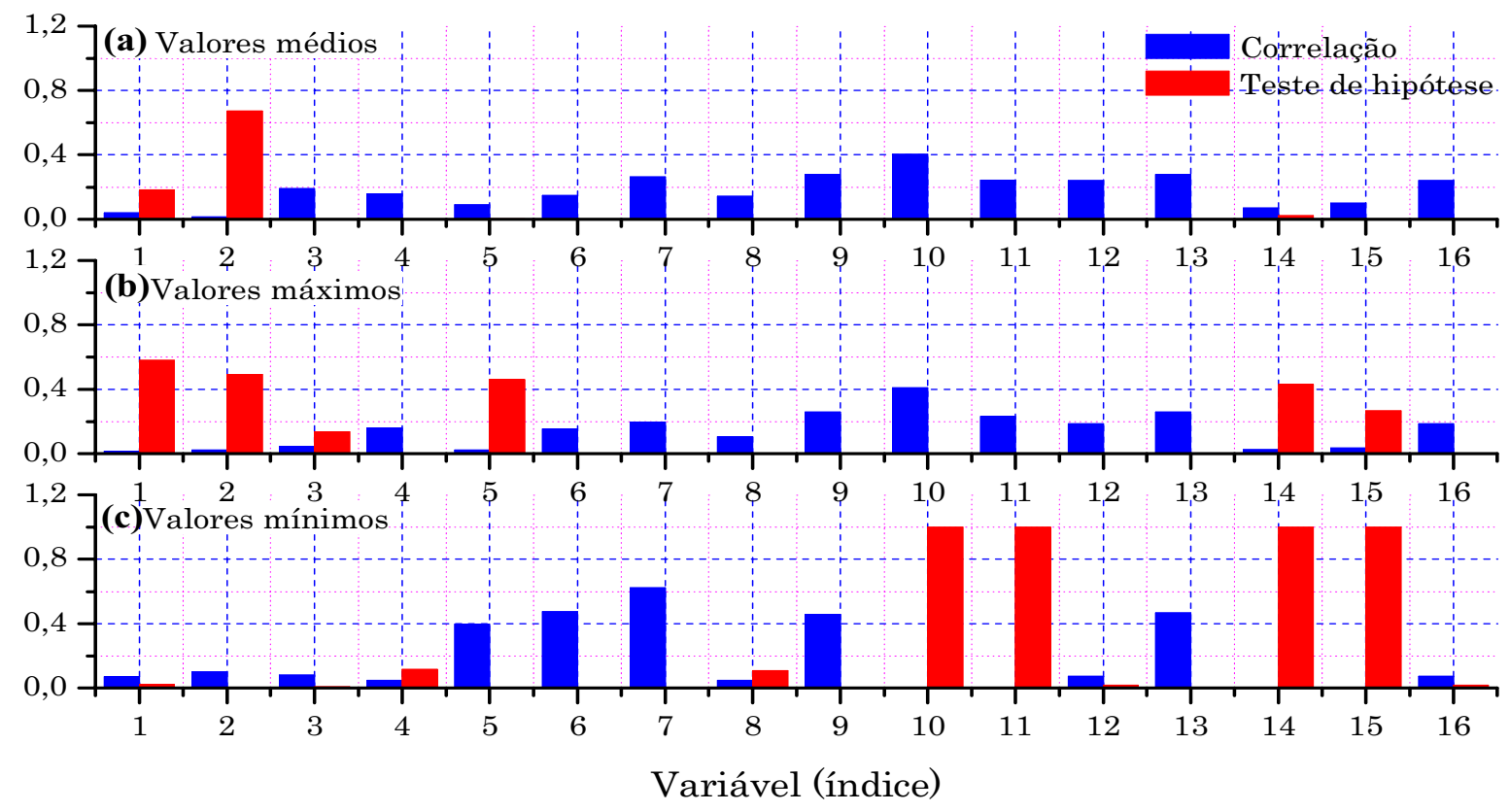

Figura 6.35 - Correlação e teste de hipótese para as componentes de corrente contidas na função planar das tensões de linha com a distância de ocorrência de falta na Fase C; (a) Correlação e teste de hipótese para os valores médios; (b) Correlação e teste de hipótese para os valores máximos; (c) Correlação e teste de hipótese para os valores mínimos. 
Tabela 6.15 - Correlação das componentes de tensão ortogonais à função planar das tensões de linha com relação à distância de ocorrência de falta na Fase C.

\begin{tabular}{|c|c|c|c|c|c|c|c|}
\hline \multirow[b]{2}{*}{$k$} & \multirow[b]{2}{*}{ Variável } & \multicolumn{2}{|c|}{ Média } & \multicolumn{2}{|c|}{ Máximo } & \multicolumn{2}{|c|}{ Mínimo } \\
\hline & & Correlação & $\begin{array}{l}\text { Teste de } \\
\text { hipótese } \\
\end{array}$ & Correlação & $\begin{array}{l}\text { Teste de } \\
\text { hipótese } \\
\end{array}$ & Correlação & $\begin{array}{r}\text { Teste de } \\
\text { hipótese } \\
\end{array}$ \\
\hline 1 & $\left\|v_{\bar{a}}^{p}(t)\right\|$ & 0,2358 & 0,0000 & 0,2291 & 0,0000 & 0,0232 & 0,4586 \\
\hline 2 & $\left\|v \frac{p}{b}(t)\right\|$ & 0,1073 & 0,0006 & 0,1073 & 0,0006 & 0,0122 & 0,6955 \\
\hline 3 & $\left\|v_{\bar{c}}^{p}(t)\right\|$ & 0,1607 & 0,0000 & 0,0138 & 0,6583 & 0,1589 & 0,0000 \\
\hline 4 & $\left\|v_{h}^{p}(t)\right\|$ & 0,1564 & 0,0000 & 0,1571 & 0,0000 & 0,0521 & 0,0952 \\
\hline 5 & $\left\|v_{a}^{q^{\prime \prime}}(t)\right\|$ & 0,0666 & 0,0330 & 0,0313 & 0,3172 & 0,0425 & 0,1735 \\
\hline 6 & $\left\|v^{q^{\prime \prime}}(t)\right\|$ & 0,0009 & 0,9761 & 0,0274 & 0,3806 & 0,0520 & 0,0957 \\
\hline 7 & $\left\|v_{\frac{q^{\prime \prime}}{c}}(t)\right\|$ & 0,1929 & 0,0000 & 0,3140 & 0,0000 & 0,0034 & 0,9124 \\
\hline 8 & $\left\|v_{h}^{q^{\|}}(t)\right\|$ & 0,0741 & 0,0175 & 0,0823 & 0,0084 & 0,4467 & 0,0000 \\
\hline 9 & $\left\|v_{\bar{a}}^{q^{\perp}}(t)\right\|$ & 0,2027 & 0,0000 & 0,1163 & 0,0002 & 0,2353 & 0,0000 \\
\hline 10 & $\left\|v \frac{q^{\perp}}{b}(t)\right\|$ & 0,2781 & 0,0000 & 0,2210 & 0,0000 & 0,0000 & 1,0000 \\
\hline 11 & $\left\|v_{c}^{q^{\perp}}(t)\right\|$ & 0,2214 & 0,0000 & 0,1793 & 0,0000 & 0,0000 & 1,0000 \\
\hline 12 & $\left\|v_{h}^{q^{\perp}}(t)\right\|$ & 0,2622 & 0,0000 & 0,2546 & 0,0000 & 0,1060 & 0,0007 \\
\hline 13 & $\left\|v_{\bar{a}}^{d}(t)\right\|$ & 0,2027 & 0,0000 & 0,1163 & 0,0002 & 0,1169 & 0,0002 \\
\hline 14 & $\left\|v_{\frac{d}{b}}^{d}(t)\right\|$ & 0,1974 & 0,0000 & 0,0962 & 0,0020 & 0,2874 & 0,0000 \\
\hline 15 & $\left\|v_{\bar{c}}^{d}(t)\right\|$ & 0,1681 & 0,0000 & 0,0657 & 0,0354 & 0,0244 & 0,4346 \\
\hline 16 & $\left\|v_{h}^{d}(t)\right\|$ & 0,2622 & 0,0000 & 0,2546 & 0,0000 & 0,1110 & 0,0004 \\
\hline
\end{tabular}
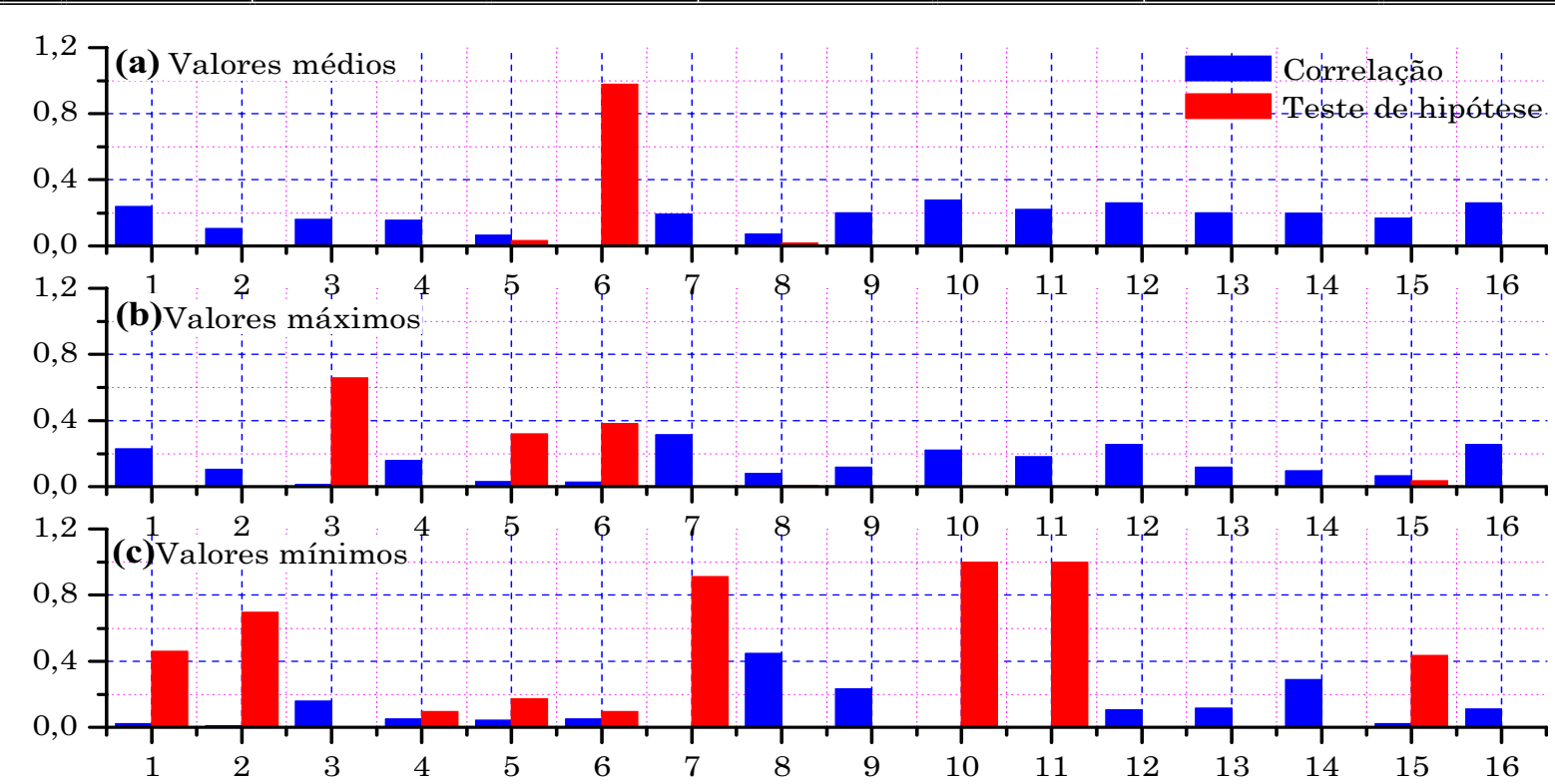

Variável (índice)

Figura 6.36 - Correlação e teste de hipótese para as componentes de tensão ortogonais à função planar das tensões de linha com a distância de ocorrência de falta na Fase C; (a) Correlação e teste de hipótese para os valores médios; (b) Correlação e teste de hipótese para os valores máximos; (c) Correlação e teste de hipótese para os valores mínimos. 
Tabela 6.16 - Correlação das componentes de corrente ortogonais à função planar das tensões de linha com relação à distância de ocorrência de falta na Fase C.

\begin{tabular}{|c|c|c|c|c|c|c|c|}
\hline \multirow[b]{2}{*}{$k$} & \multirow[b]{2}{*}{ Variável } & \multicolumn{2}{|c|}{ Média } & \multicolumn{2}{|c|}{ Máximo } & \multicolumn{2}{|c|}{ Mínimo } \\
\hline & & Correlação & $\begin{array}{l}\text { Teste de } \\
\text { hipótese }\end{array}$ & Correlação & $\begin{array}{l}\text { Teste de } \\
\text { hipótese } \\
\end{array}$ & Correlação & $\begin{array}{l}\text { Teste de } \\
\text { hipótese } \\
\end{array}$ \\
\hline 1 & $\left\|i_{\bar{a}}^{p}(t)\right\|$ & 0,2372 & 0,0000 & 0,2350 & 0,0000 & 0,0071 & 0,8206 \\
\hline 2 & $\left\|i_{\frac{p}{b}}^{p}(t)\right\|$ & 0,1082 & 0,0005 & 0,1150 & 0,0002 & 0,0196 & 0,5310 \\
\hline 3 & $\left\|i_{\bar{c}}^{p}(t)\right\|$ & 0,1615 & 0,0000 & 0,0108 & 0,7301 & 0,1549 & 0,0000 \\
\hline 4 & $\left\|i_{h}^{p}(t)\right\|$ & 0,1567 & 0,0000 & 0,1560 & 0,0000 & 0,0200 & 0,5230 \\
\hline 5 & $\left\|i_{a}^{q^{\|}}(t)\right\|$ & 0,0442 & 0,1575 & 0,0593 & 0,0577 & 0,1313 & 0,0000 \\
\hline 6 & $\left\|i^{q^{\prime \prime}}(t)\right\|$ & 0,0150 & 0,6308 & 0,0820 & 0,0086 & 0,0413 & 0,1863 \\
\hline 7 & $\left\|i_{c}^{q^{\|}}(t)\right\|$ & 0,0987 & 0,0015 & 0,2265 & 0,0000 & 0,4789 & 0,0000 \\
\hline 8 & $\left\|i_{h}^{q^{\|}}(t)\right\|$ & 0,0765 & 0,0143 & 0,0505 & 0,1059 & 0,0172 & 0,5828 \\
\hline 9 & $\left\|i_{\bar{a}}^{q^{\perp}}(t)\right\|$ & 0,0371 & 0,2353 & 0,0378 & 0,2264 & 0,0594 & 0,0573 \\
\hline 10 & $\left\|i \frac{q^{\perp}}{b}(t)\right\|$ & 0,0786 & 0,0118 & 0,0914 & 0,0034 & 0,3638 & 0,0000 \\
\hline 11 & $\left\|i_{c}^{q^{\perp}}(t)\right\|$ & 0,2767 & 0,0000 & 0,2605 & 0,0000 & 0,0000 & 1,0000 \\
\hline 12 & $\left\|i_{h}^{q^{\perp}}(t)\right\|$ & 0,0432 & 0,1672 & 0,0569 & 0,0687 & 0,0793 & 0,0111 \\
\hline 13 & $\left\|i_{\bar{a}}^{d}(t)\right\|$ & 0,0370 & 0,2367 & 0,0377 & 0,2275 & 0,1996 & 0,0000 \\
\hline 14 & $\left\|i_{\bar{b}}^{d}(t)\right\|$ & 0,0786 & 0,0118 & 0,0914 & 0,0034 & 0,3222 & 0,0000 \\
\hline 15 & $\left\|i_{\bar{c}}^{d}(t)\right\|$ & 0,1690 & 0,0000 & 0,0882 & 0,0047 & 0,1447 & 0,0000 \\
\hline 16 & $\left\|i_{h}^{d}(t)\right\|$ & 0,0431 & 0,1674 & 0,0568 & 0,0687 & 0,0837 & 0,0073 \\
\hline
\end{tabular}
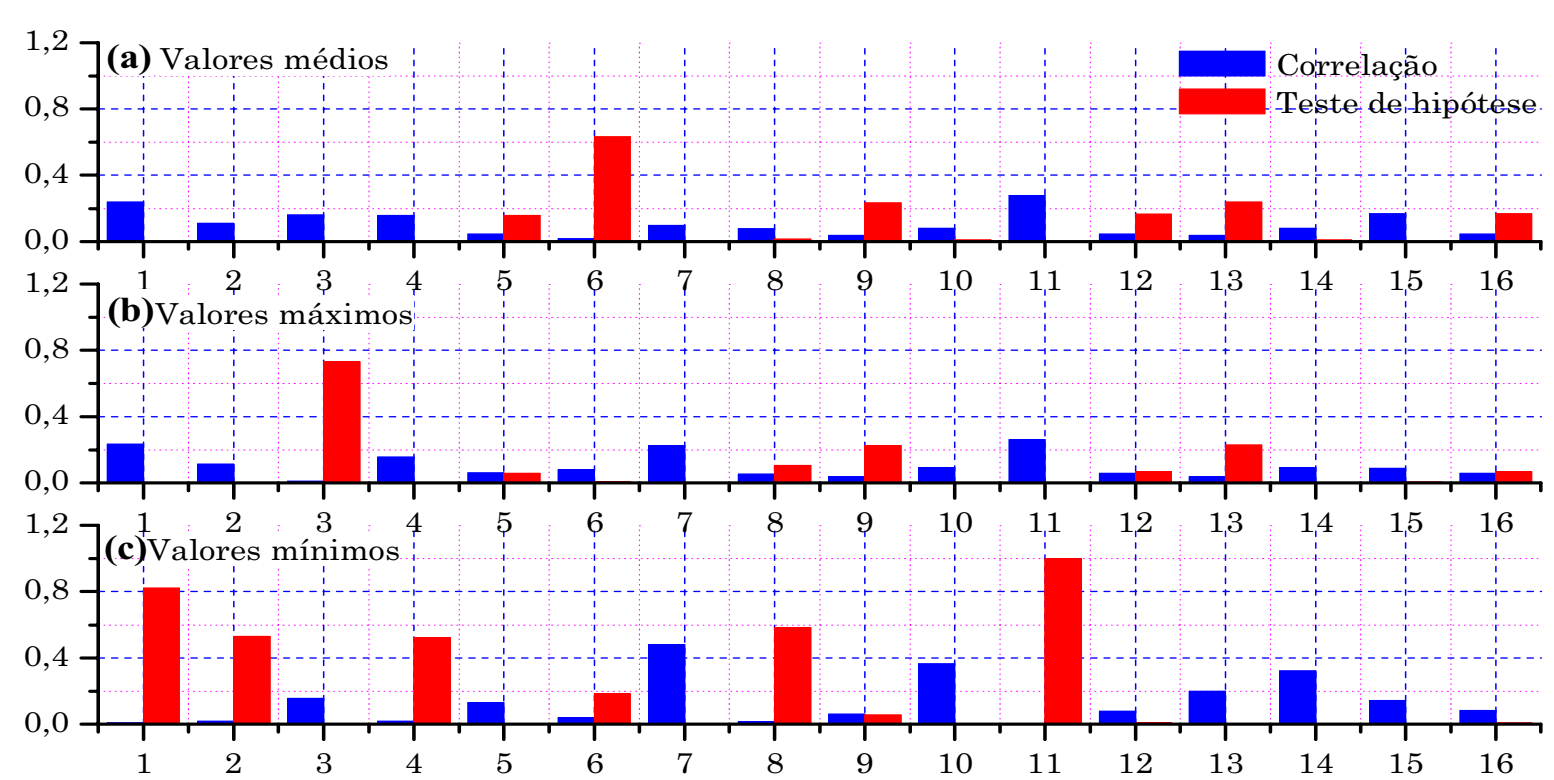

Variável (índice)

Figura 6.37 - Correlação e teste de hipótese para as componentes de corrente ortogonais à função planar das tensões de linha com a distância de ocorrência de falta na Fase C; (a) Correlação e teste de hipótese para os valores médios; (b) Correlação e teste de hipótese para os valores máximos; (c) Correlação e teste de hipótese para os valores mínimos. 
Por meio dos valores de correlação apresentados nas tabelas anteriores é possível verificar que as doze variáveis mais correlacionadas com a distância de ocorrência de faltas na Fase C são aquelas destacadas na Tabela 6.17, a qual destaca também as referidas correlações.

Tabela 6.17 - Variáveis mais correlatas à localização de faltas fase-terra na Fase C.

\begin{tabular}{|c|c|c|c|c|}
\hline Índice & Variável & Característica & Símbolo & Correlação \\
\hline 1 & $\left\|v_{b}^{q^{\prime \prime}}(t)\right\|$ & Mínimo & $\left\|v_{b}^{q^{\|}}(t)\right\|^{\min }$ & 0,4207 \\
\hline 2 & $\left\|v_{c}^{q^{\prime \prime}}(t)\right\|$ & Médio & $\overline{\left\|v_{c}^{q^{\|}}(t)\right\|}$ & 0,5345 \\
\hline 3 & $\left\|v_{c}^{q^{\prime \prime}}(t)\right\|$ & Mínimo & $\left\|v_{c}^{q^{\|}}(t)\right\|^{\min }$ & 0,6915 \\
\hline 4 & $\left\|v_{b}^{q^{\perp}}(t)\right\|$ & Mínimo & $\left\|v_{b}^{q^{\perp}}(t)\right\|^{\min }$ & 0,3975 \\
\hline 5 & $\left\|i_{b}^{q^{\|}}(t)\right\|$ & Mínimo & $\left\|i_{b}^{q^{\prime \prime}}(t)\right\|^{\min }$ & 0,4750 \\
\hline 6 & $\left\|i_{c}^{q^{\|}}(t)\right\|$ & Mínimo & $\left\|i_{c}^{q^{\prime \prime}}(t)\right\|^{\min }$ & 0,6234 \\
\hline 7 & $\left\|i_{a}^{q^{\perp}}(t)\right\|$ & Mínimo & $\left\|i_{a}^{q^{\perp}}(t)\right\|^{\min }$ & 0,4572 \\
\hline 8 & $\left\|i_{b}^{q^{\perp}}(t)\right\|$ & Médio & $\overline{\left\|i_{b}^{q^{\perp}}(t)\right\|}$ & 0,4028 \\
\hline 9 & $\left\|i_{b}^{q^{\perp}}(t)\right\|$ & Máximo & $\left\|i_{b}^{q^{\perp}}(t)\right\|^{\max }$ & 0,4071 \\
\hline 10 & $\left\|i_{a}^{d}(t)\right\|$ & Mínimo & $\left\|i_{a}^{d}(t)\right\|^{\min }$ & 0,4673 \\
\hline 11 & $\left\|v_{h}^{q^{\prime \prime}}(t)\right\|$ & Mínimo & $\left\|v_{h}^{q^{\|}}(t)\right\|^{\min }$ & 0,4467 \\
\hline 12 & $\left\|i_{\frac{q^{\prime \prime}}{c}}(t)\right\|$ & Mínimo & $\left\|i_{c}^{q^{\prime \prime}}(t)\right\|^{\min }$ & 0,4789 \\
\hline
\end{tabular}

As variáveis apresentadas na Tabela 6.17 representam as variáveis mais correlatas com a distância de ocorrência da falta quando essa envolver a Fase C. Além de constituírem as variáveis mais correlatas, essas foram aquelas empregadas como entrada do sistema fuzzy responsável pela estimação da distância de ocorrência da falta. O sistema fuzzy responsável pela estimação da distância de ocorrência da falta fora constituído por 40 regras de inferência, número esse de regras que, durante os testes computacionais, se mostrou adequado na estimação da distância.

O sistema fuzzy fora ajustado segundo o algoritmo delineado no Capítulo 4 e fazendo uso de um conjunto de ajuste constituído por 1026 pares entrada-saída. Todo o conjunto de ajuste fora construído se fazendo uso das simulações computacionais descritas no Capítulo 5 referentes às faltas fase-terra com participação da Fase C. 
O algoritmo de ajuste delineado no Capítulo 4 é composto de duas etapas de ajuste. A primeira dessas etapas responde pelo ajuste estrutural do sistema fuzzy que, conforme abordado, é dedicado à extração das regras de inferência fuzzy que melhor correlacionam o espaço fuzzy das entradas com o espaço fuzzy da saída. Dessa forma, tem-se como produto da primeira etapa de ajuste a base de regra do sistema fuzzy que, nesse caso, será responsável pela estimação da distância de ocorrência da falta quando a mesma envolver a Fase C.

A fim de apresentar como o erro quadrático médio do sistema fuzzy se portou ao longo das iterações do processo de ajuste estrutural, retrata-se à Figura 6.38, onde tal comportamento é ilustrado.

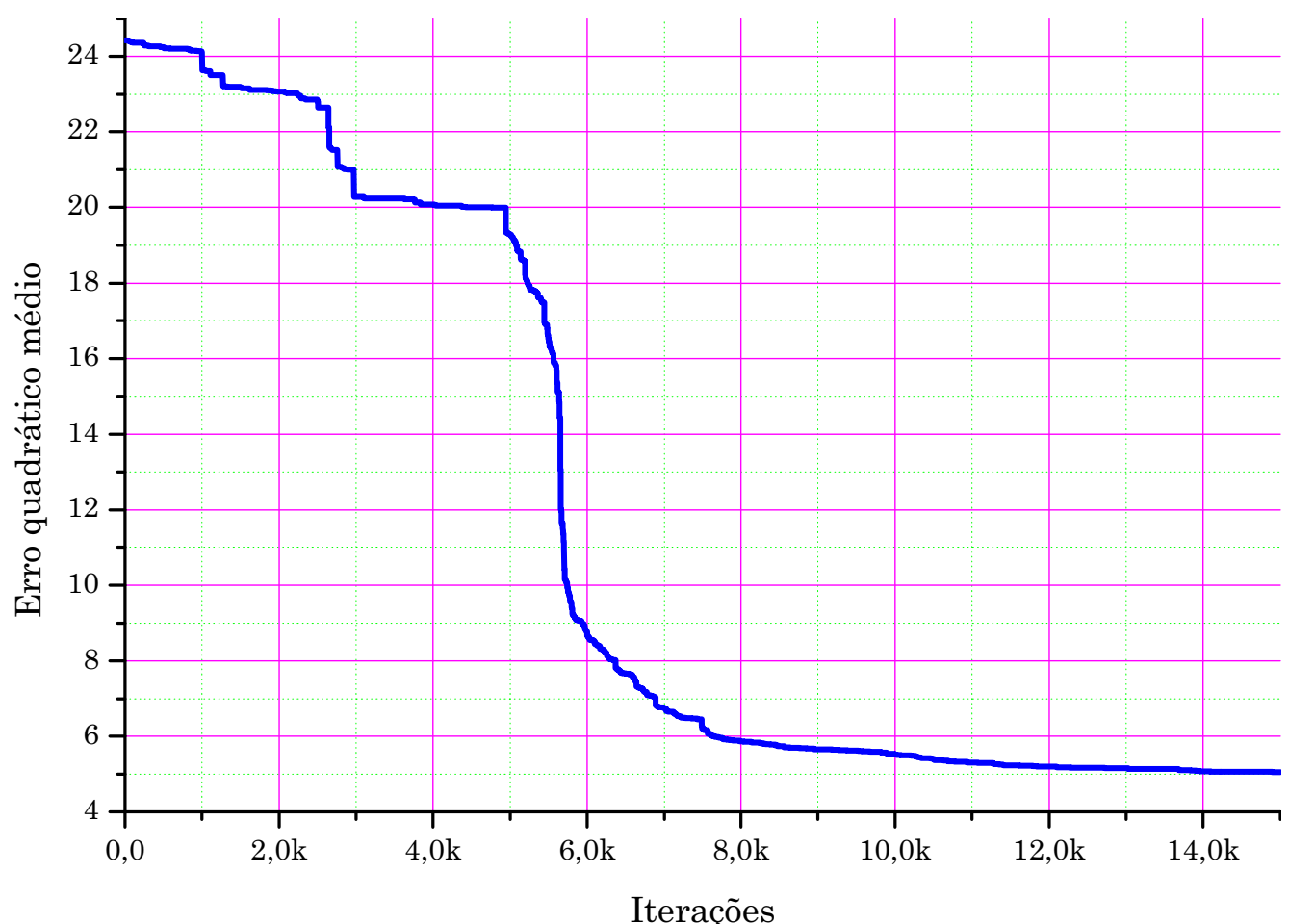

Figura 6.38 - Comportamento do erro quadrático médio do sistema fuzzy dedicado à estimação da distância de ocorrência da falta quando essa envolver a Fase C ao longo das iterações da primeira etapa de ajuste.

O gráfico da Figura 6.38 apresenta a sensível redução do erro quadrático médio ao longo das iterações da primeira etapa de ajuste para o sistema fuzzy responsável pela estimação da distância de ocorrência de uma falta fase-terra quando essa envolver a Fase C. Ao término dessa primeira etapa de ajuste, assim como anteriormente citado, tem-se como produto a base de regras responsável pelo relacionamento entre o espaço fuzzy das variáveis de entrada com o espaço fuzzy da variável de saída. Retratando a base de regras determinada por essa etapa de ajuste, apresenta-se a Figura 6.39. 


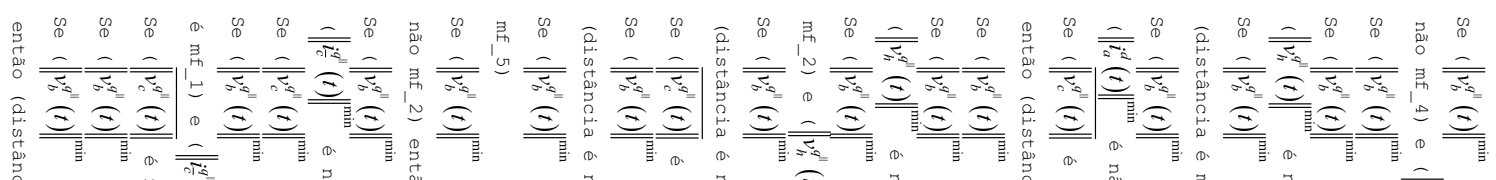

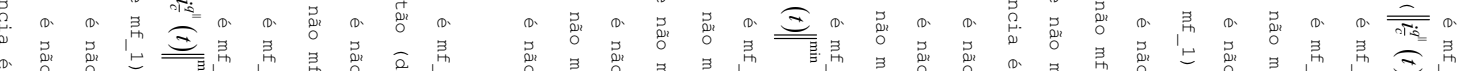

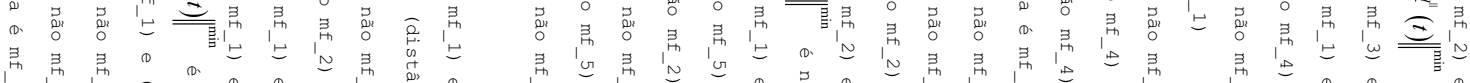

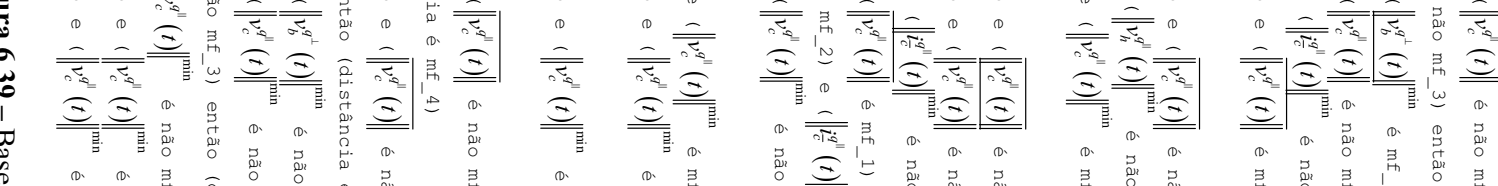

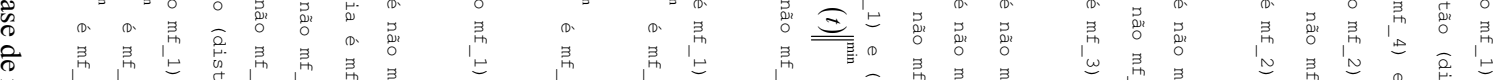
$\overrightarrow{0}$

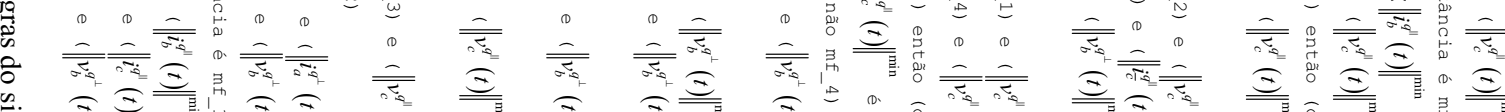

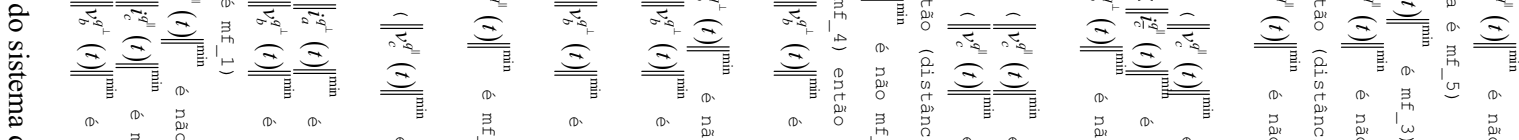

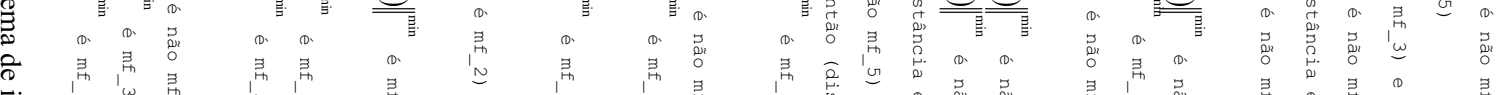

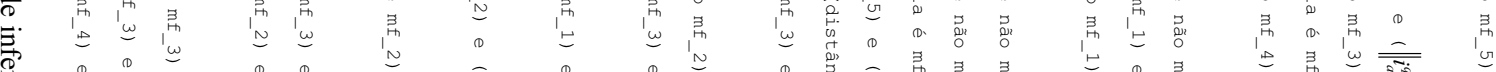

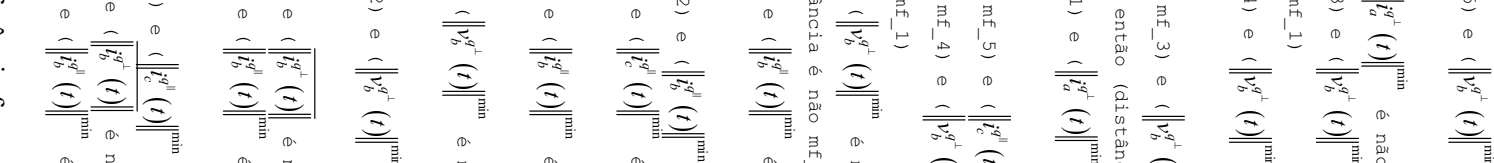

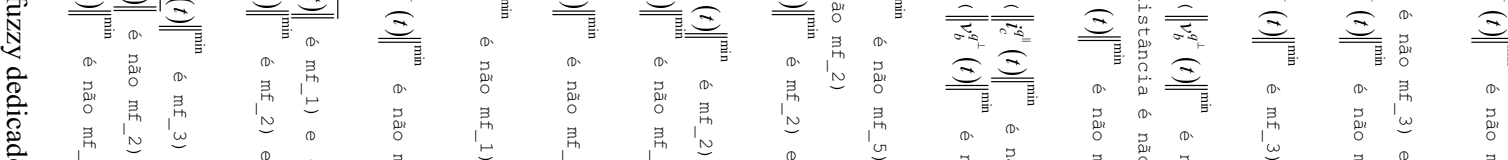

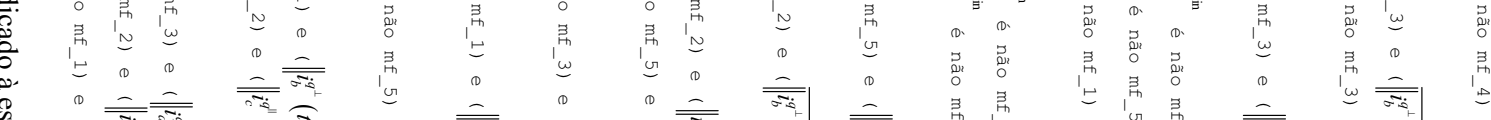

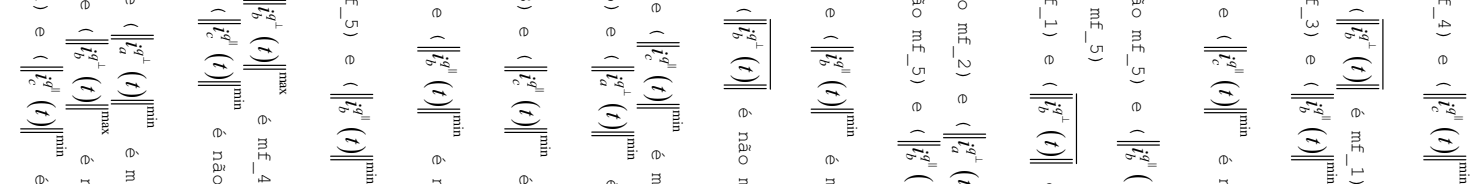

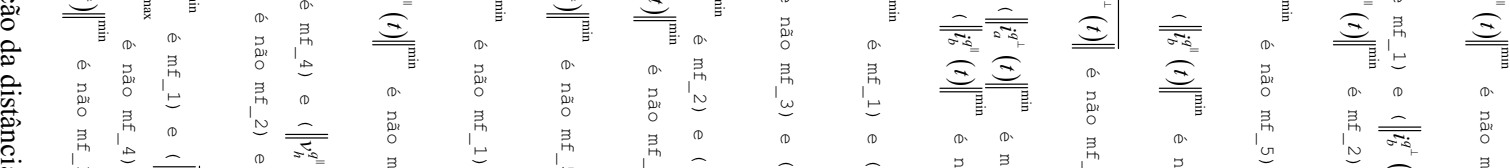

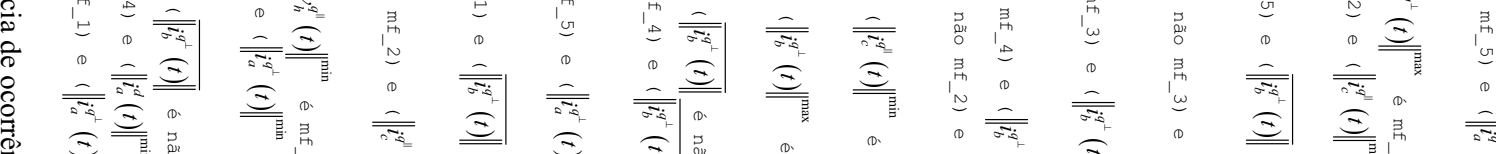

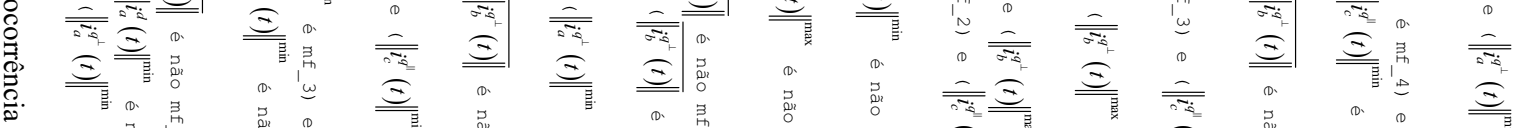

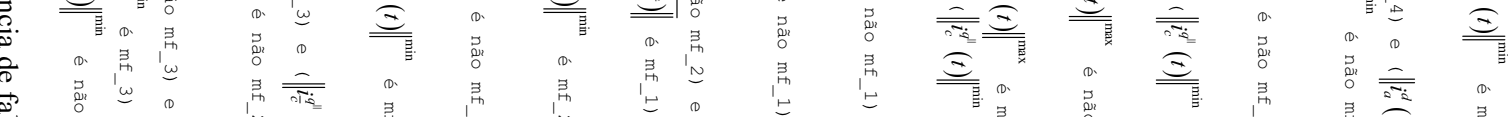

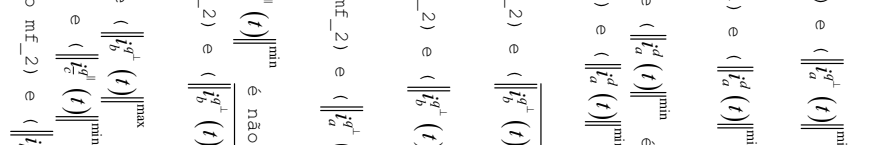

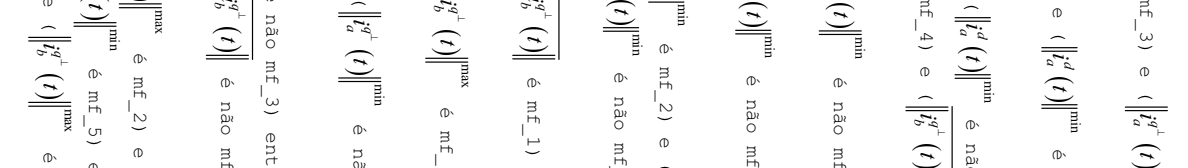

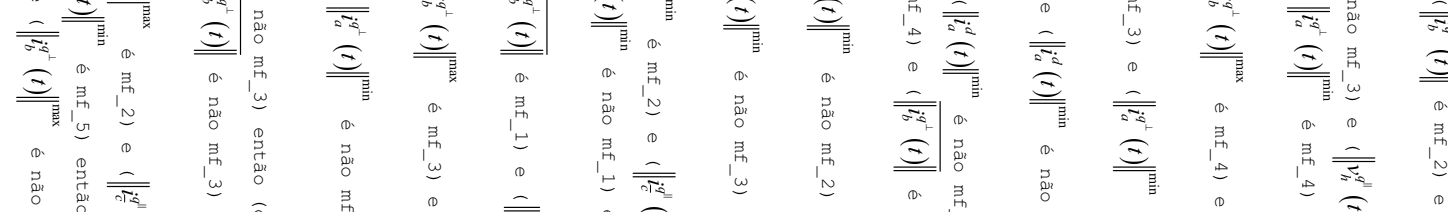

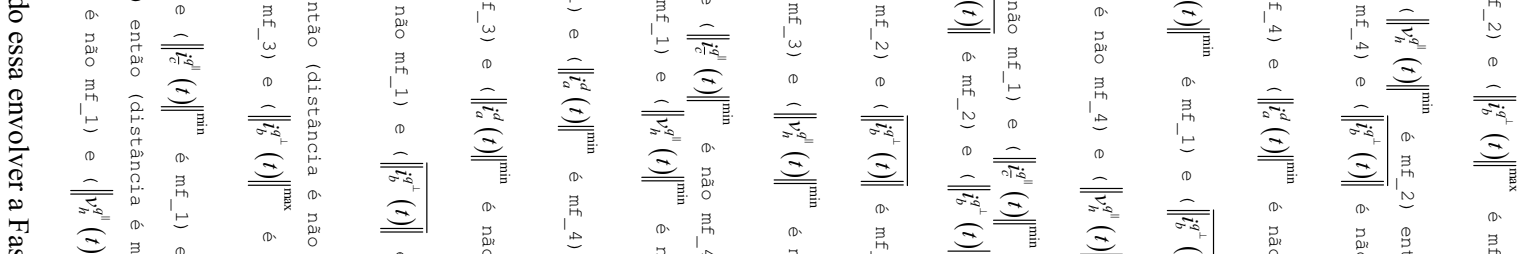

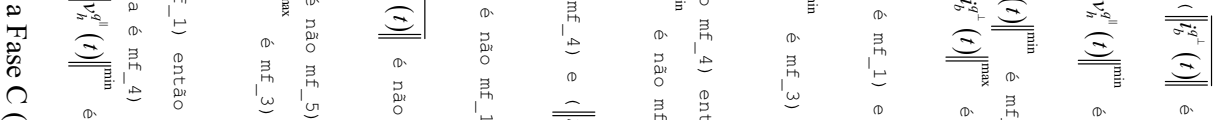

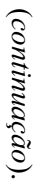

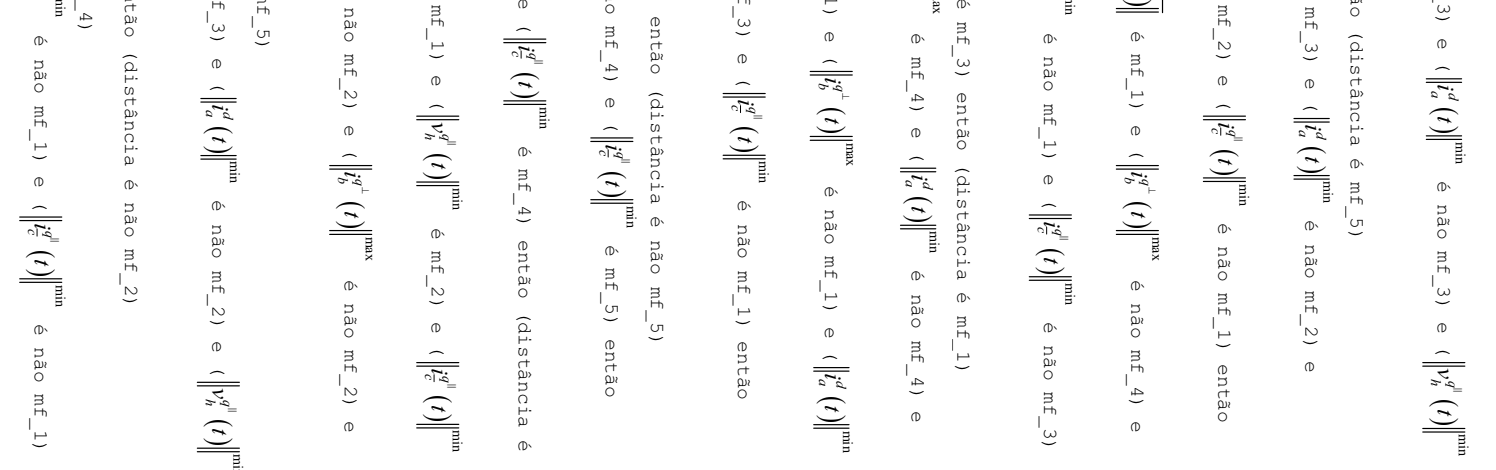


Após a determinação da base de regras representada por meio da Figura 6.38, o sistema de inferência fuzzy fora submetido à segunda etapa de ajuste o qual é dedicado ao ajuste paramétrico do sistema. O ajuste paramétrico tem por meta prosseguir com a redução do erro quadrático iniciada na primeira etapa. Para tanto, a segunda etapa de ajuste, denotada por ajuste paramétrico, modifica os parâmetros que definem as funções de pertinência das entradas e da saída, bem como procede com a ponderação das regras fuzzy ora obtidas na primeira etapa de ajuste. Apresentando como o erro quadrático médio se portou ao longo das iterações dessa segunda etapa de ajuste, tem-se a Figura 6.40.

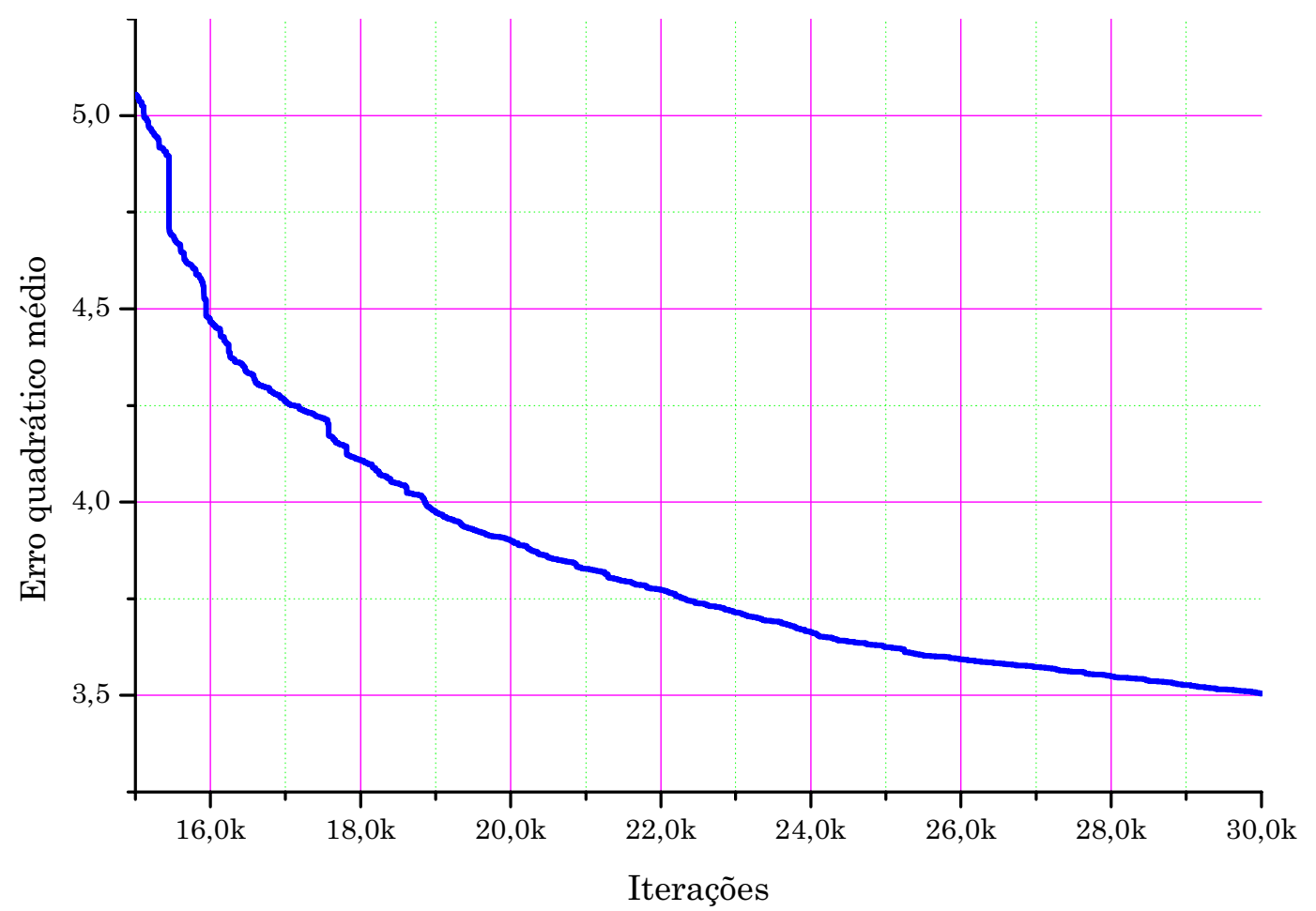

Figura 6.40 - Comportamento do erro quadrático médio do sistema fuzzy dedicado à estimação da distância de ocorrência da falta quando essa envolver a Fase C ao longo das iterações da segunda etapa de ajuste.

Por meio da Figura 6.40 é possível verificar o quão o erro quadrático médio se reduz ao longo da etapa de ajuste paramétrico. Essa etapa, assim como já referenciado, é responsável por ajustar as funções de pertinência das entradas e da saída, além de ponderar as regras de inferência fuzzy. Complementando, a apresentação dos resultados advindos do processo de ajuste paramétrico, ilustra-se por meio da Figura 6.41 as funções de pertinência ajustadas para as seis primeiras entradas, ou seja, para as entradas $\left\|v_{b}^{q^{\prime \prime}}(t)\right\|^{\min }, \overline{\left\|v_{c}^{q^{\prime \prime}}(t)\right\|}\|,\| v_{c}^{q^{\prime \prime}}(t) \|^{\min }$, $\left\|v_{b}^{q^{\perp}}(t)\right\|^{\min },\left\|i_{b}^{q^{\prime}}(t)\right\|^{\min }$ e $\left\|i_{c}^{q^{\prime}}(t)\right\|^{\min }$. Da mesma maneira, por meio da Figura 6.42 tem-se as funções de pertinência para as outras seis entradas, ou seja, para as entradas $\left\|i_{a}^{q^{\perp}}(t)\right\|^{\min },\left\|i_{a}^{q^{\perp}}(t)\right\|^{\min }$, $\left\|i_{b}^{q^{\perp}}(t)\right\|^{\max },\left\|i_{a}^{d}(t)\right\|^{\min },\left\|v_{h}^{q^{\prime \prime}}(t)\right\|^{\min } \mathrm{e}\left\|i_{c}^{q^{\prime \prime}}(t)\right\|^{\min }$. 

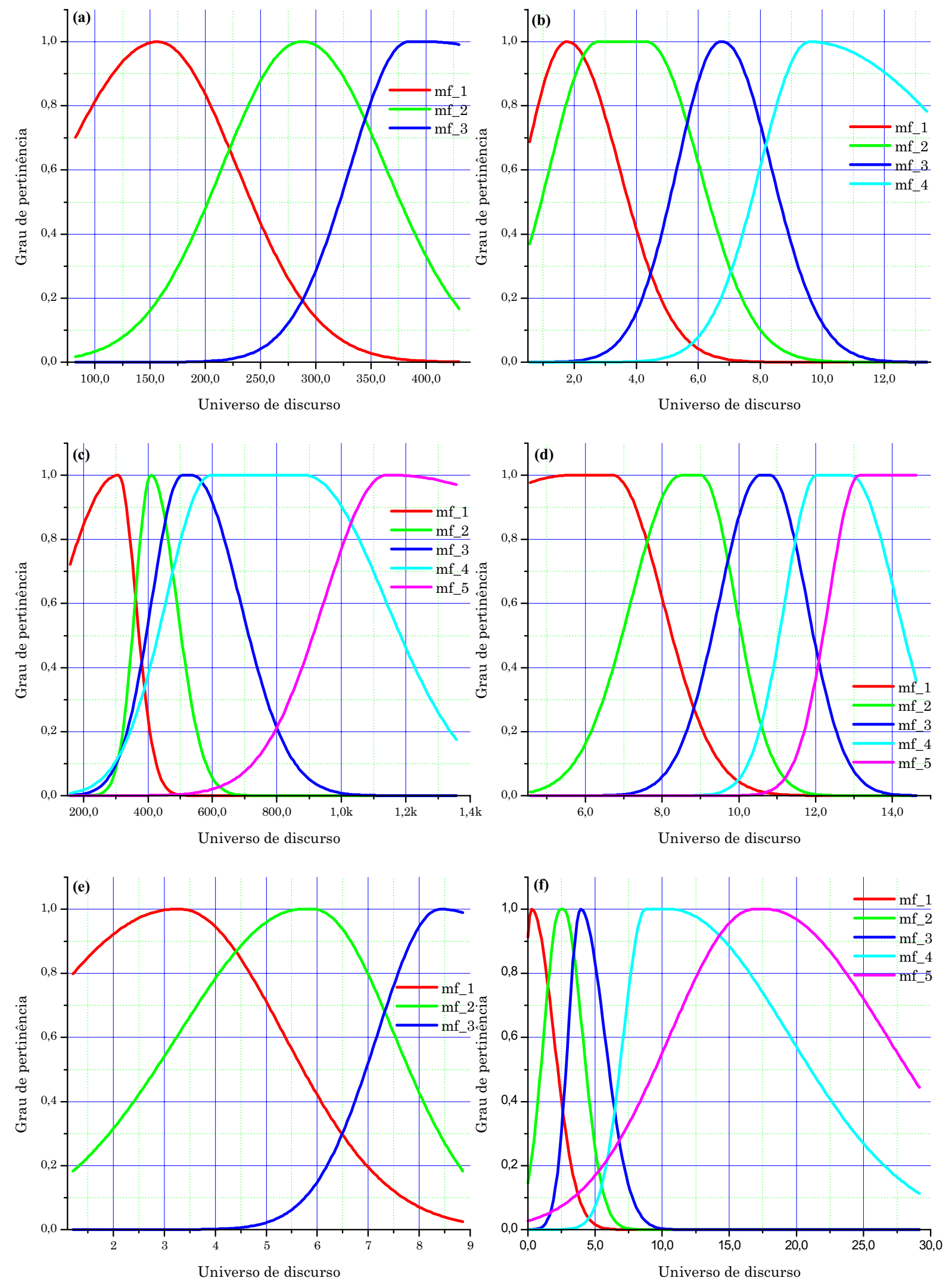

Figura 6.41 - Funções de pertinência ajustadas para as seis primeiras entradas; (a) Entrada $\left\|v_{b}^{q^{\prime \prime}}(t)\right\|^{\text {min }}$; (b) Entrada $\overline{\left\|q_{c}^{q^{\prime \prime}}(t)\right\|} ;$ (c) Entrada $\left\|v_{c}^{q^{\prime \prime}}(t)\right\|^{\text {min }} ;$ (d) Entrada $\left\|v_{b}^{a^{+}}(t)\right\|^{\text {min }} ;$ (e) Entrada $\left\|i_{b}^{q^{\prime \prime}}(t)\right\|^{\min } ;$ (f) Entrada $\left\|i_{c}^{q^{q}}(t)\right\|^{\text {min }}$. 

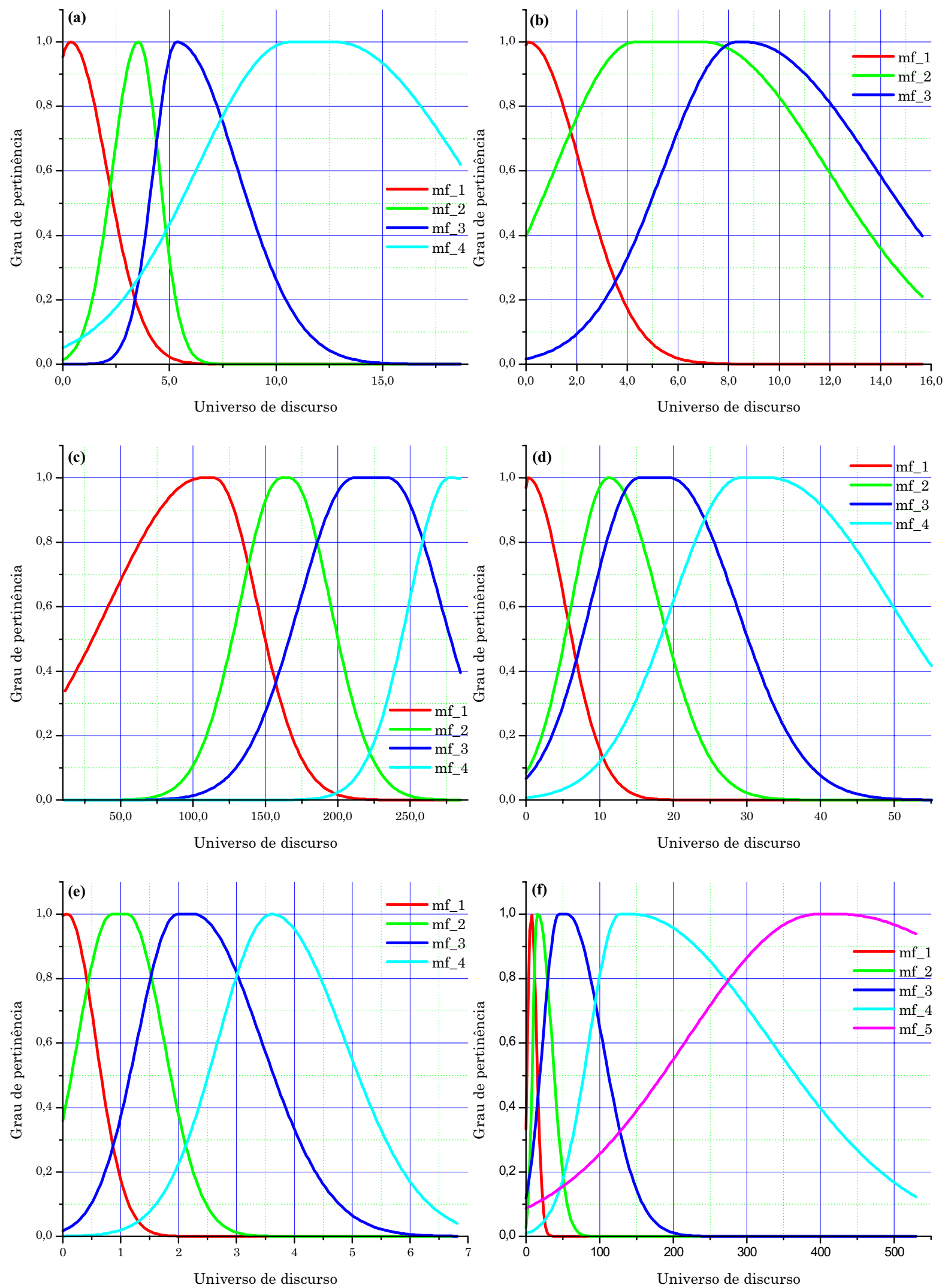

Figura 6.42 - Funções de pertinência ajustadas para as seis primeiras entradas; (a) Entrada $\left\|v_{c}^{d}(t)\right\|^{\min } ;$ (b) Entrada $\left\|i_{a}^{q^{\perp}}(t)\right\|^{\min } ;$ (c) Entrada $\left\|i_{b}^{q^{+}}(t)\right\|^{\max } ;$ (d) Entrada $\left\|i_{a}^{d}(t)\right\|^{\min }$; (e) Entrada $\left\|v_{h}^{q^{\prime \prime}}(t)\right\|^{\min } ;$ (f) Entrada $\left\|i_{c}^{q^{\prime}}(t)\right\|^{\min }$. 
A etapa de ajuste paramétrico não apenas sintoniza as funções de pertinência do espaço das entradas como também ajusta as funções de pertinência da saída. Assim, por meio da Figura 6.43 apresentam-se as funções de pertinência da saída, que nesse caso representam a distância de ocorrência da falta em relação à subestação.

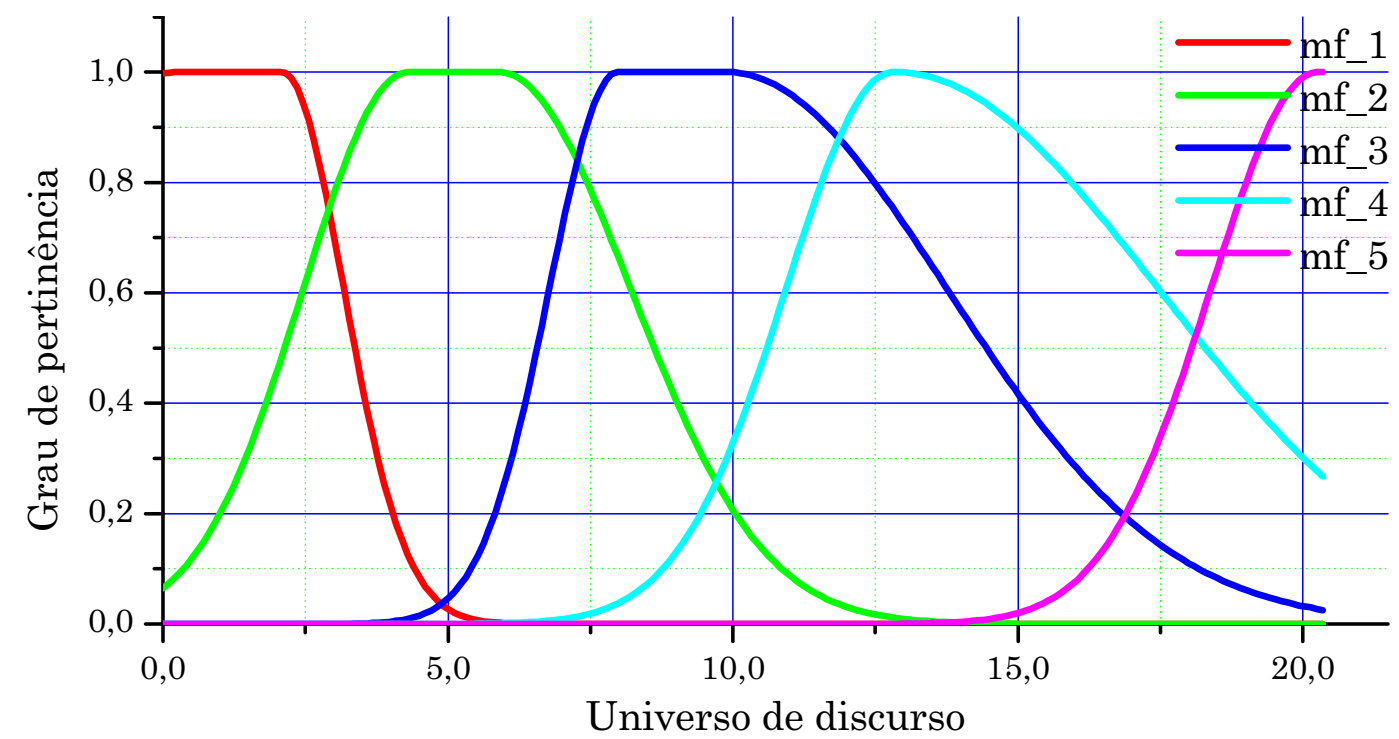

Figura 6.43 - Funções de pertinência associadas à distância de ocorrência de faltas fase-terra na Fase C.

Findando a apresentação do sistema fuzzy dedicado à estimação da distância de ocorrência da falta quando de sua ocorrência na Fase C, tem-se na Figura 6.44 a maneira pela qual as regras fuzzy, destacadas na sua forma verbal por meio da Figura 6.39, foram ponderadas pela etapa de ajuste paramétrico.

O sistema fuzzy ajustado para fins de estimação da distância de ocorrência de faltas fase-terra na Fase $\mathrm{C}$ fora ajustado, tanto estrutural como parametricamente, tendo como base os resultados providos por um conjunto de 1026 simulações de faltas ocorridas na Fase C. Tais simulações computacionais, apresentadas em detalhes no Capítulo 5, possuíram como variáveis independentes a distância de ocorrência da falta, a resistência de falta, o instante inicial da falta e a duração das mesma. Assim, após o processo de ajuste é primordial a verificação da eficácia do sistema no desempenho da tarefa de estimação da distância de ocorrência da falta.

Para tanto, o sistema fuzzy fora, inicialmente, testado com os dados advindos das simulações empregadas na constituição do conjunto de ajuste do mesmo. Apresentando como o erro relativo se porta para a estimação da distância de ocorrência da falta, tem-se o gráfíco da Figura 6.45 onde se destaca o histograma do referido erro. 


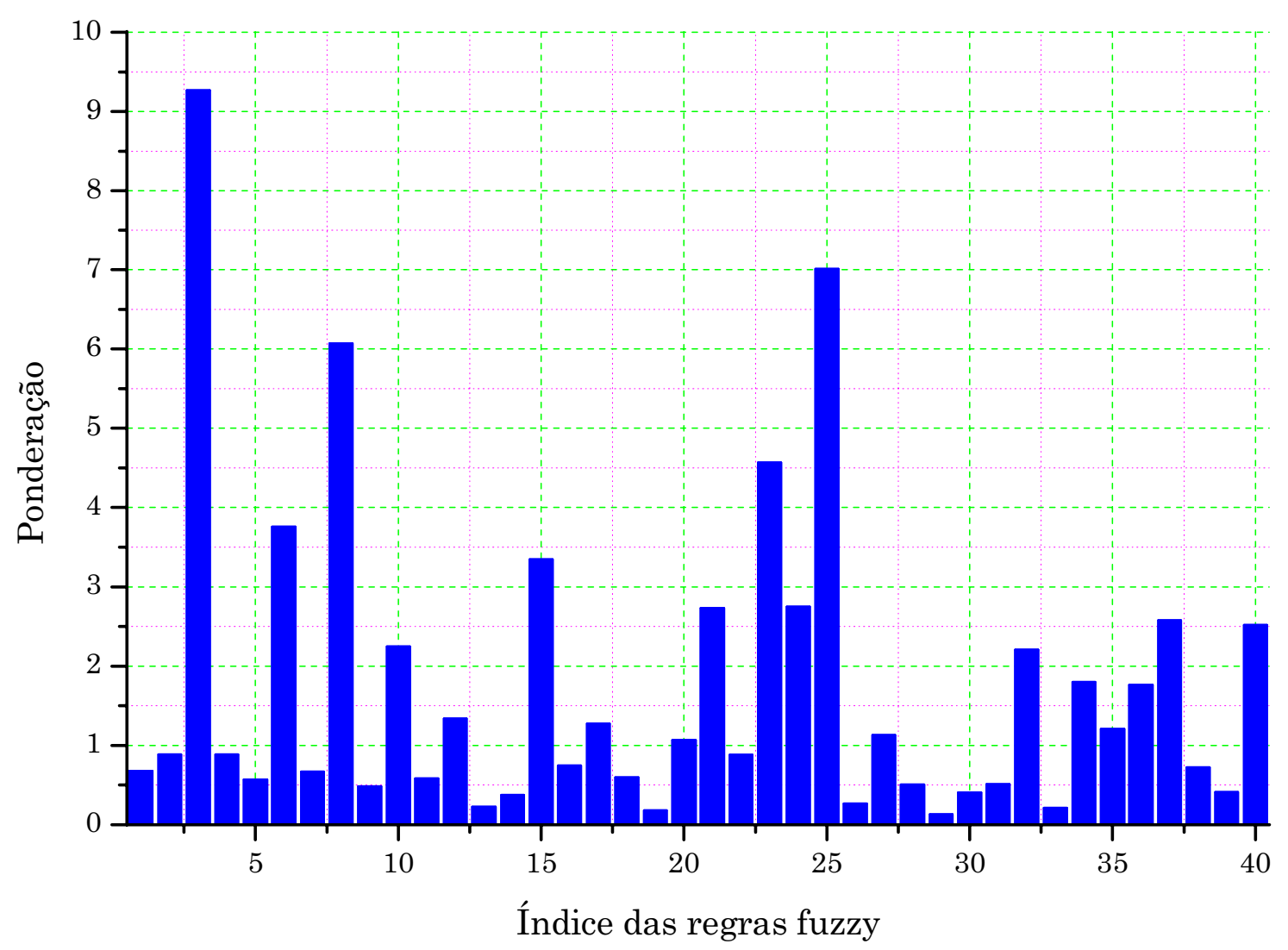

Figura 6.44 - Ponderação das regras fuzzy do sistema de inferência fuzzy dedicado à estimação da distância de ocorrência de faltas fase-terra na Fase C.

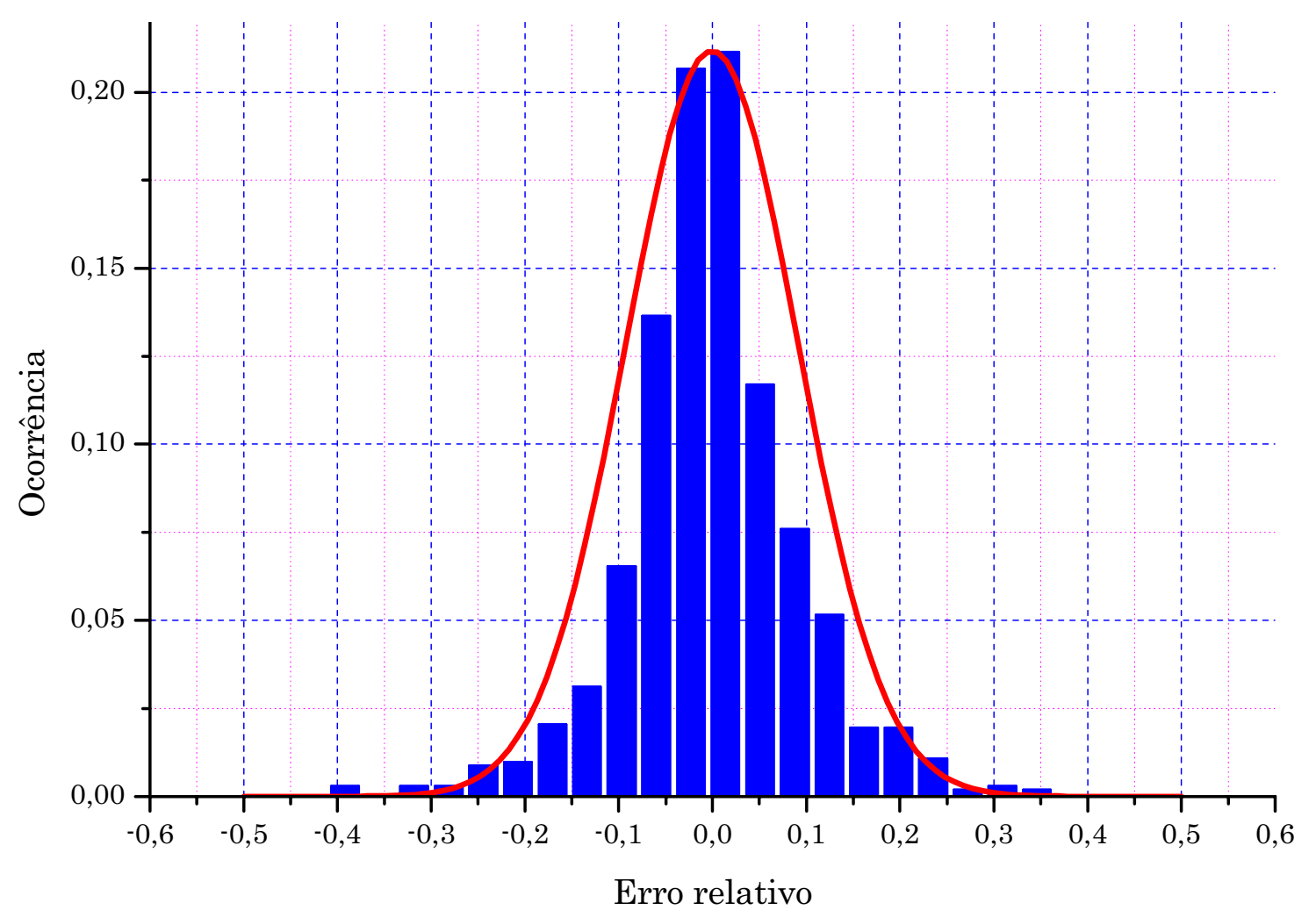

Figura 6.45 - Histograma do erro relativo de estimação da distância de ocorrência de faltas fase-terra na Fase C. 
Por meio do gráfico apresentado na Figura 6.45 além de destacar o histograma do erro relativo de estimação da distância de ocorrência da falta se tem o gráfico da distribuição normal que mais se aproxima. A distribuição normal do erro relativo possui média de $-6,2891 \times 10^{-4}$ e desvio padrão de 0,0921, ou seja, em $68,25 \%$ dos casos, a estimação da distância de ocorrência da falta é realizada possuindo o erro relativo de estimação posicionado entre $-0,0921$ e 0,0921 .

Complementando a análise do erro relativo de estimação da distância de ocorrência da falta, apresenta-se na Tabela 6.18 a correlação entre o erro relativo e as variáveis independentes das simulações computacionais, ou seja, a correlação entre o erro relativo e a distância de ocorrência da falta, a resistência de falta, o ângulo de falta e a duração da falta.

Tabela 6.18 - Correlação entre o erro relativo e as variáveis independentes das simulações computacionais.

\begin{tabular}{lr}
\hline \hline $\begin{array}{l}\text { Variável independente da } \\
\text { simulação }\end{array}$ & $\begin{array}{r}\text { Correlação com erro } \\
\text { relativo de estimação }\end{array}$ \\
\hline \hline Distância de ocorrência da falta & 0.4558 \\
\hline Resistência de falta & 0.0078 \\
\hline Ângulo da falta & 0.0192 \\
\hline Duração da falta & 0.0705 \\
\hline \hline
\end{tabular}

Por meio da Tabela 6.18 é possível verificar a forte dependência do erro relativo com a distância de ocorrência da falta, ou seja, com a própria variável de estimação. Ainda, verifica-se correlação do erro com a duração da falta, sendo que as correlações existentes entre o erro e a resistência de falta e o ângulo de falta é ínfimo. A fim de ilustrar a forte correlação do erro de estimação da distância com a distância real de ocorrência se apresenta o gráfico da Figura 6.46.

Verifica-se pelo gráfico da Figura 6.46 a tendência tanto do máximo erro quanto do mínimo erro aumentarem com o aumento da distância de ocorrência da falta. No entanto, a faixa de erro, a distância entre o máximo erro e o mínimo erro, tende a permanecer constante em relação à distância de ocorrência da falta. A Figura 6.47 apresenta o relacionamento do erro relativo para as demais variáveis independentes das simulações computacionais. 


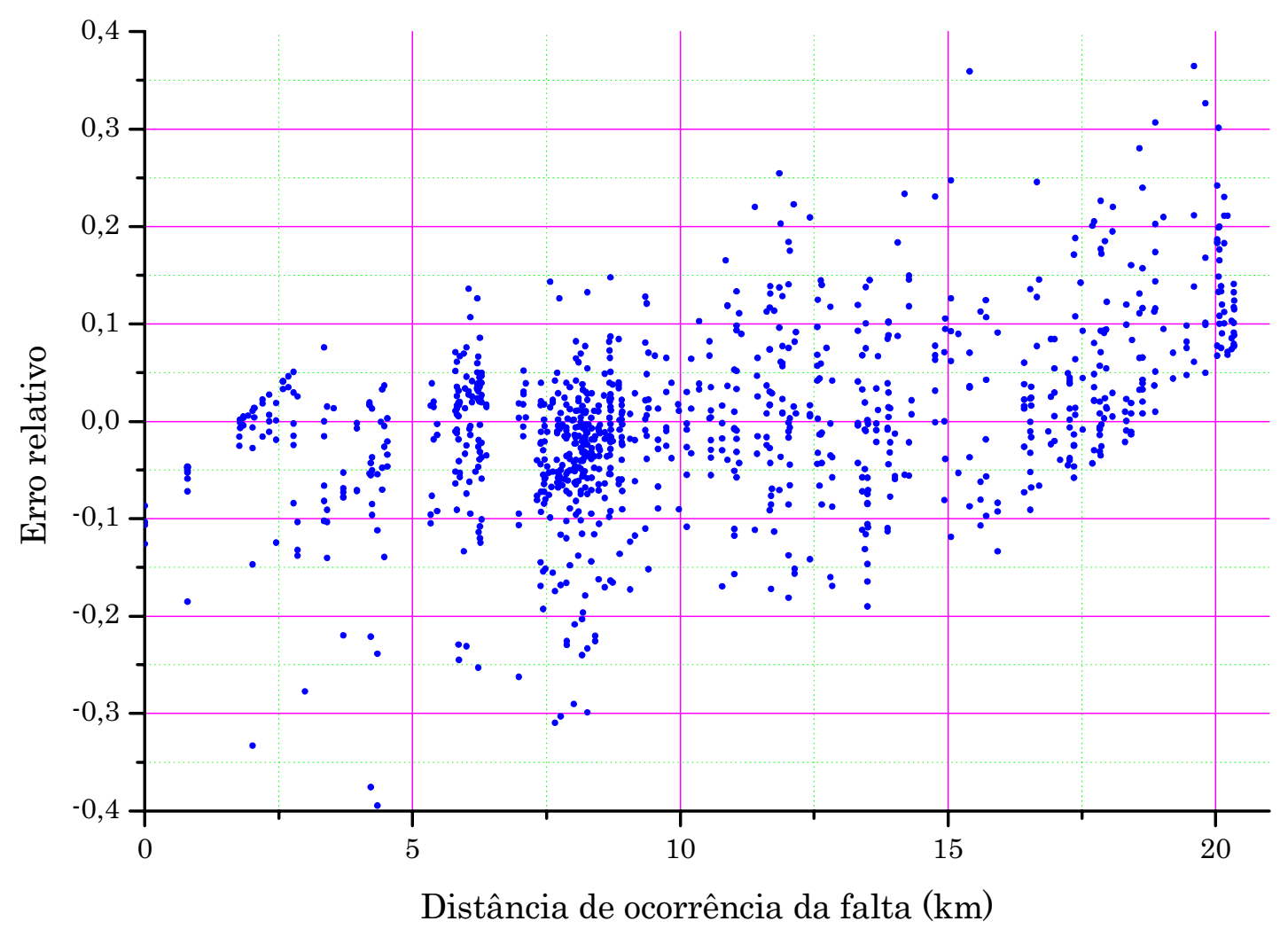

Figura 6.46 - Relacionamento entre o erro relativo e a distância de ocorrência da falta.

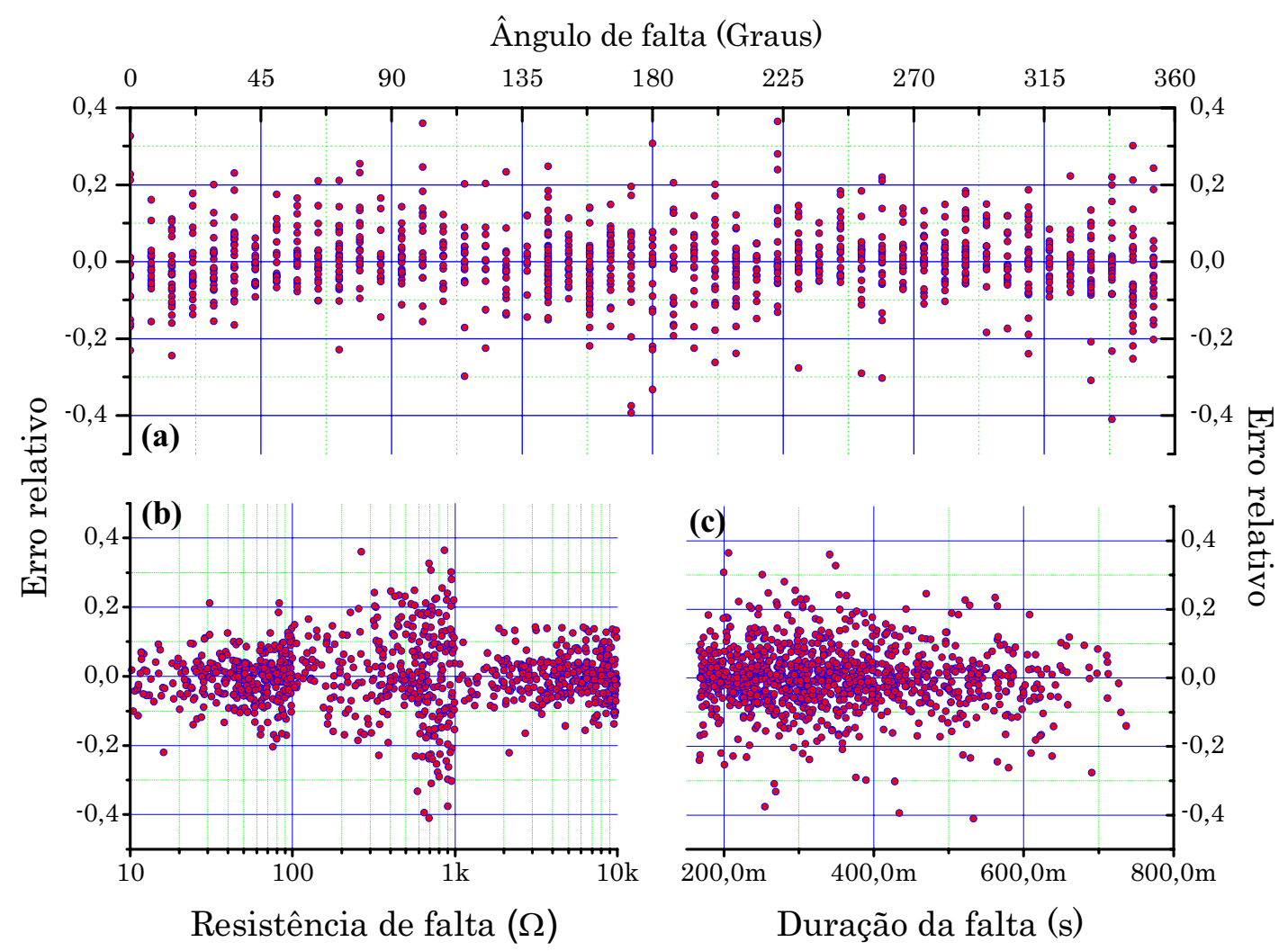

Figura 6.47 - Relacionamento entre o erro relativo e as demais variáveis independentes de simulação; (a) Relacionamento entre o erro relativo e o ângulo de falta; (b) Relacionamento entre o erro relativo e a resistência de falta; (c) Relacionamento entre o erro relativo e a duração da falta. 
O sistema fuzzy dedicado à estimação da distância de ocorrência da falta, além de ser testado com os dados provenientes do conjunto de ajuste, fora também testado com dados advindos de simulações computacionais não contidos no conjunto de ajuste. Assim, um total de 310 situações de falta na Fase $\mathrm{C}$ foram simuladas e os resultados dessas simulações foram submetidos à técnica de decomposição em componentes ortogonais. De posse dos valores eficazes das componentes ortogonais, as variáveis mais correlatas à localização de faltas na Fase C, apresentadas na Tabela 6.17, foram selecionadas e apresentadas ao sistema fuzzy previamente ajustado. Os resultados obtidos para a localização de faltas quando de sua ocorrência na Fase C são apresentados por meio da Figura 6.48 na forma de histograma do erro relativo.

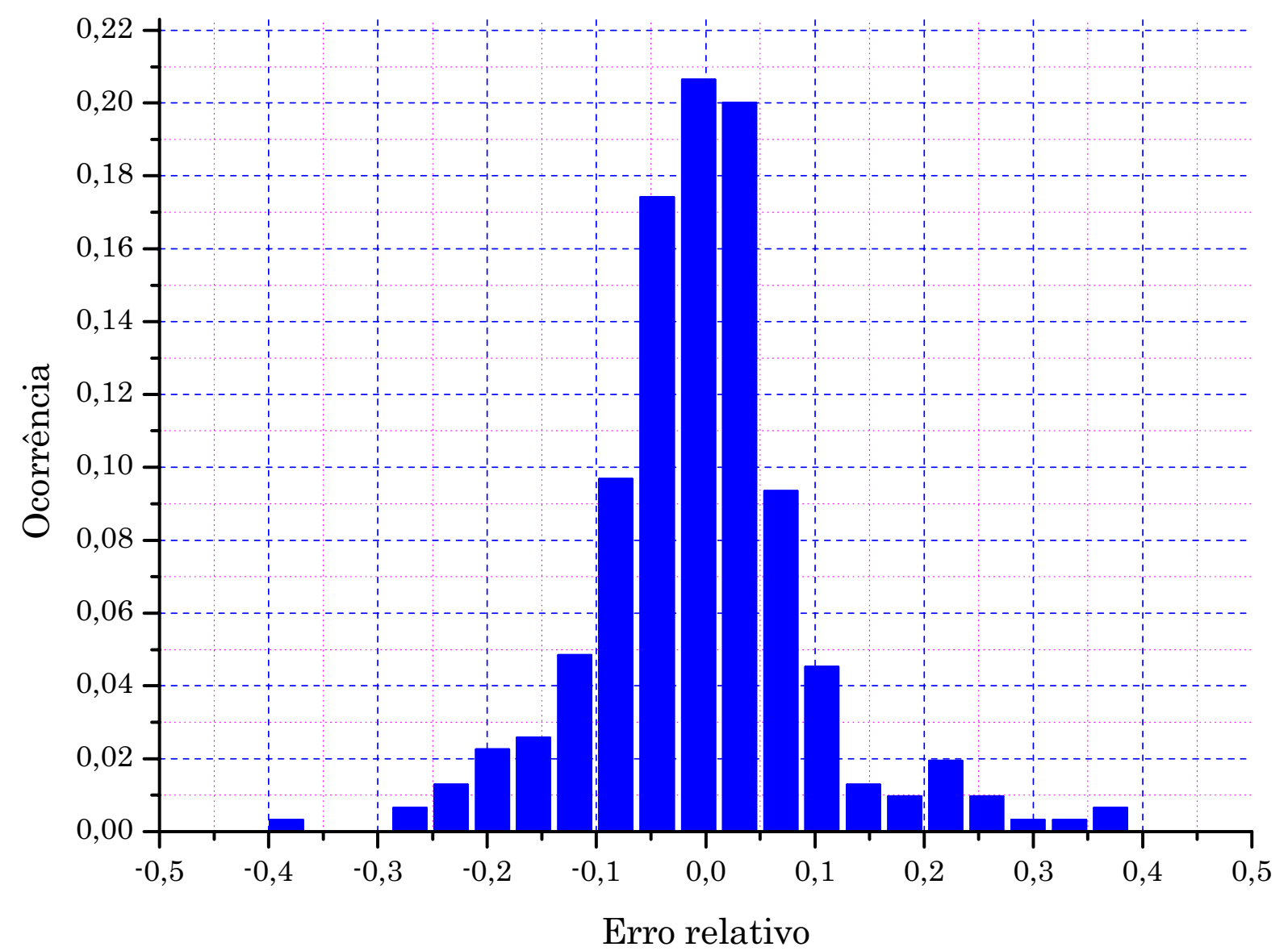

Figura 6.48 - Histograma do erro relativo de estimação da distância de ocorrência de faltas fase-terra ma Fase $\mathrm{C}$ para os dados do conjunto de teste.

Assim como a distribuição do erro relativo para os dados de ajuste se assemelha a uma distribuição normal, o mesmo pode ser verificado para o erro relativo apresentado para o conjunto de teste. A fim de ilustrar como a distribuição estatística do erro relativo para os dados de ajuste é semelhante à distribuição do erro verificado para os dados de teste, 
apresenta-se a Figura 6.49 onde ambas as distribuições estatísticas são confrontadas para propósitos comparativos.

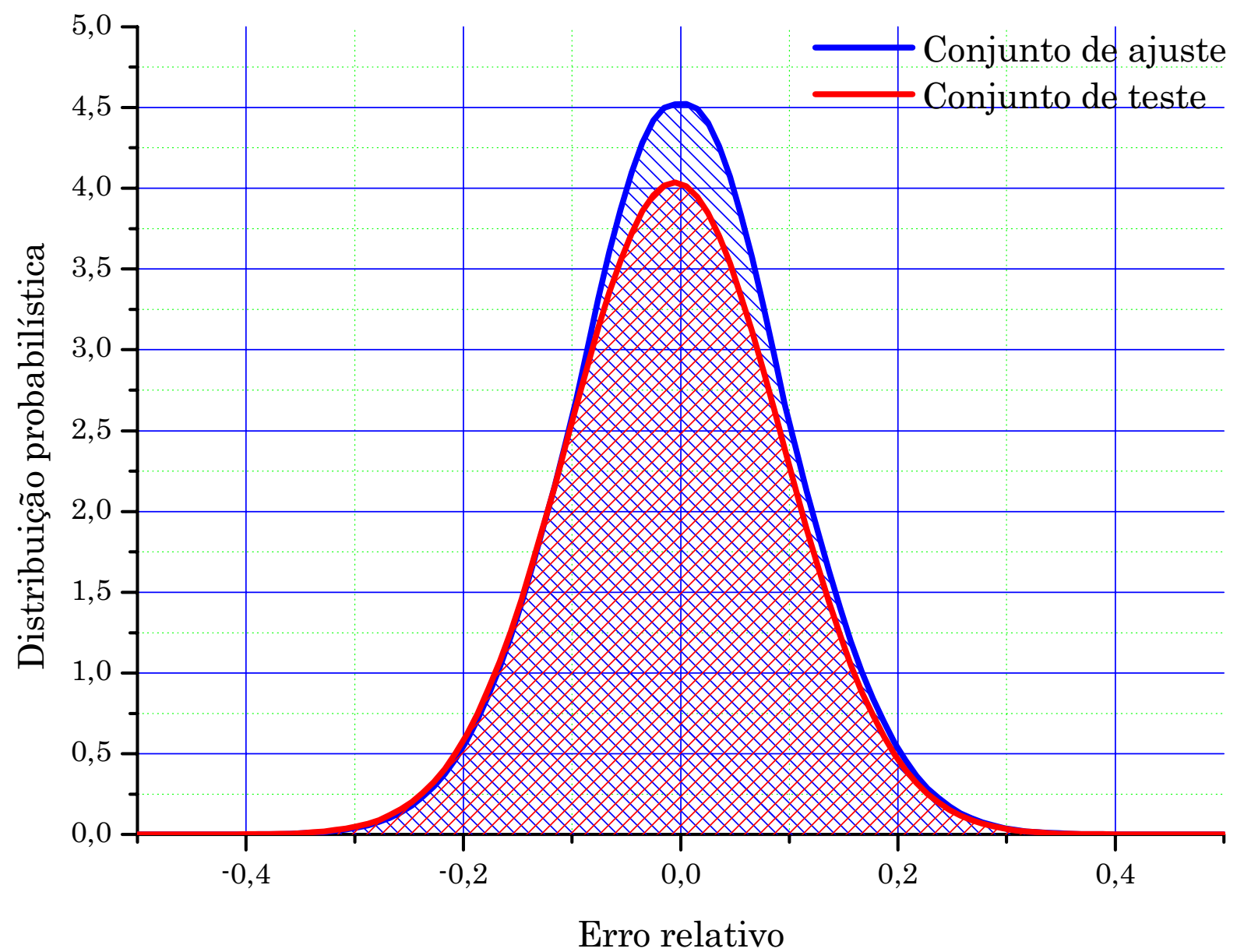

Figura 6.49 - Distribuição normal para o conjunto de ajuste e para o conjunto de teste quando da localização de falta na Fase C.

Por meio da Figura 6.49 é possível verificar que a distribuição normal verificada para os dados de teste se enquadrou com aquela verificada quando da modelagem do erro observado para os dados de ajuste. Ainda, quando da distribuição normal apresentada na Figura 6.32, tem-se que sua média fora de $-0,0055$ e o desvio padrão de 0,0989.

\subsection{SISTEMA de INFERÊNCIA FUZZY PARA ESTIMAÇÃO DA RESISTÊNCIA DE FALTA}

Na seção anterior fora apresentado como por meio de sistemas de inferência fuzzy e decomposição em componentes ortogonais é possível estimar a distância, relativa à subestação, que uma falta fase-terra em um alimentador de distribuição ocorrera. De maneira mais detalhada, mostrou-se o desenvolvimento para a localização desse tipo de falta quando essa ocorre em cada uma das fases do sistema. O desenvolvimento individualizado para cada 
fase mostrou que a metodologia culmina em resultados semelhantes para cada uma das fases. Essa constatação valida o emprego das componentes ortogonais para a finalidade de localização, bem como faz o mesmo para o algoritmo de ajuste de sistema fuzzy, o qual também constitui em contribuições desse trabalho. Mais do que isso, a semelhança dos referidos resultados permite a constatação de que a forma pela qual as variáveis foram eleitas, ou seja, pela correlação existente entre essas e a variável de estimação, também pode ser considerada adequada para os propósitos em questão.

Dessa forma, metodologia idêntica a anteriormente empregada será, nessa seção, replicada para a implementação dos sistemas fuzzy responsáveis pela estimação da resistência de falta.

Quando da localização do ponto de ocorrência de uma falta fase-terra em um sistema de distribuição de energia elétrica, tem-se na estimação da distância de sua ocorrência um fator de primordial importância para a efetiva localização da mesma. No entanto, tal como discutido nos capítulos introdutórios, uma falta fase-terra, com destaque para aquelas de alta impedância, pode ocorrer de diferentes maneiras como, por exemplo, por meio da queda do condutor fase sobre a cruzeta ou como a queda desse condutor diretamente ao solo. Essa falta pode ainda ser oriunda da degradação de isoladores do sistema ou da falha de pára-raios apenas para citar algumas possibilidades. Assim, a rápida localização de faltas fase-terra é função da qualidade da estimativa da distância de sua ocorrência, podendo a causa da falta contribuir para a ligeira execução dessa tarefa.

Dessa maneira, o objetivo dessa seção é apresentar os desenvolvimentos empregados no ajuste dos sistemas fuzzy dedicados à estimação da resistência de falta e, assim, contribuir para sua localização, pois, como é sabido, para cada tipo de causa se pode associar uma faixa de resistência para a mesma. Contudo, o objetivo dessa seção não é de fornecer as possíveis causas da falta, mas sim possibilitar que trabalhos futuros o façam a partir das estimativas de resistência de falta conduzidas nessa seção.

Portanto, para conduzir a apresentação dos desenvolvimentos realizados e dos resultados obtidos correlatos à estimação da resistência de falta, essa seção fora organizada em subseções tendo, na Subseção 6.3.1, os delineamentos pertinentes à estimação da resistência de falta quando essa ocorrer na Fase A. Os desenvolvimentos e resultados relativos à Fase $\mathrm{B}$ e à Fase C são tema da Subseção 6.3.2 e da Subseção 6.3.3, respectivamente. 


\subsubsection{SISTEMA DE INFERÊNCIA FUZZY PARA ESTIMAÇÃO DA RESISTÊNCIA DE FALTA NA FASE A}

A estimação da resistência de falta quando essa ocorrer na Fase A será realizada por meio de sistema de inferência fuzzy e da técnica de decomposição em componentes ortogonais, assim como será feito para as demais fases do sistema de distribuição. Para fins de identificação das componentes ortogonais mais correlatas com a resistência de falta as mesmas componentes e suas respectivas características empregadas na estimação da distância de falta serão empregadas, ou seja, será avaliada a correlação dos valores médios, máximos e mínimos para cada componente oriunda do processo de decomposição em componentes ortogonais.

Dessa forma, para apresentar como cada componente advinda do resultado da decomposição ortogonal se correlaciona com a resistência de falta, apresentam-se por meio da Tabela 6.19 as correlações e os testes de hipótese, que mensuram o quão significativo é a correlação, das componentes de tensões contidas na função planar das tensões de linha com a resistência de falta quando essa for observada na Fase A. Os valores contidos na Tabela 6.19 são graficamente apresentados por meio da Figura 6.50.

Por meio da Tabela 6.20 se apresentam as correlações das componentes de corrente contidas na função planar das tensões de linha com a resistência de falta, assim como por meio da Figura 6.51 se tem a representação gráfica dos valores contidos nessa tabela.

A correlação das componentes de tensão ortogonais à função planar das tensões de linha com a resistência de falta é apresentada na Tabela 6.21 e tais valores para as componentes de corrente ortogonais à função planar das tensões de linha são conteúdo da Tabela 6.22. A representação dos valores expressos na Tabela 6.21 e Tabela 6.22 é realizada por meio da Figura 6.52 e da Figura 6.53, respectivamente. 
Tabela 6.19 - Correlação das componentes de tensão contidas na função planar das tensões de linha com relação à resistência de falta na Fase A.

\begin{tabular}{|c|c|c|c|c|c|c|c|}
\hline \multirow[b]{2}{*}{$k$} & \multirow[b]{2}{*}{ Variável } & \multicolumn{2}{|c|}{ Média } & \multicolumn{2}{|c|}{ Máximo } & \multicolumn{2}{|c|}{ Mínimo } \\
\hline & & Correlação & $\begin{array}{l}\text { Teste de } \\
\text { hipótese } \\
\end{array}$ & Correlação & $\begin{array}{l}\text { Teste de } \\
\text { hipótese } \\
\end{array}$ & Correlação & $\begin{array}{l}\text { Teste de } \\
\text { hipótese }\end{array}$ \\
\hline 1 & $\left\|v_{a}^{p}(t)\right\|$ & 0,0243 & 0,4480 & 0,1102 & 0,0006 & 0,0398 & 0,2143 \\
\hline 2 & $\left\|v_{b}^{p}(t)\right\|$ & 0,0685 & 0,0325 & 0,0639 & 0,0462 & 0,0356 & 0,2669 \\
\hline 3 & $\left\|v_{c}^{p}(t)\right\|$ & 0,0144 & 0,6544 & 0,0145 & 0,6521 & 0,0371 & 0,2480 \\
\hline 4 & $\left\|v_{n}^{p}(t)\right\|$ & 0,0312 & 0,3312 & 0,0320 & 0,3183 & 0,0308 & 0,3371 \\
\hline 5 & $\left\|v_{a}^{q^{\prime \prime}}(t)\right\|$ & 0,0655 & 0,0411 & 0,0008 & 0,9790 & 0,1221 & 0,0001 \\
\hline 6 & $\left\|v_{b}^{q^{\prime \prime}}(t)\right\|$ & 0,0470 & 0,1430 & 0,0946 & 0,0031 & 0,1271 & 0,0001 \\
\hline 7 & $\left\|v_{c}^{q^{\prime \prime}}(t)\right\|$ & 0,0362 & 0,2587 & 0,0362 & 0,2586 & 0,1030 & 0,0013 \\
\hline 8 & $\left\|v_{n}^{q^{\|}}(t)\right\|$ & 0,0402 & 0,2104 & 0,0476 & 0,1380 & 0,0117 & 0,7146 \\
\hline 9 & $\left\|v_{a}^{q^{\perp}}(t)\right\|$ & 0,0770 & 0,0162 & 0,0727 & 0,0233 & 0,0230 & 0,4725 \\
\hline 10 & $\left\|v_{b}^{q^{\perp}}(t)\right\|$ & 0,0485 & 0,1307 & 0,0578 & 0,0714 & 0,0396 & 0,2168 \\
\hline 11 & $\left\|v_{c}^{q^{\perp}}(t)\right\|$ & 0,0823 & 0,0102 & 0,0929 & 0,0037 & 0,0474 & 0,1396 \\
\hline 12 & $\left\|v_{n}^{q^{\perp}}(t)\right\|$ & 0,1298 & 0,0000 & 0,1853 & 0,0000 & 0,0000 & 0,9997 \\
\hline 13 & $\left\|v_{a}^{d}(t)\right\|$ & 0,0770 & 0,0162 & 0,0727 & 0,0233 & 0,0122 & 0,7043 \\
\hline 14 & $\left\|v_{b}^{d}(t)\right\|$ & 0,0485 & 0,1307 & 0,0578 & 0,0714 & 0,0382 & 0,2336 \\
\hline 15 & $\left\|v_{c}^{d}(t)\right\|$ & 0,0823 & 0,0102 & 0,0929 & 0,0037 & 0,0462 & 0,1499 \\
\hline 16 & $\left\|v_{n}^{d}(t)\right\|$ & 0,1298 & 0,0000 & 0,1853 & 0,0000 & 0,0006 & 0,9848 \\
\hline
\end{tabular}
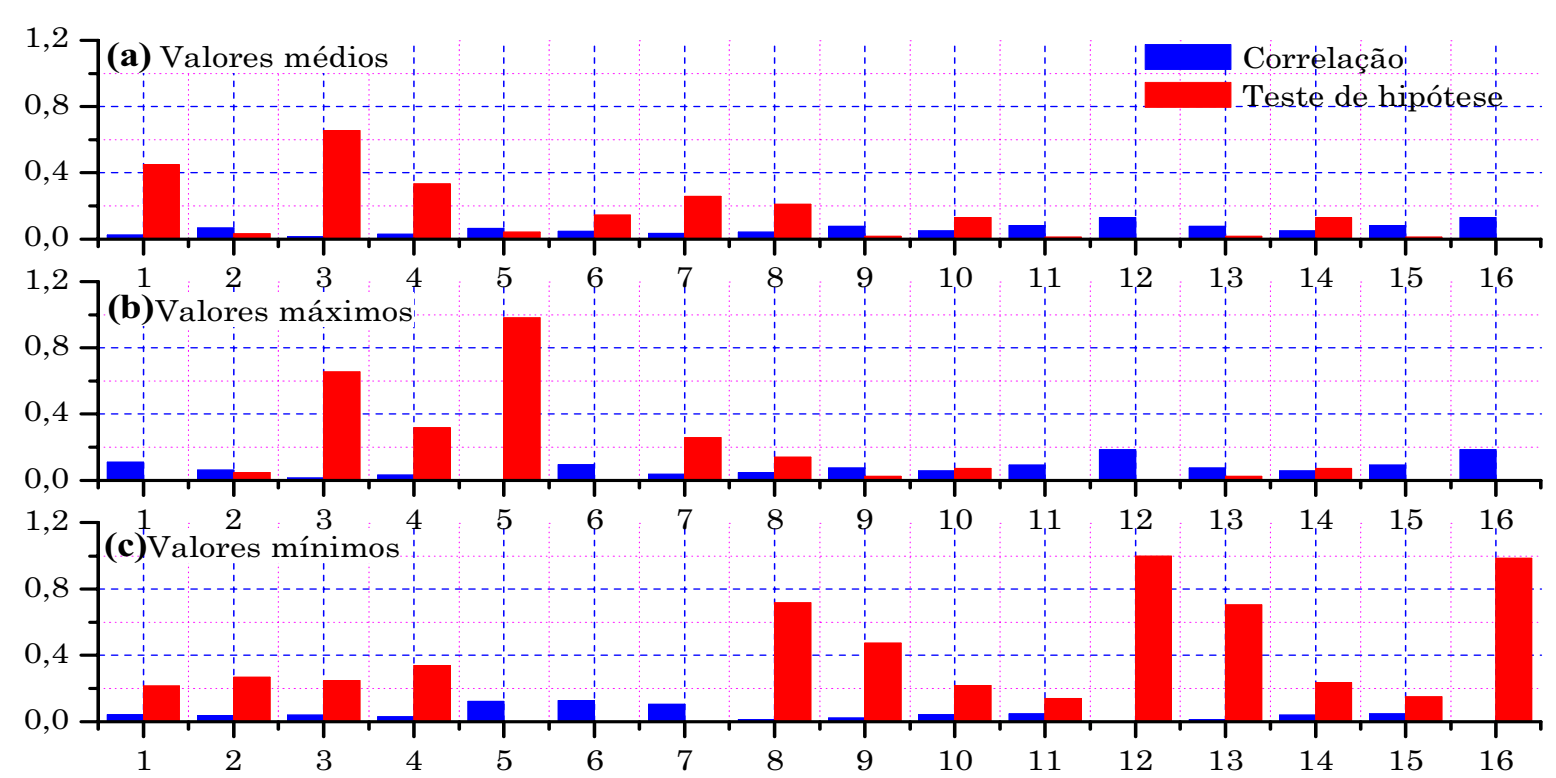

Variável (índice)

Figura 6.50 - Correlação e teste de hipótese para as componentes de tensão contidas na função planar das tensões de linha com a resistência de falta na Fase A; (a) Correlação e teste de hipótese para os valores médios; (b) Correlação e teste de hipótese para os valores máximos; (c) Correlação e teste de hipótese para os valores mínimos. 
Tabela 6.20 - Correlação das componentes de corrente contidas na função planar das tensões de linha com relação à resistência de falta na Fase A.

\begin{tabular}{ll||cc||cc||cc}
\hline \hline \multirow{2}{*}{$k$} & \multirow{2}{*}{ Variável } & \multicolumn{2}{|c|}{ Média } & \multicolumn{2}{c|}{ Máximo } & \multicolumn{2}{c}{ Mínimo } \\
\cline { 3 - 8 } & & Correlação & $\begin{array}{c}\text { Teste de } \\
\text { hipótese }\end{array}$ & Correlação & $\begin{array}{c}\text { Teste de } \\
\text { hipótese }\end{array}$ & Correlação & $\begin{array}{c}\text { Teste de } \\
\text { hipótese }\end{array}$ \\
\hline \hline 1 & $\left\|i_{a}^{p}(t)\right\|$ & 0,0314 & 0,3284 & 0,0098 & 0,7591 & 0,0200 & 0,5332 \\
\hline 2 & $\left\|i_{b}^{p}(t)\right\|$ & 0,0118 & 0,7139 & 0,0282 & 0,3794 & 0,0102 & 0,7501 \\
\hline 3 & $\left\|i_{c}^{p}(t)\right\|$ & 0,0175 & 0,5855 & 0,0273 & 0,3946 & 0,0066 & 0,8361 \\
\hline 4 & $\left\|i_{n}^{p}(t)\right\|$ & 0,0311 & 0,3317 & 0,0320 & 0,3180 & 0,0203 & 0,5265 \\
\hline 5 & $\left\|i_{a}^{q^{\prime \prime}}(t)\right\|$ & 0,0860 & 0,0072 & 0,0327 & 0,3087 & 0,1078 & 0,0008 \\
\hline 6 & $\left\|i_{b}^{q^{\prime \prime}}(t)\right\|$ & 0,0180 & 0,5741 & 0,0689 & 0,0315 & 0,0747 & 0,0198 \\
\hline 7 & $\left\|i_{c}^{q^{\prime \prime}}(t)\right\|$ & 0,0642 & 0,0452 & 0,0635 & 0,0475 & 0,1020 & 0,0014 \\
\hline 8 & $\left\|i_{n}^{q^{\prime \prime}}(t)\right\|$ & 0,0395 & 0,2175 & 0,0474 & 0,1396 & 0,0343 & 0,2849 \\
\hline 9 & $\left\|i_{a}^{q^{+}}(t)\right\|$ & 0,0118 & 0,7125 & 0,0089 & 0,7822 & 0,0302 & 0,3461 \\
\hline 10 & $\left\|i_{b}^{q^{+}}(t)\right\|$ & 0,0630 & 0,0492 & 0,0469 & 0,1438 & 0,0000 & 1,0000 \\
\hline 11 & $\left\|i_{c}^{q^{+}}(t)\right\|$ & 0,0543 & 0,0902 & 0,0512 & 0,1103 & 0,0000 & 1,0000 \\
\hline 12 & $\left\|i_{n}^{q^{+}}(t)\right\|$ & 0,0037 & 0,9073 & 0,0186 & 0,5623 & 0,0244 & 0,4469 \\
\hline 13 & $\left\|i_{a}^{d}(t)\right\|$ & 0,0118 & 0,7134 & 0,0089 & 0,7822 & 0,0140 & 0,6616 \\
\hline 14 & $\left\|i_{b}^{d}(t)\right\|$ & 0,0331 & 0,3022 & 0,0276 & 0,3898 & 0,0000 & 1,0000 \\
\hline 15 & $\left\|i_{c}^{d}(t)\right\|$ & 0,0207 & 0,5197 & 0,0256 & 0,4244 & 0,0000 & 1,0000 \\
\hline 16 & $\left\|i_{n}^{d}(t)\right\|$ & 0,0037 & 0,9073 & 0,0186 & 0,5623 & 0,0243 & 0,4484 \\
\hline \hline
\end{tabular}
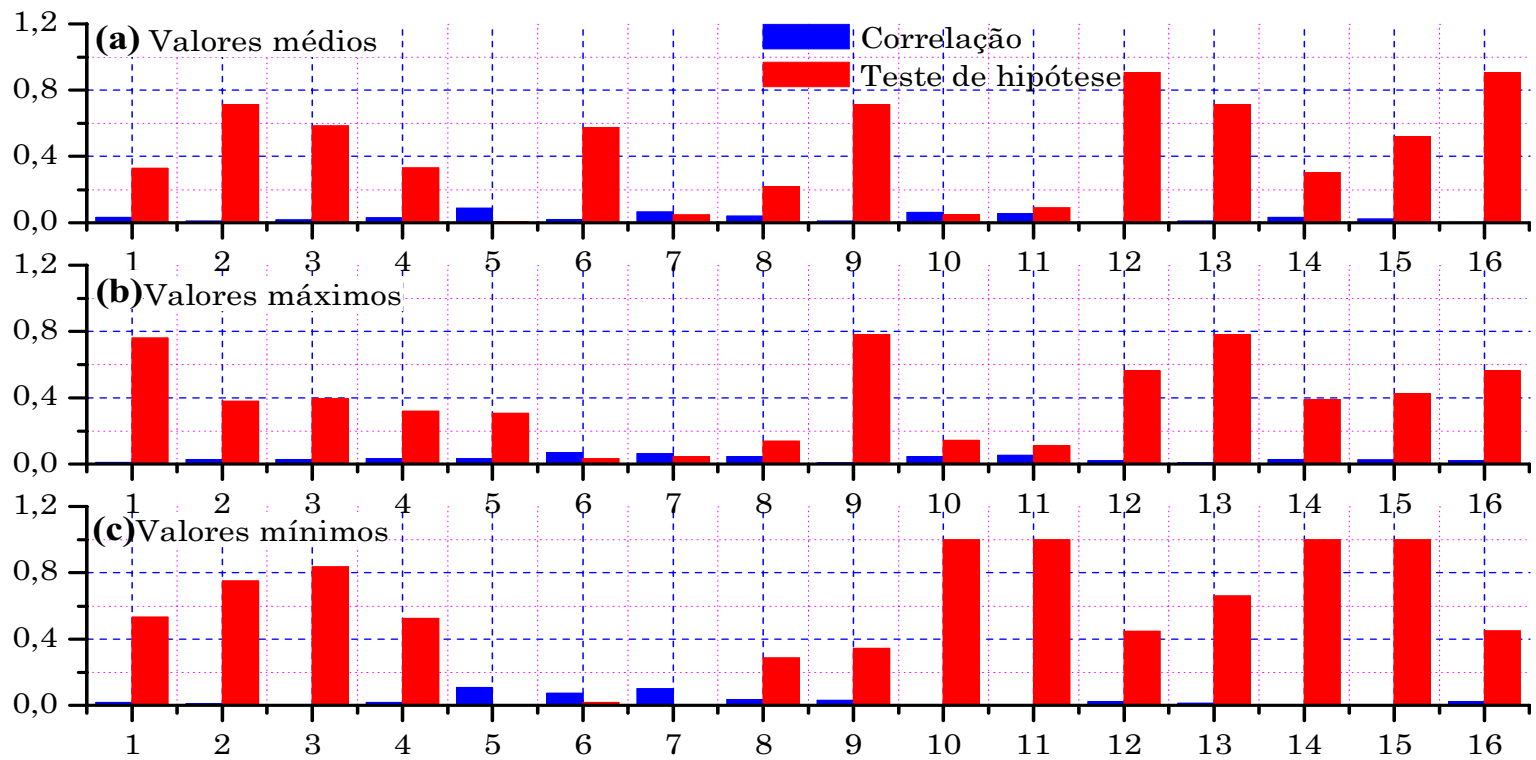

Variável (índice)

Figura 6.51 - Correlação e teste de hipótese para as componentes de corrente contidas na função planar das tensões de linha com a resistência de falta na Fase A; (a) Correlação e teste de hipótese para os valores médios; (b) Correlação e teste de hipótese para os valores máximos; (c) Correlação e teste de hipótese para os valores mínimos. 
Tabela 6.21 - Correlação das componentes de tensão ortogonais à função planar das tensões de linha com relação à resistência de falta na Fase A.

\begin{tabular}{|c|c|c|c|c|c|c|c|}
\hline \multirow[b]{2}{*}{$k$} & \multirow[b]{2}{*}{ Variável } & \multicolumn{2}{|c|}{ Média } & \multicolumn{2}{|c|}{ Máximo } & \multicolumn{2}{|c|}{ Mínimo } \\
\hline & & Correlação & $\begin{array}{l}\text { Teste de } \\
\text { hipótese } \\
\end{array}$ & Correlação & $\begin{array}{l}\text { Teste de } \\
\text { hipótese } \\
\end{array}$ & Correlação & $\begin{array}{l}\text { Teste de } \\
\text { hipótese }\end{array}$ \\
\hline 1 & $\left\|v_{\bar{a}}^{p}(t)\right\|$ & 0,0331 & 0,3021 & 0,0022 & 0,9465 & 0,0264 & 0,4106 \\
\hline 2 & $\left\|v \frac{p}{b}(t)\right\|$ & 0,0302 & 0,3464 & 0,0296 & 0,3556 & 0,0203 & 0,5275 \\
\hline 3 & $\left\|v_{\bar{c}}^{p}(t)\right\|$ & 0,0019 & 0,9537 & 0,0045 & 0,8896 & 0,0388 & 0,2267 \\
\hline 4 & $\left\|v_{h}^{p}(t)\right\|$ & 0,0323 & 0,3134 & 0,0323 & 0,3137 & 0,0296 & 0,3568 \\
\hline 5 & $\left\|v_{\bar{a}}^{q^{\prime \prime}}(t)\right\|$ & 0,0358 & 0,2648 & 0,0127 & 0,6928 & 0,3759 & 0,0000 \\
\hline 6 & $\left\|v^{q^{\|}}(t)\right\|$ & 0,0517 & 0,1072 & 0,0319 & 0,3194 & 0,2402 & 0,0000 \\
\hline 7 & $\left\|v_{\bar{c}}^{q^{\|}}(t)\right\|$ & 0,0617 & 0,0541 & 0,0387 & 0,2280 & 0,2833 & 0,0000 \\
\hline 8 & $\left\|v_{h}^{q^{\|}}(t)\right\|$ & 0,0524 & 0,1020 & 0,0455 & 0,1560 & 0,0599 & 0,0618 \\
\hline 9 & $\left\|v_{\bar{a}}^{q^{\perp}}(t)\right\|$ & 0,0381 & 0,2351 & 0,0330 & 0,3040 & 0,0272 & 0,3962 \\
\hline 10 & $\left\|v_{\frac{q^{\perp}}{b}}(t)\right\|$ & 0,0796 & 0,0130 & 0,0557 & 0,0825 & 0,0000 & 1,0000 \\
\hline 11 & $\left\|v_{\bar{c}}^{q^{\perp}}(t)\right\|$ & 0,0917 & 0,0042 & 0,0614 & 0,0552 & 0,0000 & 1,0000 \\
\hline 12 & $\left\|v_{h}^{q^{\perp}}(t)\right\|$ & 0,0040 & 0,9013 & 0,0143 & 0,6559 & 0,0320 & 0,3190 \\
\hline 13 & $\left\|v_{\bar{a}}^{d}(t)\right\|$ & 0,0381 & 0,2351 & 0,0330 & 0,3040 & 0,0523 & 0,1027 \\
\hline 14 & $\left\|v_{\bar{b}}^{d}(t)\right\|$ & 0,0370 & 0,2480 & 0,0129 & 0,6877 & 0,1121 & 0,0005 \\
\hline 15 & $\left\|v_{\bar{c}}^{d}(t)\right\|$ & 0,0309 & 0,3360 & 0,0171 & 0,5944 & 0,0464 & 0,1477 \\
\hline 16 & $\left\|v_{h}^{d}(t)\right\|$ & 0,0040 & 0,9013 & 0,0143 & 0,6559 & 0,0343 & 0,2853 \\
\hline
\end{tabular}
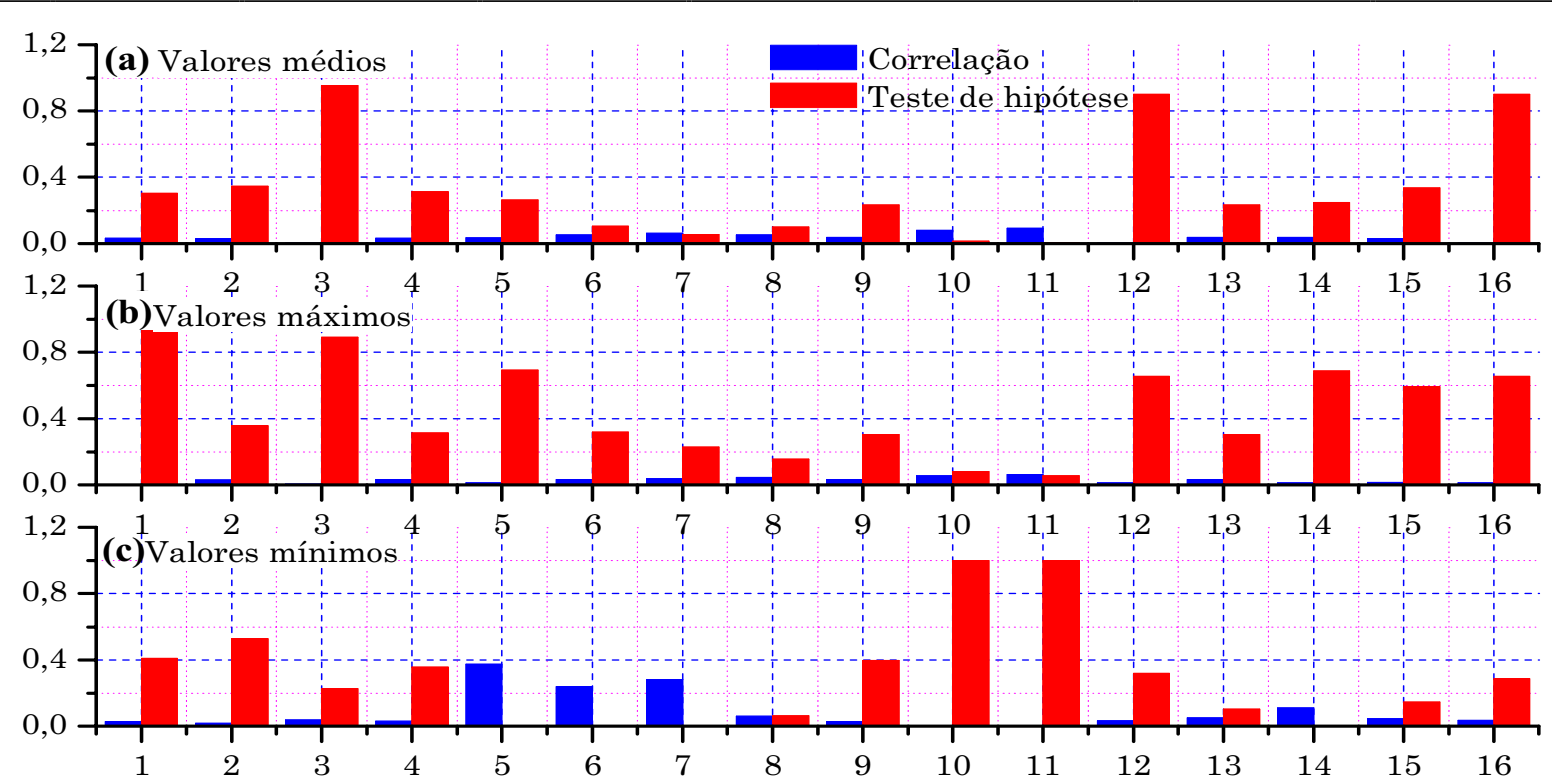

Variável (índice)

Figura 6.52 - Correlação e teste de hipótese para as componentes de tensão ortogonais à função planar das tensões de linha com a resistência de falta na Fase A; (a) Correlação e teste de hipótese para os valores médios; (b) Correlação e teste de hipótese para os valores máximos; (c) Correlação e teste de hipótese para os valores mínimos. 
Tabela 6.22 - Correlação das componentes de corrente ortogonais à função planar das tensões de linha com relação à resistência de falta na Fase A.

\begin{tabular}{|c|c|c|c|c|c|c|c|}
\hline \multirow[b]{2}{*}{$k$} & \multirow[b]{2}{*}{ Variável } & \multicolumn{2}{|c|}{ Média } & \multicolumn{2}{|c|}{ Máximo } & \multicolumn{2}{|c|}{ Mínimo } \\
\hline & & Correlação & $\begin{array}{l}\text { Teste de } \\
\text { hipótese }\end{array}$ & Correlação & $\begin{array}{l}\text { Teste de } \\
\text { hipótese }\end{array}$ & Correlação & $\begin{array}{l}\text { Teste de } \\
\text { hipótese }\end{array}$ \\
\hline 1 & $\left\|i_{\bar{a}}^{p}(t)\right\|$ & 0,0314 & 0,3273 & 0,0176 & 0,5823 & 0,0251 & 0,4344 \\
\hline 2 & $\left\|i_{\frac{p}{b}}^{p}(t)\right\|$ & 0,0302 & 0,3464 & 0,0289 & 0,3681 & 0,0305 & 0,3418 \\
\hline 3 & $\left\|i_{\bar{c}}^{p}(t)\right\|$ & 0,0029 & 0,9277 & 0,0076 & 0,8123 & 0,0177 & 0,5812 \\
\hline 4 & $\left\|i_{h}^{p}(t)\right\|$ & 0,0306 & 0,3402 & 0,0320 & 0,3181 & 0,0079 & 0,8063 \\
\hline 5 & $\left\|i_{a}^{q^{\| \prime}}(t)\right\|$ & 0,0280 & 0,3824 & 0,0292 & 0,3623 & 0,0735 & 0,0217 \\
\hline 6 & $\left\|i^{q^{\|}}(t)\right\|$ & 0,0594 & 0,0638 & 0,0191 & 0,5513 & 0,0210 & 0,5127 \\
\hline 7 & $\left\|i^{q^{\|}}(t)\right\|$ & 0,0780 & 0,0149 & 0,0669 & 0,0368 & 0,2612 & 0,0000 \\
\hline 8 & $\left\|i_{h}^{q^{\|}}(t)\right\|$ & 0,0196 & 0,5408 & 0,0247 & 0,4414 & 0,0201 & 0,5301 \\
\hline 9 & $\left\|i_{\bar{a}}^{q^{\perp}}(t)\right\|$ & 0,1033 & 0,0012 & 0,0174 & 0,5868 & 0,0000 & 1,0000 \\
\hline 10 & $\left\|i_{\frac{q^{\perp}}{b}}(t)\right\|$ & 0,0250 & 0,4362 & 0,0771 & 0,0161 & 0,1130 & 0,0004 \\
\hline 11 & $\left\|i_{c}^{q^{\perp}}(t)\right\|$ & 0,0415 & 0,1960 & 0,0137 & 0,6694 & 0,0000 & 1,0000 \\
\hline 12 & $\left\|i_{h}^{q^{\perp}}(t)\right\|$ & 0,2130 & 0,0000 & 0,1204 & 0,0002 & 0,0076 & 0,8135 \\
\hline 13 & $\left\|i_{\bar{a}}^{d}(t)\right\|$ & 0,0382 & 0,2341 & 0,0068 & 0,8324 & 0,0438 & 0,1721 \\
\hline 14 & $\left\|i_{\bar{b}}^{d}(t)\right\|$ & 0,0249 & 0,4379 & 0,0770 & 0,0162 & 0,1105 & 0,0006 \\
\hline 15 & $\left\|i_{\bar{c}}^{d}(t)\right\|$ & 0,0312 & 0,3308 & 0,0166 & 0,6038 & 0,1341 & 0,0000 \\
\hline 16 & $\left\|i_{h}^{d}(t)\right\|$ & 0,2130 & 0,0000 & 0,1204 & 0,0002 & 0,0076 & 0,8137 \\
\hline
\end{tabular}
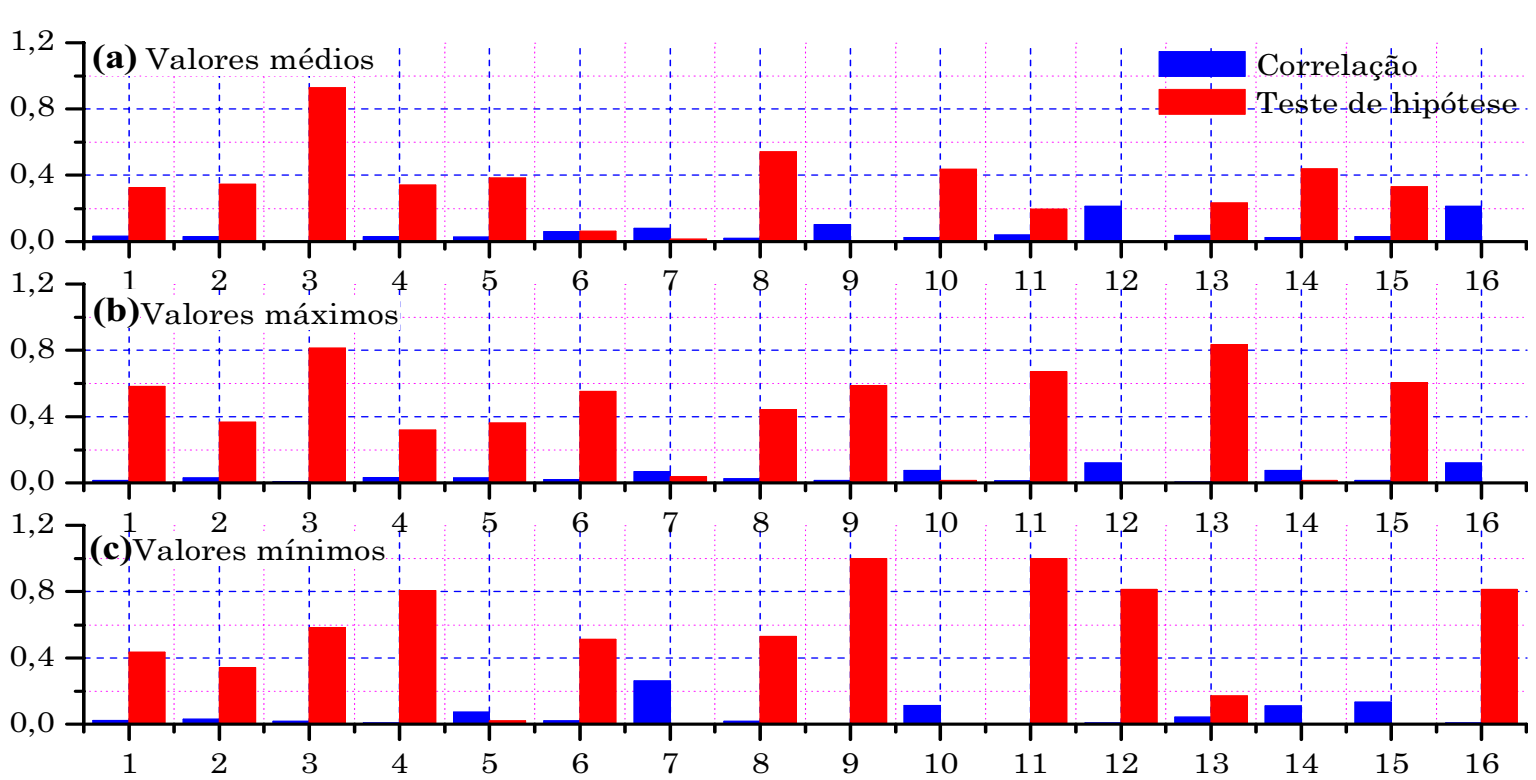

Variável (índice)

Figura 6.53 - Correlação e teste de hipótese para as componentes de corrente ortogonais à função planar das tensões de linha com a resistência de falta na Fase A; (a) Correlação e teste de hipótese para os valores médios; (b) Correlação e teste de hipótese para os valores máximos; (c) Correlação e teste de hipótese para os valores mínimos. 
Por meio dos valores de correlação apresentados nas tabelas anteriores é possível verificar que as oito variáveis mais correlacionadas com a resistência de falta na Fase A são aquelas destacadas na Tabela 6.23, a qual destaca também as referidas correlações.

Tabela 6.23 - Variáveis mais correlatas à estimação da resistência de falta na Fase A.

\begin{tabular}{ccccc}
\hline \hline Índice & Variável & Característica & Símbolo & Correlação \\
\hline \hline 1 & $\left\|v_{\bar{a}}^{q^{\prime \prime}}(t)\right\|$ & Mínimo & $\left\|v_{\bar{a}}^{q^{\prime \prime}}(t)\right\|^{\min }$ & 0,3759 \\
\hline 2 & $\left\|v_{\bar{c}}^{q^{\prime \prime}}(t)\right\|$ & Mínimo & $\left\|v_{\bar{c}}^{q^{\prime \prime}}(t)\right\|^{\min }$ & 0,2833 \\
\hline 3 & $\left\|i_{\bar{c}}^{q^{\prime \prime}}(t)\right\|$ & Mínimo & $\left\|i_{\bar{c}}^{q^{\prime \prime}}(t)\right\|^{\min }$ & 0,2612 \\
\hline 4 & $\left\|v_{\bar{b}}^{q^{\prime \prime}}(t)\right\|$ & Mínimo & $\left\|v_{\bar{b}}^{q^{\prime \prime}}(t)\right\|$ & 0,2402 \\
\hline 5 & $\left\|i_{h}^{q^{\perp}}(t)\right\|$ & Médio & $\left\|i_{h}^{q^{\perp}}(t)\right\|$ & 0,2130 \\
\hline 6 & $\left\|i_{h}^{d}(t)\right\|$ & Médio & $\left\|i_{h}^{d}(t)\right\|$ & 0,2130 \\
\hline 7 & $\left\|v_{n}^{q^{\perp}}(t)\right\|$ & Máximo & $\left\|v_{n}^{q^{\perp}}(t)\right\|^{\max }$ & 0,1853 \\
\hline 8 & $\left\|v_{n}^{d}(t)\right\|$ & Máximo & $\left\|v_{n}^{d}(t)\right\|^{\max }$ & 0,1853 \\
\hline \hline
\end{tabular}

As variáveis apresentadas na Tabela 6.23 representam as variáveis mais correlatas com a resistência de falta quando essa envolver a Fase A. Além de constituírem as variáveis mais correlatas, essas foram aquelas empregadas como entrada do sistema fuzzy responsável pela estimação da resistência de falta. O sistema fuzzy responsável pela estimação da resistência da falta fora constituído por 40 regras de inferência, número esse de regras que, durante os testes computacionais, se mostrou adequado na estimação da resistência.

O sistema fuzzy fora ajustado segundo o algoritmo delineado no Capítulo 4 e fazendo uso de um conjunto de ajuste constituído por 975 pares entrada-saída. Todo o conjunto de ajuste fora construído se fazendo uso das simulações computacionais descritas no Capítulo 5 referentes às faltas fase-terra com participação da Fase A.

O algoritmo de ajuste delineado no Capítulo 4 é composto de duas etapas de ajuste. A primeira dessas etapas responde pelo ajuste estrutural do sistema fuzzy que, conforme abordado, é dedicado à extração das regras de inferência fuzzy que melhor correlacionam o espaço fuzzy das entradas com o espaço fuzzy da saída. Dessa forma, tem-se como produto da primeira etapa de ajuste a base de regra do sistema fuzzy que, nesse caso, será responsável pela estimação da resistência de falta quando a mesma envolver a Fase A. 
A fim de apresentar como o erro quadrático médio do sistema fuzzy se portou ao longo das iterações do processo de ajuste estrutural, retrata-se à Figura 6.54, onde tal comportamento é ilustrado.

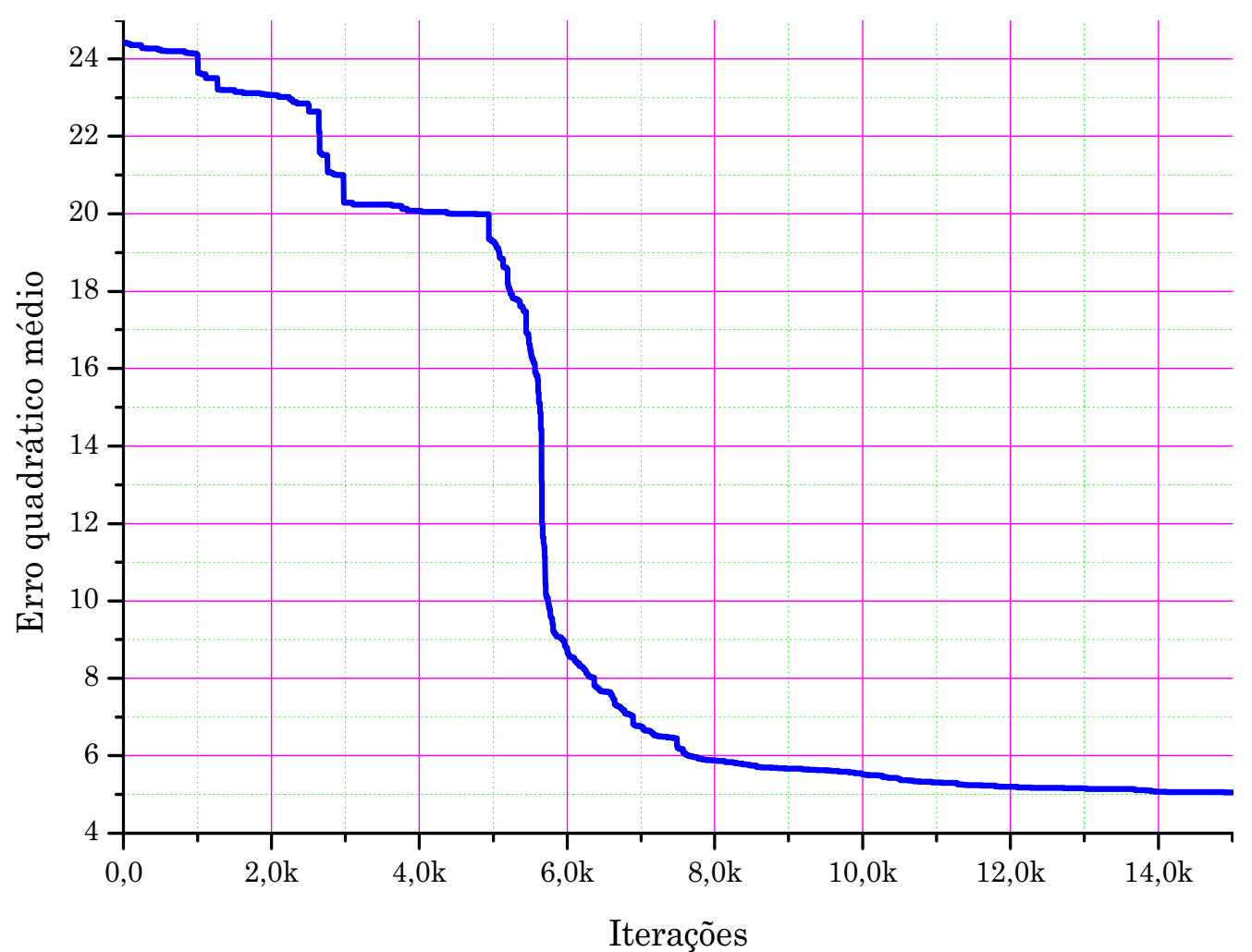

Figura 6.54 - Comportamento do erro quadrático médio do sistema fuzzy dedicado à estimação da resistência de falta quando essa envolver a Fase A ao longo das iterações da primeira etapa de ajuste.

O gráfico da Figura 6.54 apresenta a sensível redução do erro quadrático médio ao longo das iterações da primeira etapa de ajuste para o sistema fuzzy responsável pela estimação da resistência de falta fase-terra quando essa envolver a Fase A. Ao término dessa primeira etapa de ajuste, assim como anteriormente citado, tem-se como produto a base de regras responsável pelo relacionamento entre o espaço fuzzy das variáveis de entrada com o espaço fuzzy da variável de saída. Retratando a base de regras determinada por essa etapa de ajuste, apresenta-se a Figura 6.55 . 


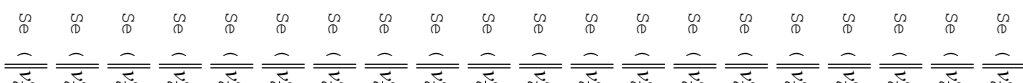

$\Xi \equiv \equiv \equiv \equiv \equiv \equiv \equiv \equiv \equiv \equiv \equiv \equiv \equiv \equiv \equiv \equiv \equiv \equiv \equiv$

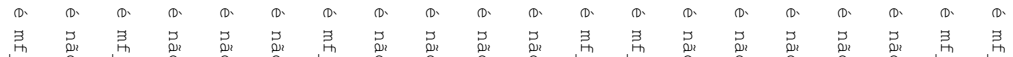

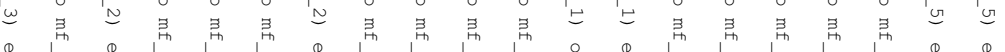

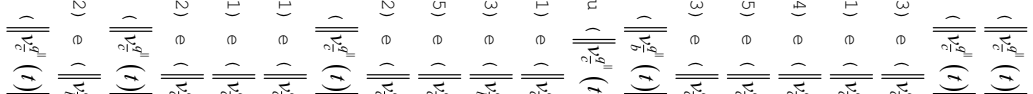

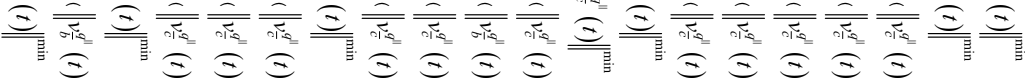

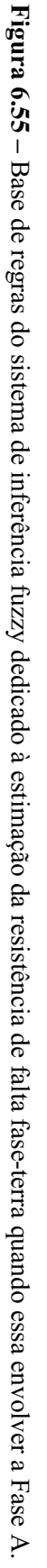

a.

上

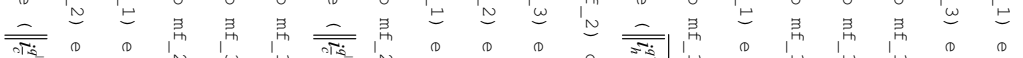

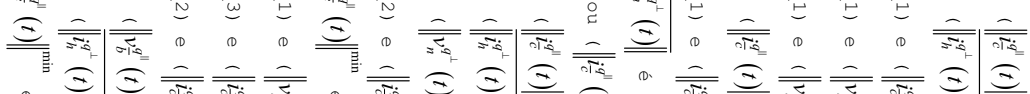

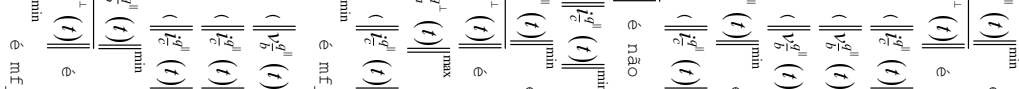

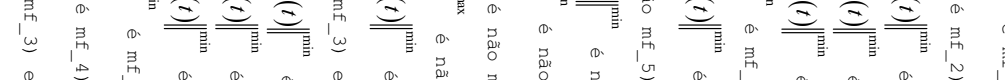

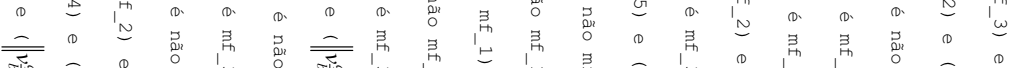

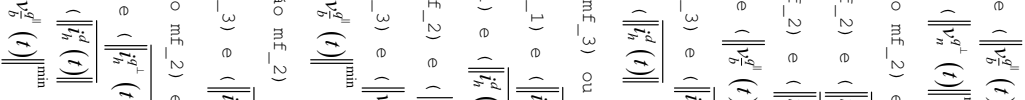

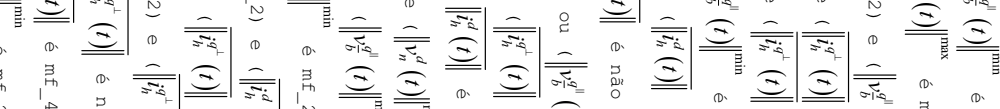

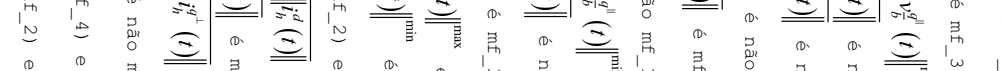

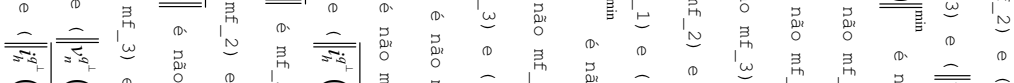

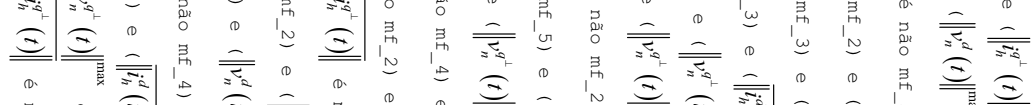

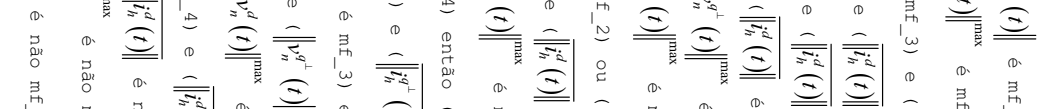

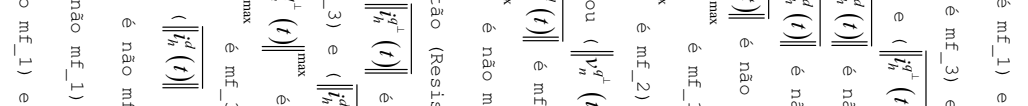

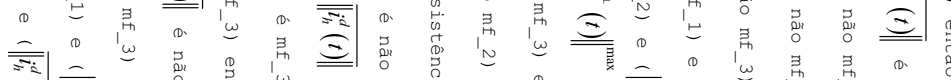

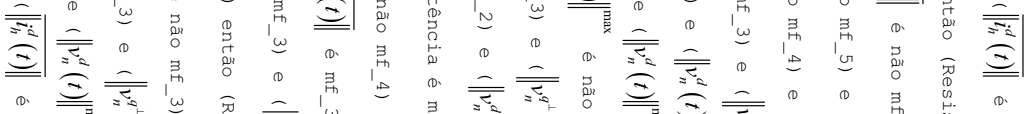

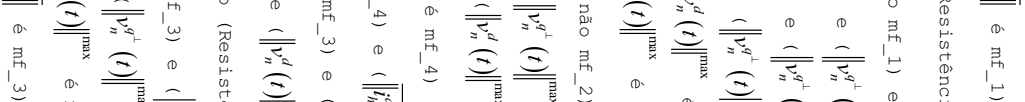

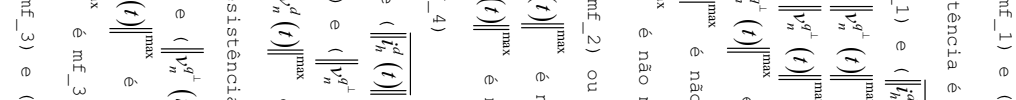

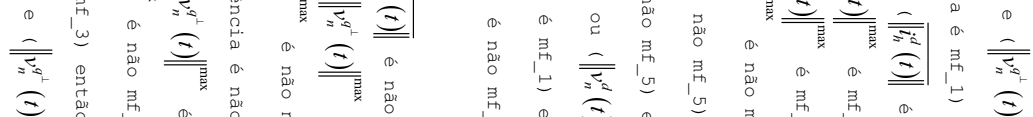

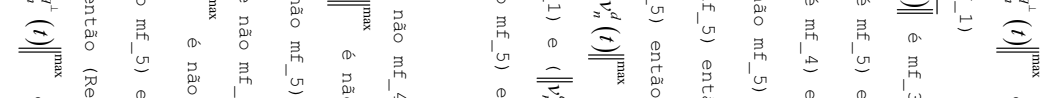

小.

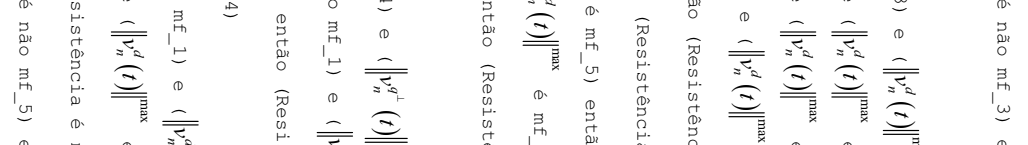

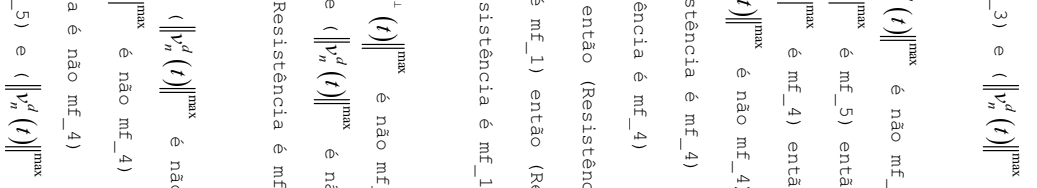




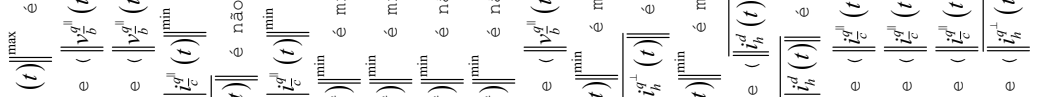

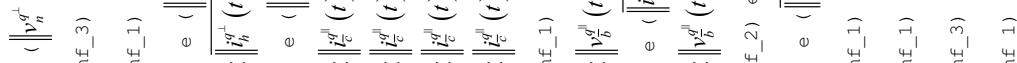
उ E है

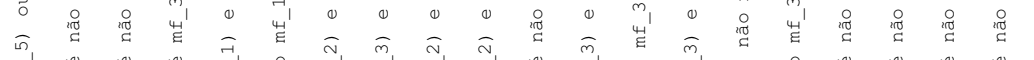

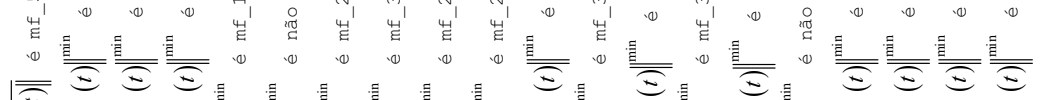

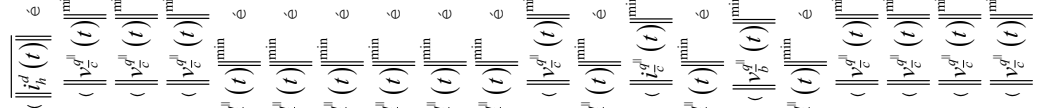

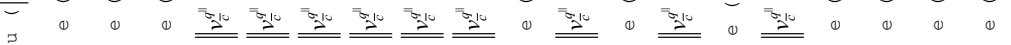
का

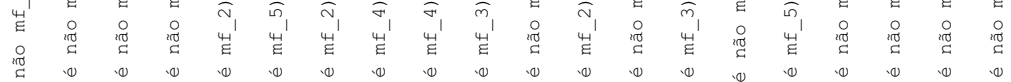


Após a determinação da base de regras representada por meio da Figura 6.55, o sistema de inferência fuzzy fora submetido à segunda etapa de ajuste o qual é dedicado ao ajuste paramétrico do sistema. O ajuste paramétrico tem por meta prosseguir com a redução do erro quadrático iniciada na primeira etapa. Para tanto, a segunda etapa de ajuste, denotada por ajuste paramétrico, modifica os parâmetros que definem as funções de pertinência das entradas e da saída, bem como procede com a ponderação das regras fuzzy ora obtidas na primeira etapa de ajuste. Apresentando como o erro quadrático médio se portou ao longo das iterações dessa segunda etapa de ajuste, tem-se a Figura 6.56.

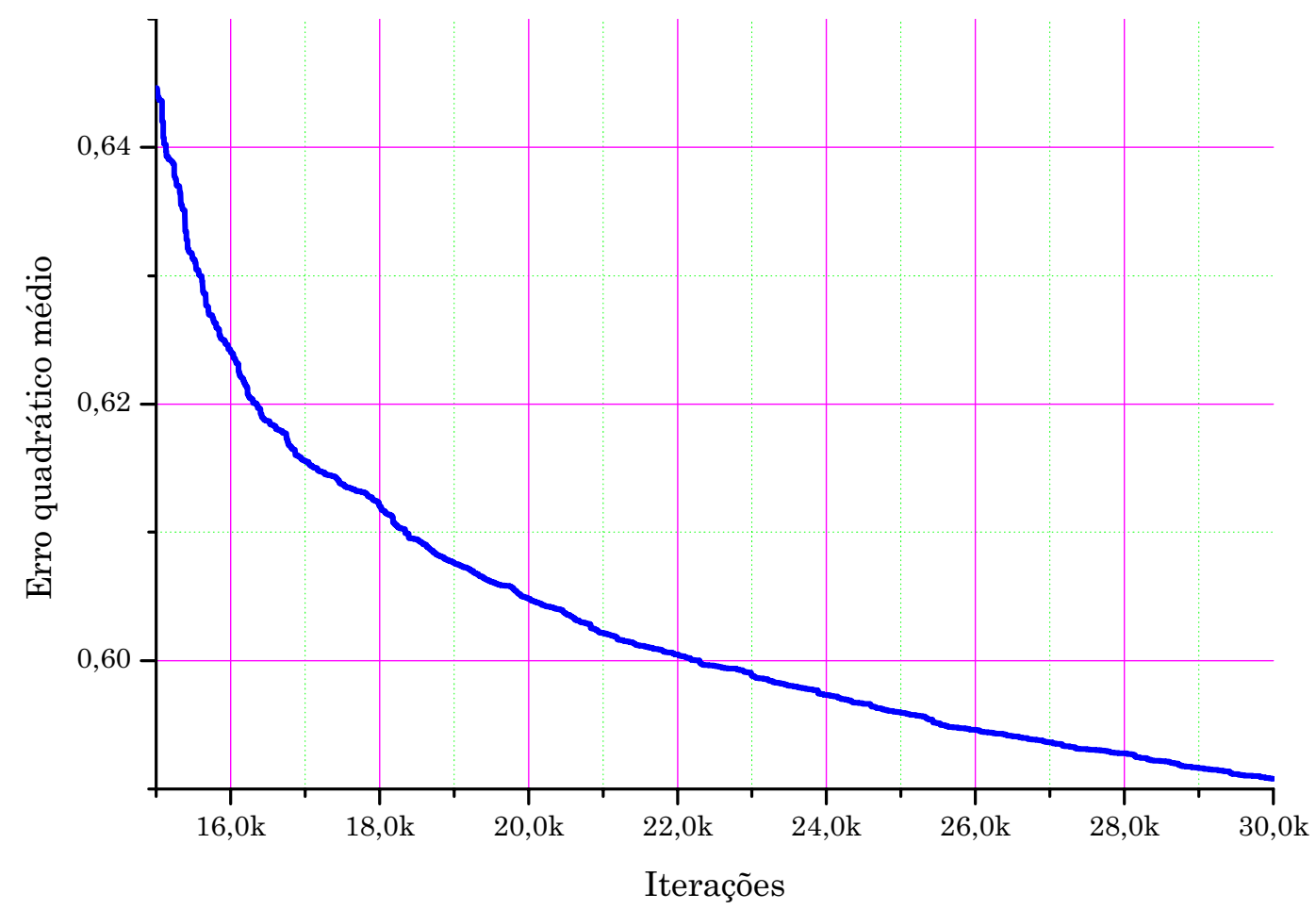

Figura 6.56 - Comportamento do erro quadrático médio do sistema fuzzy dedicado à estimação da resistência de falta quando essa envolver a Fase A ao longo das iterações da segunda etapa de ajuste.

Por meio da Figura 6.56 é possível verificar o quão o erro quadrático médio se reduz ao longo da etapa de ajuste paramétrico. Essa etapa, assim como já referenciado, é responsável por ajustar as funções de pertinência das entradas e da saída, além de ponderar as regras de inferência fuzzy. Complementando, a apresentação dos resultados advindos do processo de ajuste paramétrico, ilustra-se por meio da Figura 6.57 as funções de pertinência ajustadas para as quatro primeiras entradas, ou seja, para as entradas $\left\|v_{\bar{a}}^{q^{\prime \prime}}(t)\right\|^{\min },\left\|v_{\bar{c}}^{q^{\prime \prime}}(t)\right\|^{\min }$, $\left\|i_{\frac{q^{\prime \prime}}{c}}(t)\right\|^{\min }$ e $\left\|v_{\frac{q^{\prime}}{b}}(t)\right\|^{\min }$. Da mesma maneira, por meio da Figura $6.58 \mathrm{tem}$-se as funções de pertinência para as outras quatro entradas, ou seja, para as entradas $\overline{\left\|i_{h}^{q^{\perp}}(t)\right\|}, \overline{\left\|i_{h}^{d}(t)\right\|}$, $\left\|v_{n}^{q^{\perp}}(t)\right\|^{\max } \mathrm{e}\left\|v_{n}^{d}(t)\right\|^{\max }$ 

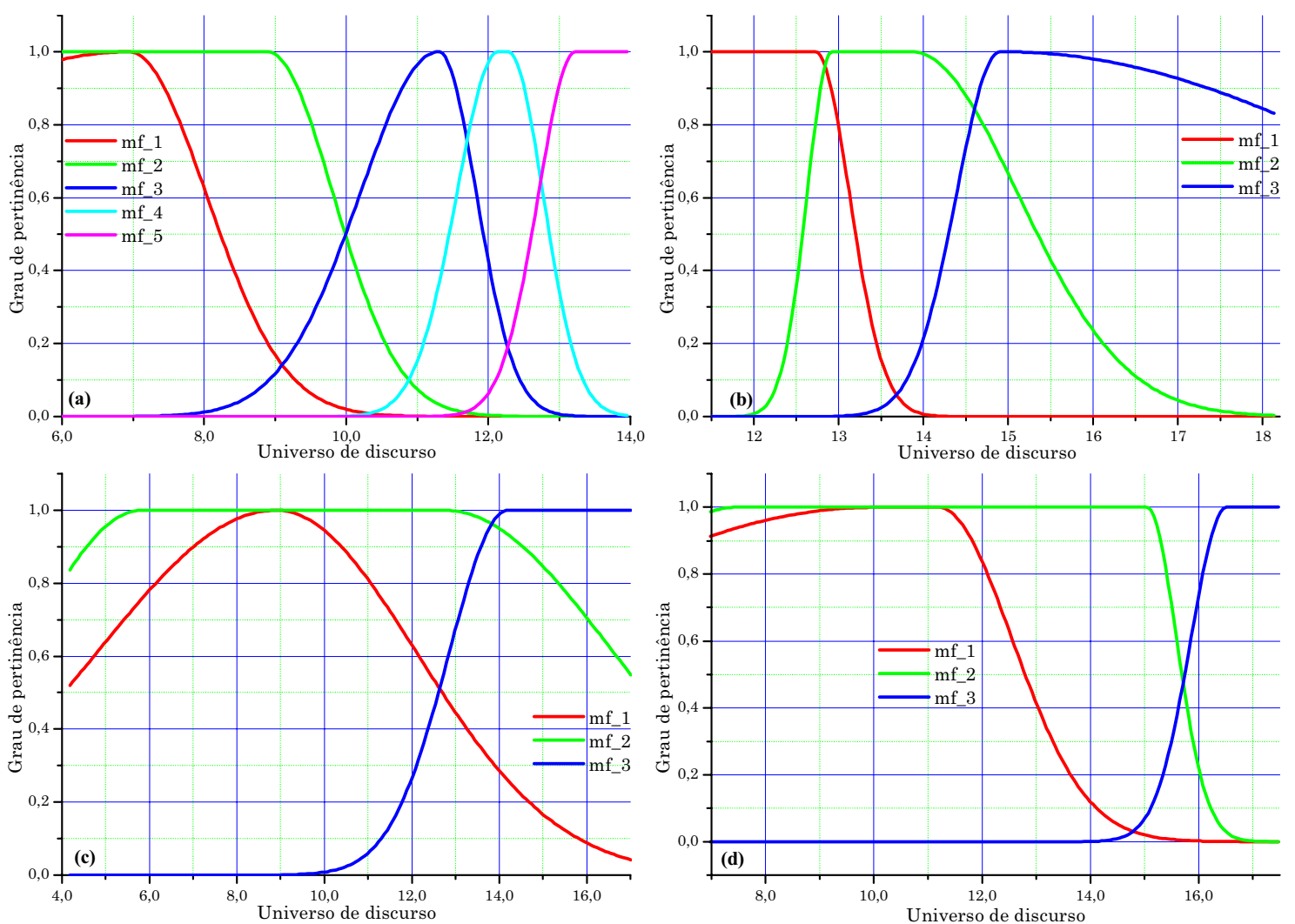

Figura 6.57 - Funções de pertinência ajustadas para as quatro primeiras entradas; (a) Entrada $\left\|v_{\bar{a}}^{q^{\prime \prime}}(t)\right\|^{\min } ;$ (b) Entrada $\left\|v_{\frac{c}{c}}^{q^{\prime \prime}}(t)\right\|^{\min } ;$ (c) Entrada $\left\|i_{\frac{q^{\prime}}{c}}(t)\right\|^{\min } ;$ (d) Entrada $\left\|v_{\frac{q^{\prime \prime}}{b}}(t)\right\|^{\min }$.
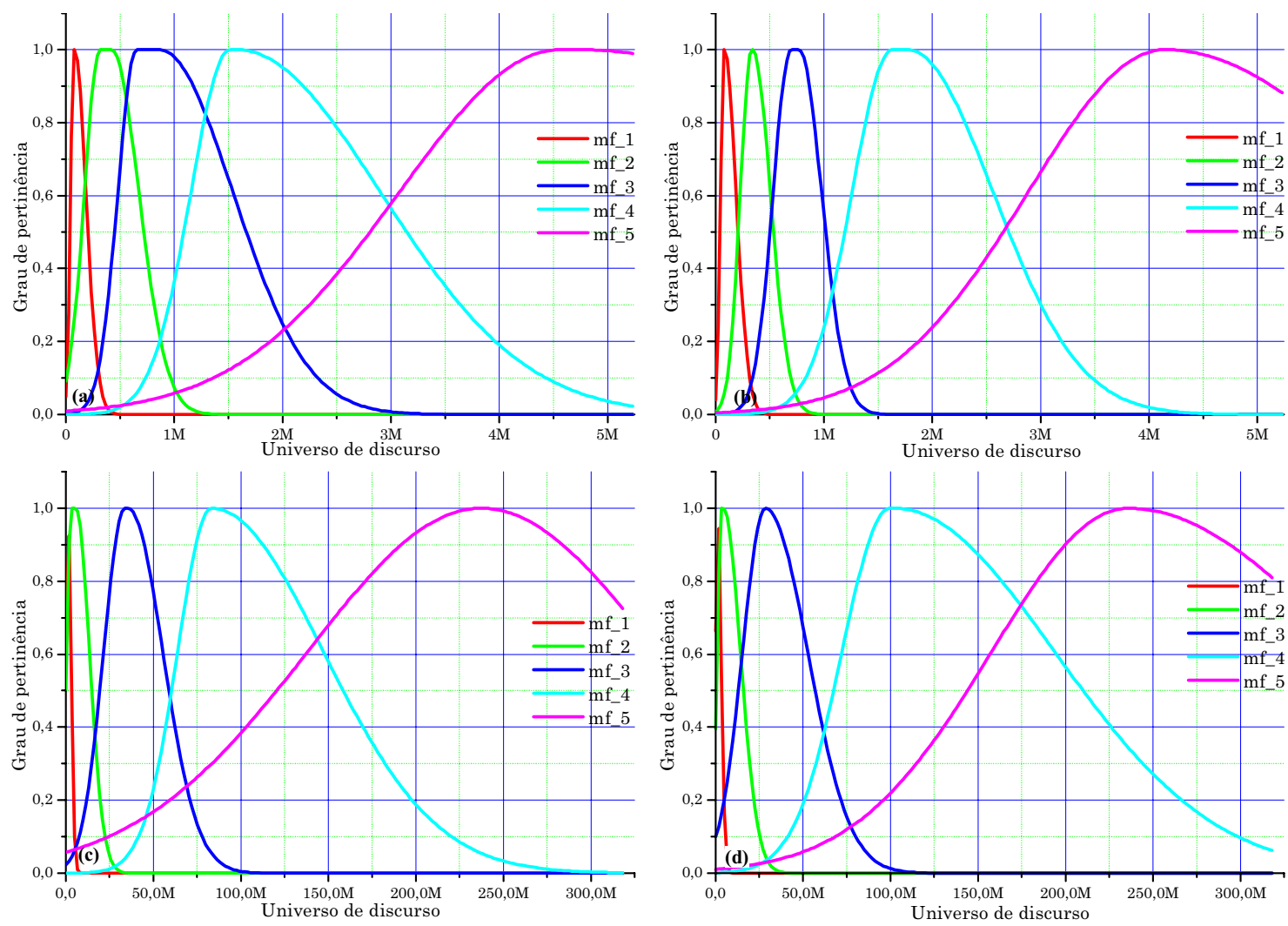

Figura 6.58 - Funções de pertinência ajustadas para as quatro primeiras entradas; (a) Entrada $\overline{\left\|i_{h}^{q^{\perp}}(t)\right\|} ;$; (b) Entrada $\overline{\left\|i_{h}^{d}(t)\right\|}$; (c) Entrada $\left\|v_{n}^{q^{\perp}}(t)\right\|^{\max } ;$ (d) Entrada $\left\|v_{n}^{d}(t)\right\|^{\max }$. 
A etapa de ajuste paramétrico não apenas sintoniza as funções de pertinência do espaço das entradas como também ajusta as funções de pertinência da saída. Assim, por meio da Figura 6.59 apresentam-se as funções de pertinência da saída, que nesse caso representa o logaritmo base 10 para a resistência falta.

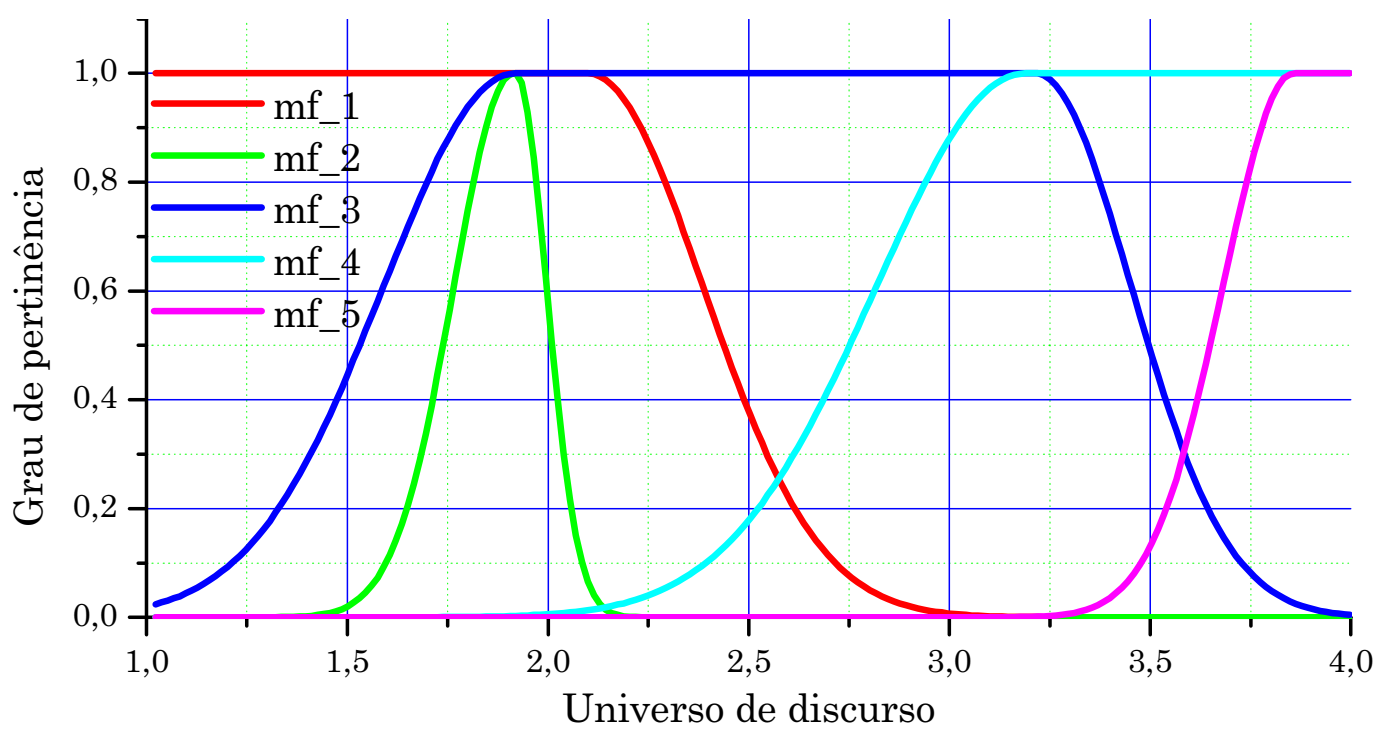

Figura 6.59 - Funções de pertinência associadas à resistência de falta na Fase A.

Findando a apresentação do sistema fuzzy dedicado à estimação da resistência de falta quando de sua ocorrência na Fase A, tem-se na Figura 6.60 a maneira pela qual as regras fuzzy, destacadas na sua forma verbal por meio da Figura 6.55, foram ponderadas pela etapa de ajuste paramétrico.

O sistema fuzzy ajustado para fins de estimação da resistência de falta fora ajustado, tanto estrutural como parametricamente, tendo como base os resultados providos por um conjunto de 975 simulações de faltas ocorridas na Fase A. Tais simulações computacionais, apresentadas em detalhes no Capítulo 5, possuíram como variáveis independentes a distância de ocorrência da falta, a resistência de falta, o instante inicial da falta e a duração da mesma. Assim, após o processo de ajuste é primordial a verificação da eficácia do sistema no desempenho da tarefa de estimação da resistência de falta.

Para tanto, o sistema fuzzy fora, inicialmente, testado com os dados advindos das simulações empregadas na constituição do conjunto de ajuste do mesmo. Apresentando como o erro relativo se porta para a estimação da resistência da falta, tem-se o gráfico da Figura 6.61, onde se destaca o histograma do referido erro. 


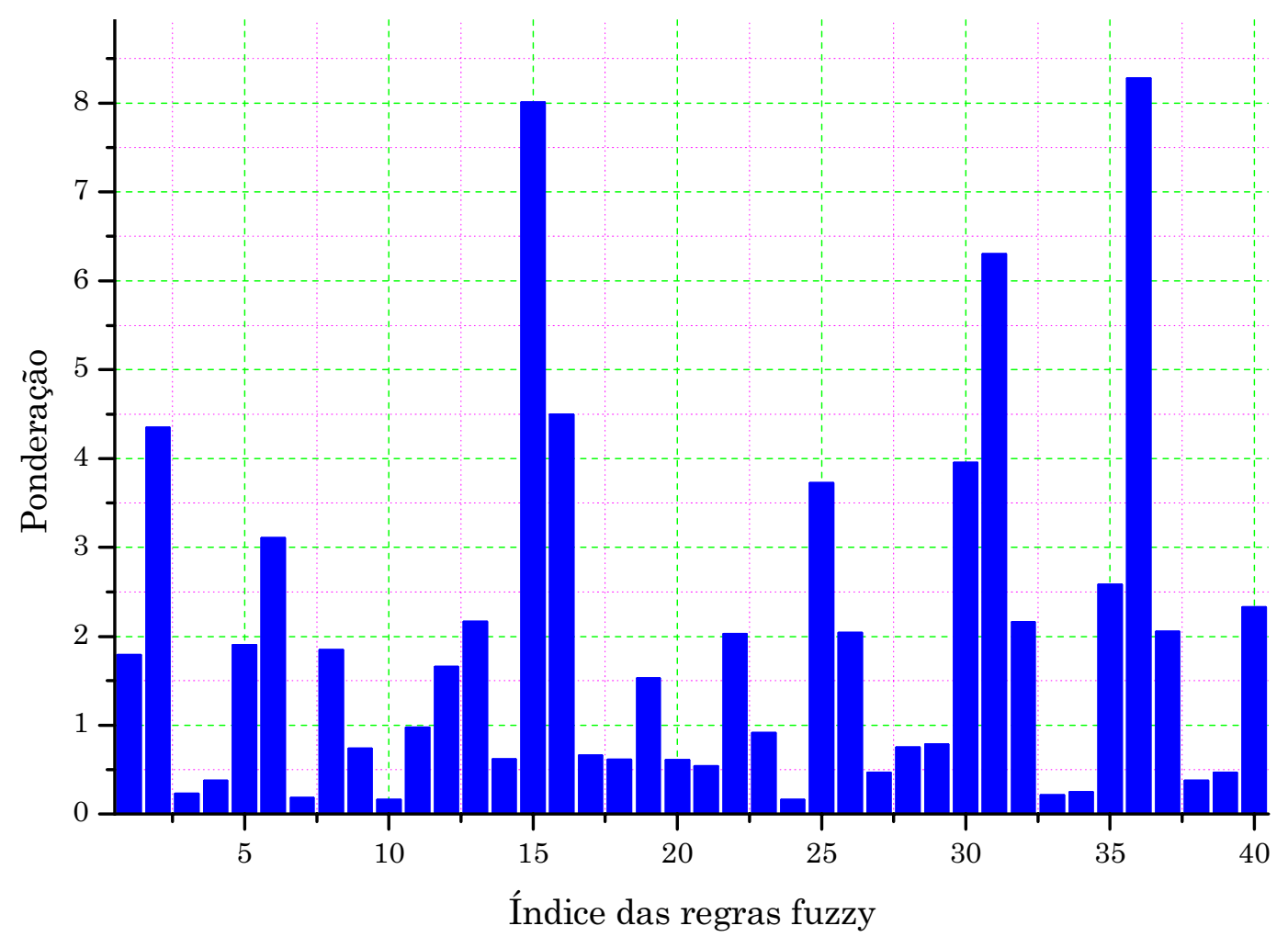

Figura 6.60 - Ponderação das regras fuzzy do sistema de inferência fuzzy dedicado à estimação da resistência de falta na Fase A.

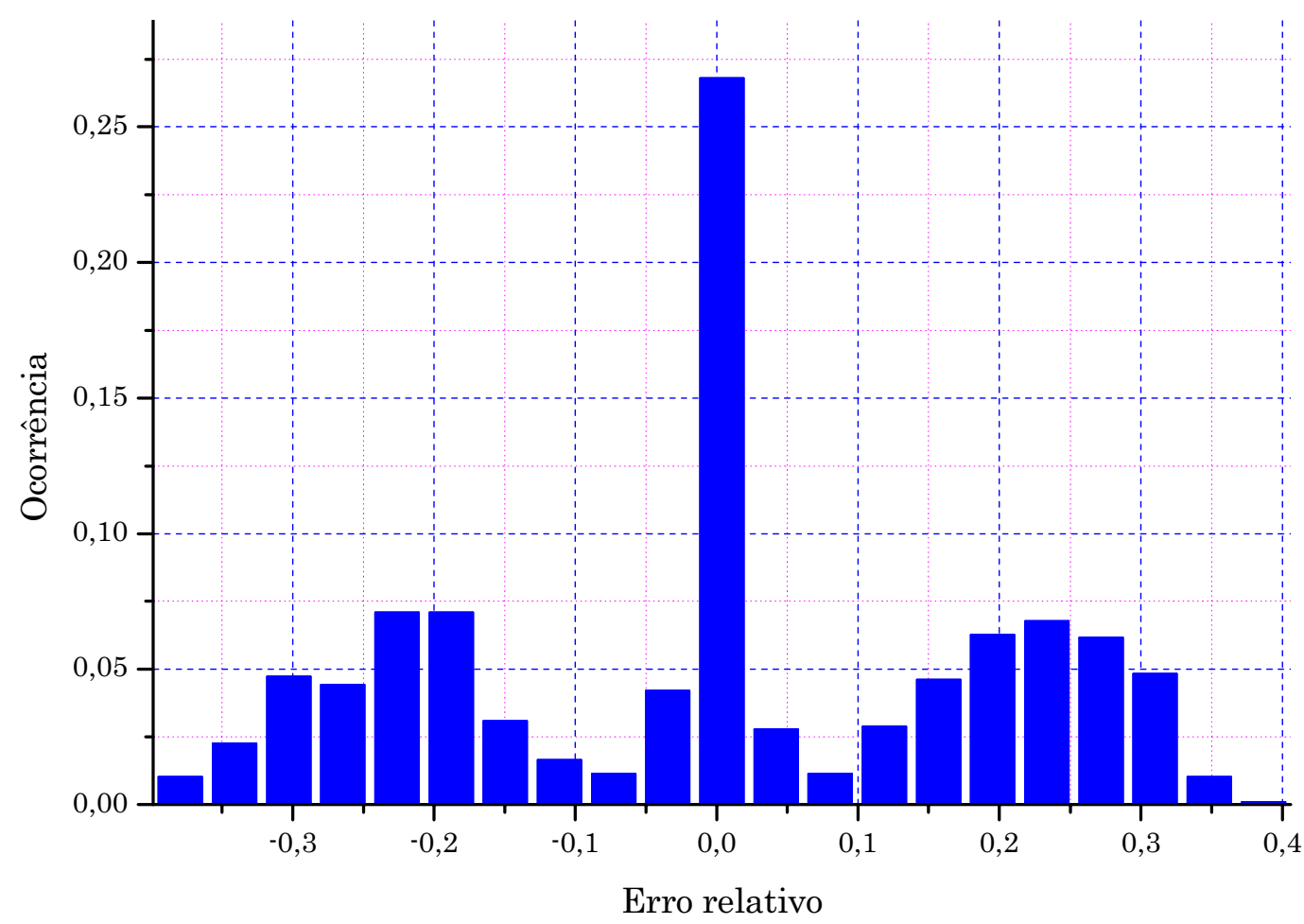

Figura 6.61 - Histograma do erro relativo de estimação da resistência de falta na Fase A.

Por meio do gráfico apresentado na Figura 6.61 é possível verificar que a distribuição probabilística do erro não segue uma distribuição normal nem mesmo alguma 
outra forma de distribuição usual. No entanto, dessa distribuição é possível obter seu respectivo valor médio o qual é de $6,2783 \times 10^{-4}$.

Apesar da distribuição de probabilidade não ser caracterizada por meio de alguma distribuição convencional, apresenta-se na Figura 6.62 a função densidade de probabilidade para o erro relativo na qual é possível constatar que, com uma confiabilidade de $90 \%$, o erro relativo se encontra entre $-0,29$ e 0,30 .

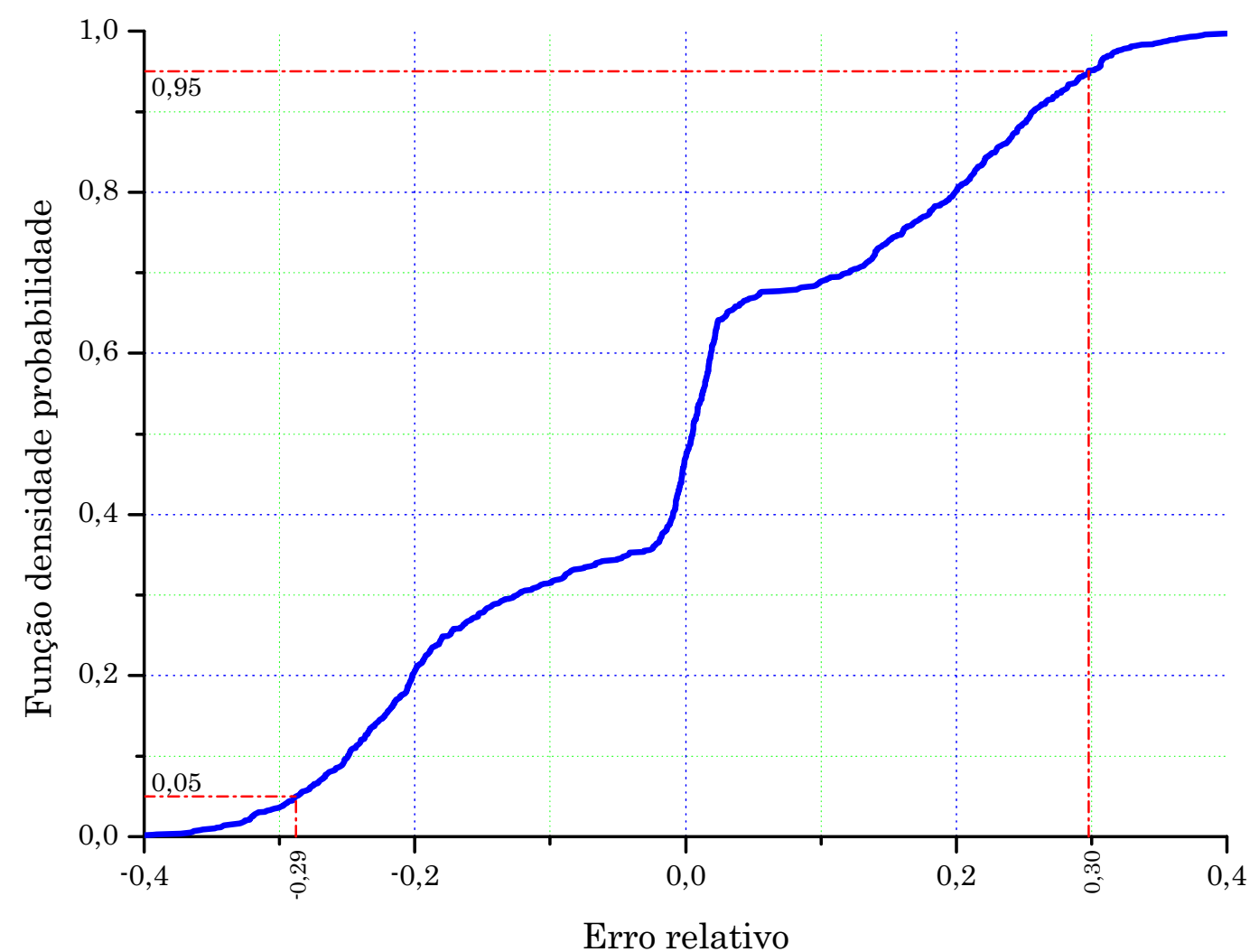

Figura 6.62 - Função densidade probabilidade para o erro relativo de estimação da resistência de falta na Fase A.

Complementando a análise do erro relativo de estimação da resistência de falta, apresenta-se na Tabela 6.24 a correlação entre o erro relativo e as variáveis independentes das simulações computacionais, ou seja, a correlação entre o erro relativo e a resistência de falta, o ângulo de falta e a duração da falta.

Por meio da Tabela 6.24 é possível verificar a forte dependência do erro relativo com a resistência de falta, ou seja, com a própria variável de estimação. Ainda, verifica-se que a correlação do erro com as demais variáveis independentes da simulação são próximas e bem inferiores que a correlação com a resistência de falta. A fim de ilustrar a forte correlação do erro de estimação da resistência de falta se apresenta o gráfico da Figura 6.63. 
Tabela 6.24 - Correlação entre o erro relativo e as variáveis independentes das simulações computacionais.

\begin{tabular}{lr}
\hline $\begin{array}{l}\text { Variável independente da } \\
\text { simulação }\end{array}$ & \multicolumn{1}{l}{$\begin{array}{l}\text { Correlação com erro } \\
\text { relativo de estimação }\end{array}$} \\
\hline \hline Distância de ocorrência da falta & 0.0351 \\
\hline Resistência de falta & 0.7328 \\
\hline Ângulo da falta & 0.0149 \\
\hline Duração da falta & 0.0269 \\
\hline \hline
\end{tabular}

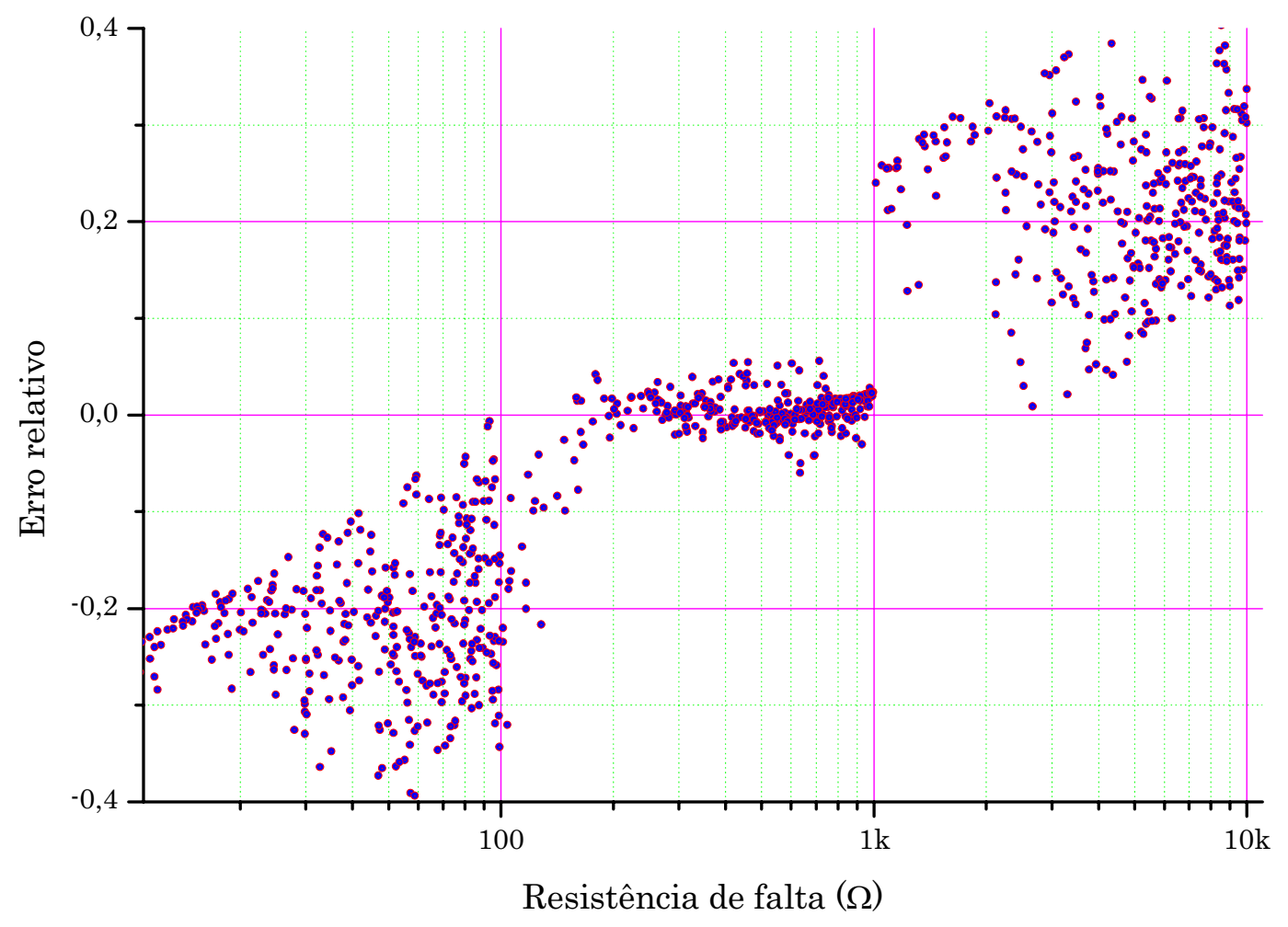

Figura 6.63 - Relacionamento entre o erro relativo e a resistência de falta.

Verifica-se pelo gráfico da Figura 6.63 a tendência tanto do máximo erro como do mínimo erro aumentarem com o incremento da resistência de falta da falta. Ainda, é possível constatar que o erro de estimação da resistência de falta se concentra melhor em torno do zero para resistências de falta entre 100 e $1 \mathrm{k} \Omega$.

O sistema fuzzy dedicado à estimação da resistência de falta, além ser testado com os dados provenientes do conjunto de ajuste, fora também testado com dados advindos de simulações computacionais não contidos no conjunto de ajuste. Assim, um total de 272 situações de falta na Fase A foram simuladas e os resultados dessas simulações foram submetidos à técnica de decomposição em componentes ortogonais. De posse dos valores eficazes das componentes ortogonais, as variáveis mais correlatas à estimação da resistência 
de falta na Fase A, apresentadas na Tabela 6.23, foram selecionadas e apresentadas ao sistema fuzzy previamente ajustado. Os resultados obtidos para a estimação da resistência de faltas quando de sua ocorrência na Fase A são apresentados por meio da Figura 6.64 na forma de histograma do erro relativo.

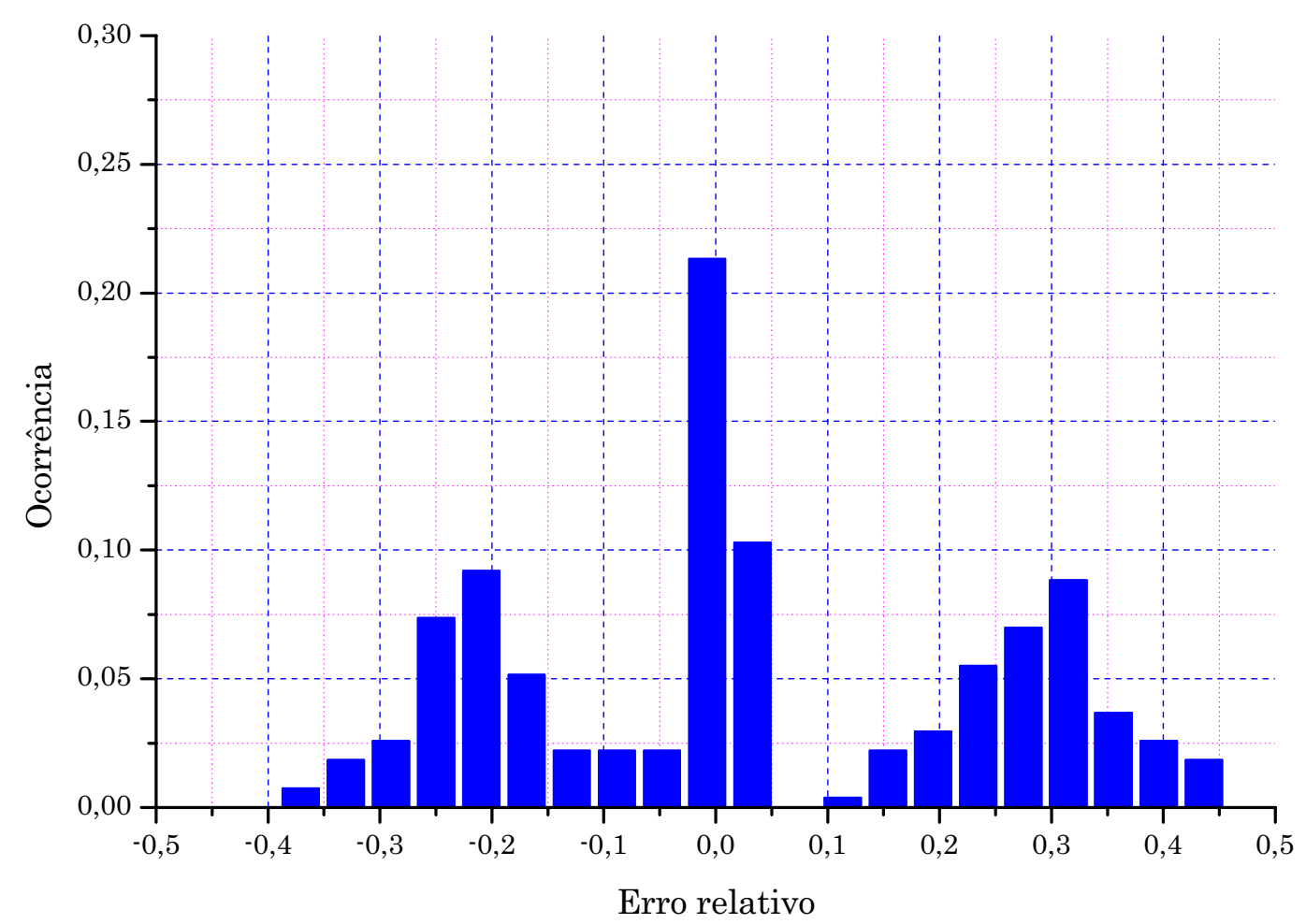

Figura 6.64 - Histograma do erro relativo de estimação da resistência de falta na Fase A para os dados do conjunto de teste.

Com o objetivo de ilustrar como a distribuição estatística do erro relativo para os dados de ajuste é semelhante à distribuição do erro verificado para os dados de teste, apresenta-se a Figura 6.65, onde ambas as funções densidade acumulada são confrontadas para propósitos comparativos. 


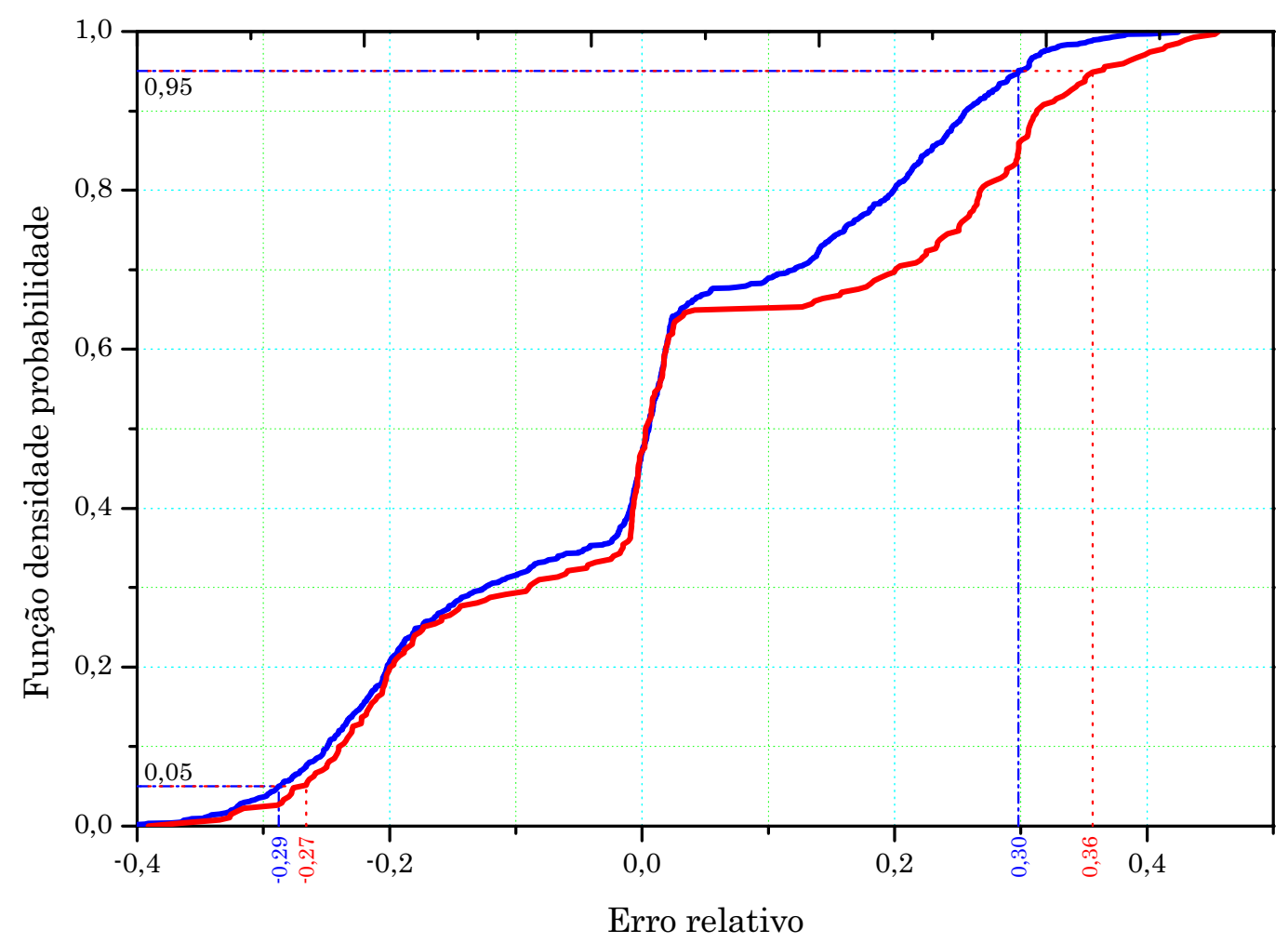

Figura 6.65 - Distribuição normal para o conjunto de ajuste e para o conjunto de teste quando da estimação da resistência de falta na Fase A.

Por meio da Figura 6.65 é possível verificar que a distribuição normal verificada para os dados de teste é semelhante com aquela verificada quando da modelagem do erro observado para os dados de ajuste. Ainda, por meio da avaliação dos dados de teste, verificouse que cerca de 79,93\% dos mesmos se enquadrou dentro do intervalo de confiança de $90 \%$ calculado sobre os dados de treinamento.

\subsubsection{SisteMA de INFERÊNCIA FUZZY PARA ESTIMAÇÃO dA RESISTÊNCIA DE FALTA NA FASE B}

Na Subseção 6.3.2 a estimação da resistência de falta fora realizada para quando da ocorrência de faltas na Fase A. Para a referida estimação, primeiramente, as variáveis empregadas para tal finalidade foram eleitas considerando-se aquelas com maior correlação com a variável de estimação, ou seja, com a resistência de falta. Após a eleição das variáveis mais correlatas, ajustou-se estruturalmente e parametricamente o sistema fuzzy responsável pela estimação da resistência de falta quando a mesma ocorrer na Fase A. A análise dos resultados obtidos tanto para o conjunto de ajuste como para o conjunto de teste retratam que o algoritmo de ajuste proposto fora eficiente no mapeamento almejado. Dessa maneira, a 
mesma metodologia será empregada na implementação do sistema fuzzy responsável pela estimação da resistência de falta na Fase B.

Assim, para apresentar como cada componente advindo do resultado da decomposição ortogonal se correlaciona com a resistência de falta, apresentam-se por meio da Tabela 6.25 as correlações e os testes de hipótese, que mensura o quão significativo é a correlação, das componentes de tensões contidas na função planar das tensões de linha com a resistência de falta quando essa for observada na Fase B. Os valores contidos na Tabela 6.25 são graficamente apresentados por meio da Figura 6.66.

Por meio da Tabela 6.26 se apresentam as correlações das componentes de corrente contidas na função planar das tensões de linha com a resistência de falta, assim como por meio da Figura 6.67 se tem a representação gráfica dos valores contidos nessa tabela.

A correlação das componentes de tensão ortogonais à função planar das tensões de linha com a resistência de falta é apresentada na Tabela 6.27 e tais valores para as componentes de corrente ortogonais à função planar das tensões de linha são conteúdo da Tabela 6.28. A representação dos valores expressos na Tabela 6.27 e Tabela 6.28 é realizada por meio da Figura 6.68 e da Figura 6.69, respectivamente. 
Tabela 6.25 - Correlação das componentes de tensão contidas na função planar das tensões de linha com relação à resistência de falta na Fase B.

\begin{tabular}{|c|c|c|c|c|c|c|c|}
\hline \multirow[b]{2}{*}{$k$} & \multirow[b]{2}{*}{ Variável } & \multicolumn{2}{|c|}{ Média } & \multicolumn{2}{|c|}{ Máximo } & \multicolumn{2}{|c|}{ Mínimo } \\
\hline & & Correlação & $\begin{array}{l}\text { Teste de } \\
\text { hipótese } \\
\end{array}$ & Correlação & $\begin{array}{l}\text { Teste de } \\
\text { hipótese } \\
\end{array}$ & Correlação & $\begin{array}{l}\text { Teste de } \\
\text { hipótese }\end{array}$ \\
\hline 1 & $\left\|v_{a}^{p}(t)\right\|$ & 0,0013 & 0,9674 & 0,0036 & 0,9093 & 0,0021 & 0,9483 \\
\hline 2 & $\left\|v_{b}^{p}(t)\right\|$ & 0,0093 & 0,7685 & 0,0980 & 0,0019 & 0,0419 & 0,1858 \\
\hline 3 & $\left\|v_{c}^{p}(t)\right\|$ & 0,0413 & 0,1916 & 0,0402 & 0,2045 & 0,0021 & 0,9481 \\
\hline 4 & $\left\|v_{n}^{p}(t)\right\|$ & 0,0154 & 0,6274 & 0,0164 & 0,6054 & 0,0126 & 0,6906 \\
\hline 5 & $\left\|v_{a}^{q^{\|}}(t)\right\|$ & 0,0209 & 0,5088 & 0,0214 & 0,4996 & 0,0715 & 0,0237 \\
\hline 6 & $\left\|v_{b}^{q^{\|}}(t)\right\|$ & 0,0416 & 0,1889 & 0,0277 & 0,3824 & 0,1233 & 0,0001 \\
\hline 7 & $\left\|v_{c}^{q^{\| \prime}}(t)\right\|$ & 0,0726 & 0,0217 & 0,1190 & 0,0002 & 0,1692 & 0,0000 \\
\hline 8 & $\left\|v_{n}^{q^{\prime \prime}}(t)\right\|$ & 0,0257 & 0,4173 & 0,0343 & 0,2788 & 0,0077 & 0,8082 \\
\hline 9 & $\left\|v_{a}^{q^{\perp}}(t)\right\|$ & 0,0119 & 0,7080 & 0,0070 & 0,8253 & 0,0944 & 0,0028 \\
\hline 10 & $\left\|v_{b}^{q^{\perp}}(t)\right\|$ & 0,0651 & 0,0396 & 0,0637 & 0,0443 & 0,0257 & 0,4169 \\
\hline 11 & $\left\|v_{c}^{q^{\perp}}(t)\right\|$ & 0,0727 & 0,0217 & 0,0507 & 0,1094 & 0,0287 & 0,3642 \\
\hline 12 & $\left\|v_{n}^{q^{\perp}}(t)\right\|$ & 0,0094 & 0,7665 & 0,0269 & 0,3949 & 0,0268 & 0,3981 \\
\hline 13 & $\left\|v_{a}^{d}(t)\right\|$ & 0,0119 & 0,7080 & 0,0070 & 0,8253 & 0,1043 & 0,0010 \\
\hline 14 & $\left\|v_{b}^{d}(t)\right\|$ & 0,0651 & 0,0396 & 0,0637 & 0,0443 & 0,0234 & 0,4598 \\
\hline 15 & $\left\|v_{c}^{d}(t)\right\|$ & 0,0727 & 0,0216 & 0,0507 & 0,1094 & 0,0203 & 0,5207 \\
\hline 16 & $\left\|v_{n}^{d}(t)\right\|$ & 0,0094 & 0,7666 & 0,0269 & 0,3949 & 0,0287 & 0,3647 \\
\hline
\end{tabular}
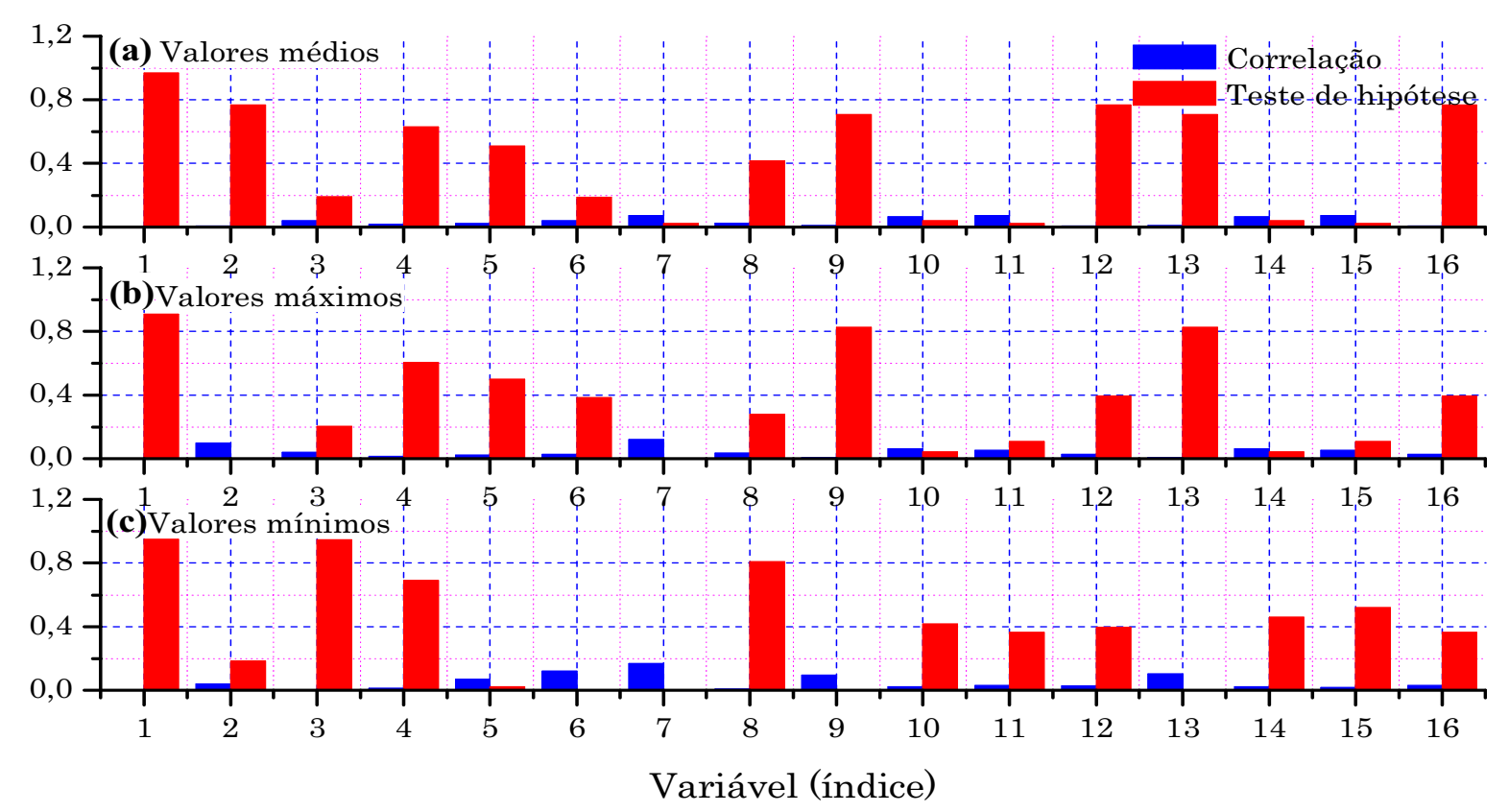

Figura 6.66 - Correlação e teste de hipótese para as componentes de tensão contidas na função planar das tensões de linha com a resistência de falta na Fase B; (a) Correlação e teste de hipótese para os valores médios; (b) Correlação e teste de hipótese para os valores máximos; (c) Correlação e teste de hipótese para os valores mínimos. 
Tabela 6.26 - Correlação das componentes de corrente contidas na função planar das tensões de linha com relação à resistência de falta na Fase B.

\begin{tabular}{|c|c|c|c|c|c|c|c|}
\hline \multirow[b]{2}{*}{$k$} & \multirow[b]{2}{*}{ Variável } & \multicolumn{2}{|c|}{ Média } & \multicolumn{2}{|c|}{ Máximo } & \multicolumn{2}{|c|}{ Mínimo } \\
\hline & & Correlação & $\begin{array}{l}\text { Teste de } \\
\text { hipótese }\end{array}$ & Correlação & $\begin{array}{l}\text { Teste de } \\
\text { hipótese }\end{array}$ & Correlação & $\begin{array}{l}\text { Teste de } \\
\text { hipótese }\end{array}$ \\
\hline 1 & $\left\|i_{a}^{p}(t)\right\|$ & 0,0247 & 0,4357 & 0,0059 & 0,8526 & 0,0210 & 0,5075 \\
\hline 2 & $\left\|i_{b}^{p}(t)\right\|$ & 0,0184 & 0,5605 & 0,0052 & 0,8693 & 0,0373 & 0,2394 \\
\hline 3 & $\left\|i_{c}^{p}(t)\right\|$ & 0,0374 & 0,2377 & 0,0027 & 0,9310 & 0,0248 & 0,4345 \\
\hline 4 & $\left\|i_{n}^{p}(t)\right\|$ & 0,0154 & 0,6277 & 0,0112 & 0,7230 & 0,0028 & 0,9287 \\
\hline 5 & $\left\|i_{a}^{q^{\|}}(t)\right\|$ & 0,0522 & 0,0989 & 0,0159 & 0,6164 & 0,0804 & 0,0111 \\
\hline 6 & $\left\|i_{b}^{q^{\prime \prime}}(t)\right\|$ & 0,0770 & 0,0149 & 0,0449 & 0,1560 & 0,0881 & 0,0053 \\
\hline 7 & $\left\|i_{c}^{q^{\|}}(t)\right\|$ & 0,0422 & 0,1825 & 0,0953 & 0,0026 & 0,1276 & 0,0001 \\
\hline 8 & $\left\|i_{n}^{q^{\|}}(t)\right\|$ & 0,0244 & 0,4413 & 0,0315 & 0,3192 & 0,0122 & 0,7000 \\
\hline 9 & $\left\|i_{a}^{q^{\perp}}(t)\right\|$ & 0,0174 & 0,5835 & 0,0178 & 0,5742 & 0,0915 & 0,0038 \\
\hline 10 & $\left\|i_{b}^{q^{\perp}}(t)\right\|$ & 0,0777 & 0,0140 & 0,0683 & 0,0310 & 0,0000 & 1,0000 \\
\hline 11 & $\left\|i_{c}^{q^{\perp}}(t)\right\|$ & 0,0352 & 0,2663 & 0,0309 & 0,3292 & 0,0000 & 1,0000 \\
\hline 12 & $\left\|i_{n}^{q^{\perp}}(t)\right\|$ & 0,0501 & 0,1134 & 0,0467 & 0,1402 & 0,0000 & 1,0000 \\
\hline 13 & $\left\|i_{a}^{d}(t)\right\|$ & 0,0174 & 0,5835 & 0,0178 & 0,5742 & 0,0975 & 0,0020 \\
\hline 14 & $\left\|i_{b}^{d}(t)\right\|$ & 0,0150 & 0,6355 & 0,0031 & 0,9232 & 0,0000 & 1,0000 \\
\hline 15 & $\left\|i_{c}^{d}(t)\right\|$ & 0,0119 & 0,7071 & 0,0027 & 0,9315 & 0,0000 & 1,0000 \\
\hline 16 & $\left\|i_{n}^{d}(t)\right\|$ & 0,0501 & 0,1134 & 0,0467 & 0,1402 & 0,0000 & 1,0000 \\
\hline
\end{tabular}
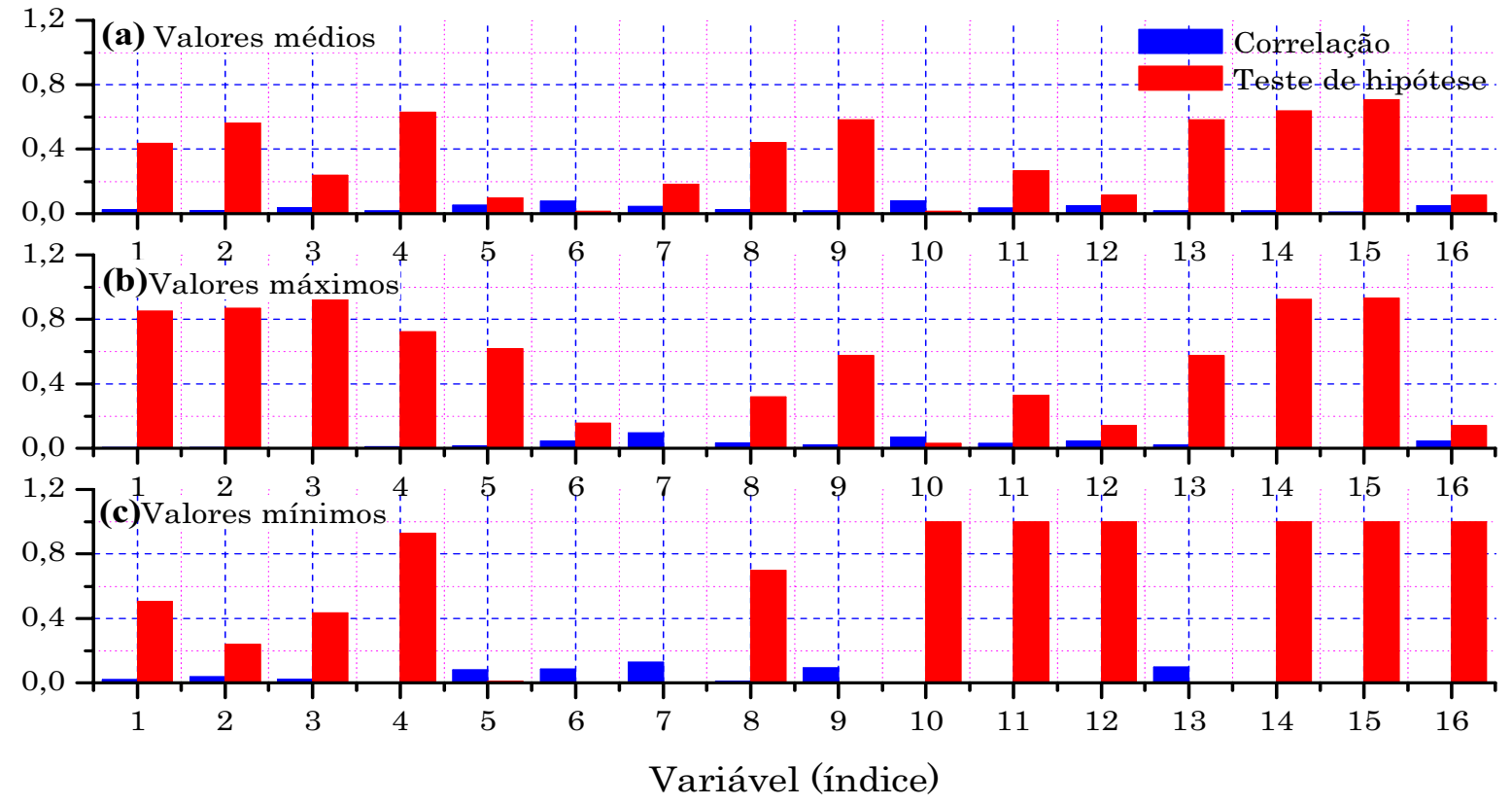

Figura 6.67 - Correlação e teste de hipótese para as componentes de corrente contidas na função planar das tensões de linha com a resistência de falta na Fase B; (a) Correlação e teste de hipótese para os valores médios; (b) Correlação e teste de hipótese para os valores máximos; (c) Correlação e teste de hipótese para os valores mínimos. 
Tabela 6.27 - Correlação das componentes de tensão ortogonais à função planar das tensões de linha com relação à resistência de falta na Fase B.

\begin{tabular}{|c|c|c|c|c|c|c|c|}
\hline \multirow[b]{2}{*}{$k$} & \multirow[b]{2}{*}{ Variável } & \multicolumn{2}{|c|}{ Média } & \multicolumn{2}{|c|}{ Máximo } & \multicolumn{2}{|c|}{ Mínimo } \\
\hline & & Correlação & $\begin{array}{l}\text { Teste de } \\
\text { hipótese }\end{array}$ & Correlação & $\begin{array}{l}\text { Teste de } \\
\text { hipótese }\end{array}$ & Correlação & $\begin{array}{l}\text { Teste de } \\
\text { hipótese }\end{array}$ \\
\hline 1 & $\left\|v_{\bar{a}}^{p}(t)\right\|$ & 0,0118 & 0,7098 & 0,0104 & 0,7431 & 0,0013 & 0,9673 \\
\hline 2 & $\left\|v_{\bar{b}}^{p}(t)\right\|$ & 0,0173 & 0,5845 & 0,0111 & 0,7261 & 0,0204 & 0,5206 \\
\hline 3 & $\left\|v_{\bar{c}}^{p}(t)\right\|$ & 0,0069 & 0,8287 & 0,0092 & 0,7704 & 0,0029 & 0,9265 \\
\hline 4 & $\left\|v_{h}^{p}(t)\right\|$ & 0,0168 & 0,5952 & 0,0173 & 0,5851 & 0,0057 & 0,8570 \\
\hline 5 & $\left\|v_{\bar{a}}^{q^{\|}}(t)\right\|$ & 0,0673 & 0,0336 & 0,0552 & 0,0811 & 0,2431 & 0,0000 \\
\hline 6 & $\left\|v^{q^{\prime \prime}}(t)\right\|$ & 0,1118 & 0,0004 & 0,0533 & 0,0922 & 0,3865 & 0,0000 \\
\hline 7 & $\left\|v_{c}^{q^{\prime \prime}}(t)\right\|$ & 0,0657 & 0,0377 & 0,0351 & 0,2678 & 0,1998 & 0,0000 \\
\hline 8 & $\left\|v_{h}^{q^{\|}}(t)\right\|$ & 0,0475 & 0,1334 & 0,0337 & 0,2866 & 0,0124 & 0,6956 \\
\hline 9 & $\left\|v_{\bar{a}}^{q^{\perp}}(t)\right\|$ & 0,0076 & 0,8114 & 0,0077 & 0,8076 & 0,0190 & 0,5490 \\
\hline 10 & $\left\|v^{q^{\perp}}(t)\right\|$ & 0,1377 & 0,0000 & 0,0292 & 0,3567 & 0,0000 & 1,0000 \\
\hline 11 & $\left\|v_{\bar{c}}^{q^{\perp}}(t)\right\|$ & 0,0713 & 0,0241 & 0,0535 & 0,0911 & 0,0000 & 1,0000 \\
\hline 12 & $\left\|v_{h}^{q^{\perp}}(t)\right\|$ & 0,0487 & 0,1243 & 0,0780 & 0,0136 & 0,0128 & 0,6853 \\
\hline 13 & $\left\|v_{\bar{a}}^{d}(t)\right\|$ & 0,0076 & 0,8114 & 0,0077 & 0,8076 & 0,1239 & 0,0001 \\
\hline 14 & $\left\|v_{\bar{b}}^{d}(t)\right\|$ & 0,0639 & 0,0435 & 0,0079 & 0,8033 & 0,0025 & 0,9365 \\
\hline 15 & $\left\|v_{\bar{c}}^{d}(t)\right\|$ & 0,0410 & 0,1950 & 0,0111 & 0,7256 & 0,0861 & 0,0065 \\
\hline 16 & $\left\|v_{h}^{d}(t)\right\|$ & 0,0487 & 0,1243 & 0,0780 & 0,0136 & 0,0210 & 0,5067 \\
\hline
\end{tabular}
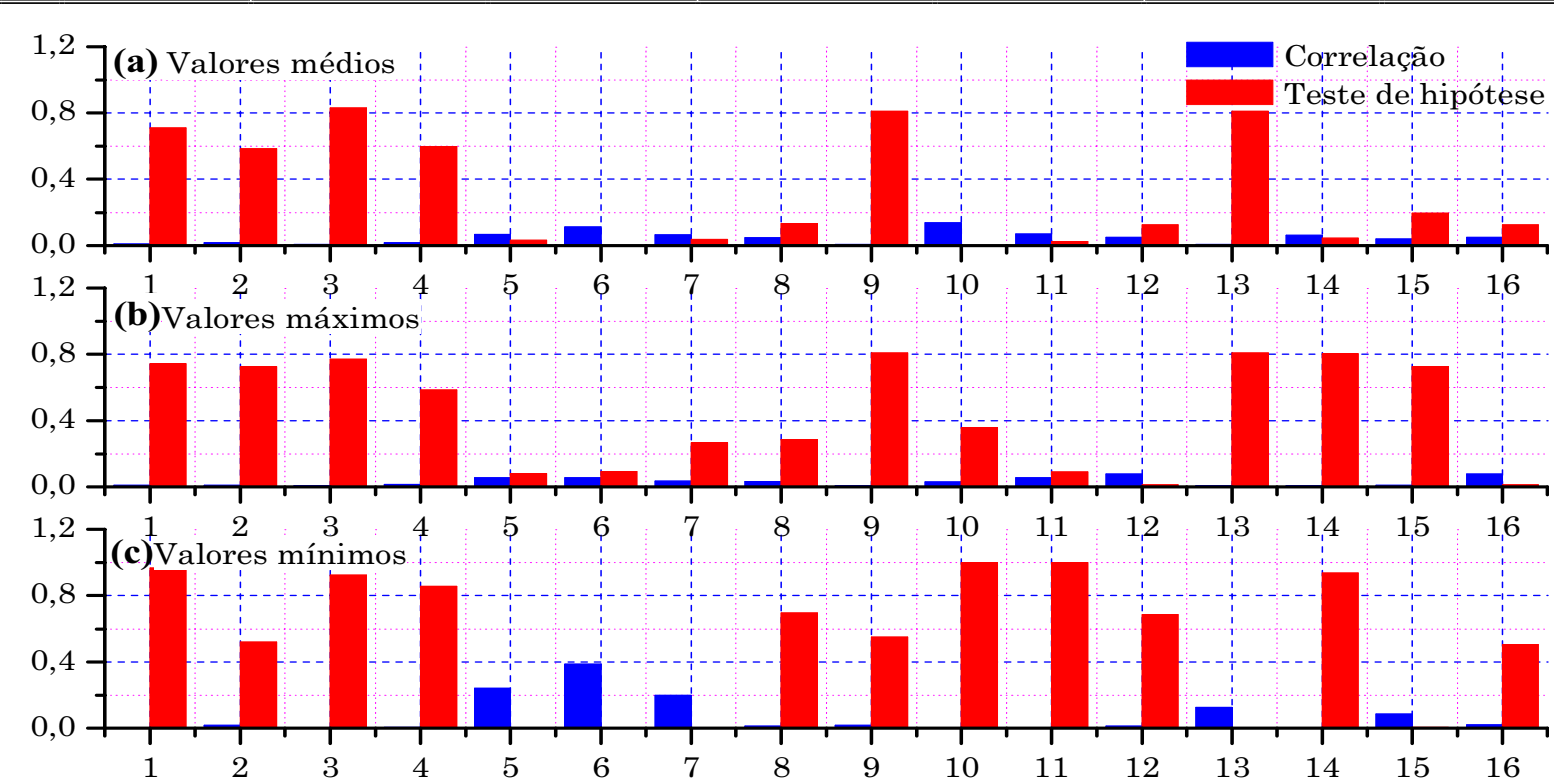

Variável (índice)

Figura 6.68 - Correlação e teste de hipótese para as componentes de tensão ortogonais à função planar das tensões de linha com a resistência de falta na Fase B; (a) Correlação e teste de hipótese para os valores médios; (b) Correlação e teste de hipótese para os valores máximos; (c) Correlação e teste de hipótese para os valores mínimos. 
Tabela 6.28 - Correlação das componentes de corrente ortogonais à função planar das tensões de linha com relação à resistência de falta na Fase B.

\begin{tabular}{|c|c|c|c|c|c|c|c|}
\hline \multirow[b]{2}{*}{$k$} & \multirow[b]{2}{*}{ Variável } & \multicolumn{2}{|c|}{ Média } & \multicolumn{2}{|c|}{ Máximo } & \multicolumn{2}{|c|}{ Mínimo } \\
\hline & & Correlação & $\begin{array}{l}\text { Teste de } \\
\text { hipótese } \\
\end{array}$ & Correlação & $\begin{array}{l}\text { Teste de } \\
\text { hipótese }\end{array}$ & Correlação & $\begin{array}{l}\text { Teste de } \\
\text { hipótese }\end{array}$ \\
\hline 1 & $\left\|i_{\bar{a}}^{p}(t)\right\|$ & 0,0115 & 0,7158 & 0,0065 & 0,8374 & 0,0119 & 0,7080 \\
\hline 2 & $\left\|i_{i}^{p}(t)\right\|$ & 0,0155 & 0,6238 & 0,0185 & 0,5583 & 0,0178 & 0,5739 \\
\hline 3 & $\left\|i_{\bar{c}}^{p}(t)\right\|$ & 0,0059 & 0,8522 & 0,0071 & 0,8222 & 0,0060 & 0,8491 \\
\hline 4 & $\left\|i_{h}^{p}(t)\right\|$ & 0,0148 & 0,6409 & 0,0162 & 0,6082 & 0,0179 & 0,5722 \\
\hline 5 & $\left\|i_{\bar{a}}^{q^{\prime \prime}}(t)\right\|$ & 0,0756 & 0,0169 & 0,0661 & 0,0367 & 0,2570 & 0,0000 \\
\hline 6 & $\left\|i \frac{q^{\prime \prime}}{b}(t)\right\|$ & 0,1143 & 0,0003 & 0,1113 & 0,0004 & 0,0802 & 0,0112 \\
\hline 7 & $\left\|i_{c}^{q^{\prime \prime}}(t)\right\|$ & 0,0716 & 0,0237 & 0,0215 & 0,4974 & 0,1082 & 0,0006 \\
\hline 8 & $\left\|i_{h}^{q^{\|}}(t)\right\|$ & 0,0103 & 0,7459 & 0,0201 & 0,5248 & 0,0267 & 0,3998 \\
\hline 9 & $\left\|i_{\bar{a}}^{q^{\perp}}(t)\right\|$ & 0,0137 & 0,6660 & 0,0134 & 0,6719 & 0,0297 & 0,3477 \\
\hline 10 & $\left\|i \frac{q^{\perp}}{b}(t)\right\|$ & 0,0142 & 0,6542 & 0,0135 & 0,6701 & 0,0921 & 0,0036 \\
\hline 11 & $\left\|i_{c}^{q^{\perp}}(t)\right\|$ & 0,0711 & 0,0246 & 0,0193 & 0,5416 & 0,0000 & 1,0000 \\
\hline 12 & $\left\|i_{h}^{q^{\perp}}(t)\right\|$ & 0,0874 & 0,0057 & 0,0669 & 0,0345 & 0,0687 & 0,0299 \\
\hline 13 & $\left\|i_{\bar{a}}^{d}(t)\right\|$ & 0,0137 & 0,6651 & 0,0135 & 0,6703 & 0,0217 & 0,4929 \\
\hline 14 & $\left\|i_{\frac{d}{b}}^{d}(t)\right\|$ & 0,0142 & 0,6542 & 0,0135 & 0,6701 & 0,0908 & 0,0041 \\
\hline 15 & $\left\|i_{\bar{c}}^{d}(t)\right\|$ & 0,0476 & 0,1323 & 0,0131 & 0,6803 & 0,0619 & 0,0506 \\
\hline 16 & $\left\|i_{h}^{d}(t)\right\|$ & 0,0874 & 0,0057 & 0,0669 & 0,0345 & 0,0734 & 0,0204 \\
\hline
\end{tabular}
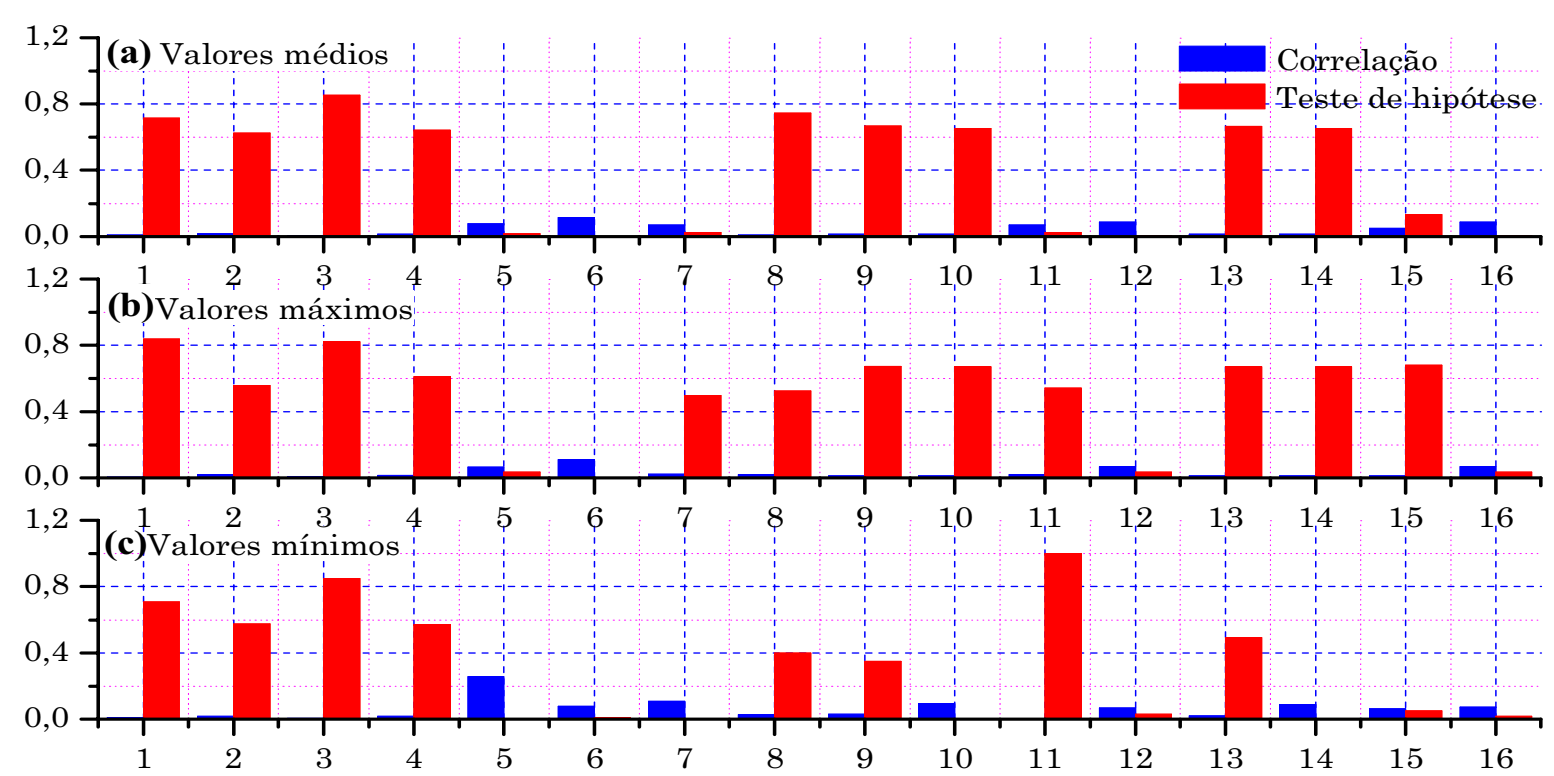

Variável (índice)

Figura 6.69 - Correlação e teste de hipótese para as componentes de corrente ortogonais à função planar das tensões de linha com a resistência de falta na Fase B; (a) Correlação e teste de hipótese para os valores médios; (b) Correlação e teste de hipótese para os valores máximos; (c) Correlação e teste de hipótese para os valores mínimos. 
Por meio dos valores de correlação apresentados nas tabelas anteriores é possível verificar que as oito variáveis mais correlacionadas com a resistência de falta na Fase B são aquelas destacadas na Tabela 6.29, a qual destaca também as referidas correlações.

Tabela 6.29 - Variáveis mais correlatas à estimação da resistência de falta na Fase B.

\begin{tabular}{ccccc}
\hline \hline Índice & Variável & Característica & Símbolo & Correlação \\
\hline 1 & $\left\|v_{\bar{b}}^{q^{\|}}(t)\right\|$ & Mínimo & $\left\|v_{\bar{b}}^{q^{\|}}(t)\right\|^{\min }$ & 0,3865 \\
\hline 2 & $\left\|i_{\bar{a}}^{q^{\|}}(t)\right\|$ & Mínimo & $\left\|i_{\bar{a}}^{q^{\prime \prime}}(t)\right\|^{\min }$ & 0,2570 \\
\hline 3 & $\left\|v_{\bar{a}}^{q^{\|}}(t)\right\|$ & Mínimo & $\left\|v_{\bar{a}}^{q^{\|}}(t)\right\|^{\min }$ & 0,2431 \\
\hline 4 & $\left\|v_{\bar{c}}^{q^{\|}}(t)\right\|$ & Mínimo & $\left\|v_{\bar{c}}^{q^{\|}}(t)\right\|^{\min }$ & 0,1998 \\
\hline 5 & $\left\|v_{c}^{q^{\|}}(t)\right\|$ & Mínimo & $\left\|v_{c}^{q^{\|}}(t)\right\|^{\min }$ & 0,1692 \\
\hline 7 & $\left\|v_{\bar{b}}^{q^{\perp}}(t)\right\|$ & Médio & $\left\|v_{\bar{b}}^{q^{\perp}}(t)\right\|$ & 0,1377 \\
\hline 8 & $\left\|i_{c}^{q^{\|}}(t)\right\|$ & Mínimo & $\left\|i_{c}^{q^{\prime}}(t)\right\|$ & 0,1276 \\
\hline \hline
\end{tabular}

As variáveis apresentadas na Tabela 6.29 representam as variáveis mais correlatas com a resistência de falta quando essa envolver a Fase B. Além de constituírem as variáveis mais correlatas, essas foram aquelas empregadas como entrada do sistema fuzzy responsável pela estimação da resistência de falta. O sistema fuzzy responsável pela estimação da resistência da falta fora constituído por 40 regras de inferência, número esse de regras que, durante os testes computacionais, se mostrou adequado na estimação da resistência.

O sistema fuzzy fora ajustado segundo o algoritmo delineado no Capítulo 4 e fazendo uso de um conjunto de ajuste constituído por 999 pares entrada-saída. Todo o conjunto de ajuste fora construído se fazendo uso das simulações computacionais descritas no Capítulo 5 referentes às faltas fase-terra com participação da Fase B.

O algoritmo de ajuste delineado no Capítulo 4 é composto de duas etapas de ajuste. A primeira dessas etapas responde pelo ajuste estrutural do sistema fuzzy que, conforme abordado, é dedicado à extração das regras de inferência fuzzy que melhor correlacionam o espaço fuzzy das entradas com o espaço fuzzy da saída. Dessa forma, tem-se como produto da primeira etapa de ajuste a base de regra do sistema fuzzy que, nesse caso, será responsável pela estimação da resistência de falta quando a mesma envolver a Fase B. 
A fim de apresentar como o erro quadrático médio do sistema fuzzy se portou ao longo das iterações do processo de ajuste estrutural, retrata-se à Figura 6.70, onde tal comportamento é ilustrado.

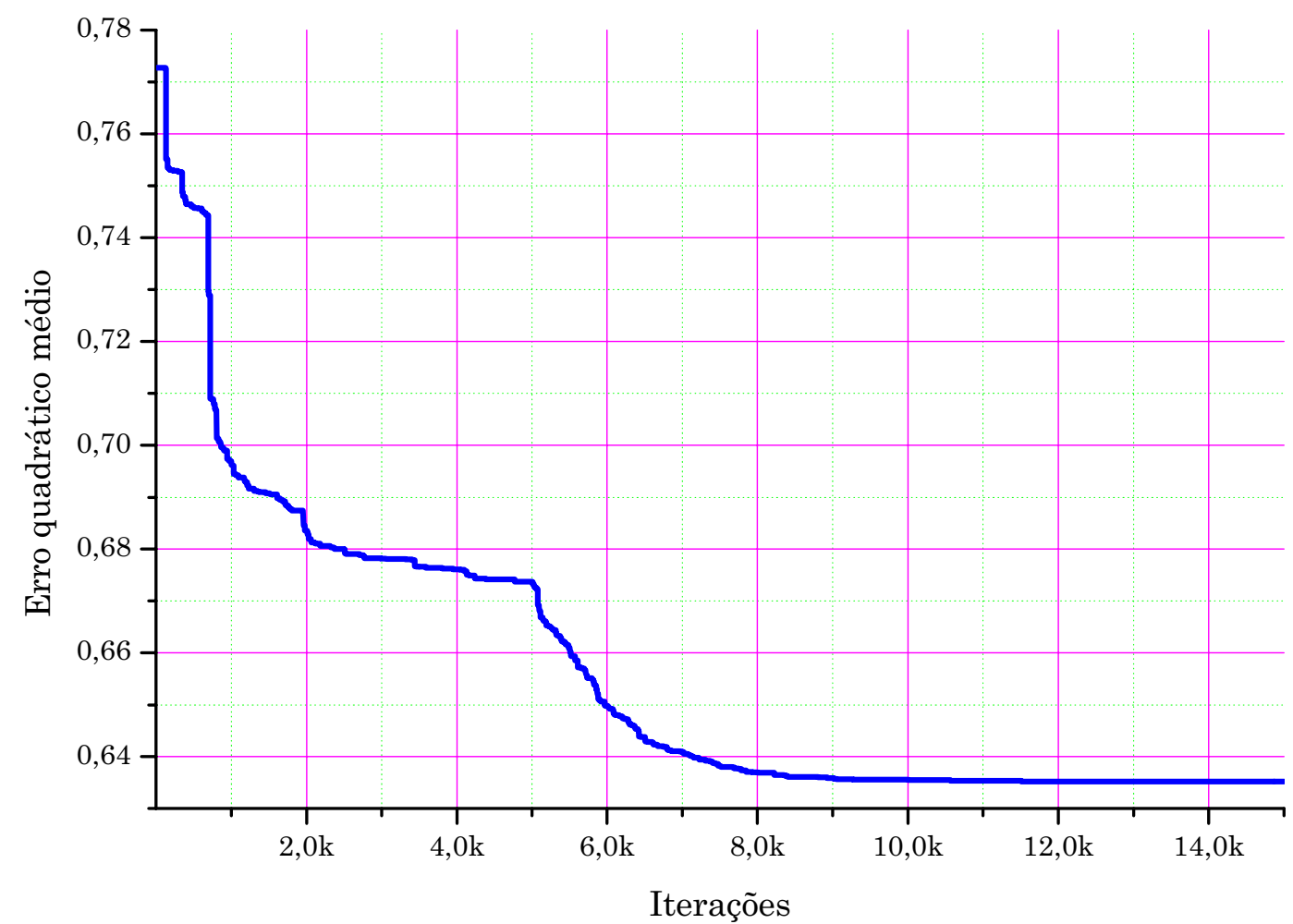

Figura 6.70 - Comportamento do erro quadrático médio do sistema fuzzy dedicado à estimação da resistência de falta quando essa envolver a Fase B ao longo das iterações da primeira etapa de ajuste.

O gráfico da Figura 6.70 apresenta a sensível redução do erro quadrático médio ao longo das iterações da primeira etapa de ajuste para o sistema fuzzy responsável pela estimação da resistência de falta fase-terra quando essa envolver a Fase B. Ao término dessa primeira etapa de ajuste, assim como anteriormente citado, tem-se como produto a base de regras responsável pelo relacionamento entre o espaço fuzzy das variáveis de entrada com o espaço fuzzy da variável de saída. Retratando a base de regras determinada por essa etapa de ajuste, apresenta-se a Figura 6.71. 


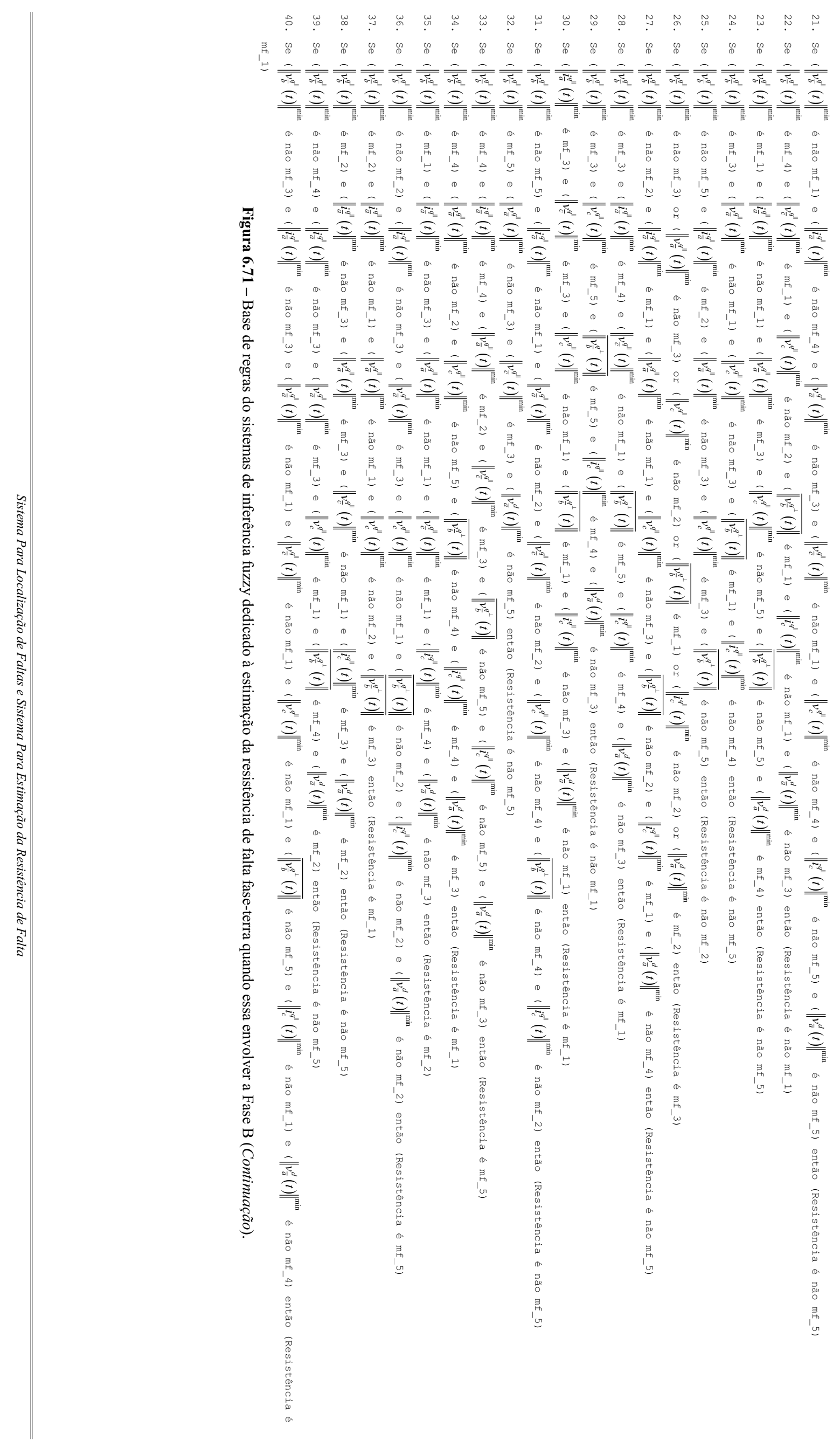


Após a determinação da base de regras representada por meio da Figura 6.71, o sistema de inferência fuzzy fora submetido à segunda etapa de ajuste o qual é dedicado ao ajuste paramétrico do sistema. O ajuste paramétrico tem por meta prosseguir com a redução do erro quadrático iniciada na primeira etapa. Para tanto, a segunda etapa de ajuste, denotada por ajuste paramétrico, modifica os parâmetros que definem as funções de pertinência das entradas e da saída, bem como procede com a ponderação das regras fuzzy ora obtidas na primeira etapa de ajuste. Apresentando como o erro quadrático médio se portou ao longo das iterações dessa segunda etapa de ajuste, tem-se a Figura 6.72.

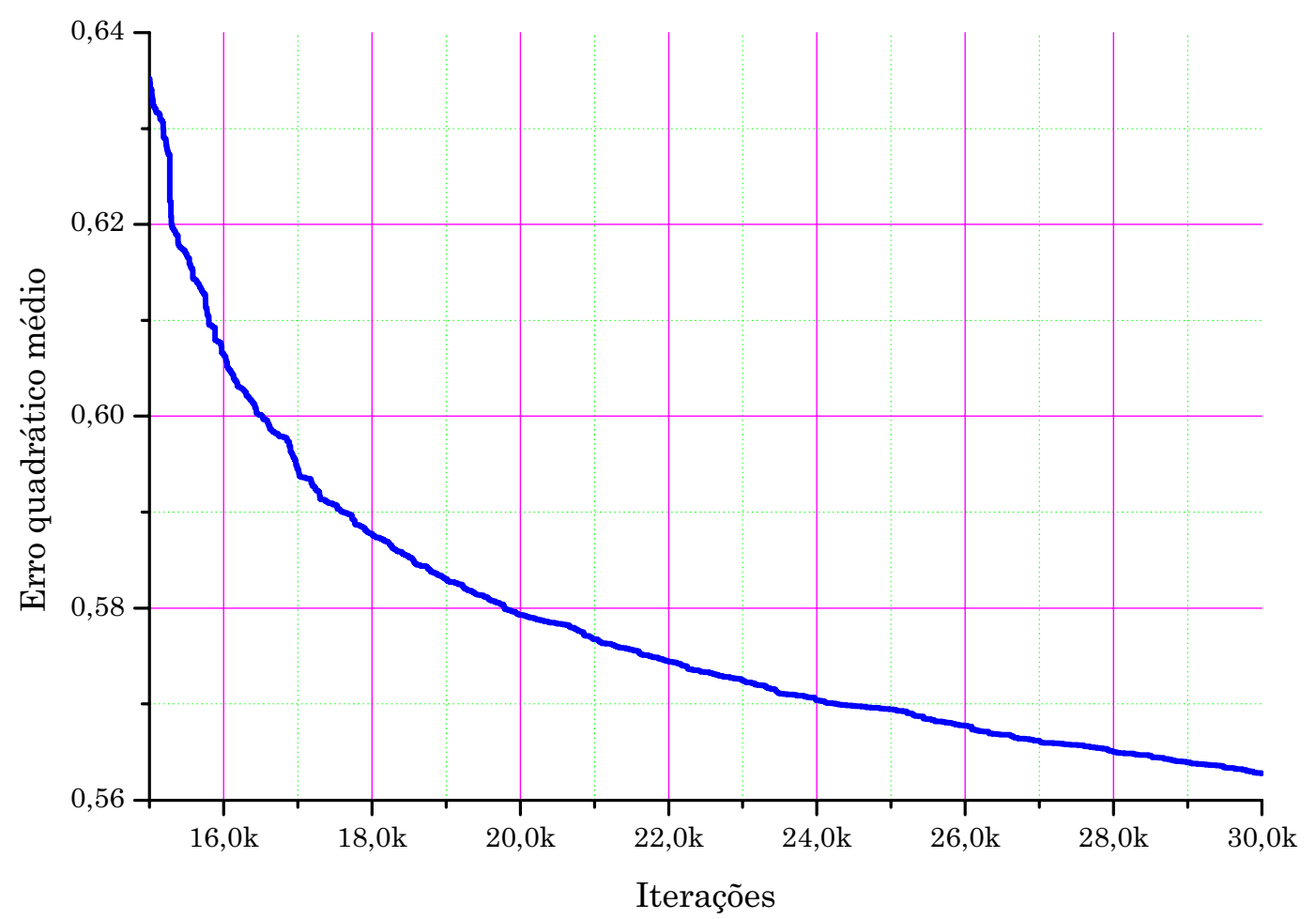

Figura 6.72 - Comportamento do erro quadrático médio do sistema fuzzy dedicado à estimação da resistência de falta quando essa envolver a Fase B ao longo das iterações da segunda etapa de ajuste.

Por meio da Figura 6.72 é possível verificar o quão o erro quadrático médio se reduz ao longo da etapa de ajuste paramétrico. Essa etapa, assim como já referenciado, é responsável por ajustar as funções de pertinência das entradas e da saída, além de ponderar as regras de inferência fuzzy. Complementando, a apresentação dos resultados advindos do processo de ajuste paramétrico, ilustra-se por meio da Figura 6.73 as funções de pertinência ajustadas para as quatro primeiras entradas, ou seja, para as entradas $\left\|v_{\frac{q}{b}}^{q^{\prime \prime}}(t)\right\|^{\min },\left\|i_{\bar{a}}^{q^{\prime \prime}}(t)\right\|^{\min }$, $\left\|v_{\bar{a}}^{q^{\prime \prime}}(t)\right\|^{\min }$ e $\left\|v_{\bar{c}}^{q^{\prime \prime}}(t)\right\|^{\min }$. Da mesma maneira, por meio da Figura 6.74 tem-se as funções de pertinência para as outras quatro entradas, ou seja, para as entradas $\left\|v_{c}^{q^{l}}(t)\right\|^{\min }, \overline{\left\|v_{\frac{q}{b}}^{\perp}(t)\right\|}$, $\left\|i_{c}^{q^{\|}}(t)\right\|\left\|^{\min },\right\| v_{\bar{a}}^{d}(t) \|^{\min }$. 

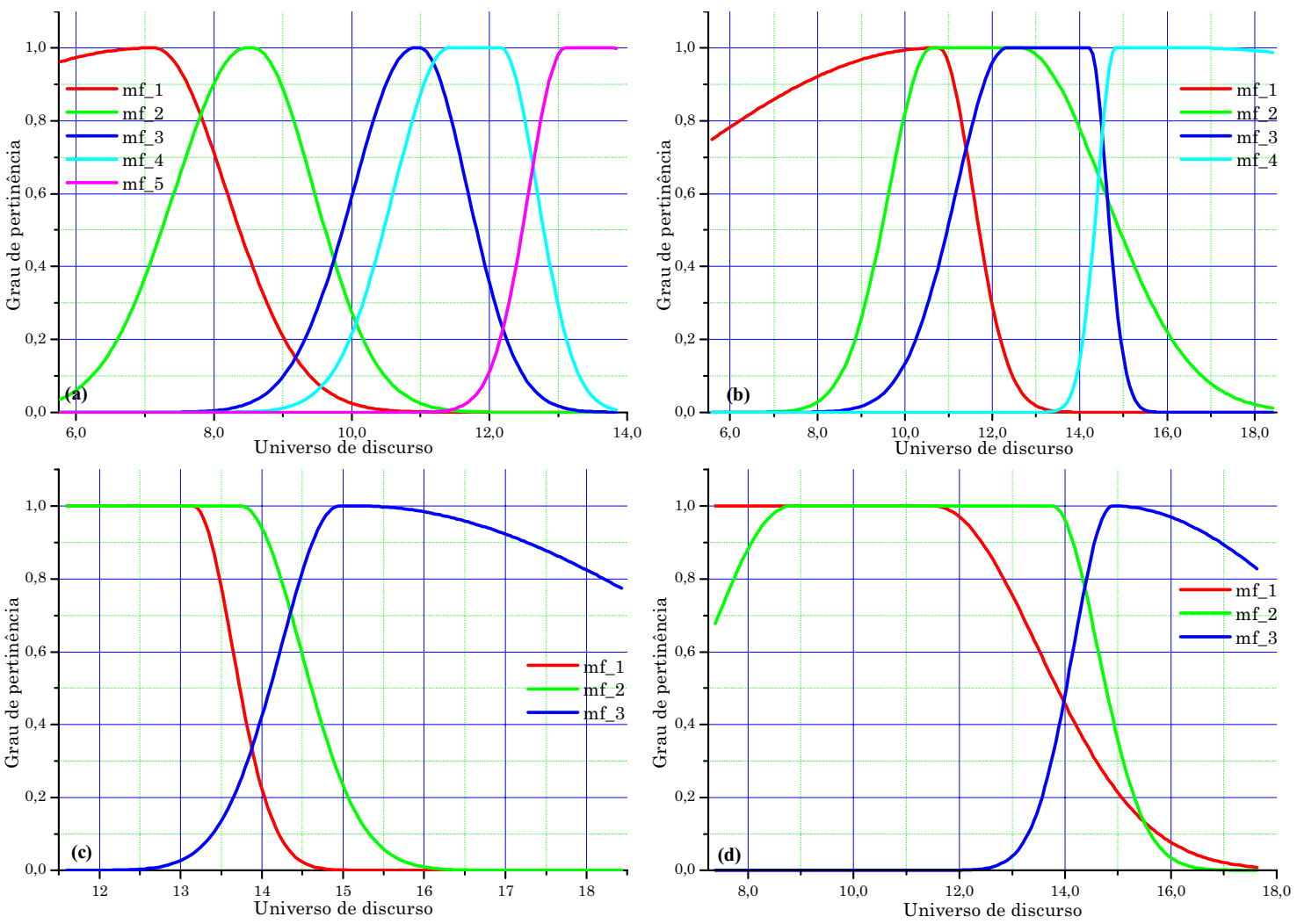

Figura 6.73 - Funções de pertinência ajustadas para as quatro primeiras entradas; (a) Entrada $\left\|v_{\frac{q^{\prime \prime}}{b}}(t)\right\|^{\min }$; (b) Entrada $\left\|i_{\bar{a}}^{q^{\prime \prime}}(t)\right\|^{\min } ;$ (c) Entrada $\left\|v_{\bar{a}}^{q^{\prime \prime}}(t)\right\|^{\min } ;$ (d) Entrada $\left\|v_{\bar{c}}^{q^{\prime \prime}}(t)\right\|^{\text {min }}$.
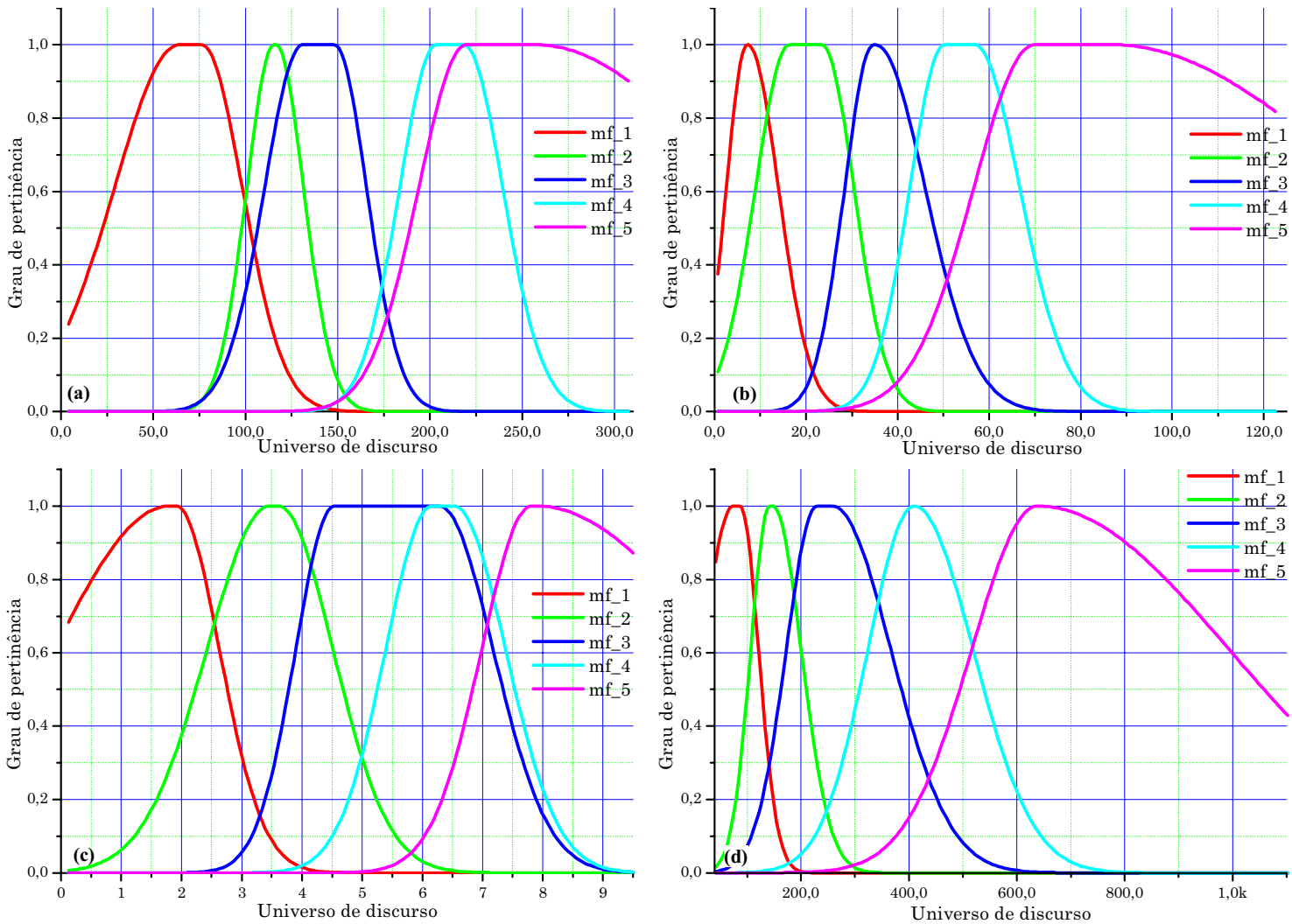

Figura 6.74 - Funções de pertinência ajustadas para as quatro primeiras entradas; (a) Entrada $\left\|v_{c}^{q^{\|}}(t)\right\|^{\min }$; (b) Entrada $\overline{\left\|v_{\bar{b}}^{q^{\perp}}(t)\right\|}$; (c) Entrada $\left\|i_{c}^{q^{\|}}(t)\right\|^{\min }$; (d) Entrada $\left\|v_{\bar{a}}^{d}(t)\right\|^{\min }$. 
A etapa de ajuste paramétrico não apenas sintoniza as funções de pertinência do espaço das entradas como também ajusta as funções de pertinência da saída. Assim, por meio da Figura 6.75 apresentam-se as funções de pertinência da saída, que nesse caso representa o logaritmo base 10 para a resistência falta.

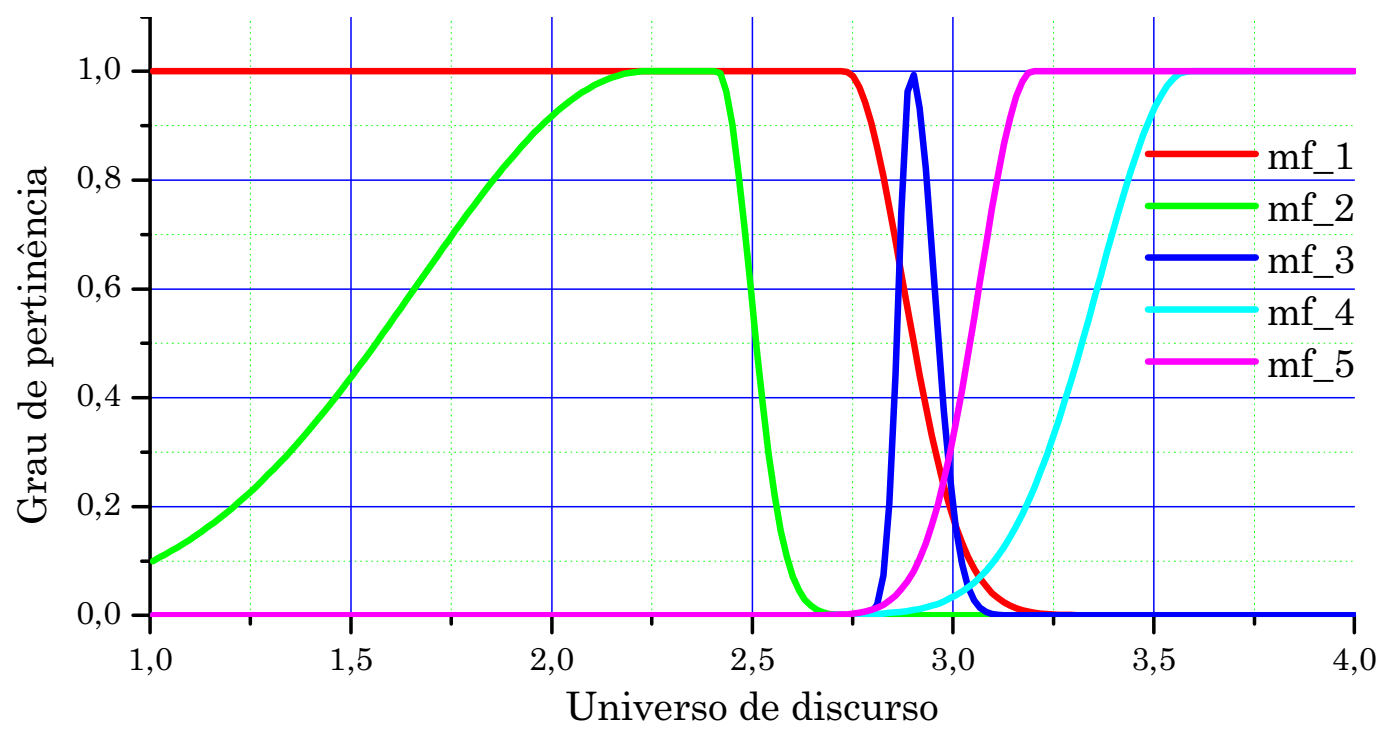

Figura 6.75 - Funções de pertinência associadas à resistência de falta na Fase B.

Findando a apresentação do sistema fuzzy dedicado à estimação da resistência de falta quando de sua ocorrência na Fase B, tem-se na Figura 6.76 a maneira pela qual as regras fuzzy, destacadas na sua forma verbal por meio da Figura 6.71, foram ponderadas pela etapa de ajuste paramétrico.

O sistema fuzzy ajustado para fins de estimação da resistência de falta fora ajustado, tanto estrutural como parametricamente, tendo como base os resultados providos por um conjunto de 999 simulações de faltas ocorridas na Fase B. Tais simulações computacionais, apresentadas em detalhes no Capítulo 5, possuíram como variáveis independentes a distância de ocorrência da falta, a resistência de falta, o instante inicial da falta e a duração da mesma. Assim, após o processo de ajuste é primordial a verificação da eficácia do sistema no desempenho da tarefa de estimação da resistência de falta.

Para tanto, o sistema fuzzy fora, inicialmente, testado com os dados advindos das simulações empregadas na constituição do conjunto de ajuste do mesmo. Apresentando como o erro relativo se porta para a estimação da resistência da falta, tem-se o gráfico da Figura 6.77, onde se destaca o histograma do referido erro. 


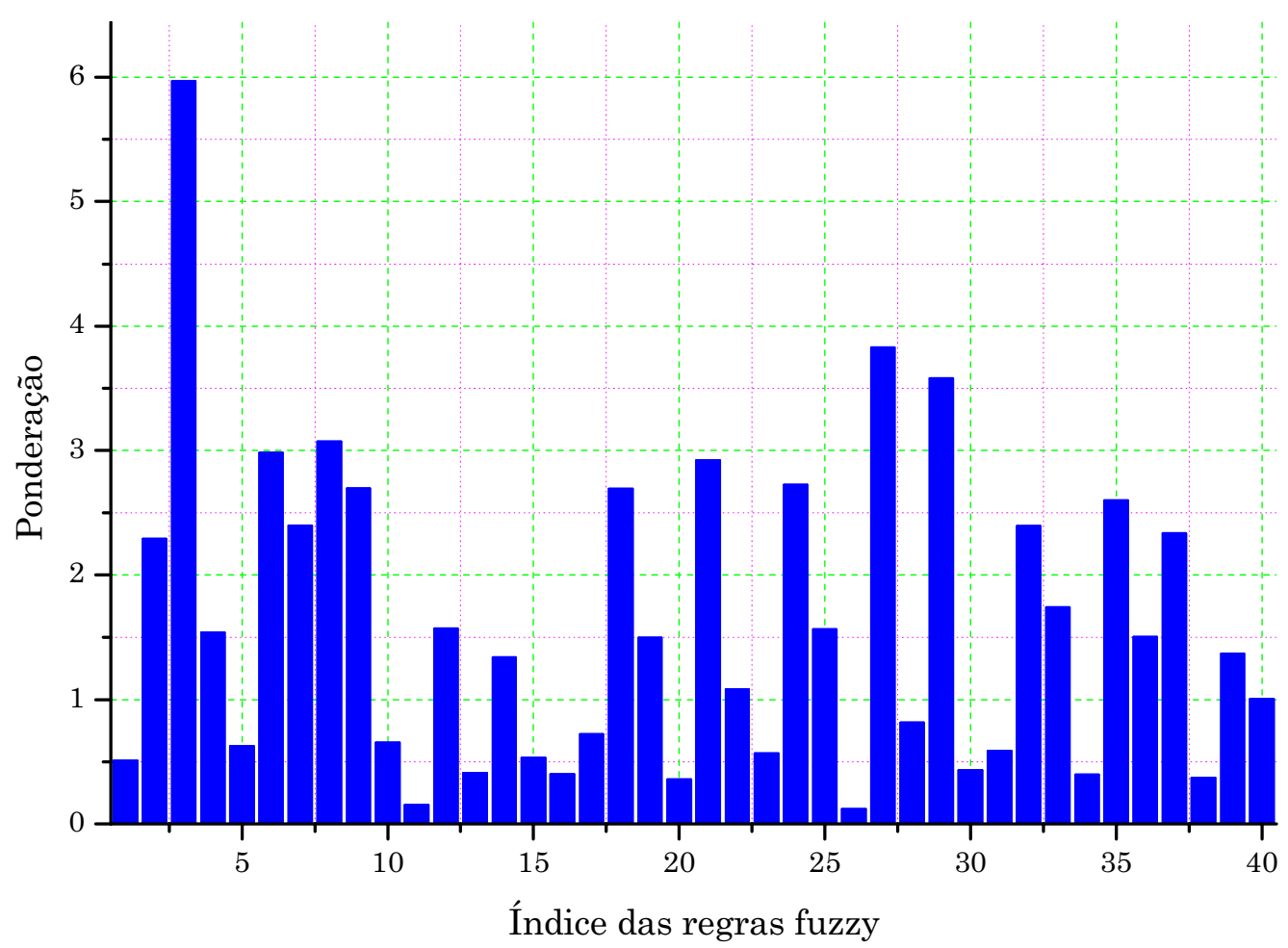

Figura 6.76 - Ponderação das regras fuzzy do sistema de inferência fuzzy dedicado à estimação da resistência de falta na Fase B.

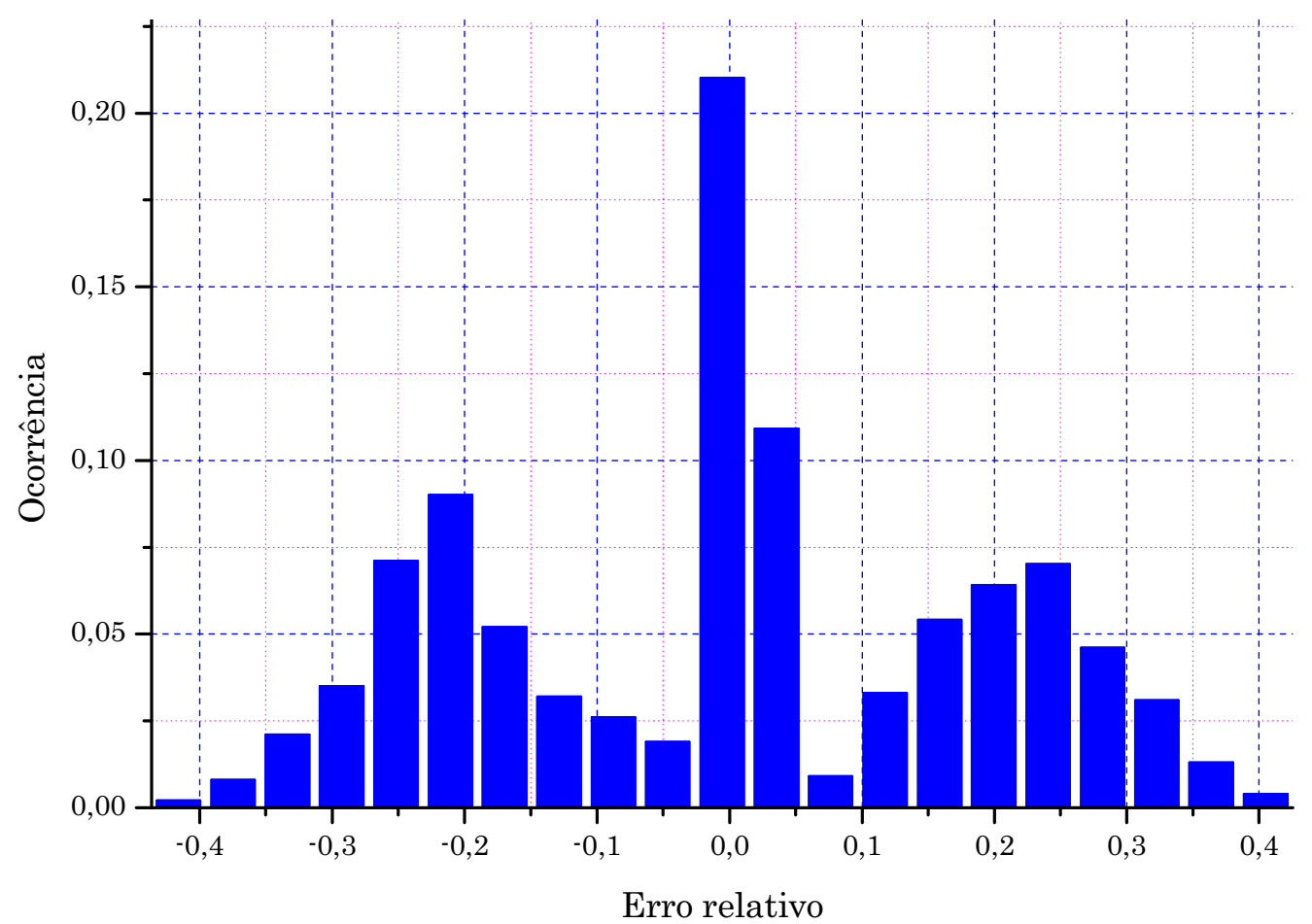

Figura 6.77 - Histograma do erro relativo de estimação da resistência de falta na Fase B.

Por meio do gráfico apresentado na Figura 6.77 é possível verificar que a distribuição probabilística do erro não segue uma distribuição normal nem mesmo alguma outra forma de distribuição usual. No entanto, dessa distribuição é possível obter seu respectivo valor médio o qual é de $-0,0018$. 
Apesar da distribuição probabilidade não ser caracterizada por meio de alguma distribuição convencional, apresenta-se na Figura 6.78 a função densidade probabilidade para o erro relativo na qual é possível constatar que, com uma confiabilidade de $90 \%$, o erro relativo se encontra entre $-0,31$ e 0,28 .

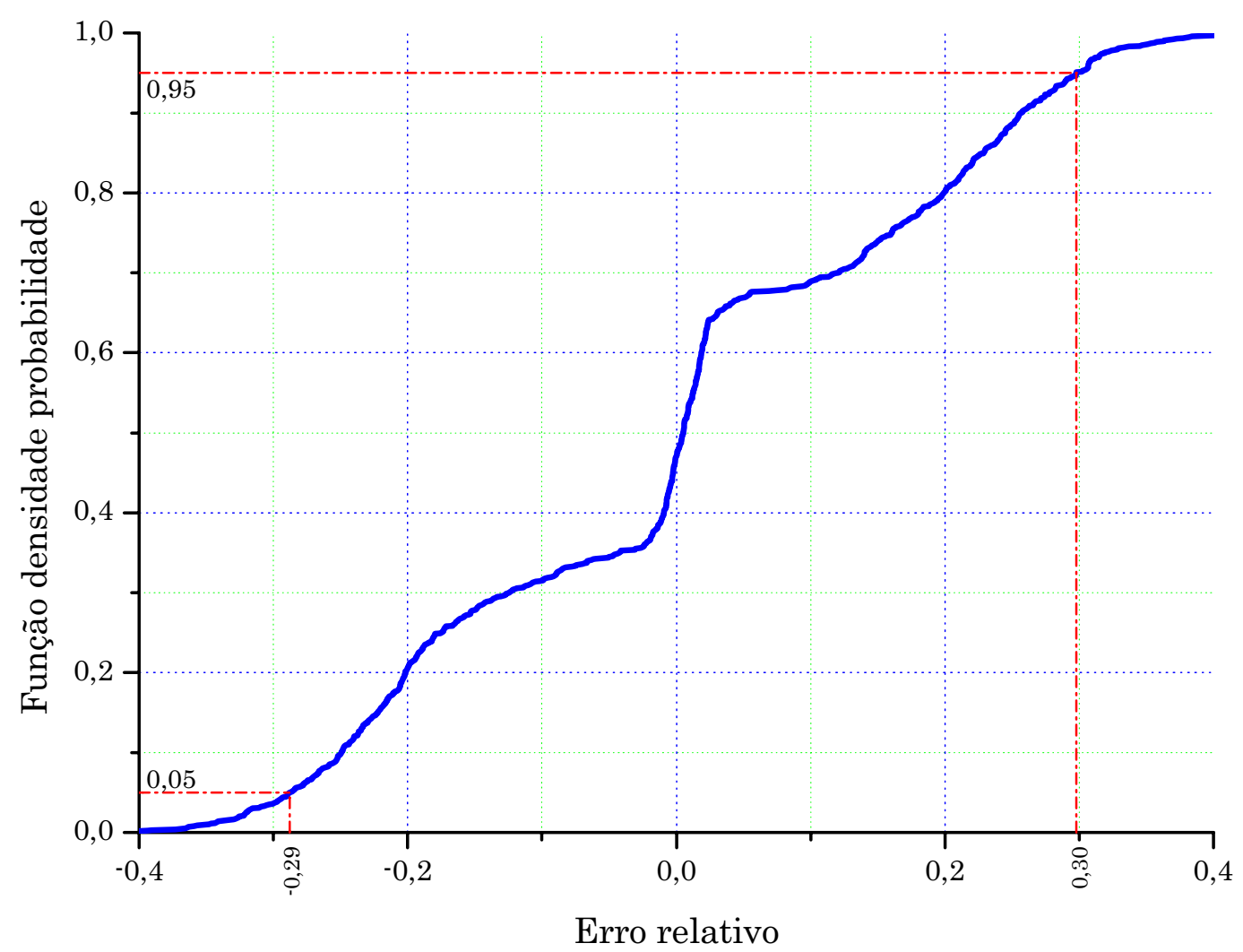

Figura 6.78 - Função densidade probabilidade para o erro relativo de estimação da resistência de falta na Fase B.

Complementando a análise do erro relativo de estimação da resistência de falta, apresenta-se na Tabela 6.30 a correlação entre o erro relativo e as variáveis independentes das simulações computacionais, ou seja, a correlação entre o erro relativo e a resistência de falta, o ângulo de falta e a duração da falta.

Tabela 6.30 - Correlação entre o erro relativo e as variáveis independentes das simulações computacionais.

\begin{tabular}{lr}
\hline \hline $\begin{array}{l}\text { Variável independente da } \\
\text { simulação }\end{array}$ & $\begin{array}{l}\text { Correlação com erro } \\
\text { relativo de estimação }\end{array}$ \\
\hline \hline Distância de ocorrência da falta & 0.0739 \\
\hline Resistência de falta & 0.7269 \\
\hline Ângulo da falta & 0.0056 \\
\hline Duração da falta & 0.0432 \\
\hline \hline
\end{tabular}


Por meio da Tabela 6.30 é possível verificar a forte dependência do erro relativo com a resistência de falta, ou seja, com a própria variável de estimação. Ainda, verifica-se correlação do erro com a distância de ocorrência da falta e com a duração da falta, sendo que a correlação existente entre o erro e o ângulo de falta é ínfima. A fim de ilustrar a forte correlação do erro de estimação da resistência de falta se apresenta o gráfico da Figura 6.79.

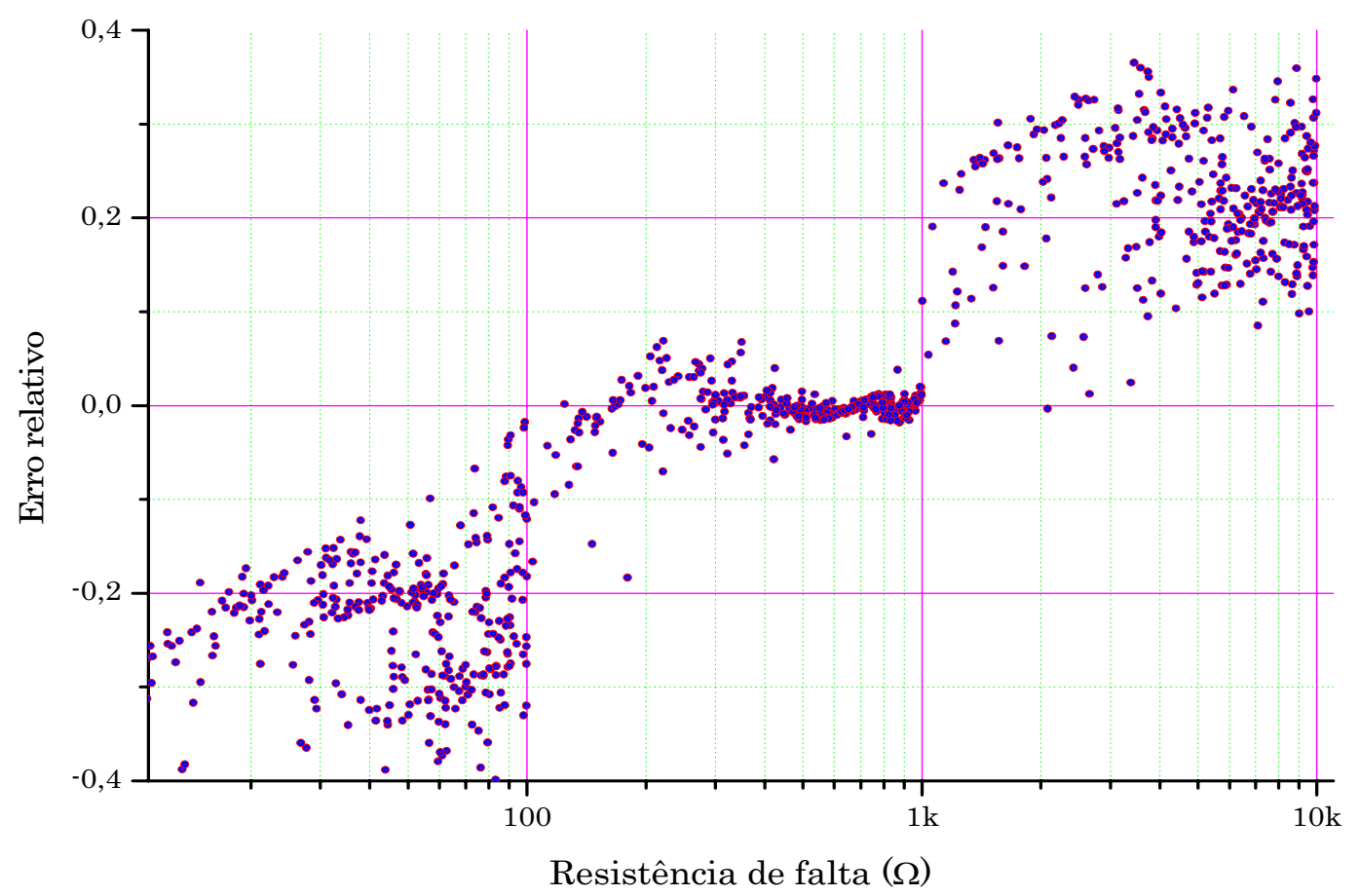

Figura 6.79 - Relacionamento entre o erro relativo e a resistência de falta.

Verifica-se pelo gráfico da Figura 6.79 a tendência tanto do máximo erro como do mínimo erro aumentarem com o incremento da resistência de falta da falta. Ainda, é possível constatar que o erro de estimação da resistência de falta se concentra melhor em torno do zero para resistências de falta entre 100 e $1 \mathrm{k} \Omega$.

O sistema fuzzy dedicado à estimação da resistência de falta além ser testado com os dados provenientes do conjunto de ajuste, fora também testado com dados advindos de simulações computacionais não contidos no conjunto de ajuste. Assim, um total de 269 situações de falta na Fase B foram simuladas e os resultados dessas simulações foram submetidos à técnica de decomposição em componentes ortogonais. De posse dos valores eficazes das componentes ortogonais, as variáveis mais correlatas à estimação da resistência de falta na Fase B, apresentadas na Tabela 6.29, foram selecionadas e apresentadas ao sistema fuzzy previamente ajustado. Os resultados obtidos para a estimação da resistência de faltas quando de sua ocorrência na Fase B são apresentados por meio da Figura 6.80 na forma de histograma do erro relativo. 


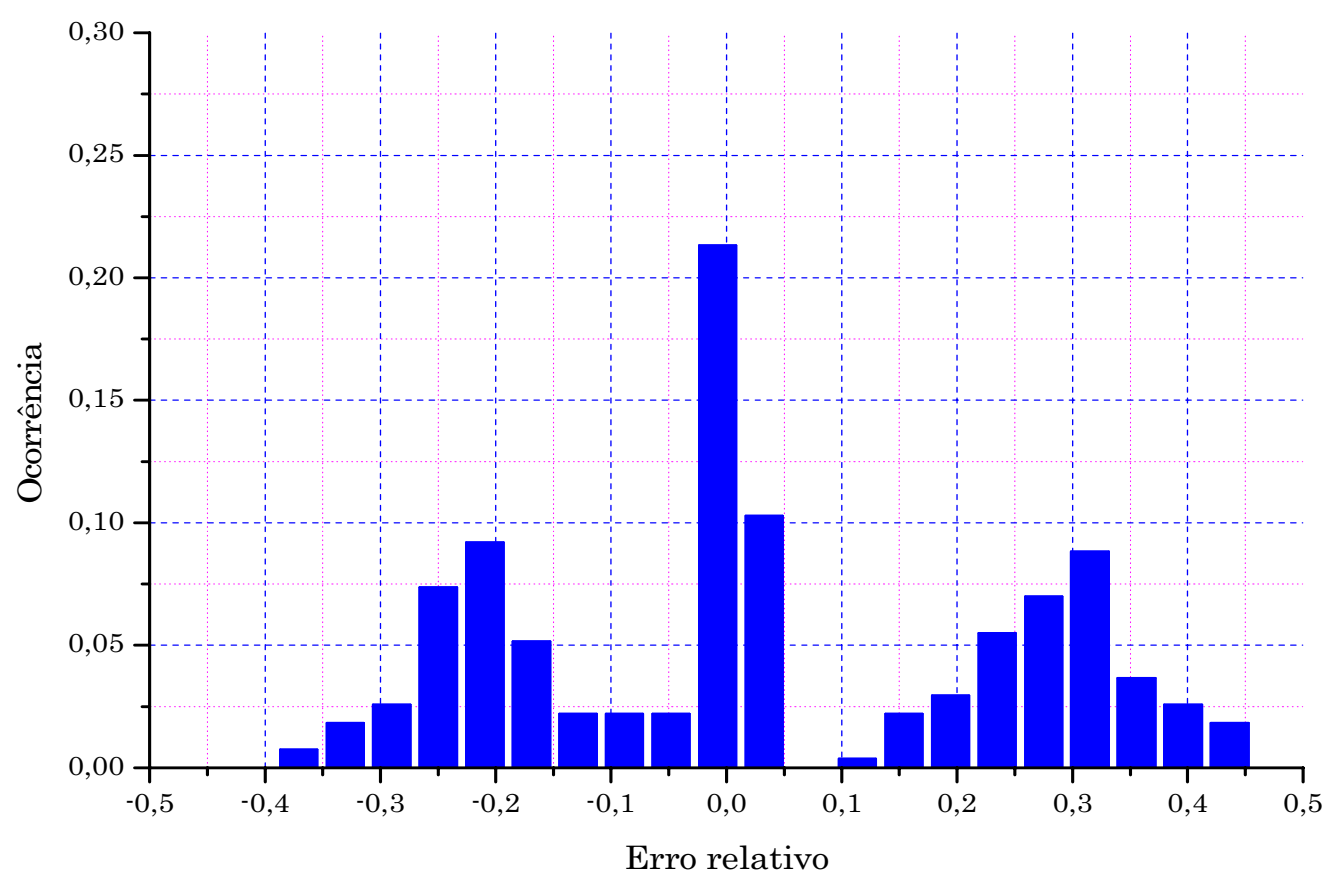

Figura 6.80 - Histograma do erro relativo de estimação da resistência de falta na Fase B para os dados do conjunto de teste.

Com o objetivo de ilustrar como a distribuição estatística do erro relativo para os dados de ajuste é semelhante à distribuição do erro verificado para os dados de teste, apresenta-se a Figura 6.81, onde ambas as funções densidade acumulada são confrontadas para propósitos comparativos.

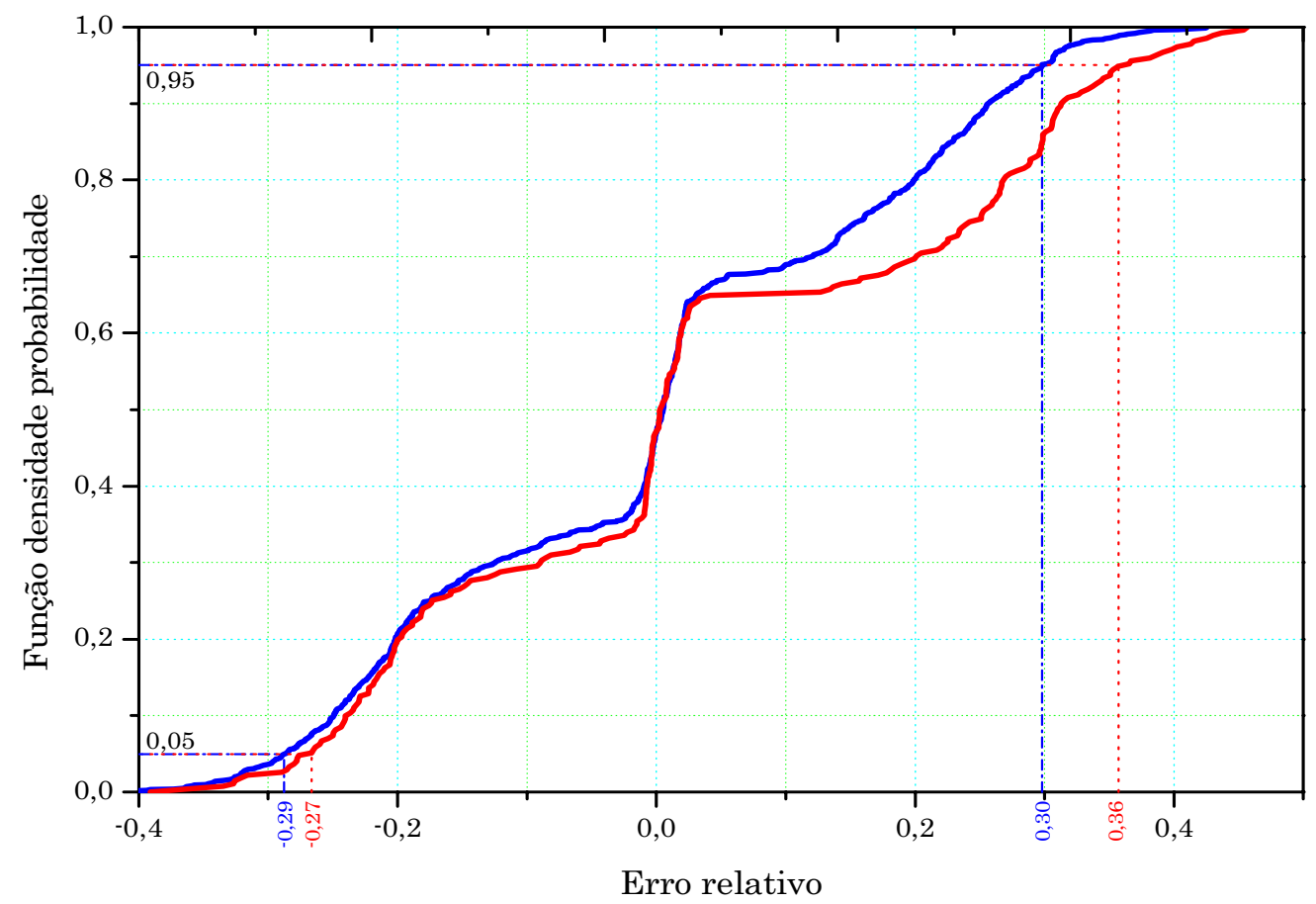

Figura 6.81 - Distribuição normal para o conjunto de ajuste e para o conjunto de teste quando da estimação da resistência de falta na Fase B. 
Por meio da Figura 6.81 é possível verificar que a distribuição normal verificada para os dados de teste é semelhante com aquela verificada quando da modelagem do erro observado para os dados de ajuste. Ainda, por meio da avaliação dos dados de teste, verificouse que cerca de $81,62 \%$ dos mesmos se enquadrou dentro do intervalo de confiança de $90 \%$ calculado sobre os dados de treinamento.

\subsubsection{SISTEMA DE INFERÊNCIA FUZZY PARA ESTIMAÇÃO DA RESISTÊNCIA DE FALTA NA FASE C}

Na Subseção 6.3.2 a estimação da resistência de falta fora realizada para quando da ocorrência de faltas na Fase A. Para a referida estimação, primeiramente, as variáveis empregadas para tal finalidade foram eleitas considerando-se aquelas com maior correlação com a variável de estimação, ou seja, com a resistência de falta. Após a eleição das variáveis mais correlatas, ajustou-se estruturalmente e parametricamente o sistema fuzzy responsável pela estimação da resistência de falta quando a mesma ocorrer na Fase A. A análise dos resultados obtidos tanto para o conjunto de ajuste como para o conjunto de teste retratam que o algoritmo de ajuste proposto fora eficiente no mapeamento almejado. Dessa maneira, a mesma metodologia será empregada na implementação do sistema fuzzy responsável pela estimação da resistência de falta na Fase C.

Assim, para apresentar como cada componente advindo do resultado da decomposição ortogonal se correlaciona com a resistência de falta, apresentam-se por meio da Tabela 6.31 as correlações e os testes de hipótese, que mensura o quão significativo é a correlação, das componentes de tensões contidas na função planar das tensões de linha com a resistência de falta quando essa for observada na Fase C. Os valores contidos na Tabela 6.31 são graficamente apresentados por meio da Figura 6.82.

Por meio da Tabela 6.32 se apresentam as correlações das componentes de corrente contidas na função planar das tensões de linha com a resistência de falta, assim como por meio da Figura 6.83 se tem a representação gráfica dos valores contidos nessa tabela.

A correlação das componentes de tensão ortogonais à função planar das tensões de linha com a resistência de falta é apresentada na Tabela 6.33 e tais valores para as componentes de corrente ortogonais à função planar das tensões de linha são conteúdo da Tabela 6.34. A representação dos valores expressos na Tabela 6.33 e Tabela 6.34 é realizada por meio da Figura 6.84 e da Figura 6.85, respectivamente. 
Tabela 6.31 - Correlação das componentes de tensão contidas na função planar das tensões de linha com relação à resistência de falta na Fase C.

\begin{tabular}{|c|c|c|c|c|c|c|c|}
\hline \multirow[b]{2}{*}{$k$} & \multirow[b]{2}{*}{ Variável } & \multicolumn{2}{|c|}{ Média } & \multicolumn{2}{|c|}{ Máximo } & \multicolumn{2}{|c|}{ Mínimo } \\
\hline & & Correlação & $\begin{array}{l}\text { Teste de } \\
\text { hipótese } \\
\end{array}$ & Correlação & $\begin{array}{l}\text { Teste de } \\
\text { hipótese }\end{array}$ & Correlação & $\begin{array}{l}\text { Teste de } \\
\text { hipótese }\end{array}$ \\
\hline 1 & $\left\|v_{a}^{p}(t)\right\|$ & 0,0371 & 0,2345 & 0,0336 & 0,2828 & 0,0242 & 0,4381 \\
\hline 2 & $\left\|v_{b}^{p}(t)\right\|$ & 0,0019 & 0,9517 & 0,0017 & 0,9555 & 0,0127 & 0,6850 \\
\hline 3 & $\left\|v_{c}^{p}(t)\right\|$ & 0,0089 & 0,7746 & 0,0828 & 0,0079 & 0,0154 & 0,6232 \\
\hline 4 & $\left\|v_{n}^{p}(t)\right\|$ & 0,0133 & 0,6715 & 0,0137 & 0,6613 & 0,0281 & 0,3691 \\
\hline 5 & $\left\|v_{a}^{q^{\|}}(t)\right\|$ & 0,0669 & 0,0321 & 0,1153 & 0,0002 & 0,1544 & 0,0000 \\
\hline 6 & $\left\|v_{b}^{q^{\|}}(t)\right\|$ & 0,0201 & 0,5202 & 0,0192 & 0,5388 & 0,0446 & 0,1536 \\
\hline 7 & $\left\|v_{c}^{q^{\| \prime}}(t)\right\|$ & 0,0301 & 0,3352 & 0,0361 & 0,2482 & 0,0815 & 0,0090 \\
\hline 8 & $\left\|v_{n}^{q^{\prime \prime}}(t)\right\|$ & 0,0183 & 0,5587 & 0,0292 & 0,3500 & 0,0060 & 0,8467 \\
\hline 9 & $\left\|v_{a}^{q^{\perp}}(t)\right\|$ & 0,0331 & 0,2900 & 0,0504 & 0,1064 & 0,0141 & 0,6512 \\
\hline 10 & $\left\|v_{b}^{q^{\perp}}(t)\right\|$ & 0,0822 & 0,0084 & 0,0812 & 0,0092 & 0,0107 & 0,7322 \\
\hline 11 & $\left\|v_{c}^{q^{\perp}}(t)\right\|$ & 0,0569 & 0,0686 & 0,0731 & 0,0191 & 0,0396 & 0,2054 \\
\hline 12 & $\left\|v_{n}^{q^{\perp}}(t)\right\|$ & 0,0232 & 0,4575 & 0,0165 & 0,5984 & 0,0071 & 0,8212 \\
\hline 13 & $\left\|v_{a}^{d}(t)\right\|$ & 0,0331 & 0,2901 & 0,0504 & 0,1064 & 0,0128 & 0,6817 \\
\hline 14 & $\left\|v_{b}^{d}(t)\right\|$ & 0,0823 & 0,0084 & 0,0812 & 0,0092 & 0,0119 & 0,7044 \\
\hline 15 & $\left\|v_{c}^{d}(t)\right\|$ & 0,0569 & 0,0686 & 0,0731 & 0,0191 & 0,0427 & 0,1722 \\
\hline 16 & $\left\|v_{n}^{d}(t)\right\|$ & 0,0232 & 0,4575 & 0,0165 & 0,5983 & 0,0023 & 0,9424 \\
\hline
\end{tabular}
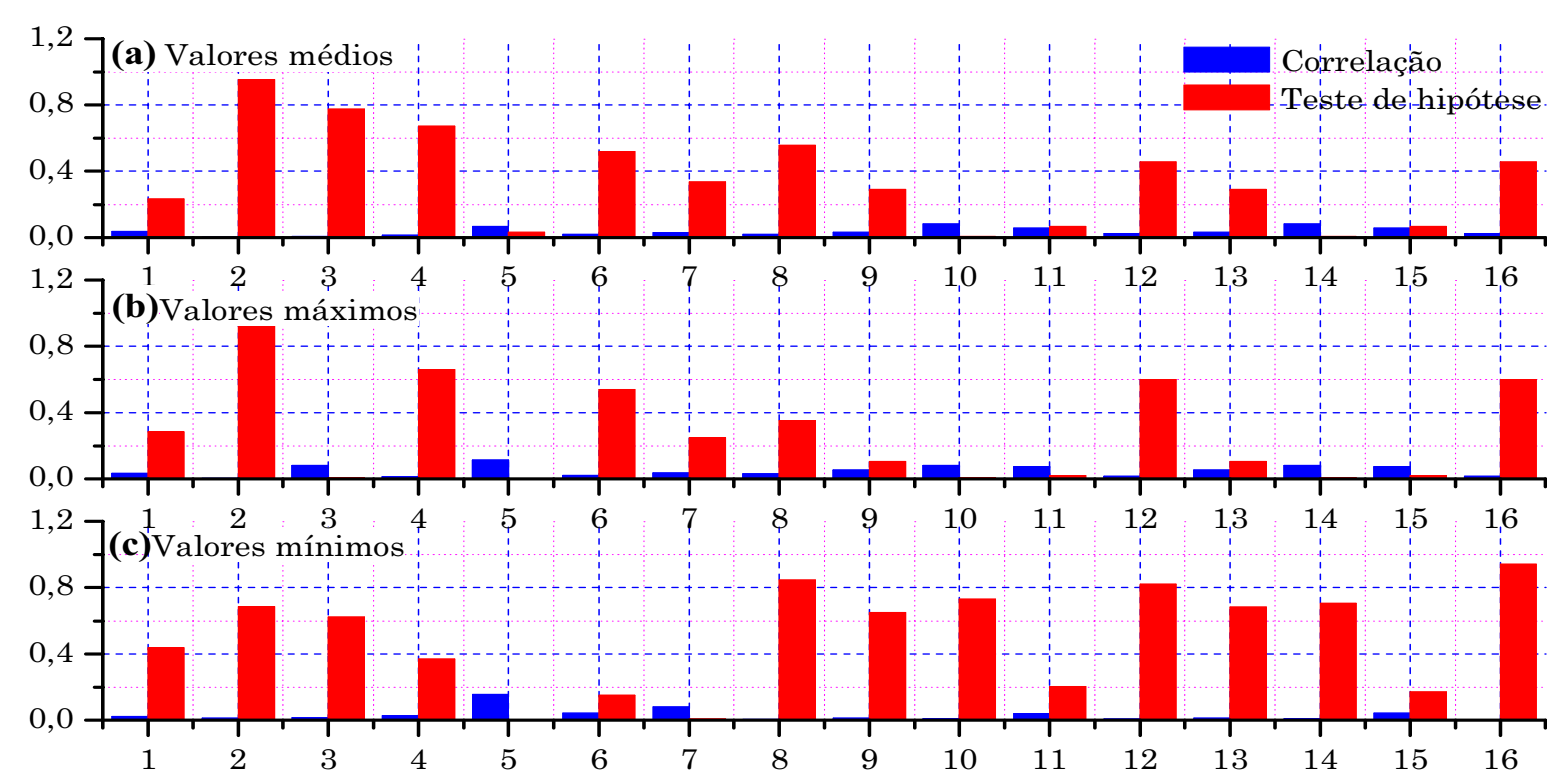

Variável (índice)

Figura 6.82 - Correlação e teste de hipótese para as componentes de tensão contidas na função planar das tensões de linha com a resistência de falta na Fase C; (a) Correlação e teste de hipótese para os valores médios; (b) Correlação e teste de hipótese para os valores máximos; (c) Correlação e teste de hipótese para os valores mínimos. 
Tabela 6.32 - Correlação das componentes de corrente contidas na função planar das tensões de linha com relação à resistência de falta na Fase C.

\begin{tabular}{|c|c|c|c|c|c|c|c|}
\hline \multirow[b]{2}{*}{$k$} & \multirow[b]{2}{*}{ Variável } & \multicolumn{2}{|c|}{ Média } & \multicolumn{2}{|c|}{ Máximo } & \multicolumn{2}{|c|}{ Mínimo } \\
\hline & & Correlação & $\begin{array}{l}\text { Teste de } \\
\text { hipótese } \\
\end{array}$ & Correlação & $\begin{array}{l}\text { Teste de } \\
\text { hipótese } \\
\end{array}$ & Correlação & $\begin{array}{l}\text { Teste de } \\
\text { hipótese }\end{array}$ \\
\hline 1 & $\left\|i_{a}^{p}(t)\right\|$ & 0,0108 & 0,7295 & 0,0196 & 0,5310 & 0,0188 & 0,5485 \\
\hline 2 & $\left\|i_{b}^{p}(t)\right\|$ & 0,0042 & 0,8920 & 0,0121 & 0,6992 & 0,0115 & 0,7126 \\
\hline 3 & $\left\|i_{c}^{p}(t)\right\|$ & 0,0135 & 0,6668 & 0,0227 & 0,4678 & 0,0267 & 0,3928 \\
\hline 4 & $\left\|i_{n}^{p}(t)\right\|$ & 0,0132 & 0,6728 & 0,0060 & 0,8478 & 0,0274 & 0,3809 \\
\hline 5 & $\left\|i_{a}^{q^{\|}}(t)\right\|$ & 0,0424 & 0,1752 & 0,0341 & 0,2756 & 0,1299 & 0,0000 \\
\hline 6 & $\left\|i_{b}^{q^{\| \prime}}(t)\right\|$ & 0,0460 & 0,1409 & 0,0446 & 0,1532 & 0,0651 & 0,0371 \\
\hline 7 & $\left\|i_{c}^{q^{\|}}(t)\right\|$ & 0,0651 & 0,0370 & 0,0411 & 0,1881 & 0,0639 & 0,0408 \\
\hline 8 & $\left\|i_{n}^{q^{\|}}(t)\right\|$ & 0,0176 & 0,5725 & 0,0281 & 0,3686 & 0,0236 & 0,4498 \\
\hline 9 & $\left\|i_{a}^{q^{\perp}}(t)\right\|$ & 0,0221 & 0,4803 & 0,0128 & 0,6826 & 0,0131 & 0,6743 \\
\hline 10 & $\left\|i_{b}^{q^{\perp}}(t)\right\|$ & 0,0111 & 0,7214 & 0,0039 & 0,9007 & 0,0000 & 1,0000 \\
\hline 11 & $\left\|i_{c}^{q^{\perp}}(t)\right\|$ & 0,0485 & 0,1208 & 0,0402 & 0,1981 & 0,0000 & 1,0000 \\
\hline 12 & $\left\|i_{n}^{q^{\perp}}(t)\right\|$ & 0,0530 & 0,0897 & 0,0585 & 0,0610 & 0,0021 & 0,9473 \\
\hline 13 & $\left\|i_{a}^{d}(t)\right\|$ & 0,0220 & 0,4808 & 0,0128 & 0,6826 & 0,0142 & 0,6507 \\
\hline 14 & $\left\|i_{b}^{d}(t)\right\|$ & 0,0044 & 0,8881 & 0,0115 & 0,7138 & 0,0000 & 1,0000 \\
\hline 15 & $\left\|i_{c}^{d}(t)\right\|$ & 0,0085 & 0,7853 & 0,0243 & 0,4375 & 0,0000 & 1,0000 \\
\hline 16 & $\left\|i_{n}^{d}(t)\right\|$ & 0,0530 & 0,0897 & 0,0585 & 0,0610 & 0,0020 & 0,9483 \\
\hline
\end{tabular}
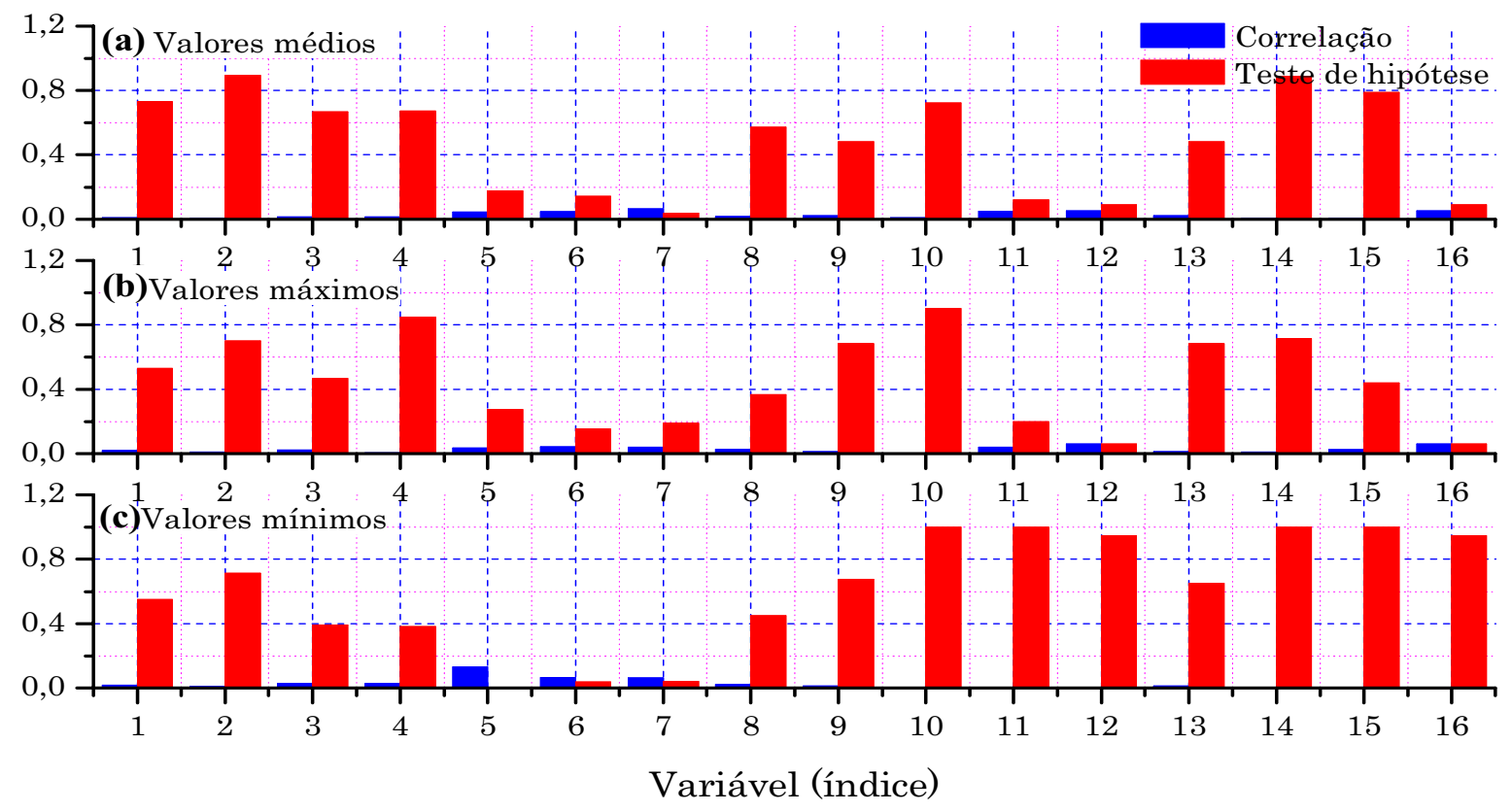

Figura 6.83 - Correlação e teste de hipótese para as componentes de corrente contidas na função planar das tensões de linha com a resistência de falta na Fase C; (a) Correlação e teste de hipótese para os valores médios; (b) Correlação e teste de hipótese para os valores máximos; (c) Correlação e teste de hipótese para os valores mínimos. 
Tabela 6.33 - Correlação das componentes de tensão ortogonais à função planar das tensões de linha com relação à resistência de falta na Fase C.

\begin{tabular}{|c|c|c|c|c|c|c|c|}
\hline \multirow[b]{2}{*}{$k$} & \multirow[b]{2}{*}{ Variável } & \multicolumn{2}{|c|}{ Média } & \multicolumn{2}{|c|}{ Máximo } & \multicolumn{2}{|c|}{ Mínimo } \\
\hline & & Correlação & $\begin{array}{l}\text { Teste de } \\
\text { hipótese } \\
\end{array}$ & Correlação & $\begin{array}{l}\text { Teste de } \\
\text { hipótese } \\
\end{array}$ & Correlação & $\begin{array}{l}\text { Teste de } \\
\text { hipótese }\end{array}$ \\
\hline 1 & $\left\|v_{\bar{a}}^{p}(t)\right\|$ & 0,0059 & 0,8502 & 0,0044 & 0,8875 & 0,0225 & 0,4718 \\
\hline 2 & $\left\|v v_{\bar{b}}^{p}(t)\right\|$ & 0,0099 & 0,7516 & 0,0096 & 0,7585 & 0,0102 & 0,7453 \\
\hline 3 & $\left\|v_{\bar{c}}^{p}(t)\right\|$ & 0,0148 & 0,6362 & 0,0060 & 0,8476 & 0,0166 & 0,5960 \\
\hline 4 & $\left\|v_{h}^{p}(t)\right\|$ & 0,0135 & 0,6656 & 0,0129 & 0,6803 & 0,0283 & 0,3658 \\
\hline 5 & $\left\|v_{\bar{a}}^{q^{\|}}(t)\right\|$ & 0,0313 & 0,3172 & 0,0068 & 0,8271 & 0,0696 & 0,0258 \\
\hline 6 & $\left\|v q^{q^{\prime \prime}}(t)\right\|$ & 0,0385 & 0,2177 & 0,0376 & 0,2285 & 0,1491 & 0,0000 \\
\hline 7 & $\left\|v_{\bar{c}}^{q^{\prime \prime}}(t)\right\|$ & 0,0688 & 0,0275 & 0,0196 & 0,5312 & 0,3481 & 0,0000 \\
\hline 8 & $\left\|v_{h}^{q^{\prime \prime}}(t)\right\|$ & 0,0273 & 0,3821 & 0,0289 & 0,3559 & 0,0261 & 0,4039 \\
\hline 9 & $\left\|v_{\bar{a}}^{q^{\perp}}(t)\right\|$ & 0,0016 & 0,9593 & 0,0138 & 0,6588 & 0,0470 & 0,1323 \\
\hline 10 & $\left\|v_{\frac{q^{\perp}}{b}}(t)\right\|$ & 0,0631 & 0,0433 & 0,0432 & 0,1670 & 0,0000 & 1,0000 \\
\hline 11 & $\left\|v_{\frac{q^{\perp}}{c}}(t)\right\|$ & 0,0810 & 0,0094 & 0,0127 & 0,6835 & 0,0000 & 1,0000 \\
\hline 12 & $\left\|v_{h}^{q^{\perp}}(t)\right\|$ & 0,0502 & 0,1077 & 0,0365 & 0,2432 & 0,0094 & 0,7625 \\
\hline 13 & $\left\|v_{\bar{a}}^{d}(t)\right\|$ & 0,0016 & 0,9593 & 0,0138 & 0,6588 & 0,0383 & 0,2206 \\
\hline 14 & $\left\|v_{\bar{b}}^{d}(t)\right\|$ & 0,0211 & 0,4989 & 0,0027 & 0,9309 & 0,0432 & 0,1664 \\
\hline 15 & $\left\|v_{\bar{c}}^{d}(t)\right\|$ & 0,0142 & 0,6486 & 0,0244 & 0,4351 & 0,0518 & 0,0971 \\
\hline 16 & $\left\|v_{h}^{d}(t)\right\|$ & 0,0502 & 0,1077 & 0,0365 & 0,2432 & 0,0089 & 0,7752 \\
\hline
\end{tabular}
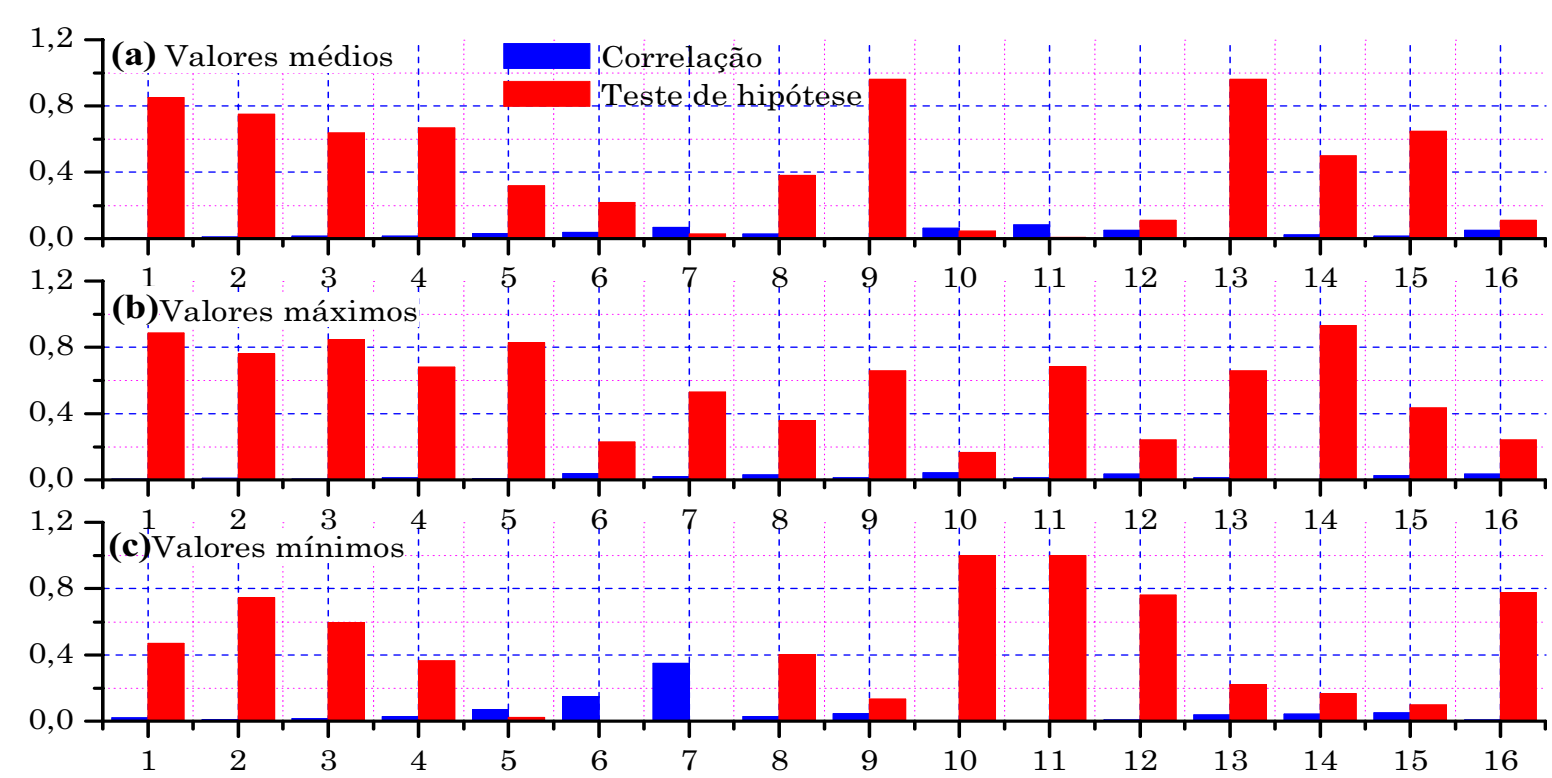

Variável (índice)

Figura 6.84 - Correlação e teste de hipótese para as componentes de tensão ortogonais à função planar das tensões de linha com a resistência de falta na Fase C; (a) Correlação e teste de hipótese para os valores médios; (b) Correlação e teste de hipótese para os valores máximos; (c) Correlação e teste de hipótese para os valores mínimos. 
Tabela 6.34 - Correlação das componentes de corrente ortogonais à função planar das tensões de linha com relação à resistência de falta na Fase C.

\begin{tabular}{|c|c|c|c|c|c|c|c|}
\hline \multirow[b]{2}{*}{$k$} & \multirow[b]{2}{*}{ Variável } & \multicolumn{2}{|c|}{ Média } & \multicolumn{2}{|c|}{ Máximo } & \multicolumn{2}{|c|}{ Mínimo } \\
\hline & & Correlação & $\begin{array}{l}\text { Teste de } \\
\text { hipótese }\end{array}$ & Correlação & $\begin{array}{l}\text { Teste de } \\
\text { hipótese }\end{array}$ & Correlação & $\begin{array}{l}\text { Teste de } \\
\text { hipótese }\end{array}$ \\
\hline 1 & $\left\|i_{\bar{a}}^{p}(t)\right\|$ & 0,0066 & 0,8324 & 0,0060 & 0,8486 & 0,0130 & 0,6783 \\
\hline 2 & $\left\|i \frac{p}{b}(t)\right\|$ & 0,0092 & 0,7674 & 0,0061 & 0,8457 & 0,0093 & 0,7649 \\
\hline 3 & $\left\|i_{\bar{c}}^{p}(t)\right\|$ & 0,0133 & 0,6715 & 0,0237 & 0,4490 & 0,0049 & 0,8767 \\
\hline 4 & $\left\|i_{h}^{p}(t)\right\|$ & 0,0131 & 0,6749 & 0,0136 & 0,6633 & 0,0123 & 0,6928 \\
\hline 5 & $\left\|i_{\bar{a}}^{q^{\prime \prime}}(t)\right\|$ & 0,0360 & 0,2494 & 0,0039 & 0,9001 & 0,1316 & 0,0000 \\
\hline 6 & $\left\|i_{\frac{q^{\prime \prime}}{b}}(t)\right\|$ & 0,0678 & 0,0299 & 0,0610 & 0,0507 & 0,2272 & 0,0000 \\
\hline 7 & $\left\|i_{c}^{q^{\prime \prime}}(t)\right\|$ & 0,0660 & 0,0345 & 0,0650 & 0,0374 & 0,1445 & 0,0000 \\
\hline 8 & $\left\|i_{h}^{q^{\| \prime}}(t)\right\|$ & 0,0041 & 0,8963 & 0,0014 & 0,9631 & 0,0285 & 0,3623 \\
\hline 9 & $\left\|i_{\bar{a}}^{q^{\perp}}(t)\right\|$ & 0,0226 & 0,4703 & 0,0222 & 0,4783 & 0,0215 & 0,4911 \\
\hline 10 & $\left\|i \frac{q^{\perp}}{b}(t)\right\|$ & 0,0105 & 0,7374 & 0,0092 & 0,7697 & 0,0200 & 0,5222 \\
\hline 11 & $\left\|i_{c}^{q^{\perp}}(t)\right\|$ & 0,0664 & 0,0335 & 0,0233 & 0,4561 & 0,0000 & 1,0000 \\
\hline 12 & $\left\|i_{h}^{q^{\perp}}(t)\right\|$ & 0,1189 & 0,0001 & 0,1268 & 0,0000 & 0,0037 & 0,9049 \\
\hline 13 & $\left\|i_{\bar{a}}^{d}(t)\right\|$ & 0,0226 & 0,4699 & 0,0222 & 0,4780 & 0,0124 & 0,6920 \\
\hline 14 & $\left\|i_{\bar{b}}^{d}(t)\right\|$ & 0,0105 & 0,7374 & 0,0092 & 0,7697 & 0,0170 & 0,5874 \\
\hline 15 & $\left\|i_{\bar{c}}^{d}(t)\right\|$ & 0,0223 & 0,4753 & 0,0134 & 0,6683 & 0,0016 & 0,9581 \\
\hline & $\left\|i_{h}^{d}(t)\right\|$ & 0,1189 & 0,0001 & 0,1268 & 0,0000 & 0,0037 & 0,9050 \\
\hline
\end{tabular}
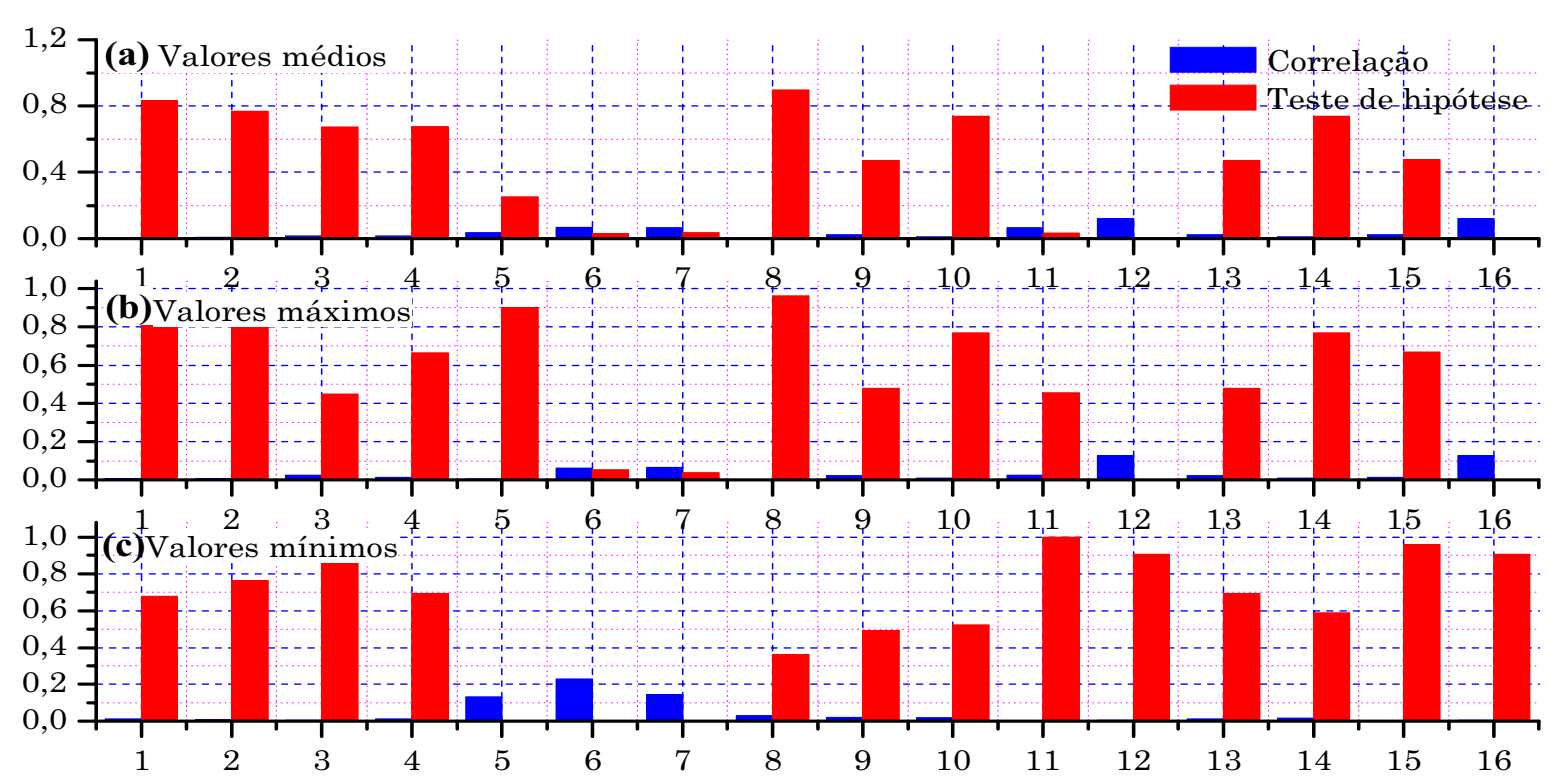

Variável (índice)

Figura 6.85 - Correlação e teste de hipótese para as componentes de corrente ortogonais à função planar das tensões de linha com a resistência de falta na Fase C; (a) Correlação e teste de hipótese para os valores médios; (b) Correlação e teste de hipótese para os valores máximos; (c) Correlação e teste de hipótese para os valores mínimos. 
Por meio dos valores de correlação apresentados nas tabelas anteriores é possível verificar que as oito variáveis mais correlacionadas com a resistência de falta na Fase C são aquelas destacadas na Tabela 6.35, a qual destaca também as referidas correlações.

Tabela 6.35 - Variáveis mais correlatas à estimação da resistência de falta na Fase C.

\begin{tabular}{ccccc}
\hline \hline Índice & Variável & Característica & Símbolo & Correlação \\
\hline \hline 1 & $\left\|v_{\bar{c}}^{q^{\prime \prime}}(t)\right\|$ & Mínimo & $\left\|v_{\bar{c}}^{q^{\prime \prime}}(t)\right\|^{\min }$ & 0,3481 \\
\hline 2 & $\left\|i_{\bar{b}}^{q^{\prime \prime}}(t)\right\|$ & Mínimo & $\left\|i_{\bar{b}}^{\|^{\prime}}(t)\right\|^{\min }$ & 0,2272 \\
\hline 3 & $\left\|v_{a}^{q^{\| \prime}}(t)\right\|$ & Mínimo & $\left\|v_{a}^{q^{\prime \prime}}(t)\right\|^{\min }$ & 0,1544 \\
\hline 4 & $\left\|v_{\bar{b}}^{q^{\prime \prime}}(t)\right\|$ & Mínimo & $\left\|v_{\bar{b}}^{q^{\prime \prime}}(t)\right\|^{\min }$ & 0,1491 \\
\hline 5 & $\left\|i_{\bar{c}}^{q^{\prime \prime}}(t)\right\|$ & Mínimo & $\left\|i_{\bar{c}}^{q^{\prime}}(t)\right\|^{\min }$ & 0,1445 \\
\hline 6 & $\left\|i_{\bar{a}}^{q^{\prime \prime}}(t)\right\|$ & Mínimo & $\left\|i_{\bar{a}}^{q^{\prime \prime}}(t)\right\|^{\min }$ & 0,1316 \\
\hline 8 & $\left\|i_{a}^{q^{\prime \prime}}(t)\right\|$ & Mínimo & $\left\|i_{a}^{i^{\prime \prime}}(t)\right\|^{\min }$ & 0,1299 \\
\hline \hline
\end{tabular}

As variáveis apresentadas na Tabela 6.35 representam as variáveis mais correlatas com a resistência de falta quando essa envolver a Fase C. Além de constituírem as variáveis mais correlatas, essas foram aquelas empregadas como entrada do sistema fuzzy responsável pela estimação da resistência de falta. O sistema fuzzy responsável pela estimação da resistência da falta fora constituído por 40 regras de inferência, número esse de regras que, durante os testes computacionais, se mostrou adequado na estimação da resistência.

O sistema fuzzy fora ajustado segundo o algoritmo delineado no Capítulo 4 e fazendo uso de um conjunto de ajuste constituído por 1026 pares entrada-saída. Todo o conjunto de ajuste fora construído se fazendo uso das simulações computacionais descritas no Capítulo 5 referentes às faltas fase-terra com participação da Fase C.

O algoritmo de ajuste delineado no Capítulo 4 é composto de duas etapas de ajuste. A primeira dessas etapas responde pelo ajuste estrutural do sistema fuzzy que, conforme abordado, é dedicado à extração das regras de inferência fuzzy que melhor correlacionam o espaço fuzzy das entradas com o espaço fuzzy da saída. Dessa forma, tem-se 
como produto da primeira etapa de ajuste a base de regra do sistema fuzzy que, nesse caso, será responsável pela estimação da resistência de falta quando a mesma envolver a Fase C.

A fim de apresentar como o erro quadrático médio do sistema fuzzy se portou ao longo das iterações do processo de ajuste estrutural, retrata-se à Figura 6.86, onde tal comportamento é ilustrado.

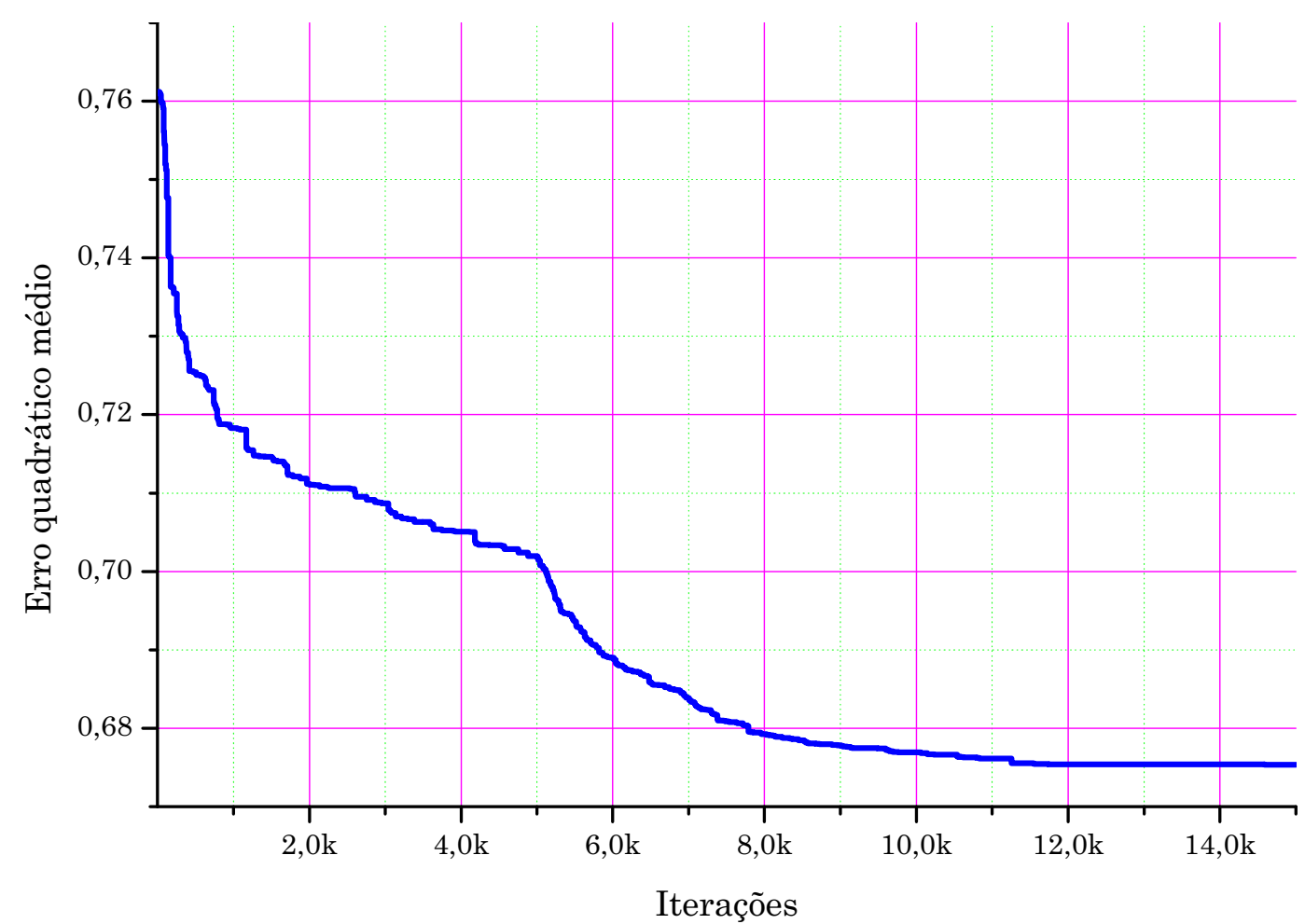

Figura 6.86 - Comportamento do erro quadrático médio do sistema fuzzy dedicado à estimação da resistência de falta quando essa envolver a Fase $\mathrm{C}$ ao longo das iterações da primeira etapa de ajuste.

O gráfico da Figura 6.86 apresenta a sensível redução do erro quadrático médio ao longo das iterações da primeira etapa de ajuste para o sistema fuzzy responsável pela estimação da resistência de falta fase-terra quando essa envolver a Fase C. Ao término dessa primeira etapa de ajuste, assim como anteriormente citado, tem-se como produto a base de regras responsável pelo relacionamento entre o espaço fuzzy das variáveis de entrada com o espaço fuzzy da variável de saída. Retratando a base de regras determinada por essa etapa de ajuste, apresenta-se a Figura 6.87. 


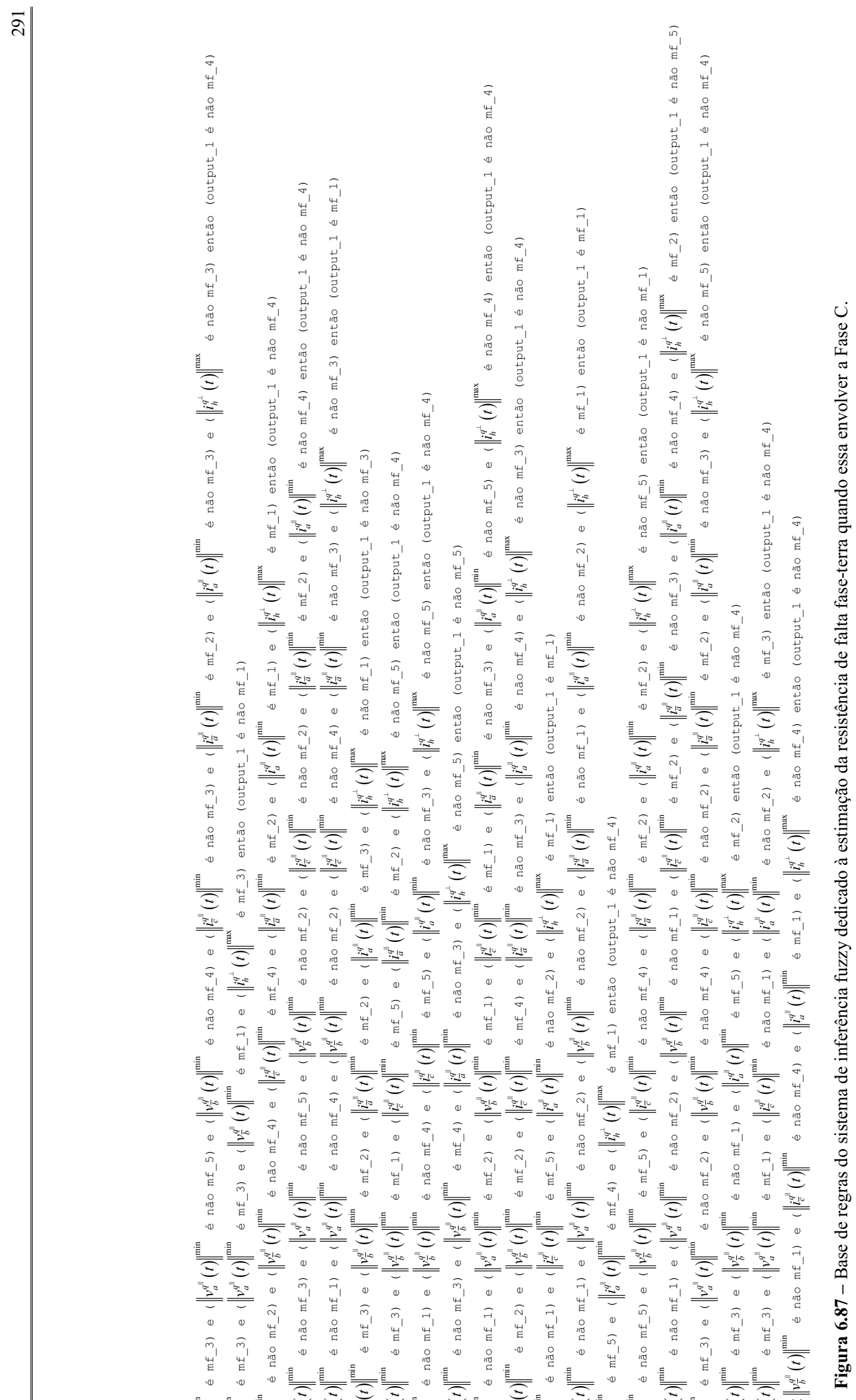

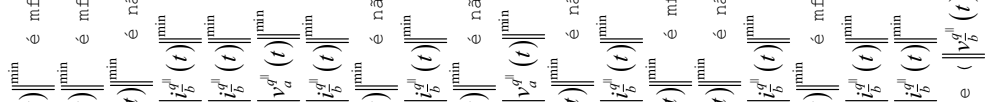

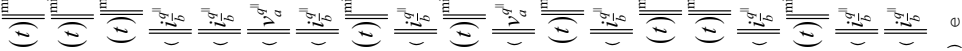

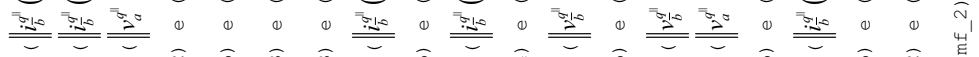

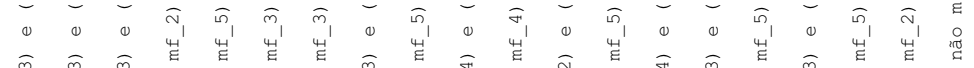

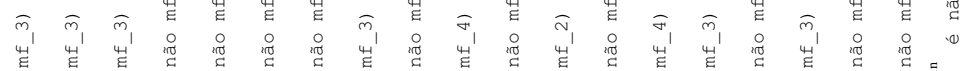

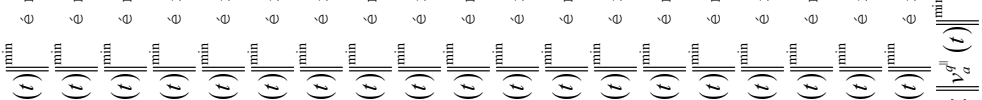

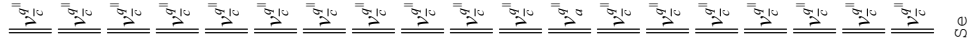

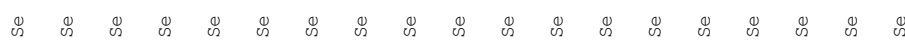




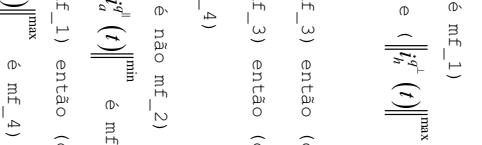

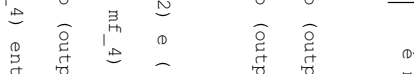

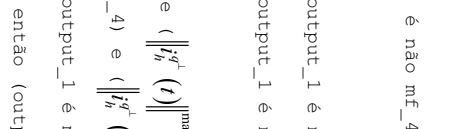

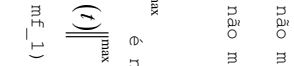

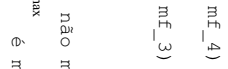

$$
\begin{aligned}
& \text { 离 }
\end{aligned}
$$

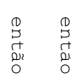


Após a determinação da base de regras representada por meio da Figura 6.87, o sistema de inferência fuzzy fora submetido à segunda etapa de ajuste o qual é dedicado ao ajuste paramétrico do sistema. O ajuste paramétrico tem por meta prosseguir com a redução do erro quadrático iniciada na primeira etapa. Para tanto, a segunda etapa de ajuste, denotada por ajuste paramétrico, modifica os parâmetros que definem as funções de pertinência das entradas e da saída, bem como procede com a ponderação das regras fuzzy ora obtidas na primeira etapa de ajuste. Apresentando como o erro quadrático médio se portou ao longo das iterações dessa segunda etapa de ajuste, tem-se a Figura 6.88.

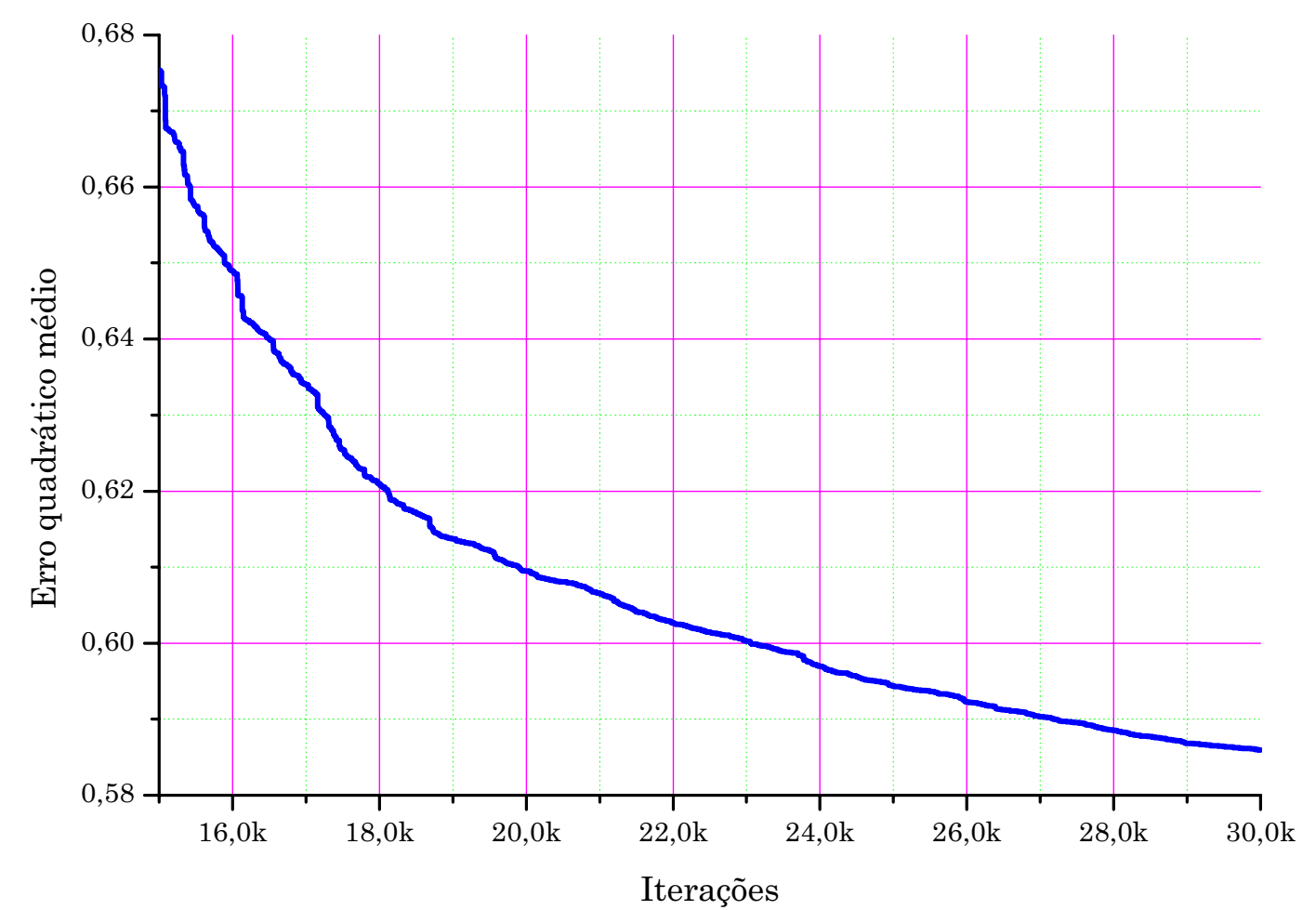

Figura 6.88 - Comportamento do erro quadrático médio do sistema fuzzy dedicado à estimação da resistência de falta quando essa envolver a Fase $\mathrm{C}$ ao longo das iterações da segunda etapa de ajuste.

Por meio da Figura 6.88 é possível verificar o quão o erro quadrático médio se reduz ao longo da etapa de ajuste paramétrico. Essa etapa, assim como já referenciado, é responsável por ajustar as funções de pertinência das entradas e da saída, além de ponderar as regras de inferência fuzzy. Complementando, a apresentação dos resultados advindos do processo de ajuste paramétrico, ilustra-se por meio da Figura 6.89 as funções de pertinência ajustadas para as quatro primeiras entradas, ou seja, para as entradas $\left\|v_{\bar{c}}^{q^{\prime \prime}}(t)\right\|^{\min },\left\|i_{\bar{b}}^{q^{\prime \prime}}(t)\right\|^{\min }$, $\left\|v_{a}^{q^{\prime \prime}}(t)\right\|^{\min }$ e $\left\|v_{b}^{q^{\prime \prime}}(t)\right\|^{\min }$. Da mesma maneira, por meio da Figura 6.90 tem-se as funções de pertinência para as outras quatro entradas, ou seja, para as entradas $\left\|i_{\frac{i^{\prime \prime}}{c}}(t)\right\|^{\min },\left\|i_{\bar{a}}^{q^{\prime \prime}}(t)\right\|^{\min }$, $\left\|i_{a}^{q^{l}}(t)\right\|^{\min } \mathrm{e}\left\|i_{h}^{q^{\perp}}(t)\right\|^{\max }$. 

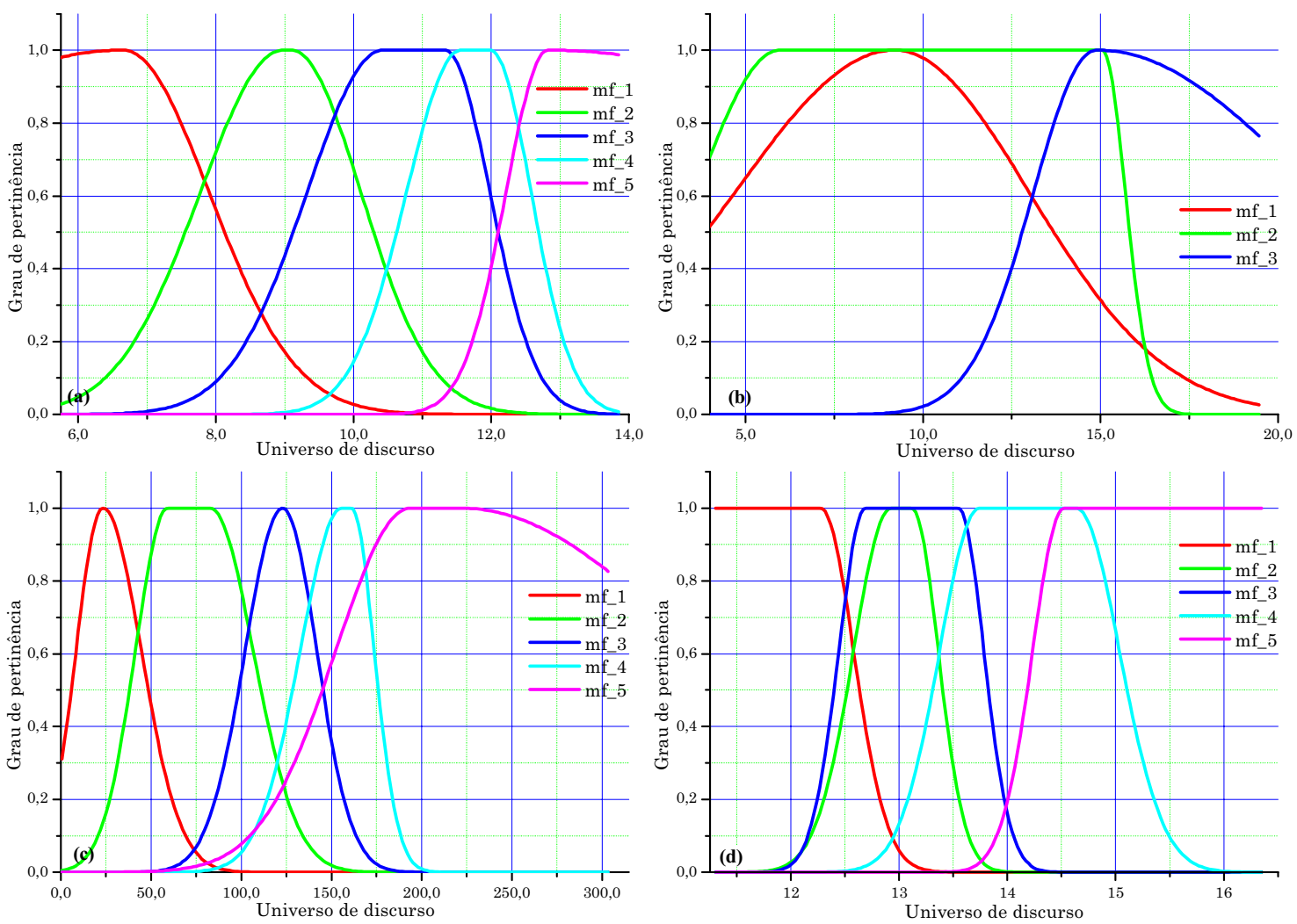

Figura 6.89 - Funções de pertinência ajustadas para as quatro primeiras entradas; (a) Entrada $\left\|v_{\bar{c}}^{q^{\prime \prime}}(t)\right\|^{\min } ;$ (b) Entrada $\left\|i_{\frac{q^{\prime \prime}}{b}}(t)\right\|^{\min } ;$ (c) Entrada $\left\|v_{a}^{q^{\prime \prime}}(t)\right\|^{\min }$; (d) Entrada $\left\|v_{\frac{q^{\prime \prime}}{b}}(t)\right\|^{\min }$.
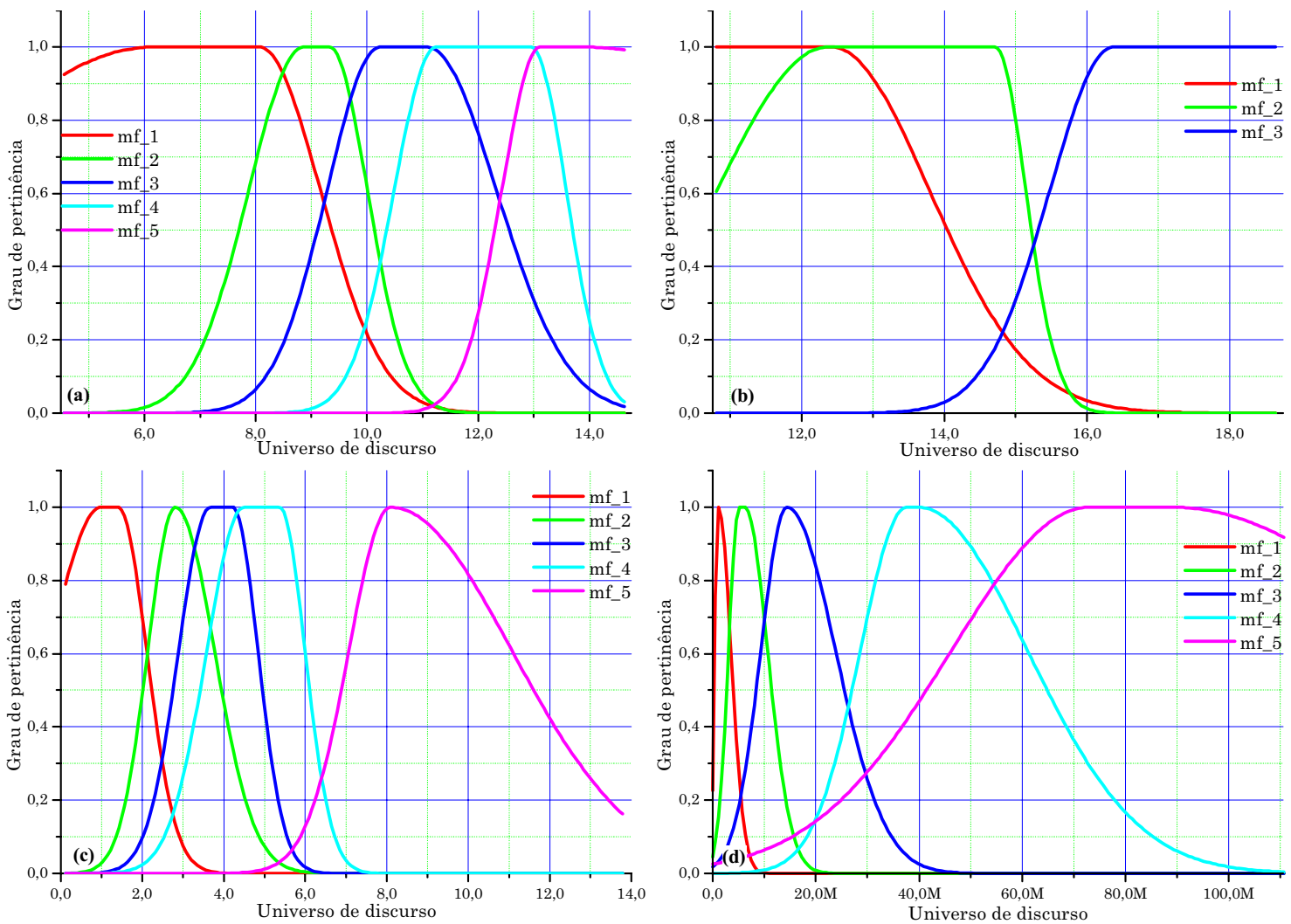

Figura 6.90 - Funções de pertinência ajustadas para as quatro primeiras entradas; (a) Entrada $\left\|i_{\bar{c}}^{q^{\|}}(t)\right\|^{\min }$; (b) Entrada $\left\|i_{\bar{a}}^{q^{\prime \prime}}(t)\right\|^{\min } ;$ (c) Entrada $\left\|i_{a}^{q^{\prime \prime}}(t)\right\|^{\min } ;$ (d) Entrada $\left\|i_{h}^{q^{\perp}}(t)\right\|^{\max }$. 
A etapa de ajuste paramétrico não apenas sintoniza as funções de pertinência do espaço das entradas como também ajusta as funções de pertinência da saída. Assim, por meio da Figura 6.91 apresentam-se as funções de pertinência da saída, que nesse caso representa o logaritmo base 10 para a resistência falta.

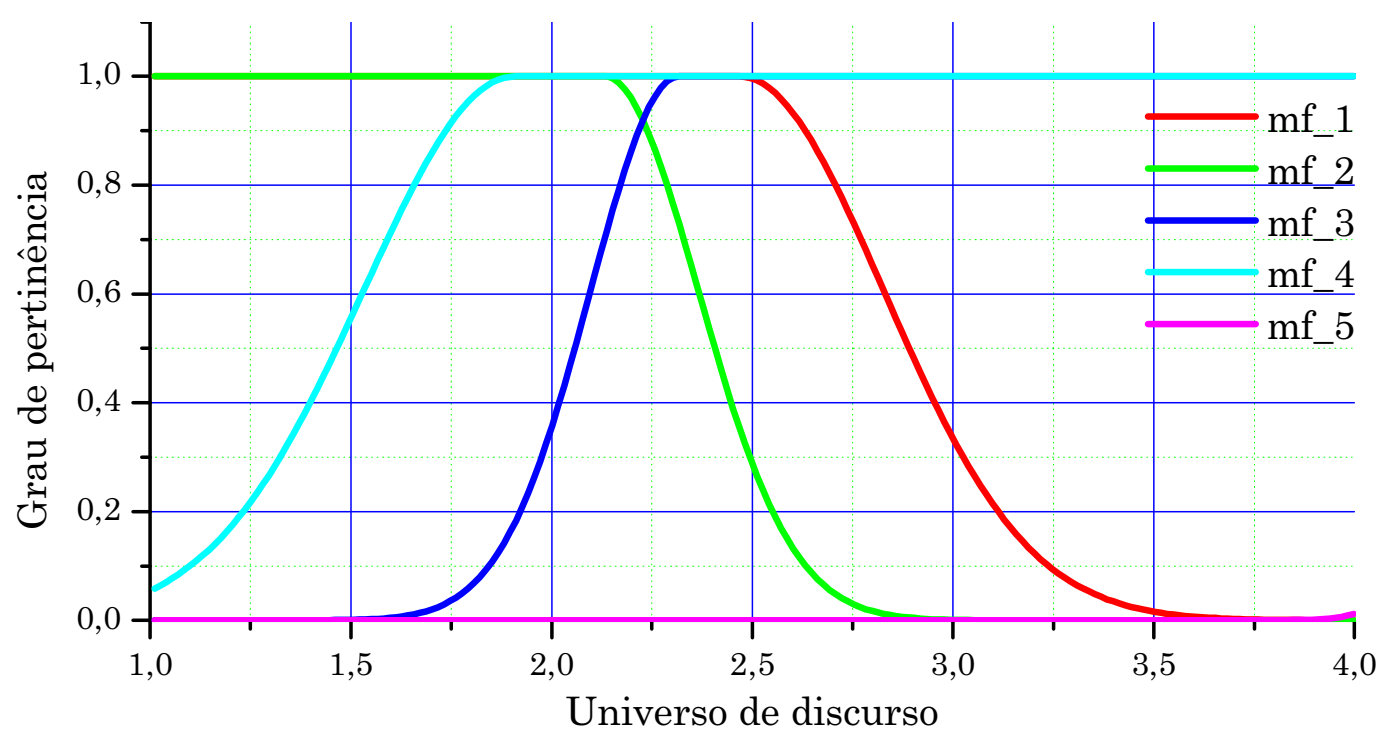

Figura 6.91 - Funções de pertinência associadas à resistência de falta na Fase C.

Findando a apresentação do sistema fuzzy dedicado à estimação da resistência de falta quando de sua ocorrência na Fase $\mathrm{C}$, tem-se na Figura 6.92 a maneira pela qual as regras fuzzy, destacadas na sua forma verbal por meio da Figura 6.87 , foram ponderadas pela etapa de ajuste paramétrico.

O sistema fuzzy ajustado para fins de estimação da resistência de falta fora ajustado, tanto estrutural como parametricamente, tendo como base os resultados providos por um conjunto de 999 simulações de faltas ocorridas na Fase C. Tais simulações computacionais, apresentadas em detalhes no Capítulo 5, possuíram como variáveis independentes a distância de ocorrência da falta, a resistência de falta, o instante inicial da falta e a duração da mesma. Assim, após o processo de ajuste é primordial a verificação da eficácia do sistema no desempenho da tarefa de estimação da resistência de falta.

Para tanto, o sistema fuzzy fora, inicialmente, testado com os dados advindos das simulações empregadas na constituição do conjunto de ajuste do mesmo. Apresentando como o erro relativo se porta para a estimação da resistência da falta, tem-se o gráfico da Figura 6.93, onde se destaca o histograma do referido erro. 


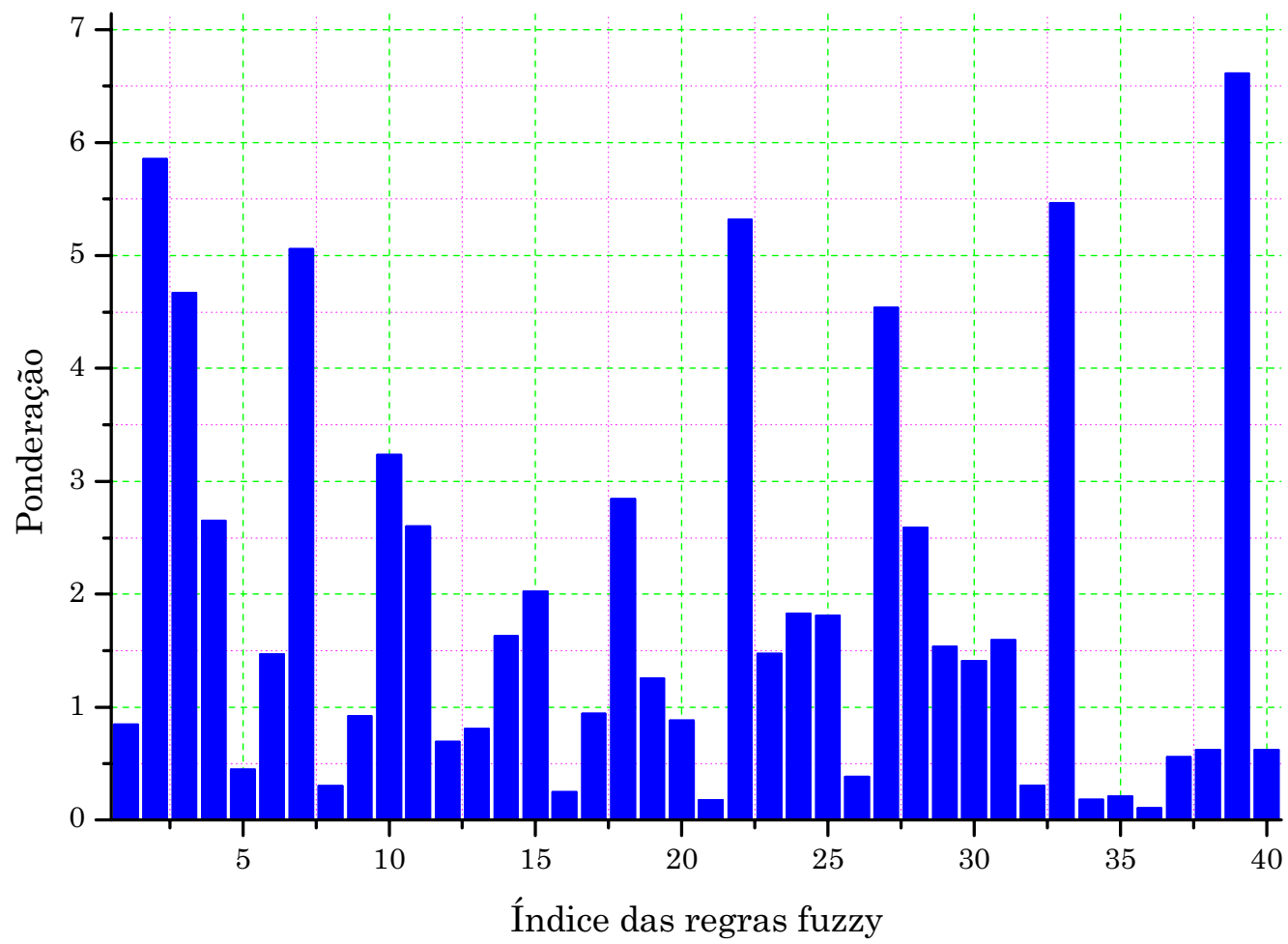

Figura 6.92 - Ponderação das regras fuzzy do sistema de inferência fuzzy dedicado à estimação da resistência de falta na Fase C.

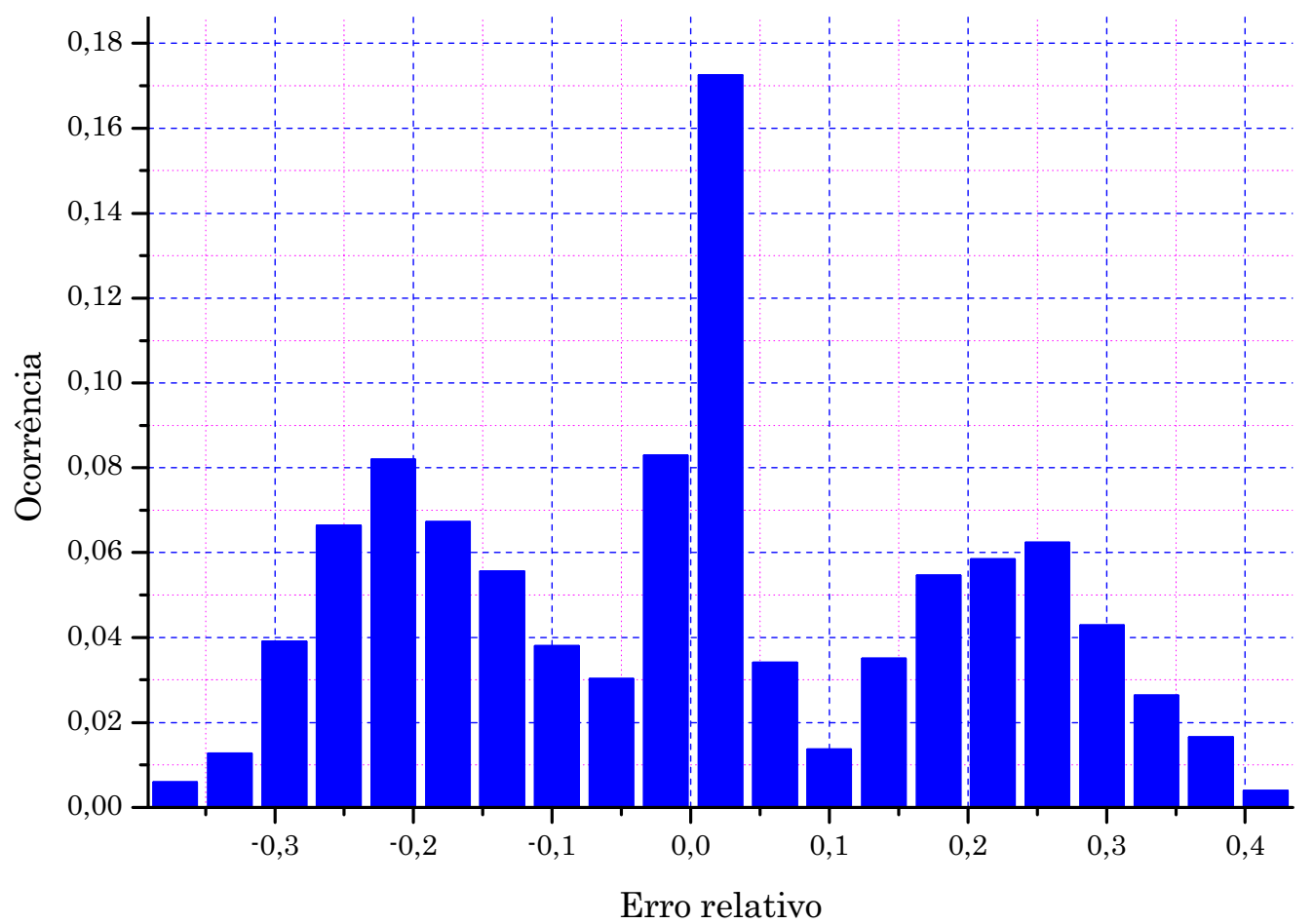

Figura 6.93 - Histograma do erro relativo de estimação da resistência de falta na Fase C.

Por meio do gráfico apresentado na Figura 6.93 é possível verificar que a distribuição probabilística do erro não segue uma distribuição normal nem mesmo alguma outra forma de distribuição usual. No entanto, dessa distribuição é possível obter seu respectivo valor médio o qual é de $-5,6605 \times 10^{-4}$. 
Apesar da distribuição probabilidade não ser caracterizada por meio de alguma distribuição convencional, apresenta-se na Figura 6.94 a função densidade probabilidade para o erro relativo na qual é possível constatar que, com uma confiabilidade de $90 \%$, o erro relativo se encontra entre $-0,28$ e 0,31 .

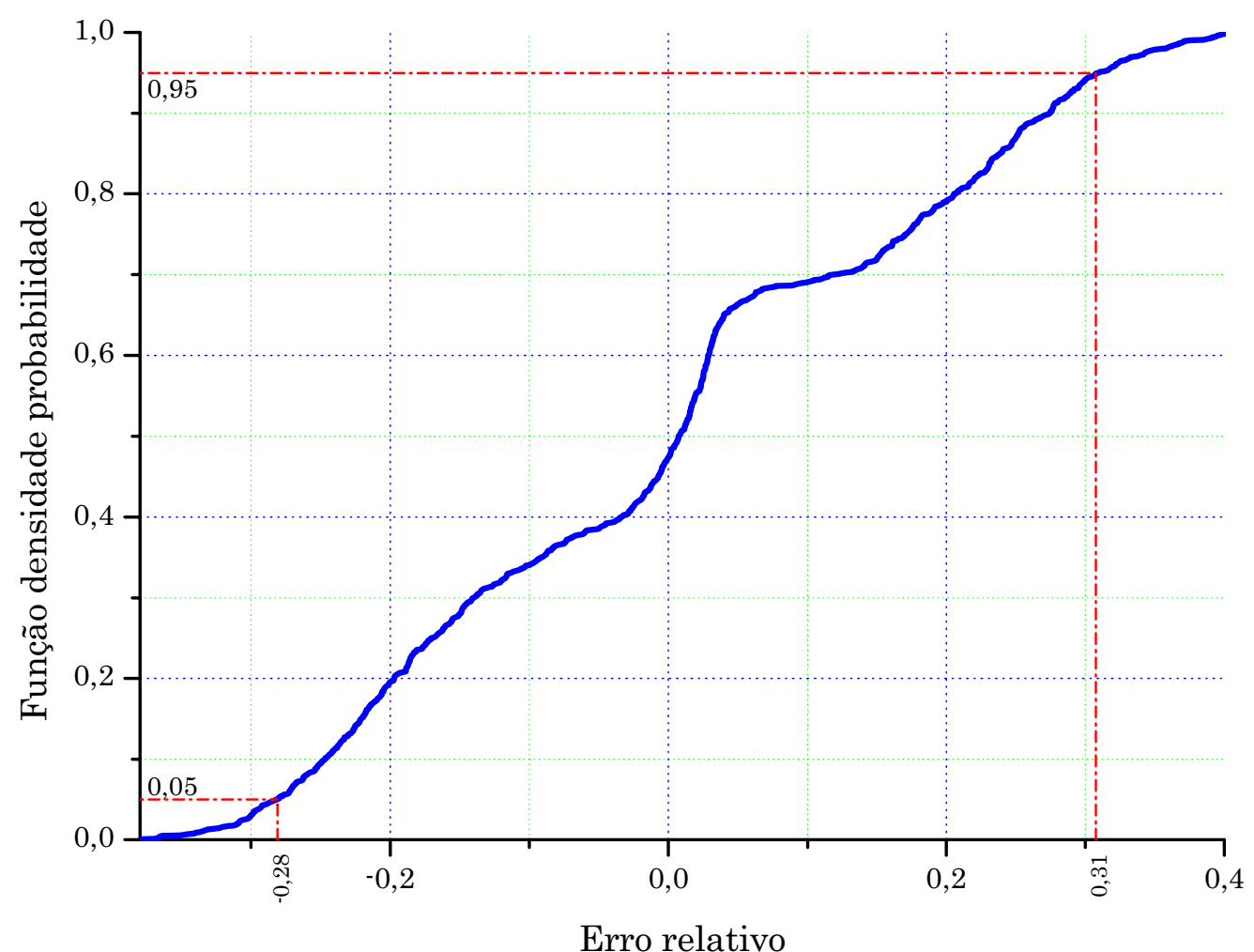

Figura 6.94 - Função densidade probabilidade para o erro relativo de estimação da resistência de falta na Fase $\mathrm{C}$.

Complementando a análise do erro relativo de estimação da resistência de falta, apresenta-se na Tabela 6.36 a correlação entre o erro relativo e as variáveis independentes das simulações computacionais, ou seja, a correlação entre o erro relativo e a resistência de falta, o ângulo de falta e a duração da falta.

Tabela 6.36 - Correlação entre o erro relativo e as variáveis independentes das simulações computacionais.

\begin{tabular}{lr}
\hline $\begin{array}{l}\text { Variável independente da } \\
\text { simulação }\end{array}$ & $\begin{array}{l}\text { Correlação com erro } \\
\text { relativo de estimação }\end{array}$ \\
\hline \hline Distância de ocorrência da falta & 0.0149 \\
\hline Resistência de falta & 0.7674 \\
\hline Ângulo da falta & 0.0176 \\
\hline Duração da falta & 0.0101 \\
\hline \hline
\end{tabular}


Por meio da Tabela 6.36 é possível verificar a forte dependência do erro relativo com a resistência de falta, ou seja, com a própria variável de estimação. Ainda, verifica-se que a correlação do erro com a distância de ocorrência da falta, com a duração da falta e com o ângulo de falta é ínfima. A fim de ilustrar a forte correlação do erro de estimação da resistência de falta se apresenta o gráfico da Figura 6.95.

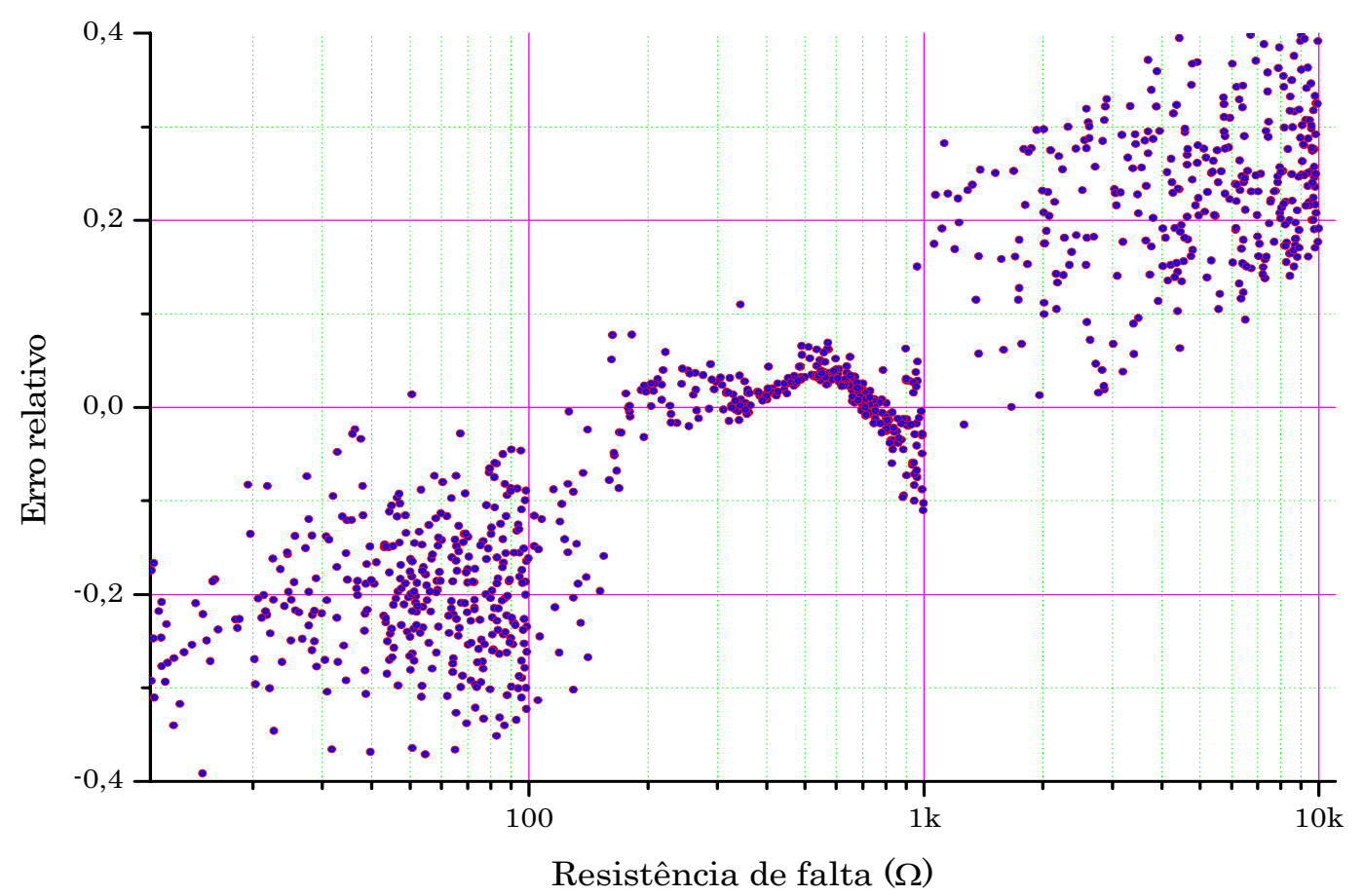

Figura 6.95 - Relacionamento entre o erro relativo e a resistência de falta.

Verifica-se pelo gráfico da Figura 6.95 a tendência tanto do máximo erro como do mínimo erro aumentarem com o incremento da resistência de falta da falta. Ainda, é possível constatar que o erro de estimação da resistência de falta se concentra melhor em torno do zero para resistências de falta entre 100 e $1 \mathrm{k} \Omega$.

O sistema fuzzy dedicado à estimação da resistência de falta além ser testado com os dados provenientes do conjunto de ajuste, fora também testado com dados advindos de simulações computacionais não contidos no conjunto de ajuste. Assim, um total de 310 situações de falta na Fase $\mathrm{C}$ foram simuladas e os resultados dessas simulações foram submetidos à técnica de decomposição em componentes ortogonais. De posse dos valores eficazes das componentes ortogonais, as variáveis mais correlatas à estimação da resistência de falta na Fase C, apresentadas na Tabela 6.35, foram selecionadas e apresentadas ao sistema fuzzy previamente ajustado. Os resultados obtidos para a estimação da resistência de faltas quando de sua ocorrência na Fase C são apresentados por meio da Figura 6.96 na forma de histograma do erro relativo. 


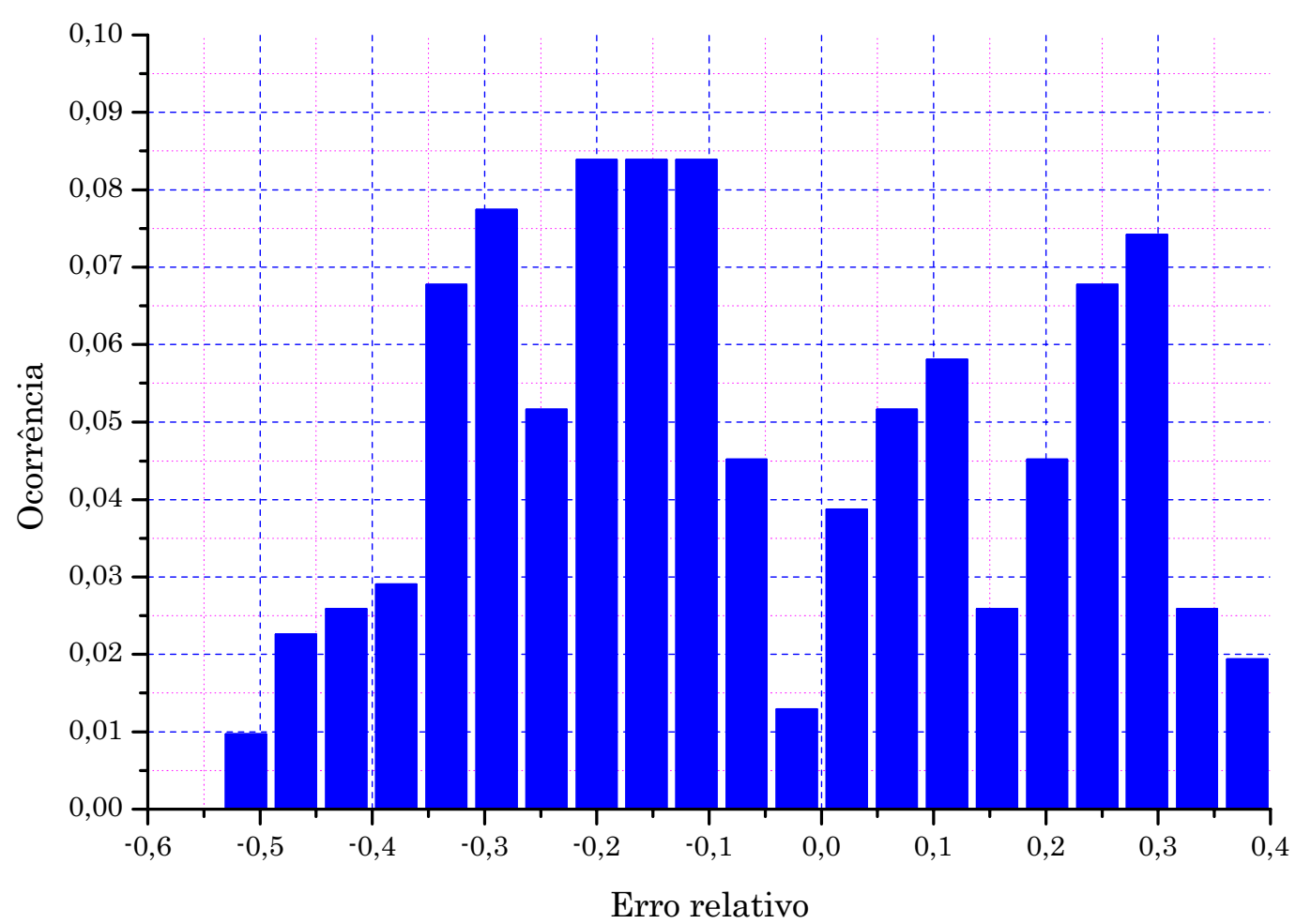

Figura 6.96 - Histograma do erro relativo de estimação da resistência de falta na Fase C para os dados do conjunto de teste.

Com o objetivo de ilustrar como a distribuição estatística do erro relativo para os dados de ajuste é semelhante à distribuição do erro verificado para os dados de teste, apresenta-se a Figura 6.97, onde ambas as funções densidade acumulada são confrontadas para propósitos comparativos.

Por meio da Figura 6.98 é possível verificar que a distribuição normal verificada para os dados de teste é semelhante com aquela verificada quando da modelagem do erro observado para os dados de ajuste. Ainda, por meio da avaliação dos dados de teste, verificouse que cerca de $75,16 \%$ dos mesmos se enquadrou dentro do intervalo de confiança de $90 \%$ calculado sobre os dados de treinamento. 


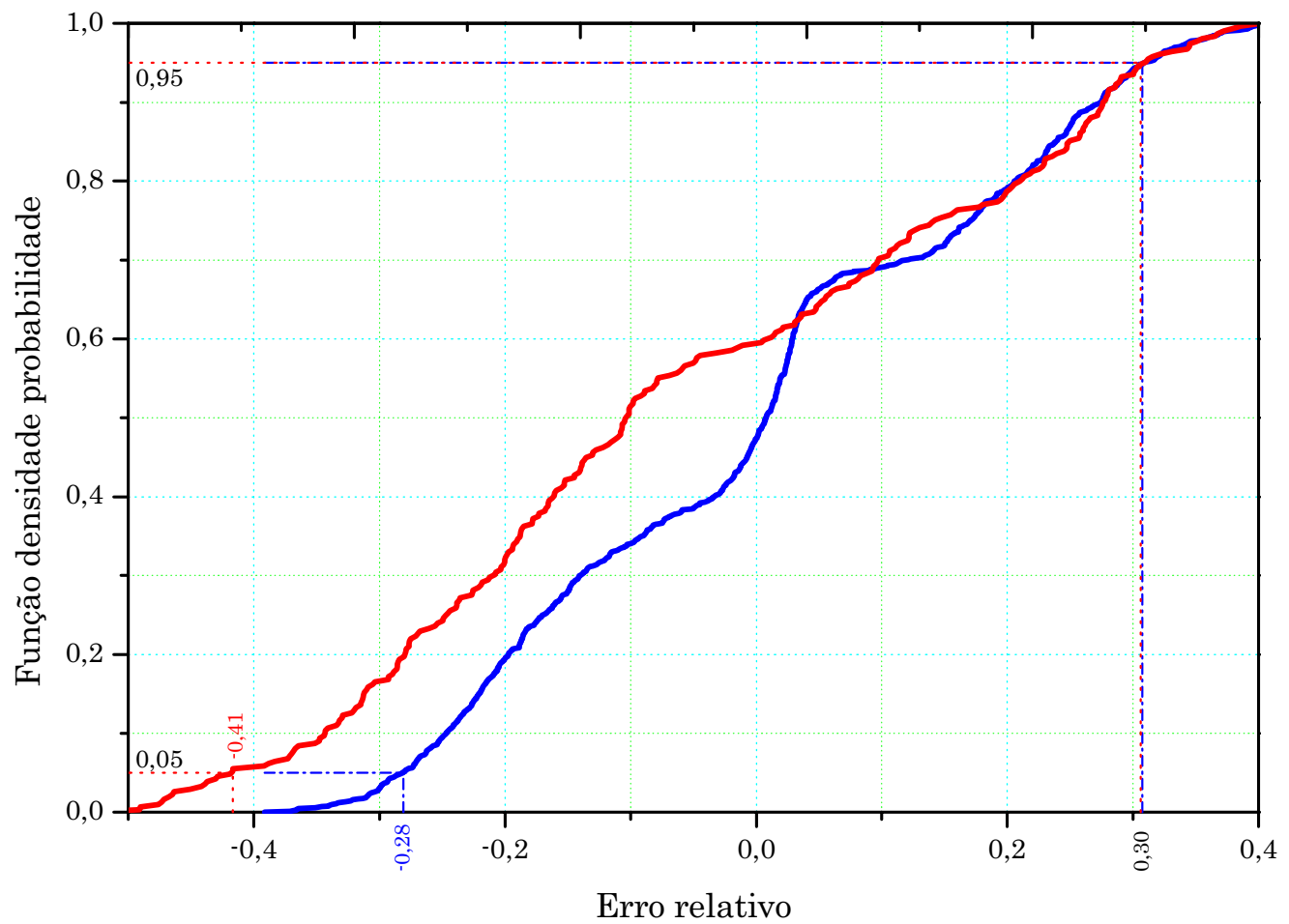

Figura 6.97 - Distribuição normal para o conjunto de ajuste e para o conjunto de teste quando da estimação da resistência de falta na Fase C.

\subsection{CONSIDERAÇÕES SOBRE OS SISTEMAS DE LOCALIZAÇÃo de FALTAS E dE ESTIMAÇÃo da RESISTÊNCIA dE FALTA}

Ao longo desse capítulo fora apresentado os desenvolvimentos e resultados obtidos para os sistemas fuzzy responsáveis pela estimação da distância de ocorrência de faltas falta-fase terra e pela estimação da resistência de falta. Essas duas tarefas podem ser classificadas como sendo um mapeamento entre espaços, uma vez que existe disponível um conjunto de variáveis a partir das quais é requerida a determinação da respectiva projeção no espaço de saída que, no caso dessa aplicação, fora tanto a distância de ocorrência da falta como a resistência de falta.

Refletindo sobre a eficácia na realização dessas tarefas de mapeamento de funções, os sistemas de inferência fuzzy implementados se mostraram eficientes, visto que as particularidades dos resultados verificados para os conjuntos de ajuste foram replicado, se não na sua totalidade mas em sua grande parte, para os conjuntos de teste. Essa constatação é premissa para que seja possível inferir sobre a referida eficácia, pois, assim como ocorre no ajuste de quaisquer sistemas, o conjunto de ajuste empregado pode ser desprovido de 
informações suficientes para que a metodologia de ajuste seja capaz de, a partir desse conjunto, extrair conhecimento e representá-los na forma estrutural e parametricamente no sistema sobre ajuste. Nessas situações, o sistema ajustado apresenta um desempenho adequado para os dados contidos no conjunto de ajuste. Porém, a apresentação de dados outros que não aqueles contidos no conjunto de ajuste pode resultar em um comportamento não consistente com aquele esperado. Assim, com o intuito de identificar esse comportamento indesejado, o sistema sob ajuste é submetido à realização de sua tarefa para dados pertencentes ao denominado conjunto de teste, ou seja, dados não pertencentes ao conjunto de ajuste, mas que a resposta esperada é conhecida. Comparando-se o comportamento do sistema ajustado frente aos dados de ajuste com aqueles obtidos por meio do conjunto de teste se tem as bases para que a competência do sistema seja julgada.

Fazendo dessa premissa de verificação uma etapa constituinte da metodologia empregada, os desenvolvimentos e resultados desse capítulo foram conduzidos. Em relação aos sistemas fuzzy responsáveis pela estimação da distância da falta, pode-se verificar que o erro relativo, tanto para os dados de ajuste como para os dados de teste, possuíram um comportamento semelhante e passíveis de serem caracterizados como pertencentes às distribuições probabilísticas normais com média, aproximadamente, nula. A proximidade da média com o elemento neutro da adição é uma importante característica, pois assim, tem-se que a esperança matemática do erro na estimação da distância também o será. Complementando a análise dos sistemas fuzzy dedicados à estimação da distância de ocorrência de faltas fase-terra, verifica-se ainda que o comportamento diante dos conjuntos de teste ocorreram dentro do verificado para os dados do conjunto de ajuste.

Além dos sistemas para estimação da distância de ocorrência de faltas, nesse capítulo foram apresentados os sistemas fuzzy responsáveis pela estimação da resistência de falta para cada uma das fases constituintes do sistema de distribuição de energia elétrica sob estudo. Os resultados obtidos para tais sistemas permitiram a comprovação de que, além da distância de ocorrência das faltas, é possível a estimação da resistência com a qual a referida ocorrera.

Assim, é possível verificar a importância que a técnica de decomposição em componentes ortogonais pode vir a ter no contexto de sistemas elétricos de potência, bem 
como verificar a capacidade do algoritmo de ajuste estrutural e paramétrico de sistema de inferência fuzzy em traduzir o conhecimento implícito nos dados de ajuste.

As conclusões desse trabalho e propostas de investigações futuras possíveis de serem desenvolvidas a partir das contribuições pautadas são abordas no Capítulo 7. 


\title{
APÍTULO 7
}

\section{CONClusões e Trabalhos Futuros}

\begin{abstract}
O principal meta desse capítulo é apresentar as conclusões finais desse trabalho de (2). realizados e dos resultados obtidos, não se eximindo da sensibilidade, inclusive, serão apresentadas propostas para trabalhos futuros que façam uso, total ou parcialmente, do exposto nesse trabalho. Para tanto, esse capítulo será organizado em duas seções. A Seção 7.1 será responsável por apresentar as conclusões do trabalho, enquanto que na Seção 7.2 a proposta de trabalhos futuros será conduzida.
\end{abstract}

\subsection{CONCLUSÕES}

O histórico evolutivo dos sistemas de energia elétrica pode ser formulado por meio da itemização de inúmeros desafios e de suas respectivas soluções, criativas e inovadoras na sua grande maioria, que fizeram e fazem desse setor ser ímpar na pesquisa e busca contínua de melhoria.

Na busca pelo desenvolvimento de ferramentas e metodologias que venham a contribuir para o setor de energia elétrica, a motivação desse trabalho fora fundamentada. De maneira mais específica, o tema identificação e localização de faltas fase-terra em sistemas de distribuição de energia elétrica fora abordado, pois, esse tipo de ocorrência corrompe a segurança do referido sistema elétrico e degrada os indicadores que mensuram a qualidade do 
fornecimento de energia elétrica. Assim, sendo tanto a qualidade como a segurança paradigmas de destaque da atual operação dos sistemas elétricos de potência, a identificação e localização de faltas recebe importante destaque. A justificativa dessa temática se dá pelo fato de que, de forma convencional, a localização do ponto de ocorrência de falta se faz, na grande maioria dos casos, por meio da inspeção visual da rede primária pelas equipes de manutenção, tarefa essa que pode demandar tempo e recursos financeiros que comprometam a operação eficiente da distribuição.

Fundamentadas nos alicerces da segurança e da qualidade do fornecimento de energia elétrica, inúmeras pesquisas foram desenvolvidas desde a década de 1970 até os dias atuais sem, contudo, fazer com que esse problema seja possuidor de uma solução geral ou, em muitos casos, detentor de uma solução particular. No entanto, por meio dos relatos apresentados por essas pesquisas, pode-se identificar um modelo geral para os sistemas identificadores ou localizadores de falta. Esse modelo geral pode ser representado por meio de uma arquitetura composta por um módulo pré-processador de sinais e por um módulo responsável ou por identificar a ocorrência de uma falta fase-terra ou por estimar a distância de sua ocorrência. Não se distanciando dessa arquitetura geral, essa tese também fizera uso da mesma.

Dessa maneira, a fim de constituir o conjunto de ferramentas empregadas para implementação do pré-processador fora desenvolvida a técnica de decomposição em componentes ortogonais. Essa técnica, diferente daquelas usualmente empregadas para propósitos semelhantes ao abordado nesse trabalho, não se baseia em um conjunto de bases pré-estabelecidas para proceder com a decomposição das formas de onda das tensões e das correntes. Ao contrário disso, a técnica de decomposição em componentes ortogonais emprega as funções a serem decompostas para obtenção do sistema de bases ortogonais para proceder com a decomposição. De maneira equivalente, pode-se dizer que a técnica de decomposição em componentes ortogonais se constitui em uma abordagem livre de coordenadas para operar. Além dessa diferença em relação as técnicas como série de Fourier e transformada wavelet, apenas para citar alguns exemplos, a técnica de decomposição por componentes ortogonais promove a decomposição em componentes inseridas no mesmo domínio das funções originais, ou seja, as componentes serão representadas por suas formas de onda no domínio do tempo.

O sistema responsável por receber os dados advindos do pré-processador e deles extraírem informações que permitam ou identificar ou localizar a falta também é tópico de 
extrema importância. Remetendo-se novamente aos estudos técnicos e científicos se pode destacar o intenso uso de ferramentas advindas da inteligência computacional, tais como as redes neurais artificiais e os sistemas de inferência fuzzy. Assim, no intuito de contribuir de maneira original também nesse módulo fora desenvolvido um algoritmo para o ajuste estrutural e paramétrico de sistemas fuzzy visto que, esse tema demanda esforços acadêmicos de digna relevância desde a proposição dos sistemas de inferência fuzzy até os dias contemporâneos.

Agregando os desenvolvimentos realizados para formulação da técnica de decomposição em componentes ortogonais com aqueles proferidos ao sistema de inferência fuzzy, procedeu-se com a implementação dos sistemas fuzzy dedicados à identificação de faltas fase-ferra, bem como para a determinação da fase participante da mesma. Os resultados obtidos permitiram verificar o quão correlacionadas as componentes ortogonais podem estar com a execução de ambas as tarefas, denotando assim, o quão promissor tal ferramenta matemática pode ser dentro desse contexto. Além disso, os sistemas fuzzy, ajustados segundo o algoritmo proposto, foram precisos na execução de ambas as tarefas, comprovando a capacidade do algoritmo em traduzir de forma estrutural e paramétrica o relacionamento existente entre as componentes ortogonais e a identificação da ocorrência de uma falta ou a discriminação da fase faltosa.

Ainda, procedeu-se com a implementação dos sistemas fuzzy responsáveis pela localização de falta e estimação da resistência de falta. Novamente, foi constatada a forte correlação de algumas das componentes ortogonais com ambas as variáveis. Essa correlação existente permitiu, em um primeiro momento, o desenvolvimento dos sistemas fuzzy responsáveis pela determinação da distância de ocorrência da falta. Os resultados apreciados vieram a comprovar o emprego das componentes ortogonais para tal finalidade e, novamente, a capacidade do algoritmo de ajuste automático de sistema fuzzy fora testado de forma bem sucedida. Resultados semelhantes foram constatados quando da estimação da resistência de falta.

Assim, os objetivos traçados para esse trabalho foram atingidos e os resultados obtidos fazem com que novas linhas de pesquisa correlacionadas ao tema abordado, seja de forma mais específica com a decomposição em componentes ortogonais ou com as técnicas de ajuste de sistemas de inferência fuzzy ou ambos, sejam delineadas. A fim de pontuar algumas das futuras linhas de pesquisa citadas, a Seção 7.2 é conduzida. 


\subsection{TrabalHOS FUtUROS}

Dentre os futuros trabalhos, correlacionados aos temas focados nessa tese, pontuase os seguintes:

* Aprimoramento da técnica de decomposição em componentes ortogonais a fim de que seja possível uma maior extração de características, a partir das mesmas componentes, as quais serão avaliadas para aplicações outras em engenharia elétrica.

* Implementação de um sistema eletrônico para aquisição de sinais de tensões e de correntes e o posterior cálculo das componentes ortogonais com a finalidade de se empregar em experimentos reais.

* Desenvolvimento de um sistema identificador e localizador de faltas baseado na técnica das componentes ortogonais e redes neurais artificiais, assim como a comparação dos resultados com os obtidos nessa tese.

* Constituição de uma base de dados de simulações abordando não apenas as faltas fase-terra mas em diversas outras situações, tendo como objetivo de estender a técnica para situações de falta mais genéricas.

* Aprimoramento do algoritmo de ajuste estrutural e paramétrico de maneira que o mesmo incorpore conceitos advindos da computação neuro-inspirada, tal como os conceitos e definições da computação evolutiva. 


\section{BIBLIOGRAFIA E LITERATURA CORRELATA $^{\dagger}$}

$\checkmark$ ANSI/IEEE C62.92.4/1991 - IEEE Guide for the application of neutral grounding in electrical utility in electrical systems, Part IV - Distribution.

$\checkmark$ AUCOIN, B. M.; JONES, R. H. "High impedance fault detection implementation issues", IEEE Transactions on Power Delivery, v. 11, p. 139-148, 1996.

$\checkmark$ BENNER, CARL L.; RUSSELL, B. DON "Practical High Impedance Fault Detection for Distribution Feeders", Proceedings of the 1996 Rural Electric Power Conference, IEEE Industry Applications Society, 28-30 de Abril de 1996, Fort Worth, TX.

* BENNER, C. L.; RUSSELL, B. D. "Characteristic Behavior of Downed Electrical Lines Including Evaluation of Various Electrocution Scenarios", 51st Annual Meeting of American Academy of Forensic Sciences, Orlando, FL, 15-20 de Fevereiro, 1999.

- BEZDEK, J. C. Pattern Recognition with Fuzzy Objective Functions Algorithms. Plenum, New York, 1981.

$\checkmark$ BI, YANQIU; ZHAO, JIANGUO; ZHANG, DAHAI "Single-phase-to-ground fault feeder detection based on transient current and wavelet packet", PowerCon 2004 - International Conference on Power System Technology, 2004, V. 1, 21-24 de Novembro de 2004, p. 936 -940 .

- BURrough, P. A., VAN GAANS, P. F. M., MACMILlAN, R. A. High-resolution landform classification using fuzzy k-means. Fuzzy Sets Systems, v. 113, n. 1, p. 37-52, 2000.

BUTLER, K. L.; MOMOH, J. A. "A neural net based approach for fault diagnosis in distribution networks", IEEE Power Engineering Society - Winter Meeting, v. 2, p. 12751278, 2000.

\footnotetext{
${ }^{\dagger}$ As citações marcadas por $\bullet$ foram citados ao longo do texto, enquanto que aqueles marcados por $\downarrow$ são recomendadas para leitura.
} 
BUTLER, K. L.; MOMOH, J. A. "Robust features selection scheme for fault diagnosis is a electrical power distribution system”, CCECE/CCGEI’ 93, p. 209-213, 1993.

$\checkmark$ CAMINHA, A. C. Introdução à Proteção dos Sistemas Elétricos, São Paulo: Edgar Blücher, 1977.

- CARPENTER, M.; HOAD, R. R.; BRUTON, T. D.; DAS, R.; KUNSMAN, S. A.; PETERSON, J. M. "Staged-fault testing for high impedance fault data collection", 58th Annual Conference for Protective Relay Engineers 2005, 5-7 de Abril de 2005, p. 9 - 17.

* CHEN, C. -S; KE, Y. -L; WU, J. -S. “Colored Petri nets approach for solving distribution system contingency by considering customer load patterns IEE Proceedings Generation, Transmission and Distribution, v. 148, p. 463-470, 2001.

* CHIU, S. L. Fuzzy model identification based on cluster estimation. Journal of Intelligent and Fuzzy Systems, v. 2, p. 267-278, 1994.

DAS, B. "Fuzzy Logic-Based Fault-Type Identification in Unbalanced Radial Power Distribution System", IEEE Transactions on Power Delivery, V. 21, Issue 1, Janeiro de 2006 , p. $278-285$.

DAUBECHIES, I. "Ten lectures on wavelets", CBMS-NSF Regional Conference Series in Applied Mathematics, Philadelphia, Pennsylvania, 1992.

DAUBECHIES, I. "The wavelet transform, time-frequency localization and signal analysis", IEEE Transactions on Information Theory, v. 36, n. 5, p. 961-1005, 1990.

$\checkmark$ DENNIS, J. E., SCHNABEL, R. B. Numerical Methods for Unconstrained Optimization and nonlinear equations, Prentice Hall, Englewood Cliffs, 1983.

DEPEW, A. C.; PARSICK, J. M.; DEMPSEY, R. W.; RUSSELL, B. D.; ADAMIAK, M. G. "Field Experience with High-Impedance Fault Detection Relays", PES TD 2005/2006, 21-24 de Maio de 2006, p. 868 - 873.

- DOMIngueS, E. T. Localizador Digital de Faltas Para Linhas de Transmissão de Múltiplos Terminais. Dissertação de Mestrado - Escola de Engenharia de São Carlos, Universidade de São Paulo, São Carlos, 1998.

$\checkmark$ DUNN, J. C. A fuzzy relative of the isodata process and its use in detecting compact wellseparated clusters. Journal of Cybernetics, v. 3, p. 32-57, 1973.

$\checkmark$ EICKHOFF, F.; HANDSCHIN, E.; HOFFMANN, W. "Knowledge based alarm handling and fault location in distribution networks", IEEE Transactions on Power Systems, v. 7, n. 2, p. 770-776, 1992. 
ELMORE, W. A. Protective Relaying Theory and Applications, New York: Marcel Dekker Inc., 1994.

EMAMI, M. R., TÜRKSEN, I. B., GOLDENBERG, A. A. Development of a systematic methodology of fuzzy logic modeling. IEEE Transactions on Fuzzy Systems, v. 6, p. 346$361,1998$.

$\checkmark$ ERIKSSON, L.; SAHE, M. M.; ROCKEFELLER, G. D. “As accurate fault locator with compensation for apparent reactance in fault resistance resulting from remote- end infeed", IEEE Transactions on Power Apparatus and Systems, v. PAS-104, n. 2, p. 424-436, 1985.

$\checkmark$ ELMORE, W. A. A protective relaying theory and applications, New York: Marcel Dekker Inc, 1994.

* FAN, CHUNJU; CAI, HUARONG; YU, WEIYONG, “Application of Six-Sequence Fault Components in Fault Location for Joint Parallel Transmission Line", Tsinghua Science \& Technology, V. 10, Issue 2, Abril de 2005, p. 247 - 253.

* FARIA, J. A. B. "Application of Clarke's transformation to thee modal analysis os asymmetrical single-circuit three-fase line configuration", ETEP European Transaction on Electrical Power, v. 10, p. 225-231, 2000.

$\checkmark$ FOURLAS, G. K.; KYRIAKOPOULOS, K. J.; KRIKELIS, N. J. “A theoretical diagnosis approach applied to a power transmission system", $43^{\text {rd }}$ IEEE Conference on Decision and Control 2004 CDC, V. 5, 14-17 Dezembro de 2004, p. 4788 - 4793.

- GIRGIS, A. A.; FAllON, C. M.; LUBKEMAN, D. L. “A Fault Location Technique for Rural Distribution Feeders", IEEE Transactions on Industry Applications, Piscataway, NJ, USA, v.29, n.6, p.1170-1175, nov./dec. 1993.

* GLORENNEC., P. -Y. Algorithmes d'Apprendissage Pour Systèmes d'inference Floue. Hèrmes, Paris, 1999.

* GOMIDE, F. A. C., GUDWIN, R. R. Modelagem, controle, sistemas e lógica fuzzy. Revista Controle e Automação, v. 4, n. 3, p. 97-115, 1994.

* GUILLAUME, S. Designing fuzzy inference systems from data: An interpretability review. IEEE Transactions on Fuzzy Systems, v. 9, n. 3, 2001.

HIROTA, K. Industrial Applications of Fuzzy Technology, Springer Verlag, New York, 1993.

• HONGJIANG, MA; XIANGJUN, ZENG; YUANYUAN, WANG; ZEWEN, LI "Grounding Fault Protection with Fault Resistance Measuring for Ineffectively Earthed 
Power Systems", 2005 IEEE/PES Transmission and Distribution Conference and Exhibition: Asia and Pacific, 15-18 de Agosto de 2005, p. 1 - 3.

* ICHIHASHI, H., SHIRAI, T., NAGASAKA, K., MIYOSHI, T. A method of inducing fuzzy decision trees with linear programming for maximizing entropy and an algebraic method for incremental learning. Fuzzy Sets Systems, v. 81, p. 157-167, 1996.

ISHIBUCHI, H., NOZAKI, K., TANAKA, T., OSAKA, Y., MATSUDA, M. Empirical study on learning in fuzzy systems by rice test analysis. Fuzzy Sets and Systems, v. 64, p. 129-144, 1994.

ISHIBUCHI, H., NOZAKI, K., YAMAMOTO, N., TANAKA, H. Selecting fuzzy if-then rules for classification problems using genetic algorithms. IEEE Transactions on Fuzzy Systems, v. 3, p. 260-270, 1995.

* Jarventausta, P.; Verho, P.; PARTANEN, J. "Using fuzzy sets to model the uncertainty in the fault location process of distribution networks", IEEE Transactions on Power Delivery, v. 9, n. 2, p. 954-960, 1994.

* JOTA, F. G.; JOTA P. R. S. "High-impedance fault identification using a fuzzy reasoning system", IEE Proceedings - Generation, Transmisstion and Distribution, v. 145, n. 6, p. 656-661, 1998.

KAWADY, T.; STENZEL, J. "Investigation of practical problems for digital fault location algorithms based on EMTP simulation", Transmission and Distribution Conference and Exhibition 2002: Asia Pacific. IEEE/PES, v. 1, p. 118 - 123, 2002.

KINDERMANN, G. Curto Circuito, Porto Alegre: Sagra-Dcluzzato, Livreiros, Editores e Distribuidores Ltda, 1992.

KO, J. H.; SHIM, J. C.; C. WAN RYU; PARK, G.; YIM, W. Y. "Detection of high impedance faults using neural nets and chaotic degree", Proceedingd of Energy Management and Power Delivery, v. 2, p. 399-404, 1998.

LEE, C. C. Fuzzy logic in control systems: fuzzy logic controllers - Part I and II. IEEE Transactions on Systems, Man and Cybernetics, v. 20, p. 404-435, 1990.

* LEE, S. J. et al. “An Intelligent and Efficient Fault Location and Diagnosis Scheme for Radial Distribution Systems", IEEE Transactions on Power Delivery, USA, v.19, n.2, p.524-532, apr. 2004. 
LIU, W. H. E.; ZHONG, W. “A fuzzy set method for fault location and identification in power distribution systems", Proccendings of the $35^{\text {th }}$ IEEE Conferente on Decision and Control, v. 2, p. 2208-2212, 1996.

$\checkmark$ LUO, SHANSHAN; KEZUNOVIC, MLADEN; R. SEVICK, DON, "Locating faults in the transmission network using sparse field measurements, simulation data and genetic algorithm”, Electric Power Systems Research, V. 71, Issue 2, Outubro de 2004, p. 169 177.

$\checkmark$ MAGNAGO, F. H.; ABUR, A. "A new fault location technique for radial distribution systems based on high frequency signals", IEEE Power Engineering Society Summer Meeting, v. 1, p. 426-431, 1999.

MAHANTY, R. N.; GUPTA, P. B. D. "Application of RBF neural network to fault classification and location in transmission lines", IEE Proceedings - Generation, Transmission and Distribution, V. 151, Issue 2, 2 de Março de 2004, p. 201 - 212.

MANDANI, E. H., ASSILIAN, S. An experiment in linguistic synthesis with a fuzzy logic controller. International Journal of Man-Machine Studies, v. 7, p. 1-13, 1975.

MARTINS, L. S.; MARTINS, J. F.; PIRES, V. F.; ALEGRIA, C. M. "The application of neural networks and Clarke-Concordia transformation in fault location on distribution power system”, IEEE Transaction on Power Delivery, v. 4, n. 2, p 2091-2095, 2002.

- MARTINS, L. S.; MARTINS, J. F.; PIRES, V. F.; ALEGRIA, C. M. "A neural space vector fault location for parallel double-circuit distribution lines", International Journal of Electrical Power \& Energy Systems, V. 27, Issue 3, Março de 2005, p. 225 - 231.

MASON, C. R. The Art and Science of Protective Relaying, New York: John Wiley \& Sons Inc., 1956.

- MURUOKA, M.; MITANI, I.; INAGAKI, J. Microprocessor-based Fault Locator, Toshiba Review, n. 48, p. 11-14, 1984.

- NIKANDER, A.; JARVENTAUSTA, P. MYLLYMAKI, J. "Novel algorithms for earth fault indication based on monitoring of shunt resistance of MV feeder as a part of relay protection", Seventh International Conference on Developments in Power System Protection, p. 430-433, 2001.

NOZAKI, K., ISHIBUCHI, H., TANAKA, H. A simple but powerful heuristic method for generating fuzzy rules from numerical data. Fuzzy Sets and Systems, v. 86, p. 251-270, 1997. 
OTHMAN, M. F.; MAHFOUF, M.; LINKENS, D. A. "Transmission lines fault detection, classification and location using an intelligent power system stabilizer", Proceedings of the 2004 IEEE International Conference on Electric Utility Deregulation, Restructuring and Power Technologies (DRPT 2004) , 2004, V. 1, 5-8 Abril de 2004, p. 360 - 365.

PAHWA, A. "Role of distribution automation in restoration of distribution systems after emergencies", Transmission and Distribution Conference and Exposition, 2001 IEEE/PES, v. 2, 28 Oct.-2 Nov, p.1204-1205, 2001.

PEDRYCZ, W., GOMIDE, F. A. C. An Introduction to Fuzzy Sets - Analysis and Design, MIT Press, 1998.

QUINLAN, J. R. Induction of decision trees. Machine Learning, v. 1, p. 81-106, 1986.

* RAmot, D., FRIEDMAN, M., LANGHOlZ, G., KANDEL, A. Complex fuzzy logic. IEEE Transactions on Fuzzy Sets, v. 11, p. 450-461, 2003.

ROGER JANG, J. -S., SUN, C. -T, MIZUTANI, E. Neuro-Fuzzy and Soft Computing, Prentice Hall, Englewood Cliffs, 1997.

ROGER JANG, R. D. ANFIS: Adaptive-network-based fuzzy inference systems, IEEE Transactions on Systems, Man and Cybernetics, v. 23, n. 3, p. 665-685, 1993.

* RUNKler, T. A., BEZDEK, J. C. Alternating cluster estimation: A new tool for clustering and function approximation. IEEE Transactions on Fuzzy Systems, v. 7, p. 377393, 1999.

* RUSSEll, B. D.; AUCOIN, B. M.; TAlleY, T. J. "Detection of Arcing Faults on Distribution Feeders", Final Report EL-2757 prepared for the Electric Power Research Institute, project 1285-3, Dezembro de 1982, $146 \mathrm{p}$.

RUSSELL, B. DON; BENNER, CARL L. "High Impedance Fault Detection Workshop, Industry interaction seminar", conducted jointly by Texas A\&M University and the Electric Power Research Institute, New Orleans, Novembro, 1988.

RUSSELL, B. DON “Detection of Downed Conductors on Utility Distribution Systems", IEEE Tutorial Course Text 90EH0310-3-PWR, course organizer, 1989, 48 p.

RUSSELL, B. D. "Downed Power Lines: Why They Can't Always Be Detected", IEEE Power Engineering Society publication, 22 de Fevereiro de 1989, 49 p.

RUSSELL, B. DON; BENNER, CARL L. “Arcing Fault Detection for Distribution Feeders: Security Assessment in Long Term Field Trials", IEEE Transactions on Power Delivery, V. 10, N. 2, Abril de 1995, p. 676-683. 
SENGER, E.C.; MANASSERO, G., JR.; GOLDEMBERG, C.; PELLINI, E.L. "Automated fault location system for primary distribution networks", IEEE Transactions on Power Delivery, v. 20, n. 2, p. 1332 - 1340, 2005.

$\checkmark$ SRINIVASAN, K.; ST-JACQUES, A. "A new fault location for radial transmission lines with load”, IEEE Transactions on Power Delivery, v. 4, n. 3, p. 1676-1682, 19889.

SUGENO, M., KANG, G. T. Structure identification of fuzzy model. Fuzzy Sets and Systems, v. 28, p. 15-33, 1988.

SUGENO, M., YASUKAWA, T. A fuzzy-logic-based approach to qualitative modeling. IEEE Transactions on Fuzzy Systems, v. 1, p. 7-31, 1993.

SYBILlE, G.; HOANG LE-HUY "Digital simulation of power systems and power electronics using the MATLAB/Simulink Power System Blockset", IEEE Power Engineering Society Winter Meeting, 2000. v. 4, 23-27 Jan. 2000, p. 2973 - 2981.

TAKAGI, T., SUGENO, M. Fuzzy identification of system and its application to modeling and control. IEEE Transactions on Systems, Man, and Cybernetics, v. 15, p. 116-132, 1985.

TAGAGI, T.; YAMAKOSHI, Y.; YAMAURA, M.; KONDOW, R.; MATSUSHIMA, T. "Development of a new type fault locator using the one-terminal voltage and current data", IEEE Transactions on Power Apparatus an Systems, v. PAS-101, n. 8, p. 2892-2898, 1982.

TAKAGI, T. et al. "Development of a New Type Fault Locator Using The One-Terminal Voltage and Current Data", IEEE Transactions on Power Apparatus and Systems, USA, v.101, n.8, p.2892-2898, aug. 1982.

TENGDin, J. T.; BAKER, E. E.; BURKE, J. J.; RUSSELL, B. D.; JONES, R. H.; T. E. WIEDMAN, R. H.; JOHNSON, N. J. “Application of High Impedance Fault Detectors: A Summary of the Panel Session Held at the 1995 IEEE PES Summer Meeting", Proceedings of the 1996 IEEE Transmission and Distribution Conference, Los Angeles, CA, 15-20 de Setembro de 1996, p. 116 - 122.

* TENG, JEN-HAO "Systematic short-circuit-analysis method for unbalanced distribution systems", IEE Proceedings on Generation, Transmission and Distribution, V. 152, Issue 4, 8 de Julho de 2005, p. 549 - 555.

- TOMSOVIC, K.; BAKKEN, D. E.; VENKATASUBRAMANIAN, V.; BOSE, A. "Designing the next generation of real-time control, communication, and computations for large power systems", Proceedings of the IEEE, V. 93, Issue 5, p. 965 - 979, Maio 2005. 
$\checkmark$ THUKARAM, D.; SHENOY, U. J.; ASHAGEETHA, H. "Neural network approach for fault location in unbalanced distribution networks with limited measurements", IEEE Power India Conference 2006, 10-12 de Abril de 2006, 8p.

ULRYCH, T.; BISHOP, T. "Maximum entropy spectral analysis and autotoregressive decomposition", Rev. Geophysic and Space Physic, v. 13, p. 183-200, 1975.

$\checkmark$ VASILIC, S.; KEZUNOVIC, M. “An improved neural network algorithm for classifying the transmission line faults", IEEE Power Engineering Society Winter Meeting 2002, V. 2, 27-31 Janeiro de 2002, p. 918 - 923.

$\checkmark$ WANG, C.; NOURI, H.; DAVIES, T. S. "A mathematical approach for identification of fault sections on the radial distribution systems: voltage sensor", $10^{\text {th }}$ Mediterranean Electrotechnical Conference, v. 3, p. 882-886, 2000.

$\checkmark$ WANG, L.-X., MENDEL, J. M. Generating fuzzy rules by learning from examples. IEEE Transactions on Systems, Man, Cybernetics, v. 22, p. 1414-1427, 1992.

* XIE X., BENI. G. A validity measure for fuzzy clustering. IEEE Transactions on Pattern Analysis and Machine Intelligence, v. 13, p. 841-847, 1991.

XU , L.; CHOW, MO-YUEN, "A classification approach for power distribution systems fault cause identification", IEEE Transactions on Power Systems, V. 21, Issue 1, Fevereiro de 2006, p. $53-60$.

* YAGER R. R, FILEV, D. P. Generation of fuzzy rules by mountain clustering. Journal of Intelligent and Fuzzy Systems, v. 2, p. 209-219, 1994.

YANQIU BI; JIANGUO ZHAO; DAHAI ZHANG; "Single-phase-to-ground fault feeder detection based on transient current and wavelet packet", International Conference on Power System Technology - PowerCon 2004, v. 1, 21-24 Nov. p. 936 - 940, 2004.

YOUSSEF, O. A. S. "Applications of fuzzy-logic-wavelet-based techniques for transformers inrush currents identification and power systems faults classification", IEEE PES 2004 Power Systems Conference and Exposition, 10-13 de Outubro de 2004, V. 1, p. $553-559$.

YOUSSEF, O. A. S. "Applications of fuzzy inference mechanisms to power system relaying”, 2004 IEEE PES Power Systems Conference and Exposition, 10-13 de Outubro de 2004, V. 1, p. $560-567$. 
- YOUSSEF, O. A. S. "Combined fuzzy-logic wavelet-based fault classification technique for power system relaying”, IEEE Transactions on Power Delivery, V. 19, Issue 2, Abril de 2004 , p. $582-589$.

* ZADEH, L. A. Fuzzy sets, Information and Control, v. 8, p. 29-44, 1965.

ZADEH, L. A. Outline of new approach to the analysis of complex systems and decision. IEEE Transactions on Systems, Man and Cybernetics, v. 3, p. 28-44, 1973.

* ZHU, J.; LUBCKEMAN, D. L.; GIRGIS, A. A. “Automated Fault Location and Diagnosis on Electric Power Distribution Feeders", IEEE Transactions on Power Delivery, USA, v.12, n.2, p.801-809, apr. 1997.

* ZIOLKOWSKI, VALMIR; "Estratégias Experimentais Para Ensaios de Faltas Fase-Terra com Alta Impedância em Sistemas de Distribuição de Energia Elétrica", São Carlos - SP, 2007. Dissertação (Mestrado em Engenharia Elétrica - EESC/USP) - Universidade de São Paulo, 2007. 
